MANFRED ALBRING

EBERHARD WILLE (HRSG.)

DIE GKV ZWISCHEN

AUSGABENDYNAMIK,

EINNAHMEN-

SCHWÄCHE UND

KOORDINIERUNGS-

PROBLEMEN 


\author{
MANFRED ALBRING \\ EBERHARD WILLE (HRSG.)
}

\title{
DIE GKV ZWISCHEN AUSGABENDYNAMIK, EINNAHMENSCHWÄCHE UND KOORDINIERUNGSPROBLEMEN
}

Der Sammelband enthält die erweiterten Referate eines interdisziplinären Workshops zu den gegenwärtigen Problemen der GKV. Diskutiert wurden drei Themenkreise: Die wesentlichen Determinanten der Ausgabendynamik; Einnahmenschwäche in der GKV; Der Wettbewerb als Koordinationsinstrument in der ambulanten und stationären Versorgung.

Manfred Albring wurde 1943 in Bochum geboren. Studium der Humanmedizin an der Universität Marburg. Er arbeitet als Leiter Gesundheitswesen in der Schering Deutschland GmbH. Er ist u. a. Mitglied der Arbeitsgemeinschaft für dermatologische Forschung, der Deutschen Pharmakologischen Gesellschaft und des Kuratoriums der Deutschen Herzstiftung.

Eberhard Wille wurde 1942 in Berlin geboren. Nach dem Dipl.-Examen 1966 an der Universität Bonn, der Promotion 1969 und der Habilitation 1973 an der Universität Mainz, ist er seit 1975 Professor für Volkswirtschaftslehre und Finanzwissenschaft an der Universität Mannheim. Er ist u.a. Mitglied des Wissenschaftlichen Beirats beim Bundesministerium für Wirtschaft und Technologie sowie Vorsitzender des Sachverständigenrates für die Konzertierte Aktion im Gesundheitswesen. 
Die GKV zwischen Ausgabendynamik, Einnahmenschwäche und Koordinierungsproblemen 


\section{ALLOKATION IM MARKTWIRTSCHAFTLICHEN SYSTEM \\ Herausgegeben von \\ Heinz König, Hans-Heinrich Nachtkamp, Ulrich Schlieper, Eberhard Wille}

\section{Band 48}

\section{(i)

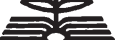 \\ PETER LANG}

Frankfurt am Main · Berlin · Bern · Bruxelles - New York · Oxford · Wien 


\section{MANFRED ALBRING \\ EBERHARD WILLE \\ (HRSG.)}

\section{DIE GKV ZWISCHEN AUSGABENDYNAMIK, EINNAHMENSCHWÄCHE UND KOORDINIERUNGS- PROBLEMEN}

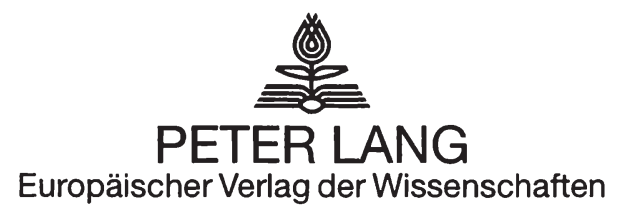

Manfred Albring and Eberhard Wille - 978-3-631-75562-4

Downloaded from PubFactory at 01/11/2019 03:33:01AM 


\title{
Bibliografische Information Der Deutschen Bibliothek
}

Die Deutsche Bibliothek verzeichnet diese Publikation in der

Deutschen Nationalbibliografie; detaillierte bibliografische

Daten sind im Internet über <http://dnb.ddb.de> abrufbar.

Open Access: The online version of this publication is published on www.peterlang.com and www.econstor.eu under the international Creative Commons License CC-BY 4.0. Learn more on how you can use and share this work: http://creativecommons. org/licenses/by/4.0.

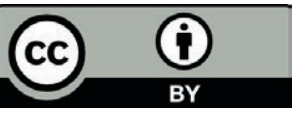

This book is available Open Access thanks to the kind support of ZBW - Leibniz-Informationszentrum Wirtschaft.

Gedruckt auf alterungsbeständigem, säurefreiem Papier.

\author{
ISSN 0939-7728 \\ ISBN3-631-51473-5 \\ ISBN 978-3-631-75562-4 (eBook) \\ (C) Peter Lang GmbH \\ Europäischer Verlag der Wissenschaften \\ Frankfurt am Main 2003 \\ Alle Rechte vorbehalten.
}

Das Werk einschließlich aller seiner Teile ist urheberrechtlich geschützt. Jede Verwertung außerhalb der engen Grenzen des Urheberrechtsgesetzes ist ohne Zustimmung des Verlages unzulässig und strafbar. Das gilt insbesondere für Vervielfältigungen, Übersetzungen, Mikroverfilmungen und die Einspeicherung und Verarbeitung in elektronischen Systemen.

Printed in Germany 124567

www.peterlang.de 


\section{Danksagung}

Die Fertigstellung des vorliegenden Symposium-Bandes der "siebten Bad Orber Gespräche" erforderte von allen Beteiligten ein hohes Engagement. Für die kurzfristige Ablieferung der Manuskripte - und damit der Möglichkeit einer zeitnahen Veröffentlichung - sei allen Referenten herzlichst gedankt.

Für die gute Zusamenarbeit „hinter den Kulissen" bis hin zur Drucklegung gilt unser Dank Dr. Michaela Flug, Ingeborg Hagedorn, Ina Lödden, Dr. Vanessa Elisabeth Schaub und Tanja Witte.

Dr. med. Manfred Albring

Prof. Dr. rer. pol. Eberhard Wille

Berlin im April 2003 
Manfred Albring and Eberhard Wille - 978-3-631-75562-4

Downloaded from PubFactory at 01/11/2019 03:33:01AM

via free access 


\section{Inhaltsverzeichnis}

$\begin{array}{llr}\text { Maria Becker } & \text { Vorwort } & 9 \\ \text { Manfred Albring } & \text { Begrüßung } & 19 \\ \text { Detlev Ganten } & \text { Molekulare Medizin: Fortschritt ohne } & 23 \\ & \text { Grenzen? } & \end{array}$

\section{Themenkreis 1}

$\begin{array}{llr}\text { Eberhard Wille } & \begin{array}{l}\text { Die wesentlichen Determinanten der Aus- } \\ \text { gabendynamik }\end{array} & 39 \\ \text { Volker Ulrich } & \begin{array}{l}\text { Demographische Effekte auf Ausgaben } \\ \text { und Beitragssatz der GKV }\end{array} & 59 \\ \begin{array}{ll}\text { Bernd Raffelhüschen } \\ \text { Stefan Fetzer } \\ \text { Stefan Moog }\end{array} & \begin{array}{l}\text { Die Nachhaltigkeit der gesetzlichen Kran- } \\ \text { ken- und Pflegeversicherung: Diagnose } \\ \text { und Therapie }\end{array} & 115 \\ \text { Peter C. Scriba } & \begin{array}{l}\text { Medizinisch-technischer Fortschritt als } \\ \text { Outcome- und Ausgabenfaktor }\end{array} & 133 \\ \text { Gerhard Schulte } & \begin{array}{l}\text { Der Leistungskatalog der GKV im Wandel } \\ \text { Hans-Jürgen Ahrens }\end{array} & \begin{array}{l}\text { Der Leistungskatalog der GKV im Wandel } \\ \text { - Anmerkungen aus praktischer Sicht }\end{array} \\ \text { Jürgen Bausch } & \begin{array}{l}\text { Leistungskatalog der gesetzlichen Kran- } \\ \text { kenversicherung im Wandel - Anmerkun- }\end{array} & 165 \\ & \text { gen aus praktischer Sicht } \\ \text { Klaus Jacobs } & \text { Der Leistungskatalog der GKV im Wandel } & 169\end{array}$

- Anmerkungen aus praktischer Sicht

\section{Themenkreis 2}

Eckhard Schupeta

Einnahmenschwäche in der GKV

Doris Pfeiffer

Zur Veränderung der Versicherungspflicht in der GKV

Volker Leienbach

Zur Veränderung der Versicherungspflicht

Peter Oberender in der GKV messungsgrundlage oder ordnungspolitische Reform? 
Dieter Cassel

Eckhard Knappe

Helmut Laschet

Andreas Meusch

Jürgen Wasem
Kapitaldeckung und höhere Rentner-

Beiträge zur ergänzenden Finanzierung

demographischer Effekte in der GKV

Selbstbeteiligung der Patienten als Finanzierungs- und Steuerungsinstrument

Versicherungsfremde Leistungen und Verschiebebahnhöfe

Versicherungsfremde Leistungen und Verschiebebahnhöfe

Versicherungsfremde Leistungen und Verschiebebahnhöfe - Anmerkungen aus praktischer Sicht

\section{Themenkreis 3}

Rolf Hoberg

Franz Knieps

Norbert Klusen

Karl-Heinz Schönbach

Manfred Richter-Reichhelm

Eugen Münch

Susanne Renzewitz

Helmut Altland

Wolfgang Holzgreve
Der Wettbewerb als Koordinationsinstrument in der ambulanten und stationären Versorgung

Kassenwettbewerb im Spannungsfeld von Patientenautonomie und Solidarität

Kassenwettbewerb im Spannungsfeld von Patientenautonomie und Solidarität

Offnung des Kollektivvertragsrechts und Übergang zu Einzelverträgen?

279

285

293

Die GKV zwischen Ausgabendynamik, Einnahmenschwäche und Koordinierungsproblemen

Wettbewerbsoptionen im Rahmen der stationären Behandlung

Wettbewerbsoptionen im Rahmen der stationären Behandlung

Wettbewerbsfelder zwischen Fachärzten und Krankenhäusern

Der Leistungskatalog der GKV im Wandel - Anmerkungen aus praktischer Sicht

Verzeichnis der Referenten

Verzeichnis der Teilnehmer 


\section{Vorwort}

Maria Becker

Die Bad Orber Gespräche des Jahres 2002 schlossen sich unmittelbar an die Bundestagswahl an. Der Koalitionsvertrag lag bereits vor, ließ aber nicht erkennen, dass die Koalition die Lage der GKV sorgfältig analysiert hatte oder gar über ein stimmiges Konzept zur Lösung der Finanzierungsprobleme verfügte. Vielmehr plante der Bundeskanzler, nach dem Vorbild der Hartz-Kommission eine weitere Kommission zur Reform der gesetzlichen Krankenversicherung einzusetzen. Bundessozialministerin Schmidt, die wie die gesamte rot-grüne Bundesregierung noch im Wahlkampf behauptet hatte, die gesetzliche Krankenversicherung würde im Jahr 2002 mit einem ausgeglichenen Finanzergebnis abschließen, sah sich in ihren Hoffnungen getäuscht und dazu veranlasst, mit dem Beitragssatzsicherungsgesetz einen Beitragssatzstopp zu verordnen und zur Stabilisierung der Einnahmenseite die Versicherungspflichtgrenze anzuheben; Gesundheitspolitik also nach altbekanntem Strickmuster.

Für Experten war dieser zweite Start der rot-grünen Koalition eine Enttäuschung. Denn Diskussionen über die Notwendigkeit grundlegender Reformen der sozialen Sicherungssysteme sind seit den 70er Jahren bekannt. Seit Mitte der 80 er Jahre markiert dabei der demographische Wandel einen erhöhten politischen Handlungsbedarf. Dennoch muss festgestellt werden, dass diese Diskussionen bis zum Jahre 2003 eher akademischer Natur blieben, weil die Politik sich bei ihren so genannten Reformen primär auf Kostendämpfungsmaßnahmen konzentrierte. Mit der fortschreitenden Alterung unserer Gesellschaft und den gleichzeitig auftretenden Einbrüchen im Wirtschaftswachstum und auf dem Arbeitsmarkt wird der Handlungsbedarf für die Politik nun aber immer unübersehbarer. Neben der vom Kanzler einberufenen Rürup-Kommission, die in jüngster Zeit mit zahlreichen, zum Teil widersprüchlichen Vorschlägen die Öffentlichkeit verwirt hat, hat auch die Parteivorsitzende der CDU die Herzog-Kommission einberufen, die Wege aufzeigen soll, wie die gefährdeten umlagefinanzierten sozialen Sicherungssysteme zukunftsfest gemacht werden können.

Zum Zeitpunkt des Erscheinens dieses Buches nimmt die große Gesundheitsreform auf der Grundlage der Regierungserklärung des Bundeskanzlers vom 14. März 2003 langsam Konturen an. Die in diesem Band dokumentierten Beiträge und Diskussionen der Bad Orber Gespräche des Jahres 2002 lassen vor diesem Hintergrund alle bislang diskutierten Optionen - angefangen von einer so genannten Bürgerversiche- 
rung über Ausgliederungen von Leistungen aus dem Leistungskatalog, höheren Selbstbeteiligungen, Verbreiterung der Beitragsbemessungsgrundlage bis hin zu einem vollständigen Systemwechsel - lebendig werden. Das Für und Wider einzelner Vorschläge und auch die manchmal durchschimmernde interessengeleitete Argumentation können in diesem Buch nachvollzogen werden.

Im Mittelpunkt der Auseinandersetzung um Inhalte einer Reform stehen vier Fragenkomplexe:

1. Ist die Bindung der Beitragsbemessung an Löhne und Gehälter angesichts hoher Arbeitslosigkeit, schwachen Wirtschaftswachstums und zunehmender Alterung unserer Gesellschaft noch zeitgemäß? Oder hat sich der als Umlagefinanzierung konzipierte Generationenvertrag überlebt?

2. Wie lässt sich die dem medizinisch-technischen Fortschritt innewohnende Dynamik mit den knappen Ressourcen einer kaum noch wachsenden Volkswirtschaft in Einklang bringen?

3. Können Effizienz und Effektivität der Leistungserbringung durch Wettbewerb verbessert werden?

4. Wie lassen sich die im Gesamtkomplex "Gesundheit" schlummernden Wachstumspotentiale bei knappen Ressourcen zugunsten unserer Volkswirtschaft nutzen?

Ein guter Ausgangspunkt für die Diskussion zu den vorgenannten Fragenkomplexen stellt der Festvortrag von Professor Dr. Detlef Ganten zum Thema "Molekulare Medizin: Fortschritt ohne Grenzen?" dar. Die Forschung an Stammzellen, Reproduktionsmedizin, Präimplantationsdiagnostik, reproduktives und therapeutisches Klonen und andere gentechnische Methoden erwecken bei vielen Menschen die Hoffnung auf Ausrottung von Krankheit und den perfekt designten Menschen. Indes gelang es Professor Ganten in eindrucksvoller Weise, in seinem durch die Evolution und Medizingeschichte führenden Festvortrag die Genomforschung zu entmystifizieren. Die Genomforschung sei weder ein in die Apokalypse führender Irrweg noch die Verheißung einer neuen Medizin, sondern eine wissenschaftliche Methode, die es erlaube, das "Woher", das "Jetzt" und das "Wohin" des Menschen zu erforschen. Gleichwohl wurde deutlich, dass mit Hilfe von DNA-Analysen Krankheiten früher erkannt, genauer charakterisiert und besser behandelt werden können oder durch geeignete Gegenmaßnahmen oder Verhaltensweisen von vornherein zu vermeiden sind. Es liegt auf der Hand, dass dieser Fort- 
schritt nicht ohne Folgen für die Kostenseite der gesetzlichen Krankenversicherung bleiben wird.

Ein weiterer für die gesundheitspolitische Debatte interessanter Aspekt war der Hinweis auf die Folgen der Molekularmedizin für die Stellung des Patienten im System. Patienten werden nach Meinung von Professor Ganten in Zukunft zunehmend selbst bestimmen, wie sie mit ihrer Krankheit bzw. ihrer Disposition umgehen, mit anderen Worten, wie sie bei einer besseren medizinischen Gesundheit ihre eigene Gesundheit bewerten. Der Aspekt des Anspruchsdenkens der Versicherten gegenüber der gesetzlichen Krankenversicherung muss neu justiert werden. Offen bleibt dabei allerdings, ob das bereits heute hohe Anspruchsdenken noch gesteigert wird oder ob es sich relativiert. Klar ist jedenfalls, dass die Kombination aus medizinisch-technischem Fortschritt und Alterung unserer Gesellschaft einen ungeahnten Druck auf Ausgaben und Beiträge in der gesetzlichen Krankenversicherung auslöst.

Professor Bernd Raffelhüschen warnt deshalb davor, so weiterzumachen wie bisher. Was bisher von der Politik an Veränderungen vorgesehen sei, reiche bei weitem nicht zur Lösung der Probleme aus. Um die gesetzliche Krankenversicherung zu retten, sind seiner Meinung nach radikale Einschnitte erforderlich. Das heutige System sei für die junge Generation nicht mehr attraktiv. Die Akzeptanz schwinde zunehmend bei jenen, die nur noch zur Zahlung verpflichtet werden, für sich selbst aber keinen Vorteil mehr hätten. Und das seien im Laufe der Zeit immer mehr junge Versicherte. Hat sich das umlagefinanzierte System also überlebt, oder gibt es Möglichkeiten, es zu retten? Macht es Sinn, die Versicherungspflichtgrenze anzuheben und so einem marodierenden System zwangsweise weitere Beitragszahler zuzuführen, die aber letztlich keine grundlegende Änderung im Sinne einer finanziellen Stabilisierung der GKV herbeiführen können? Diese Frage diskutierten mit kontroversen Positionen Dr. Pfeiffer als Vertreterin des Verbandes der Angestelltenkrankenkassen, die eine Ausweitung des Versichertenkreises befürwortet, und Dr. Leienbach, der als Vorstand der privaten Krankenversicherung nicht nur eine existentielle Gefährdung der PKV befürchtet, sondern auch die solidarisch finanzierte GKV beschädigt sieht.

Ein radikaler Systemwechsel im Sinne einer grundsätzlichen Abkehr von der Umlagefinanzierung wurde auf dem Symposium nicht vollzogen. Vielmehr wurde nach Lösungen gesucht, das Umlageverfahren wieder funktionsfähig und attraktiv für die junge Generation zu machen. Dabei bieten vor allem die Vorschläge der Professoren Raffelhüschen und Cassel zwei neuartige Alternativen an. Während Professor Raffelhüschen mit seiner Freiburger Agenda vorschlägt, den stationären Be- 
reich rein marktwirtschaftlich auszurichten, einen verpflichtenden Selbstbehalt für ambulante Behandlungen und Medikamente einzuführen und die zahnmedizinischen Behandlungen komplett aus dem Leistungskatalog auszugliedern, spricht sich Professor Cassel dafür aus, das Umlageverfahren der GKV durch ein Verfahren zur kollektiven Bildung von Realkapital in Form einer GKV-spezifischen "solidarischen Alterungsreserve" zu ergänzen und mit einer höheren Beitragsbelastung der künftigen Rentner zu verbinden. Letzteres scheint vor allen Dingen mit Rücksicht auf die Tatsache, dass die Rentner zwar rund zwei Drittel der Ausgaben verursachen, aber nur mit einem Drittel zur Finanzierung beitragen, ein lohnenswerter Ansatz. Dieser hat aber - wie Professor Cassel selbst einräumt - den entscheidenden Nachteil, dass er nicht ohne sofortige Beitragssatzerhöhungen zu haben ist. Damit ist relativ klar, dass er angesichts der wirtschaftlichen Situation kaum politische Befürworter finden wird. Eine gerechtere Verteilung der Lasten aus der Krankenversicherung der Rentner ließe sich aber ohne weiteres über die von Professor Peter Oberender empfohlene Verbreiterung der Beitragsbemessungsgrundlage erzielen. Freilich hat sie einen von Kassenseite oft gerügten kleinen Schönheitsfehler. Der Beitragseinzug von Miet-, Zins- und Kapitaleinkünften würde die Kassen in die Rolle des Finanzamtes drängen. Dennoch wird dieser Ansatz vor allem bei den Grünen erörtert.

Der von Professor Raffelhüschen gemachte Vorschlag einer Ausgliederung der kompletten zahnmedizinischen Behandlung ist zwischenzeitlich schon von der CDU/CSU-Bundestagsfraktion mit Beschluss vom 11. Februar 2003 aufgegriffen worden. Auch der Bundeskanzler hat sich in seiner Regierungserklärung vom 14. März 2003 für eine private Absicherung einzelner Leistungen ausgesprochen und dafür das Krankengeld ausgewählt. Diese Kehrtwendung des Bundeskanzlers ist insofern beachtlich, als noch im Wahlkampf die Ausdifferenzierung des Leistungskataloges als Weg in die Zwei-Klassen-Medizin verpönt war. Mit Blick auf die Art und Weise, wie Bundessozialministerin Schmidt die Ankündigungen des Bundeskanzlers handwerklich umsetzen will, bleibt jedoch abzuwarten, ob mit der privaten Absicherung tatsächlich eine kapitalgedeckte Versicherung gemeint ist. Grundsätzliche Bedenken gegen eine zusätzliche private Absicherung von Leistungen aus dem Leistungskatalog resultieren vor allem aus der Überzeugung, dass kapitalgedeckte Systeme Inflationsrisiken in sich bergen und keine dauerhaft rentablen Kapitalmärkte existieren.

Wie schwer sich der Gesetzgeber ganz allgemein mit Leistungseinschränkungen tut, zeigt der Beitrag von Gerhard Schulte "Der Leistungskatalog der GKV im Wandel". Im Ergebnis wurde der Leistungskatalog im Laufe der Zeit eher ausgeweitet als beschränkt. Die aktuelle Diskus- 
sion um die Ausgliederung von Krankengeld einerseits und zahnmedizinischer Behandlung andererseits führt denn auch sehr deutlich vor Augen, mit welchen Argumenten die Politik konfrontiert wird: Aufgabe der Solidarität, Aufkündigung der Parität, Verletzung verfassungsrechtlich geschützter und erworbener Vertrauenstatbestände und schließlich finanzielle Überforderung sozial schwacher und chronisch kranker Menschen.

Angesichts dieser Schwierigkeiten, denen sich die Politik stellen muss, geht Schulte in seinem Beitrag der Frage nach, inwieweit sich die Selbstverwaltung und die Versicherten selbst an der Differenzierung des Leistungskataloges beteiligen können. Dabei wird offen angesprochen, dass das Misstrauen in den mündigen Patienten oftmals seine Ursache in der Verfolgung eigener Kasseninteressen hat. Denn eine Differenzierung des Leistungskataloges hat nicht nur für den Solidargedanken Konsequenzen, sondern auch für den Risikostrukturausgleich. Bei einer Ausgliederung von Leistungen schrumpft sein Volumen unvermeidlich.

Eine Begrenzung des Leistungskataloges allein vermag sich auf Dauer nur dann positiv auf die Ausgabendynamik auszuwirken, wenn der Bundesausschuss Ärzte und Krankenkassen bei der Bewertung neuer Therapie- und Behandlungsmethoden in der Lage ist, deren therapeutischen Zusatznutzen zu erkennen. In diesem Sinne sind auch Aufgaben von Bedeutung, die mit dem von Bundessozialministerin Schmidt geplanten "Institut zur Sicherung der Qualität in der Medizin" in Verbindung gebracht werden. Statt ein neues Institut zu gründen, könnte man aber auch der Frage nachgehen, inwieweit die vorhandenen Gremien der Selbstverwaltung mit diesen Instrumenten ausgestattet und ihre Rechtsstellung verbessert werden könnte. Denn das wäre vermutlich nötig, um die von Dr. Bausch geäußerte Kritik an dem politischen Druck zu unterbinden, den Ressort und Parlament bei anstehenden Verfahren auf den Bundesausschuss Ärzte und Krankenkassen ausüben.

Obgleich die gesetzliche Krankenversicherung sich nicht unmittelbar an der Forschungsfinanzierung beteiligt, wirken sich Forschungsergebnisse auf die Ausgaben der gesetzlichen Krankenversicherung aus. Professor Scriba versucht deshalb in seinem Vortrag „Der medizinisch-technische Fortschritt als Outcome - und Ausgabenfaktor" Wege aufzuzeigen, wie die Effizienz der Forschung im Interesse der GKV gesteigert werden kann, indem Forschung verstärkt auf die Bedarfe der Bevölkerung konzentriert wird, eine Bewertung des therapeutischen Nutzens erfolgt und Forschungsergebnisse durch absolute Transparenz eine objektive Relativierung erfahren. 
$\mathrm{Zu}$ der Thematik „rationaler Umgang mit dem medizinisch-technischen Fortschritt angesichts knapper Ressourcen" gehört auch die Frage, wie man Patienten und Versicherte zu einer rationalen Inanspruchnahme medizinischer Leistungen veranlassen kann. Dieser Frage ging Professor Eckhard Knappe in seinem Referat „Selbstbeteiligung der Patienten als Finanzierungs- und Steuerungsinstrument" nach. In der aktuellen gesundheitspolitischen Diskussion wird die Einführung eines Selbstbehaltes favorisiert. Einem von Professor Raffelhüschen geforderten Selbstbehalt in Höhe von 900 Euro pro Jahr hat die Politik jedoch schon eine Absage erteilt. Aus sozialpolitischen Erwägungen heraus begnügt sich die Politik hier in der Regel mit einem Selbstbehalt von durchschnittlich 300 Euro im Jahr, wobei dieser dann sozial gestaffelt sein soll. Aber reicht ein derartiger Selbstbehalt aus, um mit anderen Finanzierungsinstrumenten wie der Ausgliederung von Leistungen aus dem gesetzlichen Leistungskatalog einschließlich versicherungsfremder Leistungen, der Verbreiterung der Beitragsbemessungsgrundlage oder etwa der Anhebung der Versicherungspflichtgrenze die Finanzierungslücken in der GKV zu schließen? Ist der Selbstbehalt überhaupt mit dem Sachleistungsprinzip vereinbar, das den einzelnen Patienten über von inm verursachte Kosten und in Anspruch genommene Leistungen vollkommen im Unklaren lässt? Muss die Einführung eines Selbsthaltes daher nicht zwangsläufig einhergehen mit der Einführung des Kostenerstattungsprinzips? Wenn der Kostenerstattung aber von der Mehrheit der amtierenden Regierung eine Absage erteilt wird und man sich nur bei der Union für die optionale Einführung des Kostenerstattungsprinzips erwärmen kann, muss es dann nicht zwangsläufig zu einem Nebeneinander von Selbstbehalten und Zuzahlungen kommen? Entfaltet ein niedriger Selbstbehalt überhaupt eine Steuerungswirkung oder geht von inm nicht vielmehr die Gefahr aus, dass der Patient nach Ausschöpfung des Selbstbehaltes versucht, durch eine überzogene Inanspruchnahme medizinischer Leistungen „sein Geld" wieder rauszuholen? Wenn dem so ist, welche Rahmenbedingungen müssen geschaffen werden, damit von Selbstbeteiligungen - die im internationalen Vergleich eine höhere Quote als in Deutschland ausweisen - steuernde Wirkungen ausgehen? Sind Zuzahlungen am Beginn der Behandlungskette die wirkungsvollere Alternative? Alles Fragen, denen sich aktuell auch die Bundesregierung stellen muss, nachdem der Bundeskanzler die Einführung eines Selbstbehaltes in seiner Regierungserklärung gefordert hat.

Eine weitere engere Verknüpfung zwischen der Beitragszahlung und der Leistung ist auch über die bereits im Referat Schulte angeklungene Möglichkeit der Zu- und Abwahl von Leistungen durch die Versicherten gegeben. Mit dieser Möglichkeit wird der Rolle des Versicherten als Nachfrager von Leistungen auf dem Gesundheitsmarkt stärker Rech- 
nung getragen. Eine Rolle, die, wie die Beiträge von Professor Dr. Klusen und Franz Knieps zeigen, bei den Kassen durchaus unterschiedlich gesehen wird. Während Professor Klusen in seinem Beitrag mit dem Bild vom unmündigen, nicht informierten Patienten aufräumt und ihn selbstständiger in die Rolle des Nachfragers entlässt, weist Franz Knieps in seinem Beitrag auf die negativen Folgen der Kassenwahlfreiheit der Versicherten hin, die auch durch den gegenwärtigen Risikostrukturausgleich nicht behoben werden können. Er fordert daher in seinem Beitrag eine Reform des Risikostrukturausgleichs hin auf einen morbiditätsorientierten Ausgleich und eine Stärkung des Vertragswettbewerbs. Zwar befürwortet auch Professor Klusen den Vertragswettbewerb, aber in seinem Konzept sind dabei Patienten und Versicherte die Hauptakteure. Hingegen bleibt Knieps insoweit konservativ und favorisiert die Kassen für diese Rolle.

Gefordert wird grundsätzlich eine Abkehr von dem Grundsatz des einheitlichen und gemeinsamen Handelns. Wenn aber nicht mehr die Spitzenverbände der Krankenkassen auf der einen und die Kassenärztliche Bundesvereinigung als Körperschaft des öffentlichen Rechts auf der anderen Seite einheitlich und gemeinsam handelnd Verträge schließen sollen, wer dann? Antwort auf die Frage, wer den Wettbewerb gestalten, welche Parameter für die wettbewerbliche Auseinandersetzung durch den Gesetzgeber freigegeben werden können, auf welche Felder sich der Wettbewerb konzentrieren soll, auf welchen Ebenen er sich vollziehen wird und wie das Marktgeschehen transparent gemacht werden kann, gibt eine Skizze von Rolf Hoberg unter dem Stichwort „Der Wettbewerb als Koordinierungsinstrument in der ambulanten und stationären Versorgung".

Wie schwierig die Öffnung des Kollektivvertragssystems gestaltet und mit welch unterschiedlichen Erwartungen und Befürchtungen Kassen auf der einen und Ärzte auf der anderen Seite dieser Öffnung entgegensehen, machten Karl-Heinz Schönbach und Dr. Richter-Reichhelm in ihren Beiträgen zum Thema „Die Öffnung des Kollektivvertragssystems“ deutlich. Eine wettbewerbliche Orientierung der Vertragsbeziehungen muss die Monopolstellung der Kassenärztlichen Vereinigungen zumindest einschränken und Vertragsbeziehungen mit konkurrierenden Anbietern zulassen. Was aber bedeutet das Nebeneinander von Kollektivverträgen und Einzelverträgen, was folgt daraus für die ärztliche Gesamtvergütung? Ist Voraussetzung für eine wettbewerbliche Neuorientierung nicht zwangsläufig die Verständigung auf ein Vergütungssystem, welches die ärztliche Therapiefreiheit auf eine rationale Basis stellt? Und müssen nicht auch die Vergütungsstrukturen zwischen dem ambulanten und dem stationären Sektor einander angeglichen werden? Immerhin zeichnen 
sich schon jetzt massive Auswirkungen des neuen Fallpauschalensystems auf den ambulanten Bereich ab.

Die Einführung eines diagnoseorientierten Fallpauschalensystems im Krankenhaussektor, die ab Januar 2004 für alle Krankenhäuser verbindlich wird, bedingt im stationären Bereich eine stärkere wettbewerbliche Orientierung. Susanne Renzewitz und Eugen Münch weisen in ihrem Beitrag "Wettbewerbsoptionen im Rahmen der stationären Behandlung" darauf hin, dass die Zuordnung einzelner Behandlungsfälle zu diagnoseorientierten Fallgruppen die Leistungen eines Krankenhauses transparenter macht und damit für eine verschärfte Konkurrenzsituation sorgt. Infolgedessen müssen sich die Krankenhäuser zunehmend als Unternehmen verstehen und sich in einem konkurrierenden Umfeld positionieren.

Deutlich wurde in den Diskussionsbeiträgen jedoch auch, dass der Wettbewerb sich unter den gegenwärtigen Rahmenbedingungen nicht voll entfalten kann. Belege dafür lieferten die Budgetierung, die integrierte Versorgung und die Disease-Management-Programme. Sollten in Zukunft Patienten, Versicherte, Leistungserbringer und Kassen im Wettbewerb flexibler agieren können, dann kommt eine weitere spannende Frage auf, die auch auf dem Workshop heftig diskutiert wurde: Wie ist es in Zukunft um den Grundsatz der Beitragssatzstabilität bestellt? Denn dieser Grundsatz leitet seine Daseinsberechtigung aus der Überzeugung $a b$, dass die Lohnnebenkosten nicht ins Uferlose steigen dürfen. Wenn jedoch die Politik in Zukunft daran denkt, den Arbeitgeberbeitrag festzuschreiben oder ihn gar auszuzahlen, dann wird die Rechtfertigung dieses Grundsatzes immer schwieriger.

Lässt man alle Beiträge noch einmal Revue passieren, dann fällt auf, dass der Mut zu einem radikalen Reformschritt nicht sehr ausgeprägt ist. Vielmehr konzentrieren sich die Diskussionen auf Veränderungen im bestehenden System. Die Gefahr, sich in der Komplexibilität des jetzigen Systems zu verlieren, ist hoch. Denn allen fällt es schwer, vertraute Denkweisen preiszugeben. Ob evolutionäre Reformschritte aber ausreichen werden, um die gesetzliche Krankenversicherung angesichts rückläufiger Einnahmen bei anhaltend schwachem Wirtschaftswachstum zukunftsfest zu machen, ist offen. Leise Zweifel stellen sich angesichts der weltwirtschaftlichen Lage ein. Andererseits stimmt optimistisch, dass das deutsche Gesundheitssystem bei seiner Bevölkerung immer noch ein hohes Ansehen genießt und die unterschiedlichen Reformansätze in anderen Ländern auch noch nicht zu einem Gesundheitswesen geführt haben, das als "ideal" zu bezeichnen wäre. So bleibt am Ende der Bad Orber Gespräche des Jahres 2002 und am Ende der Lektüre dieser Doku- 
mentation sicher ein Stück Ernüchterung, aber mit Blick auf die Diskussionen, die in den Parteien stattfinden, auch ein Stück Hoffnung. Es könnte sein, dass sich endlich etwas bewegt. 
Manfred Albring and Eberhard Wille - 978-3-631-75562-4

Downloaded from PubFactory at 01/11/2019 03:33:01AM

via free access 
Manfred Albring

Meine sehr geehrten Damen und Herren!

Herzlich willkommen zu den 7. Bad Orber Gesprächen in Berlin.

In Namen der Schering Deutschland $\mathrm{GmbH}$ möchte ich mich bei Ihnen bedanken, dass Sie unserer Einladung gefolgt sind. Bedanken möchte ich mich aber auch bei denjenigen, die im vergangenen Jahr zum Gelingen dieses Symposiums beigetragen haben. Die außerordentlich positive Resonanz auf unsere letzte Veranstaltung ist sicherlich nicht nur dem Umstand zu verdanken, dass sie hier in Berlin stattgefunden hat. Im Übrigen haben wir Hauptstädter allen Grund, bescheiden zu sein. Nein: Das positive Echo war das Ergebnis exzellenter Referate und fruchtbarer Diskussionen. Damit wurde aber auch eine Benchmark gesetzt hinsichtlich der Erwartung an die diesjährigen Bad Orber Gespräche.

\section{Meine Damen und Herren!}

Hätte es noch eines Beweises bedurft, dass strukturelle Reformen im Gesundheitswesen dringend notwendig sind, so wurde uns dieser Beweis mit der Vorlage eines Vorschaltgesetzes geliefert. Ich glaube, wir brauchen nicht darüber zu diskutieren, dass die Instrumente dieses Kostendämpfungsgesetzes kaum geeignete Maßnahmen sind, die Probleme einer solidarisch finanzierten Krankenversicherung auch nur mittelfristig zu lösen. Eingriffe in die Satzungsautonomie der Krankenkassen, Preis- und Rabattdiktate für Arzneimittel, staatlich festgelegte sektorale Budgets für Krankenhäuser und niedergelassene Ärzte - das sind Notnägel, die nicht lange Halt bieten. So sehr wir uns alle darüber erregen mögen, die Notoperation im Gesundheitswesen sollte uns nicht dazu verleiten, das Thema unserer Veranstaltung aus dem Gesichtsfeld zu verlieren.

Umso wichtiger ist es, dass wir uns den auf der Hand liegenden Strukturproblemen des deutschen Gesundheitswesens zuwenden. Seiner Ausgabendynamik - oder sagen wir vielleicht noch etwas zutreffender, seiner Leistungsdynamik - einer nun schon säkularen Einnahmenschwäche, und seiner Koordinierungsprobleme.

Ich bin froh, Herrn Professor Ganten vom Max-Delbrück-Centrum für molekulare Medizin in Berlin-Buch und Mitglied des Nationalen Ethikra- 
tes, für das Eröffnungsreferat gewonnen zu haben. Sein Thema: „Molekulare Medizin: Fortschritt ohne Grenzen?"

Das hört sich heute eher wie eine Bedrohung denn eine Hoffnung an.

Eine Bedrohung mit ethischen Grenzüberschreitungen, eine Bedrohung, zusätzliche Ressourcen einer kaum noch wachsenden Volkswirtschaft zu beanspruchen. Eine Bedrohung für all jene, die bei dramatisch wachsenden Handlungsmöglichkeiten gezwungen werden, nur noch äußerst knappe Ressourcen zuzuteilen und damit in eine Situation der Triage und offenen Rationierung von medizinischem Fortschritt zu geraten.

Dergestalt inspiriert, steigen wir morgen früh ein in die Diskussion um die Ausgabendynamik: Es geht um die unstreitig objektiv wachsende Nachfrage nach Leistungen der Medizin aufgrund der Überalterung unserer Gesellschaft und um die auf der anderen Seite dramatisch wachsenden Möglichkeiten durch den medizinisch-technischen Fortschritt.

Ich freue mich, unter dem bewährten Vorsitz von Professor Wille neue Referenten gewonnen zu haben und damit hoffentlich auch neue Einsichten erhalten zu können.

Ich erhoffe mir eine Klärung folgender Fragen:

- Wird der Beitragssatz in den kommenden Jahren so hoch, dass die nachfolgende Generation einfach damit überfordert sein wird, die gesundheitliche Versorgung zu schultern?

- Kann es aber auch sein, dass der medizinische Fortschritt durch therapeutisch hervorragende Ergebnisse so überzeugend ist, dass die Bereitschaft zu seiner Finanzierung wächst?

- Kann es vielleicht sogar gelingen, durch den Einsatz von neuen medizinischen Entwicklungen Dauer von Krankheiten zu verkürzen oder Krankenhausaufenthalte zu verhindern, dass also durch weniger Inanspruchnahme von Gesundheitsleistungen der fulminante Ausgabenanstieg in der GKV gedämpft werden kann?

- Wird durch den medizinischen Fortschritt trotz immenser demographischer Probleme der Generationenvertrag vielleicht doch noch stabilisiert?

In jedem Fall - davon bin ich überzeugt - stellt sich in naher Zukunft die Frage nach der aktiven Gestaltung des Leistungskataloges der gesetzlichen Krankenversicherung. 
Und diese Gestaltung kann nur bedeuten:

Striktere Auswahl aus der Summe der zur Verfügung stehenden Handlungsmöglichkeiten. Ich bin nämlich sicher, dass das sozialdemokratisch fridericianische liberale Kredo der gegenwärtigen Gesundheitspolitik: "Jedem das Seine", wenn es dann notwendig, ausreichend und zweckmäßig ist, schon jetzt mehr schwankt als das ptolemäische Weltbild zu den Zeiten Galileis. Ich glaube, die Themenbeteiligten in der Gesundheitspolitik sind heute in der Verantwortung, den Versicherten in der GKV eine realistische Perspektive zu erarbeiten und zu klären, welche gesundheitlichen Risiken auf jeden Fall und welche möglicherweise oder wahrscheinlich nicht mehr abgesichert sein werden.

Klare Perspektiven sind aber genauso wichtig für diejenigen, die die Dienste für Patienten erbringen: In welche Qualifikation soll investiert werden, und in welche Projekte sollen Forschung und Industrie investieren? Denn das ist eine der wichtigsten Fragen: Welche Art und welche Struktur muss das Humankapital im Gesundheitswesen der Zukunft haben? Wenn wir uns heute darüber nicht erfolgreich den Kopf zerbrechen, werden wir schon in 10 Jahren vor einem Scherbenhaufen verschwendeter Ressourcen bei gleichzeitiger Unterversorgung stehen.

Doch wie man sich auch anstrengen mag, die Möglichkeiten der Medizin nach ihrer Sinnhaftigkeit zu sortieren - es wird frustran bleiben, solange die inzwischen immense Einnahmenschwäche der gesetzlichen Krankenversicherung andauert. Dabei ist eines klar: Alle Modelle für veränderte Finanzierungsmodalitäten der GKV können vergessen werden, wenn es nicht gelingt, die deutsche Volkswirtschaft auf einen stabilen Wachstumspfad mit mehr Beschäftigung, mehr Produktivität und als Folge dessen auch höhere Entlohnung des Faktors Arbeit zu führen. Das ist eine schwierige Aufgabe für die Politik, aber genauso gut für alle, die wirtschaftliche Verantwortung tragen. Pure, auf kurzfristige Gewinnmaximierung wie Kostenminimierung gezielte Geschäftspolitik, sei es in erwerbswirtschaftlichen Unternehmen oder in korporatistischen Organisationen, kann dann schon mittelfristig übelste Nebenwirkungen verursachen.

Trotzdem, die Hausaufgaben im System müssen gemacht werden. Ob die Bundesgesundheitsministerin diese mit der Veränderung der Friedensgrenze zwischen gesetzlicher und privater Krankenversicherung gemacht hat, darüber werden wir morgen Nachmittag diskutieren. Wir werden aber nicht bei den im Augenblick politisch akzeptabel erscheinenden Veränderungen stehen bleiben und deshalb alles auf den Prüfstand stellen: Die Erweiterung der Beitragsbemessungsgrundlagen, den Aufbau einer kapitalgedeckten Versicherung, um demographische Ef- 
fekte aufzufangen, aber auch die Möglichkeit einer erhöhten Selbstbeteiligung.

Fast parteienübergreifend besteht heute Konsens darüber, dass eine Einheitsversicherung nicht erwünscht ist. Im Gegenteil: Monopole und kartellähnliche Organisationen im Gesundheitswesen kommen auf den Prüfstand. Der Wettbewerb als ein System der Suche nach besseren Verwendungen knapper Ressourcen gilt - zumindest politisch - nicht unbedingt bei den Betroffenen als akzeptiert. Konsens herrscht aber auch darüber: Die Wettbewerbsordnung im Gesundheitswesen ist höchst unvollkommen und von Asymmetrien und Inkonsistenzen geprägt. Wir brauchen also eine klare Ordnungspolitik im Gesundheitswesen.

\section{Meine Damen und Herren!}

Selten ist wie jetzt deutlich geworden, welche schwere Verantwortung auf den Entscheidungsträgern von Politik, Wirtschaft und Gesellschaft lastet, um die Zukunftsfähigkeit Deutschlands zu sichern. Der Kreis derer, die an unserem Symposium teilnehmen, zählt zu den Personen, die das Privileg haben, an wichtigen Entscheidungen mitzuwirken und sie voranzutreiben. Dabei ist es immer ein Vorteil dieses Symposiums gewesen, dass wir den Diskurs interdisziplinär und vorurteilslos führen konnten.

Ich wünsche uns zwei lebhafte Tage, kontroverse Diskussionen und fruchtbare neue Erkenntnisse.

Vielen Dank. 


\section{Molekulare Medizin: Fortschritt ohne Grenzen?}

Detlev Ganten

\section{Gene und Gesundheit}

Die Forschung an Stammzellen, Reproduktionsmedizin, Präimplantationsdiagnostik, reproduktives und therapeutisches Klonen und andere gentechnische Methoden der Medizin werden häufig - nicht ganz korrekt - unter dem Stichwort "Genomforschung" zusammengefasst.

Sie sind Reizworte gesellschaftlicher Diskussion und durch Beiträge unterschiedlichster Art in den letzten Wochen und Monaten in Bezug auf ihre medizinische Anwendung, aber auch hinsichtlich der gesellschaftlichen Folgen bereichert worden.

Es haben u. a. Stellung genommen: die Enquete Kommission des Deutschen Bundestages, der Nationale Ethikrat, die Kirchen Deutschlands, europäische Gremien und Kommissionen, zahlreiche WissenschaftsOrganisationen, Ärztevereinigungen, Fachgesellschaften auf nationaler und internationaler Ebene, Parlamente und Regierungen. Neue Gesetze wurden verabschiedet oder werden vorbereitet.

Die Ergebnisse dieser vielfältigen Beschäftigungen sind bemerkenswert unterschiedlich, zum Teil völlig entgegengesetzt. Immer geht es um die Fragen: Was können Kranke von den neuen wissenschaftlichen Methoden erwarten? Werden schicksalhafte Erkrankungen heilbar? Aber auch: Mit welchen wissenschaftlichen Methoden wollen und dürfen wir forschen? Welche Zellen, Materialien, Forschungsobjekte stehen zur Verfügung? Welche Anwendungen der Forschung wollen wir erlauben? Wie können wir Missbrauch verhindern? Was bleibt unantastbar? Überschreiten wir unerlaubte Grenzen, wenn wir mit gentechnischen Methoden unser biologisches Schicksal zunehmend in die Hand nehmen?

Politisch sind diese Fragen durch den Gesetzgeber zu entscheiden. Zu hinterfragen ist allerdings, wie weit es weise und möglich ist, durch spezifische gesetzgeberische Maßnahmen Ergebnisse zukünftiger Forschung im Vorgriff zu regeln. Andere Länder finden andere Lösungen: England, Belgien, Holland, Schweden, Australien, Japan, Israel beispielsweise sind durch einen eher liberalen, verkürzt ausgedrückt, wissenschaftsfreundlichen Kurs gekennzeichnet. In den USA gibt es eine für uns nicht ganz verständliche Trennung zwischen den öffentlich finanzierten und dem privaten Bereich. 
In Deutschland wird die Diskussion bezüglich des Für und Wider der Grenzen der Wissenschaft, speziell der Genomforschung, ausführlich, engagiert und auf hohem akademischen Niveau geführt - aber bevor die Diskussion zu einem Ergebnis gekommen ist, befürchte ich, sind die Wissenschaftler, um deren Forschung es geht, nicht mehr im Lande: ausgewandert, aus dem Ausland, meist aus den USA, nicht zurückgekehrt oder auf anderen Forschungsgebieten tätig, weil die Förderung im eigenen Land fehlt.

Die Zukunftsfähigkeit eines Landes wie Deutschland hängt zunehmend von seiner Forschung auf vielen verschiedenen Gebieten $a b$, von denen einzelne Forschungsthemen, wenn sie wirkliches Neuland beschreiten, natürlich immer auch kontrovers sein werden. Wissenschaft kann aber nur gedeihen in einem Klima gegenseitiger Achtung und Vertrauens sowie gesellschaftlicher Akzeptanz. Die derzeitige Diskussion im großen Bereich der Genomforschung hat in diesem Sinne einen über den aktuellen Anlass hinausgehenden, wichtigen exemplarischen Stellenwert für unser Land.

Das Vertrauen der Politik und der Gesellschaft in die Wissenschaft und in die Selbstkontrolle wissenschaftlicher Organisationen und des wissenschaftlichen Prozesses ist von größter Bedeutung.

Die großen deutschen Wissenschaftsorganisationen haben sogar eine eigenständige gemeinsame Organisation gegründet: „Wissenschaft im Dialog", die genau diesen Zweck verfolgt: Besseres Verstehen und Vertrauen für die Wissenschaft zu erreichen.

Die Genomforschung und die genannten Stichworte stehen für ein großes neues Wissenschaftsgebiet, dass das Äußere und das Innere unseres Bildes vom Menschen und von der Gesellschaft verändern wird. Im äußeren Bereich wird aus dieser Forschung eine biotechnologische Industrie entstehen und zusammen mit der molekularen Medizin für ein neues Verständnis von Gesundheit und Krankheit sorgen.

Im inneren Bereich geht es um das Menschenbild, zu dem die Lebenswissenschaften unter dem Eindruck neuer Erkenntnisse beitragen und Anstöße geben. Es geht darum, in Frage zu stellen und Fragen zu formulieren: aus philosophischer, naturwissenschaftlicher, poetischer, betroffener subjektiver und natürlich auch aus politischer und gesellschaftlicher Sicht. Zum Beispiel die Frage, ob "Genomforschung ein in die Apokalypse führender Irrweg oder die Verheißung einer neuen Medizin ist". $\mathrm{Ob}$ wir Antworten finden, ist nicht sicher, aber wir wollen und müssen sie gemeinsam suchen. 
Unser neues genomisches und genetisches Verständnis der Evolution bestätigt die Theorien von Darwin in wunderbarer Weise. Manche nennen das die "Darwin'sche Kränkung des Menschen“, weil der Mensch genomisch nicht nur der Ratte, sondern den primitivsten Lebewesen so ähnlich ist. Es ergeben sich aber auch aus der evolutionären Sicht ganz überraschende neue Gesichtspunkte zum Verständnis des Beginns und des Endes des Lebens und zum Verhältnis von Gesundheit und Krankheit.

\section{Die genomischen Fakten und die Gene}

1. Das Genom, unsere Erbsubstanz mit ihren 3 Milliarden Basenpaaren, auf denen 30.000 Gene auf 46 Chromosomen gebildet werden, ist beim Menschen und vielen Modellorganismen über Bakterien, Fruchtfliege, Zebrafisch, Maus und Ratte in der Struktur und Sequenz der Bausteine bekannt. Die Funktion kennen wir allerdings nur von einigen Tausend Genen.

Der Wurm C. elegans hat 19.000 Gene, fast so viele wie der Mensch, und viele Gene sind denen des Menschen sehr ähnlich. Dieser Wurm ist zwar nicht selber, aber sein menschlicher Protektor, Sidney Brenner, ist Träger des Nobelpreises 2002 für Medizin und Physiologie. Darwin lässt grüßen!

2. Bei der Entwicklung eines Menschen bis zu seiner Geburt vollziehen sich viele Einzelschritte, die wir von der Evolution anderer Lebewesen sehr ähnlich, zum Teil identisch kennen. Bei der Verschmelzung von Samen und Eizelle der sexuellen Vermehrung entsteht in der Zygote die Erbsubstanz (gemischt von Vater und Mutter) eines neuen potentiellen Lebens. Wichtige Etappen bis zur Geburt sind: die "Morula" und dann die "Blastula", aus der die Stammzellen gewonnen werden können; die Nidation des menschlichen Embryos am 14. Tag, die Entwicklung der Organe und des Nervensystems bis zur 12. Woche, die Lebensfähigkeit des Fötus nach der 24. Woche und die Geburt nach 38 Wochen. Bis auf die Zeitabläufe ist alles identisch bei den Primaten, am besten studiert ist die Embryologie der Maus. Mit den präzisen, effizienten Methoden der Gentechnik kann im Prinzip aus einer Zelle, der totipotenten Stammzelle, gelernt werden, nach welchen Prinzipien sich das Leben in diesen Stufen entwickelt: Es geht zuvorderst und in erster Linie um Erkenntnisgewinn!

3. Viele erhoffen sich von dieser Wissenschaft Heilung unheilbarer Krankheiten oder Vorhersage und Schaffung gesunden Lebens. 
Vielleicht genauso viele befürchten ein "gendiagnostiziertes" und "genmanipuliertes" unfreies Leben. Diese übertriebenen Erwartungen, aber auch die Befürchtungen haben keine wissenschaftliche Basis, denn es gibt keinen genetischen Determinismus. Ich möchte das den „1. Hauptsatz der GENETIK" nennen, weil er so grundsätzlich und so wichtig ist. Die Gene selber haben überhaupt keine Funktion! Sie sind reine Informationsträger, die meisten von Ihnen (90 Prozent) sind unerkannte "Schläfer" im Kern ihrer Zelle. Sie müssen erst aktiviert und in ihre Produkte, die Eiweiße, übersetzt werden.

Die „Nichtschläfer", die aktiven Gene, sind über vielfältige Netzwerke und Zwischenstufen (RNA-Eiweiße-Peptide) in komplexe Signalketten untereinander eingebunden, die wiederum vielfältigen AuBeneinflüssen und Veränderungen unterliegen.

4. Ein wichtiger Grund für die Unberechenbarkeit des genetischen Netzwerkes und der genomischen Variabilität ist das Auftreten von Veränderungen der Gensequenz und Genstruktur, d. h. von Genmutationen. Dazu ein kleines Rechenexempel: Von der Entwicklung einer Zygote, nach der Verschmelzung der Eizelle mit der Samenzelle, erfolgen 1.014 Zellteilungen, bis ein ganzer Mensch entsteht. Aus der einen Ursprungszelle ist dann ein Mensch entstanden mit 100 Billionen (100 x 1.012) Zellen. Beim Verdoppeln einer Zelle in 2 neue Zellen, dann 4, dann 8, 16, 32 Zellen und so weiter, müssen alle Zellbestandteile, also auch die gesamte Erbanlage, das Genom, mit den 3 Milliarden Bausteinen verdoppelt werden. Nichts geht fehlerfrei, auch nicht in der Natur und in der Genetik. Wir wissen, dass wir bei der Zellteilung und bei der Verdoppelung der Erbanlage, des Genoms, mit einem Fehler pro 1 Milliarde (109) Bausteinen rechnen müssen. Wir verdanken unsere Evolution zum „biologischen Wunderwerk Mensch" diesen Genmutationen, die es natürlich auch schon bei unseren evolutionären Ahnen, den Bakterien, dem Wurm und den Schimpansen gab.

Da das menschliche Genom aus 3 Milliarden Bausteinen besteht, da in der Doppelhelix der Chromosomen 2 komplette Genstränge vorliegen, und da wir alle Chromosomen doppelt besitzen, bedeutet dies, es entstehen: $3 \times 2 \times 2=12$ Fehler bei jeder Zellteilung. Das heißt, das Genom jeder einzelnen Zelle ist etwas verschieden, „variabel", und jede der 100 Billionen Zellen unseres Körpers führt ein Eigenleben.

5. So genannte somatische Mutationen der Gene in einer normalen Körperzelle des Erwachsenen bleiben ohne Konsequenzen für die 
Nachkommenschaft und damit für die Evolution. Sie sind aber medizinisch wichtig. Die Mehrzahl aller Krebsformen entsteht durch solche Erbveränderungen in den wachsenden, sich teilenden, ursprünglich gesunden normalen Körperzellen. Diese Zellen „entarten“ durch Genveränderungen, bei der Zellteilung zu Krebszellen und wachsen zu unkontrollierten Tumoren. Die Gene und deren Funktion sind also schon sehr wichtig, manchmal entscheidend für Gesundheit und Krankheit. Durch Genanalyse können wir schon jetzt in Einzelfällen neue wirksame Krebsmittel entwickeln und einsetzen.

6. Aus der Zygote entstehen in der fötalen Entwicklung alle verschiedenen etwa 200 Zellen, Gewebe und Organe des Menschen, natürlich auch die neuen Keimzellen, die Eizellen der Frau und die Samenzelle des Mannes. Veränderungen, die in diesen Zellen stattfinden, werden auf die Nachkommenschaft übertragen und sind entscheidend für die Vererbung und damit für die Evolution.

Von der Zygote, also dem Beginn des genomischen individuellen Lebens, zur reifen weiblichen haploiden Eizelle in der erwachsenen Frau sind 24 Zellteilungen nötig. Dieses bedeutet, dass nach der vorhergehenden Rechnung $6 \times 24=144$ Fehler in der reifen Eizelle auftauchen.

Das Sperma, die männliche Samenzelle, teilt sich während der gesamten Lebenszeit, je nach Alter des Vaters, noch häufiger, da die Samenzellen während des ganzen Lebens produziert werden. Wir haben daher mit zunehmendem Alter zunehmende Mutationen. Die Samenzelle eines Mannes von 25 Jahren ist von der Ausgangszygote durch 312 Zellteilungen getrennt. Wir hätten beim Mann dann also $6 \times 312=1.872$ Mutationen im Genom einer Samenzelle. Bei älteren Männern sind es mehr Zellteilungen und damit eine höhere Mutationszahl.

Unter diesem Aspekt der sich ständig bei der Zellteilung verändernden Erbanlagen, einem wichtiges medizinisches Ergebnis der Genomforschung, kann man den Satz von Guillaume Appolinaire auch genomisch verstehen, der in seinen „Calligrammen" sagte:

„Et tout a tant changé en moi.“ - „Alles hat sich so sehr in mir geändert."

Jede unserer 100 Billionen Zellen hat ein anderes Genom! 
Man muss sich aufgrund dieser Berechnung wundern, wie stabil die Arten auf dieser Welt sind. Dieses liegt unter anderem daran, dass es sehr wirksame Korrekturmechanismen in der Natur gibt. Lebenswichtige Veränderungen des Erbmaterials werden $z$. B. früh, noch im zellulären Stadium oder vor der Geburt, eliminiert, und diese Veränderungen werden nicht fortgetragen. Daher werden $\mathbf{z}$. B. „normalerweise" nur weniger als 50 Prozent aller von der schnellsten Samenzelle befruchteten Eizellen ausgetragen und sehen das Licht der Welt.

7. Die wichtigste Schlussfolgerung aus diesen Überlegungen ist aber, dass die Erbveränderungen, die Ablesefehler bei der Verdoppelung des Genoms, von Zellteilung zu Zellteilung zufällig, d. h. stochastisch erfolgen und nicht zielgerichtet (deterministisch) sind. In keiner Zelle des gleichen Menschen ist das Genom identisch mit der Nachbarzelle. Allein im Gehirn haben wir über 1 Billion Zellen und damit ebenso viele verschiedene Genome.

Mensch, Menschlichkeit und Schicksal sind nicht und können aufgrund dieser Überlegungen gar nicht genomisch determiniert sein. Das eigentlich Menschliche, die geistige Leistungsfähigkeit, Charakter, Willenskraft, Emotionalität, Sozialkompetenz, Mitgefühl und moralisch/ethisches Urteilsvermögen sind ohnehin überwiegend von individuellen Einflüssen abhängig und zum geringen Teil biologisch bedingt.

Reproduktionsgenetische Optimierung und Manipulationen entbehren daher jeden wissenschaftlichen Anlasses und sind irrsinnige Phantasien.

Stammzellforschung und Genomforschung sind sehr wichtige wissenschaftliche Methoden und Arbeitsgebiete von hoher Relevanz, mit hoher Aussicht auf Erkenntnisgewinn, wie z. B. die obigen Rechnungen zeigen - aber auch nicht mehr.

8. Genomforschung, Verheißung oder Apokalypse? Keines von beiden: Genomforschung ist eine wissenschaftliche Methode - nicht mehr, aber auch nicht weniger - sie ist aufregend und revolutionär, weil sie erlaubt, die Biologie des Menschen von innen heraus zu verstehen. Stammzellen - von ihrem Mythos entkleidet - sind ein reduktionistisches Modell (kein Mensch), dass uns aber erlaubt, völlig, wirklich völlig neue Einsichten in die Entstehung des Lebens zu bekommen. Stammzellforschung und Genomforschung zusammen werden uns helfen, ein phylogenetisch und onkogenetisch neues Bild vom Menschen zu entwickeln. 
Die Beschäftigung mit der Entwicklung des Lebens und der Evolution, mit der Methode der Genomforschung am Modell auch der menschlichen Stammzellen, ist ein naturwissenschaftlicher Zugang, das "Woher", das "Jetzt" und das "Wohin" des Menschen zu erforschen. Das muss man im möglichst internationalen Konsens regeln. Das kann und darf man aber nicht verbieten.

9. Wir nehmen die Sorge vor dem „Dammbruch" ernst, aber: Überflutung und Katastrophen nach einem Dammbruch können (weitgehend, nie gänzlich) vermieden werden durch den Einbau von intelligenten Vorwarn- und Sicherungssystemen. Nur eine Gesellschaft, die kein Vertrauen und Selbstbewusstsein bezüglich der selbstgeschaffenen Regeln, Gesetze und Kontrollsysteme hat, reagiert mutlos und ängstlich. Misstrauen gegen die Wissenschaft ist keine $\mathrm{Ba}-$ sis für die Zukunft unseres Landes. Die besten und vermutlich einzig wirklich wirksamen demokratischen Kontrollen wissenschaftlicher Entwicklungen und Anwendungen sind: Kritikfähigkeit einer aufgeklärten Öffentlichkeit, ein gutes Bildungssystem, Transparenz und Offenheit, besonders auch der Wissenschaft, die Pflege einer Kultur wechselseitiger Achtung.

Trotz aller neuen Fragen haben die alten bioethischen Grundsätze Bestand. Dazu gehören die Achtung vor dem Leben, die Unantastbarkeit der Menschenwürde und das Recht auf Selbstbestimmung sowie der Eid des Hippokrates und die Deklaration von Helsinki sind damit das ärztliche Mandat: Natur zu verstehen und zu überlisten, um "Leiden zu lindern und Krankheiten zu heilen".

\section{Die Evolution zum Menschen und zur Menschlichkeit}

Eine der zentralen Aufgaben der künftigen Lebenswissenschaften wird es sein, den Weg zu finden, der über das Genom hinausführt, um die Sonderstellung des Menschen zu verstehen - seine Menschlichkeit. Dies ist deshalb keineswegs selbstverständlich, weil die westliche Welt seit der Antike eher statisch denkt, eine Welt, in der Platon Wert auf unveränderliche (ewige) Ideen legte und in der Euklid meisterhaft unbewegliche geometrische Figuren berechnete. Bis heute beweisen wir unsere ungebrochene Vorliebe für das Unbewegliche, den Augenblick (,... verweile doch, du bist so schön..."), indem wir ganz selbstverständlich Attribute wie "platonisch" für die Liebe - oder "euklidisch" für den Raum verwenden, während wir der entsprechenden Wendung "heraklitisch" eher verständnislos gegenüberstehen. Dabei hat Heraklit die Aufmerksamkeit schon sehr früh auf das Werden lenken wollen. „Niemand steigt 
zweimal in denselben Fluss" und "Alles fließt" lauten Einsichten, die mehr Beachtung verdienen.

Die Evolution ist kein Ding, sondern ein Prozess, und daher ist sicher anzunehmen, dass aus ihr keine Dinge - und also auch keine festen Genomsequenzen -, sondern Prozesse hervorgehen. Die Evolution bringt in dieser heraklitischen Sicht weder Gene noch Lebewesen hervor. Die Evolution zeigt aus der Vergangenheit in die Zukunft und lehrt uns Perspektive und Bescheidenheit für die Momentaufnahme, die wir "Heute" oder "Gegenwart" nennen.

Vor mehr als 4 Milliarden Jahren, als der Feuerball "Erde" entstand und die Erdkruste sich langsam durch Erkaltung bildete, entwickelte sich erstes Leben, möglicherweise auf den heißen Meeresvulkanen, bei glühender Hitze und hoher Konzentration von Schwefel und Metallen. Die schwefel- und schwermetallhaltigen Moleküle und Prinzipien wie z. B. der "Cyanobakterien" der ersten Stunde gibt es noch heute bei hoch entwickelten Lebewesen und bei uns Menschen. Leicht umgebaut, mit neuen Funktionen, tragen wir noch heute gewissermaßen die Entwicklungsgeschichte mit uns herum: die Moleküle der „Extremophilen“. Die Umweltbedingungen und die Genome veränderten sich beständig und dramatisch. Aus der einen Landscholle auf der Erde, der "Pangäa“, entstanden die Kontinente. Meteore schlugen ein auf der Erde und führten zu saurem Regen und Klimastürzen, Eiszeiten kamen und gingen, Leben wurde dramatisch ausgelöscht und entstand neu - nichts blieb, wie es war.

Seit dem Auftauchen der ersten Primaten vor 40 Millionen Jahren und des Homo sapiens vor 400.000 Jahren ging es dann scheinbar beständig aufwärts mit uns Menschengeschlecht. Zwar sind der Neandertaler und andere Hominiden vor 100.000 Jahren offensichtlich wieder ausgestorben, dafür gab es aber dann einen Trupp von einigen tausend Menschen, die vor ziemlich genau 52.000 Jahren von Afrika aus die Welt kolonisiert haben und von denen wir alle abstammen: die "Schwarzen" in Afrika, die "Gelben" in Asien, die fast ausgelöschten "Rothäute" in Amerika.

Die Kolonialisierung der Welt durch diese erfolgreiche Menschengruppe aus Afrika war verbunden mit einer wahrhaftigen Kulturrevolution, eingeleitet durch die Befähigung zu Abstraktion, Symbolik, Mathematik und durch die Entwicklung von Kunst, Schrift, Sprache und damit der Dialogfähigkeit, dokumentiert z. B. durch die Höhlenmalerei in Chauvet und in den Ardèches vor 40.000 Jahren sowie durch die frühen Kulturen der Sumerer und Babylonier. 
Evolutionsgeschichtlich war das vor wenigen Sekunden. Die alten Kulturen - sie existieren fast alle noch heute in ihrer ursprünglichen Form sogenannter primitiver Völker irgendwo in geschützten oder vergessenen Ecken auf unserer Erde. Sicher ist, wir werden hier nicht stehen bleiben. $\mathrm{Ob}$ wir wollen oder nicht, wir Menschen werden uns weiter entwickeln, die Evolution, die wir lernen zu verstehen, macht auch bei uns nicht halt, sie geht weiter, unaufhaltsam und mit gleicher Dramatik wie in der Vergangenheit.

Variabilität und Diversität bilden die einzige Konstante der Genomik und die Grundlage unserer Existenz. Unser heutiger Standpunkt wäre dann in der Tat nur ein gefrorenes Standbild im laufenden Film der Evolution.

\section{Das neue evolutionäre Bild der molekularen Medizin}

Gesundheit ist nach diesem Verständnis nicht, wie von der Weltgesundheitsorganisation falsch und unerreichbar definiert, ein „... Zustand vollkommenen körperlichen, geistigen und sozialen Wohlbefindens ...", sondern Gesundheit und Krankheit sind integraler Teil des Evolutionsprozesses.

Wie bei dem kleinen Rechenexempel dargelegt, verdankt nicht nur der Mensch als Spezies, sondern jeder von uns seine Existenz dem genetischen Zufall sexueller Fortpflanzung und dem ständigen Zustrom erblicher Mutationen und deren zwangsläufiger Durchmischung in den Keimzellen. Daraus resultiert ein unerschöpfliches Reservoir an individuellen, verschiedenen genetischen Konstitutionen inklusive der Anlagen für $\mathrm{Ge}-$ sundheit und Krankheit. Die fundamentale genetische Botschaft ist, dass es für die Spezies Mensch wie für jede andere Spezies keine genetisch definierbare Norm, keinen Standard, keinen Idealtyp gibt. Auch Gesundheit und Krankheit sind somit durch fließende Übergänge gekennzeichnet, wie die meisten übrigens intuitiv spüren.

Die moderne molekulare Medizin basiert wesentlich auf den Erkenntnissen der Genomforschung, der Genetik und der Evolution, sie bezieht aber die Kenntnisse der "klassischen" Medizin ein. In der molekularen Medizin geht es darum, den Genotyp mit den Methoden der molekularen Biologie zu verstehen und ihm Sinn zu geben mit der Erfassung des klinischen Bildes, des Phänotyps, in seiner komplexen Gesamtheit. Die moderne Wissenschaft hat mit den Genen und dem Genom die Grundlage gefunden, von der aus die Ordnung der gesamten lebenden Natur zu erfassen und ihre innere Einheit zu erkennen ist. 
Ein wesentlicher Unterschied zwischen der modernen molekularen Medizin und der klassischen Biologie besteht darin, dass niemand molekulare Medizin alleine betreiben kann - weder eine einzelne Person, noch eine einzelne Institution. Molekulare Medizin entsteht in einer Zusammenarbeit, die über disziplinäre Grenzen und wissenschaftliche Kooperationen hinausgeht und den ganzen Weg einer Entwicklung ins Auge fassen muss, der von der grundlegenden Forschung ausgeht, sich über die klinische Erkundung und Erprobung dieser Ergebnisse fortsetzt und bis zur wirtschaftlichen Entwicklung eines Produktes führt.

Die Erfahrungen der Kliniker können dabei die Fragen der Grundlagenforscher ebenso verändern wie die Anforderungen der Patienten und des Marktes, und so stellen die Möglichkeiten der molekularen Medizin eine gemeinsame Herausforderung für Forscher, Ärzte und in der Wirtschaft Tätige dar, für deren Bewältigung es die geeigneten Voraussetzungen und Rahmenbedingungen zu schaffen gilt.

Das Konzept der molekularen Medizin vereinigt biologische Grundlagenforschung, klinische Praxis und ökonomische Umsetzung mit dem Ziel, Krankheiten früher erkennen, genauer charakterisieren und besser behandeln zu können oder durch geeignete Gegenmaßnahmen oder Verhaltensweisen von vornherein zu vermeiden, d. h. Prävention, Vorbeugung zu betreiben.

Die Idee besteht darin, die beiden unterschiedlichen Blickrichtungen zu verbinden, die ein Arzt und ein Wissenschaftlicher gewöhnlich einnehmen. Während der Forscher nach universellen Gesetzen und allgemeingültigen Aussagen über die uns umgebende Natur sucht, fragt der Arzt nach dem individuellen Befinden und dem besonderen Leiden seines inm anvertrauten Patienten.

Während es in der Klinik ganz konkret um einzelne Fälle, z. B. von Herzund Kreislaufkranken, geht, fragt der Forscher im Laboratorium eher abstrakt nach den gemeinsamen Faktoren, die in den entsprechenden Geweben oder Zellen unvollständig oder fehlerhaft funktionieren und möglicherweise zu Einschränkungen der Funktion führen. Der in den Jahren vor dem Zweiten Weltkrieg kaum beachtete Begriff "Molekularbiologie" bekam mit der 1953 erfolgten Entdeckung der Doppelhelix als Struktur des Erbmaterials bzw. der Gene seine moderne und maßgebliche Bedeutung. Seit dieser Zeit kann man sagen, dass Molekularbiologen nach einem genetischen - genauer: nach einem genbasierten Verständnis der Lebensprozesse suchen. Vertreter einer molekularen Medizin versuchen entsprechend, ein Verständnis von Krankheiten und 
Möglichkeiten für Diagnose und Therapie zu entwickeln, indem sie von Genen und ihren Varianten (Mutationen) ausgehen.

Tatsächlich steckt in den Genen sowohl das Allgemeine - etwa in Form der Erbgesetze, des universellen Vorhandenseins von DNA in nahezu allen Zellen und der umfassenden Gültigkeit des genetischen Codes als auch das Besondere, da jeder Einzelne von uns mit individuellen Genen ausgestattet ist, die sich durch die dazugehörigen persönlichen, spezifischen DNA-Sequenzen charakterisieren lassen.

Die Idee solch einer chemischen oder organischen Individualität ist schon sehr früh im 20. Jahrhundert formuliert worden, und zwar durch den britischen Arzt Archibald Garrod, der kurz nach 1900 nicht nur bemerkte, dass es Krankheiten (in Form von Stoffwechselstörungen) gibt, die sich nach den Mendel'schen Regeln vererben, sondern der zugleich erkannte, dass sich auch individuelle Anfälligkeiten, etwa gegenüber Infektionen, so verhalten.

Auch Krankheitsdispositionen werden in Familien von Generation zu Generation weitergegeben, wie vor 100 Jahren beobachtet werden konnte.

Historisch gesprochen stellte Garrod der damals neuen Wissenschaft von der Vererbung - der Genetik - die Aufgabe, die chemische Basis für die Individualität zu erkunden, da diese Kenntnis seine Tätigkeit als Arzt erleichtern würde. Die kürzlich erfolgte Offenlegung (Entzifferung) des menschlichen Genoms im Rahmen des humanen Genomprojektes ist die zwar späte, aber immer noch zeitige Antwort der Wissenschaft auf diese frühe Frage. Mit der menschlichen Gensequenz können wir erkennen, wie die Lösung von Garrods Aufgabe zu bewerkstelligen ist.

Zwar war zu Beginn der 80er Jahre zum ersten Mal verstanden worden, wie die Werkzeuge der Gentechnik es erlaubten, Genkarten des Menschen anzufertigen, aber lange Zeit hindurch konnten viele Wissenschaftler keinen Sinn in dem ungeheuren Aufwand erblicken, der mit der Erstellung der menschlichen Gensequenz und ihren rund 3 Milliarden Bausteinen verbunden sein würde.

Die Hoffnung auf genetische Analysen von Krankheiten beruhte damals mehr auf Optimismus als auf empirischer Evidenz. Erst als klinische Beobachtungen in Verbindung mit molekularbiologischen Forschungen deutlich vor Augen führten, dass z. B. Krebs eine genetische Krankheit ist und die Bildung von Tumoren von DNA-Varianten beeinflusst wird, kam das Projekt in Schwung, mit dem sich heute das humane Genom sequenzieren lässt und das der Idee der molekularen Medizin öffentliche Anerkennung und umfassende Perspektiven für die Zukunft bietet. 
Mit dem Beginn der 90er Jahre hat dann endgültig eine neue Form der Zusammenarbeit auf dem Gebiet der Medizin begonnen, bei der genetisch orientierte Wissenschaftler mit biotechnischen Methoden klinisch relevante Fragestellungen zu beantworten versuchen und ihre jeweiligen Lösungen häufig zu neuen Produkten für den Gesundheitsmarkt führen.

Es ist heute möglich, vom vergangenen Jahrzehnt als einem ersten Zeitalter der Biomedizin zu sprechen, in dem nicht nur das Spektrum der Gendiagnostik enorm erweitert wurde, sondern in dem auch viele neue Zielstrukturen (Targets) erkannt wurden, die als Ausgangspunkt für die Entwicklung künftiger Medikamente dienen. Diese Entwicklung ist nicht nur durch ihre ungeheure Dynamik und das konsequent interdisziplinäre Vorgehen der Wissenschaft charakterisiert, sondern auch durch die nahtlose Zusammenarbeit von Grundlagenforschung, Klinik und Industrie, die - so lässt sich vorhersagen - in Zukunft noch intensiviert wird.

Der Campus in Berlin-Buch hat von Anfang an diese Entwicklung wahrgenommen, er hat sie sofort aufgenommen, zu ihr beigetragen und sein Vorgehen an diesem wissenschaftlichen, gesellschaftlichen und ökonomischen Verbund orientiert.

Die Stätte der Grundlagenforschung ist dabei das Max-DelbrückCentrum für molekulare Medizin (MDC) Berlin-Buch, dessen Forschungen sich an den klinischen Fragestellungen orientieren, und die beiden Kliniken, mit denen die Wissenschaftler kooperieren, sind die RobertRössle-Krebs-Klinik und die Franz-Volhard-Herz-Kreislauf-Klinik für Erkrankungen, die beide zur Charité gehören und jetzt in einem Verbund mit dem großen traditionsreichen Klinikum in Berlin-Buch privat vom Helios Konzern betrieben werden.

Der molekularen Medizin ist es inzwischen gelungen, viele tausend $\mathrm{Ge}$ ne mit Krankheitswert („Krankheitsgene”) zu identifizieren und genetisch bedingte Krankheiten auf der molekularen Ebene zu verstehen. Diese molekulare Dimension der Medizin wird zunehmend genutzt.

So schreitet die Charakterisierung von Erbkrankheiten voran. Nach Auskunft des Berufsverbandes Medizinische Genetik (aus dem Jahr 2001) gibt es in Deutschland weit mehr als 100 Testanbieter, die zurzeit rund 280 Krankheiten diagnostizieren können.

Gentests bzw. DNA-Analysen, meist auf Chip-Basis, erlauben die Absicherung klinischer Verdachtsdiagnosen und therapierelevanter Entscheidungen. Sie geben Prognosen in Einzelfällen; sie erlauben prädiktive genetische Tests, die z. B. Auskunft über die Empfindlichkeit gegenüber therapeutischen Maßnahmen geben; sie ermöglichen darüber hin- 
aus bei Individuen die Feststellung eines erhöhten familiären oder individuellen Risikos; sie erlauben die Ermittlung genetischer Faktoren bei der Reaktion auf Medikamente, individuelle Anpassung der Dosis, Vermeidung unerwünschter Nebenwirkungen; sie können schließlich für genetische Reihenuntersuchungen eingesetzt werden, wobei sich in den USA schon Gruppen gebildet haben, die darauf bestehen, an einem Neugeborenen sämtliche verfügbaren Tests durchzuführen, um auch nur das kleinste Risiko zu erkennen.

Tatsächlich werden in den kommenden Jahren die Möglichkeiten und die Angebote, Gentests durchzuführen, stark zunehmen. Dabei kann sich ein Wechsel von der bisherigen prognostischen Medizin zu einer mehr prädiktiven Medizin vollziehen, in deren Rahmen Patienten mit ärztlicher Hilfe versuchen, ihre Krankheitsdisposition zu erfahren, um darauf frühzeitig reagieren zu können.

Wie in der Vergangenheit mit der "Gerätemedizin" und der "Labormedizin" ist auch bei der genetischen Analyse vor Missbrauch dringend zu warnen. Wie bereits gesagt, haben Gene selber keine Funktion, erst deren Übersetzung in Eiweiße und Folgeprodukte vermittelt die Wirkung der Gene. Die Komplexität der biologischen Vorgänge und stochastische Veränderungen der Genstruktur machen eindeutige Aussagen auch der Gentests für den Einzelfall unmöglich. Gentests, wie jede andere Maßnahme, bedürfen der sorgfältigen ärztlichen Betrachtung, die den ganzen Patienten einschließt. Daran wird sich auch in Zukunft nichts ändern.

In diesen Tagen ist viel davon die Rede, dass individuelle Genprofile (die in Zukunft vielleicht aus individuellen DNA-Sequenzen auf CD-ROMs bestehen) Wege zu einer maßgeschneiderten Therapie eröffnen.

Im Bereich der Krebstherapie ist die „personalized medicine” bereits in Einzelfällen umgesetzt worden. Langfristiges Ziel können und müssen individualisierte Maßnahmen zur Prävention sein, wobei dies im Rahmen einer genombasierten Gesundheitsversorgung erfolgen kann, die eine aktivere Beteiligung der Patienten als die voraussetzt, die derzeit die Praxis der Medizin kennzeichnet.

Es könnte sein, dass über diesen Umweg verwirklicht wird, was einige Ärzte schon länger vermuten und erwarten, dass nämlich die Bildung der Patienten das wichtigste Arzneimittel der Zukunft wird und die Kenntnisse der Gene vor allem auf diesem Weg zur Gesundheit beitragen.

Damit ist nicht nur gemeint, dass die Patienten zunehmend selbst bestimmen, wie sie mit ihrer Krankheit bzw. mit ihrer Disposition umgehen, bzw. dass die Menschen sich von den Objekten der Medizin, die sie bislang immer noch sind, zu den Subjekten wandeln, die sie sein wollen und können. 
Damit ist vor allem gemeint, dass verstanden wird, dass ein Gentest einen Menschen nicht automatisch in einen Patienten verwandelt. Wenn genügend Gene getestet werden, werden sich immer potentiell krankheitsrelevante Varianten und Dispositionen zeigen, ohne dass damit eine klinische Krankheit entdeckt wäre.

Die bereits erwähnte Bildung der Patienten wird weiter benötigt, um zum einen zu verhindern, dass aus normalen Wechselfällen des Lebens Krankheiten werden, und um zum anderen dem merkwürdigen Trend zu begegnen, der darin besteht, dass mit einer besseren medizinischen Versorgung der Bevölkerung die eigene Gesundheit immer schlechter bewertet wird.

Die Tatsache, dass wir zwar objektiv gesünder sind, uns aber subjektiv genau gegenteilig fühlen, kann wahrscheinlich nur im Gespräch (Dialog) zwischen Arzt und Patient behandelt werden.

An dieser Stelle ist mit Nachdruck darauf hinzuweisen, dass Krankenhäuser zurzeit kaum geeignete, auch ästhetisch angemessene Räume für vertrauensvolle Gespräche zwischen Arzt und Patient anbieten und dass es sich lohnt, über eine künftige Verbesserung dieser Situation nachzudenken.

Wenn man hier visionär sein möchte, könnte man vorschlagen, neben den traditionellen Krankenanstalten "Gesundheitszentren" zu errichten, in denen das diagnostische Angebot der molekularen Medizin den Patienten im Gespräch und durch verständliche Information nahegebracht wird, um so seine volle Qualität und Wirkung durch Einsichten des um Rat und Hilfe Suchenden entfalten zu können.

An dieser Stelle soll auch darauf hingewiesen werden, dass natürlich die Patienten informiert werden müssen, dass insbesondere aber auch die Fortbildung der Ärzte unabhängig und wirksam überprüft mit dem Fortschritt der Wissenschaft Schritt halten muss.

Wie sehr es die genetischen Informationen sind, die der künftigen Medizin ihren Stempel aufdrücken (und zwischen Arzt und Patient verständlich zu erörtern sind), wurde im Rahmen der ersten publizierten Offenlegung des humanen Genomprojektes im Februar 2001 klar, als Szenarien vorgestellt wurden, die einen konkreten Zeitrahmen für die zu erwartenden Änderungen in der Medizin nennen: Bis zum Jahre 2010 wird erwartet, dass prädiktive Gentests für rund ein Dutzend Krankheiten (z. B. Krebs, Diabetes, Herzkrankheiten) leicht verfügbar sein und verbreitet Anwendung finden werden. Gleichzeitig werden Gesetze zur Verhinderung genetischer Diskriminierung, auch durch Versicherungen oder Arbeitgeber, erlassen werden. 
In den folgenden Jahren wird sich die Krebsbehandlung nicht mehr nach dem Organ, sondern nach dem genetischen Fingerabdruck des Tumors richten; genetische Tests werden es ermöglichen, Patienten individuell zu helfen. Es wird eine umfassende Gesundheitsversorgung und Vorsorge geben, die sich wesentlich an der Genomanalyse orientiert. Die genetische Sequenzierung wird so zuverlässig und preisgünstig durchgeführt werden können, dass sie als Massentechnologie zum Einsatz kommt und vielleicht sogar zur Routineuntersuchung bei der Einlieferung in ein Krankenhaus wird.

Gendiagnosen können schon heute sinnvolle Informationen für $z$. B. den Pharmakologen und Anästhesisten liefern, die durch Gensequenzen auf Unverträglichkeiten hingewiesen werden.

Ein "genombasiertes" Gesundheitswesen wird den Menschen neue individualisierte Präventionsmaßnahmen anbieten. Die diagnostischen Möglichkeiten werden dabei im Detail durch die Entwicklung der so genannten DNA-Chiptechnologie erweitert werden. DNA-Chips erlauben bereits heute viele tausend Gentests in einem Arbeitsgang. Ihre Einsatzmöglichkeiten werden dabei vor allem bei häufigen Krankheiten mit ausgeprägter genetischer Heterogenität (wie z. B. Brustkrebs oder Fettstoffwechselstörungen) gesehen.

\section{Die Pharmakogenetik}

Die eben gemachten Vorhersagen beruhen vor allem auch auf der Annahme, dass mit Hilfe der Genomsequenzen eine neue Wissenschaft begründet werden kann, die dem individuellen Genom eines Menschen Rechnung trägt, wenn er seine Arznei, sein Medikament bekommt.

Diese Wissenschaft heißt Pharmakogenetik oder Pharmakogenomik. Sie basiert auf der Existenz von polymorphen („vielgestaltigen”) Genen, deren unterschiedliche Wirkung auf Variationen in einer einzelnen Position des Genoms zurückgeführt werden kann, die "single nucleotide polymorphisms" (SNP; „Einzel-Nukleotid-Polymorphismus”).

Für jeden Menschen lassen sich charakteristische "SNP"-Muster aufstellen, mit denen dann Schlüsse auf die individuelle Wirksamkeit gegebener Medikamente oder auf die entsprechende Anfälligkeit für bekannte Krankheiten möglich werden.

Auch hier gilt jedoch, dass Genanalysen keine Vorhersagen über das Einzelschicksal erlauben. Wie bereits ausführlich dargestellt, gibt es keinen genetischen Determinismus.

Ärztliche Diagnosen und Entscheidungen bleiben Sache des Arztes im Hinblick auf den ganzen Menschen. Das Recht auf Nichtwissen und der 
Grundsatz der Selbstbestimmung des Patienten bleiben von der Art der Diagnoseverfahren unberührt bestehen.

Der mündige Patient, der von seinem Arzt in verständlicher Weise informiert und aufgeklärt wird und bewusst selbst entscheidet, bleibt auch in der zukünftigen molekularen Medizin im Mittelpunkt ärztlicher Fürsorge.

Wenn ein Naturforscher und Arzt über Gene und Gesundheit sprechen will, orientiert er sich zwangsläufig an Krankheiten. Sie sind leichter zu erforschen als die Gesundheit, die bekanntlich nicht so ohne weiteres quantifizierbar ist.

Gesundheit ist weniger messbar und mehr angemessen. Sie ist ein "Schweigen der Organe", wie einmal gesagt wurde, und beruht auf einer inneren Ausgewogenheit, also auf einer Übereinstimmung des Individuums mit sich selbst. Oder, um den Philosophen Hans Georg Gadamer zu zitieren: "Gesundheit ist nicht etwas, das sich bei der Untersuchung zeigt, sondern etwas, das gerade dadurch ist, dass es sich entzieht."

Während Gesundheit etwas ist, das verborgen bleibt, machen sich Krankheiten oft nachhaltig bemerkbar, weshalb eher und mehr über sie gesprochen wird. Die Zeitungen sind dann auch regelmäßig voll von Meldungen, die Gene mit Krankheiten verbinden. Beim oberflächlichen Hinhören könnte man fast meinen, Gene dienten dazu, uns krank zu machen. Natürlich könnte nichts weiter von der Wahrheit entfernt sein. Gene sind nicht da, um uns zu stören.

Die medizinische Lehre aus der Genomforschung ist im Gegenteil, dass es das biologische Wesen des Menschen, wie jeder Spezies, ausmacht, Populationen mit einer äußerst reichhaltigen vielgestaltigen Häufigkeitsverteilung genetischer Zufälligkeiten und Individualitäten zu bilden. Wir verdanken dieser genetischen Diversität den farbigen Reichtum der Menschenvielfalt und den Reichtum an einzigartigen Talenten.

Mensch, Menschlichkeit und Schicksal sind nicht genomisch determiniert und können es aufgrund dieser Überlegungen auch gar nicht sein. Das eigentlich Menschliche, die geistige Leistungsfähigkeit, Charakter, Willenskraft, Emotionalität, Sozialkompetenz, Mitgefühl und moralisch/ ethisches Urteilsvermögen sind ohnehin überwiegend von individuellen Einflüssen abhängig und zum geringen Teil biologisch bedingt.

Die Gene haben sich im Laufe der Evolution so herausgebildet, dass sie unser Überleben sichern. Gene machen uns von Natur aus stark.

Die molekulare Medizin kann dafür sorgen, dass uns diese Stärke als Gesundheit zugute kommt und bewahrt bleibt. 


\section{Themenkreis 1}

\section{Die wesentlichen Determinanten der Ausgabendynamik}

Eberhard Wille

\section{Die GKV zwischen Wachstumsschwäche der Finanzierungsbasis und Ausgabendynamik}

Die Finanzierungsbasis der gesetzlichen Krankenversicherung bilden zu ca. 97 Prozent die beitragspflichtigen Einnahmen, die im Wesentlichen aus dem Arbeitseinkommen aus einer versicherungspflichtigen Beschäftigung und dem Zahlbetrag der Rente bestehen. Wie Abbildung 1 zeigt, blieben die beitragspflichtigen Einnahmen je Mitglied in den alten Bundesländern zwischen 1980 und 2000 im Wachstum um 31Prozentpunkte hinter dem Bruttoinlandsprodukt (BIP) je Erwerbstätigem zurück. Die quantitative Bedeutung dieser Wachstumslücke für das Beitragsaufkommen verdeutlicht eine fiktive Berechnung, die unterstellt, dass die beitragspflichtigen Einnahmen je Mitglied in diesem Zeitraum mit der Steigerungsrate des BIP je Erwerbstätigem zugenommen hätten. Diese fiktive Berechnung weist für das Jahr 2000 fiktive Mehreinnahmen von 35,6 Mrd. DM aus. Mit Hilfe dieser fiktiven Mehreinnahmen ließen sich die gegebenen Ausgaben bei einem durchschnittlichen Beitragssatz von knapp 11,6 Prozent decken. Dieser fiktive Beitragssatz weicht in seiner Größenordnung unwesentlich von den tatsächlichen Beitragssätzen der Jahre 1980 bis 1984 ab.

Für diese Wachstumsschwäche der Finanzierungsbasis in der GKV ist, wie bereits eine kursorische empirische Analyse zeigt (siehe Wille, E., 2001, S. 12 ff.; Wille, E., und Igel, C., 2002), neben der unterproportionalen Zunahme der Arbeitsentgelte die steigende Arbeitslosenzahl verantwortlich. Daneben trugen ein leicht zunehmender Anteil von Rentnern und diverse Verlagerungen von Defiziten zwischen den Teilen der Sozialversicherung dazu bei, dass die beitragspflichtigen Einnahmen je Mitglied im Wachstum deutlich hinter dem BIP je Erwerbstätigem zurückblieben (siehe auch den Beitrag von E. Schupeta in diesem Band). Die Entwicklung der beitragsfrei Mitversicherten, d. h. die je Beitragszahler zu finanzierenden Versicherten, führte dagegen nicht zu einer Schwächung der Finanzierungsbasis, und vom zunehmenden Anteil der freiwillig versicherten Mitglieder gingen sogar leicht gegenläufige bzw. fiskalisch stabilisierende Effekte aus. 
Abb. 1: Wachstum der beitragspflichtigen Einnahmen je Mitglied und des BIP je Erwerbstätigem von 1980 bis 2000 (alte Bundesländer)

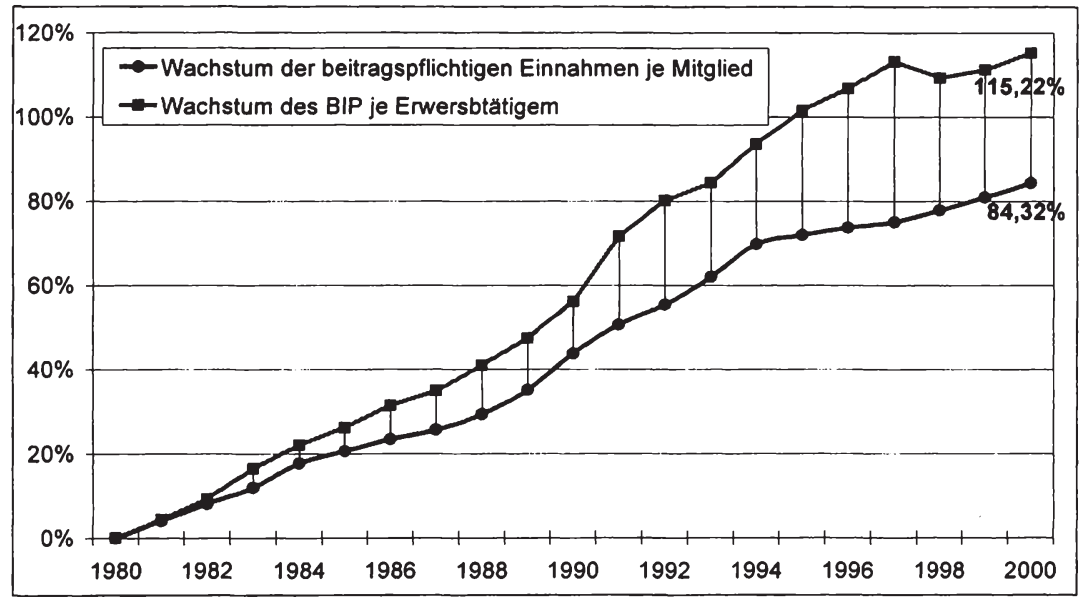

Quelle: Sachverständigenrat für die Konzertierte Aktion im Gesundheitswesen 1994, Bundesministerium für Arbeit und Sozialordnung 1998 - 2000, Bundesdruckerei 1999, Bundesministerium für Gesundheit 2001, Statistisches Bundesamt 2000, 2002, Arbeitskreis VGR 2002 , eigene Berechnungen.

Ein Blick auf die Determinanten dieser Wachstumsschwäche der Finanzierungsbasis in der GKV lässt vermuten, dass die relativ bescheidene, d. h. zur Steigerung des BIP je Erwerbstätigem unterproportionale Zunahme der beitragspflichtigen Einnahmen bei gegebener Beitragsgestaltung noch auf absehbare Zeit anhält. Diese Wachstumsschwäche der Finanzierungsbasis wurzelt nicht nur in konjunkturellen Einflussfaktoren, die zu einer geringen Zunahme von Löhnen und Gehältern, zu einer hohen Arbeitslosenzahl und zu vorgezogenen Verrentungen führen, sondern auch in den im Folgenden genannten, eher strukturellen Determinanten:

- der Druck auf die Arbeitsentgelte, insbesondere in den unteren Lohngruppen, infolge der Globalisierung

- veränderte Arbeitsverhältnisse bzw. Berufskarrieren (z. B. unstete Beschäftigung, nicht versicherungspflichtige Dienst- und Werkverträge)

- die Zunahme von nicht versicherungspflichtigen Teilen des Arbeitsentgeltes, vor allem durch Entgeltumwandlung im Rahmen der betrieblichen Altersvorsorge 
- $\quad$ eine weitere Flucht in die illegale Schattenwirtschaft und Intensivierung der (legalen) Eigenwirtschaft bzw. Haushaltsproduktion sowie

- $\quad$ eine längere Lebens- und damit Verrentungszeit

Dieser Wachstumsschwäche der Finanzierungsbasis steht in der GKV eine Ausgabenentwicklung gegenüber, die unter Status-quo-Bedingungen, d. h. ohne so genannte Kostendämpfungsmaßnahmen, dahin tendiert, die Zunahme des BIP zu übersteigen. Gleichwohl vermag sich die plakative These von der "Kostenexplosion im Gesundheitswesen" nicht auf eine empirische Grundlage zu stützen. Das Verhältnis zwischen den Leistungsausgaben der GKV und dem BIP blieb vielmehr, wie Abbildung 2 ausweist, in den alten Bundesländern von 1975 bis 2000 nahezu konstant, während die Leistungsausgaben der GKV, bezogen auf die beitragspflichtigen Einnahmen in diesem Zeitraum, um 2 Prozentpunkte zunahmen. Diese Konstanz stellte sich allerdings nicht automatisch als endogene Entwicklung ein, sondern bildete das Resultat zahlreicher so genannter Kostendämpfungsmaßnahmen bzw. Gesundheitsreformen. Ohne diese diskretionären staatlichen Eingriffe wäre der Anteil der GKVLeistungsausgaben am BIP zweifellos deutlich angestiegen.

Abb. 2: Verhältnis von GKV- Leistungsausgaben zu BIP und beitragspflichtigen Einnahmen von 1970 bis 2000 (alte Bundesländer)

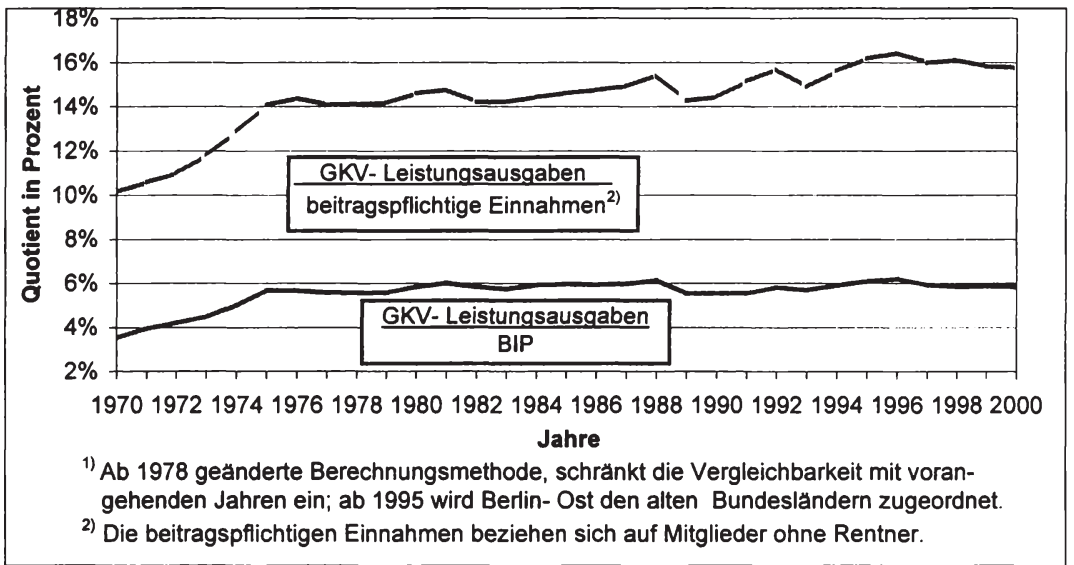

Quelle: Sachverständigenrat für die Konzertierte Aktion im Gesundheitswesen 1994, Bundesministerium fur Gesundheit 2000, 2001, Statistisches Bundesamt 1999, Arbeitskreis VGR der Lănder 2002, eigene Berechnungen. 
Derzeit sprechen nahezu alle Anzeichen dafür, dass sich dieser Trend, d. $h$. die Wachstumsschwäche der Finanzierungsbasis und eine die Zunahme des BIP übersteigende Ausgabendynamik, fortsetzt. Die GKV steht damit vor folgendem Dilemma: Entweder orientieren sich ihre Ausgaben am Wachstum des BIP, dann steigen zwangsläufig die Beitragssätze. Stabile Beitragssätze setzen andererseits voraus, dass die GKVAusgaben schwächer zunehmen als das BIP. Die erste Alternative führt bei den Arbeitgebern zu einer Erhöhung der Lohnnebenkosten und bei den Arbeitnehmern zu einer Verminderung ihres verfügbaren Einkommens. Die zweite Alternative engt vor allem bei einer wenig prosperierenden Wirtschaftsentwicklung, die schon mit einem bescheidenen Wachstum des realen BIP einhergeht, den Finanzierungsspielraum der GKV stark ein und lässt ohne Reformen eine Verschärfung der impliziten Rationierung befürchten. Die implizite Rationierung verstößt insofern gegen ethische Kriterien, als sie sich nicht auf eine nachvollziehbare Entscheidung auf der Grundlage expliziter Kriterien stützt, sondern mehr oder weniger zufällig bzw. willkürlich erfolgt. Die implizite Rationierung zeugt häufig von einer fehlenden Schwerpunkt- und Prioritätenbildung, die als Grundlage für zielorientierte, explizite Bedarfsbestimmung dienen kann. Um in der GKV sowohl eine implizite Rationierung, die unter normativen Aspekten die schlechteste aller Handlungsalternativen darstellt, als auch weitere Beitragssatzsteigerungen zu vermeiden, bedarf es einer eingehenden, zielorientierten Analyse von Reformoptionen.

Der empirische Befund mittel- und langfristig weltweit steigender Gesundheitsquoten, die auch partiell und temporär nicht endogen, sondern nur infolge von Kostendämpfungsmaßnahmen vereinzelt einmal absinken, deutet neben Steuerungsdefiziten auf grundlegende Determinanten der Ausgabenentwicklung hin. Diese Faktoren, die auch ziemlich unabhängig von der Finanzierungsstruktur und den ordnungspolitischen Rahmenbedingungen auf die Gesundheitsausgaben einwirken, lassen sich unbeschadet aller Wechselwirkungen in angebots- und nachfrageseitige Einflussgrößen einteilen (siehe ausführlicher Wille, E., und Ulrich, V., 1991, S. 24 ff., sowie Sachverständigenrat für die konzertierte Aktion im Gesundheitswesen 1995, Ziffer 26 ff.):

\section{Angebotsseitige Determinanten:}

- die angebotsinduzierte Nachfrage aufgrund asymmetrischer Information, insbesondere mangelnde Transparenz über Leistungsqualitäten (siehe Breyer, F., und Zweifel, P. ,1997, S. 242 ff.) 
- der technische Fortschritt, der im medizinischen Bereich nur selten Kosten senkend, sondern zumeist Ausgaben erhöhend wirkt (siehe den Beitrag von P. Scriba in diesem Band)

- die Preissteigerungen, die im dienstleistungsintensiven Gesundheitswesen durchschnittlich die allgemeine Inflationsrate übertreffen (so genannter negativer Preisstruktureffekt zuungunsten des Gesundheitswesens)

- der zunehmende Hang zu einer so genannten Defensivmedizin, um potentiellen Regressen vorzubeugen

Nachfrageseitige Determinanten:

- die Verschiebung der Bevölkerungsstruktur mit einer Zunahme von älteren und multimorbiden Patienten (siehe auch die Beiträge von $B$. Raffelhüschen und V. Ulrich in diesem Band)

- die Zunahme von Einzelhaushalten bzw. -personen, die bereits bei relativ geringfügiger Morbidität bzw. Pflegebedürftigkeit einer externen Hilfe bedürfen

- die Veränderung des Krankheitsspektrums in Richtung langwieriger, chronisch-degenerativer Krankheitszustände

- die gestiegene Anspruchshaltung gegenüber medizinischer Versorgung

- $\quad$ der Anreiz bzw. die moralische Versuchung (moral hazard), wegen des nahezu umfassenden Versicherungsschutzes die persönliche Gesundheitsvorsorge zu vernachlässigen und im Schadensfalle die Gesundheitsgüter übermäßig in Anspruch zu nehmen

\section{Die Reformoptionen im Überblick}

Die Reformoptionen, die bei drohenden Budgetdefiziten zur Wahrung der Beitragssatzstabilität und zur Vermeidung einer impliziten Rationierung grundsätzlich offen stehen, lassen sich zunächst danach unterscheiden, ob sie einen Übergang zu einem alternativen Gesundheitssystem erfordern oder ob sie als adaptive Reformschritte in den Strukturen des geltenden Systems bleiben. Alternative Gesundheitssysteme stellen

- die rein steuerfinanzierte Gesundheitsversorgung, 
- $\quad$ der Übergang zu einer kapitalgedeckten Finanzierung und

- die Finanzierung mit Hilfe von fixen Pro-Kopf-Beiträgen

dar.

Die adaptiven Reformoptionen umfassen im Prinzip

- die Ausschöpfung von Wirtschaftlichkeitsreserven durch strukturelle Reformen,

- $\quad$ eine Neufassung des Leistungskataloges der GKV sowie

- eine Änderung von Finanzierung bzw. Beitragsgestaltung.

Dabei existieren zwischen den alternativen Gesundheitssystemen und den adaptiven Reformoptionen schon prima vista sowohl komplementäre als auch substitutive Beziehungen. So genießt unabhängig von der Entscheidung für alternative Gesundheitssysteme oder adaptive Reformschritte die Ausschöpfung von Wirtschaftlichkeitsreserven durch strukturelle Reformen auf der Ausgabenseite in normativer Hinsicht allererste Priorität. Unbeschadet der Interdependenzen, die zwischen der Finanzierungs- und der Ausgabenseite der GKV bestehen, schließt vor allem die Beschäftigung mit einer Änderung von Finanzierung und Beitragsgestaltung weitere Bemühungen um eine Verbesserung von Effizienz und Effektivität der Gesundheitsversorgung keineswegs aus. So stellen der Befund einer konjunkturellen und strukturellen Wachstumsschwäche der Finanzierungsbasis in der GKV und der Hinweis auf Effizienz- und Effektivitätsreserven des Systems keine widersprüchlichen Thesen dar. Die Beschäftigung mit Reformoptionen auf der Einnahmen- bzw. Finanzierungsseite verfolgt keineswegs den Zweck, von den Wirtschaftlichkeitsreserven der derzeitigen Gesundheitsversorgung abzulenken. Umgekehrt vermag der Hinweis auf bestehende Unter-, Über- und Fehlversorgung die anstehenden Finanzierungsprobleme kurzfristig nicht zu lösen und auch mittelfristig nur abzumildern. Der Übergang zu einem alternativen Gesundheitssystem würde allerdings weitere Diskussionen über eine Änderung von Finanzierung und Beitragsgestaltung erübrigen.

Die Neufassung des Leistungskataloges der GKV schließt im Detail die Reformschritte

- Reorganisation der Finanzierung innerhalb der Teilsysteme der Sozialversicherung bzw. Revision der Politik der so genannten Verschiebebahnhöfe,

- Verlagerung von krankenversicherungsfremden Leistungen auf andere Ausgabenträger sowie 
- Einengung des Leistungskataloges der GKV

ein.

Als Reformoptionen im Rahmen einer Änderung von Finanzierung und Beitragsgestaltung stehen zur Diskussion:

- eine teilweise Steuerfinanzierung durch gesundheitsbezogene Verbrauchsteuern, z. B. auf Tabak und Alkohol

- eine Ausweitung der Selbstbeteiligung der Patienten

- $\quad$ eine Modifikation der Beitragsgestaltung

\section{Der Übergang zu alternativen Gesundheitssystemen}

Von den alternativen Gesundheitssystemen steht ein Wechsel zu einer rein steuerfinanzierten Gesundheitsversorgung derzeit in Wissenschaft und Politik am wenigsten zur Diskussion. Mit dem Wechsel von beitragszu steuerfinanzierten sozialen Gesundheitssystemen gehen die Versicherten bzw. Bürger ihrer Versicherungsrechte bzw. -ansprüche verlustig, denn das Wesen einer allgemeinen Steuer besteht darin, dass kein Steuerpflichtiger mit seiner Abgabe einen Anspruch auf irgendeine staatliche Leistung erwirbt. Die beitragsfinanzierte Gesundheitsversorgung stellt dagegen keine staatliche Transferleistung dar wie z. B. die Sozialhilfe, sondern eine mit spezifischen Abgaben bezahlte Versicherungsleistung. Ein Wechsel von der beitrags- zur steuerfinanzierten Gesundheitsversorgung mindert die Gestaltungs- und Souveränitätsrechte der Bürger, die Gesundheitsleistungen dann nicht mehr als anspruchsberechtigte Versicherte, sondern wie staatliche Transferempfänger erhalten. Nach repräsentativen Studien über die Einstellungen und Erwartungen der Bürger findet eine Einheitskasse, auf die eine steuerfinanzierte Gesundheitsversorgung praktisch hinausläuft, eine klare Ablehnung und das Kassenwahlrecht eine überwiegende Zustimmung (siehe Wasem, J., 1999; Zok; K., 1999).

Die Vorschläge, von der umlagefinanzierten GKV zu einer kapitalgedeckten Finanzierung überzugehen, zielen primär darauf ab, den künftigen Ausgabeneffekten zu begegnen, die aus dem zu erwartenden Wandel der demographischen Struktur erwachsen. Im Hinblick auf die Unterschiede zwischen Kapitaldeckungs- und Umlageverfahren stammen die Begrifflichkeiten, die Modelle und die aus innen abgeleiteten Tendenzaussagen aus der Beschäftigung mit Problemen der Alterssicherung. Diese Aussagen zu den unterschiedlichen Effekten, die vom Kapitaldeckungs- und Umlageverfahren im demographischen Wandel auf die ge- 
setzliche Rentenversicherung (GRV) ausgehen, lassen sich qualitativ und quantitativ nur sehr eingeschränkt auf die künftige Absicherung des Krankheitsrisikos übertragen. Die beiden Umlagesysteme GRV und GKV weichen nämlich im Hinblick auf ihre intergenerativen Transfers deutlich voneinander ab. Während die junge Generation in der GRV nahezu ausschließlich Beiträge zum Unterhalt der Rentner leistet, finanziert sie in der GKV auch ihr eigenes Krankheitsrisiko bzw. die entsprechenden Gesundheitsausgaben. Ihre intergenerative Umlage besteht lediglich zwischen ihren tatsächlichen und ihren altersgruppenspezifisch äquivalenten Beiträgen.

Im Unterschied zur GRV entrichten in der GKV auch die Rentner bzw. die höheren Alterskohorten Beiträge, so dass sie nur insoweit intergenerative Transfers erhalten, wie ihre tatsächlichen Beiträge ihre altersgruppenspezifisch äquivalenten unterschreiten. Verglichen mit der GRV fallen somit in der GKV die intergenerativen Transfers und damit auch die implizite Schuld, d.h. Forderungen, die junge Beitragszahler erwerben, deutlich niedriger aus. Im Hinblick auf die Ausgaben- und Einnahmendeterminante des demographischen Wandels besitzt die partielle Kapitaldeckung der PKV bei negativer Wachstumsrate der Bevölkerung gegenüber der umlagefinanzierten GKV zwar Vorzüge, aber diese erreichen bei weitem nicht die Relevanz wie die entsprechenden Unterschiede zwischen GRV und kapitalgedeckter Altersvorsorge. Zudem stellt die kapitalgedeckte Finanzierung des Krankheitsrisikos unter Wettbewerbsaspekten solange keine attraktive Alternative zur GKV dar, wie die private Krankenversicherung (PKV) im Falle eines beabsichtigten Versicherungswechsels keine individualisierten Altersrückstellungen mitzugeben vermag.

Die Finanzierung des Krankheitsrisikos mit Hilfe von fixen Pro-KopfBeiträgen entspricht als Umlageverfahren dem geltenden deutschen System mehr als die steuerfinanzierte oder kapitalgedeckte Gesundheitsversorgung. Im Unterschied zur GKV beschränkt sie allerdings die Solidarfunktion auf einen Ausgleich zwischen geringen und hohen Gesundheitsrisiken sowie jungen und alten Versicherten, d. h., sie beinhaltet keine beitragsfreie Mitversicherung von Familienangehörigen und mit Ausnahme der sozialpolitisch motivierten, steuerfinanzierten Zuschüsse zur Beitragsreduktion ${ }^{1}$ - keine Beiträge, die von der Höhe des Arbeitsentgeltes bzw. der Rente abhängen. Die Finanzierung mit festen Kopfbeiträgen trennt die Sicherstellung einer adäquaten Gesundheits-

1

Je nach Ausgestaltung dieser Beitragsreduktion können die Beiträge dann, wie z. B. in der Schweiz, in einem relativ weiten Tarifbereich ebenfalls vom (Haushalts-)Einkommen abhängen. 
versorgung, die der sozialen Krankenversicherung obliegt, von den übrigen verteilungspolitischen Aufgaben, die dann in die Zuständigkeit der Steuer- und Transferpolitik fallen. Theoretisch betrachtet können die GKV und eine Finanzierung über fixe Kopfbeiträge, ergänzt um distributive Maßnahmen, die gleichen verteilungspolitischen Effekte erzielen.

Die Finanzierung über fixe Kopfbeiträge besitzt im Vergleich zur GKV den Vorzug, die Gesundheitsausgaben von den Arbeitskosten abzukoppeln. Sie entlastet damit den Faktor Arbeit und beseitigt die Wachstumsschwäche der Finanzierungsbasis des geltenden Systems. Mit ihrer klaren Trennung von allokativen Gesundheitsaufgaben und verteilungspolitischen Funktionen stellt die Finanzierung über feste Kopfbeiträge ein überzeugendes wirtschaftspolitisches Konzept dar. Problematisch erscheinen die mit dem erheblichen Transferbedarf und seiner noch völlig offenen Finanzierung einhergehenden Friktionskosten. Die Betroffenen hegen in dieser Hinsicht nicht unberechtigte Zweifel, ob bei diesem Übergang die bisherigen distributiven Effekte angesichts der Haushaltslage der Gebietskörperschaften auch in entsprechendem Umfang erhalten bleiben.

\section{Ausschöpfung von Wirtschaftlichkeitsreserven durch strukturelle Reformen}

Unbeschadet vorhandener Effizienz- und Effektivitätsmängel bietet das deutsche Gesundheitswesen auch aus internationaler Perspektive für alle Bürger einen sehr weitgehenden Versicherungsschutz, ein nahezu flächendeckendes Angebot an Gesundheitsleistungen und einen hohen Versorgungsstandard. Verglichen mit anderen sozialen Krankenversicherungen bietet die GKV einen sehr umfassenden Leistungskatalog sowie eine gute Erreichbarkeit der Leistungen und konfrontiert die Patienten kaum mit Rationierungen, z. B. in Form von Warteschlangen. Das deutsche Gesundheitswesen weist jedoch unter Effizienz- und Effektivitätsaspekten vor allem folgende Schwachstellen auf:

- $\quad$ Die medizinisch wie ökonomisch fragmentierten medizinischen Behandlungsarten setzen keine bzw. zu geringe Anreize für eine effektive und effiziente sektorenübergreifende Versorgung.

- Die Versicherten und Patienten verfügen über eine zu geringe Transparenz über die Behandlungsabläufe, allfällige Leistungsqualitäten und die Leistungserbringer. Diese Defizite gehen einher mit einem Mangel an Patientenautonomie und unzureichenden Voraussetzungen sowie Anreizen für die Wahrnehmung von Eigenverantwortung. 
- Gesundheitsförderung und Prävention fristen ebenso wie eine effektive Qualitätssicherung, eine Zertifizierung von Gesundheitseinrichtungen und evidenzbasierte Behandlungsleitlinien noch ein Schattendasein.

- Die Vergütungssysteme orientieren sich kaum an gesundheitlichen Outcomes im Sinne einer ergebnisorientierten Vergütung und fördern teilweise von ihren Anreizen her Unter-, Über- und Fehlversorgung. Die Leistungserbringer können sich gegenüber Versicherten und Patienten zu wenig mit ihren speziellen Qualifikationen und Fertigkeiten profilieren.

- Die im Gesundheitsstrukturgesetz angelegte Intensivierung des Wettbewerbs der Krankenkassen führte bisher nicht in erwünschtem Maße zu einem Leistungs- und Qualitätswettbewerb, der die Effizienz und Effektivität der Gesundheitsversorgung spürbar verbessert. Zudem verfügen die Krankenkassen auf der Leistungsseite kaum über Wettbewerbsparameter, was zu einer extrem hohen Gewichtung von Beitragssatzunterschieden führt und den Übergang von der allgemeinen, parafiskalischen Leistungsverwaltung zum kassenspezifischen, zielorientierten Gesundheitsmanagement behindert.

- Im Rahmen der ambulanten vertragsärztlichen Versorgung schließen die Kassenärztlichen Vereinigungen mit den Landesverbänden der Krankenkassen und den Verbänden der Ersatzkassen Gesamtverträge, so dass die einzelnen Ärzte lediglich als Mengenanpasser fungieren. Bei steigender Menge sinkt der Punktwert einer Leistung, was vielfach einen circulus vitiosus auslöst.

- Die Krankenhäuser vereinbaren ihren Versorgungsvertrag mit den Krankenkassen auf Landesebene kassenartenübergreifend und gemeinsam. Infolge der dualen Krankenhausfinanzierung können die Krankenhäuser über die notwendigen Investitionen nicht nach eigenen Prioritäten entscheiden. Die Investitionsfinanzierung orientiert sich daher zu stark an landespolitischen und zu wenig an betriebswirtschaftlichen Aspekten. Zudem führt die duale Finanzierung zu Wettbewerbsverbesserungen zwischen öffentlich-rechtlichen, freigemeinnützigen und privaten Krankenhausträgern, wobei die ungleiche Finanzierung der Länder diese Verzerrungen noch verstärkt. Der starre BAT-Tarif schränkt Möglichkeiten zu einer leistungsgerechten Entlohnung ein. 
- Die Arzneimitteldistribution erfolgt immer noch in nahezu mittelalterlichen Vertriebsstrukturen und bedarf einer wettbewerblichen Liberalisierung.

Das Wissen um diese Wirtschaftlichkeitsreserven vermag aber keine Budgetdefizite zu finanzieren oder innen vorzubeugen. Eine Ausschöpfung des Rationalisierungspotentials setzt zunächst strukturelle Reformen voraus, die zumeist erst mit einer zeitlichen Verzögerung zu Ressourceneinsparungen und/oder Verbesserungen der gesundheitlichen Outcomes führen. Letztere besitzen unter normativen Aspekten keineswegs einen geringeren Wert als Kosteneinsparungen, können aber keinen Beitrag zur Finanzierung von Budgetdefiziten leisten. So versuchte die Bundesregierung in der abgelaufenen Legislaturperiode, die Effektivität und Effizienz der Gesundheitsversorgung vornehmlich über eine Förderung von Prävention und Rehabilitation, eine Stärkung der Qualitätssicherung, einen Ausbau der integrierten Versorgung und eine Morbiditätsorientierung des Risikostrukturausgleiches zu verbessern. Die möglichen Outcome-Effekte dieser Reformmaßnahmen entziehen sich derzeit zwangsläufig noch einer empirischen Evaluation. Die fiskalische Zielsetzung vermochte diese Maßnahmen, wie die steigenden Beitragssätze belegen, jedoch zumindest zunächst nicht zu realisieren. Die Ausschöpfung von Wirtschaftlichkeitsreserven bildet insofern eine wichtige Daueraufgabe der Gesundheitspolitik. Die entsprechenden Bemühungen reichen angesichts der Wachstumsschwäche der Finanzierungsbasis ohne weitere Reformen jedoch nicht aus, um gleichzeitig die Beitragssatzstabilität in der GKV zu verwirklichen und implizite Rationierungen zu vermeiden.

\section{Zur Neufassung des Leistungskataloges der GKV}

Der historisch gewachsene Leistungskatalog der GKV beinhaltet nicht nur Leistungen, die einen eindeutigen Morbiditätsbezug aufweisen, sondern auch solche, die primär oder gar ausschließlich sozial- oder familienpolitischen Zielen dienen. Bei einer Neufassung des Leistungskataloges gilt es daher zunächst - vor allem im Sinne der Leistungsempfänger - zu unterscheiden, ob eine Leistung entfällt, oder ob lediglich ein anderer Ausgabenträger ihre Finanzierung übernimmt. Im ersten Fall geht es um die Neubestimmung des objektiven Bedarfs im Rahmen einer solidarisch finanzierten Gesundheitsversorgung, im zweiten um eine adäquate bzw. funktionsgerechte Zuordnung von Leistungen und ihrer Finanzierung auf die einzelnen Sozialversicherungszweige und Gebietskörperschaften. 
Die krankenversicherungsfremden Leistungen auf der Ausgabenseite umfassen vor allem

- Sterbegeld,

- Schwangerschafts- und Mutterschaftsleistungen gemäß $\S 195 \mathrm{ff}$. RVO,

- Empfängnisverhütung,

- Sterilisation,

- Schwangerschaftsabbruch,

- Haushaltshilfe nach § 38 SGB V,

- Krankengeld bei Erkrankung des Kindes sowie

- $\quad$ Finanzierung der allgemeinmedizinischen Weiterbildung nach Art. 8 des GKV-Solidaritätsstärkungsgesetzes (GKV-SolG).

Diese krankenversicherungsfremden Leistungen belaufen sich auf jährlich ca. 2,5 Mrd. Euro, was etwa 0,25 Beitragssatzpunkten entspricht. Bei weiterer Interpretation lassen sich hier auch die Aufwendungen hinzurechnen, die aus privaten gefahrengeneigten Aktivitäten oder generell aus privaten Unfällen resultieren. Ihre Verlagerung auf eine obligatorische private Unfallversicherung als Pendant zur betrieblichen Unfallversicherung würde die GKV um schätzungsweise 8 bis $10 \mathrm{Mrd}$. Euro jährlich und damit knapp um 1 Beitragssatzpunkt entlasten (ähnlich Sachverständigenrat zur Begutachtung der gesamtwirtschaftlichen Entwicklung 2002, Ziffer 492). Die Finanzierung dieser privaten Unfallversicherung könnte kapitalgedeckt und risikoäquivalent, aber auch im Rahmen eines Umlageverfahrens über Pro-Kopf-Prämien erfolgen. Im letzten Fall würde die Pro-Kopf-Prämie bei Beitragsfreiheit von Kindern und Jugendlichen etwa 15,50 Euro im Monat betragen (ebenda). ${ }^{2}$

Krankenversicherungsfremde Leistungen (im weiteren Sinne) können auch auf der Einnahmenseite auftreten, wenn bestimmte Versichertengruppen aus sozial- oder familienpolitischen Gründen keine oder nur ermäßigte Beiträge entrichten. Hierzu zählen u. a. die Beitragsausfälle bei

- Personen während des Erziehungsurlaubs,

- Studierenden und Praktikanten,

- Personen in Einrichtungen der Jugendhilfe und im Strafvollzug,

- Teilnehmern an berufsfördernden Maßnahmen,

Eine Möglichkeit bestünde daneben darin, bestimmte abgrenzbare Unfallrisiken, wie z. B. solche aus dem Kraftfahrverkehr und aus Risikosportarten, risikoäquivalent sowie kapitalgedeckt sowie den allgemeinen Rest im Rahmen eines Umlageverfahrens zu finanzieren. 
- Leistungsbeziehern nach dem Arbeitsförderungsgesetz,

- Härtefällen sowie

- beitragsfrei mitversicherten Familienmitgliedern.

Die Mindereinnahmen bei den Leistungsbeziehern nach dem Arbeitsförderungsgesetz gehören zu den Beitragsausfällen, mit denen die GKV im Zuge von "Verschiebebahnhöfen" innerhalb der Sozialversicherung zur Entlastung anderer Zweige der sozialen Sicherung beitrug. Die jährlichen Einnahmenausfälle, die der GKV daraus erwachsen, liegen je nach Abgrenzung bei 4 bis 6 Mrd. Euro, d. h. bei 0,4 bis 0,6 Beitragssatzpunkten (vgl. Beske, F., Drabinski, T., und Michel, C., 2002). Die stärksten Einnahmenausfälle verursacht die beitragsfreie Mitversicherung von Familienangehörigen mit schätzungsweise fast $21 \mathrm{Mrd}$. Euro im Jahr, was 2,1 Beitragssatzpunkte ausmacht. Darunter erreichen die jährlichen Beitragsausfälle durch die beitragsfreie Mitversicherung von Kindern und Jugendlichen bis 19 Jahren immer noch fast 11 Mrd. Euro und damit 1,1 Beitragssatzpunkte.

Da sich bereits

- die krankenversicherungsfremden Leistungen auf der Ausgabenseite,

- die Entlastung durch eine private Unfallversicherung,

- die Revision der so genannten Verschiebebahnhöfe,

- die Mindereinnahmen durch Personen im Erziehungsurlaub sowie

- die beitragsfreie Mitversicherung von Kindern und Jugendlichen

auf über $30 \mathrm{Mrd}$. Euro summieren, würde eine solche Umfinanzierung in der GKV zu einer Beitragssatzabsenkung von über 3 Beitragssatzpunkten führen. ${ }^{3}$

Bei den meisten krankenversicherungsfremden Leistungen steht nicht ihre Streichung, sondern die Übernahme ihrer Finanzierung durch die Gebietskörperschaften zur Diskussion. In diesem Kontext können die Krankenkassen diese Leistungen im Rahmen einer Auftragsverwaltung auch weiterhin erbringen und erstattet erhalten. Eine solche Lösung nutzt die bestehenden Verwaltungs- und Organisationsstrukturen der Krankenkassen und erübrigt ihren Neuaufbau bei den Gebietskörperschaften. Für eine Verlagerung der krankenversicherungsfremden Leistungen von der Beitrags- in die Steuerfinanzierung sprechen auch ar-

3 Da es sich bei der Revision der so genannten Verschiebebahnhöfe um eine Verlagerung der Finanzierung innerhalb der Sozialversicherung handelt, sinken die Sozialversicherungsbeiträge insgesamt nur um gut 2,5 Beitragssatzpunkte. 
beitsmarktpolitische Gründe. Bei gleichem Leistungsvolumen erfordert die Beitragsentlastung der GKV zwar eine Erhöhung von Steuern und/oder öffentlicher Schuld in gleicher Höhe, dabei können aber unterschiedliche beschäftigungspolitische Effekte anfallen. Die Beitragsentlastung reduziert die Lohnnebenkosten und fördert damit den Einsatz des Produktionsfaktors Arbeit, während sich die Steuererhöhungen auf den Konsum konzentrieren können.

Das Sozialgesetz definiert für die GKV keinen eindeutigen Leistungskatalog, der den objektiven Bedarf determiniert, sondern gewährt den Versicherten einen sehr weitgehenden Leistungsanspruch (ähnlich Schwartz, F. W., und Jung, K., 2000; siehe auch den Beitrag von Schulte, G., in diesem Band). Die Notwendigkeit, den jeweiligen Leistungskatalog auf der Grundlage von Evaluationsergebnissen ständig auf den Prüfstand zu stellen, ergibt sich schon aus dem Erfordernis, Freiräume für neue, effektivere Behandlungsmethoden zu gewinnen. Der Versuch, diesen Leistungskatalog auf seinen notwendigen Kern einzuengen, sieht sich mit dem Problem konfrontiert, dass das Rationalisierungspotential der deutschen Gesundheitsversorgung weniger in dem zu umfangreichen Leistungsspektrum als vielmehr in seinem zu intensiven, $d$. h. nicht indikations- und situationsbezogenen Gebrauch wurzelt. Medizinischethische und ökonomische Kriterien können bei der Abgrenzung des Leistungskataloges einer solidarisch finanzierten Krankenversicherung zwar Orientierungshilfe leisten, sie vermögen aber in konkreten Einzelfällen auf deduktivem Wege noch keine eindeutige Entscheidung herbeizuführen. Vor dem Hintergrund dieser Einschränkungen stehen vor allem die folgenden Leistungen in der Diskussion bzw. im Rahmen der GKV zur Disposition:

- Fahrtkosten (ohne solche für Rettungsdienste) in Abhängigkeit von den Verkehrsverhältnissen und der Behandlungsintensität

- ambulante Vorsorgeleistungen in Kur- oder Badeorten

- $\quad$ kieferorthopädische Leistungen für Erwachsene und auch für Jugendliche, soweit die Behandlungsbedürftigkeit nicht bestimmten validen Indizes genügt

- in Abhängigkeit von ihrer Evidenzbasierung Indikationen und Formen der ambulanten Psychotherapie bei Erwachsenen

- Verfahren der so genannten Alternativmedizin

- Arzneimittel der besonderen Therapierichtungen 
- indikationsabhängig Heil- und Hilfsmittel, wie Massagen und Sehhilfen

\section{Änderung der Finanzierungs- und Beitragsgestaltung}

Bei einer Heranziehung von gesundheitsbezogenen, speziellen Verbrauchssteuern, z. B. auf Tabak und Alkohol, zur Deckung von Budgetdefiziten handelt es sich im Gegensatz zur Steuerfinanzierung von krankenversicherungsfremden Leistungen um eine entsprechende Finanzierung von genuinen Gesundheitsleistungen. Wie beim so genannten Maschinenbeitrag, der die Bemessung der Arbeitgeberbeiträge auf den Produktionsfaktor Kapital oder die gesamte Wertschöpfung des Unternehmens ausdehnt, führt eine solche Finanzierung dazu, dass die gruppenmäßige Äquivalenz der GKV und damit ihr Versicherungscharakter weiter abnimmt. Unabhängig vom kausalen Verhältnis, das zwischen Tabak- und Alkoholkonsum und den Gesundheitsausgaben besteht, verletzt eine solche Finanzierung auch den Budgetgrundsatz der NonAffektation öffentlicher Einnahmen. Zudem erzeugt eine Erhöhung dieser Steuern sehr regressive Verteilungseffekte. Unter fiskalischen Aspekten weist eine Finanzierung von Gesundheitsleistungen mit Hilfe von speziellen Verbrauchsteuern schließlich den Nachteil auf, dass sie die Wachstumsschwäche der Finanzierungsbasis der GKV verfestigt, denn die Einnahmen aus diesen Steuern nehmen im Wachstumsprozess deutlich unterproportional zum BIP zu.

Eine Ausweitung der Selbstbeteiligung der Patienten steht von allen Reformoptionen am stärksten im Mittelpunkt kontroverser, nicht selten ideologischer Diskussionen. Die entsprechenden Missverständnisse setzen häufig schon beim Begriff an, denn bei der unmittelbaren Teilzahlung für eine Versicherungsleistung, $d$. h. der Selbstbeteiligung im engeren Sinne, handelt es sich keineswegs um die einzige finanzielle Beteiligung des Patienten an den Gesundheitsausgaben der GKV. Der Patient entrichtet darüber hinaus als Versicherter Beiträge zur Finanzierung der GKV und beteiligt sich auch im Zuge der Selbstmedikation an seiner eigenen Gesundheitsversorgung. Ferner lässt sich ein gesundheitsbewusstes Verhalten als Selbstbeteiligung interpretieren. Die dadurch ausgelösten Effekte können die Gesundheitsaufwendungen der GKV möglicherweise weit stärker entlasten als unmittelbare Teilzahlungen. Im Sinne der Inzidenz der Beiträge zur GKV tragen die Patienten und Versicherten als Konsumenten schließlich auch überwiegend die Arbeitgeberanteile, denn diese erlauben wie Kostensteuern bei normalen Angebotsund Nachfrage-Elastizitäten eine weitgehende Überwälzung auf die Konsumgüterpreise. 
Die Selbstbeteiligung im engeren Sinne besitzt primär eine Finanzierungs- und eine allokative Steuerungsfunktion, während Verteilungsaspekte eher restriktive Nebenbedingungen darstellen. Unter diesen Aspekten bedürfen die Selbstbeteiligungsregelungen in der GKV, z. B. beim Zahnersatz und bei Arzneimitteln, unabhängig von ihrem fiskalischen Umfang einer Korrektur, denn sie erfüllen weder die allokative Funktion noch die distributive Nebenbedingung zufriedenstellend. So sollte sich die Befreiungsregelung nicht an medizinischen Indikationen, sondern ausschließlich am verteilungspolitisch relevanten Einkommen der Patienten orientieren. Angesichts der im internationalen Vergleich bei dem umfangreichen Leistungskatalog der GKV sehr niedrigen Selbstbeteiligung erscheint auf der Grundlage von Härtefallregelungen und $\ddot{U}$ berforderungsklauseln eine moderate Erhöhung des Umfangs der Selbstbeteiligung vertretbar und je nach fiskalischer Lage sogar angezeigt. Sie belastet viele Patienten unter Umständen weniger als eine Eingrenzung des Leistungskataloges, die auf eine 100-prozentige Selbstbeteiligung hinauslaufen kann. Die Selbstbeteiligung besitzt unter normativen Aspekten, auch gegenüber einer impliziten Rationierung, eindeutige Vorzüge. Ihre normative Position gegenüber anderen adaptiven Reformoptionen gilt es, zielorientiert abzuwägen.

\section{Eine Änderung der Beitragsgestaltung kann vor allem an}

- der Versicherungspflicht in der GKV bzw. dem Pflichtversichertenkreis,

- der Beitragsbemessungsgrenze,

- der Beitragsbemessungsgrundlage und

- der beitragsfreien Mitversicherung

ansetzen.

Von diesen Reformoptionen im Rahmen der Beitragsgestaltung standen in jüngster Zeit vor allem die Erhöhung der Versicherungspflicht- und Beitragsbemessungsgrenze im Zentrum kontroverser Diskussionen. Die für das Jahr 2003 diskretionär auf monatlich 3.825 Euro angehobene Versicherungspflichtgrenze erscheint nach wie vor sachlich willkürlich, d. h. unter Solidaritätsaspekten zu niedrig und unter Subsidiaritätsaspekten zu hoch. Insofern überrascht es nicht, dass sich hier Befürworter einer weiteren Erhöhung oder gar Aufhebung dieser Grenze und ihrer Absenkung auf das zuvor geltende Niveau von monatlich 3.450 Euro mit ihren Ansichten und Argumenten gegenüberstehen (siehe auch die Beiträge von Pfeiffer, D., und Leienbach, V., in diesem Band). Eine isolierte Anhebung der Versicherungspflichtgrenze auf das Niveau der Beitragsbemessungsgrenze in der GRV, d. h. auf derzeit (2003) monatlich 
5.100 Euro, entlastet die GKV fiskalisch allerdings kaum (siehe Wille, E., und Igel, C., 2002) und nutzt ihr somit weit weniger als sie der PKV schadet. Eine parallele Anhebung von Versicherungspflicht- und Beitragsbemessungsgrenze auf dieses Niveau erlaubt dagegen eine Beitragssatzsenkung um etwa 0,7 - mittelfristig 0,9-Beitragssatzpunkte. Eine kombinierte Erhöhung dieser beiden Grenzen belastet allerdings gerade jene Versicherten zusätzlich, die mit einem monatlichen Arbeitsentgelt zwischen 3.340 Euro und 5.100 Euro bereits einer sehr hohen Grenzabgabenbelastung unterliegen. Für diese Versichertengruppe wirkt diese Zusatzbelastung wie eine Steuer, da ihr mit Ausnahme des Krankengeldes keine Mehrleistungen gegenüberstehen.

Für eine Verbreiterung der Beitragsbemessungsgrenze (siehe hierzu auch den Beitrag von Oberender, P., in diesem Band) sowie eine Änderung der beitragsfreien Mitversicherung sprechen sowohl allokative als auch distributive Gründe. Die Verbreiterung der Beitragsbemessungsgrundlage, die neben Arbeitsentgelten und Rentenzahlungen auch andere Einkunftsarten, wie $z$. B. Zinsen und Mieten, generell, d. $h$. auch bei Pflichtversicherten, in die Beitragsbemessung einbezieht, trägt der gegenüber der Nachkriegszeit veränderten Einkommens- und Vermögenssituation der Versicherten Rechnung. Eine Reformoption im Rahmen der beitragsfreien Mitversicherung sieht für Ehepartner ein Splitting des gemeinsamen Arbeitsentgeltes bzw. Einkommens mit anschließender Anwendung des hälftigen Beitragssatzes auf beide Entgeltteile vor. Das Splittingverfahren entspricht insofern dem bisherigen Prinzip der Beitragsgestaltung, als es zu keiner zusätzlichen Belastung bei einer Familie führt, bei der das Arbeitsentgelt bzw. Einkommen des berufstätigen Partners unter der Beitragsbemessungsgrenze liegt.

Diese beiden Reformoptionen weisen je nach Ausgestaltung ein Beitragssatz-Senkungspotential zwischen 0,7 und 1,3 Beitragssatzpunkten auf. Die fiskalische Wirkung einer Verbreiterung der Beitragsbemessungsgrundlage, die bei maximal 0,4 Beitragssatzpunkten liegt, hängt vor allem davon $a b$, ob die übrigen Einkunftsarten dem vollen oder halben Beitragssatz unterliegen und ob die Empfänger von Zinsen in den Genuss eines Freibetrages oder einer Freigrenze kommen. Das Splittingverfahren, das eine Senkung der Beitragssätze um maximal 0,9 Prozentpunkte erlaubt, könnte zunächst den nichtberufstätigen Partner, der Kinder erzieht bzw. erzogen hat und/oder häusliche Pflegedienste leistet, von der Beitragsbelastung freistellen. Der fiskalische Ertrag dieser Reformoption nimmt weiter ab, wenn für die Versicherten hier die Option besteht, zwischen dem Splittingverfahren und der Zahlung eines Mindestbeitrages für den nichtberufstätigen Partner zu wählen. 


\section{Beziehungen zwischen den Reformoptionen}

Zwischen den diskutierten Reformoptionen existieren sowohl komplementäre Beziehungen als auch konkurrierende Alternativen. Eine komplementäre Kombination von mehreren Reformoptionen bietet sich an, wenn erhebliche Budgetdefizite drohen oder eine deutliche Senkung der Beitragssätze angestrebt wird. Eine deutliche Senkung der Beitragssätze besitzt im Rahmen einer Reform auch den Vorzug, dass den Mehreinnahmen und/oder Minderausgaben, die für Patienten, Versicherte und Steuerzahler zwangsläufig mit Belastungen einhergehen, gleichzeitig spürbare Entlastungen bei den Beiträgen entgegenstehen. Schließlich spricht für einen kombinierten Einsatz von Elementen mehrerer Optionen neben dem stärkeren Beitragssatzeffekt die größere Chance, die damit verbundenen Belastungen gleichmäßiger zu verteilen.

Für die budgetäre Situation der GKV spielt es keine Rolle, ob im Zuge von Reformen bestimmte Leistungen aus dem geltenden Katalog gänzlich entfallen oder ob ihre Finanzierung auf einen anderen Ausgabenträger übergeht. Anders verhält es sich im Hinblick auf die Lohnnebenkosten, die implizite Staatsschuld und die Interessenlage der Versicherten bzw. Patienten. Letztere ziehen eine Verlagerung der Finanzierung bestimmter Leistungen auf andere öffentliche Ausgabenträger, Leistungskürzungen im Sinne einer Einengung des Leistungskataloges der GKV offensichtlich vor. Eine Revision der so genannten Verschiebebahnhöfe innerhalb der Sozialversicherungszweige entlastet zwar fiskalisch die GKV, reduziert aber weder die Lohnnebenkosten noch die implizite Staatsschuld. Die Entlastung der GKV durch eine private Unfallversicherung führt zwar zu einer Senkung der Lohnnebenkosten, aber im Falle ihrer Umlagefinanzierung nicht zu einer Reduktion der impliziten Staatsschuld. Die finanzielle Verlagerung der (übrigen) krankenversicherungsfremden Leistungen auf die Gebietskörperschaften senkt neben der Entlastung der GKV sowohl die Lohnnebenkosten als auch, sofern dort steuerfinanziert, die (implizite) Staatsschuld.

Interdependenzen bestehen auch zwischen den adaptiven Reformoptionen und den alternativen Gesundheitssystemen. So weisen kapitalgedeckte Systeme den Vorzug auf, keine implizite Staatsschuld aufzubauen und bei demographischem Wandel keine verteilungspolitischen Generationenprobleme auszulösen. Indem mehrere adaptive Reformoptionen die implizite Staatsschuld reduzieren, schwächen sie die intergenerativen Verteilungsprobleme zumindest etwas ab. Die damit einhergehende Senkung der Beitragssätze dient zwar nicht mit der gleichen Konsequenz, aber gleichwohl in der Tendenz dem auch mit fixen Pro-KopfBeiträgen verfolgten Ziel, die ausschließliche Bindung der Gesundheitsausgaben an die Lohnnebenkosten zu lockern. Die Verlagerung der 
krankenversicherungsfremden Leistungen auf andere Ausgabenträger benötigt ebenso wie der Übergang zu einer Kapitaldeckung oder die Finanzierung mit Hilfe von Pro-Kopf-Beiträgen ein Transfervolumen aus anderen öffentlichen Haushalten. Schließlich führt die Erweiterung der Beitragsbemessungsgrundlage zu einer Einbeziehung aller Einkunftsarten und das Splittingverfahren tendenziell zu einem Wechsel vom Individual- zum Haushaltsprinzip. Beide Elemente, d. h. die Berücksichtigung aller Einkunftsarten sowie das Haushaltsprinzip, kennzeichnen auch die kapitalgedeckte Finanzierung und die fixen Pro-Kopf-Beiträge.

\section{Literatur}

Arbeitskreis "Volkswirtschaftliche Gesamtrechnung der Länder" (2002): Bruttoinlandsprodukt, Internet, ohne Ortsangabe.

Beske, Fritz, Drabinski, Thomas und Michel, Claus (2002): Politische Entscheidungen zu Lasten der gesetzlichen Krankenversicherung, Kiel.

Breyer, Friedrich, und Zweifel, Peter (1997): Gesundheitsökonomie, 2. Aufl., Berlin et al.

Bundesdruckerei (1999): STATIS, Die Zeitreihen des Statistischen Bundesamtes, CD-Rom, Version 1.1 (ohne Ortsangabe).

Bundesministerium für Arbeit und Sozialordnung (1998-2000): Statistisches Taschenbuch, Arbeits- und Sozialstatistik, Bonn.

Bundesministerium für Gesundheit (2000): Statistisches Taschenbuch Gesundheit 2000, Bonn.

Bundesministerium für Gesundheit (2001): Daten des Gesundheitswesens, Ausgabe 2001, Band 137, Schriftenreihe des Bundesministeriums für Gesundheit, Bonn.

Klose J., und Schnellschmidt, Henner (2001): Finanzierung und Leistungen der gesetzlichen Krankenversicherung, einnahmen- und ausgabenbezogene Gestaltungsvorschläge im Überblick, Bonn.

Sachverständigenrat für die konzertierte Aktion im Gesundheitswesen (1994): Sachstandsbericht 1994, Gesundheitsversorgung und Krankenversicherung 2000, Baden-Baden.

Sachverständigenrat für die konzertierte Aktion im Gesundheitswesen (1995): Sondergutachten 1995. Gesundheitsversorgung und Krankenversicherung 2000. Mehr Ergebnisorientierung, mehr Qualität und mehr Wirtschaftlichkeit, Baden-Baden. 
Sachverständigenrat zur Begutachtung der gesamtwirtschaftlichen Entwicklung (2002): Jahresgutachten 2002/03, BT-Drucksache 15/100, Bonn, den 15.11.2002.

Statistisches Bundesamt (1994 - 2000): Statistisches Jahrbuch für die Bundesrepublik und für das Ausland, Wiesbaden.

Statistisches Bundesamt (2002): D-Statis, Erwerbstätigkeit früheres Bundesgebiet, Internet, Wiesbaden.

Wasem, Jürgen (1999): Das Gesundheitswesen in Deutschland: Einstellungen und Erwartungen der Bevölkerung. Wissenschaftliche Analyse und Bewertung einer repräsentativen Bevölkerungsstudie, Neuss.

Wille, Eberhard, und Ulrich, Volker (1991): Bestimmungsfaktoren der Ausgabenentwicklung in der gesetzlichen Krankenversicherung (GKV), in: Hansmeyer, KarlHeinrich (Hrsg.): Finanzierungsprobleme der sozialen Sicherung II, Schriften des Vereins für Sozialpolitik, N. F. Bd. 194/II, Berlin, S. 9-115.

Wille, Eberhard (1998): Zukünftige finanzielle Absicherung des Krankheitsrisikos, in: Arbeit und Sozialpolitik, Heft $1 / 2$, S. $16-27$.

Wille, Eberhard (2001): Basis- und Zusatzversorgung in der gesetzlichen Krankenversicherung, Stuttgart.

Wille, Eberhard (2002): Reformoptionen der Beitragsgestaltung in der gesetzlichen Krankenversicherung, in: Gesundheit und Gesellschaft, 2. Jg., Ausgabe 3 (Juli), S. $7-14$.

Wille, Eberhard, und Igel, Christian (2002): Zur Reform der Beitragsgestaltung, insb. der Pflichtversicherungsgrenze in der gesetzlichen Krankenversicherung - eine empirische Analyse. Gutachten im Auftrag des Verbandes der privaten Krankenversicherung e.V., Mannheim.

Zok, Karl (1999): Anforderungen an die gesetzliche Krankenversicherung. Einschätzungen und Erwartungen aus Sicht der Versicherten, WIdO-Materialien 43, Bonn. 


\section{Demographische Effekte auf Ausgaben und Beitragssatz der GKV}

Volker Ulrich

\section{Einleitung}

Der Beitrag analysiert die Bedeutung der demographischen Alterung auf die Ausgaben und den Beitragssatz der gesetzlichen Krankenversicherung (GKV). Insbesondere für die Beitragssatzentwicklung kommen verschiedene Modellrechnungen und Prognosen zu stark divergierenden Ergebnissen, welche die Bandbreite möglicher Entwicklungen aufzeigen, von eher moderaten Steigerungsraten bis hin zu Beitragssätzen von über 30 Prozent. Eine Hinnahme von Beitragssatzsteigerungen in einem solchen Ausmaß allein in der GKV ist nicht vorstellbar und stellt sicherlich einen potenziellen Sprengsatz für die Finanzierung der GKV dar.

Wie lassen sich diese unterschiedlichen Resultate erklären? Liegen die Probleme der GKV eher auf der Einnahmenseite - Stichwort „Strukturelles Einnahmendefizit" -, oder ist es die Ausgabendynamik, kombiniert mit den Effekten des medizinisch-technischen Fortschritts, welche die zukünftige Finanzierung der GKV in Frage stellt? Möglich und durchaus realistisch erscheint natürlich auch, dass beide Effekte gemeinsam auftreten und sich sogar verstärken. Wie kann das gegenwärtige System auf diese Herausforderungen reagieren? Gibt es generell ein Finanzierungsverfahren, das geeigneter erscheint, die Auswirkungen des demographischen Wandels abzufedern?

\section{Demographische Alterung}

In Deutschland leben zurzeit über 82 Millionen Menschen. In 50 Jahren werden es rund 20 Prozent weniger sein, also rund 65 Millionen Menschen. Deutschland befindet sich damit auf dem Weg zu einer schrumpfenden und alternden Bevölkerung. Die zentralen Determinanten der Bevölkerungsentwicklung, Geburtenrate, Sterberate und Nettozuwanderungsrate weisen letztlich zu wenig "Vitalität" auf, um den demographischen Alterungsprozess aufhalten bzw. inm entgegenwirken zu können.

Natürlich sind Prognosen, die sich auf solche langen Zeiträume erstrecken, unsicher. Dennoch dürfte der demographische Wandel bereits seit längerem feststehen und erscheint auch nur noch bedingt beeinflussbar. 
Da die Geburtenrate zeitlich sehr stabil verläuft und auch die Entwicklung der Lebenserwartung einen eindeutigen Trend aufweist, besteht die größte Unsicherheit bei der Prognose der Bevölkerungsentwicklung hinsichtlich des Ausmaßes der Wanderungsbewegungen. Die Diskussionen über das Zuwanderungsgesetz haben zum einen gezeigt, dass Zuwanderungen nach bestimmten Kriterien gesteuert werden können und sollen, zeigen aber zum anderen auch, wie politisch brisant die Materie ist. Um diesen Aspekt zu berücksichtigen, arbeiten die meisten Bevölkerungsprognosen mit mehreren Varianten, die unterschiedliche (Netto-)Wanderungssalden unterstellen.

Die demographische Entwicklung wird damit im Wesentlichen von Kohorten bestimmt, die heute bereits geboren sind und den demographischen Wandel vergleichsweise genau zu prognostizieren gestatten. Mehr Einwanderung wird das Problem letztlich nicht lösen können, allerdings kann durch eine gezielte Einwanderungspolitik eine signifikante Entlastung bei den ökonomischen Folgen der demographischen Alterung erreicht werden (vgl. Hof 1999, S. 129).

Der Altersaufbau der deutschen Bevölkerung wird sich durch die skizzierte Entwicklung der drei zentralen Einflussgrößen Geburten, Sterbefälle und Wanderungen erheblich verändern. Abb. 1 zeigt die eingetretene Veränderung innerhalb von 100 Jahren $(1910$ - 2000) und die prognostizierte Veränderung der so genannten Alterspyramide bis zum Jahr 2050 aufgrund der 9. koordinierten Bevölkerungsvorausberechnung des Statistischen Bundesamtes (vgl. Statistisches Bundesamt 2000).

Zu Beginn des 20. Jahrhunderts ähnelte der Altersaufbau der deutschen Bevölkerung einer Pyramide mit starken Besetzungszahlen der unteren, jungen Altersklassen und geringen Besetzungszahlen der hohen Altersklassen. Aus dieser Pyramide wird bis zum Jahr 2050 ein Bevölkerungspilz werden, der sich genau umgekehrt beschreiben lässt. 


\section{Abb. 1: Altersaufbau der Bevölkerung in Deutschland}

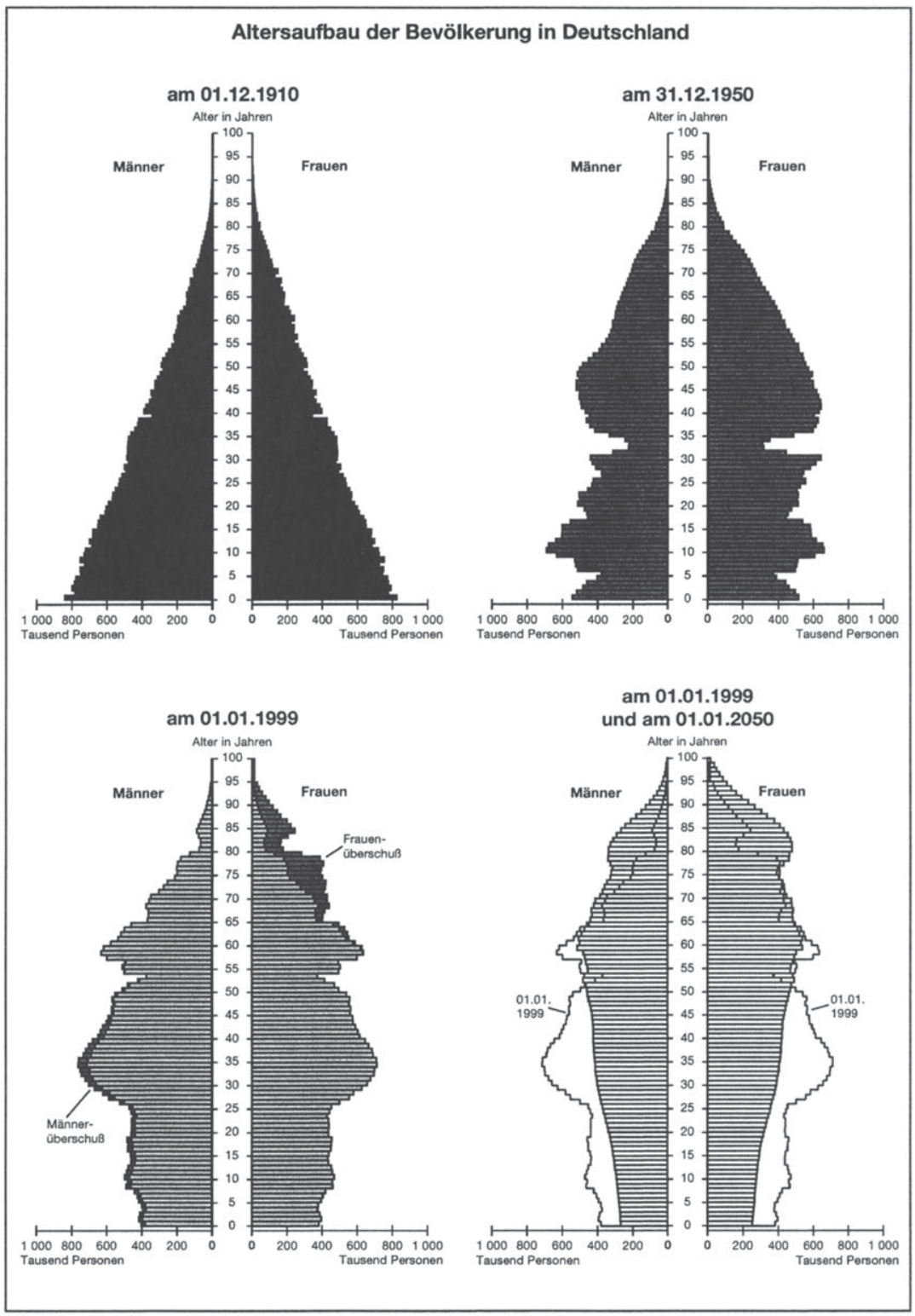

Quelle: Zusammengestellt aus: Statistisches Bundesamt 2000, S. 14 
Der so genannte doppelte Alterungsprozess (niedrige Geburtenrate und steigende Lebenserwartung) führt zu einer drastischen Veränderung der Altersstruktur der Bevölkerung, wobei die jungen und mittleren Jahrgänge nur noch schwach besetzt sind, während die höheren Altersgruppen immer stärker besetzt werden. Der demographische Wandel der letzten 100 Jahre hat bereits heute Spuren hinterlassen und aus der Pyramide einen Tannenbaum werden lassen. Insbesondere die mittleren Altersklassen zwischen 30 und 40 Jahren sind gegenwärtig noch stark besetzt (so genannte Babyboomer der 60er Jahre).

Die momentane Struktur ist sehr wichtig für die Entwicklung der nächsten Jahrzehnte, da in 30 bis 40 Jahren durch die geschilderte Entwicklung eine starke Gruppe von Personen über 60 Jahre einer relativ schwach besetzten Gruppe von jungen Menschen gegenübersteht (vgl. Statistisches Bundesamt 2000, S. 13).

Um die Verschiebungen im Altersaufbau noch plastischer werden zu lassen, bietet sich die Analyse des so genannten Altenquotienten an. Dabei wird die Zahl der 60-Jährigen und Älteren in Beziehung gesetzt zu je 100 Personen im „erwerbsfähigen Alter" von 20 bis unter 60 Jahren. Es ist offensichtlich, dass die Frage, „wie viele abhängige ältere Menschen auf je 100 Erwerbspersonen kommen“, gerade für die umlagefinanzierten sozialen Sicherungssysteme von zentraler Bedeutung ist (vgl. Abb. 2).

Abb. 2 zeigt, dass gegenwärtig auf 100 Personen zwischen 20 und 60 Jahren 40 Personen über 60 Jahre entfallen. Dieser Altenquotient erhöht sich, je nachdem, welches Bevölkerungsszenario man unterstellt, auf Werte zwischen 75 und 80 . Der Altenquotient wird sich demnach in den nächsten 50 Jahren etwa verdoppeln. Rechnet man zu den Altenquotienten noch den so genannten Jugendquotienten, $d . h$. die Zahl der unter 20-Jährigen je 100 Personen zwischen 20 und 60 Jahren, erhält man für den Gesamtquotienten in den nächsten Jahrzehnten Werte von über 100. Auf jeden Erwerbstätigen kommt damit mehr als eine junge oder alte, wirtschaftlich von ihm abhängige Person.

Die bereits beschlossene Anhebung des durchschnittlichen Rentenzugangsalters von derzeit 60 Jahren auf zukünftig 65 Jahre ist im unteren Teil von Abb. 2 dargestellt. Ganz offensichtlich führt eine solche Verlängerung der Lebensarbeitszeit zu einem geringeren erwarteten Anstieg des Altersquotienten auf 52 bis 56 im Jahr 2050. Verglichen mit der heutigen Bevölkerungsstruktur ergäbe sich aber auch hier eine starke Zunahme. 
Abb. 2: Zur Entwicklung des Altenquotienten „60“ und „65“

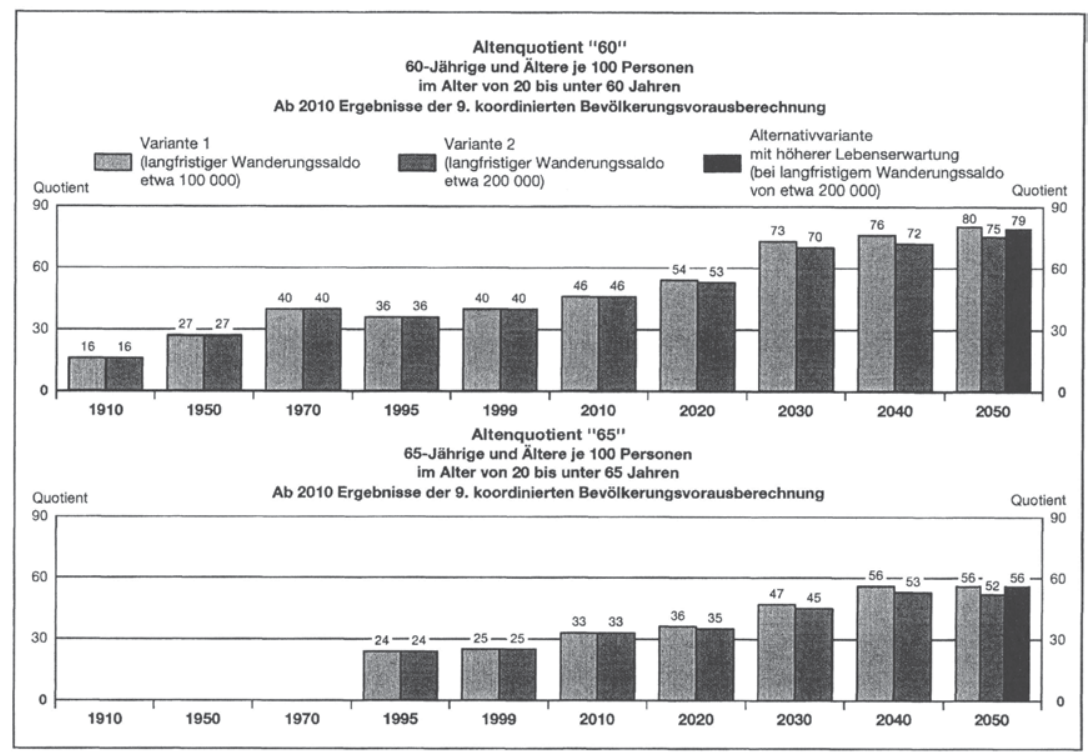

Quelle: Zusammengestellt aus: Statistisches Bundesamt 2000, S. 16

Aus volkswirtschaftlicher Sicht bestehen die ökonomischen Konsequenzen dieser Entwicklung $\mathrm{zu}$ allererst in einem makroökonomischen Strukturproblem (vgl. Börsch-Supan 2001, S. 205). Es wird zukünftig deutlich weniger Erwerbstätige geben, die das von allen nachgefragte, langfristig zudem höhere Konsumniveau produzieren müssen. Dies impliziert makroökonomisch entweder einen steigenden Importanteil und/ oder eine höhere Arbeitsproduktivität bzw. Kapitalintensität. Zudem wird das fehlende Humankapital durch Realkapital ersetzt werden müssen.

In Deutschland wird diesen Fragen zunehmend eine größere Bedeutung beigemessen, da sie zwar noch die fernere Zukunft betreffen, aber bereits heute entscheidungsrelevant sind. In diesem Kontext wird auch die so genannte fehlende Nachhaltigkeit der gegenwärtigen Gesundheitspolitik beklagt (vgl. den Beitrag von Raffelhüschen in diesem Band). Die seit Jahrzehnten anhaltende Dominanz der eher kurzfristig ausgerichteten Einnahmen- und Ausgabenpolitik blockiert die Ausrichtung hin zu einer langfristigen strukturverändernden Politik und impliziert zudem erhebliche Lastverschiebungen zuungunsten der zukünftigen Generationen. Die Kinder und Enkelkinder werden erwartungsgemäß „den Preis" 
für das reproduktive Verhalten der Eltern zu zahlen haben, wenn die heutigen Generationen sich nicht auf Strukturreformen einigen können.

Aber bereits an dieser Stelle sei betont, dass der demographische Wandel und seine ökonomischen Folgen keine Entwicklung darstellen, die nicht gestaltbar wäre. Als Schlagwörter mögen hier neben der bereits thematisierten Einwanderung längere Arbeitszeiten, kürzere Ausbildungszeiten, eine höhere Frauenerwerbsbeteiligung, das Verrentungsalter, die Höhe der Renten oder der Hinweis auf eine kinder- und familienfreundliche Steuer- und Transferpolitik genügen.

\section{Gesundheit, Alterung und medizinisch-technischer Fortschritt}

\subsection{Demographische Effekte}

Die demographische Alterung betrifft die GKV auf vielfältige Art und Weise, sowohl auf der Einnahmen- als auch auf der Ausgabenseite. Da die GKV zu den umlagefinanzierten Systemen rechnet, erkennt man unmittelbar die grundlegende Bedeutung einer stabilen Bevölkerung, d. h. einer Bevölkerung mit einer konstanten Altersstruktur. Nur in einer solchen Situation treten demographiebedingt keine Lastverschiebungen zwischen den Generationen auf.

Konkreter lassen sich die beiden folgenden Finanzierungseffekte unterscheiden (vgl. Cassel 2001, Ulrich 2001):

- demographischer Finanzierungseffekt

- demographischer Ausgabeneffekt

Der demographische Finanzierungseffekt betrifft die Einnahmenseite der GKV. Durch die Umlagefinanzierung führt ein Anstieg des Rentnerquotienten zu einer stärkeren finanziellen Belastung der Erwerbstätigen. Dies lässt sich dadurch erklären, dass die beitragspflichtigen Einnahmen der Rentner im Durchschnitt signifikant unter denen der Erwerbstätigen liegen, so dass die Beitragszahlungen der Rentner nur etwa die Hälfte ihrer Gesundheitsausgaben ausmachen. Abb. 3 verdeutlicht diesen Zusammenhang mit Hilfe eines repräsentativen Ausgabenprofils. 
Abb. 3: Repräsentatives Ausgabenprofil in der GKV

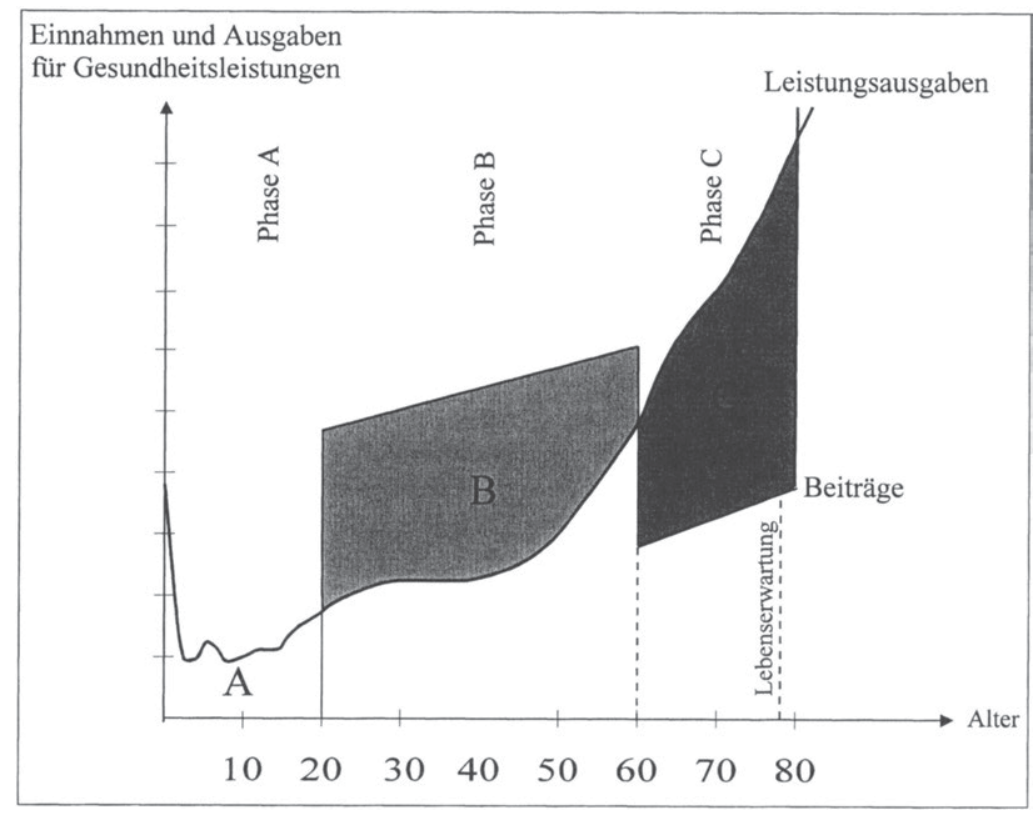

Quelle: Zusammengestellt aus: Knappe und Rubart 2001, S. 101

Abb. 3 illustriert, dass lediglich die Erwerbsphase B eines repräsentativen GKV-Versicherten eine Überschussphase darstellt, während sowohl die jungen Jahre als auch die älteren Lebensjahre aus GKV-Sicht Defizitphasen darstellen. Die Verschiebung der Altersstruktur hin zu den höheren Altersklassen geht daher mit sinkenden durchschnittlichen Beitragseinnahmen pro Mitglied einher. Dabei dürfte das Beitragsaufkommen bis zum Jahr 2020 weitgehend konstant bleiben, danach wird ein Rückgang auf 86 Prozent des Niveaus des Jahres 2000 prognostiziert (vgl. Deutscher Bundestag 2002, S. 190 ff.). Knappe und Optendrenk (1999, S. 157 ff.) können weiterhin zeigen, dass etwa die Hälfte des zukünftigen Beitragssatzanstiegs auf die zu erwartenden Einnahmenausfälle zurückgehen, die aus dem Rückgang der Erwerbspersonenzahlen resultieren.

Der demographische Finanzierungseffekt erscheint weitgehend unstrittig. Solange die Beitragszahlung an die GKV dem obigen Ausgabenprofil folgt und eng an das Vorliegen eines Beschäftigungsverhältnisses geknüpft ist, wird der demographische Wandel die Beitragssatzspirale 
weiter nach oben drehen. Aber auch für den demographischen Finanzierungseffekt lassen sich Einflussfaktoren aufzählen, die den Rückgang des Beitragssatzaufkommens determinieren und die der engen Ceterisparibus-Betrachtung Grenzen ziehen:

- Erwerbsquote

- Lohnniveau

- Lohnquote

- Ausbildungsdauer

- Rentenhöhe

- Renteneintrittsalter

Viel stärker umstritten ist dagegen der demographische Ausgabeneffekt. Gemeint ist dabei, dass bei älteren Menschen die Gesundheitsausgaben im Durchschnitt mit dem Lebensalter ansteigen (vgl. Abb. 4).

Wie Abb. 4 zeigt, findet sich in einer Querschnittsbetrachtung eine stark altersabhängige Inanspruchnahme. Die Gesundheitsausgaben pro Kopf erreichen bei Personen über 80 Jahren im Durchschnitt das 6fache jenes Betrages, der auf die Gruppe der 0- bis 14-Jährigen entfällt. Der Ausgabenanstieg setzt bereits in der Altersklasse der 65- bis 69-Jährigen ein, die wiederum im Vergleich zur jüngsten Altersklasse viermal so hohe Ausgaben verzeichnet. Ein unmittelbarer demographischer Ausgabeneffekt resultiert dann daraus, dass in den nächsten Jahrzehnten der demographische Wandel zu einer zahlenmäßig starken Besetzung der höheren Altersklassen führen wird und sich dadurch insbesondere die ProKopf-Ausgaben deutlich erhöhen werden (vgl. Ulrich 2000, S. 166).

Gegen diese Vorgehensweise bei der Berechnung demographischer Effekte wird eingewendet, dass die in Querschnittsdaten beobachtbaren Differenzen in den Gesundheitsausgaben zwischen Älteren und Jüngeren nicht allein die Konsequenz des Lebensalters sind, sondern sehr stark mit der zeitlichen Nähe zum Tod zusammenhängen. 


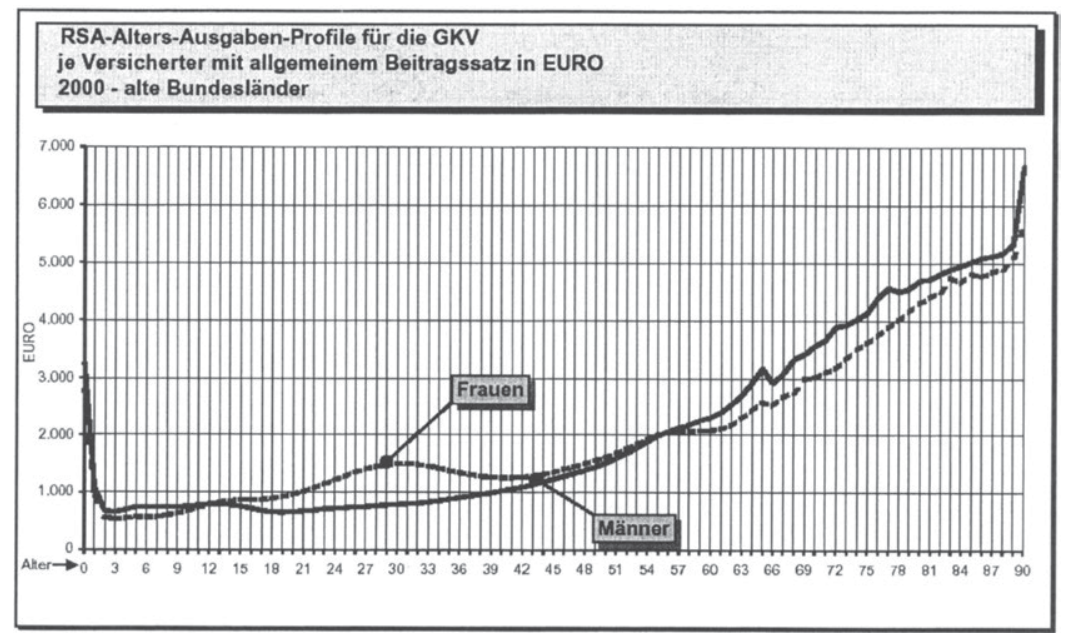

Quelle: Zusammengestellt aus: Verband der Angestellten-Krankenkassen/Arbeiter-ErsatzkassenVerband 2002.

Es ist empirisch gut belegt, dass insbesondere die Kosten des letzten Lebensjahres die hohen Ausgaben im Alter mitverursachen (vgl. Lubitz und Riley 1993, Lubitz, Beebe und Baker 1995, Busse 1996, Zweifel, Felder und Meier 1996, Felder, Meier und Schmitt 2000). Die Behandlungsausgaben werden am Ende des Lebens noch einmal massiert, in dem meist nicht sehr erfolgreichen Versuch, den Tod noch einmal abzuwenden bzw. zu verzögern.

Allerdings beantwortet auch dieser so genannte Restlebenszeiteffekt nicht die Frage, wie sich die Zunahme der Lebenserwartung insgesamt auf die Gesundheitsausgaben auswirken wird. Es ist ja nicht auszuschließen, dass sich bei einer Verschiebung der Altersstruktur ein entlastender Effekt einstellt, wenn für die Älteren und ganz Alten insgesamt ein geringerer Aufwand betrieben wird (vgl. Lubitz, Beebe und Baker 1995, S. 1000 ff.). Zu bedenken ist auch, dass die in einem Jahr Versterbenden nur einen geringen Anteil aller Versicherten darstellen. Diese Zusammenhänge lassen erkennen, dass die zentrale Frage lautet: Wie verändert sich der durchschnittliche Gesundheitszustand älterer Menschen? Auch hierzu konkurrieren zwei Hypothesen:

- Medikalisierungsthese

- Kompressionsthese 
Nach der Kompressionsthese nimmt die Morbidität im Alter dank einer immer leistungsfähigeren Medizin nur geringfügig zu (vgl. Cassel 2001). Bei den zusätzlich gewonnenen Lebensjahren handelt es sich überwiegend um gesund verbrachte Lebensjahre. Ein Anstieg der Lebenserwartung um 4 Jahre impliziert, dass der dann 84-Jährige die gleichen

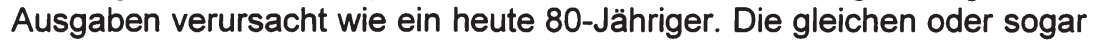
sinkenden Ausgaben finden einfach später im Lebenszyklus statt. Neuere geriatrische Forschungsergebnisse geben erste Hinweise, dass sich das Morbiditätsniveau in den letzten drei Jahrzehnten um etwa 5 Jahre verschoben hat (vgl. Mollenkopf 2002, S. 255 ff.).

Die Kompressionsthese kann aber auch kritisch hinterfragt werden, wenn man sich die Wirkungsweise des medizinisch-technischen Fortschritts vor Augen hält, der über Produktinnovationen und so genannte Add-on-Technologien ausgabensteigernd wirkt. Der demographische Wandel dürfte nicht nur mit einer längeren Überlebenszeit in einem guten Gesundheitszustand, sondern auch mit einer stärkeren Zunahme chronischer Erkrankungen einhergehen, die in den gewonnenen Lebensjahren therapiert werden müssen (so genannte These von den konkurrierenden Risiken). Über eine Verbesserung der Therapie ist der Wettlauf mit den Kosten nicht zu gewinnen (vgl. Krämer 1996, Lauterbach 2001). Auch wenn die fortschrittsbedingte bessere Therapie nicht teurer wäre als die alte Therapie, führt die neue, bessere Therapie zu Kostensteigerungen. Dies liegt daran, dass mehr Patienten ihre Erkrankungen überleben und weiter zu behandeln sind.

Allerdings kann die Krankheitskompression durchaus als eine Zieldimension für eine zukünftige Gesundheitspolitik angesehen werden. Falls es gelingt, insbesondere die teure Phase chronischer Erkrankungen zu verkürzen, sind finanzielle Einsparungen im Gesundheitswesen denkbar, nicht aber zwingend. Dazu erscheinen insbesondere Präventivprogramme geeignet zu sein.

Nach der Medikalisierungsthese steigen dagegen die Gesamtmorbidität und die altersspezifische Morbidität im demographischen Wandel weiter an und implizieren einen überproportionalen Anstieg der Gesundheitsausgaben. Insbesondere die Wechselwirkungen zwischen steigender Lebenserwartung und medizinisch-technischem Fortschritt führen dazu, dass Leistungen länger und in steigendem Ausmaß in Anspruch genommen werden. Es scheint ein Paradoxon der modernen Medizin zu sein, dass die Hochleistungsmedizin den durchschnittlichen Gesundheitszustand der Bevölkerung verschlechtern kann, da sie die Überlebensschwelle absenkt und damit auch ein Überleben derjenigen ermög- 
licht, die zu den so genannten „schlechten Risiken“ rechnen und die ohne Hochleistungsmedizin sterben würden (vgl. Krämer 1996).

Die Gültigkeit beider Thesen bleibt zu überprüfen. Bisher steht einer empirischen Überprüfung vor allem der Mangel an geeigneten kohortenspezifischen Längsschnittdaten entgegen. Die erste derartige deutsche Studie von Dinkel (1999) liefert die Evidenz für die Kompressionsthese. Allerdings wird auch die Medikalisierungsthese durch einzelne empirische Untersuchungen bzw. für Teilbereiche des Gesundheitswesens (stationäre Leistungen, Arzneimittel) gestützt (vgl. Hof 2001). Insgesamt besteht damit Uneinigkeit bezüglich der finanziellen Konsequenzen einer steigenden Lebenserwartung. Zentral für die Diskussion erscheinen folgende Aspekte (vgl. Deutscher Bundestag 2002, Sachverständigenrat für die Konzertierte Aktion im Gesundheitswesen 1994):

- Mit steigendem Alter nehmen die durchschnittlichen Gesundheitsausgaben insbesondere im Krankenhaus und bei Arzneimitteln zu.

- Technischer Fortschritt führt zumindest kurz- bis mittelfristig zu Kostensteigerungen in fast allen Altersgruppen.

- In den gewonnenen Lebensjahren besteht Bedarf an gesundheitlichen Leistungen.

- Der Anteil chronisch kranker Menschen nimmt zu.

- Preissteigerungen bei Gesundheitsleistungen (Personal, Kapital, Forschung \& Entwicklung) überlagern die Mengenentwicklung.

- Der medizinische Versorgungsbedarf hängt ab von der Art und der Häufigkeit von Krankheiten sowie von der Entwicklung des durchschnittlichen Gesundheitszustandes.

- Der Vermeidung der Entstehung chronischer Krankheiten und damit der Prävention wird eine zunehmende Bedeutung beikommen.

In jüngster Zeit wurde auch eine Synthese der Kompressions- und Medikalisierungsthese unter dem Namen "Bimodaler Ansatz" (Deutscher Bundestag 2002, S. 184.) formuliert. Der bimodale Ansatz geht davon aus, dass sich sowohl der Gesundheitszustand zukünftiger Generationen verbessert als auch ein gleichzeitiger Anstieg beeinträchtigter und pflegebedürftiger Menschen stattfinden wird. Dies wird zudem korreliert sein mit der entsprechenden Schichtzugehörigkeit, so dass für Angehörige 
der Oberschicht eher die Kompressionsthese, während in den unteren Einkommensschichten eher die Medikalisierungsthese gelten dürfte.

\subsection{Alterung und medizinisch-technischer Fortschritt}

Der so genannte "reine" demographische Effekt auf die Gesundheitsausgaben wird üblicherweise dadurch errechnet, dass man das konstante Ausgabenprofil eines Basisjahres mit der für die Zukunft zu erwartenden Besetzung der einzelnen Altersklassen multipliziert (vgl. Prognos 1998, Erbsland, Ried und Ulrich 1999). Eine solche Vorgehensweise, die häufig als Referenzfall gewählt wird, abstrahiert aber von einer Vielzahl von Wechselwirkungen, wie sie bereits unter Punkt 3.1 formuliert wurden.

Zur Darstellung des reinen demographischen Effektes auf die GKVLeistungsausgaben werden im Folgenden zwei Alternativen vorgestellt (vgl. Breyer 1999, DIW 2002):

- die Berechnung des Referenzfalles anhand eines konstanten Ausgabenprofils

- die Berechnung anhand eines Ausgabenprofils bei reduzierter Morbidität, um den erwähnten Zugewinn an gesunden, aktiven Lebensjahren abzubilden; dabei wird eine Verschiebung des Morbiditätsniveaus um 5 Jahre unterstellt

Bei der Prognose der Beitragssatzentwicklung im Abschnitt 5 wird zusätzlich der Zusammenhang zwischen demographischen Veränderungen und den altersklassenabhängigen Gesundheitsausgaben sowie die Ausgabenwirksamkeit des medizinisch-technischen Fortschritts berücksichtigt. Wenn zwischen der demographischen Entwicklung und dem medizinisch-technischen Fortschritt erhebliche Wechselwirkungen bestehen, lassen sich die altersspezifischen Ausgabenprofile nicht einfach fortschreiben (vgl. Knappe 1995). Die bisherigen Ausführungen sprechen eher dafür, dass sich beide Größen in ihrer Wirkung auf die Gesundheitsausgaben verstärken (vgl. Krämer 1982 und 1996, Zweifel 1990, Oberdieck 1998, Breyer 1999). Dazu gibt es allerdings auch eine Gegenposition, die unterstellt, dass die Kostendynamik des technischen Fortschritts nicht so gravierend ausfällt. Es finden sich zahlreiche Beispiele für Innovationen der Vergangenheit, die sogar zur Kostenverringerung beitrugen. Zudem treten die extrem teuren Sprunginnovationen eher selten auf (vgl. Pfaff 1994, Kühn 2001, Lauterbach 2001). Schließlich wirkt auch die Einbettung der Fortschrittsfinanzierung in den Rahmen um Managed Care und Disease Management tendenziell disziplinierend. 
Die dämpfende Wirkung besitzt ohne Zweifel ihre Berechtigung, dürfte aber deutlich dominiert werden von der sich verstärkenden Wirkung zwischen Alterung und technischem Fortschritt. In einer neueren Regressionsanalyse wurden die realen Pro-Kopf-Ausgaben der GKV erklärt durch die Entwicklung der realen Einnahmen pro Mitglied, einem Zeittrend als produktinnovatorischer Komponente des medizinisch-technischen Fortschritts sowie der Altersstruktur (vgl. Breyer und Ulrich 2000). Die Größe realer Einnahmen pro Mitglied lässt sich zum einen als Indikator für die Nachfrage nach Gesundheitsleistungen interpretieren, zum anderen bildet sie auch den medizinisch-technischen Fortschritt als Prozessinnovation ab. Die Regressionsanalyse zeigt, dass aufgrund des produkttechnischen Fortschritts die Gesundheitsausgaben im Mittel des Zeitraums 1970 bis 1995 mit 1 Prozent stärker zunahmen als die realen Einnahmen. Auch die Altersstruktur führt in diesem Ansatz zu einem deutlichen Anstieg der Ausgaben. Nimmt der Anteil der Personen über 65 Jahre um 1 Prozent zu, steigen die Pro-Kopf-Ausgaben im Stichprobenmittel um rund 8 Prozent.

Die skizzierten Fortschrittseffekte implizieren ein Phänomen, für das sich die Bezeichnung "Versteilerung" der Ausgabenprofile eingebürgert hat (vgl. Buchner und Wasem 2000, Buchner 2002) und das ein schnelleres Wachstum der Gesundheitsausgaben bei älteren Versicherten als bei jüngeren Versicherten beschreibt. Abb. 5 zeigt diese Versteilerung anhand der Entwicklung des Ausgabenprofils im untersuchten Altersbereich zwischen 30 und 80 Jahren im Beobachtungszeitraum von 1979 bis 1996 für einen konstruierten Tarif KOMBI, der aus den Kopfschäden der Bausteintarife STATIONÄR, AMBULANT und ZAHN des größten deutschen PKV-Unternehmens konstruiert wurde (vgl. Buchner 2002, S. 167). Dabei erfährt das relativ flache Ausgabenprofil des Jahres 1979 bis zum Jahr 1996 eine signifikante Versteilerung. 
Abb. 5: Versteilerung der Ausgabenprofile

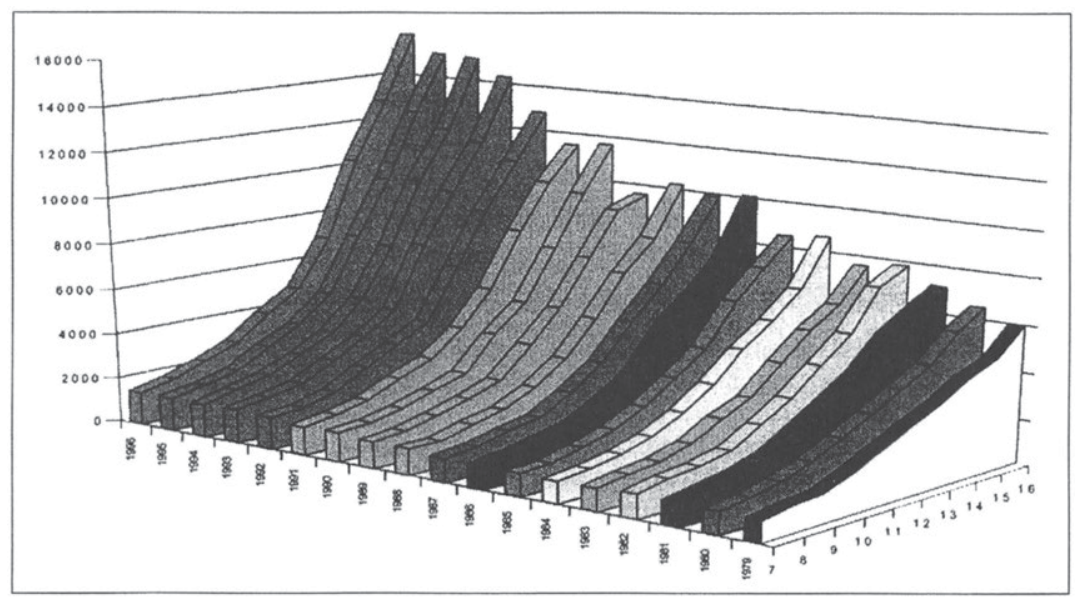

Quelle: Zusammengestellt aus: Buchner 2002, S. 167

Die Frage nach der Übertragbarkeit dieses Phänomens auf die GKV lässt sich nicht abschließend beantworten. Es sprechen allerdings eine ganze Reihe von Argumenten für eine Übertragbarkeit auf die Verhältnisse der GKV (vgl. Buchner 2002, S. 220):

- Versteilerung gilt auch im Zusatztarif für gesetzlich Versicherte

- Auftreten der Versteilerung im gesamten Versichertenklientel der PKV

- weitgehendes Fehlen von Gründen, die unterschiedliche Profilentwicklungen vermuten lassen (Versicherungsstrukturen, versicherter Personenkreis)

Bei der Prognose der Beitragssatzentwicklung werden daher auch die Wechselwirkungen zwischen demographischer Alterung und medizinisch-technischem Fortschritt berücksichtigt. In diesem Szenario wachsen die Leistungsausgaben der GKV fortschrittsbedingt um 1 Prozentpunkt stärker pro Jahr als der allgemeine Produktivitätsfortschritt. Diese spezielle Kostensteigerung, die zunächst auf alle Altersgruppen in gleicher Weise wirkt, verursacht aber bei den höheren Altersgruppen aufgrund der höheren Ausgaben absolut größere Steigerungen. 


\section{Ausgabeneffekte}

Die prognostizierte Entwicklung der Leistungsausgaben in der GKV für den Zeitraum zwischen 1999 und 2050 bei einem konstanten Ausgabenprofil (Referenzmodell) zeigt Tab. 1. Rein demographiebedingt wachsen die GKV-Leistungsausgaben in diesem Zeitraum um knapp 28 Prozent von 217,0 Mrd. DM im Jahr 1999 auf 276,7 Mrd. DM im Jahr 2050. Der größte Teil dieses Anstiegs vollzieht sich im Zeitraum bis zum Jahr 2020, hervorgerufen durch die Verschiebung der Altersstruktur. Danach ergibt sich ein entlastender Effekt auf die Gesamtausgaben, da die Nachfrage nach medizinischen Leistungen durch die sinkende Gesamtbevölkerungszahl zurückgeht. ${ }^{1}$

Tab. 1: Demographische Effekte auf die GKV-Leistungsausgaben $1999-2050$

\begin{tabular}{|c|c|c|c|c|c|c|c|c|c|c|}
\hline \multirow{3}{*}{$\begin{array}{c}\text { Im Alter } \\
\text { von ... bis } \\
\text { unter ... Jahren }\end{array}$} & \multirow[b]{2}{*}{1999} & \multirow[b]{2}{*}{2010} & \multirow[b]{2}{*}{2020} & \multirow[b]{2}{*}{2030} & \multirow[b]{2}{*}{2040} & \multirow{3}{*}{2050} & \multicolumn{4}{|c|}{ Veränderung } \\
\hline & & & & & & & \multicolumn{2}{|c|}{$2050 / 1999$} & \multicolumn{2}{|c|}{$2020 / 1999$} \\
\hline & \multicolumn{5}{|c|}{ in Mrd.DM } & & absolut & in $\%$ & absolut & in $\%$ \\
\hline 0.15 & 17,2 & 14,4 & 13,2 & 12,3 & 10,9 & 10,0 & $-7,2$ & $-41,74$ & - 4,1 & $-23,58$ \\
\hline $15 \cdot 30$ & 20,4 & 19,9 & 17,6 & 15,3 & 14,6 & 13,4 & $-7,0$ & $.34,40$ & - 2,8 & $-13,79$ \\
\hline 30.45 & 35,3 & 29,4 & 26,2 & 24,7 & 20,9 & 19,5 & - 15,8 & $-44,69$ & $-9,0$ & $-25,63$ \\
\hline $45-60$ & 40,4 & 47,5 & 50,2 & 39,9 & 39,7 & 35,1 & $-5,4$ & $-13,29$ & 9,7 & 24,06 \\
\hline $60 \cdot 75$ & 60,2 & 68,2 & 72,0 & 90,9 & 81,1 & 73,5 & 13,3 & 22,02 & 11,8 & 19,59 \\
\hline $75-80$ & 19,4 & 22,1 & 27,0 & 30,8 & 40,8 & 32,2 & 12,8 & 65,83 & 7,6 & 38,97 \\
\hline $80-85$ & 10,0 & 18,2 & 26,4 & 24,1 & 33,6 & 38,2 & 28,2 & 280,31 & 16,4 & 162,85 \\
\hline 85.90 & 9,7 & 12,0 & 14,8 & 19,4 & 24,5 & 33,2 & 23,5 & 242,46 & 5,1 & 52,76 \\
\hline go u.ä. & 4,2 & 5,1 & 8,4 & 13,5 & 15,1 & 21,6 & 17,4 & 418,00 & 4,3 & 102,73 \\
\hline Insgesamt & 217,0 & 236,8 & 255,9 & 271,0 & 281,2 & 276,7 & 59,8 & 27,56 & 38,9 & 17,95 \\
\hline
\end{tabular}

Quelle: Zusammengestellt aus: DIW 2001, S. 98

Der demographische Wandel schlägt sich zudem sehr ungleich in den einzelnen Hauptleistungsbereichen der GKV nieder (vgl. Tab. 2). Insgesamt führt die alternde und schrumpfende Bevölkerungsentwicklung zu

Es gibt inzwischen eine Vielzahl von Modellrechnungen und Prognosen, die für den reinen demographischen Effekt zu ähnlichen Ergebnissen gelangen. Vgl. Schmähl 1983, Sachverständigenrat für die Konzertierte Aktion im Gesundheitswesen 1994, Knappe 1995, Erbsland 1995, Erbsland und Wille 1995, Oberdieck 1998, Prognos 1998, Buttler, Fickel und Lautenschlager 1999, Erbsland, Ried und Ulrich 1999, Knappe und Optendrenk 1999, Hof 2001, Breyer und Ulrich 2000, Ulrich 2001. 
einer Verschiebung hin zum stationären Bereich und den Arzneimitteln. Der Anteil der Ausgaben für Krankenhäuser an den Leistungsausgaben der GKV insgesamt steigt von 39,2 Prozent (1999) auf 42,4 Prozent (2050). Der Arzneimittelanteil steigt im gleichen Zeitraum von 16,9 Prozent auf 17,4 Prozent. Dagegen werden die Anteile für die ambulante Behandlung und für die Behandlung für Zahnärzte rückläufig sein.

Tab. 2: Demographische Effekte auf die einzelnen Leistungsbereiche der GKV

\begin{tabular}{|l|r|r|r|r|r|r|}
\hline & 1999 & 2010 & 2020 & 2030 & 2040 & 2050 \\
\cline { 2 - 7 } \multicolumn{1}{|c|}{ Hauptleistungsbereiche } & \multicolumn{7}{|c|}{ in \% } \\
\hline & & & & & \\
Ärzte & 20,2 & 19,7 & 19,2 & 18,7 & 18,4 & 18,2 \\
Zahnärzte & 9,7 & 9,1 & 8,5 & 8,0 & 7,6 & 7,4 \\
Apotheker & 16,9 & 17,3 & 17,6 & 17,9 & 18,0 & 17,9 \\
Krankenhäuser & 39,2 & 40,1 & 40,7 & 41,3 & 41,9 & 42,1 \\
Sonstige Leistungsausgaben & 14,0 & 13,9 & 14,1 & 14,1 & 14,2 & 14,4 \\
& & & & & \\
\hline
\end{tabular}

Quelle: Zusammengestellt aus: DIW 2001, S. 99

Tab. 3 zeigt das Szenario mit dem "gedämpften Ausgabenprofil", das versucht, den Zugewinn an aktiven Lebensjahren abzubilden. Die Annahme einer verringerten Morbidität führt im Prognosezeitraum zu einem Wachstum der GKV-Leistungsausgaben in Höhe von 15 Prozent auf 250,2 Mrd. DM, verglichen mit den 28 Prozent Wachstum des Referenzmodells. Auch hier impliziert der Altersstruktureffekt, der die Entwicklung zum Jahr 2020 alleine dominiert, einen Anstieg des Ausgabenanteils um 14 Prozent. Der Niveaueffekt einer verringerten Morbidität, sofern er tatsächlich stattfindet, würde demnach das Ausgabenwachstum merklich abschwächen. 
Tab. 3: Demographische Effekte auf die GKV-Leistungsausgaben bei verringerter Morbidität 1999 - 2050

\begin{tabular}{|c|c|c|c|c|c|c|c|c|c|c|}
\hline \multirow{3}{*}{$\begin{array}{c}\text { Im Alter } \\
\text { von ... bis } \\
\text { unter ... Jahren }\end{array}$} & & & \multirow[b]{2}{*}{2020} & \multirow[b]{2}{*}{2030} & \multirow[b]{2}{*}{2040} & \multirow{3}{*}{2050} & \multicolumn{4}{|c|}{ Veränderung } \\
\hline & 1999 & 2010 & & & & & \multicolumn{2}{|c|}{$2050 / 1999$} & \multicolumn{2}{|c|}{$2020 / 1999$} \\
\hline & \multicolumn{5}{|c|}{ in Mrd. DM } & & absolut & in $\%$ & absolut & in $\%$ \\
\hline 0.15 & 17,2 & 14,4 & 13,2 & 12,3 & 10,9 & 10,0 & - 7,2 & $-41,74$ & - 4,1 & $-23,58$ \\
\hline $15-30$ & 20,4 & 19,9 & 17,6 & 15,3 & 14,6 & 13,4 & $-7,0$ & $-34,40$ & $-2,8$ & $-13,79$ \\
\hline $30-45$ & 35,3 & 29,4 & 26,2 & 24,7 & 20,9 & 19,5 & - 15,8 & $-44,69$ & - 9,0 & $-25,63$ \\
\hline $45 \cdot 60$ & 40,4 & 47,5 & 50,2 & 39,9 & 39,7 & 35,1 & $-5,4$ & $-13,29$ & 9,7 & 24,06 \\
\hline $60-75$ & 60,2 & 65,1 & 65,6 & 80,2 & 67,9 & 58,9 & $-1,3$ & $-2,21$ & 5,4 & 8,92 \\
\hline $75-80$ & 19,4 & 21,4 & 25,3 & 27,8 & 35,4 & 27,0 & 7,5 & 38,81 & 5,8 & 30,07 \\
\hline 80.85 & 10,0 & 17,9 & 25,4 & 22,6 & 30,7 & 33,9 & 23,9 & 237,76 & 15,3 & 152,38 \\
\hline $85-90$ & 9,7 & 11,9 & 14,5 & 18,8 & 23,3 & 31,2 & 21,5 & 221,29 & 4,8 & 49,44 \\
\hline 90 u.ä. & 4,2 & 5,2 & 8,6 & 13,5 & 15,0 & 21,2 & 17,1 & 409,89 & 4,4 & 106,54 \\
\hline Insgesamt & 217,0 & 232,6 & 246,5 & 255,1 & 258,5 & 250,2 & 33,3 & 15,34 & 29,6 & 13,63 \\
\hline
\end{tabular}

Quelle: Zusammengestellt aus: DIW 1999, S. 102

\section{Beitragssatzentwicklung}

Tab. 4 gibt einen Überblick über die resultierende Beitragssatzentwicklung aufgrund der reinen demographischen Entwicklung. Für das Jahr 2050 liefert der Referenzfall (konstante Morbidität) einen Beitragssatz in Höhe von 18,95 Prozent, wenn man unterstellt, dass das gegenwärtige Rentenniveau konstant bleibt. Eine 10-prozentige Reduzierung des Rentenniveaus, wie sie politisch beschlossen wurde, impliziert einen Beitragssatzauftrieb für die GKV, da sich die Beitragszahlungen der Rentner an die GKV entsprechend verringern. Die Reduzierung des Rentenniveaus um 10 Prozent würde ceteris paribus den Beitragssatz auf 19,58 Prozent ansteigen lassen. Wie unter Punkt 4 bereits ausgeführt, schwächt die Annahme einer "verringerten Morbidität" das Ausgabenwachstum merklich ab. Entsprechend resultiert aus diesem Szenario eine niedrige Beitragssatzentwicklung. Für das Jahr 2050 würde sich ein Beitragssatz in Höhe von 17,13 Prozent (bei einem konstanten Rentenniveau) ergeben und in Höhe von 17,71 Prozent bei einer Reduzierung des Rentenniveaus um 10 Prozent. Aus Tab. 4 lassen sich auch noch die entsprechenden Werte für die Beitragssätze für das Jahr 2040 ablesen. Da viele Prognosen und Modellrechnungen bis zum Jahr 2040 reichen, bieten sich hier unmittelbar Vergleichsmöglichkeiten mit anderen Berechnungen. 
Tab. 4: Demografischer Wandel und Beitragssatzentwicklung in der GKV

\begin{tabular}{|c|cc|cc|}
\hline & \multicolumn{2}{|c|}{2040} & \multicolumn{2}{c|}{2050} \\
& Rentenniveau & \multicolumn{2}{|c|}{ Morbidität } & \multicolumn{2}{c|}{ Morbidität } \\
\hline & & & & \\
Gegenwärtiges Rentenniveau konstant & 18,15 & 16,68 & 18,95 & 17,13 \\
Reduzierung des Rentenniveaus um 10\% & 18,72 & 17,21 & 19,58 & 17,71 \\
Reduzierung des Rentenniveaus um 20\% & 19,34 & 17,77 & 20,26 & 18,32 \\
\hline
\end{tabular}

Quelle: Zusammengestellt aus: DIW 1999, S. 105

Im Kern unterscheiden sich die unterschiedlichen Berechnungen dadurch, ob sie isoliert den demographischen Wandel abbilden oder ob sie auch die zukünftige Versteilerung der Ausgabenprofile erfassen, die überwiegend auf Fortschrittseffekte zurückzuführen ist.

Tab. 5 enthält den Vergleich der Beitragssatzprojektionen für das Jahr 2040 für die drei verschiedenen Szenarien „Referenzfall", „reduzierte Morbidität" sowie "Kostendruck durch medizinischen Fortschritt". Während die beiden ersten Szenarien versuchen, den reinen demographischen Effekt abzubilden, berücksichtigt Szenario 3 die Kostensteigerung durch den technischen Fortschritt, die 1 Prozentpunkt über der allgemeinen Produktivitätsentwicklung liegt.

Die Berücksichtigung der Wechselwirkungen zwischen demographischer Alterung und medizinisch-technischem Fortschritt führt zu einem wesentlich höheren Beitragssatzanstieg, der im Jahr 2040 bei über 28 Prozent liegen wird. Auf der Basis der ökonometrischen Schätzung ergibt sich in diesem „Kostendruck-Szenario" sogar ein Beitragssatz von 34 Prozent. $\mathrm{Ob}$ ein Beitragssatz in dieser Höhe realistisch erscheint, ist dabei nicht die entscheidende Frage, sondern der Hinweis, den diese Studien auf die notwendigen Reformschritte geben, die durchgeführt werden müssen, wenn man das Gesundheitswesen auch längerfristig finanzierbar erhalten möchte. 
Tab. 5 Vergleich der Beitragssatzprognosen für die GKV 1999 - 2040

\begin{tabular}{|l|c|c|c|}
\hline Annahme & \multicolumn{2}{|c|}{$\begin{array}{c}\text { Keine autonomen Kosten des } \\
\text { medizin. Fortschritts }\end{array}$} & $\begin{array}{c}\text { Kostensteigerung } \\
\text { durch med. Fort- } \\
\text { schritt 1\% p.a. }\end{array}$ \\
\hline Berechnungsmethode & $\begin{array}{c}\text { reduzierte } \\
\text { Morbidität }\end{array}$ & unveränderte Morbidität \\
\hline Altersprofile $^{1)}$ & 17,2 & 18,7 & 28,2 \\
\hline Regression $^{2)}$ & - & 22,6 & 34,0 \\
\hline $\begin{array}{l}\text { 1) Annahmen: unveränderte Morbidität, Rentenniveauabsenkung um } 10 \% . \\
\text { 2) Produktivitätswachstum 2,1 \% p.a. }\end{array}$
\end{tabular}

Quelle: Zusammengestellt aus: DIW 1999, S. 117

Eine Hinnahme von Beitragssatzsteigerungen in dem oben skizzierten Ausmaß ist nicht vorstellbar. Sie würden einen Sprengsatz für die Finanzierung der sozialen Sicherungssysteme bedeuten und über die Steigerung der Lohnnebenkosten auch die internationale Wettbewerbsfähigkeit der deutschen Unternehmen gefährden. Eine Volkswirtschaft, die unter hohen Lohnnebenkosten leidet, erleidet mittel- und langfristig weitere Wachstumseinbußen, und die Basis für die Finanzierung des Umlageverfahrens würde weiter schrumpfen.

Unter diesem Gesichtspunkt stellt sich die Frage, über welche Einflussgrößen bzw. Stellschrauben das GKV-System verfügt, an denen die politisch Verantwortlichen drehen können, um die ökonomischen Konsequenzen des Alterungsprozesses abzufedern, oder ob das Augenmerk verstärkt auf einen Systemwechsel hin zu einem kapitalgedeckten Finanzierungsverfahren gelegt werden sollte (vgl. den Beitrag von Cassel in diesem Band).

Da zu dieser Thematik eine Vielzahl konkreter Vorschläge sowohl für die Leistungs- als auch für die Einnahmenseite vorliegen (vgl. etwa Sachverständigenrat für die Konzertierte Aktion im Gesundheitswesen 2002, Sachverständigenrat für die Begutachtung der gesamtwirtschaftlichen Entwicklung 2000, Wille 1998 und 2000, Schmähl und Ulrich 2001, Zweifel und Breuer 2002), soll an dieser Stelle lediglich etwas grundsätzlicher argumentiert werden (vgl. für die Rentenversicherung BörschSupan 2003). 
Der „Preis“ des Alterns der Bevölkerung ist in jedem System der Gesundheitsversorgung zu bezahlen, unabhängig davon, ob es im Umlageoder im Kapitaldeckungsverfahren finanziert wird (vgl. Sinn 1999). Dieser Preis kann entweder den jeweiligen Erwerbstätigen durch höhere Beitragssätze aufgebürdet werden oder den jeweiligen Versicherten, die eine größere Eigenverantwortung für ihre Gesundheit übernehmen und damit letztlich auch mehr sparen müssen, oder man entlastet die umlagefinanzierten Systeme und damit auch das Gesundheitswesen, indem die Menschen länger arbeiten und damit auch länger Beiträge zahlen. ${ }^{2}$

All diese Wege sind unbequem. Der Geburtenrückgang, d. h. die historische Abfolge von geburtenstarken und geburtenschwachen Jahrgängen, liefert eine Rechtfertigung, die geburtenstarken Jahrgänge der Babyboomer stärker in die Pflicht zu nehmen. Sie sind friedlicher und wohlhabender aufgewachsen als ihre Elterngeneration und sollten sich daher durch eine verstärkte Eigenverantwortung an dem Babyboom-Finanzierungsproblem beteiligen. Das durch den medizinisch-technischen Fortschritt ermöglichte Geschenk der längeren Lebenserwartung lässt sich durch ein längeres Erwerbsleben ausgleichen, auch dies erscheint aus heutiger Perspektive durchaus zumutbar. Nicht zumutbar ist dagegen eine weitere Belastung der Erwerbstätigen, da dies der Volkswirtschaft insgesamt schadet.

Diese Argumentation stellt ausdrücklich kein Plädoyer für einen Systemwechsel dar, allerdings aber für die Ergänzung des bestehenden Umlageverfahrens um private Vorsorge- und Versicherungselemente. Nur kapitalgedeckte Systeme machen sich den Faktor Zins zu Eigen, der mithilft, die demographischen Belastungen zu entzerren und damit partiell auch vorfinanzieren zu können.

\section{Zusammenfassung und Ausblick}

Der Beitrag analysiert die Auswirkungen der demographischen Entwicklung auf die Gesundheitsausgaben und den Beitragssatz der GKV. Die vorliegenden Berechnungen unterscheiden sich im Kern dadurch, ob sie isoliert den demographischen Wandel abbilden oder auch den Kostendruck mit abbilden, der auf den medizinisch-technischen Fortschritt zurückzuführen ist.

2 In der Langfristigkeitsbetrachtung abstrahieren wir von der Frage, ob diese Entwicklung zu Lasten jüngerer Erwerbstätiger geht. 
Alle Hochrechnungen weisen ein beachtliches Potenzial zu Ausgabenund Beitragssatzsteigerungen aus. Die traditionellen Hochrechnungen von altersspezifischen Ausgabenprofilen führen in der Tendenz in den nächsten 4 Jahrzehnten zu einem Anstieg des Beitragssatzes auf 16 Prozent bis 18 Prozent. Die Arbeiten, die den Einfluss des technischen Fortschritts explizit berücksichtigen, gelangen dagegen zu Beitragssätzen zwischen 23 Prozent und 26 Prozent bzw. sogar noch darüber.

Das Dilemma der Gesundheitspolitik besteht darin, dass es keinen bequemen Lösungsweg für die langfristige Finanzierung der Gesundheitsausgaben gibt. Entweder belastet man die Erwerbstätigen stärker, oder die Versicherten oder die Erwerbstätigen müssen länger arbeiten. Die Reformschritte hin zu mehr Eigenverantwortung und privater Ersparnisbildung scheinen dabei am geeignetsten, um das Babyboom-Finanzierungsproblem und die Langlebigkeit auszugleichen, d. h. ein Schritt hin zur Ergänzung des bestehenden Systems um private Versicherungselemente.

\section{Literatur}

Börsch-Supan, A. (2001), Quo Vadis Rentenversicherung? Alternativen und Ergänzungen zur umlagefinanzierten Rente, in: Schmähl, W., Ulrich, V. (Hrsg.), Soziale Sicherungssysteme und demographische Herausforderungen, Mohr Siebeck, Tübingen, S. $205-220$.

Börsch-Supan, A. (2003), Genießen, aber auch zahlen, in: Forschung \& Lehre, 2/2003, S. $64-65$.

Breyer, F. (1999), Lebenserwartung, Kosten des Sterbens und die Prognose der Gesundheitsausgaben, in: Jahrbuch für Wirtschaftswissenschaften, Bd. 50, S. 53-65.

Breyer, F. und Ulrich, V. (2000), Gesundheitsausgaben, Alter und medizinischer Fortschritt: eine Regressionsanalyse, in: Jahrbücher für Nationalökonomie und Statistik, 220, S. 1 - 17.

Buchner, F. und Wasem, J. (2000), Versteilerung der alters- und geschlechtsspezifischen Ausgabenprofile von Krankenversicherern, Ernst-Moritz-Arndt-Universität Greifswald, Wirtschaftswissenschaftliche Diskussionspapiere, Nr. 1/00, Greifswald, Januar 2000.

Buchner, F. (2002), Versteilerung von Ausgabenprofilen in der Krankenversicherung, Nomos, Baden-Baden. 
Busse, R. (1996), Welche Kosten verursacht das letzte Lebensjahr?, in: Walter, U., Paris, W. (Hrsg.), Public Health - Gesundheit im Mittelpunkt, Alfred \& Söhne, Meran, S. $89-92$.

Buttler, G., Fickel, N., Lautenschlager, B. (1999), Die Auswirkungen der demographischen Entwicklung auf die Kosten im Gesundheitswesen, in: Allgemeines Statistisches Archiv, 83, S. $120-136$.

Cassel, D. (2001), Schriftliche Stellungnahme zum Reformbedarf des Gesundheitswesens. In: Deutscher Bundestag: Anhörung der Enquête-Kommission Demographischer Wandel 22. Berlin (2001).

Cassel, D. (2003), Kapitaldeckung zur Stützung der Finanzierung von demographischen Effekten in diesem Band.

Deutscher Bundestag (1998), Zweiter Zwischenbericht der Enquete-Kommission "Demographischer Wandel" - Herausforderungen unserer älter werdenden Gesellschaft an den einzelnen und die Politik, Bundestagsdrucksache 13/11460 vom 05.10.1998, Berlin und Bonn.

Deutscher Bundestag (2002), Schlussbericht der Enquete-Kommission „Demographischer Wandel" - Herausforderungen unser älter werdenden Gesellschaft an den einzelnen und die Politik -, Bundestagsdrucksache 14/8800 vom 28.03.2002, Berlin und Bonn.

Dinkel, R. H. (1999), Demographische Entwicklung und Gesundheitszustand - Eine empirische Kalkulation der Healthy Life Expectancy für die Bundesrepublik Deutschland auf der Basis von Kohortendaten, in: Häfner, H. (Hrsg.), Gesundheit - unser höchstes Gut?, Berlin, S. 61 - 83.

DIW (2001), Wirtschaftliche Aspekte der Märkte für Gesundheitsleistungen, Ökonomische Chancen unter sich verändernden demographischen und wettbewerblichen Bedingungen in der Europäischen Union, Gutachten im Auftrag des Bundesministeriums für Wirtschaft und Technologie, Berlin.

Enquête-Kommission demographischer Wandel (2002), Endbericht der Herausforderungen unserer älter werdenden Gesellschaft an den einzelnen und die Politik, Bundestagsdrucksache 13/11460, vom 05.10.1998, Berlin und Bonn.

Erbsland, M. (1995), Demographische Effekte auf die zukünftigen Behandlungsausgaben und den Beitragssatz der GKV. ZEW-Discussion Paper 18/95, Zentrum für Europäische Wirtschaftsforschung, Mannheim. 
Erbsland M., Wille, E. (1995), Bevölkerungsentwicklung und Finanzierung der gesetzlichen Krankenversicherung. Zeitschrift für die gesamte Versicherungswissenschaft, 4, S. $661-686$.

Erbsland, M., Ried, W., Ulrich, V. (1999), Die Auswirkungen der Bevölkerungsstruktur auf Ausgaben und Beitragssatz der gesetzlichen Krankenversicherung, in: Wille, $E$ (Hrsg.), Entwicklung und Perspektiven der Sozialversicherung, Bd. 33, Schriftenreihe des ZEW, Nomos, Baden-Baden, S. 173 - 198.

Felder, S., Meier, M., Schmitt, H. (2000), Health Care Expenditure in the Last Months of Life, in: Journal of Health Economics, 19 (5), S. $679-695$.

Hof, B. (1999), Demographische Alterung und ökonomische Aspekte der Migration, in: Grünheid, E. und Höhn, C. (Hrsg.), Demographische Alterung und Wirtschaftswachstum, Schriftenreihe des Bundesinstituts für Bevölkerungsforschung, Bd. 29, Leske + Budrich, Opladen, S. 108 - 131.

Hof, B. (2001), Auswirkungen und Konsequenzen der demographischen Entwicklung für die gesetzliche Kranken- und Pflegeversicherung, Gutachten im Auftrag des Gesamtverbandes der Deutschen Versicherungswirtschaft, Köln.

Knappe, E. (1995), Auswirkungen des demographischen Wandels auf den Gesundheitssektor, in: Oberender, P. (Hrsg.), Transplantationsmedizin. Ökonomische, ethische, rechtliche und medizinische Aspekte, Nomos, Baden-Baden, 11 - 41.

Knappe E., Optendrenk, S. (1999), Der Einfluss des demographischen Wandels auf die Kranken- und Pflegeversicherung. In: Grünheid, E., Höhn, C. (Hrsg.), Demographische Alterung und Wirtschaftswachstum. Schriftenreihe des Bundesinstituts für Bevölkerungsforschung 29 Leske + Budrich, Opladen, S. 15 - 179.

Knappe, E. , Rubart, T (2001), Auswirkungen des demographischen Wandels - Gesetzliche Pflege- und Krankenversicherung im Vergleich, in: Schmähl, W., Ulrich, V. (Hrsg.), Soziale Sicherungssysteme und demographische Herausforderungen, Mohr Siebeck, Tübingen, S. $95-122$.

Krämer, W. (1982), Wer leben will, muss zahlen. Die Kostenexplosion im Gesundheitswesen und ihre möglichen Auswirkungen. Düsseldorf.

Krämer, W. (1996), Hippokrates und Sisyphus. Die moderne Medizin als Opfer ihres eigenen Erfolgs, in: Kirch, W. und Kliemt, H. (Hrsg.), Rationierung im Gesundheitswesen, Regensburg.

Kühn, H. (2001), in: Deutscher Bundestag: Anhörung der Enquête-Kommission Demographischer Wandel, 22. Januar 2001, Protokoll, Berlin. 
Lauterbach K. (2001), Einfluss demographischer und epidemiologischer Faktoren auf Krankheitslast und -kosten am Beispiel der koronaren Herzkrankheit auf der Grundlage eines Simulationsmodells: Notwendigkeit eines nationalen Bevölkerungsprogramms zur Primärprävention, in: Deutscher Bundestag: Anhörung der EnquêteKommission Demographischer Wandel, 22. Januar 2001, Protokoll, Berlin.

Lubitz, J. D. und G. F. Riley (1993), Trends in Medicare Payments in the Last Year of Life, in: New England Journal of Medicine, 328, S. 1093 - 1096.

Lubitz, J. D., Beebe, J. und Baker, C. (1995), Longevity and Medicare Expenditures, in: New England Journal of Medicine, 330, S. $999-1003$.

Mollenkopf, H. (2002), Mobilität und Lebensqualität im Alter - objektive Vorraussetzungen und subjektive Bedeutung in der mobilen Gesellschaft, in: Glatzer, W., Habich, R., Mayer, K. U. (Hrsg.), Sozialer Wandel und gesellschaftliche Dauerbeobachtung, Leske + Budrich, Opladen, S. 255-271.

Oberdieck, V. (1998), Beitragssatzexplosion in der gesetzlichen Krankenversicherung? Demographische und medizintechnische Determinanten der Beitragssatzdynamik und ihre reformpolitischen Implikationen, Band 26 der Duisburger Volkswirtschaftliche Schriften, Duisburg.

Pfaff, M. (1994), Können wir uns die soziale Krankenversicherung in Zukunft noch leisten?, in: Arbeit und Sozialpolitik, Jg. 48, Heft 9-10, S. 19-32.

Prognos (1998), Auswirkungen veränderter ökonomischer und rechtlicher Rahmenbedingungen auf die gesetzliche Rentenversicherung in Deutschland, DRV-Schriften, Band 9, Frankfurt/M.

Raffelhüschen, B. (2003), Der Bestand der GKV als Generationenvertrag, in diesem Band.

Sachverständigenrat für die Konzertierte Aktion im Gesundheitswesen (1994), Gesundheitsversorgung und Krankenversicherung 2000, Sachstandsbericht 1994, Baden-Baden.

Sachverständigenrat für die Konzertierte Aktion im Gesundheitswesen (2002), Bedarfsgerechtigkeit und Wirtschaftlichkeit - Band I bis III: Nomos, Baden-Baden.

Sachverständigenrat zur Begutachtung der gesamtwirtschaftlichen Entwicklung (2000), Chancen auf einen höheren Wachstumspfad, Jahresgutachten 2000/2001, Metzler Poeschel, Stuttgart. 
Schmähl W. (1983), Auswirkungen von Veränderungen der Altersstruktur der Bevölkerung auf die Finanzsituation der gesetzlichen Krankenversicherung im Vergleich zur gesetzlichen Rentenversicherung - Eine modelltheoretische Analyse, in: Konjunkturpolitik, 29/2, S. $100-120$.

Sinn, H. W. (1999), Why a Funded Pension System is Needed and Why it is Not Needed, CESifo Working Paper Series, No. 195, Munich.

Statistisches Bundesamt (2000), Bevölkerungsentwicklung Deutschlands bis zum Jahr 2050, Ergebnisse der 9. koordinierten Bevölkerungsvorausberechnung, Wiesbaden, CD-ROM-Version.

Ulrich, V. (2000), Medizinisch-technischer Fortschritt, demographische Alterung und Wachstum der Gesundheitsausgaben: was sind die treibenden Faktoren?, in: Gesundheitsökonomie und Qualitätsmanagement, 5, S. 163 - 172.

Ulrich, V. (2001), Alters- und Fortschrittseffekte auf die Nachfrage nach medizinischen Leistungen, in: Michaelis.

Wille, E. (1998), Zukünftige finanzielle Absicherung des Krankheitsrisikos, in: Arbeit und Sozialpolitik, 52, S. $16-27$.

Wille, E. (2000), Reformbedarf bei der Beitragsgestaltung, in: Wirtschaftsdienst, 80, S. $263-265$.

Verband der Angestellten-Krankenkassen/Arbeiter-Ersatzkassen-Verband (2002), Basisdaten des Gesundheitswesens 2002, online verfügbar,

URL: http://www.vdak.de/basisdaten2002.htm (Stand: 06.02.2003).

Zweifel, P. (1990), Bevölkerung und Gesundheitswesen: Ein Sisyphus-Syndrom?, in: Felderer, B. (Hrsg.), Bevölkerung und Wirtschaft, Berlin, S. $373-386$.

Zweifel, P., Felder, S. und Meier, M. (1996), Demographische Alterung und Gesundheitskosten: Eine Fehlinterpretation, in: Oberender, P. (Hrsg.), Alter und Gesundheit, Gesundheitsökonomische Beitrăge, Bd. 26, Nomos, Baden-Baden, S. 29 - 46.

Zweifel, P. Breuer, M. (2002), Weiterentwicklung des deutschen Gesundheitssystems, Gutachten im Auftrag des Verbands Forschender Arzneimittelhersteller, Zürich. 
Manfred Albring and Eberhard Wille - 978-3-631-75562-4

Downloaded from PubFactory at 01/11/2019 03:33:01AM

via free access 


\title{
Die Nachhaltigkeit der gesetzlichen Kranken- und Pflege- versicherung: Diagnose und Therapie
}

\author{
Bernd Raffelhüschen \\ Stefan Fetzer \\ Stefan Moog
}

\section{Einleitung}

Die langfristige Finanzierbarkeit der gesetzlichen Kranken- und Pflegeversicherung ist angesichts des doppelten Alterungsprozesses nicht gewährleistet. Ebenso wie die gesetzliche Rentenversicherung (GRV) fuBen sie auf dem Prinzip des Generationenvertrags, d. h., alle Ausgaben an Kranke oder Pflegebedürftige finanzieren sich aus den laufenden Einnahmen der lohnabhängigen Beiträge der erwerbstätigen Generation. Eine solche Umlagefinanzierung kann aber langfristig nur dann Bestand haben, wenn hinreichend starke junge Jahrgänge nachwachsen. Dies ist seit Jahrzehnten nicht mehr der Fall, denn die Fertilität bewegt sich seit nunmehr über 30 Jahren konstant auf einem Niveau, welches historisch nur mit den relativ kurzfristigen Effekten des Zweiten Weltkriegs vergleichbar ist.

Sowohl die anhaltend niedrige Fertilität als auch die ansteigende Lebenserwartung führen zu einem steigenden Durchschnittsalter der Bevölkerung. Die Konsequenzen dieses "doppelten Alterungsprozesses" für die umlagefinanzierte gesetzliche Kranken- und Pflegeversicherung liegen klar auf der Hand. Auf der einen Seite sinken die durchschnittlichen Beitragseinnahmen, auf der anderen steigen die durchschnittlichen Leistungsausgaben pro Krankem oder Pflegebedürttigem erheblich an. Immer weniger tendenziell gesunde Junge finanzieren mithin immer mehr Alte, deren Krankheits- bzw. Pflegebedürftigkeits-Wahrscheinlichkeit mit dem Alter deutlich zunimmt. Die sich daraus ergebenden zukünftigen Finanzierungslücken machen weitere Anhebungen der Beitragssätze oder drastische Leistungskürzungen unumgänglich.

Im Folgenden sollen die Konsequenzen des demographischen Wandels für die Nachhaltigkeit der gesetzlichen Kranken- und Pflegeversicherung mit Hilfe der Generationenbilanzierung und anhand ergänzender Beitragssatzprojektionen auf derzeitiger Gesetzesgrundlage quantifiziert werden. Ausgehend von der Diagnose des gesetzlichen Status quo soll dann aufgezeigt werden, ob und inwieweit spezifische Reformmaßnahmen eine echte Therapie darstellen und somit zukünftig mehr Nachhaltigkeit in der gesetzlichen Kranken- und Pflegeversicherung generieren könnten. Im Ergebnis zeigt sich, dass für die Strukturreform der gesetzli- 
chen Krankenversicherung (GKV) ein schlichtes Jetzt oder Nie gilt, will heißen: Aus einer Kombination von mehr Wettbewerb im stationären Sektor, absoluten Selbstbehalten in der ambulanten und medikamentösen Versorgung und der Privatisierung von zahnärztlichen Leistungen, der sogenannten Freiburger Agenda, kann wieder eine Nachhaltigkeit in das System getragen werden. Aus dem Selbstbedienungsladen heutiger zu Lasten zukünftiger Generationen könnte so wieder ein echter Generationenvertrag werden. Anders hingegen im Fall der gesetzlichen Pflegeversicherung (GPV). Sie war entgegen der ursprünglichen (Blüm'schen) Intention noch nie ein Generationenvertrag, ${ }^{1}$ und sie kann angesichts der demographischen Entwicklung auch nicht nachhaltig reformiert werden. Einzig mögliche Handlungsalternative ist schlicht die sukzessive Abschaffung der Pflegeversicherung. Beide Gesundheitssysteme sollen im Folgenden nacheinander analysiert werden.

\section{Zur Nachhaltigkeit der gesetzlichen Krankenversicherung}

\subsection{Diagnose des gesetzlichen Status quo ${ }^{2}$}

Auf einen ersten Blick scheint der Generationenvertrag GKV eine Leistungsgewährung an die Kranken, finanziert durch die überwiegend einkommensabhängigen Beiträge der Gesunden, und damit eine (ex post) Umverteilung von den gesunden an die kranken Teile der Bevölkerung zu sein. Warum die Beiträge einkommens- und nicht risikoabhängig erhoben werden, ist ökonomisch nicht begründbar, wird im Allgemeinen jedoch als Solidarprinzip bezeichnet, indem die "Reichen" für die gleiche Leistung mehr zahlen als die "Armen“. ${ }^{3}$ Schon hier verlässt das System jede ökonomische Rationalität, denn effizient wäre die rein private Versicherungslösung, kombiniert mit direkter Subjektförderung für Bedürftige, z. B. chronisch Kranke. Rational wäre es auch, die Finanzierung der be-

1 Schon während der Gesetzesinitiative des früheren Arbeitsministers Blüm wurde erhebliche Kritik laut, die in der gesetzlichen Pflege eher ein Erbschaftsbewahrungsgesetz der deutschen Mittelschicht oder auch ein GemeindefinanzreformVerschiebungsgesetz sahen.

2 Die Ausführungen zur GKV enthalten im Wesentlichen eine aktualisierte Version der Analyse von Fetzer und Raffelhüschen (2003).

3 Die im derzeitigen System der GKV und GPV herrschende Solidarität erscheint völlig willkürlich, da Personen mit einem hohen Einkommen keine Pflichtmitglieder mehr sind. Zudem werden durch die Möglichkeit der freiwilligen Versicherung für Personen mit hohem Einkommen gerade diejenigen in die GKV eingeladen, die in einer privaten Krankenversicherung aufgrund von mitversicherten Familienmitgliedern eine wesentlich höhere Prämie zu bezahlen hätten, da die Familienmitglieder natürlich auch zusätzliche Kosten verursachen. Für weitere Verletzungen der Beitragsgerechtigkeit siehe Wille (2000). 
dürftigkeitsgeprüften Subventionen nicht über proportionale Beiträge, sondern allein über die progressive Besteuerung des Gesamteinkommens vorzunehmen. Akzeptiert man jedoch die "gesellschaftliche Nichtakzeptanz" des ökonomisch Sinnvollen und argumentiert damit im Bereich eines politökonomischen Second-Best, so stellt sich dennoch die Frage, ob das umlagefinanzierte Gesundheitssystem überhaupt ein $\mathrm{Ge}$ nerationenvertrag ist, also ein System, in dem junge Erwerbstätige die alten Nichterwerbstätigen versorgen.

Eine erste naive Antwort auf diese Frage könnte "Nein" lauten, denn Leistungen der GKV werden von allen Jahrgängen in Anspruch genommen. Auch zahlen Rentner wie die Erwerbstätigen auf ihr Einkommen sprich Renten - Beiträge zur GKV, wobei die GRV den hälftigen Arbeitgeberbeitrag übernimmt. Zweifelsohne ist letztere allerdings ein reiner Generationenvertrag, und das Nettorentenniveau für einen vergleichsweise überdurchschnittlich versorgten Eckrentner liegt gerade einmal bei 70 - in Zukunft eher 65 Prozent des durchschnittlichen Lebenslohneinkommens. Darüber hinaus zahlen Rentner im Vergleich zu den Erwerbstätigen einen geringeren Beitragssatz. Damit sind die Beiträge der Rentner nicht nur geringer als die der Erwerbstätigen, sondern mindestens zur Hälfte auch aus einem Generationenvertrag geboren. Auf der anderen Seite werden, wie gleich veranschaulicht werden wird, Gesundheitsleistungen verstärkt im Alter in Anspruch genommen.

Um obige Frage möglichst exakt zu beantworten, sind in Abb. 1 die altersspezifischen Zahlungsströme zwischen der Bevölkerung und der GKV für jeweils fiktive Durchschnittsindividuen ihres Jahrgangs dargestellt. Für die Berechnung dieser Zahlungsströme wurden die in der Volkswirtschaftliche Gesamtrechnung (VGR) ausgewiesenen Einnahmen und Ausgaben der GKV des Jahres 2000 mit Hilfe von altersspezifischen Profilen den einzelnen Jahrgängen zugewiesen. Auf der Einnahmenseite sind dies die Beitragszahlungen der Erwerbstätigen, der Rentner und der Arbeitslosen. ${ }^{4}$ Die Ausgaben wurden nach Profilen des Risikostrukturausgleiches (RSA) des Jahres 2000 verteilt. Im Einzelnen sind dies Profile für ärztliche Leistungen, zahnärztliche Leistungen (inkl. Zahnersatz), Arzneimittel, Krankenhausleistungen und sonstige Sachleistungsausgaben sowie Krankengeldleistungen. Der Rest der Ausgaben, der haupt-

4

Die Profile für die Beitragszahlungen der Erwerbstätigen und Arbeitslosen stammen aus der Einkommens- und Verbrauchsstichprobe 1998. Die Zahlungsprofile der Rentner aus direkten und durch die gesetzliche Rentenversicherung gezahlten indirekten Beiträgen wurden mit Hilfe der VDR-Statistik 2000 (Verband deutscher Rentenversicherungsträger) gewonnen. 
sächlich aus Verwaltungskosten besteht, wurde mit einem uniformen Profil gleichmäßig auf alle Jahrgänge verteilt.

Bei Betrachtung der altersspezifischen Ein- und Ausgabenprofile über die Gesamtbevölkerung zeichnet sich klar das Bild eines größtenteils zwischen den Generationen umverteilenden, nicht verbrieften Gesellschaftsvertrages ab. ${ }^{5}$ Wie aus Abb. 1 hervorgeht, steigen die Beitragszahlungen im Alter zwischen 15 und 30 Jahren kontinuierlich an und verharren bis zum Renteneintritt auf einem relativ konstanten Niveau von etwa 2.600 Euro. Mit Renteneintritt sinken die Pro-Kopf-Beiträge, so dass pro durchschnittlichem Rentner etwa 1.500 Euro im Jahr an Zahlungen von der GKV eingenommen werden. Ganz anders als die durchschnittlichen Einzahlungen entwickelt sich die Inanspruchnahme von Leistungen über den Lebenszyklus. Eine relativ hohe Inanspruchnahme erfolgt bei Geburt und in den ersten zwei Lebensjahren. Ab dem dritten Lebensjahr steigt die durchschnittliche Leistungsinanspruchnahme von etwa 700 kontinuierlich auf 2.000 Euro zum Renteneintritt an. Zwischen 60 und 65 beginnt dann ein akzelerierender Anstieg der Gesundheitsausgaben, die durchschnittlich von 2.000 auf fast 5.000 Euro ansteigen.

\section{Abb. 1: Altersspezifische Beiträge und Leistungen der GKV}

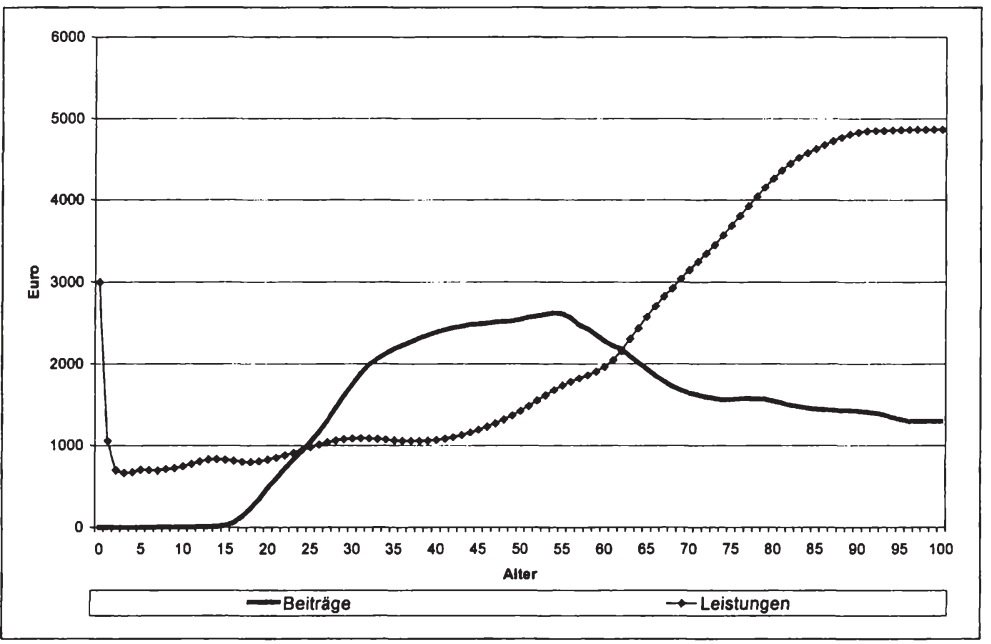

Da bei jungen Jahrgängen (bei den 0 - bis 20-Jährigen), ähnlich wie bei den Rentnern die durchschnittlichen Leistungen die Beiträge übersteigen, wird hier auch häufig vom 3-Generationenvertrag gesprochen, vgl. beispielsweise Schulenburg (1989) oder Knappe und Rachold (1997). 
Ganz offensichtlich scheint die GKV also ein echter Generationenvertrag zu sein, denn während der Erwerbstätigkeit sind die durchschnittlichen Einzahlungsströme um etwa 1.000 Euro größer als die Inanspruchnahme von Leistungen. Während des Ruhestandes ist dies genau umgekehrt, und die Differenz steigt altersbedingt von 0 auf fast 4.000 Euro an. Wie hoch die intergenerative Umverteilungskomponente in der GKV ist, kann anhand des mit der Jahrgangsstärke gewogenen Flächenvergleichs von Ein- und Auszahlungsdifferenz über die Gesamtbevölkerung quantitativ erfasst werden. Demnach kann man die staatliche Gesundheitsvorsorge gegenwärtig zu etwa vier Fünftel als einen Generationenvertrag zwischen Erwerbstätigen und Rentnern ansehen. Schon in statischer Hinsicht erhöht sich dieser Anteil, wenn man die durch die Rentenversicherung importierten Generationenvertragsanteile hinzurechnet. $\mathrm{Zu}$ einem fast reinen Generationenvertrag dürfte die GKV allerdings in dynamischer Sicht werden, denn die potentiell erwerbstätigen Bevölkerungsanteile gehen relativ und absolut zurück, und die Verdoppelung des Alterslastquotienten (65 und älter zu 18- bis 64-Jährigen) verstärkt die intergenerative Umverteilung in der Zukunft noch weiter.

Für die im Folgenden vorzunehmende Analyse der Nachhaltigkeit der GKV resultieren aus dem doppelten Alterungseffekt vier unmittelbare Konsequenzen, von denen erst zwei beschrieben wurden. Aus der Verdoppelung des Alterslastquotienten ergibt sich ein direkter negativer Finanzierungseffekt, der aus den altersspezifischen Einzahlungsströmen der Abb. 1 ablesbar ist. Der zweite negative Finanzierungseffekt des demographischen Wandels folgt aus dem mit steigendem Alter stark ansteigenden Ausgabenprofil, welches steigende durchschnittliche Leistungsausgaben je Mitglied in der Zukunft impliziert. Die dritte Konsequenz für die zukünftige Entwicklung der Einnahmen- und Ausgabenströme der GKV resultiert aus der steigenden Lebenserwartung. Hinsichtlich der quantitativen und auch der qualitativen Richtung dieses Effektes herrscht von wissenschaftlicher Seite aus aber keine Einigkeit.

Gemäß der so genannte Medikalisierungsthese steigt die Morbidität, d. h. die Häufigkeit der Erkrankung innerhalb einer Bevölkerungsgruppe, mit dem Alter an, so dass das Ausgabenprofil in den obigen Abbildungen mit zunehmendem Alter weiter ansteigen müsste. Leistungen würden dann nicht nur länger, sondern auch in steigendem Ausmaß in Anspruch genommen werden. Gemäß der so genannten Kompressionsthese steigen die Gesundheitsausgaben erst kurz vor dem Todeszeitpunkt sprunghaft an, das Ausgabenprofil würde infolge einer höheren Lebenserwartung dann in der Horizontalen gestreckt und keineswegs steiler werden. Steigt die Lebenserwartung z. B. um 2 Jahre an, so würde ein dann 82-Jähriger die gleichen Ausgaben verursachen wie ein heute 80- 
Jähriger. Will heißen: Die gleichen Gesundheitsausgaben finden einfach später statt. Eine höhere Lebenserwartung, für sich genommen, würde dann auch nicht mit höheren durchschnittlichen Leistungsausgaben einhergehen. In der Literatur findet sich keine ausreichende Evidenz für die eine oder die andere These. ${ }^{6}$ Für die im Folgenden unterstellten altersspezifischen Gesundheitsausgaben wird deshalb vereinfachend angenommen, dass die durchschnittlichen Leistungsausgaben ab einem Alter von 90 Jahren nicht mehr weiter anwachsen (Abb. 1). Dies entspricht einem Mittelweg beider Thesen oder einer abgeschwächten Form der Medikalisierungsthese.

Die vierte unmittelbare Konsequenz des demographischen Alterungseffektes auf die Nachhaltigkeit der GKV resultiert aus der Hebelwirkung, die der medizinisch-technische Fortschritt bei doppelter Alterung induziert. Da es sich beim medizinisch-technischen Fortschritt im Wesentlichen um Produktinnovationen handelt, die im Gegensatz zu kostensenkenden Prozessinnovationen den Umfang des praktisch Machbaren erweitern, ist die Medizin in der Lage, immer mehr Krankheiten zu heilen. Dies induzierte in der Vergangenheit, also unabhängig vom demographischen Wandel, eine stetige Ausdehnung des Leistungskatalogs der GKV und steigende durchschnittliche Leistungsausgaben je Mitglied. Die demographische Alterung verstärkt diesen Effekt nochmals.

Wie sich die vier oben genannten Konsequenzen des demographischen Alterungseffektes auf die nachhaltige Finanzierbarkeit der GKV auswirken, soll im Folgenden mit Hilfe der Methodik der Generationenbilanzierung untersucht werden. Aus der Saldierung der in Abb. 1 dargestellten durchschnittlichen Beitragszahlungen mit den erhaltenen Leistungen für jeden Jahrgang berechnet man in dieser Methodik die Nettobeitragszahlungen der im Basisjahr 2000 lebenden Jahrgänge für das entsprechende Jahr. Diese jährlichen Differenzen werden dann mit einer Produktivitätswachstumsrate $(\mathrm{g})$ in Zukunft fortgeschrieben. ${ }^{7}$ Werden alle

6 Vgl. z. B. Buchner und Wasem (2000) für die Medikalisierungsthese und Zweifel, Felder und Meiers (1999) für die Kompressionsthese. Den Ergebnissen von Nocera (1996) zufolge gilt im stationären Sektor eher die Medikalisierungs-, während im ambulanten Sektor eher die Kompressionsthese zutrifft.

7 Damit bezahlt beispielsweise ein 25-Jähriger im Jahr 2005 einen um $(1+g)^{5}$ höheren Nettobeitrag als ein Gleichaltriger im Basisjahr 2000. Der Faktor spiegelt mithin das Wachstum der Bemessungsgrundlage der GKV, d. h. das Lohnsummenwachstum, wider. Bei konstanter Lohnquote und politökonomisch rational verhandelnden Tarifpartnern entspricht das Lohnwachstum wiederum der Inflationsrate zuzüglich der Rate des arbeitsvermehrenden technischen Fortschrittes. Da die Beiträge der Rentner sich auf die Renten insgesamt beziehen und diese mit der so genannten modifizierten Bruttolohnanpassung indexiert sind, wachsen 
jährlichen Nettobeitragszahlungen eines Durchschnittsindividuums über seinen verbleibenden Lebenszyklus mit dem Realzins ( $r$ ) diskontiert und summiert, ergibt sich dessen Generationenkonto. Die Generationenkonten der Durchschnittsindividuen werden daraufhin mit der Jahrgangsstärke gewichtet und über alle lebenden und zukünftigen Kohorten addiert. Daraus ergibt sich die so genannte Nachhaltigkeitslücke, die im Prinzip ausdrückt, ob die Gesamtheit aller Generationen mehr Leistungen erhält, als sie selbst an Beiträgen über die restliche Lebenszeit zahlt oder vice versa. ${ }^{8}$ Genau genommen handelt es sich dabei also um die implizite und statistisch nicht dokumentierte Verschuldung der GKV.

Eine (positive) Nachhaltigkeitslücke impliziert, dass die heute lebenden Jahrgänge zusammengenommen eine Last vor sich herschieben, die im Wesentlichen durch ihre Kinder abgegolten werden muss. Zur Aufrechterhaltung des gegenwärtigen Niveaus in der GKV müsste dann ein höherer Preis in Form steigender Beitragssätze bezahlt werden. Werden allein zukünftige Generationen zur Schließung der Nachhaltigkeitslücke mit höheren Nettobeitragszahlungen herangezogen und erfolgt dies wachstumsbereinigt und für alle gleich, so illustriert das Generationenkonto des 1-Jährigen (oder jedes anderen zukünftigen Jahrgangs) die Belastung der zukünftigen Beitragszahler. Da dieser wie auch der im Basisjahr geborene 0-Jährige über seinen gesamten Lebenszyklus erfasst wird, kann man die Generationenkonten der beiden unmittelbar vergleichen und somit die Mehrbelastung zukünftiger Generationen als absolute Differenz der beiden Generationenkonten berechnen.

Um die Auswirkungen des medizinisch-technischen Fortschrittes zu veranschaulichen, werden zwei Szenarien betrachtet. Das Szenario ohne Kostendruck konzentriert sich auf die oben angesprochenen ersten drei Konsequenzen des demographischen Alterungsprozesses, also den negativen Finanzierungseffekt, die steigenden durchschnittlichen Leistungsausgaben und die von uns verwendete abgeschwächte Medikalisierungsthese. Hierbei wird angenommen, dass die Beitragseinnahmen und die Leistungsausgaben parallel mit dem allgemeinen Produktivitätsfortschritt anwachsen.

auch die Einnahmen der GKV von den Rentnern im Prinzip mit der Lohnsumme. Vgl. Borgmann, Krimmer und Raffelhüschen (2001) für weitere Einzelheiten.

Für die Ermittlung der Jahrgangsstärken in den Perioden nach dem Basisjahr sind umfassende Bevölkerungsvorausschätzungen notwendig. Für die nachfolgenden Untersuchungen wurde die zweite Variante der 9. koordinierten Bevölkerungsvorausberechnungen des Statistischen Bundesamtes gewählt.

Unterschiede in den folgenden Ergebnissen zu Fetzer, Moog und Raffelhüschen (2002) begründen sich auf der Wahl eines anderen Basisjahres sowie der Verwendung anderer Profile. 
Abb. 2: Generationenbilanz der GKV im Status quo

(Basisjahr 2000, r = 3 \%, g= 1,5\%)

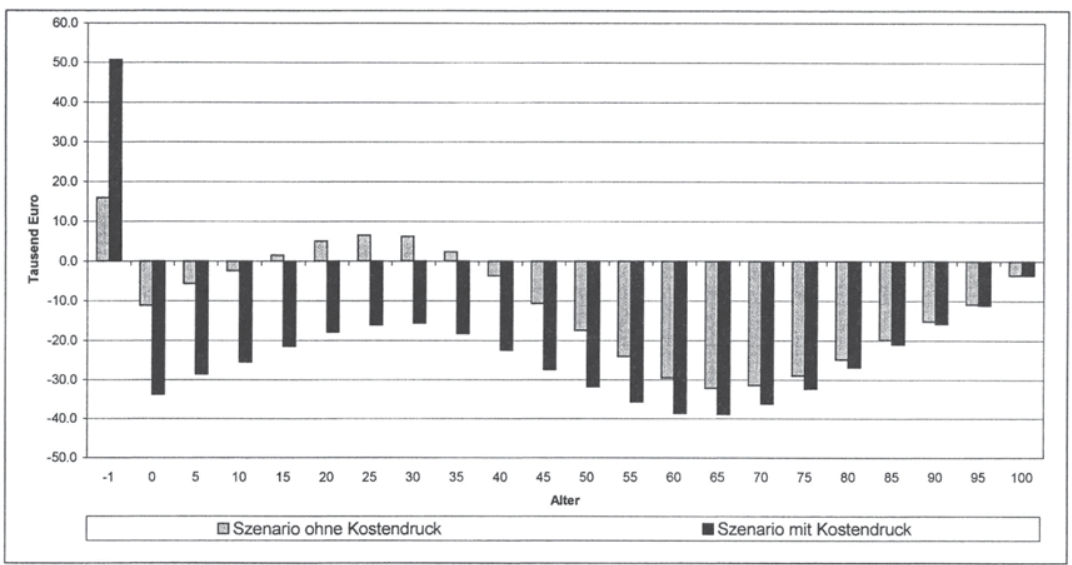

Auf wie schwachem Fundament der Generationenvertrag schon in diesem (unrealistisch) optimistischen Szenario ohne Kostendruck steht, zeigt die in Abb. 2 dargestellte Generationenbilanz. Die Generationenkonten der einzelnen Kohorten weisen nur die 14- bis 37-Jährigen als wirkliche Nettobeitragszahler aus, wohingegen alle anderen Jahrgänge, ob jünger oder älter, im Erwartungswert Nettotransferempfänger der GKV sind. Im Maximum wird ein 27-Jähriger 6.900 Euro netto an Beiträgen über seine verbleibende Lebenszeit in die GKV einzahlen. Demgegenüber beziffert sich der maximale Nettotransfer über den restlichen Lebenszyklus für einen 67-Jährigen auf 32.300 Euro. Intergenerativ legitimiert werden die Transfererhalte durch eine - wenn auch nur kurze vorgelagerte Periode der Beitragsdominanz. Summiert man die mit der Jahrgangsstärke gewogenen Nettobeitragszahlungen aller heute und zukünftig lebenden Generationen, so ergibt sich eine Nachhaltigkeitslücke in Höhe von 65,3 Prozent des BIP. Dies entspricht 1,3 Bio. Euro, oder anders ausgedrückt, einer (fiktiven) Mehrbelastung zukünftiger Generationen in Höhe von 27.100 Euro pro Kopf.

Im zweiten Szenario, dem Kostendruckszenario, wird zusätzlich den zu erwartenden technologischen Konsequenzen Rechnung getragen. Insbesondere wird unterstellt, dass die Ausgabenkomponenten Arztleistungen, Zahnarztleistungen, Medikamente, Krankenhausleistungen und sonstige Leistungsausgaben mittelfristig mit einer um 1 Prozentpunkt 
höheren Rate von 2,5 Prozent anwachsen. ${ }^{10}$ Dies illustriert - je nach Blickwinkel - den Kostendruck oder die Erosion der Bemessungsgrundlage der GKV-Beiträge, also in beiden Fällen das Auseinanderklaffen der Einnahmen- und Ausgabenentwicklung. Ein Blick auf Abb. 3 lässt die erschreckenden Auswirkungen des Kostendrucks erkennen: Tatsächlich sind dann nämlich alle lebenden Generationen Nettoleistungsempfänger der GKV, so dass es in keinem Jahrgang ein Durchschnittsindividuum gibt, welches auch nur annähernd den Barwert der voraussichtlichen Leistungen durch Beiträge bezahlt. Entsprechend verwundert es nicht, dass sich im Kostendruckszenario eine Nachhaltigkeitslücke in Höhe von 203,8 Prozent des BIP (4,1 Bio. Euro) ergibt. Für den Fall, dass wiederum nur die zukünftigen Generationen diese Nachhaltigkeitslücke schließen, beziffert sich deren Mehrbelastung auf 84.600 Euro pro Kopf. Von einem Generationenvertrag kann angesichts dieser Zahlen eigentlich nicht mehr gesprochen werden, vielmehr handelt es sich bei der GKV um ein allgemeines Bereicherungsabkommen zu Lasten zukünftiger Generationen.

Welche Konsequenzen haben diese Nachhaltigkeitslücken aber nun hinsichtlich der zukünftig zu erwartenden Beitragssätze für die oben beschriebenen Szenarien? Bislang war implizit unterstellt worden, dass sich die Defizite der GKV zu einer Nachhaltigkeitslücke akkumulieren. Da die GKV jedoch vom Gesetzgeber zu einer einnahmenorientierten Ausgabenpolitik verpflichtet ist, d. h. die Ausgaben in gesamtem Umfang durch Beitragseinnahmen zu decken sind, kann die Finanzierung etwaiger Defizite nicht in die Zukunft verschoben, sondern muss durch laufende Beitragssatzanhebungen sichergestellt werden.

10 Für alle anderen Leistungen (Krankentagegeld, Verwaltungsausgaben u. Ä.) wird kein höheres differentielles Wachstum unterstellt, da der medizinisch-technische Fortschritt auf diese Aufgabengrößen keinen Einfluss hat. Breyer und Ulrich (1999) haben auf Grundlage einer ökonometrischen Untersuchung gezeigt, dass die Leistungsausgaben der GKV aufgrund des medizinisch-technischen Fortschrittes um 1 Prozentpunkt stärker wachsen als der allgemeine Produktivitätsfortschritt. Die von uns unterstellte mittlere Frist umfasst den Zeitraum 2001 bis 2041. Die an sich arbiträre Annahme einer Begrenzung ist insofern notwendig, als dass sonst die Gesundheitsausgaben langfristig oberhalb des BIP lägen. Die im Folgenden beschriebenen qualitativen Aussagen sind jedoch nicht davon abhängig, ob der unterstellte Zeitraum ein Jahrzehnt früher oder später endet. Langfristig wachsen die Gesundheitsausgaben wieder in Höhe des allgemeinen Produktivitätsfortschrittes. 
Abb. 3: Beitragssatzentwicklung in der GKV im Status quo (Basisjahr 2000, $r=3 \%, g=1,5 \%$ )

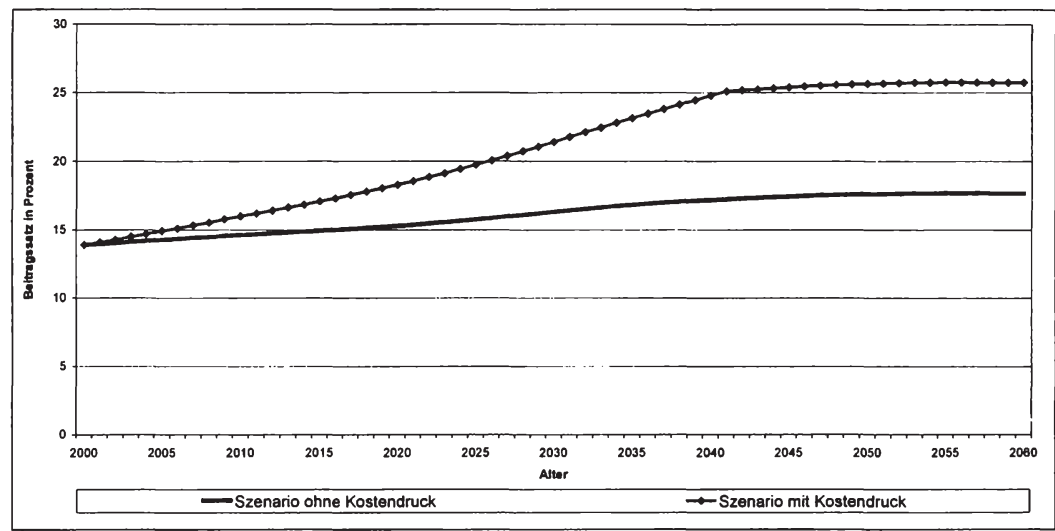

In Abb. 3 sind deshalb Beitragssatzprojektionen für beide Szenarien dargestellt. ${ }^{11}$ Im unrealistisch optimistischen Szenario ohne Kostendruck steigt der Beitragssatz von 13,8 Prozent im Basisjahr 2000 auf 17,2 Prozent im Jahr 2040 und erreicht sein Maximum im Jahr 2055 mit 17,6 Prozent. Wird das realistischere Szenario mit Kostendruck betrachtet, so kommt es zu einer regelrechten Explosion der Beitragssätze. Bis zum Jahr 2040 würde der Beitragssatz um 11 Prozentpunkte auf 24,7 Prozent ansteigen und im Jahr 2055 sein Maximum mit 25,7 Prozent erreichen. ${ }^{12}$

Angesichts der in diesem Abschnitt dargestellten Ergebnisse ist es mehr als fraglich, ob zukünftige Generationen quasi bedingungslos und ad infinitum bereit sind, das vermeintlich solidarische System der GKV unverändert weiterzuführen. Es erscheint eher wahrscheinlich, dass sie den so

Die Beitragssatzprojektion orientiert sich am durchschnittlichen Beitragssatz Deutschlands im Basisjahr 2000 (13,8 Prozent).

12 Eine Reihe anderer Studien kommen zu ganz ähnlichen Ergebnissen. Beispielsweise zeigen Erbsland, Ried und Ulrich (1999), dass der Beitragssatz infolge des rein demographischen Effektes von 12,9 Prozent im Jahr 1995 auf 15,5 Prozent im Jahr 2040 ansteigen wird. Breyer und Ulrich (1999) und PROGNOS (1998) prognostizieren einen Anstieg der Beitragssätze auf 15,3 Prozent bzw. 15,4 Prozent im Jahr 2040. Zieht man auch die Auswirkungen des medizinischtechnischen Fortschrittes in Betracht, so steigt der Beitragssatz bei Breyer und Ulrich (1999) auf 23,1 Prozent im Jahr 2040 an, während Oberdieck (1998) auf Basis der Medikalisierungsthese sogar einen Anstieg auf 31,2 Prozent im Jahr 2040 prognostiziert. Ein umfassender Überblick und Vergleich bezüglich der Annahmen einzelner Studien findet sich auch im Gutachten des DIW (2001). 
genannten Generationenvertrag kündigen, es sei denn, es kommt in der GKV zu einem Paradigmenwechsel und mit diesem zu einer Wiederbelebung des Generationenvertrages. Wie ein derart fundamentaler Paradigmenwechsel aussehen könnte, soll nun näher erläutert werden. Dabei wird allein auf das realistische Szenario unter Kostendruck bzw. das Auseinanderklaffen der Einnahmen- und Ausgabenentwicklung Bezug genommen.

\subsection{Therapie der GKV: Die Freiburger Agenda}

Das deutsche Gesundheitssystem ist durch eine regelrechte Flut von Gesetzesänderungen und Verordnungserlassen innerhalb der letzten 25 Jahre gekennzeichnet. ${ }^{13}$ Es ist jedoch schon in der Vergangenheit nicht gelungen, dem festgeschriebenen Ziel der Beitragssatzstabilität gerecht zu werden. Erst recht ist es nicht gelungen, die GKV für die zukünftige Herausforderung des demographischen Alterungsprozesses zu wappnen, was die Ergebnisse des vorherigen Abschnitts mehr als deutlich gemacht haben dürften. Einschneidende Eingriffe in das Gesundheitssystem sind fast schon ein Tabuthema, aber angesichts der katastrophalen Lage, in der sich die GKV langfristig befindet, wird ein weiteres Kurieren am Symptom schon bald der Weg in eine Sackgasse ohne Umkehrmöglichkeit sein.

Von Seiten der Gesundheitsökonomie gibt es seit geraumer Zeit nicht nur Warnungen, sondern auch Vorschläge für echte Strukturreformen. Diese wurden bislang allerdings von den politischen Entscheidungsträgern nahezu vollständig ignoriert. Dennoch soll ein Vorschlag zur Reform der GKV unterbreitet werden, der einen großen Schritt in Richtung Nachhaltigkeit und damit langfristige Finanzierungssicherung macht und zudem relativ schnell und einfach umgesetzt werden kann. Diese so genannte Freiburger Agenda wird mit empirisch aufgearbeiteten Generationenbilanzen untermauert und hat konkret drei Komponenten:

a) die Ausgliederung von Zahnarzt- und Zahnersatzleistungen

b) ein absoluter Selbstbehalt für ambulante Leistungen und Medikamente

c) eine über wettbewerbs- und ordnungspolitische Regeln stattfindende Reduzierung des Kostendrucks im stationären Sektor

13 Henke (1997) zählt allein für den Zeitraum 1977 bis 1997 insgesamt 46 Gesetze und über 6.800 Einzelbestimmungen und Verordnungen. 
Die erste Komponente der Freiburger Agenda sieht vor, zahnärztliche Leistungen und Zahnersatzleistungen vollständig aus dem Katalog der GKV zu streichen. Vorbilder hierfür sind eine Reihe anderer Länder, wie beispielsweise die Schweiz oder Norwegen. Die individuelle Zusatzbelastung bei einer Ausgliederung dieser Leistungen in den privaten Krankenversicherungsbereich dürfte relativ gering sein, denn gegenwärtig sind bereits bis zu 55 Prozent der Kosten durch private Zuzahlungen zu leisten. ${ }^{14}$ Dadurch sind Patienten und Leistungsanbieter schon heute zumindest partiell an Marktprinzipien und direkte Rechnungsstellung gewöhnt. Zudem werden Zahnarztleistungen nur wenig altersspezifisch in Anspruch genommen, so dass private Versicherungen bei der Prämienkalkulation auf die teure Rücklagenbildung verzichten könnten. ${ }^{15}$ Konkret sieht die Freiburger Agenda vor, Zahnarztleistungen und Zahnersatz von 2005 bis 2014 schrittweise um jeweils 10 Prozentpunkte p. a. auszugliedern. Dieser Übergang soll die Umstellung für die (privaten) Krankenkassen und die Versicherten erleichtern.

Die zweite Komponente der Freiburger Agenda sieht die Einführung eines absoluten jährlichen Selbstbehaltes vor. Selbstbeteiligungen sind im System der GKV nichts Neues, denn bereits heute gibt es viele Bereiche, wie etwa bei Arzneimitteln, Verbandsmitteln, Zahnersatz- und zahnärztlichen Leistungen, in denen geringe Zuzahlungen durch Patienten zu leisten sind. In anderen Ländern sind Selbstbeteiligungen in weitaus größerem Ausmaß die Regel. Theoretisch dienen sie dazu, dem Phänomen des so genannten Moral Hazard ${ }^{16}$ entgegenzusteuern bzw. die Gesundheitskosten transparent und für den Patienten spürbar zu machen. Unabdingbare Voraussetzung hierfür ist zunächst ein vollständiger Übergang auf das Kostenerstattungsprinzip.

Hinsichtlich der Ausgestaltung von Selbstbeteiligungen lassen sich eine Reihe verschiedener Konzepte aufführen. ${ }^{17}$ Die zwei bekanntesten und

Die relative Selbstbeteiligung vermindert sich bei regelmäßiger Vorsorge auf maximal 45 Prozent.

Da die Zahnbehandlung ein relativ uniformes Leistungsprofil über den Lebenszyklus aufweist und damit wenig altersspezifisch ist, gehört sie nicht in den Leistungskatalog eines umlagefinanzierten Generationenvertrages. Hierin kann ein Grund dafür gesehen werden, dass in fast allen industrialisierten Ländern Zahnbehandlung schlicht "Privatsache" ist.

Moral Hazard beschreibt den Umstand, dass sich durch die Möglichkeit einer Versicherung die Verhaltensanreize für den Versicherten ändern. Ein umfassender Überblick über verschiedene Formen des Moral Hazard findet sich in Breyer und Zweifel (1999).

17 Einen Überblick über verschiedene Selbstbeteiligungsformen liefert Schulenburg (1987). 
meist verwendeten sind der absolute Selbstbehalt und die relative (prozentuale) Selbstbeteiligung. Ersterer fixiert die private Zuzahlung auf einen fixen Kostenerstattungsbetrag pro Periode, letztere bemisst die Zuzahlung auf einen prozentualen Anteil der Kosten. Die Anreizwirkungen der absoluten und relativen Selbstbehalte unterscheiden sich - bei entsprechenden Tarifen - nur unwesentlich. Hinsichtlich der Verteilungswirkungen unterscheiden sich beide jedoch erheblich. Individuen mit einem sehr hohen Krankheitsrisiko würden den auf sie zukommenden Eigenanteil beim relativen Selbstbehalt nur schwer finanzieren können, während sie den absoluten Selbstbehalt nur bis zur vorgesehenen Höchstgrenze aufwenden müssen. Da die Leistungsinanspruchnahme mit zunehmendem Alter steigt, wäre ein relativer Selbstbehalt für viele Teile der älteren Bevölkerung schlicht zu teuer. Deswegen erscheint die Einführung eines absoluten Selbstbehaltes sehr viel praktikabler, da dieser für alte und krankheitsanfällige Individuen eher finanzierbar ist als eine relative Selbstbeteiligung. Dies bedeutet aber auch, dass die sozialpolitisch intendierten Kompensationszahlungen für die älteren Jahrgänge durch andere staatliche Träger kleiner sind. ${ }^{18}$ Allerdings besteht bei wirkungsvollen Selbstbeteiligungen ein erheblicher sozialpolitischer Flankierungsbedarf - weniger für die alten als vielmehr für die einkommensschwachen Teile der Bevölkerung sowie für kinderreiche Familien. Für diese dürfte eine hohe und damit wirkungsvolle Selbstbeteiligung eine kaum zu bewältigende Belastung darstellen, so dass über die bedürftigkeitsgeprüfte Sozialhilfe und/oder den Familienlastenausgleich auf andere staatliche Institutionen zurückgegriffen werden muss.

Für die Berechnung der Wirkungsweise des absoluten Selbstbehaltes in der Freiburger Agenda wurde der Quotient aus einem Tarif mit Selbstbehalt und ohne Selbstbehalt für alle Jahrgänge aus Kopfschadensprofilen der Deutschen Krankenversicherung (DKV) berechnet. Dieser Quotient spiegelt die prozentuale Senkung der Leistungsinanspruchnahme für jeden Jahrgang wider. ${ }^{19}$ Mit Hilfe dieses "Verhaltenveränderungsprofils" wurden dann die zu den ambulanten GKV-Leistungen und Medikamenten gehörenden RSA-Profile ab dem Jahr 2005 altersspezifisch angepasst.

18 Alternativ könnte man den absoluten Selbstbehalt mit einer proportionalen und gedeckelten Selbstbeteiligung kombinieren. Einen solchen Vorschlag, der weitgehend dem gegenwärtigen Schweizer System entspricht, macht Felder (1999). Da hierbei die Daten einer privaten Krankenversicherung verwendet wurden, ist damit implizit unterstellt, dass die Versicherten der gesetzlichen Krankenversicherung auf die Einführung eines Selbstbehaltes so reagieren wie privat versicherte Personen. Die damit verbundene statistische Repräsentationsproblematik wird aufgrund mangelnder Alternativen in Kauf genommen. 
Die dritte Komponente der Freiburger Agenda besteht darin, über wettbewerbs- und ordnungspolitische Maßnahmen den Kostendruck im stationären Sektor zu dämpfen. Konkret geht es dabei um die Vertragsfreiheit für Krankenkassen und Krankenhausträger bezüglich der Entgeltgestaltung im stationären Sektor. ${ }^{20}$ Noch konkreter geht es um einen echten Wettbewerb zwischen den Kassen, wobei es jeder Krankenkasse anheim steht, mit Krankenhäusern ihrer Wahl Einzelverträge auszuhandeln. ${ }^{21}$ Eine Krankenkasse müsste bei einer ineffizienten Vertragswahl entweder höhere Ausgaben und damit höhere Beiträge oder eine schlechtere Leistung bei gleichen Beiträgen gegenüber ihren Konkurrenten anbieten, was deren Versicherte zu einem Kassenwechsel veranlassen würde. Somit würden sich nach einiger Zeit die effizienten Vergütungssysteme herauskristallisieren, denn, so Breyer (2000), "mit welcher Vergütung eine ausreichende medizinische Versorgung hoher Qualität zu geringstmöglichen Kosten erreichbar ist, kann nur die Praxis erweisen".

Vorraussetzung, um einen solchen „Wettbewerb als Entdeckungsverfahren" für effiziente Vertragsformen zu nutzen, ist allerdings, dass der Versicherte Kassenwahlfreiheit hat. Dies ist in der GKV zwar seit 1996 formal gegeben, jedoch verhindert der Zwang für Krankenkassen, einheitliche Verträge abzuschließen, dass ein wirklicher Wettbewerb zwischen Kassen neue Lösungen für Verträge mit Krankenhäusern generieren kann. Grundvoraussetzung für eine Vertragsfreiheit ist zudem ein funktionierender Risikostrukturausgleich, der eine reine Risikoselektion der Kassen unterbindet, da es ansonsten Krankenkassen für reiche Gesunde und Krankenkassen für arme Kranke geben würde. ${ }^{22}$ Um die Auswir-

Es bedürfte dann einer Neuregelung von $\S 109$ SGB V, in dem der bisherige Zwang für Kassen, einheitliche Verträge abschließen zu müssen, geregelt ist. Prinzipiell wäre es auch denkbar, dass man den Kassen Vertragsfreiheit für den ambulanten Sektor einräumt. Dies erscheint aber angesichts des derzeitigen Standes der Kartellbildung im ambulanten Bereich nur sehr langfristig umsetzbar zu sein.

21 Es besteht in der gesundheitsökonomischen Literatur ein allgemeiner Konsens, dass ein effizientes Verhalten der Leistungserbringer von der Wahl des Entgeltes abhängt. Diese Erkenntnis hat schon in der Vergangenheit zu Veränderungen der Vergütungssysteme im stationären Bereich geführt, die aber bislang nicht das gewünschte Ergebnis einer langfristigen Kostenreduktion generieren konnten. Ein relativ neues Beispiel für eine sich durch Vertragsfreiheit ergebende Kostendämpfungsmaßnahme sind die diagnosebezogenen Fallpauschalen im Krankenhaussektor, welche ab 2003 eingeführt werden sollen. Durch die Einführung soll vor allem die im internationalen Vergleich hohe durchschnittliche Verweildauer in deutschen Krankenhäusern gesenkt werden. Vgl. Breyer und Kiffmann (2001) für eine effizientere Gestaltung des Risikostrukturausgleiches. 
kungen der Kostendämpfung im stationären Bereich quantitativ zu erfassen, soll im Referenzfall davon ausgegangen werden, dass es gelingt, durch die wettbewerbspolitischen Maßnahmen den Kostendruck vollständig herauszunehmen.

Abb. 4: Generationenbilanz der GKV: Freiburger Agenda vs. Status quo (Basisjahr 2000, $r=3 \%, g=1,5 \%$ )

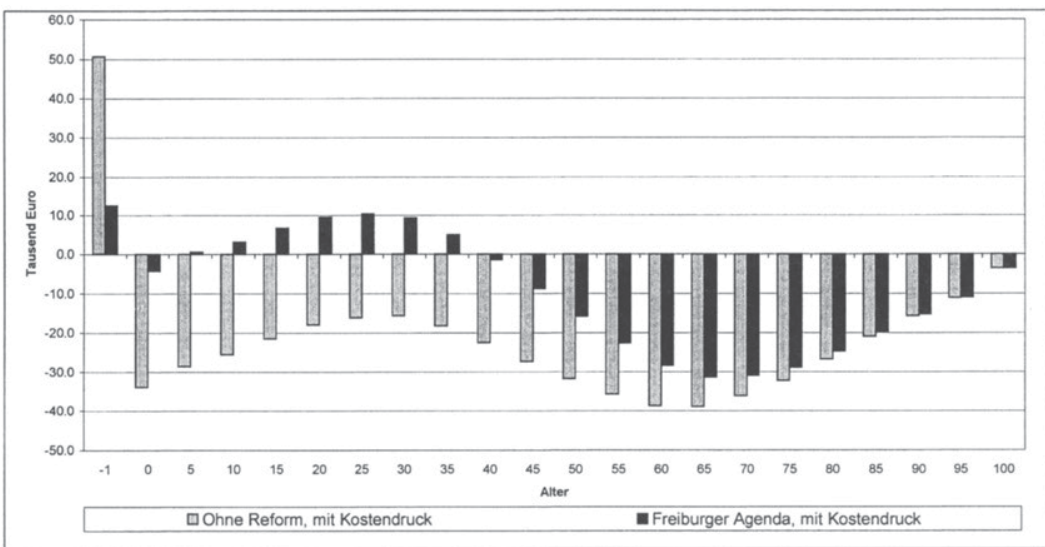

Abb. 4 zeigt die Generationenkonten vor und nach Einführung der Freiburger Agenda jeweils für das realistischere Kostendruckszenario. Offensichtlich gelingt es durch die Einführung der Freiburger Agenda, aus der GKV wieder einen Generationenvertrag zu machen, denn zumindest die 4- bis 38-Jährigen wären dann wieder Nettobeitragszahler. Allerdings steht der Generationenvertrag trotz dieser einschneidenden Reform immer noch auf recht wackligen Beinen, da der maximale Nettobeitrag eines im Basisjahr 24-Jährigen bei 10.300 Euro liegt, der maximale Nettotransfer an einen 67-Jährigen aber 31.700 Euro beträgt. Man kann aus diesem Schaubild auch erkennen, wen die Freiburger Agenda besonders stark belastet, indem man die Differenz der Generationenkonten ohne Reform und bei Regelung der Freiburger Agenda für jeden Jahrgang vergleicht. So sind es vor allem die im Basisjahr jungen Jahrgänge der 0bis $40-J a ̈ h r i g e n$, die hoch belastet werden, wohingegen die älteren Jahrgänge geringfügigere Lasten zu tragen hätten. In Relation zur mittleren fernen Lebenserwartung ist die Belastung hingegen relativ gleichmäßig. Das wichtigste Ergebnis der Freiburger Agenda ist aber, dass zukünftige Generationen erheblich entlastet werden und so überhaupt noch einen Anreiz haben, im System der GKV zu verbleiben. 


\section{Abb. 5: Nachhaltigkeitslücke der Komponenten der Freiburger Agenda}

(Basisjahr 2000, r = $3 \%, g=1,5 \%$ )

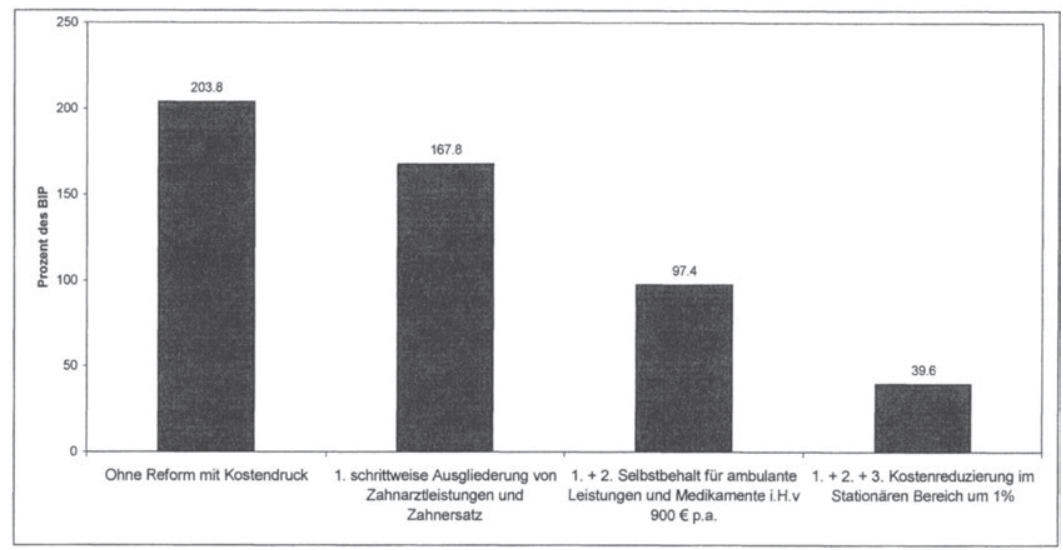

Wie stark die Entlastung der zukünftigen Generationen ausfällt, zeigt Abb. 5, die die Verminderung der Nachhaltigkeitslücke insgesamt und durch die einzelnen Komponenten der Freiburger Agenda veranschaulicht. Die Gesamtlast reduziert sich für zukünftige Beitragszahler von 203,8 auf 39,6 Prozent des BIP und damit auf weniger als ein Viertel des ursprünglichen Niveaus. Wie oben schon erwähnt, sei dabei unterstellt, dass die Kosten im stationären Bereich mit dem BIP wachsen und der Selbstbehalt bei ambulanter Versorgung und bei Medikamenten auf 900 Euro p. a. festgesetzt wird. Die Wirkungsweisen der einzelnen Komponenten auf die Nachhaltigkeitslücke, ausgehend vom Szenario mit Kostendruck des vorherigen Abschnitts, sind durch die differentiellen Zwischenschritte in Abb. 5 veranschaulicht. Die größte Reduktion in Höhe von 70,4 Prozentpunkten erfährt die Nachhaltigkeitslücke durch den absoluten Selbstbehalt. ${ }^{23}$ Nur unwesentlich geringer fällt die Wirkung der vollständigen Kostendämpfung aus, die die Nachhaltigkeitslücke um insgesamt 57,8 Prozentpunkte reduziert. ${ }^{24}$ In Relation zu diesen beiden

23 Unterstellt man einem Selbstbehalt von 580 Euro p. a., so sinkt die Nachhaltigkeitslücke um 39,1 Prozentpunkte, während bei einem Selbstbehalt von 1.800 Euro p. a. die Differenz 134,9 Prozentpunkte beträgt. Die unterproportionale Wirkung des Selbstbehaltes auf die Nachhaltigkeitslücke erklärt sich dadurch, dass die Anreizwirkung bei älteren Jahrgängen nachlässt. Man könnte daraus folgern, dass deren Nachfrage unelastischer als die der jungen Jahrgänge ist.

Geht man davon aus, dass die durchschnittlichen Kosten im stationären Sektor um 0,5 Prozentpunkte stärker wachsen als das BIP und damit nur eine partielle 
Komponenten fällt die vollständige Herausnahme der Zahnbehandlung aus dem Leistungskatalog der GKV vergleichsweise gering aus. Dennoch würde bei einem solchen Vorhaben, ausgehend vom Szenario des Kostendrucks, die Nachhaltigkeitslücke um 36 Prozent des BIP sinken eine immer noch große Entlastung zukünftiger Beitragszahler.

Die Gesamtwirkung der Agenda bringt also einen großen Schritt in Richtung nachhaltige Finanzierung der GKV. Dass damit wieder ein Generationenvertrag hergestellt werden kann, der diesen Namen auch verdient, zeigt sich, wenn man die in der Nachhaltigkeitslücke kumulierten zukünftigen Defizite (Überschüsse) jedes Jahr durch entsprechende Beitragserhöhungen (Beitragssenkungen) auffängt. Abb. 6 dokumentiert den Vergleich der Beitragssatzentwicklung mit und ohne Reform der GKV nach Maßgabe der Freiburger Agenda im realistischen Kostendruckszenario. Aufgrund der Einführung des absoluten Selbstbehaltes kommt es zu einer Senkung des Beitragssatzes auf 12,4 Prozent im Jahr 2005. Dieses vergleichsweise niedrige Niveau kann durch die schrittweise Ausgliederung der Zahnarztleistungen bis 2015 gehalten werden. Danach beginnt wie im Status quo der Anstieg der Beitragssätze, der sein Maximum im Jahr 2055 bei etwa 17,4 Prozent erreicht und danach nur leicht abfällt. Offensichtlich ist also selbst bei gravierenden Reformmaßnahmen wie der Freiburger Agenda keine Beitragssatzkonstanz in der langen Frist zu gewährleisten. Zur echten Nachhaltigkeit des Systems der gesetzlichen Krankenversicherung bedarf es weiterer Leistungskürzungen im Bereich der Bagatellmedizin bzw. wettbewerblicher Entgeltgestaltung auch im ambulanten Sektor. ${ }^{25}$ Ökonomisch vorzuziehen wäre allerdings, wie eingangs erläutert, eine privatwirtschaftliche Versicherungslösung mit sozialpolitischer Flankierung.

Kostendämpfung gelingt, dann würde sich die Nachhaltigkeitslücke nur um 31,4 Prozentpunkte verringern. Gelänge es, die Kostenentwicklung um 0,5 Prozentpunkte unter das Wachstum der Einnahmen zu drücken, so wäre sogar ein entsprechender Rückgang um 80 Prozentpunkte des BIP möglich. genverantwortung und Wettbewerb im Gesundheitswesen bietet der Kronberger Kreis (2002). 
Abb. 6: Beitragsentwicklung in der GKV: Freiburger Agenda vs. Status quo (Basisjahr 2000, $r=3 \%, g=1,5 \%$ )

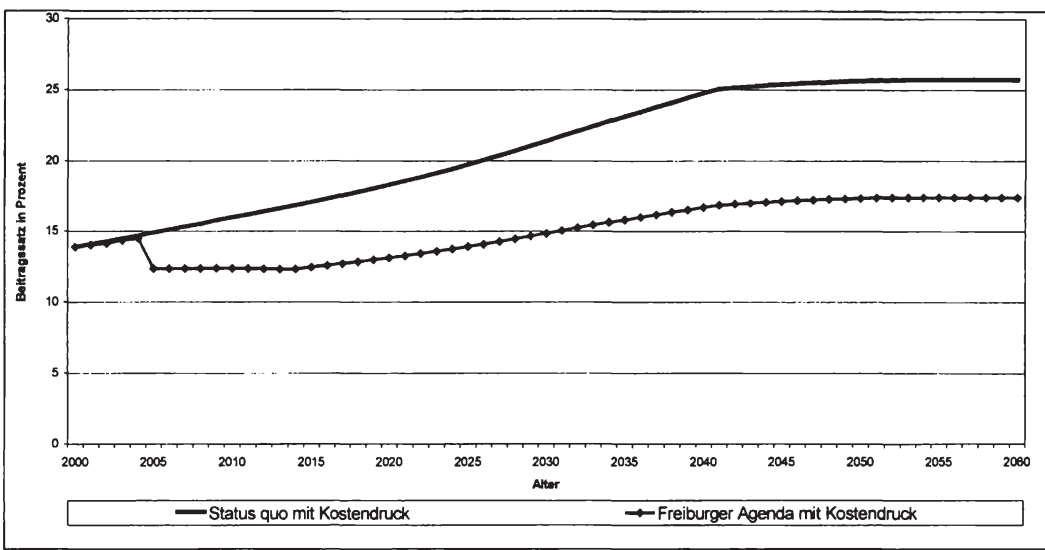

\section{Zur Nachhaltigkeit der gesetzlichen Pflegeversicherung}

\subsection{Diagnose Di $^{26}$}

Die gesetzliche Pflegeversicherung wurde in Deutschland 1995 als fünfte Säule der sozialen Sicherung begründet. In den ersten 6 Jahren konnte der Beitragssatz nicht nur konstant gehalten werden, sondern durch den verzögerten Beginn der Leistungsauszahlungen wurde sogar ein Vermögen akkumuliert. ${ }^{27}$ Jedoch ist schon allein aufgrund der oben beschriebenen demographisch bedingten Finanzierungseffekte nicht zu erwarten, dass die Beitragssätze auch in Zukunft stabil bleiben. Da die Leistungen auf der Ausgabenseite bislang nicht einmal nominell angepasst wurden, soll zunächst analysiert werden, ob hierin eine Besonderheit der GPV vorliegt oder ob in Zukunft nicht vielmehr damit zu rechnen ist, dass die Leistungen mit dem allgemeinen Produktivitätsfortschritt wachsen.

Um eine Annäherung für eine Schätzung des künftigen Ausgabenwachstums der GPV zu bekommen, können einige Anhaltspunkte aus

26 Vgl. Fetzer, Moog und Raffelhüschen (2002) zu den Ausführungen zur GPV. Die hier vorgelegten Zahlen und Daten entsprechen im Wesentlichen einer reinen Aktualisierung.

27 Der Beitragssatz wurde bereits ab 01.01.1995 mit 1 Prozent erhoben (ab 01.07.1996 1,7 Prozent), Leistungen im ambulanten Bereich aber erst seit 01.04.1995, im stationären Bereich ab 01.07.1996 erstattet. 
der Vergangenheit gewonnen werden. Bis zur Einführung der Pflegeversicherung wurden Pflegeleistungen für Bedürftige aus der Sozialhilfekomponente "Hilfe in besonderen Lebenslagen" finanziert. Die jährliche reale Wachstumsrate dieser Ausgabenkomponente, die zu rund 60 Prozent aus Pflegeleistungen bestand, lag im Zeitraum 1980 bis 1994 um 6,5 Prozentpunkte über dem BIP-Wachstum. ${ }^{28}$ Bei dieser Sozialhilfekomponente kam das Selbstkostendeckungsprinzip zum Tragen, welches mit der Einführung der GPV abgeschafft und durch eine bisher nominell nicht angepasste, leistungsorientierte Vergütung ersetzt wurde. ${ }^{29}$ Es stellt sich allerdings die Frage, ob es zukünftig gelingen wird, diese kostendämpfende Vergütung weiterhin aufrecht halten zu können.

Einige Indizien für mögliche Antworten lassen sich bereits durch eine schlaglichtartige Bestandsaufnahme finden. So spiegelt sich im Schlagwort „Pflegenotstand" die Unzufriedenheit von Pflegebedürftigen, Pflegeeinrichtungen und Pflegepersonal gleichermaßen wider. Deswegen scheint es nur eine Frage der Zeit zu sein, bis den Forderungen der Pflegeeinrichtungen und deren Personal nach einer offenbar längst überfälligen Vergütungsanpassung nachgekommen wird. Tatsächlich gibt es auch keinen ersichtlichen Grund, weshalb die Löhne für das Pflegepersonal unter der allgemeinen gesamtwirtschaftlichen Lohnentwicklung liegen sollten. Schließlich sind Pflegedienstleistungen in höchstem Grade personalintensiv, weshalb auch Schmähl (1999) das Rationalisierungspotential eher gering einstuft. Insofern dürfte es den Pflegeeinrichtungen kaum gelingen, höhere Lohnkosten allein durch Stelleneinsparungen zu kompensieren. Insgesamt ist mithin zu erwarten, dass sich die Entwicklung der Pro-Kopf-Ausgaben langfristig mindestens der allgemeinen Produktivitätsentwicklung angleichen wird.

Um zu überprüfen, ob darüber hinaus noch Faktoren in der GPV wirken, die einen weiteren Kostenanstieg verursachen, sollen zunächst die $\ddot{U}$ berlegungen zur GKV aufgegriffen werden. Wie bereits für die GKV gezeigt, hängt das Ausmaß intergenerativer Lastverschiebung bzw. die Entwicklung des Beitragssatzes entscheidend vom medizinisch-technischen Fortschritt ab. Ein entsprechender "medizinisch-pflegerischer" Verschiebungstrend für den Pflegebereich ist aber Knappe und Optendrenk (1999) zufolge nicht zu diagnostizieren. Hingegen spielt die Annahme über die Entwicklung der Inanspruchnahme der Pflege bei einer höheren Lebenserwartung in der GPV eine noch entscheidendere

Vgl. die in Raffelhüschen (2002), Tab. 2.

Der neue Leistungskatalog umfasst dabei je drei Pflegestufen für ambulante Geldleistung, ambulante und stationäre Sachleistung sowie eine Härtefallregelung bei vollstationärer Pflege und ambulanter Sachleistung. 
Rolle: Da die altersbezogenen Ausgabenprofile erst in sehr hohem Alter, dann aber sehr viel steiler ansteigen, wäre der individuelle Pflegebedarf bei Unterstellung der Medikalisierungsthese weitaus größer als bei Gültigkeit der Kompressionsthese. Wegen der fehlenden empirischen Evidenz wird aber analog zum obigen Vorgehen eine abgeschwächte Form der Medikalisierungsthese unterstellt.

Ein möglicher überproportionaler Kostenanstieg in der GPV ist vergleichsweise weniger stark zu erwarten als in der GKV. Er wird davon abhängig sein, inwiefern bisher privat geleistete Pflegeausgaben durch eine Inanspruchnahme der im ambulanten Bereich erstatteten Geldleistungen substituiert werden. Auch durch die Veränderung familiärer Strukturen könnte sich ein überproportionaler Kostenanstieg ergeben: Momentan wird noch ein Großteil der Pflegebedürttigen von ihren Lebenspartnern oder Kindern versorgt. In einer schrumpfenden Bevölkerung sinkt jedoch die Wahrscheinlichkeit, dass junge Generationen für ihre Eltern sorgen können. Hinzu kommt noch der ansteigende Trend zu Einpersonenhaushalten und eine zunehmende Erwerbsbeteiligung der Frauen. Insgesamt ist absehbar, dass in Zukunft immer mehr Pflegebedürftige auf professionelle Hilfe angewiesen sein werden. Hinsichtlich der Ausgaben hat dies den Effekt, dass in Zukunft die Geldleistungen im ambulanten Bereich durch die teureren Sachleistungen substituiert werden müssen (vgl. Schmähl [1999]). Über dies hinaus könnte die zunehmende Nachfrage nach professioneller Pflege einen zusätzlichen Lohnanstieg des Pflegepersonals verursachen, der die Ausgaben um ein Weiteres steigen ließe (vgl. Breyer [1995]).

Ausgangspunkt für die Umsetzung einer isolierten Generationenbilanz der GPV sind wiederum die altersspezifischen Beitragszahlungen und Leistungen des Basisjahres, die in Abb. 7 dargestellt sind. Für die Einnahmenseite der GPV wurde dabei wie bei der GKV zwischen Beitragszahlungen der Erwerbstätigen, der Rentner und der Arbeitslosen unterschieden. Die Leistungsausgaben der GPV wurden mit Hilfe eines Profils, das aus Daten des Verbandes der privaten Krankenversicherung e.V. aus dem Jahr 2000 generiert wurde, altersspezifisch verteilt. ${ }^{30}$ Alle sonstigen Ausgaben wurden mit einem uniformen Profil verteilt. Da, wie bereits oben erwähnt, wiederum eine Mischform zwischen Medikalisierungs- und Kompressionsthese unterstellt wird, steigen die Leistungsausgaben ab einem Alter von 90 Jahren nicht mehr weiter an.

Dies impliziert die Annahme, dass sich die Versicherten der gesetzlichen Pflegeversicherung genauso verhalten wie diejenigen der privaten. Diese Annahme wird mangels der Verfügbarkeit weiterer Daten in Kauf genommen. 


\section{Abb. 7: Altersspezifische Beiträge und Leistungen der GPV}

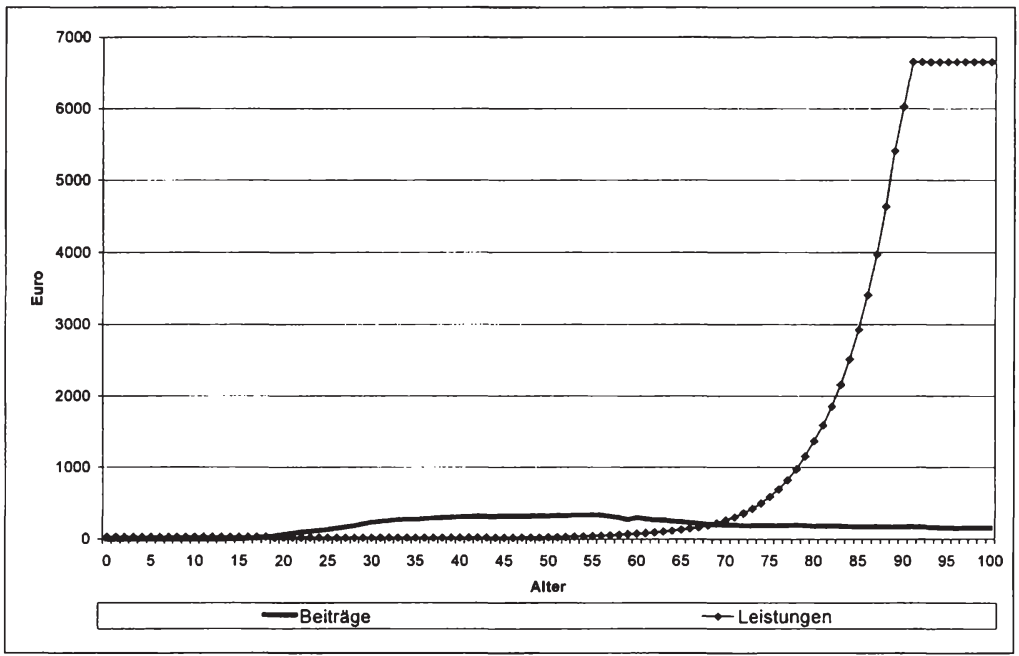

Ein Blick auf Abb. 7 lässt erkennen, dass die durchschnittlichen Leistungsausgaben der GPV in extremem Ausmaß mit zunehmendem Alter ansteigen. Diese sind bis zu einem Alter von etwa 60 Jahren konstant und liegen im Durchschnitt bei 30 Euro p. a. Danach beginnt ein exponentieller Anstieg auf 6.650 Euro p. a. für die über 90-Jährigen. Die demgegenüber winzig erscheinenden durchschnittlichen Beitragszahlungen erreichen im Maximum 335 Euro p. a. für einen 53-Jährigen, entsprechen ansonsten in ihrem Verlauf den gleichen lohnbezogenen Profilen, die in der Analyse der GKV verwendet worden sind. Angesichts dieses Sachverhaltes ist es nicht verwunderlich, dass die GPV bei einer alternden Gesellschaft unter massive Finanzierungsschwierigkeiten kommt, die im Folgenden quantifiziert werden sollen.

Aus den altersspezifischen Leistungen und Beiträgen wurde analog zum Vorgehen bei der GKV eine isolierte Generationenbilanz für die GPV erstellt. Dabei sind wiederum zwei Szenarien unterstellt: Das Szenario ohne Kostendruck konzentriert sich auf die rein demographische Komponente und unterstellt ein Wachstum der Pflegeversicherungsausgaben nach Maßgabe des allgemeinen Produktivitätsfortschrittes. Das Szenario mit Kostendruck unterstellt einen überproportionalen Anstieg der alters- 
spezifischen Pflegeausgaben, der um einen Prozentpunkt höher liegt. ${ }^{31}$ $\mathrm{Da}$, wie bereits oben erwähnt, ein kostentreibender Faktor in der GPV weniger zu erwarten ist als in der GKV, ist hier eher eine Obergrenze eines möglichen zukünftigen Kostendrucks in der GPV modelliert worden. Bei beiden Varianten wird zusätzlich berücksichtigt, dass in der Pflegeversicherung zum 31.12.1999 ein Vermögen von 4,95 Mrd. Euro aufgelaufen ist.

Abb. 8: Generationenbilanz der GPV im Status quo

(Basisjahr 2000, r = $3 \%, g=1,5 \%$ )

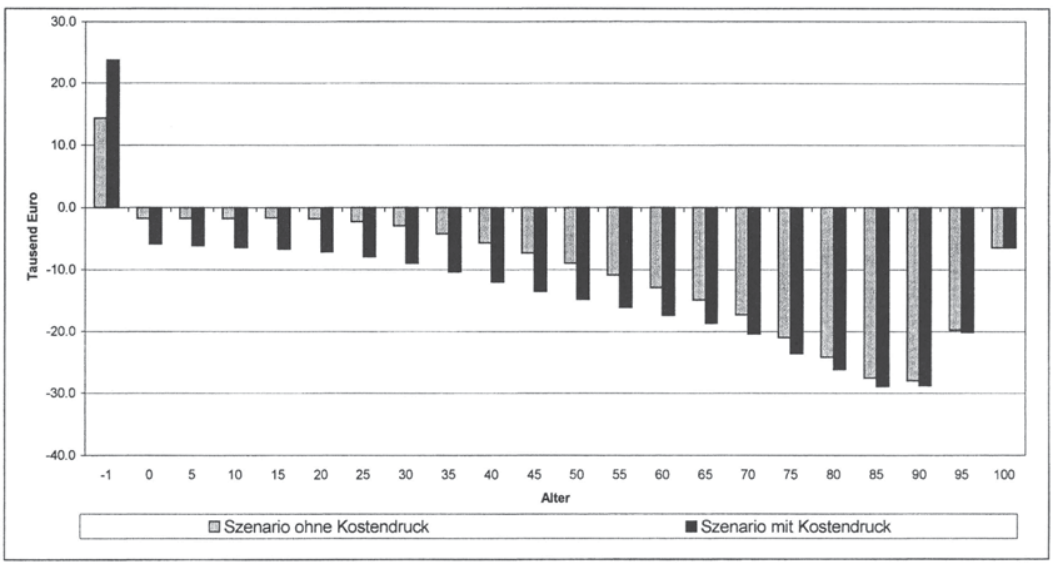

Abb. 8 zeigt die Generationenbilanzen für beide Szenarien. Ihr jeweiliger Verlauf kann schlicht als katastrophal bezeichnet werden: Selbst im Szenario ohne Kostendruck gibt es unter den lebenden Generationen keine einzige, die mit ihren Beiträgen über die verbleibende Lebenszeit den zu erwartenden Leistungsstrom der GPV deckt. Die langfristige Finanzierung der GPV wird also allein durch zukünftige Generationen getragen, so dass die Pflegeversicherung nicht als Generationenvertrag gelten kann. Mithin ist die absolute Mehrbelastung der zukünftigen $\mathrm{Ge}-$ nerationen für den Fall, dass diese allein zur Deckung der Defizite herangezogen werden, im pessimistischen Szenario mit Kostendruck mit 29.700 Euro fast doppelt so hoch wie in der optimistischeren Variante (16.200 Euro). Die Nachhaltigkeitslücke beträgt im günstigsten Fall

31 Die Begrenzung der differentiellen Wachstumsraten erfolgt wie im Fall der GKV für den Zeitraum 2001 bis 2041. 
38,9 Prozent, im ungünstigsten 71,2 Prozent des BIP. ${ }^{32}$ Wird berücksichtigt, dass die Höhe des Budgets der GKV fast das 8fache des Pflegebudgets, die Nachhaltigkeitslücke der GKV aber beim Standardszenario mit 65,1 Prozent weniger als das Doppelte beträgt, kann das Ausmaß der intergenerativen Lastverschiebung durch die GPV nur als schlicht verheerend bezeichnet werden.

Abb. 9: Beitragssatzentwicklung in der GPV im Status quo (Basisjahr 2000, r = $3 \%, g=1,5 \%$ )

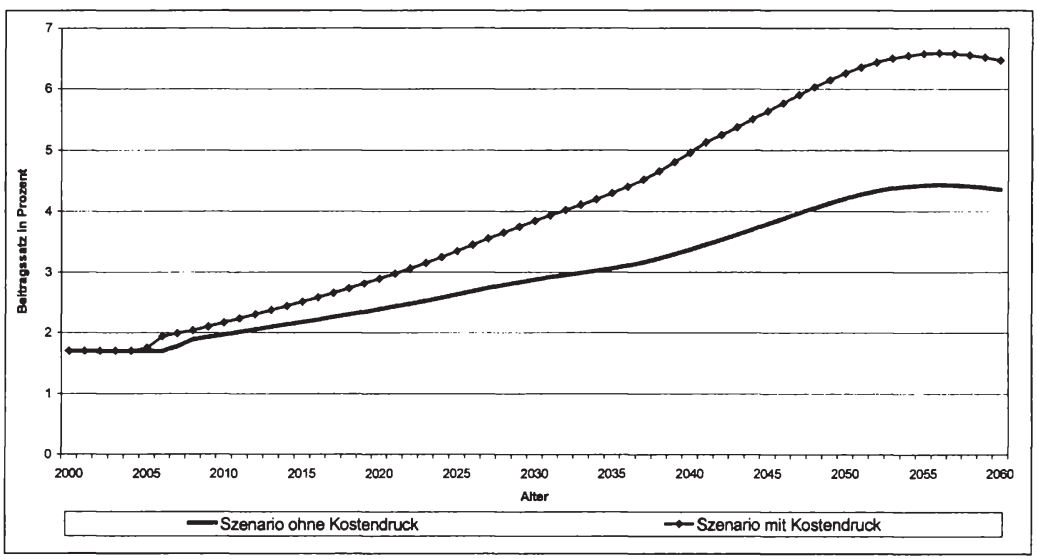

Wie bereits im Fall der GKV soll auch für die Pflegeversicherung eine Beitragssatzprojektion durchgeführt werden (Abb. 9). Hierbei sei unterstellt, dass das bislang buchhalterische Vermögen der GPV dazu dient, das Defizit so lange zu decken, bis es aufgebraucht ist - danach erfolgt eine laufende Anpassung der Beitragssätze. ${ }^{33}$ Abb. 9 illustriert diese Beitragssatzentwicklung für den Zeitraum 2000 bis 2060 . In beiden Szenarien bleiben die Beitragssätze zunächst konstant, bis der Kapitalstock der GPV aufgezehrt ist. Dies ist im Experiment mit Kostendruck im Jahr 2004 der Fall, ohne eine überproportionale Ausgabensteigerung reicht der "fiktive" Kapitalstock bis 2006. Im pessimistischeren Szenario

Die implizite Staatsschuld ist bei der Pflegeversicherung etwas höher, da das Vermögen mit ca. 0,2 Prozent des BIP als explizites Staatsvermögen in die Nachhaltigkeitslücke eingeht.

Dabei wird von der gesetzlich vorgeschriebenen Finanzreserve von 1,5 Monatsausgaben ( $\S 63,64$ SGB) abgesehen. Bei ihrer Berücksichtigung würde sich das zur Finanzierung von Defiziten zur Verfügung stehende Vermögen verringern und wäre in beiden Szenarien früher aufgezehrt. 
mit Kostendruck erreicht der Beitragssatz im Jahre 2055 mit 6,6 Prozent sein Maximum und würde danach wieder absinken. Aber selbst im optimistischeren Fall des Szenarios ohne Kostendruck wäre der Beitragssatz im Jahr 2055 mit 4,4 Prozent etwa zweieinhalb Mal so hoch wie im Basisjahr. ${ }^{34}$

\subsection{Therapie}

Auch im Bereich der Pflegeversicherung ist schon allein aufgrund der demographischen Veränderung definitiv mit einem erheblichen Beitragsanstieg zu rechnen. Im Gegensatz zur GKV ist hier die demographische Komponente deutlich ausgeprägter, da sich die Beitragssätze bereits im Fall des Szenarios ohne Kostendruck mehr als verdoppeln werden. Angesichts dieser düsteren Zukunftsprognosen und des offensichtlich nicht tragfähigen Generationenvertrages ist zu bezweifeln, ob der maßgebliche Initiator der Pflegeversicherung, Norbert Blüm (1997), auch heute noch sagen würde: „Die Finanzsituation der Pflegeversicherung bietet die besten Voraussetzungen dafür, auch mit den künftigen Herausforderungen $-z$. B. mehr leistungsberechtigte Pflegebedürftige aufgrund der demographischen Entwicklung - gut fertig zu werden."

Eine Reform der gesetzlichen Pflegeversicherung, die auf eine Beitragskonstanz abzielt und entsprechende Leistungskürzungen im Zuge des demographischen Alterungsprozesses vornimmt, würde das reale Transferniveau in den einzelnen Pflegestufen auf etwa die Hälfte des heutigen Niveaus reduzieren. Unter der Annahme, dass auch im Pflegebereich ein moderater Kostendruck unvermeidbar ist, läge das Transferniveau langfristig bei weniger als einem Drittel. Da bereits gegenwärtig die Pflegeversicherung im Regelfall nicht die tatsächlichen Kosten abdeckt, dürften die Transferleistungen im Laufe der Zeit eher den Charakter eines Grundversorgungszuschusses haben. Den betroffenen Generationen muss dies unverzüglich zur Kenntnis gebracht werden, damit sie sich auf die notwendige erhöhte private Pflegevorsorge einstellen können. Eine nahe liegende Lösung ginge sogar noch weiter: Gegeben, dass die gesetzlichen Leistungen der GPV in den einzelnen Pflegestufen nominell fixiert sind, bestünde eine nachhaltige Reformoption darin, diese grundsätzlich nicht anzupassen. Im Prinzip ist dies eine Fortführung dessen, was bisher in der GPV praktiziert wurde, nur „auf Kosten“ der Pflegebedürftigen und nicht „auf Kosten“ des Pflegepersonals. Abb. 10

Auch hier bestätigen Vergleichsstudien die vorgelegten Beitragssatzprojektionen: Wille et al. (1998) kommen für das Jahr 2040 zu Beitragssätzen zwischen 2,8 und 3,8 Prozent. Hof (2001) prognostiziert Beitragssätze zwischen 3 und 6 Prozent für das Jahr 2050. 
zeigt, dass eine solche Reform zu einer vollständig nachhaltigen Situation führt: Die Nachhaltigkeitslücke der GPV beträgt ohne Reformen im Szenario ohne (mit) Kostendruck 38,9 $(71,2)$ Prozent des BIP. Werden die Pflegestufen hingegen nominell fixiert, so "verwandelt" sich die Nachhaltigkeitslücke der GPV in ein Nachhaltigkeitsvermögen von 4,3 Prozent des BIP.

Abb. 10: Nachhaltigkeitslücken in der GPV bei unterschiedlichem Wachstum der Leistungsausgaben (Basisjahr 2000, $r=3 \%, g=1,5 \%$ )

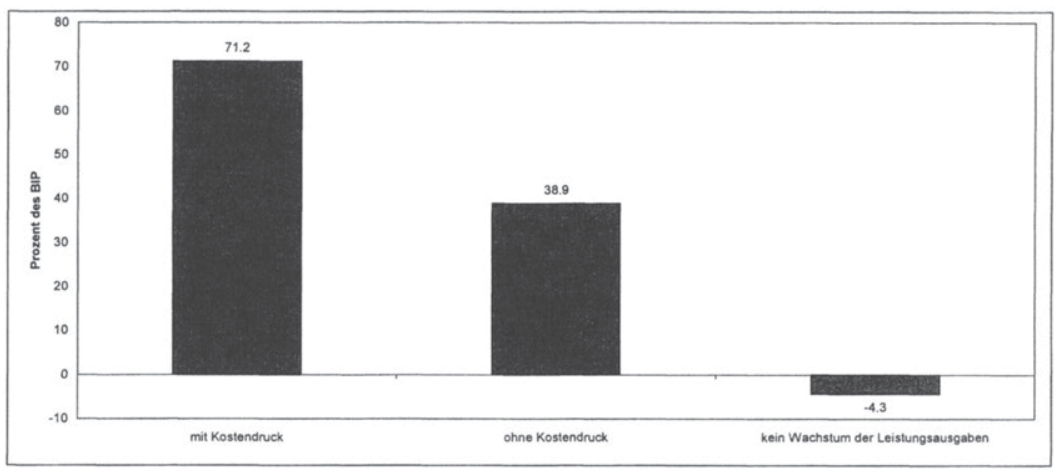

Faktisch läuft diese Option auf eine sukzessive Abschaffung der GPV hinaus. Sollte sich die Wirtschaftspolitik wider Erwarten zu einem solchen Schritt entschließen, so müsste aufgrund der Kurzsichtigkeit breiter Bevölkerungskreise für die Dimension des Pflegeproblems flankierend eine private Versicherungspflicht eingeführt werden. Die einzige und zugleich zwingend gebotene Regulierungsmaßnahme bestünde dann darin, das die Versicherer zur aktuarischer Rücklagenbildung verpflichtet werden. Dies ist bereits gegenwärtig in (fast) ausreichendem Maß gesichert. Damit würde die private Pflegepflichtversicherung ebenso wie die notwendige verstärkte private Krankenvorsorge den Charakter einer ersetzenden Gesundheitsvorsorge erhalten. Mithin wäre es dann steuersystematisch zwingend geboten, die entsprechenden Versicherungsprämien als Sonderausgaben von der Bemessungsgrundlage der Einkommensteuer abziehbar zu machen.

\section{Schlussbemerkungen und Ausblick}

Offenkundig ist die gegenwärtige Fiskalpolitik nicht nachhaltig. Offenkundig ist auch, dass dies hauptsächlich an den Generationenverträgen der umlagefinanzierten Sozialversicherungssysteme liegt. Welches Aus- 
maß allerdings die Nachhaltigkeitslücken in diesen Systemen annehmen, wird selbst von pessimistischen Zeitgenossen hoffnungslos unterschätzt. Die isolierte Betrachtung der Pflege- und Krankenversicherung zeigte, dass beide schon dann unter vehementen Druck geraten und nur noch mit deutlich zunehmenden Beitragssätzen finanzierbar sein werden, wenn kein Kostendruck im Gesundheitssektor zu verzeichnen wäre. Unter diesen optimistischen Voraussetzungen beziffern sich die kapitalisierten Mehrbelastungen zukünftiger Generationen allein in diesen beiden Sicherungssystemen auf ein ganzes Bruttoinlandsprodukt. Realistischere Annahmen, die den medizinisch-technischen Fortschritt mit ins Kalkül einbeziehen, implizieren eine deutlich größere Nachhaltigkeitslücke von fast 3 Bruttoinlandsprodukten.

Es wäre mehr als gewagt, anzunehmen, dass zukünftige Beitragszahler bereit sein werden, etwa 30 Prozent Kranken- und Pflegeversicherungsbeiträge zu zahlen. Mit realistischen Annahmen hinsichtlich der Rentenund Arbeitslosenversicherung käme man unter diesen Umständen zu Sozialversicherungsabgaben in der Größenordnung von fast zwei Drittel des Einkommens. Mithin liegt es im Eigeninteresse der heutigen Erwerbstätigen, zukünftige Generationen nicht zur Kündigung der Generationenverträge zu zwingen. Damit ist eine umfassende Reform der Kranken- und Pflegeversicherung unausweichlich.

Mit Hilfe der Freiburger Agenda kann es im Gesundheitssystem gelingen, den Generationenvertrag partiell wiederherzustellen und einen großen Schritt in Richtung Nachhaltigkeit zu gehen. Die dazu notwendigen Reformschritte sind allerdings einschneidend, denn es wäre nötig, alle Zahnarzt- und Zahnersatzleistungen aus dem Leistungskatalog der GKV zu streichen, einen Selbstbehalt für ambulante Leistungen und Medikamente in Höhe von etwa 900 Euro und eine über wettbewerbs- und ordnungspolitische Regeln stattfindende Reduzierung des Kostendrucks im stationären Sektor zu implementieren. Für den Fall funktionierender Versicherungsmärkte ist davon auszugehen, dass kostengünstige private Versicherungslösungen greifen. Dies gilt insbesondere für die Zahnbehandlung, bei der man auch an eine allgemeine Versicherungspflicht denken sollte. Die Rückversicherung des absoluten Selbstbehaltes wäre nur partiell möglich, weil sonst allein schlechte Risiken die Vollabsicherung wählen würden und diese damit gar nicht erst zustande käme. Private Versicherungsverträge über die partielle Deckung des absoluten Selbstbehaltes sind eher zu erwarten, und diese würden auch zu einer stärkeren Rücklagenbildung und damit zu einer partiellen Kapitalfundierung der Gesundheitsvorsorge insgesamt führen. 
Hinsichtlich der Pflegeversicherung sind die notwendigen Maßnahmen tendenziell noch drastischer. Die GPV kann nur bei extrem hohen Beitragssätzen nachhaltig finanziert werden. Dies ist zukünftigen Generationen nicht zuzumuten. Daher plädieren wir für ein Einfrieren der nominell fixierten Pflegeleistungen und damit für eine sukzessive Abschaffung der GPV. An die Stelle des Staates sollte eine private Versicherungspflicht mit rücklagengedeckten Tarifen treten. Die stärkere Kapitaldeckung kann die demographischen Lasten partiell auf die Generationen verteilen, die nicht nur das Problem selbst darstellen, sondern zugleich die Ursache des Problems sind. Die Pflegefälle der Jahre 2040 bis 2060 werden nämlich die geburtenstarken Jahrgänge der 50er, 60er und 70er Jahre sein, die ihrerseits nicht für ausreichend viele Beitragszahler gesorgt haben. Alles in allem also keine frohe Botschaft, die von den Trägern der Politik zu verkünden wäre.

\section{Literatur}

Blüm, N. (1997), Positive Zwischenbilanz, in: Bundesarbeitsblatt, 10/1997, Stuttgart, S. $5-8$.

Borgmann, C., P. Krimmer und B. Raffelhüschen (2001), Rentenreformen 1998 bis 2001: Eine (vorläufige) Bestandsaufnahme, Perspektiven der Wirtschaftspolitik, 2, S. $319-334$.

Breyer, F. (2000), Zukunftsperspektiven der Gesundheitssicherung, Zeitschrift für Wirtschafts- und Sozialwissenschaften, Beiheft 8: Die Zukunft des Sozialstaats, S. $167-199$.

Breyer, F. (1995), Ókonomische Grundlagen der gesetzlichen Pflegeversicherung, Diskussionsbeiträge der Fakultät für Wirtschaftswissenschaften und Statistik der Universität Konstanz, Nr. 277.

Breyer, F., und M. Kifmann (2001), Optionen der Weiterentwicklung des Risikostrukturausgleiches in der GKV, DIW Diskussionspapier Nr. 236, Berlin.

Breyer, F. und V. Ulrich (1999), Gesundheitsausgaben, Alter und medizinischer Fortschritt: eine Regressionsanalyse, Wirtschaftswissenschaftliche Diskussionspapiere der Rechts- und Staatswissenschaftlichen Fakultät an der Ernst-Moritz-ArndtUniversität Greifswald, Nr. 1/99.

Breyer, F., und P. Zweifel (1999), Gesundheitsökonomie, 3. Aufl., Springer, Berlin u.a. 
Buchner, F. und J. Wasem (2000), Versteilerung der alters- und geschlechtsspezifischen Ausgabenprofile von Krankenversicherern, Wirtschaftswissenschaftliche Diskussionspapiere der Rechts- und Staatswissenschaftlichen Fakultät an der EmstMoritz-Amdt-Universität Greifswald, Nr. 1/00.

DIW (2001), DIW-Gutachten: Wirtschaftliche Aspekte der Märkte für Gesundheitsdienstleistungen - Okonomische Chancen unter sich verändernden demographischen und wettbewerblichen Bedingungen in der europäischen Union, Endbericht, Berlin.

Erbsland, M., W. Ried und V. Ulrich (1999), Die Auswirkungen der Bevölkerungsstruktur auf Ausgaben und Beitragssatz der gesetzlichen Krankenversicherung, in: E. Wille (Hrsg.), Entwicklung und Perspektiven der Sozialversicherung, ZEW Wirtschaftsanalysen, Band 33, Nomos, Baden-Baden, S. 173 - 197.

Felder, S. (1999), Neue Konzepte für die Selbstbeteiligung in Deutschland, in: H. R. Vogel (Hrsg.), Selbstbeteiligung im deutschen Gesundheitswesen - Sachstand, Ausblick und internationaler Vergleich, Georg Thieme Verlag, Stuttgart, S. $67-74$.

Fetzer, S., S. Moog und B. Raffelhüschen (2002), Zur Nachhaltigkeit der Generationenverträge: Eine Diagnose der Kranken- und Pflegeversicherung, in: Zeitschrift für die gesamte Versicherungswissenschaft, 3, S. 279-302.

Fetzer, S., und B. Raffelhüschen (2003), Zur Wiederbelebung des Generationenvertrages in der gesetzlichen Krankenversicherung: Die Freiburger Agenda, in: Perspektiven der Wirtschaftspolitik, erscheint demnächst.

Henke, K.-D. (1997), Die Zukunft der Gesundheitssicherung, Jahrbücher für Nationalökonomie und Statistik, 216/4 + 5, S. $478-497$.

Hof, B. (2001), Auswirkungen und Konsequenzen der demographischen Entwicklung für die gesetzliche Kranken- und Pflegeversicherung, Gutachten im Auftrag des Gesamtverbandes der deutschen Versicherungswirtschaft e.V. und des Verbandes der privaten Krankenversicherung, Köln.

Knappe, E., und S. Optendrenk (1999), Der Einfluss des demographischen Wandels auf die Kranken- und Pflegeversicherung, in: Grünheid, E (Hrsg.), Demographische Alterung und Wirtschaftswachstum, S. 157 - 178.

Knappe, E. und U. Rachold (1997), Demographischer Wandel und gesetzliche Krankenversicherung, in: E. Knappe und A. Winkler (Hrsg.), Sozialstaat im Umbruch, Frankfurt, S. $91-118$. 
Kronberger Kreis (J. Donges, J. Eekhoff, W. Franz, W. Möschel, M.J.M Neumann, O. Sievert) (2002), Mehr Eigenverantwortung und Wettbewerb im Gesundheitswesen, Schriftenreihe der Stiftung Marktwirtschaft, Band 39, Berlin.

Nocera, S. (1996), Alterung und Gesundheit, in: P. Zweifel und S. Felder (Hrsg.), Eine ökonomische Analyse des Alterungsprozesses, Verlag Paul Haupt, Bern u. a., S. $61-99$.

Oberdieck, V. (1998), Beitragssatzexplosion in der gesetzlichen Krankenversicherung. Demographische und medizintechnische Determinanten der Beitragssatzdynamik und ihre reformpolitischen Implikationen, Duisburger Volkswirtschaftliche Schriften, Band 25, Hamburg.

PROGNOS (1998), PROGNOS-Gutachten 1998: Auswirkungen veränderter ökonomischer und rechtlicher Rahmenbedingungen auf die gesetzliche Rentenversicherung in Deutschland, DRV-Schriften, Band 9, Frankfurt/Main.

Raffelhüschen, B. (2002), Soziale Grundsicherung in der Zukunft: Eine Blaupause, in: B. Genser (Hrsg.), Finanzpolitik und Arbeitsmärkte, Schriften des Vereins für Sozialpolitik, N. F. Bd. 289, Berlin, S. 83-118.

Schmähl, W. (1999), Pflegeversicherung in Deutschland: Finanzbedarf und Finanzverflechtung. Empirische Befunde und offene Fragen, Allgemeines statistisches Archiv, 83, S. 5- 26 .

Schulenburg, J. M. Graf von der (1987), Selbstbeteiligung: Theoretische und empirische Konzepte für die Analyse ihrer Allokations- und Verteilungswirkungen, Mohr, Tübingen.

Schulenburg, J. M. Graf von der (1989), Gesundheitswesen (Krankenversicherung) und demographische Evolution, in: H. C. Recktenwald, Der Rückgang der Geburten - Folgen auf längere Sicht : ein Symposion der Akademie der Wissenschaften und der Literatur, Mainz, 22. - 23.06.1988, S. $279-297$.

Wille, E. (2000), GKV: Reformbedarf bei der Beitragsgestaltung, Wirtschaftsdienst, $2000 / 5$, S. $263-265$.

Wille, E., M. Erbsland, I. Frohwitter und G. Neubauer (1998), Finanzwirtschaftliche und strukturelle Entwicklungen in der Pflegeversicherung vor dem Hintergrund des demographischen Wandels bis zum Jahr 2040, Expertise für die EnqueteKommission "Demographischer Wandel" des Deutschen Bundestages, Endbericht, Mannheim. 
Zweifel, P., S. Felder und M. Meiers (1999), Ageing of Population and Health Care Expenditure: A Red Herring?, Health Economics, 8, S. 485- 496. 


\section{Medizinisch-technischer Fortschritt als Outcome- und Aus- gabenfaktor}

Peter C. Scriba

Die älteste bekannte römische Münze zeigt einen Januskopf. Bekanntlich hatte die Nymphe Carna die Angewohnheit, ihre Freier in eine Höhle zu schicken und dann wegzulaufen. Aber Janus konnte sie mit seinem "Zweiten Gesicht" sehen, holte sie ein und gewann ihre Gunst.

Ein Januskopf ist ein gutes Emblem für meinen Vortrag. Das eine Gesicht lächelt über die Erfolge der Forschung. Das andere Gesicht drückt Sorge und Missbehagen aus wegen der durch Forschung und Fortschritt steigenden Kosten.

\section{Was ist Fortschritt?}

Zunächst komme ich zu der Aussage, dass es den Fortschritt tatsächlich gibt. 40 Jahre Berufsausübung haben mich dafür zum Zeugen werden lassen, wie ich mit zwei kurzen Beispielen beleuchten möchte.

Als Student habe ich noch erlebt, wie ein Addison-Patient - das sind Patienten mit einem kompletten Ausfall der Nebennierenrinde - über Nacht an einer Addison-Krise sterben musste. Damals wurde DOCA, das ist Desoxycorticosteronacetat, in die Therapie eingeführt. Mit diesem Mineralocorticosteroid überlebten die Addison-Patienten, wenn auch schlecht; sie blieben braun, und sie bekamen kalkharte Ohren. Dann kamen die Glukokortikoide, und mit einer an den Tagesrhythmus angepassten Cortisol-Dosierung wurde die Lebensqualität dieser Patienten in den 60er Jahren erheblich verbessert. Im Anschluss daran wurden orale Mineralokortikoide, wie das 9-Alphafludrocortison, eingeführt. Man kann mit der Reninbestimmung heute genau feststellen, welche Patienten das Mineralokortikoid benötigen und wieviel davon. Und in den letzten Jahren stellte sich nun noch heraus, dass die dritte Gruppe von adrenalen Steroiden, das sind die adrenalen Androgene, ebenfalls ihre Indikation haben. So wird DHEA (Dehydroepiandrosteron) für die Verbesserung von Leistungsfähigkeit und gegen depressive Verstimmung bei AddisonPatientinnen eingesetzt: also in 40 Jahren eine Reihe von Fortschritten, die dem Addison-Patienten heute ein praktisch normales Leben ermöglichen.

Mein zweites Beispiel gibt die Zeittafel der Entwicklung der Schilddrüsenfunktions-Diagnostik wieder. Es begann vor über 100 Jahren mit der 
Grundumsatzbestimmung, die ich wiederum selbst noch als diagnostische Methode erlebt habe. Ab 1938 kam der Radiojodspeicherungstest $\left({ }^{131} \mathrm{I}\right)$ auf, ab 1960 die Bestimmung des proteingebundenen Jods $\left({ }^{127} \mathrm{I}\right)$, wiederum 10 Jahre später die Radioimmunoassays, heute in der Form der Bestimmung der freien Schilddrüsenhormone. Und noch einmal 10 Jahre später die Bestimmung der TSH-Rezeptor-Antikörper.

Das sind nur zwei von zahllosen Beispielen, die völlig klar belegen, dass sich die Versorgung durch Forschung und Fortschritt vielfach verbessert hat, und ich möchte nicht, dass das vergessen wird, wenn im Folgenden auch Kritisches zum Fortschritt gesagt werden muss.

\section{Wie sieht es mit den Kosten aus?}

Warum steigen die Kosten für das Gesundheitswesen unaufhörlich, quasi einem Naturgesetz folgend, und in allen Industrieländern?

Es lassen sich neben fiskalischen Gründen (Einnahmeschwund der GKV sowie politische Zuordnung versicherungsfremder Leistungen) fünf hauptsächliche, im Versorgungsgeschehen angesiedelte Gründe finden:

1. Ineffizienz im Versorgungsablauf: Es wird nicht immer das Richtige zur richtigen Zeit an den richtigen Patienten gegeben. Dies führt zu Überversorgungen, an anderer Stelle aber zugleich zu Unter- und Fehlversorgung.

2. Überkapazitäten: Diese gibt es z. B. bei Krankenhäusern, Apotheken, aber auch bei wettbewerbenden Krankenversicherungen und in schnell abnehmender Form bei Ärzten. Das Phänomen der angebotsinduzierten Nachfrage ist ja genügend bekannt.

3. Der Fortschritt: Dieser geht meist mit Kostensteigerungen einher. Neben echten Verbesserungen ergeben sich hier zweifellos nicht immer ganz rationale Effekte der Vertriebsförderung durch Industrien.

4. Der demographische Effekt: Eine immer älter werdende Bevölkerung bedarf der Versorgung über eine wachsend längere Zeit.

5. Anspruchsmentalität: Es geht hier vor allem um fehlende Gelegenheit für und den tatsächlichen Mangel an Eigenverantwortung unserer Patienten. 
Für mich geht es heute um die Beziehung zwischen Fortschritt und Kostensteigerung. Dabei soll von vornherein nicht vergessen werden, dass der Fortschritt selbstverständlich seinen Preis hat und dass er auch nicht zum Nultarif weitergegeben werden kann. Wir werden im weiteren Verlauf daher auch den Aspekt der Fortschrittsfinanzierung und der Forschungsfinanzierung nicht völlig übergehen können.

\section{Wo brauchen wir weiteren Fortschritt?}

Erlauben Sie mir, aus meiner Eröffnungsrede für den Wiesbadener Internisten-Kongress 1995 zu zitieren (1):

„Wenn ich heute drei Wünsche an die Fortschrittsfee frei hätte, so würde ich folgende Ziele wählen:

1. Den Krebs im Stadium der genomischen Disposition zu verhindern und auch bei Metastasierung erfolgreich behandeln zu können.

2. Die Atherosklerose, z. B. vor dem Infarkt oder vor dem Apoplex, früh diagnostizieren und im Sinne einer Sekundärprävention behandeln zu können.

3. Organspezifische und systemische Autoimmunerkrankungen früh diagnostizieren und behandeln zu können, also vor der Manifestation, $\mathbf{z}$. B. des Diabetes mellitus Typ 1, oder z. B. vor der destruktiven Phase der chronischen Polyarthritis.

Diese Wünsche sollte man noch mit dem Stoßgebet ergänzen: Keine neuen Katastrophen durch Infektionen von der Dimension der HIVPlage!"

Der Sachverständigenrat für die konzertierte Aktion im Gesundheitswesen hat in seinen Gutachten wiederholt die Frage nach den Fortschrittszielen diskutiert.

Das Sondergutachten 1995 (2) bringt mit Tab. 10 eine Übersicht des VFA (Verband der forschenden Arzneimittelindustrie). Wir haben seinerzeit 156 erwartete Entwicklungen zu den 16 wichtigsten Krankheiten ausgewählt. Von diesen wären ca. 125 nur symptomatisch wirksam, während etwa 30 auf Ursachenbehandlung bzw. Heilung abzielen würden. Zu den von mir bereits genannten Wünschen kommen vor allem der Morbus Alzheimer und die Osteoporose dazu.

Erwähnt wird auch der Deutsche Delphi-Bericht des BMFT (2), der in der Liste der Entwicklungen bis zum Jahr 2020 neben vielen schon genannten die Möglichkeit der Vorhersage des individuellen Ansprechens auf 
eine Onkotherapie aufführt. Stichworte wie Multi-Drug-Resistance oder Pharmakogenetik müssen hier heute genügen.

Auch in Band I unseres letzten Gutachtens (3) findet sich ein diesbezüglicher Bericht, und zwar über die Umfrage Delphi 98 des FraunhoferInstituts ISI. Die befragten Experten erwarten in den nächsten 30 Jahren große Fortschritte: Zu den bereits genannten Themen kommen u. a. hinzu der Morbus Parkinson und die chronische Alkoholkrankheit.

Das sind bis heute zum einen Hoffnungen, Hoffnungen für die betroffenen Patienten, aber auch für diejenigen, die ihren Kranken gerne besser helfen möchten. Die diesbezügliche Forschung wird sich zum anderen weder national noch international durch die Sorgen aufhalten lassen, die man bezüglich der Finanzierung der Umsetzung solcher Fortschritte natürlich haben kann und muss.

\section{Was bedeutet medizinischer Fortschritt für den Ressourceneinsatz?}

Der Sachverständigenrat führt aus: „Aus ökonomischer Sicht bedeutet medizinischer Fortschritt das mit der Anwendung neuen Wissens verbesserte Verhältnis zwischen dem Einsatz von Ressourcen und dem damit erzielten gesundheitlichen Ergebnis."

\section{Abb. 1: Kombinationen von Ressourceneinsatz und Zielerreichung (2)}

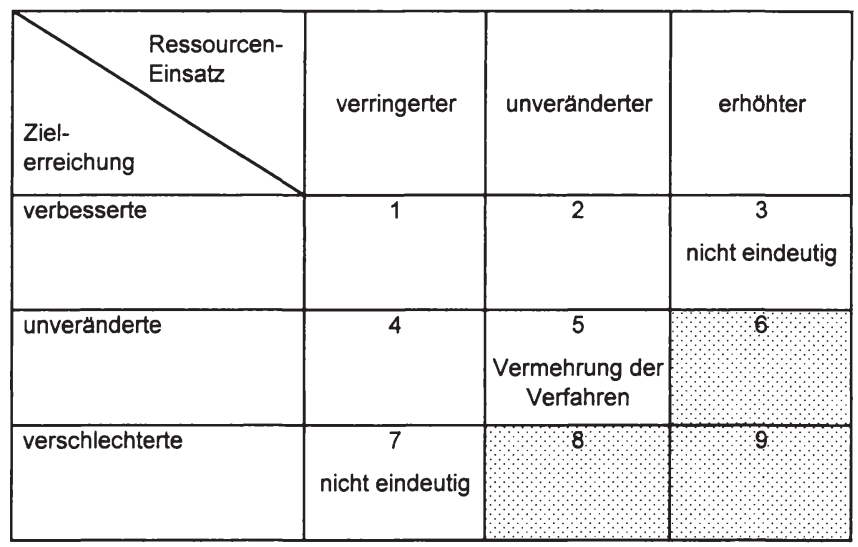

Die Neun-Felder-Tafel (Abb. 1) zeigt mit der Nr. 1 den Idealfall von verbesserter Zielerreichung bei gleichzeitig verringertem Ressourceneinsatz. Die Felder 2 und 4 weisen eindeutigen Fortschritt aus im Sinne des verbesserten Verhältnisses von Ressourceneinsatz zu Zielerreichung. Die Kombinationen 6, 8 und 9 stellen eindeutig keinen Fortschritt dar. Bei 
der Kombination 3 ist zu prüfen, ob der erhöhte Ressourceneinsatz durch die Verbesserung der Zielerreichung zu rechtfertigen ist; bei Nr. 7 ist zu prüfen, ob die Verschlechterung der Zielerreichung noch tragbar ist, und bei Kombination 5 handelt es sich lediglich um eine Verbesserung im Sinne der Vermehrung der zur Auswahl stehenden Verfahren.

\section{Wie ist diese medizin-ökonomische Betrachtung der Nutzen-I Kostenbeziehung zu ergänzen?}

Wie ist diese medizin-ökonomische Betrachtung der Nutzen-/Kostenbeziehung zu ergänzen?

Der Sachverständigenrat (4) hat weitere Kriterien für die Bewertung des Fortschritts in die Diskussion eingeführt (SG 1997, Textziffer 65 ff.):

- Effektivität von Verfahren und Technologien

- Zugänglichkeit der medizinischen Versorgung

- Qualifikation der Anwender von Verfahren und Technologien und Angemessenheit der Anwendung

- Kontinuität der Versorgung

- Grad der Einbeziehung von Patientenperspektive

- unerwünschte Wirkung in anderen gesellschaftlichen Bereichen

- Effizienz der Versorgung

Ich kann im Folgenden nicht auf alle diese Kriterien eingehen. Ich denke aber, dass mit dieser Aufzählung die Komplexität der Fortschrittsbewertung schon einmal etwas deutlicher geworden ist.

Es lohnt sich ferner, daran zu denken, dass die Beziehung zwischen Nutzen und Kosten eine dynamische ist in dem Sinne, dass der Zeitfaktor berücksichtigt werden muss (2). 
Abb. 2: Ausgaben für die Behandlung einer Krankheit in den drei Phasen des medizinischen Fortschritts (2)

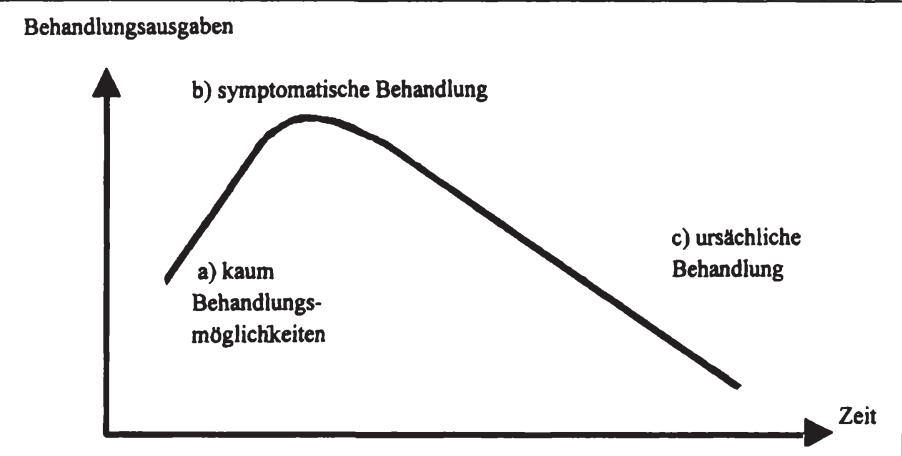

Abb. 2 zeigt die Kosten auf der Ordinaten, ihren Anstieg, wenn symptomatische Behandlung möglich wird, und ihr zumindest wünschenswertes Absinken, wenn es zu ursächlicher Behandlung kommt.

Abb. 3: Phasen des medizinisch-technischen Fortschritts (4)

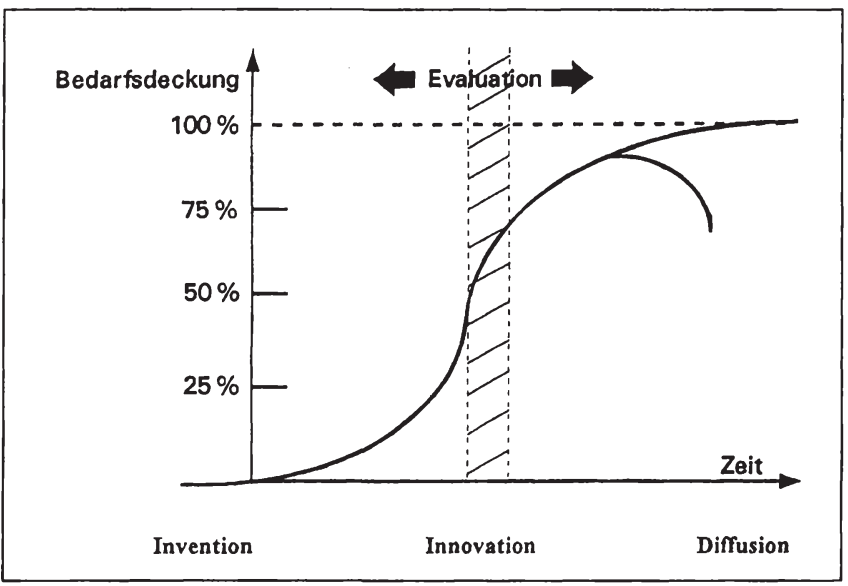

Abb. 3 zeigt ein Schema der Entwicklung der Kosten in den drei Phasen des medizinisch-technischen Fortschritts (4). Der Erfindung folgt ein steiler Anstieg in der Phase der Innovation, der sich mit der Durchsetzung des neuen Prinzips im Sinne der Diffusion aber abschwächt bzw. bei günstigem Verlauf sogar zu einem Wiederabsinken führt. 
Vor dem Hintergrund dieser eher abstrakten Schemen muss man sich fragen, welche Anreize gesetzt werden können, um Entwicklungen zu begünstigen, die bei gleicher oder besserer Wirksamkeit ressourcensparend wirken. In diesem Sinne sind pauschalierte Vergütungssysteme voraussichtlich wirksam. Wenn es für den Anwender darauf ankommt, ein möglichst gutes, ein optimiertes Ergebnis mit möglichst geringem Ressourceneinsatz zu erzielen, so ist das zugleich ein Marktsegment, in das der Anbieter eines wirtschaftlicheren Produktes hinein expandieren kann. Ich kann mir vorstellen, dass auch im Medizingeschehen vermehrte Anreize für "Billigflüge" im Wettbewerb zunehmend zum Tragen kommen könnten.

\section{Weiter mit der Fortschrittsbewertung}

Vom Sachverständigenrat wurde mit dem Sondergutachten 1997 die Entwicklung einer HTA-Kultur (4) empfohlen. "Health-TechnologyAssessment ist die strukturierte Analyse im Sinne der umfassenden und systematischen Bewertung der direkten und indirekten Folgen der Anwendung neuer, aber auch bereits auf dem Markt befindlicher medizinischer Technologien. Dies schließt medizinische und ökonomische, aber auch soziale, gesellschaftliche und ethische Wirkungen u. a. mit ein." Diese Vorschläge finden sich inzwischen in Aktivitäten der Bundesärztekammer, aber auch des BMBF und auch anderer wieder. Worum geht es?

Ich möchte dies am Beispiel des Vergleichs der Wirksamkeit unter Idealbedingungen und unter Alltagsbedingungen erläutern (Tab. 1).

Tab. 1: Ermittlung der Effektivität unter Ideal- und Alltagsbedingungen (4)

\begin{tabular}{|l|l|l|}
\hline & Idealbedingungen ("efficacy") & $\begin{array}{l}\text { Altagsbedingungen } \\
\text { ("effectiveness") }\end{array}$ \\
\hline Patientencharakteristika & $\begin{array}{l}\text { homogen zusammengesetzt, oft } \\
\text { nur männlich und auf } \\
\text { bestimmte, meist jüngere } \\
\text { Altersgruppen begrenzt, meist } \\
\text { keine Komorbidität }\end{array}$ & $\begin{array}{l}\text { heterogen zusammengesetzt, } \\
\text { Patienten unselektiert, beide } \\
\text { Geschlechter, alle Alters- } \\
\text { gruppen }\end{array}$ \\
\hline Prozeduren & standardisiert & variabel \\
\hline Studienbedingungen & $\begin{array}{l}\text { ideal, meist unter strikter Ein- } \\
\text { haltung eines Studienproto- } \\
\text { kolls, meist in Universitätskli- } \\
\text { niken }\end{array}$ & $\begin{array}{l}\text { Bedingungen der täglichen } \\
\text { Praxis }\end{array}$ \\
\hline Ärzte & $\begin{array}{l}\text { Experten eines bestimmten } \\
\text { Gebiets }\end{array}$ & alle Ärzte \\
\hline
\end{tabular}

Quelle: Szczepura A., Kankaanpää J., Assessment of Health Care Technologies, Case Studies, Key Concepts and Strategic Issues, Chichester-New York-Brisbane-Toronto-Singapore: Wiley, 1996. 
Wir haben es unter Studienbedingungen in der Regel mit homogen zusammengesetzten Patientengruppen, meist nur männlichen Geschlechts und jüngeren Alters und ohne Begleitkrankheiten, zu tun (4). Die eingesetzten Prozeduren sind standardisiert, die Anwender sind Experten. Die gefundene Wirksamkeit wird auch Efficacy genannt. Unter Alltagsbedingungen sieht das ganz anders aus, und zwar sowohl hinsichtlich der Zusammensetzung der Patientengruppe als auch hinsichtlich der Qualifikation der anwendenden Ärzte. Niemanden kann es überraschen, dass unter diesen Bedingungen die Wirksamkeit (Effectiveness) in aller Regel geringer ist.

Abb. (4) zeigt, wie Versorgungsforschung in diese Aufgaben des Health Technology Assessments eingreift.

Abb. 4: Elemente der Evaluation im Gesundheitswesen (4)

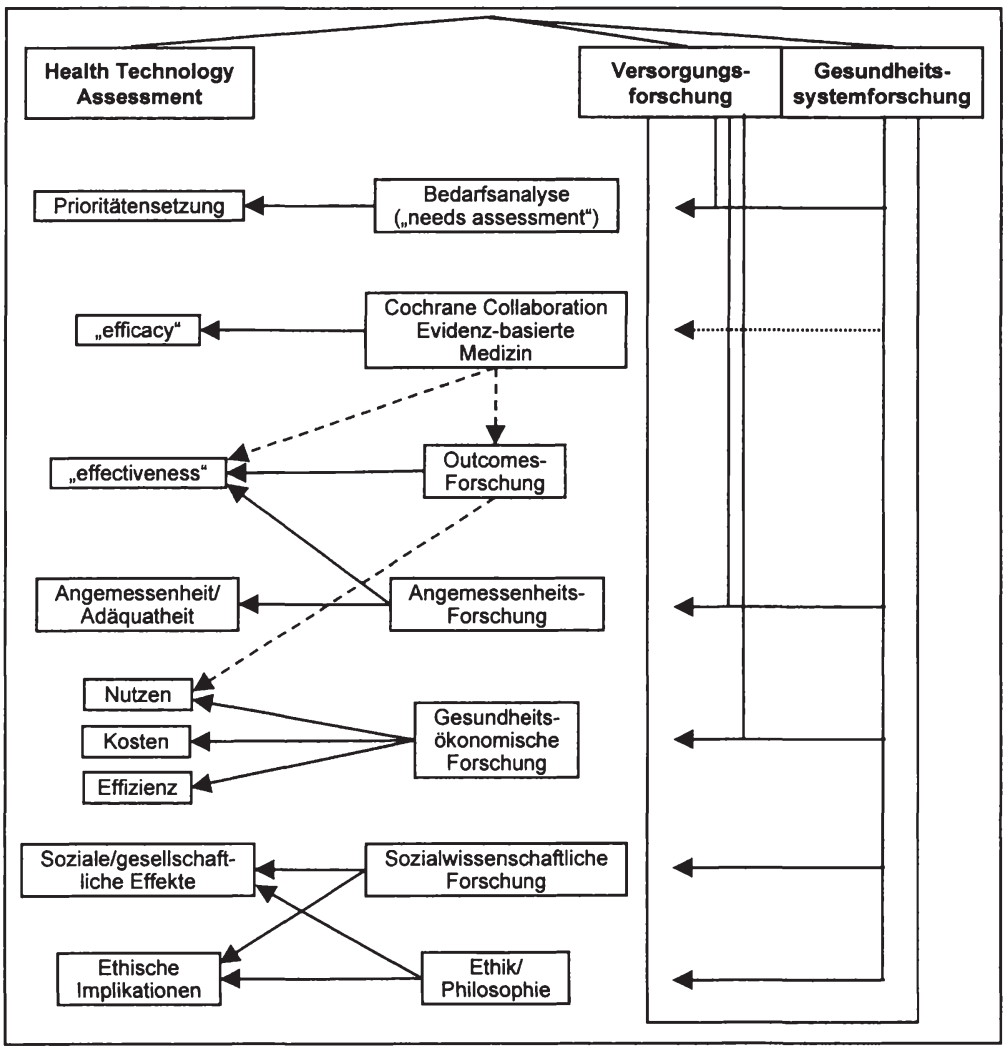


„Efficacy" - dem entspricht im Allgemeinen die evidenzbasierte Medizin, während die "effectiveness" durch Outcomes-Forschung dargestellt wird. Versorgungsforschung beschäftigt sich darüber hinaus mit Angemessenheit, Gesundheitsökonomie, aber auch mit sozialwissenschaftlichen Aspekten. Sie wird auch ihren Beitrag zur ethischen Beurteilung leisten. Dem Sachverständigenrat liegt in diesem Zusammenhang ganz besonders daran, dass auch vernachlässigte Gebiete wie das der Versorgung im Alter und das der Prävention von der Versorgungsforschung berücksichtigt werden.

\section{Vierte Hürde:}

Im Addendum zum Gutachten 2000/2001 (4) hat der Sachverständigenrat sich über die "Vierte Hürde" geäußert. Das ist in folgendem Sinne zu verstehen: Die drei Zulassungskriterien Qualität, Wirksamkeit und Unbedenklichkeit werden als "Efficacy" erfasst. Bei der "Effectiveness" geht es um Kosten-Effektivität, die unter Alltagsbedingungen ermittelt werden muss. Eine vierte Hürde soll zur Erfassung dieser Art von Wirksamkeit anhalten und darüber hinaus dazu, dass nicht nur die Besserung von Surrogat-Parametern, sondern auch die Verbesserung der langfristigen Ergebnisqualität gemessen wird. Die praktische Umsetzung dieses Gedankens wird bestimmt Schwierigkeiten bereiten. Dies macht einerseits Verfahrensvorschläge von Seiten der Anbieter, also der Pharmaindustrie, wünschenswert, zugleich ist dies aber auch ein Aufgabengebiet für Versorgungsforschung. Vielleicht ist eine befristete Zulassung ein gangbarer Weg, um hier zu neuen Maßstäben zu kommen.

\section{Versorgungsforschung, was ist das eigentlich?}

Mein bisheriges Beraterdasein hat mir schon verschiedentlich die Gelegenheit gegeben, Schlagworte zu benutzen. Schlagworte sind an sich nichts Schlechtes und um so wirkungsvoller, je mehr Freiräume für die Phantasie erschlossen werden.

Das war so, als 1991 der Wissenschaftsrat in Mecklenburg-Vorpommern die beiden bald 500 Jahre alten Universitäten Rostock und Greifswald evaluieren musste. Die Greifswalder Medizinische Fakultät wurde durch den Vorschlag gerettet, sie solle auf der "Community Medicine" aufbauen. Auch der Gesundheitsforschungsrat wusste nicht so ganz genau, worum es gehen sollte, als das Förder-Programm für "Public Health" Anfang der 90er Jahre anlief.

Jetzt hat der Sachverständigenrat in seinem letzten Gutachten (3) mit großem Nachdruck eine Intensivierung der "Versorgungsforschung" gefordert. Ich zitiere aus Kapitel 5.5 des III. Bandes: „In Deutschland be- 
stehen Defizite hinsichtlich der Daten zum Versorgungsgeschehen...". Übrigens listet schon das SVR-Sondergutachten 1995 eine Reihe von Themenfeldern der Versorgungsforschung auf (2), „bei denen es für die Kassen unter Berücksichtigung ihrer gesetzlichen Aufgaben und ihrer Interessenlage durchaus attraktiv ist, sich an der inhaltlichen Mitgestaltung und finanziellen Forschungsförderung zu beteiligen" (Textziffer 338). Lange hat dieser Vorschlag gebraucht, bis er vor 2 Jahren zum ersten Mal ganz vorsichtig grünes Licht sah.

Im Konkreten lassen sich aus der Befragung von rund 300 Organisationen, die im Jahre 2000 für das letzte SVR-Gutachten (GA 2000/2001, Band III) durchgeführt wurde (www.svr-gesundheit.de), zahlreiche Datenlücken ableiten (3). Dieses gilt für die bekannten thematischen Schwerpunkte des Gutachtens:

- koronare Herzkrankheit

- Schlaganfall

- Asthma/COPD

- Rückenleiden

- Lungenkrebs

- Brustkrebs

- allgemeine Krebsprobleme

- Depression

- ZMK-Krankheiten

- chronisch Kranke, Diabetes

Es gilt auch für weitere, bisher nicht bearbeitete Themen:

- regionale Versorgungsdisparitäten

- die Versorgung sozial benachteiligter Bevölkerungsgruppen

- Pflegeversorgung

- Prävention von Unfällen

- teilstationäre Versorgungsstrukturen

- Rettungs- und Transportdienste

Es geht dem Sachverständigenrat bei seinen Vorschlägen um ein ausreichend ausgestattetes, befristetes und mehrgliedriges Programm zur Gesundheitsforschung, insbesondere zur Versorgungsforschung, an dessen Umsetzung sich BMBF und BMG inhaltlich und finanziell beteiligen. Die Einbindung der Kassen in Programmgestaltung, Begutachtung von Anträgen, Finanzierung und Bewertung der Ergebnisse soll helfen, die Versorgungsrelevanz sicherzustellen. 
Der Sachverständigenrat hat darüber hinaus gefordert, dass die Fachgesellschaften gezielt beteiligt werden sollen. Unsere Fachgesellschaften könnten durch eine forschungsbezogene Drittmittel-Ausstattung mit Hilfe zusätzlichen qualifizierten Personals projektbezogen unabhängige Forschungsarbeit leisten. Fachgesellschaften könnten den Zugang zu den Quellen für Versorgungsdaten erheblich erleichtern. Ganz in diesem Sinne könnte ein finanziell unabhängiges Urteil von Fachgesellschaften bei der Entwicklung evidenzbasierter Leitlinien ebenfalls von großer Bedeutung sein.

Steigerung der Transparenz des Leistungsgeschehens und laienverständliche Nutzerinformation sind weitere Forderungen des letzten SVRGutachtens (3). Hier besteht die Aufgabe, jeweils fachspezifische Modelle, z. B. für obligatorische Leistungsberichte und für geeignete Informationsmaterialien, für Nutzer zu entwickeln. Bereits gegebene Fortschritte im Bereich der Patienteninformationen seitens der Fachgesellschaften einschließlich der AWMF (Arbeitsgemeinschaft der wissenschaftlichen medizinischen Fachgesellschaften) könnten durch ein Förderprogramm noch an Schwung gewinnen. Kapitel 5.5 in Band III zeigt ferner (3), dass nicht nur Datenlage und Epidemiologie, Priorisierung von Präventionsmaßnahmen und von Maßnahmen der Gesundheitsvorsorge, sondern nach Ansicht des SVR auch die Entwicklung methodischer Standards für die Versorgungsforschung wichtig sind und Ansatzpunkte für eine Versorgungsforschung durch Fachgesellschaften bieten könnten.

Insgesamt betrachtet der Rat diese Vorschläge als dem Ziel dienlich, den Sachverstand der wissenschaftlichen Fachgesellschaften noch besser als bisher für die Optimierung der tatsächlichen Krankenversorgung einzubinden. Sicher sind Ergänzungen der bereits genannten Fragestellungen möglich, der Fragestellungen für das empfohlene mehrgliedrige Förderungsprogramm

- durch das BMBF,

- durch das immer leicht bremsende BMG und

- durch die Krankenversicherungen.

\section{Kompetenzbündelung und Mindestzahlen}

Die Fachgesellschaften und allen voran die AWMF haben in der Vergangenheit schon eine Menge für die Entwicklung von Leitlinien getan. Der Sachverständigenrat hat im Gutachten 2000/2001 Band III Mindestzahlen gefordert (3), insbesondere für risikobehaftete Verfahren, die ein gewisses Maß an Erfahrung, persönlicher Qualifizierung und Weiterbil- 
dungsmöglichkeiten für den Nachwuchs voraussetzen. Er hat darüber hinaus im Anhang zum Addendum dieses Gutachtens (3) Kompetenzbündelung gefordert und dies am Beispiel der Hämophilie-Therapie erläutert. Ich kann hier auf Einzelheiten nicht näher eingehen. Mir liegt aber daran, den einen Gesichtspunkt noch einmal herauszustreichen, dass es nicht Aufgabe einer Interessengruppe und seiner Fachgesellschaften sein kann, hier unkontrolliert Monopolstellungen zu schaffen. Der Sachverständigenrat stellt sich das Vorgehen viel mehr so vor, dass die Notwendigkeit von Mindestzahlen und auch von Kompetenzbündelung ableitbar sein muss; es kommt darauf an zu zeigen, dass die Ergebnisse bei Einhaltung von Mindestzahlen und in einem extern evaluierten Comprehensive Care Center besser sind als bei der sporadischen Versorgung.

\section{Klinische Forschung}

Aber Versorgungsforschung ist nicht alles. Wir brauchen auch eine leistungsfähige klinische Forschung. Diese ist in Gefahr aus vielen Gründen, aber $u$. a. auch wegen der immer schwierigeren Finanzierung. Neben vielen anderen hat auch der Sachverständigenrat auf diese durchaus dramatische Gefahr immer wieder hingewiesen (4).

Man kann die Finanzierung der Aufgaben der Hochschulklinika nach ihren drei Hauptquellen Land, Kassen und Drittmittel gliedern (Tab. 2).

Tab. 2: Finanzierung der Universitätsklinika (4)

\begin{tabular}{|l|l|}
\hline Land & $\begin{array}{l}\text { Lehre } \\
\text { Gemeinschaftseinrichtungen (Tierstall,Bibliothek etc.) } \\
\text { Forschung - Grundausstattung } \\
\text { - Bonus für Leistung }\end{array}$ \\
\hline Kassen & $\begin{array}{l}\text { Krabvention der regionalen Industrieentwicklung? } \\
\text { angewandte klinische Forschung, zum Teil? } \\
\text { Weiterbildung? }\end{array}$ \\
\hline Drittmittel & Forschung - grundlagennahe \\
& \\
\hline
\end{tabular}

Das Land wäre $u$. a. für die Grundausstattung der Forschung und für einen leistungsbezogenen Bonus zuständig. Die Einwerbung von Drittmitteln ist sowohl für grundlagennahe als auch für angewandte klinische 
Forschung in großem Umfang möglich. Mir geht es hier noch einmal um die Krankenkassen. Angewandte klinische Forschung, d. h., Studien, welche die Diagnose oder die Behandlung von Krankheiten direkt verbessern sollen, sind Krankenversorgung. Der einzelne Patient, der Aufnahme in eine solche Studie findet, wird im gleichen Moment wissenschaftlich untersucht und nimmt Krankenversorgung in Anspruch. Es ist in Deutschland gesetzlich geregelt, dass eine kontrollierte Studie die Ethikkommission zu passieren hat, die eine vorgeschlagene neue Behandlung oder Untersuchung nur dann akzeptiert, wenn sie einen höheren Nutzen für den einzelnen Patienten verspricht als das Standardprogramm. Somit ist klinische Forschung hoffentlich bessere Krankenversorgung, und diese im Standardumfang zu finanzieren, ist Aufgabe der Krankenkassen, auch unter den zukünftigen Bedingungen der DRGs (Diagnosis Related Groups).

Für die Krankenkassen kann diese angewandte klinische Forschung darüber hinaus lohnend und interessant sein. Krankenkassen müssen an vielen Fragestellungen dieser klinischen Forschung ein hohes Interesse haben. Zum Beispiel:

- Welche Verbesserungen der medizinischen Möglichkeiten machen Kosteneinsparungen durch Vermeidung von Überflüssigem möglich?

- Wer untersucht und weist nach, dass praktizierte Methoden nicht wirksam sind? Die Industrie wird den Nachweis, dass eine Prozedur diagnostisch wenig brauchbar oder ein Medikament nicht wirksam ist, nicht gerne finanzieren.

- Wie wird der Komplex der Qualitätssicherung, der schon Aufgabe der GKV und in hohem Maße entwicklungsbedürftig ist, gesteuert?

- Ein zusätzliches Problem stellen seltene und ausgefallene Krankheiten dar (Orphan-Drug-Problematik): Staat allein oder zusätzlich Krankenkassen?

Das alles sagt nicht, dass die Krankenkassen zur Forschungsfinanzierung verpflichtet werden sollen; es fordert lediglich, dass sich Krankenkassen beteiligen dürfen.

\section{Krise der wissenschaftlichen Autorität?}

Herr Schmacke hat in einem lesenswerten Artikel im vergangenen Monat zur evidenzbasierten Medizin Stellung genommen (5). Man findet in die- 
sem Artikel u. a. aufgeführt als Vorzug der evidenzbasierten Medizin, dass EBM die konkrete Einzelfallentscheidung natürlich nicht ersetzt, dass der Arzt aber begründen muss, wenn er von gut abgesicherten Empfehlungen abweicht. EBM schränkt die Beliebigkeit der Therapie ein und lässt auch die Grenzen der Medizin klarer erkennbar werden. Der Autor gibt ferner eine Auflistung der Pionierleistung der evidenzbasierten Medizin mit den Beispielen

- Verbesserung der Depressionsbehandlung,

- Behandlung von Rhythmusstörungen,

- Hormonersatztherapie (HET),

- Hochdrucktherapie bei Diabetikern u. a. m.

Der Autor geht kritisch mit den so genannten Experten ins Gericht, er verweist auf Irrtümer medizinischer Schulrichtungen. Schulen werden als verkrustet bezeichnet, es ist die Rede von Großmeistern und Zunftdenken. Fachgesellschaften werden als in ihrer speziellen Methode gefangen und als nicht ganzheitlich charakterisiert.

Auf der anderen Seite wird anerkannt, dass Medizin ohne Expertenmeinung nicht denkbar ist. Dem Artikel ist noch eines entgegenzuhalten: Mit welchem Recht monopolisiert EBM den Austausch von Expertenmeinungen über gute klinische Studien? Ist es nicht genau das, was in den häufig interdisziplinären wissenschaftlichen Tagungen der Fachgesellschaften geschieht?

Ich will jetzt versuchen, über die Beschränktheit der wissenschaftlichen Aussage zu sprechen:

Aussagen der Wissenschaft werden mit einem vergleichsweise hohen Eigen- und Fremdanspruch an deren Richtigkeit gemacht und entgegengenommen.

Wissenschaftliche Ergebnisse sind dabei in ihrer Richtigkeit a priori eingeschränkt

- durch ihre Abhängigkeit von der Methodik (Grundaussage der Erkenntnistheorie),

- durch die Begrenztheit des Untersuchungsgegenstandes (Unterschied von "efficacy" und "effectiveness" als Beispiel),

- $\quad$ durch die in jedem Einzelfall zu prüfende Qualität der methodischen Durchführung der jeweiligen Untersuchung. 
Werden diese Einschränkungen berücksichtigt, so äußern sich Wissenschaftler mit vergleichsweise hoher Autorität.

Jedes wissenschaftliche Ergebnis kann aber Auswirkungen haben, die in (gesellschafts-)politischen, verbandspolitischen, rechtlich-sozialen, moralischen oder ethischen Dimensionen und Bereichen Bedeutung haben. Bei unserem heutigen Thema sind die ökonomischen Auswirkungen besonders wichtig. Eine komplette Abgrenzung zwischen wissenschaftlichen Aussagen zum Fortschritt und den anderen Bereichen ist nicht möglich. Die Schwierigkeiten in der Diskussion zwischen Wissenschaftlern und Nichtwissenschaftlern beruhen vor allem auch darauf, dass die natürliche Autorität des Wissenschaftlers in seinem Metier, der Wissenschaft, bei Äußerungen zu ökonomischen, ethischen, moralischen, berufsrechtlichen oder politischen Fragen durchschimmert. So etwas wird von Nichtwissenschaftlern dann gerne als Arroganz aufgefasst. Es kommt darauf an, sich (dem Wissenschaftler) und dem jeweiligen Zuhörer klar zu machen, dass man im nichtwissenschaftlichen Bereich mit keiner höheren Autorität spricht als jeder andere Laie, der natürlich das Recht hat, sich zu politischen, ethischen, moralischen usw. Fragen zu äußern. Wissenschaftler sollten daher klarmachen, wie weit die eigentlich wissenschaftliche Aussage geht, und sich bei den übrigen, meist strittigen Themen mit einer optionsweisen Darstellung begnügen, welche durchaus eigene Präferenzen angeben kann.

Dies versucht auch der Sachverständigenrat mit zugegebenermaßen und insbesondere auch von Person zu Person wechselhaftem Erfolg.

Ich möchte dies zum Schluss noch einmal an einem praktischen Beispiel erklären: Lautstarker und zum Teil erbitterter Streit beherrscht die Debatten über das jüngst von der Bundesregierung eingeführte Programm für die Behandlung von Zuckerkranken (Disease-Management-Programm für Diabetiker). Das eine Lager, das der gesetzlichen Krankenkassen und der mit diesen kooperierenden Wissenschaftler steht auf dem folgenden Standpunkt: Disease-Management-Programme sind ein Angebot der Kassen, die selbstverständlich den Leistungsumfang definieren und den Ablauf kontrollieren müssen. Als von wissenschaftlicher Evidenz gestützte Grenze für die Absenkung des HbA1c werden 8,0 Prozent für erforderlich gehalten, da mit einer weiteren Absenkung kein zusätzlicher Gewinn für die Lebenserwartung der Diabetiker mit schlechter Stoffwechseleinstellung zu erwarten sei.

Das andere Lager, also z. B. die Deutsche Diabetes Gesellschaft und der nationale Konsens zur Diabeteseinstellung (Bundesärztekammer), hat einen ganz anderen Ansatz. Sie gehen von der ebenfalls durch wissenschaftliche Evidenz belegten Tatsache aus, dass die obere Grenze 
des Normalbereiches für das $\mathrm{HbA1c}$ des Gesunden bei 6,0 Prozent liegt und dass oberhalb dieser Grenze der noch weniger kranke Diabetiker ein erhöhtes Risiko für das Auftreten typischer diabetischer Komplikationen hat: also des diabetischen Fußes, der diabetischen Schädigung von Augen, Niere und Nervensystem $u$. a. Diesem Lager geht es also um die Sekundärprävention, d.h. die zusätzliche Verminderung der diabetischen Komplikationen durch ein Disease-Management-Programm.

Mein Fazit: Jeder Verantwortliche muss entscheiden, welche Strategie er für angemessen hält: den Kampf um Lebensverlängerung beim schwer erkrankten Diabetiker oder die darüber hinausgehende zusätzliche Vermeidung von Komplikationen bei noch nicht so schwer kranken Diabetikern. Und noch eine Anmerkung: In der Umwelttoxikologie wird bekanntlich jede kleinste Überschreitung der Risikoschwelle gegeißelt; warum sollte dieses vorsichtige Präventivdenken beim Diabetes mellitus falsch sein? Und ferner: Durch sachlichere Beachtung des ganz unterschiedlichen strategischen Ansatzes könnten die beiden oben genannten Lager vielleicht dazu gebracht werden, weniger emotionsgeladen zu diskutieren.

Transparenz: Transparenz, das ist das Stichwort für mein allerletztes Anliegen. Mehr als 20 Jahre der wissenschaftlichen Politikberatung haben mir klar gemacht, dass es eine Beratung, die völlig frei von Interessenkollisionen ist, nicht geben kann. Wissenschaftler sind - wie alle Lebewesen - dem Einfluss von Anreizmechanismen ausgesetzt. Da gibt es keinen prinzipiellen Unterschied, ob man seine Drittmittel z. B. von der Industrie bekommen kann oder $z$. B. von irgendwelchen Kassenverbänden. Aber es gibt Schutzmechanismen: Transparenz ist der eine, d. h. also, die Offenlegung aller Verbindungen sollte obligatorisch sein. Der andere Schutz ist nach meinem Verständnis darin zu sehen, dass der Wissenschaftler seinen Ruf ruiniert, wenn seine Äußerungen zu sehr durch den jeweiligen Sponsor beeinflusst werden.

Zusammenfassung: Janus ist übrigens ein latinischer, kein römischer Gott. In manchen Schilderungen hat er sogar vier Gesichter.

Die zwei Gesichter der Freude über den Fortschritt und der Sorge über die Kosten kennen wir schon. Das dritte Gesicht drückt die Hoffnung auf Kostenminderung aus, durch neue ursächliche Behandlung, durch Prävention und durch ressourcensparende Innovation (Billigflüge).

Und das vierte Gesicht erwartet von uns Versorgungsforschung, Fortschrittsbewertung und skeptische Relativierung jeder Autorität. 


\section{Literatur}

1. Scriba, P. C.: Die Zukunft. Eröffnungsansprache des Vorsitzenden des 101. Kongresses der Deutschen Gesellschaft für Innere Medizin. Med. Klin. (1995), 90, S. $271-276$

2. Sachverständigenrat für die Konzertierte Aktion im Gesundheitswesen: Sondergutachten 1995 - Gesundheitsversorgung und Krankenversicherung 2000. Nomos-Verlagsgesellschaft Baden-Baden (1995)

3. Sachverständigenrat für die Konzertierte Aktion im Gesundheitswesen: Gutachten 2000/2001 - Bedarfsgerechtigkeit und Wirtschaftlichkeit (3 Bände und Anhang). Nomos Verlagsgesellschaft Baden-Baden (2002)

4. Sachverständigenrat für die Konzertierte Aktion im Gesundheitswesen: Sondergutachten 1997 - Gesundheitswesen in Deutschland. Kostenfaktor und Zukunftsbranche. Nomos Verlagsgesellschaft Baden-Baden (1997/98)

5. Schmacke, N.: Evidenzbasierte Medizin: Fundament zur Vereinbarung individueller Therapieziele. GGW (2002) 4, S. $16-25$ 
Manfred Albring and Eberhard Wille - 978-3-631-75562-4

Downloaded from PubFactory at 01/11/2019 03:33:01AM

via free access 


\section{Der Leistungskatalog der GKV im Wandel}

Gerhard Schulte

\section{Die Koalitionsvereinbarung vom Oktober 2002}

Angesichts der Finanzierungsprobleme und der Tragfähigkeit des Generationenvertrages in der GKV stellt sich die Frage, ob es Sinn macht, sich mit den eher zweitrangigen Fragen des Leistungskataloges auseinander zu setzen. Am Beispiel des Leistungskataloges lässt sich allerdings auf die Entscheidungsfähigkeit und den Entscheidungsmut der politisch Verantwortlichen für eine Gesundheitsreform schließen, die ihren Namen verdient.

Es gehört zur Standard-Sonntagsrede eines Gesundheitspolitikers, darauf hinzuweisen, dass nach über 100 Jahren gesetzlicher Krankenversicherung in Deutschland der Leistungskatalog grundsätzlich überprüft und den heutigen Erfordernissen angepasst werden muss. Deswegen nimmt es nicht Wunder, dass in der Koalitionsvereinbarung von Oktober 2002 bekannte Aussagen zu diesem Themenkreis zu finden sind:

„Im Rahmen der gesetzlichen Krankenversicherung muss ein einheitlicher Leistungsanspruch sichergestellt sein. Wir orientieren die Versorgung strikt am medizinisch Notwendigen. Der Leistungskatalog der gesetzlichen Krankenversicherung muss angesichts der demographischen Entwicklung und des medizinischen Fortschritts auf der Basis gesicherter wissenschaftlicher Erkenntnisse und unter Sicherung der Therapievielfalt stetig angepasst werden."

Diese ebenso richtige wie neutrale Aussage lässt keinen Schluss darauf zu, ob der Leistungskatalog eingeschränkt oder ausgeweitet werden soll oder beides gleichzeitig. Gesicherte wissenschaftliche Erkenntnisse und die Sicherung der Therapievielfalt sind allerdings noch nie Maßstab für den durch den Gesetzgeber definierten Leistungskatalog gewesen. Dies ist vielmehr in Teilbereichen des Leistungskataloges Aufgabe des Bundesausschusses Ärzte und Krankenkassen, von dem noch zu sprechen sein wird.

„Möglichkeiten, unterschiedliche Therapieansätze im Rahmen von Satzungsleistungen zu etablieren, werden geprüft."

Bei dieser vorsichtigen Aussage ist die Handschrift der Grünen zu erkennen. Zu begrüßen ist, dass den Krankenkassen ein Entscheidungs- 
rahmen eingeräumt werden soll, wenn er sich auch auf unterschiedliche Therapieansätze beschränkt. Da unterschiedliche Therapieansätze ohnehin zu den Selbstverständlichkeiten der Medizin und damit auch des Leistungskataloges gehören, darf sicher vermutet werden, dass diese Aussage in Richtung chinesischer Medizin o. Ä. geht.

„Um einen dynamischen Prozess der Fortentwicklung der medizinischpflegerischen Standards und der Einbeziehung neuer Erkenntnisse zu gewährleisten, werden wir das "Deutsche Zentrum für Qualität in der Medizin" einrichten. Durch die Arbeit unabhängiger Sachverständiger werden die zügige Erstellung von Behandlungsleitlinien und die Fortschreibung des Leistungskataloges unter gleichberechtigter Einbeziehung komplementärer Therapierichtungen ebenso gewährleistet wie eine Kosten-Nutzen-Bewertung neuer Arzneimittel. Alle Verfahren werden transparent ausgelegt und eine Beteiligung der Patientinnen und Patienten vorgesehen."

Bei dieser Aussage wird die Fortschreibung des Leistungskataloges in einen unmittelbaren Zusammenhang mit der Einbeziehung komplementärer Therapierichtungen gebracht. Die einzig konkrete Aussage dieses Abschnittes ist die Einrichtung des Deutschen Zentrums für Qualität in der Medizin. Die Beschreibung der Aufgaben des Instituts erschöpft sich allerdings in Tautologien wie "dynamischer Prozess der Fortentwicklung". Konkret erscheint mir nur die beabsichtigte Kosten-NutzenBewertung neuer Arzneimittel.

\section{Der Leistungskatalog in der Gesetzgebung von 1988 bis 2002}

1988 ist das Recht der gesetzlichen Krankenversicherung in das Sozialgesetzbuch als SGB V eingegliedert worden. Das ist Anlass genug zu untersuchen, wie sich der Leistungskatalog der gesetzlichen Krankenversicherung seitdem entwickelt hat. Zunächst einmal sind im Gesundheitsreformgesetz 1988 selbst eine Fülle von Änderungen des Leistungskataloges beschlossen worden. Der weitere Reformprozess ist bis zum heutigen Tag erstaunlich umfangreich. Die folgende Aufstellung verzichtet zunächst einmal auf die Veränderungen und wechselseitigen Regelungen der Härtefall- und Zuzahlungsregelungen, um die Überschaubarkeit noch zu gewährleisten. Die Aufstellung ist nicht vollzählig, da sich Änderungen des Leistungskataloges nicht nur in Gesundheitsgesetzen, sondern auch in anderen Gesetzgebungsbereichen verbergen. Um auf einen Blick das Rein in den Leistungskatalog und das Raus aus dem Leistungskatalog zu verdeutlichen, sind Leistungseinschränkungen 
einfach gerahmt und Leistungsausweitungen doppelt gerahmt gedruckt. Im Rahmen der zur Verfügung stehenden Zeit kann ich nur einzelne Entscheidungen des Gesetzgebers kommentieren.

Gesundheitsreformgesetz vom 20.12.1988 (GRG), gültig ab 01.01.1989

Ausschluss von Arzneimitteln, die ihrer Zweckbestimmung nach üblicherweise bei geringfügigen Gesundheitsstörungen (z. B. zur Anwendung bei Erkältungskrankheiten und grippalen Infekten, Schnupfenmittel, Schmerzmittel, Abführmittel, gegen Reisekrankheiten etc.) verordnet werden ( $\$ 34$ Abs. 1 SGB V).

Ermächtigung des BMA, im Einvernehmen mit dem BMG und dem BM für Wirtschaft durch Rechtsverordnung mit Zustimmung des Bundesrates unwirtschaftliche Arzneimittel nach § 31 SGB V von der Versorgung auszuschließen.

Ermächtigung des BMA, durch Rechtsverordnung mit Zustimmung des Bundesrates Heil- und Hilfsmittel von geringem oder umstrittenem therapeutischen Nutzen oder geringem Abgabepreis zu bestimmen, deren Kosten die Krankenkasse nicht übernimmt.

Von dieser Möglichkeit hat das Bundesministerium für Arbeit bzw. später das Bundesministerium für Gesundheit niemals Gebrauch gemacht. Die Entschlossenheit des Gesetzgebers von 1988 ist offensichtlich schon bald zerronnen.

Übernahme der Fahrkosten ( $\S 60$ SGB V) nur noch bei stationären Leistungen, Rettungsfahrten zum Krankenhaus, Krankentransporten:

- keine Übernahme bei Fahrten zur ambulanten Behandlung (Ausnahme Härtefall)

- Zuzahlung des Versicherten statt 5 DM jetzt 20 DM pro Fahrt

Erlöschen des Leistungsanspruches Versicherungspflichtiger längstens 1 Monat nach dem Ende der Mitgliedschaft (vorher bis zu 6 Monaten nach dem Ausscheiden).

Ausschluss des Leistungsanspruches bei Arbeitsunfall und Berufskrankheit.

Wegfall der Möglichkeit, in der Satzung Fürsorge für Genesende, vor allem durch Unterbringung in einem Genesungsheim, vorzusehen 
Festsetzung von Festbeträgen für dafür geeignete Hilfs-, Arznei- und Verbandsmittel

Zweifelsohne die erfolgreichste Maßnahme des GRG.

Wegfall des Krankengeldes bei Zubilligung von EU-Rente oder Altersruhegeld während des Krankengeldanspruches, kein Wiederaufleben des Anspruches bei Wegfall der EU-Rente oder des Altersruhegeldes.

Wegfall des Sterbegeldes für Personen, die erst nach dem 01.01.1989 versichert werden. Reduzierung des Sterbegeldes für Anspruchsberechtigte auf 2.100 DM beim Tod des Mitglieds und 1.050 DM beim Tod eines Familienangehörigen.

Das Sterbegeld ist unbestritten eine versicherungsfremde Leistung, dem Grunde nach eine Leistung an Erben und insoweit auch ein Erbenschutzprogramm. Gleichwohl hat sich der Gesetzgeber 1988 nur dazu durchgerungen, das Sterbegeld für zukünftig Geborene zu streichen mit der Folge, dass 1988 Geborene ggf. auch noch im Jahre 2070 einen Anspruch hätten. Ein wirklich sehr langfristiges Programm.

Einführung von Leistungen zur Gesundheitsförderung als Ermessensleistung.

Einführung von Maßnahmen zur Verhütung von Zahnerkrankungen für Kinder unter 12 Jahre in Form von Gruppenprophylaxe ( 21 SGB V) oder Individualprophylaxe ( $\$ 22$ SGB V) für Versicherte vom 12. bis 20 . Lebensjahr.

Kinderuntersuchung bis zur Vollendung des 6. Lebensjahres zur Früherkennung von Krankheiten.

In diesem Kontext ist die Frage interessant, woher der Gesetzgeber seine Erkenntnis nimmt, dass Untersuchungen zur Früherkennung von Krankheiten nur bis zur Vollendung des 6 . Lebensjahres wertvoll seien. Im weiteren Verlauf der Gesetzgebung ist dann auch eine Untersuchung nach Vollendung des 10. Lebensjahres ermöglicht worden, wobei auch bei dieser Erweiterung medizinisch-wissenschaftliche Erkenntnisse kaum Pate gestanden haben. 
Einführung von Kostenerstattung bei kieferorthopädischer Behandlung als Regelleistung in Höhe von 80 Prozent (1. Kind) bzw. 90 Prozent (für 2. Kind im Haushalt); Resterstattung nach erfolgreichem Abschluss der Behandlung.

Einführung von Zahnersatz als Regelleistung. Erbringung der Leistung durch Kostenerstattung (50 Prozent der zahntechnischen Leistungen und zahnärztlichen Behandlung).

\section{Einführung einer Bonusregelung für Zahnersatz ab 01.01.1991}

Die Bonusregelung für Zahnersatz ist aus heutiger Sicht eine der erfolgreichsten Erweiterungen des Leistungskataloges. Sie hat wesentlich zur Verbesserung der Zahngesundheit in Deutschland beigetragen und darf heute als Vorbild für weitergehende Überlegungen in anderen Leistungsbereichen bezeichnet werden.

Einführung von Müttergenesungskuren als Regelleistung, die nach pflichtgemäßem Ermessen gewährt werden (volle Kostenübernahme oder Zuschuss).

Einführung von ergänzenden Leistungen zur Rehabilitation ( $z$. B. Rehabilitationssport) als Regelleistung nach pflichtgemäßen Ermessen.

Einführung von Leistungen bei Schwerpflegebedürftigkeit (\$§ 53 ff. SGB V); dazu gehören

- häusliche Pflegehilfe bis 750 DM monatlich (ab 01.01.1991),

- Urlaubs- und Verhinderungspflege bis 1.800 DM im Kalenderjahr (ab 01.01.1989),

- Geldleistung 400 DM je Kalendermonat (ab 01.01.1991).

Mit der Einführung von Leistungen bei Schwerpflegebedürftigkeit hat der Gesetzgeber schon vor Schaffung des Pflegeversicherungsgesetzes bemerkenswerte Leistungen im Recht der gesetzlichen Krankenversicherung eingeführt. Heute stellt sich die Frage, ob eine Weiterentwicklung dieser Leistungen im SGB V sinnvoller gewesen wäre als ein eigenständiges Pflegeversicherungsgesetz. 

KOV-Anpassungsgesetz 1990 (KOVAnpG 1990), gültig ab
01.01.1989

Einführung medizinischer Maßnahmen zur Herbeiführung einer Schwangerschaft ( $\$ 27$ a SGB V).

Zweites Gesetz zur Änderung des SGB V vom 20.12.1991, gültig ab 01.01 .1992

Haushaltshilfe(§ 38 SGB V)-Anspruch besteht, wenn ein Kind das 12. Lebensjahr (bisher 8 . Lebensjahr) noch nicht vollendet hat.

Anspruch auf nichtärztliche sozialpädiatrische Leistungen (Diagnostik, Aufstellung eines Behandlungsplanes).

Kinderkrankengeld, Erweiterung des Anspruches durch Heraufsetzung der Altersgrenze von 8 auf 12 Jahre und

Ausweitung des Anspruchszeitraums von 5 auf 10 Arbeitstage je Kalenderjahr je Kind, bei allein erziehenden Versicherten auf 20 Arbeitstage, für mehrere Kinder insgesamt auf 50 Arbeitstage im Kalenderjahr.

Schwangeren- u. Familienhilfegesetz vom 27.07.1992, gültig ab 05.08.1992

Bis zum vollendeten 20. Lebensjahr Anspruch auf Versorgung mit ärztlich verordneten empfängnisverhütenden Mitteln.

Anspruch auf Leistungen bei einer nicht rechtswidrigen Sterilisation und bei einem nicht rechtswidrigen Abbruch der Schwangerschaft durch einen Arzt.

Die beiden Gesetze des Jahres 1991 und 1992 kann man guten Gewissens als sozialpolitische Wohltaten bezeichnen. Sie haben das Spektrum der versicherungsfremden Leistungen beträchtlich erweitert, und dies in einer Zeit steigender Beitragssätze der GKV.

Gesundheitsstrukturgesetz vom 21.12.1992, gültig ab 01.01.1993

Leistungen zur Verhütung von Krankheiten während eines nicht beruflich bedingten Auslandsaufenthaltes (Schutzimpfungen) dürfen in der Satzung nicht vorgesehen werden. 
Anspruch auf kieferorthopädische Behandlung entfällt für Versicherte, die zu Beginn der Behandlung das 18. Lebensjahr vollendet haben (gilt nicht für Versicherte mit schweren Kieferanomalien, die kombinierte kieferchirurgische Maßnahmen erfordern).

Zahnersatz - zahnmedizinisch umstrittene oder unnötig aufwendige prothetische Versorgungsformen werden nicht mehr übernommen (z. B. Brücken zum Ersatz von mehr als 4 fehlenden Zähnen je Kiefer oder mehr als 3 fehlenden Zähnen je Seitenzahngebiet).

Die detaillierte Regelung zum Zahnersatz dokumentiert die Regelungstiefe der Gesetzgebung und provoziert zugleich die Frage nach der Sinnhaftigkeit des gesetzgeberischen Eifers.

Das gleiche gilt auch für die im Folgenden erwähnten Altersgrenzen bei Individualprophylaxe bzw. bei Fissurenversiegelung. Hier stellt sich wie schon zuvor die Frage, ob die Abgrenzung nicht sinnvollerweise der Selbstverwaltung der GKV überlassen werden sollte.

Zahnersatz - Einführung einer Vorversicherungszeit für bestimmte Personengruppen (z. B. Personen mit Wohnsitz im Ausland, Bürgerkriegsflüchtlinge, Asylbewerber, Vertriebene i. S. des $\S 1$ Abs. 2 Nr. 3 BVFG).

Ausgabendeckelung für medizinische Vorsorge- und Rehabilitationsmaßnahmen.

Kostenübernahme bei vorübergehendem Auslandsaufenthalt für längstens 6 Wochen, wenn Versicherten wegen einer Vorerkrankung oder ihres Lebensalters nachweislich eine private Auslands-Krankenversicherung nicht möglich war.

Erweiterung der Zahnprophylaxe (Gruppenprophylaxe) auf Untersuchung der Mundhöhle, Erhebung des Zahnstatus.

Altersgrenze bei Individualprophylaxe wird vom 12. auf das 6. Lebensjahr herabgesetzt.

Krankenkassen können Selbsthilfegruppen und Selbsthilfekontaktstellen mit gesundheitsfördernder oder rehabilitativer Zielsetzung durch Zuschüsse fördern. 
Anspruch auf Fissurenversiegelung der Molaren für Versicherte, die das 6., aber noch nicht das 20. Lebensjahr vollendet haben.

Einführung von vor- und nachstationärer sowie ambulanter Krankenhausbehandlung.

Übernahme von Fahrkosten zur ambulanten Krankenbehandlung, wenn dadurch eine an sich gebotene vollstationäre oder teilstationäre Krankenhausbehandlung vermieden oder verkürzt wird.

Zweites Gesetz zur Umsetzung des Spar-, Konsolidierungs- und Wachstumsprogramms (2. SKWPG) vom 21.12.1993, gültig ab 01.01.1994

Streichung des $\$ 200$ a RVO, was bedeutet, dass die Krankenkassen für jeden Fall, in dem sie Mutterschaftsgeld nach $\S 200$ RVO gezahlt haben, den Pauschbetrag in Höhe von 400 DM nicht mehr aus Steuermitteln erhalten.

Die Streichung des $\S 200$ a RVO gehört in den Kontext Verschiebebahnhof. Bei der Einführung der Leistung wurde den Krankenkassen die Rückfinanzierung aus dem Bundeshaushalt zugesichert, bei nächster Gelegenheit - wie schon der schöne Name des Gesetzes sagt - gestrichen.

Gesetz zur sozialen Absicherung des Risikos der Pflegebedürftigkeit (Pflege-Versicherungsgesetz - PflegeVG) vom 26.05.1994, gültig für den Leistungsbereich (ohne vollstationäre Pflege) ab 01.04.1995

Häusliche Krankenpflege nach § 37 SGB V, Ausschluss der Mehrleistung bei Pflegebedürftigkeit (Grundpflege, hauswirtschaftliche Versorgung).

Streichung der Leistungen bei Schwerpflegebedürftigkeit nach $\S \S 53$ bis 57 ff. SGB V.

Gesetz zur Entlastung der Beiträge in der gesetzlichen Krankenversicherung (Beitragsentlastungsgesetz - BeitrEnt|G) vom 01.11.1996, gültig ab 01.01.1997

Leistungen zur Förderung der Gesundheit ( $\$ 20$ SGB V) werden gestrichen. 
Die radikale Einschränkung der Leistungen zur Förderung der Gesundheit hat zweifelsohne ihre Ursache in einem vielfältigen Missbrauch durch die Krankenkassen aus Marketinggründen. Zwischenzeitlich ist man parteiübergreifend zu der Einschätzung gekommen, die präventiven Möglichkeiten der GVK wieder auszuweiten.

Medizinische Vorsorgeleistungen nach $\$ 23$ Abs. 5 SGB V sollen
längstens für 3 Wochen (bisher 4 Wochen) erbracht werden.

Zahnärztliche Behandlung - implantologische Leistungen einschließlich Suprakontruktion, funktionsanalytische und funktionstherapeutische Maßnahmen gehören nicht zur zahnärztlichen Behandlung; sie dürfen von den Krankenkassen nicht bezuschusst werden.

Anspruch auf Zahnersatz entfällt grundsätzlich für Versicherte, die nach dem 31.12.1978 geboren sind.

Ausnahme:

- wenn Versorgung mit Zahnersatz aufgrund eines Unfalls erforderlich ist

- durch eine schwere, nicht vermeidbare Erkrankung des Kausystems bedingt ist

- durch eine schwere Allgemeinerkrankung oder ihre Folgen bedingt ist

- zur Behandlung einer schweren Allgemeinerkrankung oder ihre Folgen notwendig ist

Die Sinnhaftigkeit von Zahnersatzleistungen in der GKV hat den Gesetzgeber annähernd in jeder Reform beschäftigt. Die Grundsatzentscheidung von 1996, für jüngere Mitglieder den Zahnersatz als GKV-Leistung auszuschließen, ist schon durch die neue Bundesregierung 1999 vollständig zurückgenommen worden. Damit ist aber die Diskussion keineswegs beendet, sie nimmt im Augenblick wieder einen interessanten Platz in der Gesundheitsreformdebatte ein.

Der Anspruch auf Zuschuss zu den Kosten eines Brillengestells in Höhe von 20 DM entfällt. 
Medizinische Rehabilitationsmaßnahmen nach $\S 40$ SGB $V$ sollen für längstens 3 Wochen (bisher 4 Wochen) erbracht werden. Wiederholungsmaßnahmen erst nach 4 Jahren (bisher 3 Jahre) möglich.

Der Anspruch auf Krankengeld verringert sich von 80 Prozent auf 70 Prozent des Regelentgeltes. Dabei darf das aus dem Arbeitsentgelt berechnete Krankengeld 90 Prozent des kalendertäglichen Nettoarbeitsentgeltes (bisher 100 Prozent) nicht übersteigen.

1. GKV-Neuordnungsgesetz - 1. NOG vom 23.06.1997, gültig ab 01.09.1997

Zuzahlungserhöhung um 1 DM bei Beitragssatzerhöhung für jeweils 0,1 Beitragssatzpunkte dieser Beitragssatzerhöhung.

Zuzahlungsminderung bei Senkung des Beitragssatzes um 1 DM für jeweils 0,1 Beitragssatzpunkte dieser Beitragssatzsenkung. Dabei dürfen die gesetzlich vorgesehenen Beträge und Anteile nicht unterschritten werden.

Teilweise Befreiung nach § 62 SGB V; Einführung einer Belastungsgrenze von 1 Prozent der jährlichen Bruttoeinnahmen zum Lebensjahr für Versicherte, die wegen derselben Krankheit in Dauerbehandlung sind und 1 Jahr lang Zuzahlungen bis zur Belastungsgrenze aufbringen mussten, für die weitere Dauer dieser Behandlung.

Mit der Einführung der teilweisen Befreiung chronisch Kranker von der Zuzahlung und deren späteren Ausweitung durch die neue Bundesregierung ist der Anteil der von der Zuzahlung Befreiten auf mittlerweile 50 Prozent gestiegen und damit die gesamte Zuzahlungsregelung in Frage gestellt worden. Man könnte auch kritisch anmerken, dass diese Regelung zu einer Förderung der Chronifizierung der Bundesbürger geführt hat.

2. GKV-Neuregelungsgesetz - 2. GKV-NOG vom 23.06.1997, gültig ab 01.07.1997

Die Altersgrenze der Versicherten für individualprophylaktische Leistungen ( $\$ 22$ SGB V) - einmalige zahnärztliche Untersuchung im Kalender - wird vom vollendeten 20. Lebensjahr auf das 18. Lebensjahr herabgesetzt. 
Einführung einer Zuzahlung in Höhe von 20 Prozent des von der Krankenkasse zu übernehmenden Betrages zu den Kosten von Bandagen, Einlagen und Hilfsmitteln zur Kompressionstherapie für Versicherte, die das 18 . Lebensjahr vollendet haben.

Festzuschüsse beim Zahnersatz werden von bisher 50 Prozent auf 45 Prozent reduziert.

Zahnärztliche Behandlung, implantologische Leistungen einschließlich der Suprakonstruktion können übernommen werden, wenn seltene vom BA der Zahnärzte $u$. Krankenkassen in Richtlinien nach $\S 92$ Abs. 1 SGB V festzulegende Ausnahmeindikationen für besonders schwere Fälle vorliegen (Sachleistung im Rahmen einer medizinischen Gesamtbehandlung).

Kostenerstattung durch Festzuschüsse beim Zahnersatz, wobei sich der Festzuschuss für die vor dem 1. Januar 1979 Geborenen um 20 Prozent erhöht, wenn der Gebisszustand des Versicherten regelmäßige Zahnpflege erkennen lässt (gilt erst, wenn Festzuschüsse nach $\S 30$ a SGB V veröffentlicht sind).

Einführung eines Anspruches auf einen Zuschuss zu stationärer oder teilstationärer Versorgung in Hospizen, in denen palliativmedizinische Behandlung erbracht wird, wenn eine ambulante Versorgung im Haushalt oder der Familie nicht erbracht werden kann.

GKV-Solidaritätsstärkungsgesetz - GKV-SolG vom 19.12.1998, gültig ab 01.01.1999

Zuschuss zum Zahnersatz beträgt 50 Prozent der Kosten auf der Berechnungsgrundlage des Heil- und Kostenplans.

Der Zuschuss für eigene Bemühungen zur Gesunderhaltung der Zähne mindert sich von 20 Prozent auf 10 Prozent.

Hier die schon erwähnte Rücknahme des Ausschlusses von Zahnersatzleistungen für die nachwachsenden Jahrgänge. 
GKV-Gesundheitsreformgesetz 2000 vom 22.12.1999, gültig ab 01.01.2000

Krankenkassen sollen in der Satzung Leistungen zur primären Prävention vorsehen.

Die Krankenkasse soll Selbsthilfegruppen, -organisationen und -kontaktstellen fördern, die sich die Prävention oder die Rehabilitation von Versicherten bei einer im Verzeichnis nach Satz 2 aufgeführten Krankheiten zum Ziel gesetzt haben.

Medizinisch notwendige stationäre Vorsorgemaßnahmen für versicherte Kinder unter 14 Jahre sollen in der Regel für 4 bis 6 Wochen erbracht werden.

Einführung von Soziotherapie für Versicherte, die wegen schwerer psychischer Erkrankung nicht in der Lage sind, ärztliche oder ärztlich verordnete Leistungen selbstständig in Anspruch zu nehmen.

Die Einführung der Soziotherapie erweitert den sozialpolitischen Teil der GKV-Leistungen und fördert ggf. den Aufbau einer neuen Versorgungsstruktur, die sich unter den Bedingungen der GKV-Finanzierung etabliert.

Einführung von Funktionstraining als ergänzende Leistung zur Rehabilitation ( $§ 43$ SGB V), ebenso Patientenschulungsmaßnahmen für chronisch Kranke (unter Einbeziehung von Angehörigen und ständigen Begleitpersonen).

Förderung von Einrichtungen zur Verbraucher- und Patientenberatung im Rahmen von Modellvorhaben.

Diese gesetzlich verordnete Förderung kann als extrem versicherungsfremde Leistung bezeichnet werden. Dahinter steht das Misstrauen der damals grünen Bundesgesundheitsministerin gegenüber den Krankenkassen und sie entlastet möglicherweise den Fiskus, jedenfalls soweit es Verbraucherzentralen betrifft. 
Einmalzahlungs-Neuregelungsgesetz vom 21.12.2000, gültig ab 22.01.2000

Einmalig gezahltes Arbeitsentgelt wird, soweit es der Beitragsberechnung unterliegt, bei der Ermittlung des Regelentgeltes berücksichtigt.

Eine Folge höchstrichterlicher Entscheidung.

Lebenspartnerschaftsgesetz - LpartG vom 16.02.2001, gültig ab 01.08.2001

Einführung der Familienversicherung (und damit volle Leistungsansprüche) für Lebenspartner und Kinder von Lebenspartnern.

Sozialgesetzbuch - Neuntes Buch - (SGB IX) Rehabilitation und Teilhabe behinderter Menschen vom 19.06.2001, gültig ab 01.07.2001

Übernahme der im Zusammenhang mit der Ausführung einer Leistung zur medizinischen Rehabilitation erforderlichen Fahr-, Verpflegungs- und Übernachtungskosten. Hierzu gehören auch Kosten

- für besondere Beförderungsmittel, deren Inanspruchnahme wegen Art oder Schwere der Behinderung erforderlich ist,

- für eine wegen der Behinderung erforderliche Begleitperson einschließlich des für die Zeit der Begleitung entstehenden Verdienstausfalls,

- für Kinder, deren Mitnahme an den Rehabilitationsort erforderlich ist, weil ihre anderweitige Betreuung nicht sichergestellt ist,

- für den erforderlichen Gepäcktransport.

Wesentliche Teile des SGB IX verlagern bzW. begründen Leistungen in das SGB V. Schaut man sich diese neuen GKV-Leistungen im Einzelnen an, so kann sich ein Land sicher glücklich schätzen, das solche Leistungen ermöglicht. Die Frage allerdings, weshalb dies eine Krankenversicherungsleistung ist (Mitnahme von Kindern, Gepäcktransport), bleibt offen. 
Verpflichtung der Sozialleistungsträger, für hörbehinderte Menschen die durch die Verwendung der Gebärdensprache und anderer Kommunikationshilfen bei der Ausführung von Sozialleistungen (z. B. ärztliche Untersuchungen und Behandlungen) entstehenden Kosten zu tragen.

Artikel 2 des Pflegeleistungs-Ergänzungsgesetztes (PfIEG) vom 15.11.2001, gültig ab 01.01.2002

- Förderung der ambulanten Hospizarbeit nach §39 a SGB V durch angemessenen Zuschuss zu den notwendigen Personalkosten. Ausgaben sollen sich für die Krankenkassen für jeden Versicherten wie folgt fortentwickeln:

- $\quad 0,15$ Euro

- 0,20 Euro

- 0,25 Euro

- 0,30 Euro

- 0,35 Euro

- 0,40 Euro

- Der Ausgangsbetrag von 0,40 Euro im Jahre 2007 soll ab dem Jahr 2008 jährlich um die prozentuale Veränderung der monatlichen Bezugsgröße nach $\S 18$ Abs. 1 SGB IV angepasst werden.

Wie schon bei der Einführung der stationären Hospize in den Finanzierungsrahmen der GKV zu erwarten war, ist nunmehr auch die ambulante Hospizarbeit Teil des Leistungskataloges. Um zu verdeutlichen, worum es hier $u$. a. geht, sei aus der Rahmenvereinbarung der Spitzenverbände der Krankenkassen und den Wohlfahrtsverbänden vom 03.09.2002 zitiert:

„Die Tätigkeit der Ehrenamtlichen erstreckt sich insbesondere auf

- Hilfen beim Verarbeitungsprozess in der Konfrontation mit dem Sterben,

- Hilfe bei der im Zusammenhang mit dem Sterben erforderlichen Auseinandersetzung mit sozialen, ethischen und religiösen Sinnfragen."

Hier wird exemplarisch deutlich, dass auch eine bisher den Kirchen und Religionsgemeinschaften zugetraute Aufgabe nach Meinung des Gesetzgebers einer Krankenkassenfinanzierung bedarf. 
Gesetz zur Reform des Risikostrukturausgleiches in der gesetzlichen KV vom 10.12.2001, gültig ab 01.01.2002

Einführung strukturierter Behandlungsprogramme bei chronischen Krankheiten.

Zweites Gesetz zur Änderung des Mutterschutzrechtes vom 16.06.2002, gültig ab 20.06.2002

Verlängerung der Anspruchsdauer auf Mutterschaftsgeld bei Frühgeburten und sonstigen vorzeitigen Entbindungen um den Zeitraum, der nach § 3 Abs. 3 MuSchG (6 Wochen vor der Geburt) nicht in Anspruch genommen werden konnte.

Erweiterung des anspruchsberechtigten Personenkreises auf Mutterschaftsgeld ( $\$ 200$ Abs. 2 RVO). Danach wird für Mitglieder, deren Arbeitsverhältnis während der Mutterschutzfristen vor oder nach der Geburt beginnt, das Mutterschaftsgeld von Beginn des Arbeitsverhältnisses an gezahlt.

Gesetz zur Sicherung der Betreuung und Pflege schwerstkranker Kinder vom 26.07.2002, gültig ab 01.08.2002

Schaffung eines Anspruches auf Krankengeld bei schwerer, unheilbarer Erkrankung eines Kindes für einen Elternteil ohne zeitliche Begrenzung. Voraussetzung ist, dass das Kind das 12. Lebensjahr noch nicht vollendet hat oder behindert und auf Hilfe angewiesen ist.

Gesetz zur Verbesserung des Zuschusses zu ambulanten Vorsorgeleistungen vom 26.07.2002, gültig ab 01.08.2002

Ambulante Vorsorgeleistungen

- Möglichkeit der Erhöhung des täglichen Zuschusses auf max. 13 Euro bzw. 21 Euro bei chronisch kranken Kleinkindern

- Wegfall der Regeldauer von drei Wochen

- Verkürzung des Wiederholungsintervalls auf 3 Jahre 
Gesetz zur Verbesserung der Vorsorge und Rehabilitation für Mütter und Väter vom 26.07.2002 (11. SGB V - Änderungsgesetz), gültig ab 01.08.2002

Leistungen zur Vorsorge und Rehabilitation für Mütter und Väter:

- Vollfinanzierung durch die gesetzlichen Krankenkassen

Diese kurz vor der Bundestagswahl 2002 verabschiedeten Minigesetze, die zwischen dem 16. Juni und 26 . Juli verabschiedet wurden, können der Schublade "Kriegskasse der Regierungsparteien in Wahlkampfzeiten", wie es kürzlich Professor Dr. Wolfgang Kersting genannt hat, zugeordnet werden.

Gesetz zur Sicherung der Beitragssätze in der gesetzlichen Krankenversicherung und der gesetzlichen Rentenversicherung vom 23.12.2002 (BSSichG), gültig ab 01.01.2003

Reduzierung des Sterbegeldes beim Tod eines Mitglieds auf 525 Euro, beim Tod eines nach $\S 10$ SGB V Versicherten (Familienangehörigen) auf 262,50 Euro.

Kaum ist die Wahl vorbei, ringt sich die Bundesregierung nach jahrelangen blauen Wohltaten durch, tatsächlich das Sterbegeld zu reduzieren. Glückwunsch!

\section{Fazit:}

Der Bundesgesetzgeber hat in den letzten Jahren nicht die Kraft gefunden, den Leistungskatalog grundsätzlich neu zu gestalten. Er hat inn vielmehr unter Berücksichtigung vorwiegend sozialpolitischer Präferenzen ausgeweitet. Soweit Einschränkungen umgesetzt wurden, sind diese partiell nach einem Regierungswechsel wieder aufgehoben worden.

Auch unter Berücksichtigung der Koalitionsvereinbarung 2002 darf nicht erwartet werden, dass sich an dieser strukturbedingten Unfähigkeit etwas ändert.

Die Verantwortungsebene muss verlagert werden. Auch hierzu sind gesetzliche Grundlagen erforderlich. 


\section{Die Differenzierung des Leistungskataloges}

\subsection{Leistungskatalog und Versichertensouveränität}

Neben dem Gesetzgeber kommen nur die Selbstverwaltung einer gesetzlichen Krankenversicherung oder der Versicherte selbst als Gestalter in Betracht. Insoweit sind folgende Varianten denkbar:

- Der Verwaltungsrat einer GKV entscheidet über die mögliche Differenzierung des Leistungskataloges für die Versicherten seiner Krankenkasse.

- Das Mitglied/der Versicherte entscheidet durch Zu- oder Abwahl über sein individuelles Leistungspaket und gestaltet dadurch die Höhe des individuellen Beitragssatzes.

Beide Varianten sind Ausdruck der Versichertensouveränität, die regelmäßig gefordert, der aber bisher wenig Rechnung getragen wurde. Zurzeit ist vielmehr eine Angst der politischen Entscheidungsträger vor der selektiven Kraft der Vernunft entscheidungsfähiger Bürger festzustellen.

Die Einheitlichkeit eines umfassenden Leistungskataloges wird mit der beabsichtigten Verhinderung einer Zwei-Klassen-Medizin begründet. Zwei-Klassen-Medizin ist jedoch nicht daran zu erkennen, dass Versicherte oder ihre Vertreter über die Sinnhaftigkeit von Vorsorgekuren entscheiden. Von Zwei-Klassen-Medizin ist vielmehr dann zu reden, wenn GKV-Versicherte von den Leistungen der Hightech-Medizin und der Behandlung durch hoch qualifizierte Ärzte mehr oder weniger ausgeschlossen werden. Das ist leider heute schon Realität. Diese Entwicklung muss bekämpft werden, $u$. a. durch eine Konzentration auf das Wesentliche im Leistungskatalog.

Das Wesentliche ist nicht das Notwendige. Qualität und Wirksamkeit der zu erhaltenden Leistungen müssen dem allgemein anerkannten Stand der medizinischen Erkenntnisse entsprechen und den medizinischen Fortschritt berücksichtigen. Die Krankenkassen müssen in die Lage versetzt werden, dies für alle Versicherten zu finanzieren.

\subsection{Der Leistungskatalog und der Risikostrukturausgleich}

Eine Differenzierung des Leistungskataloges macht auch deswegen Schwierigkeiten, weil Folgen für den RSA unvermeidlich sind. Gewinne oder Verluste im RSA sind häufig die tragenden Motive für eine Zustimmung oder Ablehnung einer Neuorientierung. Eine Reduzierung des für 
alle verpflichtenden Leistungskataloges führt zwangsläufig zu einer Verminderung des Volumens im Risikostrukturausgleich. Die damit verbundenen Verluste der Empfängerkrankenkassen hindern diese daran, für eine Neuorientierung einzutreten. Entsprechend sind auch Äußerungen aus diesem Lager einzuordnen.

\subsection{Die Konkretisierung des Leistungskataloges}

Die wesentlichen Leistungsarten der GKV sind im SGB V nicht näher definiert, $z$. B.

- ärztliche Behandlung,

- Krankenhausbehandlung.

Deshalb ist eine Konkretisierung des Leistungskataloges erforderlich, jedenfalls soweit es sich um einheitliche Leistungen für alle Krankenkassen handelt. Dies kann geschehen durch

- den Verordnungsgeber, z. B. Positiv- oder Negativlisten für Arzneimittel,

- durch den Bundesausschuss der Ärzte und Krankenkassen.

In der gesundheitspolitischen Diskussion wird diese Konkretisierung des Leistungskataloges häufig verwechselt mit der normativen Aufgabe des Gesetzgebers. Die Konkretisierung des Leistungskataloges dagegen ist im Wesentlichen ein auf wissenschaftlicher Grundlage zu treffender Entscheidungsprozess. Dies trifft sowohl für den Verordnungsgeber im Kontext der Positivliste für Arzneimittel als auch für den Bundesausschuss Ärzte und Krankenkassen zu.

Die Bewertung von Untersuchungs- und Behandlungsmethoden ist traditionell in der GKV begrenzt auf die ambulante Versorgung. Für den Bereich der stationären Versorgung wurde eine entsprechende Aufgabe erst im Jahre 2000 in das SGB V aufgenommen: Ergebnisse liegen bisher noch nicht vor.

Das beabsichtigte Deutsche Institut für Qualität in der Medizin muss, wenn es einen sinnvollen Beitrag zur Qualitätssicherung leisten soll, in die bestehenden Strukturen eingebunden werden. Ansonsten ist eine eher hinderliche Parallelarbeit zu befürchten. Für eine Einbindung sprechen auch die begrenzten Ressourcen, die für eine solch schwierige Arbeit in Deutschland zur Verfügung stehen. 
Aus der bisherigen Arbeit des Bundesausschusses der Ärzte und Krankenkassen sollen einige Beispiele genannt werden, um zu verdeutlichen, worum es geht:

\section{Akupunkturbehandlung mit Nadeln}

Nicht anerkannt durch Bundesausschuss am 18.01.2001 mit Ausnahme der Kostenübernahme im Rahmen eines Modellvorhabens bei den Indikationen chronische Kopfschmerzen, chronische LWS-Schmerzen und chronische osteoarthritische Schmerzen.

\section{Extrakorporale Stoßwellentherapie (ESWT)}

Nicht anerkannt durch Bundesausschuss am 25.07.1998.

Positronen-Emmissions-Tomographie (PET)

Spezielle Diagnostikmethode, v. a. in der Neurologie, Kardiologie und Onkologie; nicht anerkannt durch Bundesausschuss am 11.05.2002.

Intracytoplasmatische Spermieninjektion (ICSI)

Seit 01.07.2002 Kassenleistung durch Beschluss des Bundesausschusses zur Änderung der Richtlinien über künstliche Befruchtung. Zuvor vom Bundesausschuss nicht als Methode der künstlichen Befruchtung anerkannt. Richtlinien mussten nach BSG-Urteil vom 03.04.2001 geändert werden.

Kernspintomographie der Mamma (MRT)

Am 17.10.2001 als Behandlungsmethode vom Bundesausschuss anerkannt.

Aktiv-spezifische Immuntherapie (ASI)

Extracorporale Tumorbehandlung mit virusmodifizierten, hochaufgereinigten, autologen Tumorzellen; am 25.07.2000 vom Bundesausschuss als Behandlungsmethode ausgeschlossen. Bis zum Ausschluss wurden die Kassen mit zahlreichen Klageverfahren konfrontiert.

Hyperbare Sauerstofftherapie

Durch Bundesausschuss ausgeschlossen am 01.02.2001. 


\section{Vorschlag für eine Neugestaltung des Leistungskataloges}

\subsection{Solidarleistungen als Pflichtleistungen}

Die folgenden Solidarleistungen werden von allen Krankenkassen auf der Grundlage der gesetzlichen Vorgaben als Pflichtleistungen übernommen. An den Ausgaben für diese Leistungen beteiligen sich die Arbeitgeber. Nur diese Solidarleistungen sind Gegenstand des Risikostrukturausgleiches. Was im Einzelnen zu den Solidarleistungen gehört, lässt sich nicht wissenschaftlich, sondern nur normativ abgrenzen. Folgende Leistungsbereiche des geltenden Rechtes sollen dieser Kategorie zugeordnet werden:

\begin{tabular}{|l|c|c|}
\hline & $\begin{array}{c}\text { Leistungsausgaben } \\
\text { in \% }\end{array}$ & $\begin{array}{c}\text { Ausgaben je Mitglied } \\
\text { pro Jahr in Euro }\end{array}$ \\
\hline $\begin{array}{l}\text { - Krankenhausbehandlung und Anschlussre- } \\
\text { habilitation }\end{array}$ & 34,5 & 884,00 \\
- ärztliche Behandlung (inkl. Früherkennung) & 17,3 & 443,00 \\
- zahnärztliche Behandlung & 5,2 & 134,00 \\
- Arzneimittel & 16,5 & 423,00 \\
- Krankengeld & 5,9 & 151,00 \\
- stationäre Hospize & 0,02 & 0,50 \\
\hline $\begin{array}{l}\text { Die Ausgaben für die Solidarleistungen als } \\
\text { Pflichtleistungen betrugen im Jahr 2001 insge- } \\
\text { samt ca. }\end{array}$ & 79,42 & $2.035,50$ \\
\hline
\end{tabular}

Die Aufstellung verdeutlicht, dass 5 bis 6 der 50 Leistungsarten des SGB V 80 Prozent der Leistungsausgaben ausmachen. Wenn man einen Gestaltungsspielraum für Selbstverwaltung oder Versicherte wünscht, dann darf man diesen nicht dadurch verkleinern, indem man bei den restlichen 44 Leistungsarten in langen Entscheidungsprozessen prüft, ob sie nicht doch in diese Kategorie einzuordnen sind. Im Übrigen zeigt die Erfahrung vereinzelter Versuche einer Differenzierung des Leistungskataloges in der Vergangenheit, dass nur ein konsequenter Schnitt in der zu erwartenden Diskussion durchzustehen ist. Im anderen Fall muss man den Vertretern der verschiedenen Leistungsarten erklären, weshalb gerade sie und nicht auch andere der Kategorie Solidarleistungen als Gestaltungsleistungen zugeordnet sind.

\subsection{Solidarleistungen als Gestaltungsleistungen}

Solidarleistungen als Gestaltungsleistungen stellen eine Option der Krankenkasse dar. Sie müssen angeboten werden, aber Art und Umfang 
werden durch die Satzung der Krankenkasse geregelt. Es handelt sich ebenfalls um Solidarleistungen, folglich sind die Arbeitgeber an der Aufbringung des Beitraganteils hierfür beteiligt. Da die Krankenkasse den Umfang der Gestaltungsleistungen selbst bestimmt, werden sie im Risikostrukturausgleich nicht berücksichtigt.

Dieser Kategorie sollen zugeordnet werden:

\begin{tabular}{|l|c|c|}
\hline & $\begin{array}{c}\text { Leistungsausgaben } \\
\text { in \% }\end{array}$ & $\begin{array}{c}\text { Ausgaben je Mitglied } \\
\text { pro Jahr in Euro }\end{array}$ \\
\hline - Zahnersatz und Kieferorthopadie & 3,7 & 94,00 \\
- Hilfsmittel & 4,4 & 112,00 \\
- Heilmittel & 2,5 & 63,00 \\
- Fahrtkosten & 2,0 & 51,00 \\
- Stationăre Rehabilitation und Vorsorgeleistun- & 0,9 & 24,00 \\
gen & 0,7 & 17,00 \\
- Prävention, soziale Dienste, Selbsthilfe & 1,2 & 32,00 \\
- Hăusliche Krankenpflege & 0,4 & 9,00 \\
- Ergänzende Leistungen zur Rehabilitation, \\
$\begin{array}{l}\text { sozialpädiatrische Zentren, psychiatrische In- } \\
\text { stitutsambulanzen }\end{array}$
\end{tabular}

Der Vorschlag, Solidarleistungen als Gestaltungsleistungen in die Verantwortung der Selbstverwaltung der einzelnen Krankenkasse zu übernehmen, beruht auf der Überzeugung, dass eine risikoäquivalente Beitragskalkulation für einzelne Mitglieder oder Versicherte nicht möglich ist. Würde man etwa Kieferorthopädie als Wahlleistung einzelnen Versicherten anbieten, würden nur diejenigen diese Leistungsart wählen, die diese mit hoher Wahrscheinlichkeit in absehbarer Zeit in Anspruch nehmen. Dies würde zu einem Zusatzbeitrag führen, der den zu erwartenden Ausgaben gleichkommt. Das gleiche lässt sich auch für einzelne Heilmittel wie beispielsweise Massagen sagen.

Insoweit kommt im Rahmen der Strukturen der GKV nur ein Leistungspaket für alle Versicherten einer Krankenkasse in Betracht. Hier findet der Risikıausgleich innerhalb der Versichertengemeinschaft statt. Der Verwaltungsrat der Krankenkasse hat es in der Hand, hier ein umfassendes oder ein eingeschränktes Paket je nach Versichertenpriorität an- 
zubieten. Die Befürchtung, dass Krankenkassen dieses Paket drastisch reduzieren würden, ist abwegig. Keine Krankenkasse wird beispielsweise Hilfsmittel der orthopädischen Versorgung streichen oder als sinnvoll einzuordnende Heilmittel wie etwa Krankengymnastik. Ebenso wenig wird eine Krankenkasse auf die Idee kommen, Fahrtkosten für Notfallrettung zu streichen. Andererseits werden Krankenkassen die augenblicklichen Finanzierungsmöglichkeiten für Prävention erweitern, wenn sie davon überzeugt sind, dass dadurch Folgekosten gespart werden können.

Im Übrigen muss man auch von einer in Deutschland verbreiteten Mentalität abrücken, Versicherte vor sich selbst schützen zu wollen.

Um ein Krankenkassen-Hopping bei kurzfristig veränderten Prioritäten zu vermeiden, muss einerseits die Bindungsfrist an die Krankenkasse ggf. verlängert werden und andererseits eine ausreichende Ausschlussfrist für Gestaltungsleistungen nach Krankenkassenwechsel eingeführt werden, wie es private Krankenversicherungen schon praktizieren.

\subsection{Aus dem Leistungskatalog ausgeschlossen werden:}

- Förderung von Einrichtungen der Verbraucherberatung

- Sterbegeld

\begin{tabular}{|l|c|c|}
\hline & $\begin{array}{c}\text { Leistungsausgaben } \\
\text { in \% }\end{array}$ & $\begin{array}{c}\text { Ausgaben je Mitglied } \\
\text { pro Jahr in Euro }\end{array}$ \\
\hline $\begin{array}{l}\text { Die Ausgaben hierfür betrugen im } \\
\text { Jahr } 2001 \text { insgesamt ca. }\end{array}$ & 0,6 & 15,00 \\
\hline
\end{tabular}

Es geht hierbei nicht nur um die ausgewiesene Einsparung, sondern auch um eine Grenzziehung zu versicherungsfremden Leistungen, die den Gesetzgeber daran hindern soll, dieses Spektrum auszuweiten.

\section{Sozial-, familien- und bildungspolitische Leistungen auf der Grundlage des SGB V}

- Empfängnisverhütung

- Künstliche Befruchtung

- Schwangerschaftsabbruch bei nichtmedizinischer Indikation, Sterilisation

- Nichtärztliche sozialpädiatrische Leistungen

- Soziotherapie 
- Soziale Dienste

- Krankengeld bei Erkrankung des Kindes, Haushaltshilfen

- Weiterbildung Allgemeinmedizin

\begin{tabular}{|l|c|c|}
\hline & $\begin{array}{c}\text { Leistungsausgaben } \\
\text { in \% }\end{array}$ & $\begin{array}{c}\text { Ausgaben je Mitglied } \\
\text { pro Jahr in Euro }\end{array}$ \\
\hline $\begin{array}{l}\text { Die Ausgaben hierfür betrugen im } \\
\text { Jahr 2001 insgesamt ca. }\end{array}$ & 3,4 & 88,00 \\
\hline
\end{tabular}

Die vorgenannten Leistungsarten sind allesamt sozialstaatliche Aufgaben und weitgehend auch unverzichtbar. Gleichwohl sind sie krankenversicherungsfremd. Die Finanzierung dieser Leistungen muss deshalb ordnungspolitisch korrekt dem Bund bzw. den Bundesländern zugeordnet werden. Diese Leistungen aus Steuermitteln zu finanzieren würde auch die Ungleichheit zwischen privat und gesetzlich Krankenversicherten aufheben und damit alle Bundesbürger in die Finanzierung einbeziehen. Um zu vermeiden, dass Bund oder Länder zur Umsetzung dieser Aufgabenbereiche eine eigene Struktur aufbauen müssen, können die Krankenkassen im Wege der Auftragsverwaltung die Umsetzung weiterhin sicherstellen. Das Gleiche können auch private Krankenversicherungen für ihre Versicherten übernehmen. Art und Umfang der jeweiligen Leistungen bleiben weiterhin in der Kompetenz des Bundes- oder Landesgesetzgebers.

\section{In den Leistungskatalog aufgenommen wird}

die Möglichkeit aller Krankenkassen, Versorgungsforschung mitzufinanzieren.

Die Versorgungsforschung ist in Deutschland zurzeit unterentwickelt, was nicht zuletzt mit der mangelnden Finanzierung zusammenhängt. Da die Ergebnisse der Versorgungsforschung für Qualitätssicherung und Wirtschaftlichkeit der Krankenkassen von hoher Bedeutung sind, sollen Krankenkassen die Option erhalten sich am Aufwand zu beteiligen.

\section{Ergänzende Leistungen}

Soweit Versicherte ausfallende Leistungen wie Sterbegeld oder über die Gestaltungsleistungen der Krankenkasse hinaus gehende Leistungen bzw. Komfortleistungen wie Zweibettzimmer im Krankenhaus in Anspruch nehmen wollen, steht dafür die private Krankenversicherung zur 
Verfügung. Den Krankenkassen wird ermöglicht, für ihre Versicherten Gruppentarife mit privaten Krankenversicherungen abzuschließen.

Gesetzliche Krankenkassen verfügen über keine Erfahrungen bei der Kalkulation risikoäquivalenter Zusatzversicherungen. Würde man innen gleichwohl die Zusatzversicherung ermöglichen, müsste sichergestellt sein, dass der gesetzlich wahrgenommene Aufgabenbereich von dem Ergänzungsversicherungsgeschäft strikt getrennt wird und Risiken aus dem jeweils anderen Bereich nicht gegenfinanziert werden dürfen. Im Falle der Schließung einer Krankenkasse wegen Leistungsunfähigkeit wird das in jedem Fall Probleme bereiten. Deshalb empfiehlt sich für sinnvoll ergänzende Leistungen eine Kooperation zwischen GKV und PKV. Die GKV kann für ihre Versicherten über Gruppentarife sicherstellen, dass eine Risikoselektion für ergänzende Leistungen ausgeschlossen wird.

\section{Fazit:}

Die Differenzierung des Leistungskataloges der GKV ist kein Königsweg aus der aktuellen Finanzierungskrise der GKV, aber ein Einstieg in eine wünschenswerte Stabilisierung. Es wird zugleich die Versichertensouveränität über die Entscheidungsgremien der Krankenkassen sowie das Kostenbewusstsein im Bereich der Gestaltungsleistungen gestärkt. Versicherungsfremde Leistungen werden entweder gänzlich ausgeschlossen oder ordnungspolitisch richtig in die Finanzierungsverantwortung des Bundes oder der Bundesländer zurückgeführt. Der Risikostrukturausgleich, der zwischenzeitlich schon Risikostrukturen überkompensiert, wird um 20 Prozent des aktuellen Volumens entlastet.

Die in Zukunft über Steuer zu finanzierenden Leistungen haben Minderausgaben von 4,9 Mrd. Euro bzw. eine Reduzierung des Beitrages um 0,47 Punkte zur Folge. Geht man davon aus, dass handlungsfreudige Krankenkassen im Rahmen ihrer Gestaltungsmöglichkeiten das aktuelle Leistungsspektrum von 16,5 Prozent um 5 Prozent der Gesamtausgaben reduzieren, ergibt sich ein Einsparpotential von ca. 7,0 Mrd. Euro bzw. eine Reduzierung des Beitragssatzes um 0,68 Punkte. Eine Senkung des Beitragssatzes um fast 1,2 Prozentpunkte führt zu einer durchaus nennenswerten Entlastung der Beitragszahler in der GKV. 


\section{Der Leistungskatalog der GKV im Wandel - Anmerkungen aus praktischer Sicht}

Hans Jürgen Ahrens

\section{Demographie}

„Präambel, da vermutlich alle nur über Kostenbelastung sprechen“

Zunächst einmal ist festzustellen, dass es eine große Erfolgsgeschichte ist, wenn die Menschen in Deutschland immer älter werden. Zu dieser Erfolgsgeschichte hat die gesetzliche Krankenversicherung wesentlich beigetragen. Das wollen wir auch in Zukunft tun.

\section{„Nicht das Kind mit dem Bade ausschütten“}

Für die gesetzliche Krankenversicherung ist der Generationenvertrag (noch) kein Sorgenkind! Aber wir müssen uns gemeinsam darum kümmern, dass aus dem Generationenvertrag in der GKV mittel- und langfristig kein Sorgenkind wird. Dabei dürfen wir nicht den Fehler begehen, aufgrund der demographischen Entwicklung die bewährten Strukturen des Gesundheitssystems zu beseitigen und damit womöglich "das Kind mit dem Bade auszuschütten“. Niemandem ist geholfen, wenn wir ein wesentliches Solidarprinzip, den Ausgleich zwischen Jung und Alt, zur Disposition stellen.

\section{Lösungen müssen Akzeptanz in der Bevölkerung haben}

Die gesetzliche Krankenversicherung steht in den nächsten Jahrzehnten unbestreitbar vor gewaltigen Herausforderungen. Eine zunehmend älter werdende Bevölkerung, die anhaltend hohe Arbeitslosigkeit und der medizinisch-technische Fortschritt sind Beispiele für die sozioökonomischen Veränderungen in unserem Land. Wir müssen auf diese Veränderungen im Interesse einer bedarfsgerechten solidarischen Krankenversicherung Antworten finden, die auch von der Bevölkerung akzeptiert werden.

\section{Zukunftskonzepte für mehr Effektivität und Effizienz}

Die Zukunftskonzepte für die GKV müssen sich insbesondere mit der Effektivität und Effizienz des gegenwärtigen Systems auseinandersetzen. Die festgestellte Über-, Unter- und Fehlversorgung muss dabei entschieden bekämpft werden. 
Allerdings muss bei der Betrachtung der Auswirkungen der demographischen Entwicklung auf die Einnahmesituation der gesetzlichen Krankenversicherung ein besonderes Augenmerk darauf gerichtet werden, dass der Rückgang der Erwerbspersonen und eine Zunahme der Personen im Rentenalter ohne Zweifel zu Einnahmerückgängen führen. Auch die gegenwärtige Situation am Arbeitsmarkt schmälert die Einnahmebasis der GKV. Ein weiteres zentrales Einnahmeproblem sind die Beiträge der Rentner. So hat sich das Verhältnis von Einnahmen zu Ausgaben für die Rentner (Deckungsquote) deutlich verschlechtert. Während in den 60er Jahren noch über 90 Prozent der Ausgaben für Rentner durch entsprechende Einnahmen für Rentner gedeckt waren, liegt dieser Anteil jetzt nur noch bei leicht über 40 Prozent. Andererseits ist der Anteil der beitragsfrei mitversicherten Familienangehörigen an der Gesamtzahl der Versicherten - infolge der geringeren Kinderzahl und einer höheren Frauenerwerbsquote - in den letzten Jahren kontinuierlich gesunken. Dies führt zu einer Stärkung der Einnahmebasis der GKV, löst jedoch nicht dass Rentner-Einnahmeproblem, zumal die Rentenreform das Problem tenedenziell noch verschärfen wird.

Da die demographischen Probleme zunehmen, wird die Lösung des Problems der KVdR zur zentralen Herausforderung bei der Lösung der Finanzprobleme der GKV. Zum Solidarprinzip der GKV gehört der Ausgleich zwischen Alt und Jung. Die Frage ist allerdings legitim, ob das jetzt erreichte Ausmaß dieses Ausgleichs noch mit dem Solidarprinzip vereinbar ist. Unabhängig davon wird die Einnahmebasis mittelfristig zu überprüfen sein.

\section{Unterschiedliche Auffassungen der kostenauslösenden Steigerung der Lebenserwartung}

Hinsichtlich der Ausgabenentwicklung wirkt der Altersstruktureffekt zunächst ausgabenerhöhend; denn in der Tendenz ist mit steigendem Alter mit einer Zunahme der durchschnittlichen Gesundheitsausgaben zu rechnen. Dies muss jedoch nach Berechnungen des Sachverständigenrates für die konzertierte Aktion im Gesundheitswesen von 1994 keine dramatische Verschlechterung der finanziellen Situation in der gesetzlichen Krankenversicherung bedeuten. Bei der Einschätzung der kostenauslösenden Steigerung der Lebenserwartung existieren unterschiedliche Auffassungen. Einerseits wird bei einer zunehmenden Lebenserwartung auch ein zunehmender Bedarf an gesundheitlichen Leistungen gesehen. Andererseits muss dies nicht zwangsläufig Beitragssatzrelevante Ausgabensteigerungen auslösen, weil die größten Ausgabenblöcke in der Regel in dem letzten Lebensjahr vor dem Tod anfallen. Bei 
einer höheren Lebenserwartung wird dieser Faktor lediglich nach hinten verschoben.

\section{Investitionen in Prävention}

Das Eintreten chronischer Krankheiten kann durch Prävention und Früherkennungen hinausgeschoben werden. Damit ist es möglich, dass Perioden chronischer Erkrankungen im Lebensverlauf verkürzt werden. Die Politik muss deshalb ihre jüngsten Vorstöße zum Ausbau der Prävention auch in der nächsten Legislaturperiode verstärkt fortsetzen. Prävention ist eine der zentralen Stellschrauben bei der Abfederung und Bewältigung der demographischen Lasten.

\section{Systemwechsel bergen hohe Risiken}

Umlagefinanzierte Sozialversicherungssysteme werden oft als von der Entwicklung grundsätzlich überholt diskreditiert. Oftmals wird dabei die prinzipielle Krisenfestigkeit einer Umlagefinanzierung ausgeblendet. Verschwiegen wird häufig, dass kapitalgedeckte Systeme stets Inflationsrisiken bergen und dauerhaft rentable Kapitalmärkte voraussetzen. Beide Risiken sind auf längere Sicht ebenso unsicher prognostizierbar wie die vorgeblich unausweichliche Spreizung der Zahl zwischen Beitragszahlern und Leistungsempfängern. Selbst wenn diese Entwicklung angenommen wird, muss die Antwort eine andere als in der gesetzlichen Rentenversicherung sein. Anders als bei der kalkulierbaren Altersrente weiß niemand, wann die Leistungen der gesetzlichen Krankenversicherung anfallen - das Eintreten des Versicherungsfalles "Krankheit“ richtet sich nicht nach der Bildung eines deckenden Kapitalstocks. Hinzu kommt, dass infolge der Umstellung auf Kapitaldeckungs-Modelle nach Berechnungen von Prof. Henke ein jährlicher Stützungsbetrag von 46 Mrd. Euro entsteht. Der Annahme liegt eine Beitragsbelastung von 200 Euro für alle Versicherungsnehmer zugrunde, bei gleichzeitiger Begrenzung der individuellen Beitragszahlung auf höchstens 15 Prozent des Einkommens.

\section{Zwischenfazit zum Thema Demographie}

Der von sozioökonomischen Veränderungen ausgehende Kosten- und Beitragssatzdruck in der gesetzlichen Krankenversicherung kann vermindert werden, wenn es gelingt, die zweifellos vorhandenen Rationalisierungspotenziale $\mathrm{zu}$ erschließen, die wirtschaftlichen und arbeitsmarktpolitischen Rahmenbedingungen zu verbessern und nicht zuletzt die Prävention als gesamtgesellschaftliche Aufgabe auszubauen. Wenn chronische Erkrankungen erst im höheren Lebensalter auftreten und die 
durchschnittliche Dauer chronischer Erkrankungen verkürzt werden, verringert sich der Kostendruck. Mittel- und langfristig muss jedoch auch über neue Finanzquellen für die Krankenversicherung nachgedacht werden.

\section{Medizinisch-technischer Fortschritt}

\section{Modellrechnung}

Der medizinisch-technische Fortschritt wird häufig als eine wesentliche Ursache für die dynamische Ausgabenentwicklung angesehen. Es gibt Modellrechnungen, wonach der in Beitragssatzpunkten ausgedrückte Finanzierungsanteil für medizinisch-technische Leistungen im Jahr 2000 etwa 6 Prozentpunkte betragen habe. Bis 2040 könne dieser auf etwa 27 Prozentpunkte ansteigen. Gegenteilige Auffassungen sehen die durch den medizinisch-technischen Fortschritt ausgelöste Kostendynamik als nicht so gravierend für die Beitragssatzentwicklung an. Wenn es nämlich gelingt, mit Hilfe neuer diagnostischer und therapeutischer Verfahren den Beginn einer chronischen Krankheit hinauszuzögern oder zu vermeiden, kann dies auch zu Einsparungen führen. Es gibt bisher jedoch noch zu wenige Untersuchungen, die die genauen finanziellen Auswirkungen des medizinisch-technischen Fortschritts exakter beziffern. Sicher ist dagegen, dass die pflegerischen Leistungen stark zunehmen werden und hierdurch Kostendruck entsteht (Professionalisierung der Pflege).

\section{Leistungskatalog der GKV}

\section{Der Status quo in der GKV}

Die GKV gerät finanziell mehr und mehr unter Druck. Die Ausgaben für Gesundheit sind seit Beginn der 90er Jahre deutlich angestiegen. Weltweit wird die Bundesrepublik nur noch von den USA und der Schweiz übertroffen. Das ist das Resultat einer politischen Abkehr von einer Globalsteuerung im Gesundheitswesen. Ursächlich für die enormen Ausgaben sind insbesondere Überkapazitäten in nahezu allen Versorgungsbereichen und auf struktureller Ebene das Fehlen von Steuerungsinstrumenten. Es bestehen erhebliche Wirtschaftlichkeitsreserven, die durch die Beseitigung struktureller Mängel zu beheben sind. Auf der anderen Seite hat die GKV ein Einnahmenproblem. Hauptursachen für die Entwicklung sind hier politisch induzierte Verschiebungen zu Lasten der GKV in Milliardenhöhe und die Massenarbeitslosigkeit. An diesen Ursachen müssen Reformen ansetzen: Reformen, die aus einem umfassenden Mix diverser Optionen zu entwickeln sein werden, die den sozial- 
und gesundheitspolitischen Zielen der sozialen Krankenversicherung ebenso gerecht werden wie den Fragen von ökonomischer Effektivität und Effizienz.

\section{Leistungsfähigkeit der GKV im internationalen Vergleich}

Das deutsche Gesundheitssystem zeigt im Vergleich zu anderen Gesundheitssystemen eine Reihe von Stärken, die es gilt, auch in Zukunft zu erhalten. Dazu zählen nach wie vor die ausreichend vorhandenen modernen medizinischen Einrichtungen, eine Versorgung ohne Wartelisten, der freie Zugang zu Arzt und Krankenhaus, der umfassende Versicherungsschutz sowie ein vom Einkommen unabhängiger Leistungsanspruch für den Versicherten, der allein durch das für seine Behandlung medizinisch Notwendige definiert wird. Bei allen Reformbestrebungen gilt es, diese grundsätzlichen Strukturen und Stärken des deutschen Gesundheitssystems zu erhalten. Außerdem wird es zu einer der größten Herausforderungen zukünftiger Gesundheitspolitik gehören, die Über-, Unter- und Fehlversorgungsstrukturen im Gesundheitswesen auszugleichen.

Was wurde bis zur Koalitionsvereinbarung aktuell zur Veränderung des Leistungskataloges diskutiert?

Als eine konkrete Reformoption wird die Veränderung des Leistungskataloges immer wieder diskutiert. In einer zum Teil emotionalisierten Debatte lassen sich dabei folgende grundsätzliche Optionen ausmachen:

- Leistungseingrenzungen (z. B. auf das medizinisch unbedingt Notwendige)

- Leistungsausgrenzungen (z. B. von Bagatell-Erkrankungen, von selbstverschuldeten Erkrankungen, von aufwändigen Therapieformen etc.)

- Einführung, Ausweitung oder Differenzierung von Zuzahlungen

- Einführung von Selbstbehalten

- Aufteilung in Grund-/Regel- und Zusatz-/Wahlleistungen mit entsprechender Differenzierung der Beitragssätze (Wahltarife)

In diesem Zusammenhang wird auch über die freiwillige oder gesetzlich fixierte (Teil-)Kostenerstattung als Alternative zum Sachleistungsprinzip diskutiert. Die meisten Vorschläge zu Veränderungen des Leistungska- 
taloges in der GKV berühren die zentralen politischen Eckpfeiler der solidarischen Grundsicherung. Sie weisen einerseits vielfältige Gestaltungsvarianten auf, bergen aber andererseits auch erhebliche gesundheitliche und soziale Risiken. Leistungsausgrenzungen, z. B. von Bagatell-Erkrankungen, und gleichzeitige Eigenfinanzierung durch den Versicherten können dazu führen, dass Arztkontakte hinausgeschoben werden. Verschlechtert sich dann der Gesundheitszustand des Patienten, können die Folgekosten wesentlich höher sein, als wenn frühzeitig eine Behandlung stattgefunden hätte. Ihre konkrete Ausgestaltung hängt von ordnungspolitischen, sozialpolitischen und gesundheitspolitischen Abwägungen $a b$. Je nach Motivationslage werden der ökonomische Anreizeffekt, der Anreiz zu gesundheitspolitisch erwünschtem Verhalten oder die fiskalische Wirkung im Vordergrund stehen.

\section{Grund- und Wahlleistungen sind keine Alternative}

Wenn die Ursachen für finanzielle Engpässe in der GKV am wenigsten im inhaltlichen Zuschnitt des medizinischen Leistungsangebotes zu suchen sind, ist die Einführung von Grund- und Wahlleistungen keine Lösungsoption. Darüber hinaus sind konkrete und detaillierte Vorschläge bis heute nicht in die öffentliche Diskussion gelangt, was angesichts der sich aufdrängenden Fragestellung nachvollziehbar ist. Was ist der solidarische Kernleistungsbereich? Nach welchen Kriterien soll eine Eingrenzung des Leistungskataloges vorgenommen werden? Wer definiert den Kern- bzw. Wahlleistungsbereich - der Gesetzgeber, die gemeinsame Selbstverwaltung oder der Markt? Wer passt wann unter welchen Voraussetzungen den solidarisch zu finanzierenden Kernleistungsbereich an?

Ziel darf es nicht sein, das Solidaritätsprinzip der GKV zur Disposition zu stellen. Versicherte mit hohem Gesundheitsrisiko dürfen nicht zugunsten Junger und Gesunder überbelastet werden.

\section{Die entscheidende Frage: Was ist medizinisch sinnvoll und notwendig?}

Nicht das derzeitige Leistungsangebot der GKV in seiner inhaltlichen Ausprägung ist das Problem, sondern die Frage seiner medizinisch sinnvollen und notwendigen Anwendung.

Es steht nicht zur Diskussion, ob z. B. Herzkatheter-Untersuchungen von der GKV finanziert werden sollten oder nicht. Vielmehr stellt sich die Frage, in welchen Fällen und wie oft solche Untersuchungen medizinisch sinnvoll und notwendig sind. Muss in Deutschland tatsächlich medizinisch notwendig ein Herzkatheter 160 Prozent häufiger gelegt werden 
als in Frankreich? Vor dem Hintergrund bestehender personeller und sächlicher Überkapazitäten in nahezu allen Versorgungsbereichen ist zu entscheiden, was medizinisch sinnvoll und was für Mediziner sinnvoll ist.

Selbstverwaltung der GKV muss die bedarfsgerechte und medizinisch notwendige Versorgung sichern

Die subsidiäre Verantwortungszuweisung an die Organe der Selbstverwaltung bietet die passende Grundlage dafür, eine bedarfsgerechte und medizinisch notwendige Versorgung zu sichern. Die Bundesausschüsse der Selbstverwaltung benötigen allerdings eine höhere Rechtssicherheit für ihre Entscheidungen.

\section{Keine Staatsmedizin}

Die Koalitionsvereinbarung sieht ein deutsches Zentrum für Qualität in der Medizin vor, um „einen dynamischen Prozess der Fortentwicklung der medizinisch-pflegerischen Standards und der Einbeziehung neuer Erkenntnisse zu gewährleisten". Wenn ein solches Institut die fachliche Grundlage für Entscheidungen der Bundesausschüsse der Selbstverwaltung im Sinne eines präzisen Steuerungsinstrumentes darstellt, ist das zu begrüßen. Eine klare Absage ist allerdings einem staatlichen Institut zu erteilen, mit dem gewissermaßen per Staatsmedizin die medizinische Versorgung in Deutschland verordnet werden soll. Die Institutionen der gemeinsamen Selbstverwaltung haben die Kompetenz, im Spannungsfeld der verschiedenen Interessen die notwendigen Entscheidungen zu treffen.

\section{Krankenkassen als Makler}

Den Krankenkassen sollte die Möglichkeit gegeben werden, Leistungen, die aus dem Leistungskatalog der GKV ausgegrenzt sind oder für die Versicherte besondere Präferenzen haben, über eine Zusatzversicherung in eigener Trägerschaft oder in Kooperation mit privaten Versicherungsgesellschaften anzubieten. Ein erster Schritt ist die Vorstellung, den Krankenkassen eine Maklerfunktion bei der Vermittlung von Zusatzversicherungsangeboten einzuräumen.

Gesamtgesellschaftliche Leistungen sind aus dem GKV-Leistungskatalog auszuschließen

Sämtliche gesamtgesellschaftlichen bzw. familienpolitischen Leistungen wie Mutterschaftsgeld, Leistungen der Empfängnisverhütung oder auch Krankengeld bei Erkrankung eines Kindes müssen unmittelbar aus 
Steuern finanziert werden. Allein hierdurch würde die GKV um ca. 2 Mrd. Euro jährlich entlastet.

\section{Präventionsleistungen ausbauen}

Es muss nicht immer darüber diskutiert werden, welche Leistungen ausgegrenzt werden sollen, sondern es muss auch darüber diskutiert werden, ob es nicht Leistungen gibt, bei denen es lohnt, sie einzuführen oder weiter auszubauen. So müssen z. B. die Leistungen der Prävention ausgebaut werden. Das Eintreten chronischer Krankheiten kann durch Prävention und Früherkennung hinausgeschoben werden, und damit können Perioden chronischer Erkrankungen im Lebensverlauf verkürzt werden. Die Politik muss deshalb ihre jüngsten Vorstöße zum Ausbau der Prävention auch in der nächsten Legislaturperiode verstärkt fortsetzen. Prävention ist eine der zentralen Stellschrauben bei der Abfederung und Bewältigung der demographischen Lasten.

\section{Vertragswettbewerb ausbauen}

Der Wettbewerb um die beste Versorgung (einschließlich der dazu notwendigen Leistungen) muss durch die Intensivierung des Vertragswettbewerbes forciert werden. Dabei wird die Vertragsfreiheit schrittweise durch einen Wegfall der Verpflichtung zum einheitlichen und gemeinsamen Handeln und einer Lockerung des Kontrahierungszwanges bei den Krankenkassen und Leistungserbringern eingeführt. Bedarfsplanung, administrierte Zulassungen oder budgetierte Gesamtvergütungen können in dem Maße zurückgeführt werden, indem die Vertragspartner Verantwortung für die Ausgestaltung und Steuerung der Versorgung übernehmen. Sicherstellungs- und Gewährleistungsaufträge müssen auf die Funktionsfähigkeit als Ganzes beschränkt werden. Die Einhaltung von Qualitätsstandards und Versichertenrechten sowie die Sicherung des Wettbewerbes obliegt der staatlichen Aufsicht, ebenso wie der Schutz vor Diskriminierung, Kartellbildung und Monopolisierung. Auch für den Ausbau des Vertragswettbewerbes müssen die wettbewerblichen Rahmenbedingungen in der GKV bestehen bleiben. Aus diesem Grunde ist der Risikostrukturausgleich nach wie vor unverzichtbar, vor allem die Weiterentwicklung zu einem morbiditätsorientierten Risikostrukturausgleich. 


\section{Leistungskatalog der gesetzlichen Krankenversicherung im Wandel - Anmerkungen aus praktischer Sicht}

Jürgen Bausch

Da kein umfassendes Referat, sondern nur eine Anmerkung zum Thema vorgesehen ist, seien hier drei aktuelle Punkte vorgestellt:

\section{Therapiehinweis Sondennahrung}

Der Bundesausschuss Ärzte/Krankenkassen hatte nach langer Vorbereitung und nach Industrie- und Sachverständigenanhörungen im Frühjahr 2002 zur rationellen und rationalen Verordnung von Sondennahrungen in der ambulanten kassenärztlichen Versorgung einen Therapiehinweis verabschiedet und dem aufsichtsführenden Ministerium (BMG) zur Genehmigung vorgelegt.

Die Beratungen des Arbeitsausschusses zu diesem Thema waren von Beginn an begleitet von heftiger Kritik aus dem Lager der Industrie, bestimmter Ernährungsexperten mit Industrienähe und von AngehörigenOrganisationen von Patienten, die auf Sondennahrungen angewiesen sind (und offenkundig - wie so viele Patientenorganisationen - nicht ohne Industriesponsoring agieren).

Bis zum Vorwurf der Euthanasie und Nazi-Ideologie ist den Mitgliedern des Arbeitsausschusses nichts erspart geblieben, was in die unterste Kiste von Gegenargumentationen gehört, wenn es um wirtschaftliche Interessen geht. Dieser agitatorische Druck wurde auch auf das BMG ausgeübt. (Und wie üblich wurde kräftig mit dem Leichentuch gewunken.)

Das BMG hat sich mit der Genehmigung der Vorlage zwei Monate Zeit gelassen und diese dann nicht genehmigt mit der Maßgabe, ein HTA(Health-Technology-Assessment)-Gutachten müsse erst noch angefertigt werden. Wer dabei daran denkt, das habe nichts mit dem Bundestagswahlkampf zu tun, bei dem das Ministerium eventuell in die Schusslinie der Gegner des Therapiehinweises hätte kommen können, wird unfreundlich behandelt. Fakt ist, das BMG behindert mit einer solchen Vorgehensweise - aus welchen Motiven auch immer - einen Therapiehinweis der gemeinsamen Selbstverwaltung zum wirtschaftlichen Umgang mit Sondennahrungen. 


\section{Positivliste}

Das Schicksal der ersten Positivliste unter Seehofer ist bekannt. Die Positivliste Nr. 2 wurde fristgerecht und planmäßig im Frühsommer 2002 offiziell dem zuständigen Staatssekretär übergeben, damit daraus eine Rechtsverordnung gefertigt werden konnte. Bei dieser Übergabe machte der Vertreter des BMG keinen besonders erfreuten Eindruck und wirkte durch den Vorgang eher belastet. Die Rechtsverordnung ist bis zum 22.09.2002 allenfalls in unsichtbarer Weise BMG-intern vorangetrieben worden. Man darf gespannt sein, ob und wann Ärzte und Kassen Hilfe und Unterstützung bei ihren Arzneimittelverordnungen durch die Positivliste bekommen, während zeitgleich aus dem gleichen Hause die Ärzte mit dem Vorwurf "unverantwortliche Verordnungsweise" konfrontiert werden.

\section{Orphan Drugs}

Im Arzneiverordnungs-Report 1998 gibt Prof. Schwabe besonders deutliche Hinweise an die Adresse von Politik und Kassen, dass sich bei einer von inm so genannten Gruppe von „Spezialpräparaten" eine dynamische Ausgabenentwicklung ankündigt. Obwohl Prof. Schwabe Recht behalten hat, wie der Arzneiverordnungs-Report 2002 zeigt, hat niemand in der Politik und bei den Krankenkassen auf diese Situation mit gegensteuernden Maßnahmen reagiert.

Die Graphik über die Entwicklung der Ausgaben für die Therapie angeborener Stoffwechselerkrankungen, festgemacht am Beispiel der nephropathischen Zystinose und des Morbus Gaucher in Hessen, zeigt im Jahresvergleich 2000 zu 2001 den Beginn einer weiteren kostenträchtigen Therapierichtung mit neuen innovativen Arzneimitteln, die den Orphan Drugs zugeordnet werden.

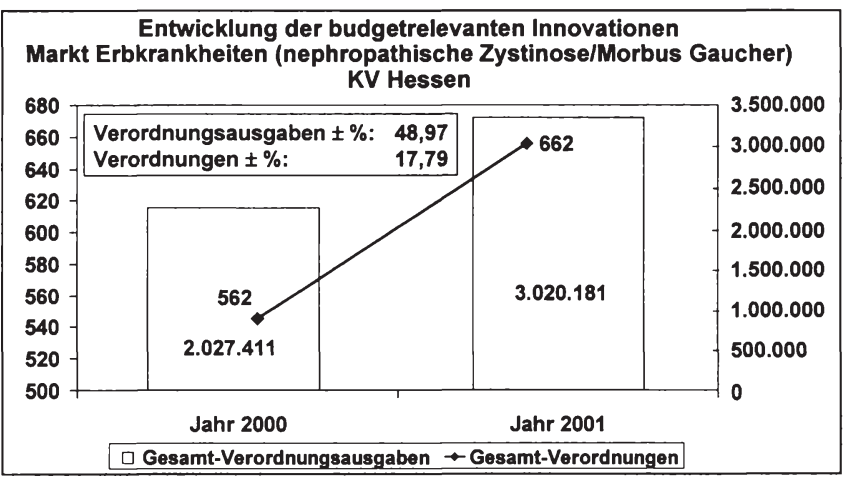


Für wenige Patienten und bei nur wenigen Verordnungen entstehen extrem hohe Kosten. Die Therapie mit Alglucerase zur Behandlung des Morbus Gaucher kann pro Patient und Jahr bis zu 400.000 Euro kosten, dürfte sich aber in der Regel, zumindest bei Kindern, auf 200.000 Euro belaufen. (Die starken Kostenschwankungen ergeben sich durch dosisabhängige Therapien im individuellen Krankheitsfall.) Die Therapie ist über lange Jahre, vermutlich lebenslang, erforderlich.

Das gleiche gilt für eine neue Therapie des Morbus Fabry, einer weiteren Speicherkrankheit. Die beiden wirksamen Präparate behandeln erstmalig und kausal dieses angeborene Leiden, welches in der Regel rund um das 40. Lebensjahr zu Herz- und Nierenversagen führt. Agalsidase $\alpha$ und $\beta$ wurden 2001 zugelassen. Die Jahrestherapiekosten liegen bei exorbitanten 260.000 Euro (AVR 2001).

Demnächst soll eine EMEA-Zulassung zur Therapie des Morbus Pompe erteilt werden; eine weitere seltene Speicherkrankheit des Kindesalters. Die Jahrestherapiekosten werden von sachkundigen Beobachtern der Szene auf 500.000 Euro prognostiziert.

Aus Zeitgründen wurde auf eine umfassende Darstellung der Problematik mit weiteren Orphan Drugs in diesem Kontext verzichtet. Es bleibt jedoch festzuhalten: Wir stehen, wie bei den Spezialpräparaten vor einigen Jahren, die inzwischen 15,8 Prozent des Gesamtverbrauchs an Arzneimitteln in Deutschland ausmachen, an der Schwelle einer neuen, kostenträchtigen Entwicklung, die eine große Herausforderung für die Politik und die Krankenkassen darstellen wird. Hier sind rechtzeitige Gegenmaßnahmen zwingend geboten! Auch wenn es sich um seltene bis extrem seltene genetisch bedingte Erkrankungen handelt, die bislang unbehandelbar waren und zu frühem Tod oder langem Siechtum führten, ist Handlungsbedarf geboten, denn die Substitution eines angeborenen Gendefekts durch ein Medikament muss in der Regel lebenslang erfolgen und befähigt den Menschen im Erfolgsfall, ein einigermaßen gesundes Leben zu führen. Dies erzwingt automatisch die Frage nach der genetischen Beratung mit der Zielsetzung, den Gendefekt nicht weiter zu vererben und damit weitere kostenträchtige Lebensbehandlungen zu provozieren. Auf die damit in Verbindung stehenden ethischen und moralischen Probleme wird absichtlich nicht eingegangen. 
Manfred Albring and Eberhard Wille - 978-3-631-75562-4

Downloaded from PubFactory at 01/11/2019 03:33:01AM

via free access 


\section{Der Leistungskatalog der GKV im Wandel - Anmerkungen aus praktischer Sicht}

Klaus Jacobs

Erlauben Sie mir zunächst eine persönliche Vorbemerkung. Ich bin seit nunmehr einem guten halben Jahr Geschäftsführer des Wissenschaftlichen Instituts der AOK und habe mich mittlerweile an die damit verbundene "doppelte Identität" gewöhnt: Mal gelte ich eher als Praktiker und mal eher als Wissenschaftler - oder etwas drastischer ausgedrückt: mal als "Kassenfuzzi“ und mal als "realitätsferner Expertokrat". Ich sehe dies jedoch grundsätzlich positiv, denn offenbar bewege ich mich unmittelbar an der höchst spannenden Schnittstelle zwischen Praxis und Wissenschaft. Ich glaube auch, dass kein unüberbrückbarer Gegensatz zwischen der vorherrschenden Handlungsorientierung der Praxis, einschließlich der Politik, und der primären Erkenntnisorientierung der Wissenschaft besteht. Vielmehr bemühe ich mich, beide Orientierungen möglichst eng miteinander zu verknüpfen $-d$. h. analytisch und empirisch fundierte Erkenntnisse im Hinblick auf handlungsrelevante Fragen zu gewinnen. Dabei gilt es, die tatsächlichen Freiräume der handelnden Akteure sowie ihre vielfältigen Handlungsrestriktionen von vornherein mit zu berücksichtigen.

\section{Fortbestand der solidarischen Finanzierung}

Hieraus ergeben sich unmittelbare Konsequenzen in Bezug auf die aktuelle Reformdiskussion über die Ausgestaltung der GKV-Finanzierung, und zwar insbesondere hinsichtlich der weiteren Verankerung des Solidarprinzips bzw. - etwas wissenschaftlicher formuliert - bei der Verortung und Ausgestaltung von Umverteilungsaufgaben, die über die versicherungsimmanente Umverteilung zwischen schadensfreien Versicherungsnehmern und solchen, die einen Schaden erleiden, hinausreichen. In der gesetzlichen Krankenversicherung zählen hierzu im Wesentlichen die Aufgaben der Einkommensumverteilung in Gestalt einkommensproportionaler Beiträge, die beitragsfreie Familienmitversicherung sowie die Abwesenheit alters-, geschlechts- und morbiditätsspezifischer Beitragsdifferenzierungen.

Die derzeit vor allem von manchen Wissenschaftlern favorisierten Kopfprämien-Modelle, bei denen - je nach Modell - einige oder sogar alle dieser dezidiert sozialpolitisch motivierten Umverteilungsaufgaben aus der GKV herausgenommen und stattdessen im Steuersystem wahrgenommen werden sollen, mögen im Einzelfall theoretisch noch so beste- 
chend sein - sie befinden sich $\mathrm{m}$. E. eindeutig außerhalb der Grenzen des in absehbarer Frist politisch Mach- und auch Wünschbaren. Dies gilt ganz besonders angesichts der weithin desolaten Haushaltslage aller Gebietskörperschaften. Wer vor diesem Hintergrund ernsthaft dafür plädiert, dem Steuersystem zusätzliche Umverteilungsaufgaben in einer Größenordnung zwischen rund 20 und 35 Mrd. Euro aufzubürden, setzt sich selbst dem Verdacht aus, dass es letztlich wohl kaum um eine bloße Verlagerung von Umverteilungsaufgaben geht, sondern zugleich um deren massiven „Rückbau“. Schließlich erfordert die Erwartung, dass ein derart umfängliches Finanzvolumen permanentes Objekt der Begierde der verantwortlichen Finanzpolitiker werden dürfte, kaum ein besonders großes Maß an Phantasie. Damit - und das wird offenkundig vielfach übersehen - könnte aber zugleich auch die Stabilität der beitragsfinanzierten Gesundheitsversorgung gefährdet werden, wenn nämlich einkommensschwache Versicherte mangels ausreichender steuerfinanzierter Unterstützung ihre Beiträge nicht mehr entrichten können - auch für den "Zukunftsmarkt Gesundheit" ganz sicher keine verlockende Perspektive.

Die kritische Bewertung des Vorschlages, die GKV von vermeintlich störenden Umverteilungsaufgaben zu befreien und diese in das Steuersystem zu verlagern, bedeutet jedoch keineswegs ein unverändertes Festhalten am Status quo der GKV-Finanzierung. Vielmehr liefern gerade die derzeit u. a. von den Professoren Henke, Knappe, Rürup oder Zweifel vorgeschlagenen Kopfprämien-Modelle durchaus einige wertvolle Hinweise für eine zielgerichtete Weiterentwicklung des bestehenden Finanzierungskonzeptes, bei der am Grundsatz der GKV-internen Wahrnehmung zentraler Umverteilungsaufgaben festgehalten wird.

Dies gilt zunächst für die Abgrenzung des Personenkreises, der an der solidarischen Finanzierung beteiligt wird, denn bei einer steuerfinanzierten Umverteilung ist grundsätzlich - von unterschiedlichen Möglichkeiten der individuellen Steuerbefreiung einmal abgesehen - keine Bevölkerungsgruppe von vornherein „außen vor", also insbesondere auch nicht die Beamten, die Selbstständigen oder besser verdienende Arbeitnehmer, die derzeit bekanntlich ab einer naturgemäß völlig willkürlichen Einkommensgrenze nach individuellem Kalkül entscheiden können, ob sich die Beteiligung am Solidarausgleich der GKV für sie lohnt oder nicht.

Dies gilt aber auch für die Operationalisierung des Leistungsfähigkeitsprinzips, die bei der Einkommensbesteuerung nicht auf Einkünfte aus abhängiger Beschäftigung bis zu einer bestimmten Höchstgrenze begrenzt bleibt, sondern sämtliche Einkommensarten vollständig zugrunde legt. Und dies gilt schließlich auch für die Möglichkeit einer differenzier- 
ten Berücksichtigung der spezifischen Familienkonstellation anstelle einer pauschalen Beitragsbefreiung von Kindern und nichterwerbstätigen Ehepartnern, unabhängig vom jeweiligen Haushaltseinkommen.

\section{Reformnotwendigkeiten im System}

Entsprechende Reformmöglichkeiten bestehen grundsätzlich auch bei einer Weiterentwicklung der GKV-Finanzierung. Dabei können praktische Probleme - etwa bei der Einbeziehung weiterer Einkommensarten in die Beitragsbemessung - kein hinreichender Grund sein, auf die damit verbundene Entlastung des Großteils der Arbeitseinkommen dauerhaft zu verzichten. Auch vermag der Hinweis, dass die GKV bei einer stärker der Einkommensbesteuerung angenäherten Beitragsbemessung und ggf. auch -erhebung endgültig ihren Versicherungscharakter verlieren würde, nicht zu überzeugen.

Abgesehen von der Einkommensersatzleistung Krankengeld gibt es bei der GKV - im Übrigen im grundlegenden Unterschied zur Rentenversicherung - ohnehin keine individuelle Äquivalenzbeziehung zwischen Beitragszahlung und Leistungsanspruch, auf die besondere Rücksicht genommen werden müsste. Und ob die GKV - schon heute oder nach entsprechenden Finanzierungsreformen "erst recht" - noch in hinreichendem Maße der reinen Versicherungslehre entspricht oder nicht, scheint für die praktische Bewertung von deutlich nachgeordneter Bedeutung. Vielleicht könnte man die Diskrepanz zwischen Theorie und Praxis auch einmal von der anderen Seite her zu verringern versuchen, indem zum Beispiel die einschlägigen Lehrbücher um ein zusätzliches Kapitel „Sozialversicherung mit Umverteilungsfunktionen“ ergänzt werden.

Zwischenfazit: Das Prinzip der solidarischen Finanzierung ist ein prägendes Merkmal der GKV und sollte auch im Interesse des längerfristigen Erhalts einer breiten Akzeptanz der GKV in der Bevölkerung nicht zur Disposition gestellt werden. So ist aus Versichertenbefragungen bekannt, dass sich gerade der dezidierte Solidarcharakter der GKV hoher Wertschätzung erfreut. Gleichwohl sind Weiterentwicklungen nicht nur möglich, sondern unbedingt notwendig. Dabei würde die Erweiterung von einbezogenem Personenkreis, Bemessungsgrenzen und -grundlagen nicht nur die Verteilungsgerechtigkeit erhöhen, sondern zugleich eine Entlastung der Arbeitskosten bewirken und wäre somit auch beschäftigungspolitisch erwünscht. Ob bzw. ggf. in welcher Form der Arbeitgeberbeitrag bei einer derartigen Weiterentwicklung der GKV in Richtung Bürgerversicherung überleben würde, kann hier nicht geson- 
dert behandelt werden; Tabus darf es aber auch in dieser Frage nicht geben.

Wichtig erscheint zudem, dass eine konsequente Finanzierungsreform der GKV, bei der zwar nicht die sozialpolitischen Umverteilungsaufgaben aus der GKV ausgelagert werden, wohl aber deren Finanzierung - innerhalb der GKV -, deutlich „einkommensteuernäher" erfolgt, nicht nur zu verteilungs- und beschäftigungspolitisch erwünschten Resultaten führt, sondern auch zu einer Verringerung der insbesondere von Professor Raffelhüschen herausgestellten demographisch bedingten Probleme beitragen würde. Dazu muss jedoch zunächst betont werden, dass diese Probleme auch nicht übertrieben werden dürfen. Denn anders als die Rentenversicherung ist die Krankenversicherung keineswegs in erster Linie durch eine Umverteilung zwischen "Generationen" gekennzeichnet, sondern durch die Umverteilung zwischen Gesunden und Kranken aller Altersgruppen. Bekanntlich entfallen rund 80 Prozent der Leistungen auf etwa 20 Prozent der Versicherten.

Auch wenn in den höheren Altersgruppen vergleichsweise mehr "Hochkosten-Versicherte" sind als in den jüngeren, ändert sich bei einer alternden Bevölkerung nichts an dem Grundprinzip, dass durch die Beitragszahlungen aller Versicherten die Schadensfälle eines eher kleinen Teils der Versicherten finanziert werden. Umverteilungswirkungen zwischen "Generationen" wirken deshalb - wenn man diese Perspektive überhaupt akzeptieren will - bestenfalls indirekt. Durch Finanzierungsreformen in der eben skizzierten Richtung - insbesondere im Hinblick auf die Berücksichtigung aller Einkommen bei der Beitragsbemessung würden sie zudem ein Stück zugunsten der jüngeren Versicherten verschoben, weil die Bedeutung weiterer Einkommen neben dem „Primäreinkommen" mit dem Alter merklich zunehmen dürfte - ein erklärtes Ziel der Rentenpolitik ist es ja gerade, die Absicherung im Alter auf möglichst viele „Säulen“ zu stellen.

\section{Solidarität und Wettbewerb}

Wenn innerhalb der GKV auch weiterhin sozialpolitisch motivierte Umverteilung erfolgen soll, hat dies unmittelbare Auswirkungen für die Ausgestaltung der Wettbewerbsordnung. Hierzu zählt zunächst die Notwendigkeit eines Risikostrukturausgleiches, der wirksam verhindert, dass unterschiedliche Anteile der Kassen an den GKV-weiten Solidaraufgaben zu Beitragssatzverzerrungen führen und entsprechend falsche Anreize für das Kassenhandeln setzen. Dies gilt übrigens auch im „Kopfprämien-System" der Schweiz, wo es zwar keine Einkommensumverteilung innerhalb der Krankenversicherung gibt, Risikoselektion nach Alter, 
Geschlecht und Morbidität der Versicherten aber ebenfalls möglichst weitgehend ausgeschlossen werden muss, um einen funktionalen Wettbewerb um Qualität und Wirtschaftlichkeit der Versorgung zu ermöglichen. Und auch im "Henke-Modell" der Vereinte Krankenversicherung gibt es einen - im Übrigen morbiditätsorientierten - Risikostrukturausgleich.

Die weitere Aufrechterhaltung eines originären Solidarauftrages in der GKV führt allerdings unzweifelhaft auch dazu, dass bei bestimmten Wettbewerbsparametern von vornherein Abstriche gemacht werden müssen. Dies gilt insbesondere im Hinblick auf Leistungs- und Tarifdifferenzierungen. Das Prinzip der solidarischen Finanzierung erfordert zwangsläufig einen einheitlichen Leistungskatalog - wie und durch wen dieser letztlich auch konkret definiert wird. Insbesondere muss auch der Forderung nach mehr Handlungsfreiräumen der Kassen durch eine Ausdifferenzierung ihrer Satzungsleistungen außerhalb der Berücksichtigung im RSA eine Absage erteilt werden, weil dies sofort zu einem Einfallstor für Wettbewerbsverzerrungen und Risikoselektion würde, wie sie durch den RSA gerade verhindert werden sollen.

Gleichwohl ist es unzutreffend $z u$ behaupten, dass in einem sozialen Krankenversicherungssystem - also in einer Krankenversicherung mit sozialpolitisch motivierten Umverteilungsaufgaben - sinnvoller Wettbewerb von vornherein unmöglich wäre. So gibt es - wenngleich begrenzt - sehr wohl Möglichkeiten zu solidarverträglichen Tarifdifferenzierungen, die weiter ausgelotet werden sollten. Ob bereits die derzeit gehandelten Bonus-Tarife der Weisheit letzter Schluss sind $-z$. B. für die Teilnahme an bestimmten Präventionsmaßnahmen -, muss allerdings eher skeptisch beurteilt werden. Zumindest erscheint zweifelhaft, ob die in Aussicht gestellten Bonuszahlungen tatsächlich über programmspezifische Minderausgaben finanziert werden können und nicht etwa durch andere Beitragszahler, die entsprechend höher belastet würden. Gleichwohl ist es allemal besser, wenn der Gesetzgeber den Kassen entsprechende Gestaltungsfreiräume einräumt und es innen überlässt, inwieweit sie diese zu nutzen gedenken, statt selbst dirigistische Regelungen GKV-weit vorzuschreiben.

\section{Differenzierte Tarif- und Versorgungsangebote}

Wenn der Wettbewerb in erster Linie dazu beitragen soll, Qualität und Wirtschaftlichkeit der Gesundheitsversorgung zu verbessern, sollte die Wirkung individueller Steuerungselemente, die auf eine zurückhaltende Leistungsinanspruchnahme der Versicherten abzielen (,Stärkung der Eigenverantwortung"), allerdings nicht überschätzt werden. Die bereits ge- 
nannte Zahl zur Verteilung des Großteils der Gesundheitsausgaben auf einen relativ kleinen Anteil der Leistungsberechtigten macht deutlich, dass die maßgeblichen Potenziale für Qualitäts- und Wirtschaftlichkeitsreserven weniger bei der Masse der "normalen" Versicherten, sondern vielmehr bei der Versorgung von teuren Kranken liegen, und zwar von chronisch wie akut erkrankten Patienten. Bei diesen dürfte die Fähigkeit zur gezielten Einflussnahme auf das Behandlungsgeschehen im Sinne einer möglichst hohen Gesamteffizienz der Versorgung jedoch von vornherein äußerst begrenzt sein. Entscheidend ist vielmehr eine in sich abgestimmte, sektorübergreifende Organisation der Gesamtversorgung, die auf die spezifischen Bedürfnisse der Patienten ausgerichtet ist und diese davor bewahrt, orientierungslos im unübersichtlichen Versorgungsdschungel verloren zu gehen - natürlich nicht, ohne in aller Regel mit einem Höchstmaß an diagnostischen und therapeutischen Leistungen ausgestattet zu werden.

Um nicht missverstanden zu werden: Ich beurteile solidarverträgliche Ansätze zur individuellen Steuerung der Leistungsinanspruchnahme keineswegs rundweg negativ, zumal auch viele Versichertenbefragungen auf eine vergleichsweise hohe Akzeptanz entsprechender Instrumente verweisen. Ich halte aber den Stellenwert, den die öffentliche Diskussion z. B. über Selbstbehalte und Bonuszahlungen derzeit einnimmt, für eindeutig überzogen. Diese Diskussion birgt insbesondere die Gefahr, von einer anderen Reformbaustelle abzulenken, der ich weitaus mehr Bedeutung im Hinblick auf eine Erhöhung von Qualität und Effizienz der beitragsfinanzierten Gesundheitsversorgung beimesse: der Förderung von integrierten Versorgungsmodellen auf der Grundlage eines lebhaften Vertragswettbewerbes zwischen Krankenkassen und Leistungsanbietern auf einzelwirtschaftlicher Ebene, also unterhalb verpflichtender Kollektivstrukturen korporativer Institutionen, aber über die starren Grenzen der tradierten Versorgungssektoren hinweg.

Diese m. E. zentrale Reformperspektive bietet zugleich beträchtliche Freiräume für individuelle Wahlentscheidungen der Versicherten in Bezug auf die Ausgestaltung ihres Versicherungsschutzes. Zwar kann die Abgrenzung des Leistungskataloges in einem solidarisch finanzierten System nicht individuell vorgenommen werden, aber die Art und Weise der Leistungserstellung und -abgabe kann sehr wohl unterschiedlich erfolgen und von den Versicherten nach ihren individuellen Präferenzen im Rahmen differenzierter Tarifangebote gewählt werden. Auf der Ebene versorgungsnaher Managed-Care-Modelle - und nicht in gesetzlich fixierten Globalregelungen - liegt auch der richtige Ansatzpunkt für die sinnvolle Implementierung von Gatekeeping-Strukturen und gezielten Präventionsmaßnahmen. Die Referate und Diskussionsbeiträge zum 
dritten Themenkreis dieser Tagung werden sich gezielt mit dieser Reformbaustelle befassen.

Mir bleibt einstweilen zusammenzufassen: Solidarität und Wettbewerb mit individuellen Wahlfreiheiten der Versicherten können in der GKV eine durchaus Erfolg versprechende Zukunft haben. Voraussetzung ist allerdings zum einen die gezielte Weiterentwicklung der Finanzierungsstrukturen in der skizzierten Richtung, die zugleich auch zu einer Entlastung der Arbeitskosten führt, und zum anderen die konsequente Flexibilisierung des Vertragsrechtes, einschließlich des spürbaren Rückbaus von plan- und kollektivwirtschaftlichen Steuerungsstrukturen, deren Fortbestand die Herausbildung flexibler Wettbewerbslösungen bereits im Keim ersticken würde. Eine Reform ohne einen dieser beiden zentralen Reformansätze bliebe einmal mehr Stückwerk.

\section{Weiterführende Veröffentlichungen}

Jacobs, Klaus, und Schellschmidt, Henner: Äquivalenz, Leistungsfähigkeit und Solidarität - Konturen einer GKV-Finanzierungsreform. In: G+G Wissenschaft 3/2002, S. 15-22.

Jacobs, Klaus, und Schräder, Wilhelm F.: Wettbewerb als Motor der Integration? In: Arnold/Klauber/Schellschmidt (Hrsg.), Krankenhaus-Report 2002, Schattauer: Stuttgart 2002, S. 103-112. 
Manfred Albring and Eberhard Wille - 978-3-631-75562-4

Downloaded from PubFactory at 01/11/2019 03:33:01AM

via free access 


\section{Themenkreis 2}

\section{Einnahmenschwäche in der GKV}

Eckhard Schupeta

Unser Themenkomplex lautet „Einnahmenschwäche in der GKV“. Warum gibt es hier Handlungsbedarf?

\section{Wir erleben eine strukturelle Schwäche der Einkommen aus Arbeit}

Die GKV-relevanten beitragspflichtigen Einnahmen stagnieren. Die Auswirkungen der Globalisierung, eine arbeitskräftebezogene Vorwegnahme der EU-Erweiterung, spielen hier eine Rolle. Gerade bei mittleren und unteren Einkommen, nämlich unterhalb der Beitragsbemessungsgrenze, macht sich diese Schwäche bemerkbar.

Veränderte Arbeitsverhältnisse und Berufskarrieren schlagen sich in dieser Entwicklung ebenfalls nieder. Es gibt eine Zunahme der Teilzeitarbeit. Nichtversicherungspflichtige Werkverträge nehmen zu.

Die Tendenz zu Frühverrentungen, eine längere Lebens- und Rentenbezugszeit trägt zur Einnahmenschwäche bei. Jüngst hinzugekommen ist die Zunahme nichtbeitragspflichtiger Entgeltanteile im Wege der „Umwandlung" von Einkommen durch die Riester-Rente.

Setzt man das Jahr $1980=100$, dann hat sich das Bruttoinlandsprodukt im Jahre 2000 auf 215 entwickelt, die beitragspflichtigen Einnahmen aber nur auf 184. Die Lohnquote hat sich von 74 Prozent (1980) auf 65 Prozent (2001) zurückentwickelt. Der heutige Durchschnittsbeitragssatz der GKV von 14,1 Prozent würde bei konstanter Lohnquote bei 11,4 Prozent liegen.

\section{Es findet ein Wechsel von GKV-Versicherten in die PKV statt}

Im Jahre 1997 wechselten 316.000, 4 Jahre später (2001) waren es 360.000 - Tendenz steigend. Die Rückwechslerzahl liegt konstant bei ca. 150.000 .

Der finanzielle Saldo dieser Wanderung (Finanzierungsentzug - Leistungen bereits berücksichtigt) liegt bei 0,5 Mrd. Euro jährlich - Tendenz ebenfalls steigend. 


\section{Verschiebebahnhöfe}

Die Politik der finanziellen Umschichtungen vom Staatshaushalt auf die Sozialversicherungshaushalte und innerhalb der Sozialversicherung zu Lasten der gesetzlichen Krankenversicherung ist nicht zum Erliegen gekommen. Begonnen hat diese Politik in den 70er Jahren. Davor galt der Grundsatz, dass jede Sparte der Sozialversicherung für den entsprechenden Risikokomplex (Krankheit, Alter, Arbeitslosigkeit etc.) autonom zu finanzieren ist.

In den Jahren 1995 bis 2003 summiert sich der „Beitragsklau“ auf rund 30 Mrd. Euro. Allein für die Jahre 2002/2003 wird jährlich eine zusätzliche Belastung von etwa 5 Mrd. Euro geschätzt.

Der Anstieg der Sozialversicherungsquote seit 1995 von etwa 35 Prozent auf 41 Prozent im Jahre 2002 geht zu zwei Dritteln auf diese Verschiebebahnhofspolitik zurück.

\section{Die Finanznot der GKV geht auch auf versicherungsfremde Leistungen zurück}

An Ausgaben für versicherungsfremde Leistungen im engeren Sinne (Haushaltshilfe, Krankengeld bei Erkrankung des Kindes, Mutterschaftsgeld, Sterbegeld z. B.) gibt Beske eine Summe von 2,3 Mrd. Euro (1997) an. Im weiteren Sinne (beitragsfreie Mitversicherung von Familienangehörigen [im Jahre 2000: 28,6 Prozent der Versicherten]) muss mit ca. $30 \mathrm{Mrd}$. Euro gerechnet werden (ebenfalls Stand 1997).

Die folgenden Beiträge beziehen sich allesamt auf dieses Szenario: Einnahmenschwäche.

Ich möchte aber betonen, dass alle Ansatzpunkte, die von den Referenten herausgearbeitet werden, keine Alternative zum Sparen in der GKV darstellen. Würde man die Finanzierung erweitern, käme dies einer Subventionierung von Unwirtschaftlichkeit gleich. Erst wenn alle Ersparnisse ausgeschöpft sind, was im gegenwärtigen System nicht der Fall ist, stellt sich die Frage, ob die Finanzierung der GKV erweitert werden muss oder ob eine Reduzierung von Ansprüchen („Leistungskatalog“) angezeigt ist.

Bei alledem gilt: Es gibt kein Analyseproblem in der GKV, das Gesundheitswesen gehört zu den bestanalysierten Politikbereichen unserer Republik. Es besteht vielmehr ein Konsensproblem. Deswegen wäre eine neue Kommission à la Hartz-Kommission für die GKV auch nicht das Mittel der Wahl. Dies als aktuelle Anmerkung zum Vorschlag einer Gutachter-Kommission für die GKV. 


\section{Zur Veränderung der Versicherungspflicht in der GKV}

Doris Pfeiffer

Die aktuelle politische Diskussion um eine „Veränderung der Versicherungspflicht in der GKV" - konkret um die An- oder Aufhebung der Versicherungspflichtgrenze - ist in aller Schärfe entbrannt. Niemand weiß derzeit, wie die „offene Feldschlacht" um das Vorschaltgesetz der neuen/alten Bundesregierung inklusive der Regelungen zur Versicherungspflichtgrenze ausgeht. Das Thema ist so brisant, dass die Politik schon mehrere Gestaltungsideen $-z$. B. Neuregelung nur für Berufsanfänger erwogen und wieder verworfen hat. Die politischen Akteure haben sich nun mit dem Entwurf des Vorschaltgesetzes auf den Weg gemacht, die Versicherungspflichtgrenze in der Krankenversicherung ab 2003 auf 3.825 Euro anzuheben. Die Beitragsbemessungsgrenze in der Krankenversicherung soll unverändert bleiben.

Dass die private Versicherungswirtschaft weiterhin schweres Geschütz auffährt, verwundert nicht. Wer schon den Börsencrash beim Kanzler heraufbeschworen hat, wird weiter den Teufel an die Wand malen. Dabei fällt die Erhöhung der Versicherungspflichtgrenze recht moderat aus. Sie ist zumindest ein Schritt in die richtige Richtung. Das Tor zur PKV wird allerdings für die Höherverdienenden nicht systematisch geschlossen. Aus Sicht der GKV bleibt zu hoffen, dass am Ende der parlamentarischen Beratungen tatsächlich eine Regelung steht, die mehr wert ist als ein Tropfen auf den heißen Stein.

Im Vordergrund einer verantwortlichen und nachhaltigen Gesundheitspolitik muss die Stabilisierung der gesetzlichen Krankenversicherung stehen. Hierzu hat sich die sozialdemokratisch/grüne Bundesregierung ja wiederholt - auch mit der Koalitionsvereinbarung - verpflichtet.

Die aktuelle Diskussion um die Versicherungspflicht ist letztlich eine Debatte um die Grenzziehung zwischen zwei unterschiedlichen Krankenversicherungssystemen. Das eine ist nach dem Solidarprinzip organisiert, bei dem die Starken für die Schwachen eintreten. Das andere System baut auf die individuelle Risikoäquivalenz und stellt die eigene Vorsorge für das eigene Risiko in den Vordergrund. Eine Grenzziehung muss daher ordnungspolitisch sauber und systematisch erfolgen. 


\section{Gemeinsame Wurzeln}

Auch wenn Ersatzkassen und private Krankenversicherung eine gemeinsame Vergangenheit haben - sie wurden beide in der zweiten Hälfte des 19. Jahrhunderts als Selbsthilfe-Organisationen ("Hilfskassen") gegründet -, so erfuhren sie schon relativ früh eine Spaltung in den Sozialversicherungs- und den Privatversicherungszweig. Anlass war die bismarcksche Gesetzgebung, mit der die gesetzliche Krankenversicherung 1883 und damit die Versicherungspflicht für Arbeiter in der jeweiligen AOK, Betriebskrankenkasse oder Innungskrankenkasse eingeführt wurde. Neben dem Versicherungszwang wurden ein einheitlicher Mindestleistungskatalog, eine soziale Beitragsgestaltung sowie das Naturalleistungsprinzip statt der Kostenerstattung gesetzlich vorgeschrieben. Die Hilfskassen waren nicht Teil der neuen gesetzlichen Krankenversicherung, mussten jedoch zu Beginn des 20. Jahrhunderts wegen ihrer zunehmenden Größe auch zur Durchführung der Aufgaben der gesetzlichen Krankenversicherung herangezogen werden. Mit der Reichsversicherungsordnung von 1911 wurde dann festgelegt, dass eine "Ersatzmitgliedschaft" in einem Hilfsverein auf Gegenseitigkeit von der Pflichtmitgliedschaft in einer gesetzlichen Krankenkasse befreite. Diese „Ersatzfunktion" der Hilfskassen führte zu der bis heute üblichen Bezeichnung "Ersatzkassen". Weiterhin blieben aber privatrechtliche Versicherungselemente und sozialrechtliche Elemente innerhalb der Ersatzkassen bestehen. Mit dem weiteren Wachsen der Ersatzkassen in den 20er Jahren wurde eine grundsätzliche Entscheidung in die eine oder andere Richtung forciert. Mit der Aufbaugesetzgebung in der ersten Hälfte der 30 er Jahre erfolgte dann die Aufspaltung in den rein privatrechtlich organisierten und den sozialrechtlich organisierten Zweig. Die Ersatzkassen wurden zu Körperschaften öffentlichen Rechts, behielten aber ihr eigenständiges Vertragsrecht sowie die Möglichkeit zur Gestaltung des Beitrags- und Leistungsrechts. Erst mit dem GesundheitsReformgesetz von 1989 wurden die Ersatzkassen in vollem Umfang zu gesetzlichen Krankenkassen und vollständig in das nahezu einheitliche neue Krankenversicherungsrecht des SGB V einbezogen.

\section{„Friedensgrenze" hart umkämpft}

Immer wieder spielt die Grenzziehung zwischen privater Krankenversicherung und Ersatzkassen eine ganz entscheidende Rolle, und dies nicht nur wegen ihrer gemeinsamen historischen Wurzeln, sondern auch wegen des bis heute hart umkämpften Marktes der freiwillig Versicherten, deren Anteil bei den Ersatzkassen von jeher besonders hoch ist. Die durch die Versicherungspflichtgrenze mögliche "Exit-Option" für Beschäftigte oberhalb eines bestimmten Einkommens schafft Probleme für 
die betroffenen Krankenkassen wegen des Risikostrukturausgleiches, aber auch für die gesetzliche Krankenversicherung insgesamt. Während in der Renten- und Arbeitslosenversicherung für alle Arbeitnehmer Versicherungspflicht herrscht und lediglich die Höhe der Beiträge durch die Beitragsbemessungsgrenze (2002: 54.000 Euro/Jahr, 4.500 Euro/Monat) begrenzt wird, gilt für diejenigen Versicherten, die die Entgeltgrenze überschreiten, die Wahlmöglichkeit zwischen privater und gesetzlicher Krankenversicherung. Bis Ende 2002 war diese Versicherungspflichtgrenze zugleich auch Beitragsbemessungsgrenze für die gesetzliche Krankenversicherung.

Um mit der Einkommensentwicklung mitzuhalten, wurde die Versicherungspflichtgrenze bis 1970 in unregelmäßigen Abständen diskretionär angepasst. Da es sich immer auch um eine Entscheidung über potenzielle Märkte für den einen wie den anderen Versicherungszweig handelte, waren diese Anpassungen regelmäßig umstritten. Um diesen Auseinandersetzungen aus dem Weg zu gehen, wurde die Höhe der Versicherungspflichtgrenze und zugleich der Beitragsbemessungsgrenze in der Krankenversicherung 1970 auf 75 Prozent der Beitragsbemessungsgrenze in der Rentenversicherung festgesetzt. Da diese Grenze in etwa dem 2 fachen des Durchschnittseinkommens der Versicherten entspricht und jährlich entsprechend der Einkommensentwicklung angepasst wird, ist damit auch die "Friedensgrenze" quasi automatisch dynamisiert.

\section{Kernproblem „Exit-Option“}

Auch wenn durch die regelhafte Dynamisierung der Versicherungspflichtgrenze der Streit um Zeitpunkt und Höhe der Anhebung beigelegt wurde, so bleibt dennoch die Versicherungspflichtgrenze ein ständiger Diskussionspunkt, weil an dieser Grenze nach wie vor zwei völlig unterschiedlich geartete und gestaltete Systeme aufeinander treffen. Dabei liegt das entscheidende Problem darin, dass gerade die besonders Leistungsfähigen, nämlich diejenigen, deren Einkommen oberhalb der Versicherungspflichtgrenze liegt, sich aus ganz individuellem Kalkül aus der Solidargemeinschaft verabschieden können. Insgesamt sind in der GKV derzeit rund 3 Millionen Arbeitnehmer versichert, die mit ihrem Arbeitsentgelt oberhalb der Versicherungspflichtgrenze von monatlich 3.375 Euro (2002) liegen. Genau um diesen Personenkreis tobt seit Jahren ein harter Wettbewerb zwischen gesetzlicher und privater Krankenversicherung.

Die Exit-Option geht vor allem zu Lasten der Krankenkassen, die - wie die Ersatzkassen - hohe Anteile an freiwillig Versicherten verzeichnen. Der Ausstieg junger, gesunder und gut verdienender Mitglieder läuft dem 
für die soziale Krankenversicherung konstitutiven Element der Leistungsfähigkeit diametral entgegen. Gerade den besonders leistungsfähigen Personen wird die Systemwahl ermöglicht. Dies führt zunehmend zu Verwerfungen und gefährdet die Stabilität der GKV.

Mit der Ausstiegsmöglichkeit an der Versicherungspflichtgrenze ist eine Entmischung der Risiken verbunden. Diejenigen, die glauben, es sich leisten zu können, gehen in die private Krankenversicherung. Diejenigen, die glauben, der Solidarität der gesetzlichen Krankenversicherung zu bedürfen, bleiben gesetzlich versichert. Die Abwanderung aufgrund individueller Kosten-Nutzen-Abwägungen führt zur Selektion von Risiken. Der Ausweitung dieses - für die GKV strukturell und finanziell nachteiligen - Selektionsprozesses muss politisch begegnet werden.

Dabei muss auch klargestellt werden, dass die soziale Sicherung nicht nur eine Schutzfunktion für die Schwachen in unserer Gesellschaft bieten soll. Nur durch die breite Einbeziehung aller Erwerbstätigen ergibt sich die Möglichkeit, den umfassenden Schutz gegen die mit Krankheit verbundenen Risiken für alle zugänglich und finanzierbar zu machen.

Kern der Solidarität ist gerade die Verantwortungsgemeinschaft der Starken und Schwachen unserer Gesellschaft. Solidarität darf nicht auf die Gemeinschaft von Schwachen oder die Fürsorge für Bedürftige reduziert werden. Auch für die Zukunft gilt es, einen Solidarverbund von Leistungsfähigen und Bedürttigen zu organisieren, bei dem die individuelle Option zum Ausstieg begründungspflichtig bleibt. Da die soziale Absicherung des Risikos Krankheit unabhängig vom Einkommen eine wesentliche Voraussetzung für die so oft geforderte Flexibilität und Mobilität der Arbeitnehmer darstellt, würde die Begrenzung der Solidargemeinschaft auf die Bedürftigen nicht nur nicht funktionieren, sondern auch eine Belastung für die Produktivität und Effizienz unserer Volkswirtschaft darstellen.

Um den umfassenden Krankenversicherungsschutz für breite Bevölkerungskreise dauerhaft zu sichern, ist eine Neubestimmung des Verhältnisses von privater und gesetzlicher Krankenversicherung erforderlich. Denn seit Jahren wechseln freiwillige Mitglieder in die PKV - bis jetzt schon weit über 300.000 - während die Anzahl der durch die Anhebung der Versicherungspflichtgrenze von der PKV in die GKV zurückkehrenden Personen rund 150.000 beträgt. Der Wanderungssaldo stellt sich für die letzten Jahre wie folgt dar (Abb. 1): 
Abb. 1: Saldo Abwanderung GKV - PKV

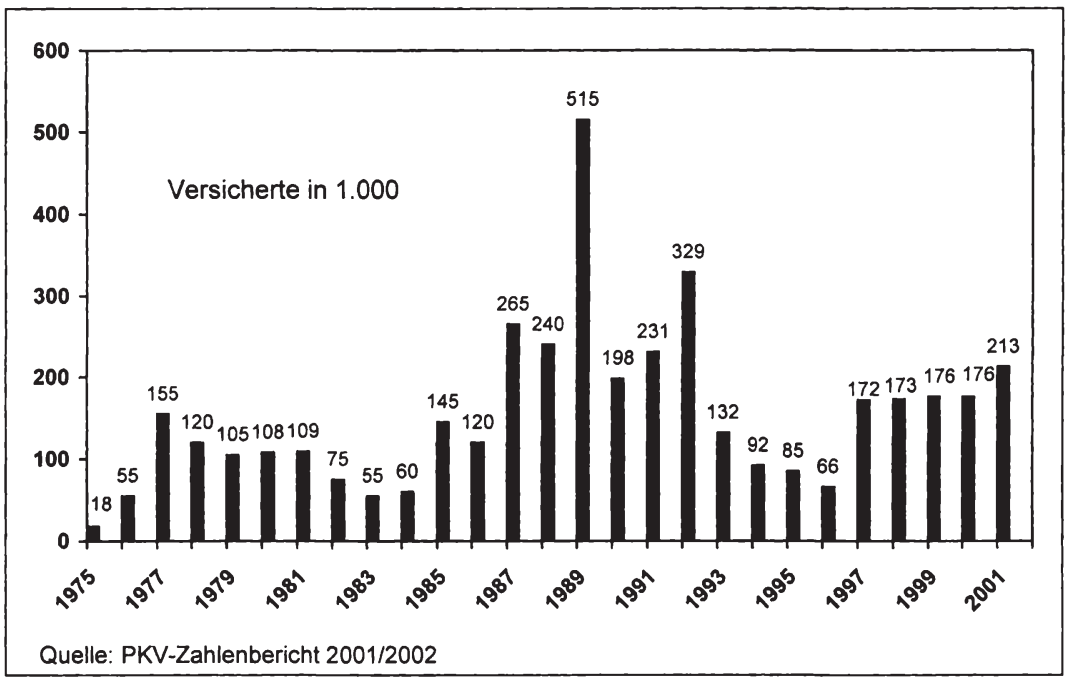

Zunächst legt die Abbildung offen, dass insbesondere in Zeiten großer Reformen bzw. der Diskussionen hierum wie $z$. B. den Reformen von 1989 und 1993, bei denen es in der Regel um Leistungsausgrenzungen oder Erhöhung von Zuzahlungen ging, die Nettoabwanderung in die private Krankenversicherung besonders hoch war. Dabei spielt noch nicht einmal die tatsächliche Veränderung der Leistungsansprüche eine Rolle. Es genügen oft schon die öffentlichen Debatten um mögliche Veränderungen, die die Abwanderung in die private Krankenversicherung forcieren. Die Abbildung macht aber auch deutlich, dass sich im Jahr 2001 die Abwanderungen aus der GKV in die PKV erneut verstärkt haben. Für das laufende Jahr ist auch aufgrund der PKV-Kampagne, die mit den irreführenden und gerichtlich untersagten Behauptungen, mit der geplanten Anhebung der Versicherungspflichtgrenze werde auch die Beitragsbemessungsgrenze erhöht, agierte, $z u$ befürchten, dass der Abgang noch größere Dimensionen annimmt.

Die Abgänge treffen aber nicht nur die Kassen mit hohen Anteilen an freiwillig Versicherten. Über den Risikostrukturausgleich bedeutet die Abwanderung besonders leistungsfähiger Mitglieder einen Entzug von Solidarkraft für die gesamte gesetzliche Krankenversicherung. Überschlägig kalkuliert bedeutet die Abwanderung von 100.000 Mitglieder einen Entzug von Finanzkraft in Höhe von ca. 500 Mio. Euro, wobei die „ersparten" Leistungsausgaben für die abgewanderten Mitglieder bereits gegengerechnet sind (Abb. 2). 
Abb. 2: Entzug von Solidarkraft

\begin{tabular}{|c|c|c|c|}
\hline Annahmen: & & \multirow{4}{*}{\multicolumn{2}{|c|}{$\begin{array}{l}\text { aber: } \\
\text { - keine durchschnittlichen Risiken } \\
\text { - keine Familien } \\
\text { Ausgaben } 1.350 € \text { je Mitglied und weniger }\end{array}$}} \\
\hline 100.000 Mitglieder zur PKV & & & \\
\hline BBG $40.500 €$ & BS $14,0 \%$ & & \\
\hline$\varnothing$ Ausgaben je AKV-Mitglied & $2.700 €$ & & \\
\hline Beitragseinnahmen & 567 Mio. $€$ & Beitragseinnahmen & 567 Mio. $€$ \\
\hline Ausgaben & 270 Mio. $€$ & Ausgaben & 135 Mio. $€$ \\
\hline Saldo & 297 Mio. $€$ & Saldo & 432 Mio. $€$ \\
\hline
\end{tabular}

Die Probleme entstehen aber nicht nur durch den Abgang "guter" Risiken, also von jungen, gesunden Mitgliedern mit einem Einkommen oberhalb der Versicherungspflichtgrenze. Hinzu kommt vielmehr, dass mit großer Wahrscheinlichkeit davon auszugehen ist, dass die in die GKV rückkehrenden Personen in einem gewissen Umfang aufgrund ihres $\mathrm{Ge}$ sundheitsstatus eher als "schlechte" Risiken anzusehen sind. Damit gestaltet sich die Bilanz der Wanderungseffekte für das Jahr 2001 folgendermaßen: Die Abwanderung von 361.000 Mitgliedern in die private Krankenversicherung kostet die gesetzliche Krankenversicherung ca. 1,8 Mrd. Euro. Die im gleichen Zeitraum von der privaten Krankenversicherung 148.000 „Zugewanderten" belasten die gesetzliche Krankenversicherung zusätzlich. Das heißt, eine bloße Berücksichtigung des Wanderungssaldos von 213.000 Mitgliedern unterschätzt die Belastung der gesetzlichen Krankenversicherung systematisch.

\section{Lösungsansätze}

Bereits in der Vergangenheit wurden die Rückkehrmöglichkeiten für privat Versicherte in die gesetzliche Krankenversicherung mit den Reformen 1989, 1993 und 2000 zunehmend eingeschränkt, so dass inzwischen weitgehend von einer "Einbahnstraße" gesprochen werden kann. Insbesondere die Rückkehr von Rentnern in die gesetzliche Krankenversicherung wurde mit der Gesundheitsreform 2000 massiv begrenzt. Da die Abwanderung jedoch weiterhin ein großes Problem für die gesetzliche Krankenversicherung darstellt, sind weitergehende Maßnahmen erforderlich, die das Verhältnis von gesetzlicher und privater Krankenversicherung neu ordnen. 


\section{Aufhebung der Versicherungspflichtgrenze}

Von der Systematik her liegt die Lösung der Problematik daher in einer Aufhebung der Versicherungspflichtgrenze für alle abhängig Erwerbstätigen. Nur damit würde eine klare Grenzziehung zwischen den beiden Systemen erreicht. Eine derartige Versicherungspflicht für alle Arbeitnehmer gilt im Übrigen ganz selbstverständlich in der Renten- und Arbeitslosenversicherung.

Die gesetzliche Krankenversicherung würde so zu einer umfassenden Arbeitnehmerversicherung und strukturell gestärkt. Während abhängig Erwerbstätige generell der Versicherungspflicht in der GKV unterlägen, sollten alle Selbständigen sich privat absichern. Beamten sollte eine Zutrittsmöglichkeit zur GKV zum Zeitpunkt ihrer Verbeamtung zugestanden werden, um auch hier die Selektion durch individuelle Entscheidungen zu verhindern und zugleich verfassungsrechtlichen Bedenken Rechnung zu tragen.

Eine Aufhebung der Versicherungspflichtgrenze hätte die klare Zuordnung der Personenkreise zu den unterschiedlichen Versicherungssystemen zur Folge. Abwanderungen aus dem Arbeitnehmerbereich in die PKV wären künftig nicht mehr möglich. Lediglich den versicherungsfreien Personengruppen (z. B. Selbständige, Beamte) stünde die PKV als Vollversicherung offen. Darüber hinaus bliebe der PKV das Zusatzversicherungsgeschäft, was dann auch ordnungspolitisch Sinn machen würde. Dem entsolidarisierenden Effekt eines wahlweisen Systemwechsels würde allerdings nachhaltig "der Garaus gemacht".

Aus Sicht der Ersatzkassen ist zudem an der bestehenden Beitragsbemessungsgrenze festzuhalten. Denn der einkommensbezogene Solidarausgleich benötigt auch eine angemessene Grenzziehung. Diese wird nach Auffassung der Ersatzkassen mit der derzeitigen Beitragsbemessungsgrenze erreicht. Im Vordergrund steht somit nicht die Erschließung neuer Finanzpotenziale, vielmehr geht es um die Sicherung des sozialund gesundheitspolitischen Auftrages der GKV. 


\section{Politische Entscheidung: Anhebung der Versicherungspflichtgren-}

ze

Die Aufhebung oder die Neufestsetzung der Versicherungspflichtgrenze ist selbstverständlich eine politische Entscheidung. Mit der am 7. November 2002 in erster Lesung im Bundestag im Rahmen des Vorschaltgesetzes eingebrachten Anhebung der Versicherungspflichtgrenze auf 3.825 Euro/Monat bei gleichzeitiger Beibehaltung der Beitragsbemessungsgrenze von 3.450 Euro/Monat (2003) wagt sich die Politik an eine systematische Neuregelung nicht heran. Gleichwohl wird versucht, der Entsolidarisierung durch Wechselmöglichkeit in die private Krankenversicherung entgegenzuwirken. Die finanzielle Entlastung der GKV wird im Gesetzentwurf für das kommende Jahr auf 200 bis 300 Mio. Euro geschätzt. Insofern bewegt sich die Politik in die richtige Richtung.

Mit der Anhebung der Versicherungspflichtgrenze wird aber die Ausstiegsoption nicht gänzlich beseitigt. Die Wechselmöglichkeit an der Versicherungspflichtgrenze zwischen "privat" und "gesetzlich" bleibt als grundlegende Fehlkonstruktion bestehen. In welchem Umfang die jährliche Abwanderung Höherverdienender in die PKV gestoppt wird, muss die Zukunft zeigen. Erst dann wird sich entscheiden, ob mit der Anhebung ein nachhaltiger Stabilisierungsbeitrag erreicht wird. Der Gesetzgeber hat es in der Hand, mehr Belastungsgerechtigkeit herzustellen, die Solidarität in der GKV zu stärken und die Organisation der Absicherung gegen Krankheit zu optimieren. Dazu bedarf es jetzt politischen Mutes und eines entsprechenden Standings. 


\section{Zur Veränderung der Versicherungspflicht in der GKV}

Volker Leienbach

\section{Vorbemerkung}

Die Regierungsparteien betonen in ihrer nach der Wiederwahl geschlossenen Koalitionsvereinbarung wiederholt die Grundsätze für ihre Politik in dieser Legislaturperiode: Die Politik soll nachhaltig sein, und sie soll Antworten geben auf die demographische Entwicklung, die eine der größten Herausforderungen für die Gesellschaft, für die Wirtschaft, für die Sozialsysteme sei. So richtig die in der Koalitionsvereinbarung beschriebenen Ziele sind, so falsch ist das konkrete Handeln der Bundesregierung, analysiert man die am 1. Januar 2003 in Kraft getretene Regelung des so genannten Vorschaltgesetzes.

Der Herausforderung der demographischen Entwicklung und dem Ziel der Nachhaltigkeit begegnet das Vorschaltgesetz u. a. mit der Regelung, die Versicherungspflichtgrenze in der gesetzlichen Krankenversicherung um über 13 Prozent anzuheben! Sie schwächt damit das vergleichsweise demographieresistente System der privaten Krankenversicherung und gibt der gesetzlichen Krankenversicherung größere Marktanteile - einem System, das jede Antwort auf Nachhaltigkeit und Generationengerechtigkeit schuldig bleibt.

Insofern schiebt das Vorschaltgesetz keine strukturellen Reformen an. Es ist vielmehr eine Notoperation, die für die gesetzliche Krankenversicherung ein wenig Luft schaffen sollte. Dabei bleibt unklar, wofür diese Luft dann anschließend gebraucht werden soll. Es fehlt das Ziel, wie unser Gesundheitssystem in 5, 10, 20 oder 30 Jahren aussehen soll, wie es organisiert sein soll, wie es finanziert sein soll.

\section{Zur Anhebung der Versicherungspflichtgrenze}

Das Vorschaltgesetz bietet aus Perspektive der privaten Krankenversicherung vielfältigen Anlass zur Kritik. Dieser Beitrag soll sich jedoch auf einen Punkt beschränken: Die mit dem Vorschaltgesetz vorgenommene Erhöhung der Versicherungspflichtgrenze. Derzeit - im Jahre 2002 liegt die Versicherungspflichtgrenze bei 3.375 Euro. Würde sie, wie in den letzten 30 Jahren, entsprechend der Entwicklung der Löhne und Gehälter angepasst, läge sie im Jahre 2003 bei 3.450 Euro. Tatsächlich soll sie jetzt auf 3.825 Euro erhöht werden. Die ursprünglichen Pläne gingen sogar weit darüber hinaus. Zunächst wollte die Regierungskoali- 
tion die Grenze für "neue Versicherungsverhältnisse" auf 5.100 Euro monatlich erhöhen.

Diese ursprünglichen Pläne hätten bedeutet, dass der AngestelltenMarkt für die private Krankenversicherung im Bereich der Vollversicherung faktisch geschlossen worden wäre. Zunächst erreichen nur wenige Erwerbstätige ein Einkommen über 5.100 Euro im Monat. Und diejenigen, die ein Einkommen dieser Größenordnung erzielen, erreichen dies im Schnitt erst im 4. oder 5. Lebensjahrzehnt. Aufgrund des dann deutlich höheren Einstiegsalters gegenüber dem Status quo und der damit geringeren Zeit, die für Ansparungen der Alterungsrückstellung zur Verfügung steht, müsste die PKV für diese Personen Beiträge nehmen, die einen Wechsel von der GKV zur PKV faktisch ausschließen. Nur noch sehr wenige abhängige Erwerbstätige hätten theoretisch die Möglichkeit, zur PKV zu wechseln. Und selbst für diese wäre ein Wechsel unattraktiv - also ein Herausdrängen der PKV aus dem Vollversicherungsmarkt für Angestellte dürfte politisch auch gewollt gewesen sein.

Angesichts dieses Bedrohungsszenarios ist die zum 1. Januar 2003 tatsächlich vorgesehene Erhöhung der Versicherungspflichtgrenze auf 3.825 Euro vergleichsweise moderat. Doch dieser erste Eindruck verliert sich bei näherer Betrachtung. Dies liegt vor allem daran, dass von dieser außerordentlichen Erhöhung der Versicherungspflichtgrenze nicht nur neue Versicherungsverhältnisse, sondern auch die bereits heute in der GKV Versicherten betroffen sind. Mehr als 750.000 Berufstätige, die in der GKV versichert sind, dürften in dem Einkommensbereich zwischen 3.450 Euro - dieser Betrag hätte sich als Versicherungspflichtgrenze bei Fortführung der jährlichen Regelanpassung ergeben - und 3.825 Euro der jetzt festgesetzten Versicherungspflichtgrenze für das Jahr 2003 verdienen. Bezieht man Familienangehörige mit ein, so ist das Potenzial für die private Krankenversicherung im Bereich der AngestelltenVersicherung um mehr als eine Million Personen gesunken. Es muss davon ausgegangen werden - wobei sich die Situation von PKVUnternehmen zu PKV-Unternehmen stark unterscheidet -, dass im Branchenschnitt rund ein Drittel weniger Angestellte von der GKV zur PKV wechseln werden als in der Vergangenheit.

Die vorgenommene außerordentliche Erhöhung der Versicherungspflichtgrenze ist mit einer weiteren Veränderung einhergegangen, die in der bisherigen politischen Diskussion fast untergegangen ist. Dies betrifft die Koppelung der Versicherungspflichtgrenze in der gesetzlichen Krankenversicherung an die Entwicklung der Beitragsbemessungsgrenze in der gesetzlichen Rentenversicherung. Bisher sah der gesetzliche Regelmechanismus vor, dass die Versicherungspflichtgrenze in der gesetz- 
lichen Krankenversicherung bei 75 Prozent der Beitragsbemessungsgrenze in der gesetzlichen Rentenversicherung liegt. Im Jahre 2003 liegt die Beitragsbemessungsgrenze in der gesetzlichen Rentenversicherung bei 5.100 Euro. Zwar ergibt dies rein rechnerisch immer noch die 75 Prozent, allerdings ist die gesetzliche Koppelung fallengelassen worden. Es gilt jetzt eine eigenständige Regelanpassung für die Versicherungspflichtgrenze in der Krankenversicherung. Damit ist ein großes Stück Beliebigkeit für weitere Veränderungen der Versicherungspflichtgrenze möglich geworden.

\section{Mehr Versicherte lösen kein einziges strukturelles Problem der gesetzlichen Krankenversicherung}

Die Erhöhung der Versicherungspflichtgrenze wird häufig mit dem Argument begründet, dass der Marktanteil der PKV immer größer werde, die GKV hingegen ausblute. Dieses Argument ist falsch. Im Jahre 1991 hatte die GKV 50,2 Millionen Mitglieder. Zehn Jahre später waren es 51,1 Millionen. Trotz Zunahme der GKV-Mitgliederzahl um fast eine Million Menschen, sind die Probleme der gesetzlichen Krankenversicherung in diesem 10-Jahres-Zeitraum nicht geringer geworden. Ganz im Gegenteil! Also kann der Zuwachs an Menschen allein der GKV nicht helfen. Im selben Zeitraum ist auch die Zahl der freiwillig Versicherten in der GKV gestiegen. Und auch dies hat der GKV nicht geholfen.

Die eigentlichen Wanderungsbewegungen finden nicht von der GKV zur PKV statt. Sie finden innerhalb der GKV statt. Hier gibt es Kassenarten, die von den Wanderungsbewegungen profitieren. Entsprechend müssen andere Kassenarten zu den Verlierern dieser wettbewerblichen Orientierung zählen. Zu den Letzteren gehören insbesondere die Ersatzkassen, die sich seit einiger Zeit besonders stark machen für eine Erhöhung bzw. Aufhebung der Versicherungspflichtgrenze. Die Ersatzkassen fordern faire Ausgangsbedingungen für einen Wettbewerb, nachdem sie jahrzehntelang von den damals vorherrschenden Wettbewerbsbedingungen in gigantischem Umfang profitiert hatten. So betrug der Marktanteil der Ersatzkassen im Jahre 1970 23,3 Prozent. Bis zum Jahr 1995 war er um fast 50 Prozent auf 34,4 Prozent gestiegen. Dies musste zwangsläufig zu Lasten der anderen Kassenarten gehen. In diesem Zeitraum ist von den Ersatzkassen die Frage nach der Wettbewerbsgerechtigkeit nie gestellt worden.

Nun erleben die Ersatzkassen erstmals, dass der Wettbewerb keine Einbahnstraße ist. Sie verlieren Versicherte. Dass dies zu Nervosität und zu den Forderungen führt, Schutzzäune zu errichten, um Versicherte zu 
halten oder neue hinzuzugewinnen, ist verständlich, verträgt sich jedoch nicht mit der ansonsten vorgebrachten Wettbewerbsideologie.

Vergleicht man die Wanderungsbewegungen innerhalb der GKV mit den Wanderungsbewegungen zwischen GKV und PKV, so nimmt sich Letztere vergleichsweise bescheiden aus - und dies nicht einmal zum Vorteil der PKV. So lag noch im Jahre 1960 der Marktanteil der PKV bei 12 Prozent. Im Jahre 2002 betrug er ganze 9,4 Prozent. Damit ist die PKV noch lange nicht wieder dort angelangt, wo sie bereits vor 40 Jahren stand.

\section{Solidarität in GKV und PKV}

Ein häufig vorgebrachtes Argument ist, dass die PKV ein unsolidarisches Sicherungssystem sei. Doch auch dieses Argument ist falsch.

Zwar ist nicht zu leugnen, dass sich an der Versicherungspflichtgrenze Menschen nach individuellen Präferenzen entscheiden. Daran jedoch den Vorwurf der Unsolidarität festzumachen, greift deutlich zu kurz.

Vergegenwärtigt man sich, dass die knapp 10 Prozent Privatversicherten rund 15 Prozent der Gesundheitsausgaben in Deutschland bestreiten, so wird allein daraus sichtbar, welch enormen Beitrag der selbstzahlende Bereich für die Infrastruktur im Gesundheitswesen in Deutschland leistet. Geht ein Privatversicherter zum Arzt, zahlt er für eine Leistung das 2,5fache bis zum 3fachen dessen, was ein gesetzlich Versicherter für die gleiche Leistung zahlen muss. Dies bedeutet, dass eine durchschnittliche Arztpraxis, die einen Privatversicherten-Anteil von rund 10 Prozent hat, ca. 25 Prozent des Praxisumsatzes mit Privatversicherten realisiert. Ohne dieses Umsatzplus gäbe es keine flächendeckende Versorgung mit niedergelassenen Arztpraxen in Deutschland. Es gäbe eine deutlich schlechtere technische Infrastruktur in der ambulanten Versorgung.

Gleiches gilt für die stationäre Versorgung. Ohne die hohen Zahlungen der Privatversicherten im Krankenhaus, ohne die Chefarztabgaben, gäbe es in vielen Krankenhäusern keinen Investitionshaushalt mehr, der eine moderne Infrastruktur bedienen kann. Auch wären viele Krankenhäuser nicht mehr in der Lage, hoch qualifiziertes Personal zu gewinnen bzw. zu halten, das nicht nur das einzelne Krankenhaus, sondern das auch der Gesundheitsstandort Deutschland insgesamt braucht. 


\section{Wechsel zur PKV schon in der Vergangenheit}

Immer wieder wird vorgebracht, dass sich die Rahmenbedingungen für einen Wechsel von der GKV zur PKV immer günstiger entwickelt hätten. Auch dieses Argument geht an der tatsächlichen Entwicklung vorbei. Die Versicherungspflichtgrenze hat sich in der Vergangenheit deutlich stärker nach oben entwickelt als die Löhne und Gehälter, deren Entwicklung sie eigentlich folgen sollte. So ist die Versicherungspflichtgrenze in den letzten 20 Jahren um 65 Prozent stärker gestiegen als die Löhne und Gehälter. Dennoch sind die Rahmenbedingungen für einen Wechsel zur PKV nicht günstiger, sondern deutlich schlechter geworden.

\section{Dualität von GKV und PKV verfassungsrechtlich abgesichert}

Die Dualität von gesetzlicher und privater Krankenversicherung ist keinesfalls nur historisch begründbar. Das im Jahre 2001 ergangene Urteil des Bundesverfassungsgerichtes zur Pflegeversicherung führt ausdrücklich aus, dass das an der Versicherungspflichtgrenze festzumachende Prinzip der Schutzbedürftigkeit nicht nur für die Vergangenheit, sondern auch aktuell und für die Zukunft Gültigkeit habe. Mit der Versicherungspflichtgrenze sei eine Trennlinie zwischen Schutzbedürftigen und Nichtschutzbedürttigen markiert. Im selben Urteil führt das Verfassungsgericht aus, dass im Bereich der gesetzlichen Pflegeversicherung - die ja nach den gleichen Prinzipien arbeitet wie die gesetzliche Krankenversicherung - Generationengerechtigkeit nicht berücksichtigt werde. Das Verfassungsgericht hat hieraus die Verpflichtung abgeleitet, die Beitragsgestaltung in der gesetzlichen Pflegeversicherung neu vorzunehmen. Bei der privaten Pflegeversicherung, die nach dem Prinzip der privaten Krankenversicherung arbeitet, sieht das Bundesverfassungsgericht demgegenüber keinen Handlungsbedarf.

Auch europarechtlich dürfte sich eine starke Anhebung oder gar eine Abschaffung der Versicherungspflichtgrenze nicht halten lassen. Die Grundsätze der europäischen Verfassung verbieten es, in funktionierende Märkte einzugreifen, und dass das Versicherungssystem der privaten Krankenversicherung funktioniert, dürfte kaum bestreitbar sein.

Auch ist kein übergeordnetes Interesse erkennbar, das einen Eingriff in die private Krankenversicherung in Form einer deutlichen Erhöhung oder gar Abschaffung der Versicherungspflichtgrenze rechtfertigen würde. Eine Schwächung der PKV geht nämlich keineswegs einher mit einer Stärkung der gesetzlichen Krankenversicherung. 


\section{Eine Anhebung der Versicherungspflichtgrenze hat keine Bei- tragssatzrelevanz für die GKV}

Professor Dr. Eberhard Wille, der Vorsitzende des Sachverständigenrates für die konzertierte Aktion im Gesundheitswesen, hat in einem gerade veröffentlichten Gutachten ${ }^{1}$ nachgewiesen, dass das Beitragsentlastungspotenzial durch eine Anhebung der Versicherungspflichtgrenze nach 16 Jahren gerade einmal bei 0,1 Beitragspunkten für die GKV liegt. Diese vernachlässigenswerte Größenordnung wird noch dadurch faktisch deutlich kleiner ausfallen, als Professor Wille bei seinen Berechnungen von einer Anhebung der Grenze auf 4.600 Euro ausgegangen ist - gegenüber 3.825 Euro, wie sie jetzt Gesetzeskraft erlangt haben. Auch hat Professor Wille noch nicht die wegfallende Quersubventionierung gegengerechnet und in seinen Rechnungen auch außer Acht gelassen, dass die PKV bereits heute einen beträchtlichen Teil der demographischen Last der GKV mitträgt. Bezieht man die demographische Entwicklung mit ein - so Professor Wille -, könne sich der theoretische, wenn auch sehr geringe Entlastungseffekt für die GKV sogar umkehren.

Damit wird deutlich, dass eine Erhöhung der Versicherungspflichtgrenze nicht einmal einen wahrnehmbaren Beitrag zur finanziellen Stabilisierung der gesetzlichen Krankenversicherung leistet. Was eine Grenzerhöhung sehr wohl mit sich bringen würde, wäre eine deutliche Schwächung der PKV.

\section{Die PKV als Korrektiv}

Die Beitragssätze in der gesetzlichen Krankenversicherung steigen unaufhaltsam - trotz Budgets, trotz Beitragssatz-Sicherungsgesetzen. Die Gründe sind vielfältig. Generell könnte man sagen, dass man gegen die Bedürfnisse der Menschen und gegen die Wirklichkeit auch mit Gesetzen nicht ankommt. Man kann auch einen konkreten Punkt herausnehmen, der die Beliebigkeit der Politik im Bereich der sozialen Sicherung unterstreicht. Dies ist die Problematik der Verschiebebahnhöfe, die seit Jahrzehnten, in unterschiedlichsten Regierungskonstellationen, bis zum heutigen Tag praktiziert wird. Eine Politik, die eine Stabilisierung der Beiträge in der gesetzlichen Krankenversicherung zum Ziel hat, kann dann nicht als konsistent bezeichnet werden, wenn sie gleichzeitig zu weiteren Defiziten in der GKV beiträgt. Dies ist in der Vergangenheit geschehen, und dies geschieht heute im Kontext der weiteren Verbreitung

1 Zur Reform der Beitragsgestaltung, insbesondere der Pflichtversicherungsgrenze in der gesetzlichen Krankenversicherung - eine empirische Analyse. 
der Riester-Rente sowie im Kontext der Umsetzung der Vorschläge der so genannten Hartz-Kommission.

Von politischen Eingriffen dieser Art ist die private Krankenversicherung weitgehend ausgespart. Vieles spricht dafür, dass die Politik in die GKV noch deutlich stärker eingreifen würde, gäbe es nicht - als konkurrierendes System - eine vergleichsweise gut funktionierende private Krankenversicherung. Eine weitere Schwächung der GKV würde die Schieflage zwischen PKV und GKV sichtbar machen und politische Widerstände hervorrufen.

\section{Realitätsdefizite in der gesetzlichen Krankenversicherung}

Der gesetzlichen Krankenversicherung ist es in der Vergangenheit gelungen, die Definitionsmarke über den Begriff Solidarität zu erobern. Große Teile der Bevölkerung - aber auch der Politik und der Medien sind sich sicher, dass in der gesetzlichen Krankenversicherung das Prinzip der Solidarität verwirklicht ist. Und die Vertreter der gesetzlichen Krankenversicherung erwecken den Eindruck, dass alles, was sich in der GKV bewegt, dem Ziel der Solidarität dient. Doch ist die GKV wirklich lückenlos solidarisch?

Ist es solidarisch, wenn sich die wirtschaftliche Leistungsfähigkeit ausschließlich darauf reduziert, welches Einkommen aus Erwerbsarbeit ein Versicherter erzielt? Ist es wirklich solidarisch, dass Haushalte mit sehr unterschiedlicher wirtschaftlicher Leistungsfähigkeit den gleichen Beitrag zahlen und Haushalte mit gleicher wirtschaftlicher Leistungsfähigkeit wiederum sehr unterschiedliche Beiträge zahlen? Ist es solidarisch, dass in reichen Ein-Verdiener-Haushalten ein Ehepartner, der weder Kinder erzieht noch Angehörige pflegt, beitragsfrei mitversichert ist? Die Beispiele ließen sich fortsetzen.

\section{Antworten von GKV und PKV zu der demographischen Heraus- forderung}

Eine fast ausnahmslos akzeptierte Ausprägung des Solidarprinzips besteht darin, dass die Jungen für die Alten zahlen. In der gesetzlichen Krankenversicherung führt dies dazu, dass ein immer kleiner werdender Kreis von Erwerbstätigen einen immer größer werdenden Kreis von Rentnern subventioniert. Bereits heute beträgt das Defizit in der gesetzlichen Krankenversicherung für die Rentner mehr als $30 \mathrm{Mrd}$. Euro jährlich. Die Tendenz ist stark steigend. Die Konsequenz wird sein, dass die heute junge Generation, die heutigen Kinder und die nachwachsenden 
Generationen immer größere Anteile ihres eigenen Einkommens aufbringen müssen, um die gesundheitliche Versorgung der steigenden Zahl alter Menschen sicherzustellen. Dies führt zu einer Überforderung der jungen und nachwachsenden Generationen - vor allem angesichts der Tatsache, dass die gleiche Entwicklung im Bereich der gesetzlichen Rentenversicherung und noch deutlich stärker im Bereich der gesetzlichen Pflegeversicherung zu stark steigenden Beitragssätzen führen muss. Diese Entwicklung ist allen Entscheidungsträgern in Politik und GKV bekannt. Es wird jedoch nicht an Lösungen gearbeitet. Sehenden Auges läuft man in die Demographie-Falle. Zudem will man mit der privaten Krankenversicherung ein System weiter schwächen, das wirksam Vorsorge für den sich weiter ändernden Bevölkerungsaufbau trifft. Jeder Versicherte in der privaten Krankenversicherung baut mit seinen Beiträgen eine Rückstellung auf, die im Alter zur Beitragsentlastung verwendet wird. Diese Alterungsrückstellung liegt heute bereits bei über 70 Mrd. Euro für knapp 10 Prozent der Bevölkerung. Dies entspricht ungefähr dem Vierfachen der jährlichen Leistungsgausgaben der Privatkrankenversicherten. Damit hat die PKV in einer Weise Vorsorge für die mit dem Alter steigenden Gesundheitsausgaben getroffen, die weltweit ohne Beispiel ist. Es bleibt unerklärlich, warum die Politik dieses strukturelle Element schwächt und nicht bereit ist, strukturelle Weichenstellungen vorzunehmen und der demographischen Herausforderung auch in der gesetzlichen Krankenversicherung wirksam zu begegnen.

Zur Pflichtrhetorik gehört es, Lösungen für Zukunftsfragen anzumahnen. Zur politischen Realität wiederum gehört es, Probleme von heute zu lösen. Hier macht auch die Gesundheitspolitik keine Ausnahme. Es wird nur geschaut, welche Maßnahme wieviel unmittelbar bringt. Die Zeitpunkt-Betrachtung steht im Vordergrund. Beiseite geschoben wird die einfache Wahrheit, dass die gesundheitliche Sicherung eine Lebenszeitveranstaltung ist. Was nutzt es denn wirklich der gesetzlichen Krankenversicherung, ein gutes Risiko zu bekommen, das nur im Zeitpunkt des Wechsels ein wirklich gutes Risiko ist, sich in der Zeitschiene jedoch zu einem Normalrisiko entwickeln wird? Auch ein Single wird heiraten, wird Kinder bekommen. Gerade bei den freiwillig Versicherten ist die Familien-Mitversicherten-Quote doppelt so hoch wie bei den Pflichtversicherten. Und auch das Leistungsinanspruchnahme-Verhalten wird sich in der Zeitschiene anders entwickeln als in der Zeitpunktbetrachtung.

Doch bereits mittelfristig wird man erkennen, dass die Probleme der gesetzlichen Krankenversicherung nicht ausschließlich außerhalb der gesetzlichen Krankenversicherung zu lösen sind. Es wird auf die Dauer nicht ausreichen, Ärzte, Apotheker, Pharmaindustrie und private Kran- 
kenversicherung zu schwächen. Man wird vielmehr strukturelle Maßnahmen innerhalb der GKV ergreifen müssen.

\section{Eine freie Gesellschaft braucht ein Gesundheitswesen mit Frei- heitsgraden}

Mittlerweile gilt es als unumstößliche ordnungspolitische Leitlinie, dass in der Krankenversicherung Wettbewerb herrschen solle. Man spricht von einer "solidarischen Wettbewerbsordnung". Dabei hat man häufig den Eindruck, dass Wettbewerb nur dann eine gute Veranstaltung ist, wenn man selber davon profitiert. Doch Wettbewerb setzt zwingend Wahlmöglichkeiten voraus. Machen Menschen jedoch von ihren Wahlmöglichkeiten Gebrauch, so wird es immer Verlierer und Gewinner geben. Da niemand verlieren will, bestehen starke Bestrebungen, es bei der Wettbewerbsidee zu belassen und faktisch gemeinsam und einheitlich vorzugehen. Dies erleben wir zurzeit in der gesetzlichen Krankenversicherung.

Parallel dazu wird die Anzahl der Kassen weiter sinken, der Risikostrukturausgleich weiter verfeinert und der Staatseinfluss durch in der Gründungsphase befindliche, staatlich kontrollierte Institute weiter wachsen.

Schaltet man dann auch die private Krankenversicherung aus, ist der schnelle Weg in die Einheitsversicherung gebahnt. Unsere europäischen und außereuropäischen Nachbarn beweisen, dass Einheitsversicherungssysteme zwangsweise zur Mangelsteuerung führen. Versorgungsdefizite und Warteschlangen sind die Regel.

Demnach sollte es darum gehen, den Wettbewerb zu stärken. Dies verlangt ein pluralistisches, gegliedertes System, in dem sowohl die gesetzliche Krankenversicherung als auch die private Krankenversicherung als selbstbewusste und nicht von dauernden politischen Eingriffen bedrohte Marktteilnehmer agieren können.

\section{Zur Forderung eines Wahlrechtes für Beamte}

Von den Ersatzkassen wird gefordert, Versicherten bei Begründung eines Beamtenverhältnisses ein einmaliges Wahlrecht zwischen GKV und PKV einzuräumen. Diese Forderung kann nicht überzeugen, zumal sie der von den Ersatzkassen selbst vorgebrachten Argumentation fundamental widerspricht.

Wenn es denn richtig ist, dass Versicherte an der Versicherungspflichtgrenze nach der jeweils eigenen Vorteilhaftigkeit entscheiden, wird dies 
im Falle der Verbeamtung kaum anders sein. Auch hier werden sich folgt man der Ersatzkassenargumentation - die neuen Beamten bei Ausübung ihres Wahlrechtes danach entscheiden, wo für sie im individuellen Fall die größten Vorteile liegen.

Diesem „Vorteilshopping“ kann aber dadurch begegnet werden, dass man der PKV ganze Kollektive zuweist. In diesem Fall könnte auf individuelle Risikoprüfungen verzichtet werden. Auch würde der kapitalgedeckte Teil des Gesundheitswesens gestärkt - mit entsprechenden Entlastungseffekten für die GKV und mit der politisch gewünschten Stärkung der Generationengerechtigkeit.

\section{Notwendige Reformen in der gesetzlichen Krankenversiche- rung}

Es gibt viele Möglichkeiten, die gesetzliche Krankenversicherung zukunftsfest zu gestalten. Dies gelingt jedoch nur, wenn Bereitschaft auch zu unpopulären Schritten besteht. Dies betrifft die Einnahmenseite, und dies betrifft die Ausgabenseite. Einnahmeseitig könnte man die GKV auf festere Füße stellen, wenn zusätzliche Einkünfte - etwa aus Kapital, Vermögen, Vermietung und Verpachtung - der Beitragsbemessung zugrunde gelegt würden. Auch könnte man im Bereich der beitragsfreien Familienmitversicherung sozialpolitisch vertretbare Eingriffe vornehmen. Ausgabenseitig gilt es, den Leistungskatalog der gesetzlichen Krankenversicherung kritisch zu überprüfen. So könnte beispielsweise daran gedacht werden, bestimmte Leistungen ganz aus der gesetzlichen Krankenversicherung herauszunehmen und diese Leistungen - ggf. obligatorisch - privat abzusichern. Dabei kommen insbesondere der Zahnersatz, private Unfälle und das Krankengeld in Frage.

Würde man alle diese Wege gleichzeitig gehen, könnte der Beitragssatz zur gesetzlichen Krankenversicherung um 5 Prozentpunkte - etwa ein Drittel des heutigen Beitrages - gesenkt werden.

Bleibt zu hoffen, dass sich die Politik nicht allein von der Ideologie leiten lässt, sondern auch Fakten und Entwicklungen zur Kenntnis nimmt.

Im Sinne der Generationengerechtigkeit gilt es, heute Vorsorge für die demographische Herausforderung zu treffen. Dies kann nur durch eine Stärkung des kapitalgedeckten Systems der privaten Krankenversicherung erreicht werden. 


\section{Zukunft der GKV: Erweiterung der Bemessungsgrundlage oder ordnungspolitische Reform?}

Peter Oberender

\section{Einführung und Problemstellung}

Die Diskussion über die Reform der Finanzierung der gesetzlichen Krankenversicherung (GKV) wird zwar schon seit Jahren geführt, erlebt aber auch gegenwärtig wieder eine Renaissance. Die Bruttolohn-bezogene Beitragsfinanzierung mit einem einheitlichen Beitragssatz, formal von den versicherungspflichtigen Arbeitnehmern und ihren Arbeitgebern jeweils zur Hälfte zu bezahlen, steht dabei zunehmend vor der Legitimationsfrage. Wie kann eine hochwertige medizinische Versorgungsqualität bei wachsenden Finanzierungsproblemen finanziert werden?

Seit Jahren wachsen die durchschnittlichen Leistungsausgaben pro Mitglied stärker als die Einnahmenbasis (Abb. 1). Der vorliegende Beitrag soll deshalb der Frage nachgehen, inwiefern über eine Erweiterung der Bemessungsgrundlage eine problemadäquate Lösung der Finanzierungs- und Steuerungsproblematik im Gesundheitssystem zu erwarten ist. Neben der Diskussion unterschiedlicher Ausgestaltungsformen auf der Finanzierungsseite soll die Betrachtung vor allem den ordnungspolitischen Rahmen einer tragfähigen Gesundheitsreform ausleuchten.

Abb. 1

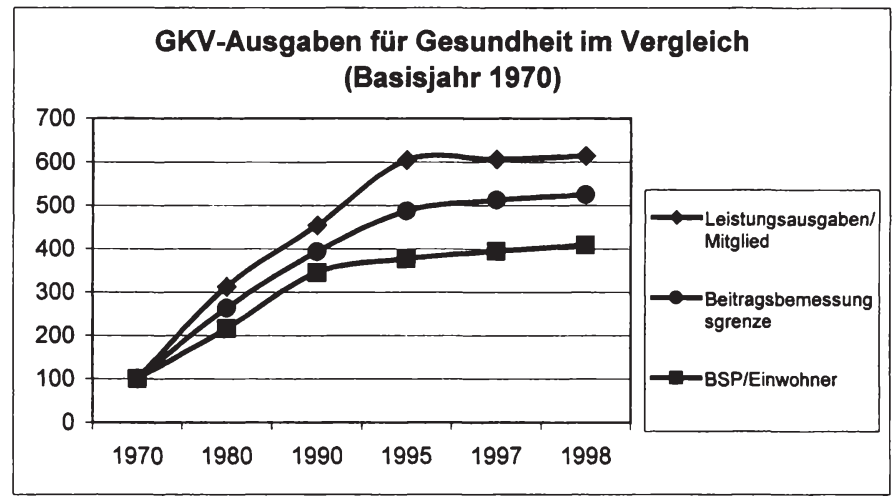

Quelle: eigene Darstellung nach Daten nach BMG, Daten des Gesundheitswesens 1999 


\section{Analyse des Status quo}

\subsection{Grundzüge des Krankenversicherungsprinzips}

Wie jede Krankenversicherung, so hat auch die gesetzliche Krankenversicherung die Aufgabe, jedes Mitglied vor dem Eintreten eines möglichen Vermögensschadens, hervorgerufen durch den Eintritt eines definierten Versicherungsfalles wie der Krankheit, zu bewahren. Aufgabe der Versichertengemeinschaft ist es, den Schaden, von dem ungewiss ist, welches Mitglied davon betroffen sein wird, durch Mitgliedschaftsbeiträge (Prämien) auszugleichen. Folglich stellt jede Krankenversicherung eine Umverteilung zwischen Kranken und Gesunden dar.

Die gesetzliche Krankenversicherung orientiert sich jedoch am Solidarprinzip, nach dem einkommensabhängige Beiträge gezahlt werden, jedoch beitragsunabhängige Leistungen garantiert sind. Ziel dieses Systems ist, dass jeder nach seiner Leistung gibt und nach seinen Bedürfnissen empfängt. Dieses Solidarprinzip hat zur Folge, dass "guten Risiken" eine wirtschaftliche Mehrbelastung auferlegt wird. Da für diese Versichertengruppe ein hoher Anreiz besteht, sich einer Versichertengemeinschaft anzuschließen, die ihre Prämien ausschließlich am Risiko des versicherten Mitglieds orientiert, ist für eine große Personenzahl die Pflichtmitgliedschaft in der GKV gesetzlich vorgeschrieben. Das Solidarprinzip ist jedoch nicht für alle Bürger verwirklicht, sondern nur für einen als schutzbedürftig eingestuften Personenkreis. Das Abgreifen der Leistungsfähigkeit erfolgt hierbei ausschließlich über Einkünfte aus unselbstständiger Beschäftigung, was sich letztendlich nur noch historisch begründen lässt. ${ }^{1}$

\subsection{Zur Effizienz der Finanzierungsbasis}

Trotz vielfältiger Reformvorhaben und Kostensenkungsdebatten, was sich vor allem in der simultanen Anhebung der Beitragssätze und Beitragsbemessungsgrenzen niederschlägt (Tab. 1), wurden immer mehr Finanzmittel notwendig, um die Ausgaben der GKV zu finanzieren.

1 Eine ausführliche Auseinandersetzung mit Strukturen und Entwicklung des Systems der gesetzlichen Krankenversicherung ist bei Oberender/Hebborn/Zerth, 2002, 33 ff., zu finden. 
Tab. 1: Beitragssätze GKV

\begin{tabular}{|c|c|c|}
\hline \multirow{2}{*}{ Jahr } & \multicolumn{2}{|c|}{$\begin{array}{c}\text { Beitragssatz in \% / Beitragsbemessungsgrenze } \\
\text { in DM, ab 2002 in } €\end{array}$} \\
& - West - & - Ost - \\
\hline \hline 1980 & $11,4 / 3.150$ & $-/$ - \\
\hline 1990 & $12,6 / 4.725$ & $-/-$ \\
\hline 1991 & $12,2 / 4.875$ & $12,8 / 2.250$ \\
& $12,8 / 5.100$ & $12,6 / 3.600$ \\
\hline 1992 & $13,2 / 5.850$ & $12,8 / 4.800$ \\
\hline 1995 & $13,5 / 6.000$ & $13,5 / 5.100$ \\
\hline 1996 & $13,5 / 6.150$ & $13,9 / 5.325$ \\
\hline 1997 & $13,6 / 6.300$ & $14,0 / 5.250$ \\
\hline 1998 & $12,2 / 6.375$ & $13,8 / 5.400$ \\
\hline 1999 & $13,5 / 6450(3297,83 €)$ & $13,8 / 5325(2722,63 €)$ \\
\hline 2000 & $13,5 / 6525(3336,18 €)$ & $13,7 / 6525(3336,18 €)$ \\
\hline 2001 & \multicolumn{2}{|c|}{$-/ 3375 €$} \\
\hline 2002 & \\
\hline
\end{tabular}

Quelle: $\quad$ zitiert nach Oberender/Zerth, 2002, 45

Die Zunahme des Anteils der älteren Menschen an der Gesamtbevölkerung in Deutschland ist mit dieser Entwicklung verbunden, weil die durchschnittlichen Kosten dieser Bevölkerungsgruppe über dem Gesamtdurchschnitt der Versicherten liegen. Dieser Effekt wird vor allem durch die Entwicklung der Medizintechnik verschärft. In der modernen Medizin dominieren immer so genannte "halfway-technologies", Technologien, die zwar das Leben des Menschen verlängern, ihn aber nicht wieder vollständig gesunden lassen und vor dem Tod bewahren können. Darüber hinaus können immer mehr Behandlungs- und Therapieverfahren zusätzlich eingeführt werden, ohne dass es zu namhaften Substitutionsprozessen kommt („Add-on-Technologien“). Es ist zwar einerseits zu erwarten, dass mit der Entwicklung der Medizintechnologie die Eintrittswahrscheinlichkeit und die Dauer medizinischer und pflegerischer Leistungen zurückgehen können, andererseits ist mit zunehmender Lebenserwartung neben der Reduzierung der Mortalitätsrate eine Erhöhung der Morbiditätsrate zu unterstellen, die sich insbesondere in Funktionseinschränkungen im Alter ausdrückt (Oberender/Hebborn/Zerth, 2002, 118). 
Die Ausgabenzuwächse, die mit den genannten Einflussfaktoren einhergehen, werden jedoch auf der Einnahmenseite der GKV nicht durch entsprechende Einnahmenzuwächse begleitet. Einerseits wächst die hauptsächliche Einnahmenbasis des GKV-Systems, die Bruttolohnsumme, nicht in erforderlichem Ausmaß, gleichzeitig sind die Beitragseinnahmen durch eine steigende Anzahl von Rentnern, Arbeitslosen und Beziehern von Unterhaltsgeld betroffen.

\subsection{Das Problem der Beitragsgerechtigkeit}

Bei anhaltender Finanzierungsproblematik wird die Legitimation der Beitragserhebung wieder virulent, wie insbesondere Wille (1998) herausgearbeitet hat. Das Solidarprinzip der GKV bietet im Gegensatz zum klassischen Äquivalenzprinzip, das in der Privatversicherung zu finden ist, oder zum Leistungsfähigkeitsprinzip der ökonomischen Steuerlehre keine eindeutige normative Fundierung. Wie bereits herausgearbeitet, ist in jedem Versicherungssystem eine Umverteilung von schadensfreien Mitgliedern zu Mitgliedern, die einen Schaden erleiden, angelegt. Im Rahmen der GKV gibt es aber aufgrund verschiedener sozialpolitischer Vorstellungen noch andere Umverteilungsprinzipien (Wille, 2002, 9):

- Umverteilung von Beziehern höherer Arbeitsentgelte zu solchen mit niedrigeren Einkünften

- Umverteilung von Alleinstehende zu kinderreichen Familien

- Umverteiung von jungen zu alten Versicherten

In diesem Zusammenhang stellt sich die Frage, ob der Solidarausgleich innerhalb der gesetzlichen Krankenversicherung die Zielsetzungen erfüllt, die vorgegeben sind.

Das Ziel der Arbeitseinkommen-Umverteilung ist grundsätzlich kein „natürliches Element" einer Krankenversicherung, sondern ist dem allgemeinen Leistungsfähigkeitsprinzip zuzuordnen (Knappe, 2001, 158). Auch der Familienlastenausgleich kann zu höchst unterschiedlichen Ergebnissen führen. Familien mit gleichen Monatseinkommen - die jedoch noch unter der Beitragsbemessungsgrenze liegen - werden teilweise unterschiedlich belastet; entscheidend ist dabei, ob nur ein Familienteil zur Einkommenserzielung beiträgt oder beide je zu gleichen Teilen. Im zweiten Fall wird die Belastung an monatlichen Beiträgen erheblich höher sein als im ersten Fall (Knappe, 2001, 159). 
Mit der Logik des Solidarausgleiches noch schwerer zu vereinbaren ist, dass einkommensstarke Personen die Möglichkeit haben, die gesetzliche Krankenversicherung zu verlassen. Es ist anzunehmen, dass gerade die Personen einen Anreiz haben, die gesetzliche Krankenversicherung zu verlassen, die sich gegenüber der GKV in einer Nettozahlerposition befinden. Dieses Verhalten ist aus ökonomischen Kalkülen durchaus rational, da besonders junge, besser verdienende und ledige Versicherte kaum einen Anreiz haben dürften, für im Durchschnitt gleiche Leistungen im System der GKV die Familien, die schlechter verdienenden und die älteren Mitglieder zu finanzieren.

\section{Systemimmanente Lösungsvorschläge}

\subsection{Erweiterung der Bemessungsgrundlage}

Eine Lösungsoption könnte in der Reform der Bemessungsgrundlage liegen. Schon aus rein fiskalischen Gründen wäre es zu überlegen, ob nicht weitere Einkünfte der Versicherten in die Bemessungsgrundlage zu integrieren wären. Aus finanzwissenschaftlicher Sicht würde eine Orientierung an den gesamten Einkünften eines Versicherten stärker dem Leistungsfähigkeitsprinzip entsprechen (Wille, 2002, 11). Organisatorisch könnte die Erweiterung der Bemessungsgrundlage nach dem Bruttoprinzip erfolgen. Da das Solidarprinzip von einer hälftigen Zahllast von Arbeitgeber und Arbeitnehmer ausgeht, bestünde die Option, die übrigen Einkommensarten entsprechend der hälftigen Finanzierung heranzuziehen. Als Vorteile lassen sich nach Wille $(2002,12)$ aufführen:

- Beseitigung der Unterschiede zur Beitragsbemessung bei den freiwilligen Mitgliedern.

- Der Druck auf die Lohnnebenkosten könnte durch eine Verbreiterung der Bemessungsgrundlage reduziert werden.

- Die konjunkturelle Abhängigkeit der GKV-Einnahmen könnte ausgeglichen werden unter der Annahme, dass die anderen Einkunftsarten stetiger fließen.

Als Nachteile lassen sich aufführen (Wille 2002, 12; auch Knappe 2001):

- Es liegen unter Umständen partiell regressive Verteilungseffekte vor, da nur Einkommen unterhalb der Beitragsbemessungsgrenze Beitragsrelevanz haben. 
- Die Abwanderungsrisiken in die PKV könnten ansteigen, da durch die Einbeziehung weiterer Einkommensarten mehr Personen oberhalb der Versicherungspflichtgrenze zu finden sind.

- Die paritätische Selbstverwaltung wird durch die Schwächung des Arbeitsentgeltes als Finanzierungsgrundlage entlegitimiert.

- Es könnten Anreize zur verstärkten Kapitalflucht bestehen.

Eine empirische Abschätzung des fiskalischen Effektes erscheint sehr schwierig. Schon der Sachverständigenrat hat 1994 auf die fehlende empirische Datenbasis hingewiesen. Generell wird darauf verwiesen, dass die Bedeutung von Kapitaleinkommen zunehmen wird. Gleichzeitig stellt sich die Frage, ob eine reine Erweiterung der Einnahmenseite als hinreichender Reformvorschlag vor dem Hintergrund dauerhafter Herausforderungen wie der demographischen Entwicklung sowie des medizinisch-technischen Fortschritts tragfähig ist. Insbesondere die Belastungsfähigkeit aller Einkünfte mit der (Zwangs-)Abgabe Krankenkassenbeitrag steht vor dem Hintergrund der internationalen Wettbewerbsfähigkeit auf dem Prüfstand. Alle bisherigen Reformvorhaben, die entweder Ausgaben- oder Einnahmen-orientiert waren, haben wieder zur nächsten Reform geführt (Abb. 2).

\section{Abb 2: Reformen und Ausgabenentwicklung}

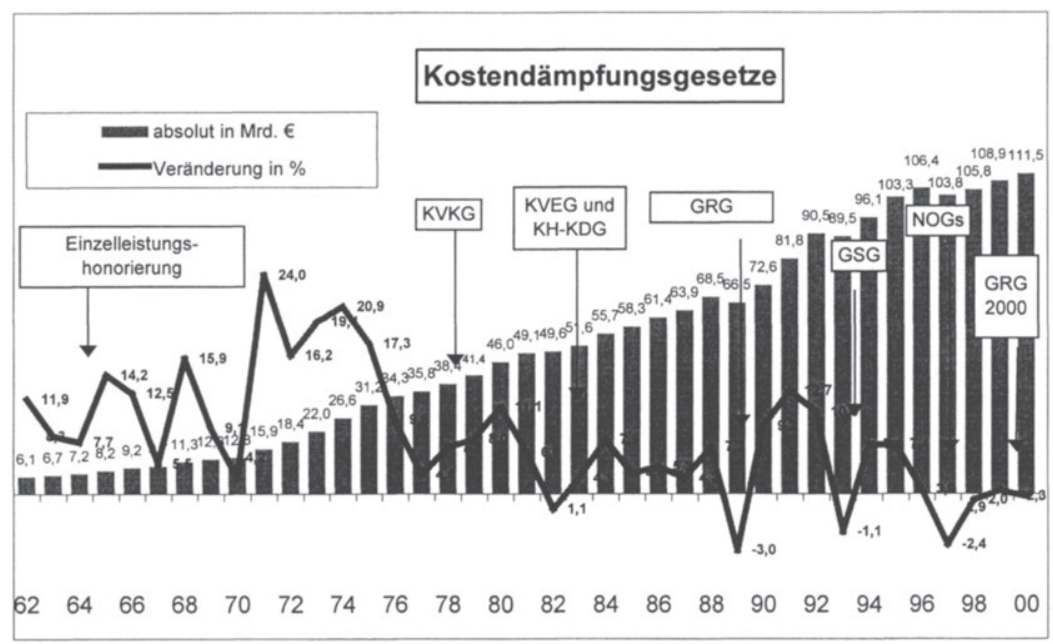

Quelle: Oberender/Zerth, 2002, 9 


\subsection{Zur Problematik immanenter Steuerungsdefizite}

In Anbetracht der bisherigen Gesundheitsreformen ist die Frage zu stellen, ob nicht jede Reformdiskussion im Gesundheitswesen neben der saldenmechanischen Herangehensweise an Einnahmen- und Ausgabengrößen auch die Anreizbeziehungen der Beteiligten untersuchen müsste. Eine derartige Ordnungs-, besser Institutionen-ökonomische Vorgehensweise würde versuchen, Reformkonzepte im Gesundheitswesen durch die explizite Auseinandersetzung mit verhaltenssteuernden Regeln anzustreben.

Das Gesundheitswesen ist infolge einer Institutionen-ökonomischen Betrachtung durch vielfältige Fehlanreize und im Resultat durch ein Verantwortungsvakuum der Beteiligten gekennzeichnet (Sauerland, 1999, 266 ff.). Das Fehlverhalten lässt sich im Groben am Solidar- und Sachleistungsprinzip festmachen. Diese beiden Prinzipien verleiten Versicherte und Leistungserbringer - bei Unterstellung eines durchschnittlich rationalen Verhaltens aller Akteure - dazu, sich nicht mit den monetären Konsequenzen ihres Handelns auseinanderzusetzen. Der Nutzen der Gesundheitsgüter wird individualisiert, die Kosten werden sozialisiert. Die fast vollständige Kollektivierung der durch individuelle NachfrageEntscheidungen verursachten Kosten lassen den Kosten-NutzenKalkülen keinen Raum - mit dem Resultat ständig wachsender Ansprüche. Da auch auf der Angebotsseite nur ein sehr rudimentärer Anreiz besteht, Wettbewerb über Kostensenkungen zu betreiben (bei gleichbleibender Qualität), haben sich Prozessinnovationen nur sehr eingeschränkt durchgesetzt. Steigende Ausgaben haben aber wiederum steigende Beitragssätze zur Folge, was das Anspruchsdenken noch fördert, im Krankheitsfalle das Bestmögliche aus dem System herauszuholen. Es bildet sich ein "Teufelskreis des Gesundheitswesens" (Oberender/Hebborn/Zerth, 2002, $57 \mathrm{ff}$.). Dieses rationale Verhalten ist übrigens aus ökonomischer Sicht nicht als unethisch oder gar unmoralisch zu beurteilen, sondern als rationales Handeln unter gegebenen Rahmenbedingungen. Alle Versuche der letzten Jahre, Rationalisierungseffekte zu erzielen, haben einerseits die Allokation der Beteiligten im Gesundheitswesen im Blick, die offensichtlich nicht optimal ist, übersehen aber den Institutionen-ökonomischen Einwand, vor allem die Anreizstrukturen der Beteiligten und das dadurch beeinflusste Verhalten bei jeder gesellschaftlichen Reform zu betrachten (Oberender/Fleischmann, 2002, 27). 


\section{Reformoptionen im Gesundheitswesen}

\subsection{Ordnungspolitische Neuorientierung}

Jede ordnungspolitische Reform des Gesundheitswesens muss sich danach orientieren, welche Zielsetzung(en) ein Gesundheitssystem einnehmen soll. Auf den ersten Blick könnte die Antwort lauten, es soll eine ausreichende Versorgung mit medizinischen Gütern und Dienstleistungen zur Verfügung stehen, und diese müssten auch entsprechend finanziert werden. In diesem Sinne ist auch die Diskussion um eine Erweiterung der Bemessungsgrundlage zu verstehen. Nur welche Konsequenzen für die Ausgestaltung eines Gesundheitssystems und vor allem für die Steuerungsmechanismen sind damit impliziert?

In einer pluralistischen Gesellschaft ist aber zu berücksichtigen, dass es häufig ein Kontinuum an unterschiedlichen Gesundheitszielen gibt und auf verschiedenen gesellschaftlichen Ebenen unterschiedliche Gesundheitsziele erreicht werden sollen. Auch der Sachverständigenrat für die konzertierte Aktion im Gesundheitswesen hat im Laufe der Jahre ein Mehr-Ebenen-Zielsystem entwickelt (Henke/Hesse, 1999, 249 ff.). Die individuelle Vorstellung korrespondiert mit der Erhaltung und Verbesserung des (individuellen) Gesundheitszustandes. Eine zweite Ebene möchte die Ausrichtung der Versorgung der Bürger an unterschiedliche Präferenzen und Zielsetzungen (Effizienz, Solidarität, Eigenverantwortung), und eine dritte Ebene fokussiert vorrangige Aufgabenfelder zur Erfüllung spezieller Versorgungsbedürfnisse (z. B. die Versorgung chronisch Kranker).

Die Gesundheitspolitik in einer pluralistischen Gesellschaft ist also eingebettet in die Prinzipien einer freiheitlichen Ordnung. ${ }^{2}$ Es gilt nun die ordnungspolitische Grundsatzentscheidung zu treffen, ob die Grundprinzipien einer derartigen Ordnung, nämlich Selbstbestimmung und Eigenverantwortung, auch im Gesundheitswesen gelten sollen. Vor dem Hintergrund der zu untersuchenden Fragestellung ist die Möglichkeit einer Alternative zum umlagefinanzierten Gesundheitssystem zu suchen.

\subsection{Ordnungspolitische Agenda}

Ziel einer freiheitlichen Reform des Gesundheitswesen muss es sein, die Ursachen von Ineffizienzen zu bekämpfen und systemimmanente, in-

2

Gäfgen (1989) stellt unterschiedliche distributive Begründungsansätze dar. Er verweist jedoch darauf, dass "Gesundheitspolitik ... zu einem guten Teil Verteilungspolitik (sei), aber ... nicht nur das" (43). 
dividuelle Anreize zu implementieren. Das Zusammenwirken von Handlungsfreiheit und Verantwortung als allgemeines Prinzip einer freiheitlichen Ordnung muss dementsprechend sowohl für die Versicherten als auch für die Krankenkassen und die Leistungserbringer gelten. Die Aufgabe des Staates würde sich darauf beschränken, allgemeine Regeln als Ordnungsregeln zu setzen, die konkrete Ausgestaltung der Gesundheitsversorgung jedoch dem Zusammenspiel der beteiligten Akteure zu überlassen.

Ein Gegenmodell zum System der gegenwärtigen gesetzlichen Krankenversicherung steht vor der Frage, ob denn Solidarität tatsächlich innerhalb der gesetzlichen Krankenversicherung verwirklicht werden muss und insbesondere, ob das Prinzip der einkommensabhängigen Beiträge bei beitragsunabhängigen Leistungen ein Ausdruck der Solidarität mit den Schwächsten ist. Wie bereits ausgeführt, sind die Verteilungswirkungen des gegenwärtigen Systems intransparent und ungewiss. Soll zugunsten einkommensschwacher Personen eine Umverteilung stattfinden, die sicherstellt, dass niemand aufgrund fehlender Kaufkraft von notwendigen Gesundheitsleistungen ausgeschlossen ist, dann sollte die Umverteilungsaufgabe konsequenterweise ins allgemeine Staatsbudget überführt werden.

Die Aufgaben der Versicherung und der Umverteilung würden insofern getrennt. Der Staat hätte als Grundprämisse eine allgemeine Versicherungspflicht zu setzen. Diese Versicherungspflicht bezöge sich auf einen (politisch zu definierenden) Regelleistungskatalog. Wie die Versicherten ihrer Versicherungspflicht im Einzelfall nachkommen, entspräche der Verantwortung der Versicherten und der Versicherer. In diesem System könnten die einzelnen Versicherten durchaus mittels aktuarischer Prämien versichert werden, d. h. entsprechend ihrem individuellen Risiko. Ökonomisch Schwache würden über eine Subjektförderung, der Idee des „Versicherungsgeldes“ entsprechend, die nötige solidarische Unterstützung erhalten.

\section{Beispiel:}

Ein multimorbider Mensch hätte eine Jahresprämie von 110.000 Euro zu zahlen. Die zumutbare Eigenleistung müsste normativ festgelegt werden. Bei einem Satz der Zumutbarkeit von 10 Prozent des steuerpflichtigen Jahreseinkommens von z. B. 30.000 Euro würde der Versicherte 3.000 Euro selbst bezahlen. Der Rest der Versicherungsprämie in Höhe von 107.000 Euro würde über ein "Versicherungsgeld" von der Allgemeinheit übernommen werden. Zur fiskalischen Absicherung kann eine Kappungsgrenze für das Versicherungsgeld eingeführt werden. 
Könnte ein derartiges System die immanenten Anreizsysteme im Gesundheitssystem lösen? Eine erste Voraussetzung ist mit der Entkoppelung der Versicherungsleistung von der Umverteilungsaufgabe geschehen. Ansonsten bleibt das Problem der Risikoselektion virulent, wenn der Beitragssatz sowohl das Versicherungs- als auch das Umverteilungsrisiko abbilden soll. Entscheidend für eine tragfähige Reform ist aber, dass die Versicherungen im Versicherungsgeldsystem eine aktivere Rolle einnehmen können. Es muss sichergestellt sein, dass die Preis-LeistungsKombination über den Status der Versicherung im Wettbewerb entscheidet. Aus diesem Grund ist nicht nur ein Wettbewerb zwischen den medizinischen Leistungserbringern zuzulassen (selektives Kontrahieren), sondern die Krankenkassen selbst müssen einer Wettbewerbsordnung unterliegen, was Formen des institutionell abgesicherten Kartells, wie etwa "einheitliche und gemeinsame" Absprachen, unmöglich machen muss (Oberender/Fleischmann, 2002, 144 ff.).

\subsection{Schritte zu einer Reform}

Die Wege zu einer grundlegenden Reform des Gesundheitswesen sind nicht ohne volkswirtschaftliche Kosten zu bewerkstelligen. Die Frage, wie ein Leitbild verwirklicht werden soll, kann theoretisch in der Schocktherapie oder in der graduellen Umsetzung liegen. Für beide Wege lassen sich Vor- und Nachteile angeben. Während eine Schocktherapie sehr schnell unumkehrbare Fakten schafft, hat die graduelle Vorgehensweise den Vorteil, die Beteiligten im Gesundheitssystem, die sich an die bisherigen Leistungen des Gesundheitssystem gewöhnt haben, behutsamer heranzuführen.

Als erster Schritt muss die Frage des Umlageverfahrens im Gesundheitssystem und damit die Bedeutung des Prinzips der Beitragssatzstabilität angegangen werden, das sich nur sozialpolitisch, jedoch nicht gesundheitspolitisch rechtfertigen lässt. Ansätze, die so genannten Lohnnebenkosten auszubezahlen und damit in die Entscheidungshoheit des einzelnen Versicherten zu überführen, wären ein Schritt in Richtung zu mehr Eigenverantwortung und Transparenz. Im Anschluss daran wären auch die generelle Pflicht zum Sachleistungsprinzip sowie die mangelnde medizinische und ökonomische Transparenz nicht mehr aus dem System heraus zu legitimieren. Entscheidend bleibt jedoch, ob die politisch Handelnden den Weg zu einer grundlegenden Reform des Gesundheitssystems eingehen wollen und dabei auch bewusst die Chancen eines wachsenden Gesundheitsmarktes berücksichtigen. 


\section{Zusammenfassung}

Die Auseinandersetzung um eine Erweiterung der Bemessungsgrundlage in der GKV knüpft unmittelbar an der erodierenden Finanzierungsbasis des sozialen Sicherungssystems an. Durch die bisherige Anknüpfung an Einkünfte aus unselbstständiger Beschäftigung wurde einem sozioökonomischen Gesellschaftsmodell gefolgt, das die Herausforderungen der Zeit nicht mehr adäquat abbilden kann. Ansatzpunkte zur Erweiterung der Bemessungsgrundlage können zwar einen kurzfristigen fiskalischen Effekt einnehmen und nähern sich wieder stärker dem Leistungsfähigkeitsprinzip an, an den grundlegenden Steuerungsproblemen des Gesundheitswesens gehen sie aber vorbei.

Eine zukunftsorientierte Reform muss die Anreizbeziehungen der Beteiligten in den Mittelpunkt der Überlegungen stellen. Es ist also weniger die Frage, wie die Finanzierungsbasis der GKV verbessert werden kann, sondern wie den beteiligten Akteuren im System adäquate Anreize zum effektiven und effizienten Umgang mit knappen Ressourcen an die Hand gegeben werden. Durch eine ordnungspolitische Neuorientierung, die im Sinne einer allgemeinen Versicherungspflicht und einer Trennung von Versicherungsmarkt und Umverteilungsebene Verwerfungen vermeiden hilft, kann ein Weg zu einem zukunftsfähigen Gesundheitswesen gefunden werden.

\section{Literatur}

Bundesministerium für Gesundheit (Hrsg.): Daten des Gesundheitswesens, Ausgabe 1999, in Schriftenreihe des Bundesministeriums für Gesundheit, Bd. 12. BadenBaden 1999.

Gäfgen, G. (1989): Gesundheit, Gerechtigkeit und Gleichheit: Distributive Ansätze der Gesundheitsversorgung, in: Gäfgen, G./Oberender, P. (Hrsg.): Verteilungsziele und Verteilungswirkungen im Gesundheitswesen, Baden-Baden.

Henke, K. D./Hesse, M. (1999): Gesundheitswesen, in: Korff, W. et al. (Hrsg.): Handbuch der Wirtschaftsethik, Band 4: Ausgewählte Handlungsfelder, Gütersloh, S. 249289.

Knappe, E. (2001): Öfnung des deutschen Gesundheitssystems zum gemeinsamen Markt, in: Schmähl, W. (Hrsg.) Möglichkeiten und Grenzen einer nationalen Sozialpolitik in der Europäischen Union, Berlin, S. 137-176. 
Oberender, P./Fleischmann, J. (2002): Gesundheitspolitik in der sozialen Marktwirtschaft. Analyse von Schwachstellen und Perspektiven einer Reform, Stuttgart 2002.

Oberender, P./Hebborn, A./Zerth, J. (2002): Wachstumsmarkt Gesundheit, Stuttgart 2002.

Oberender, P./Zerth, J. (2002): Gesundheitspolitik in Deutschland, 2. Auflage, Bayreuth.

Sachverständigenrat für die Konzertierte Aktion im Gesundheitswesen (1994): Gesundheitsversorgung und Krankenversicherung 2000: Eigenverantwortung, Subsidiarität und Solidarität bei sich ändernden Rahmenbedingungen, Baden-Baden.

Sauerland, D. (1999): Zur Notwendigkeit einer anreizorientierten Gesundheitspolitik, in: Zeitschrift für Wirtschaftspolitik, Jg. 48 (1999), Heft 3, S. 265-294.

Wille, E. (1998): Zukünftige finanzielle Absicherung des Krankheitsrisikos, in: Arbeit und Sozialpolitik, 1-2 (1998), S. 16-27.

Wille, E. (2002): Reformoptionen der Beitragsgestaltung in der gesetzlichen Krankenversicherung, in: Gesundheit und Gesellschaft: Wissenschaft, Ausgabe 3 (2002), 7-14. 


\section{Kapitaldeckung und höhere Rentner-Beiträge zur ergän- zenden Finanzierung demographischer Effekte in der GKV}

Dieter Cassel

\section{Zentrale Herausforderungen der Gesundheitspolitik}

Noch bis zur Bundestagswahl im Herbst 2002 haben sich Kassenverbände und Gesundheitspolitik im Euphemismus über die finanzielle Lage der gesetzlichen Krankenversicherung (GKV) überboten. Inzwischen mussten die meisten Kassen ihre Beitragssätze zum Teil beträchtlich anheben, so dass der durchschnittliche Beitragssatz in der GKV bis Ende 2002 auf 14 Prozent angestiegen ist. Große Publikumskassen starteten in das Jahr 2003 mit Beitragssätzen, die noch vor wenigen Jahren als undenkbar galten. So mussten z. B. DAK und AOK BadenWürttemberg ihre allgemeinen Beitragssätze um satte 0,7 Punkte auf 15,2 Prozent bzw. 14,9 Prozent erhöhen, während die Barmer Ersatzkasse und die Kaufmännische Krankenkasse ihre Beitragssätze "nur" um 0,4 und 0,3 Punkte auf 14,9 Prozent bzw. 14,8 Prozent anzupassen brauchten. Die gesundheitspolitischen Akteure wurden dadurch rasch wieder auf den harten Boden der Tatsachen zurückgeholt.

Die alte und neue Bundesgesundheitsministerin Ulla Schmidt hat dann auch gleich nach den Wahlen auf die absehbare Beitragssatzentwicklung mit einem dirigistischen Notprogramm reagiert: Mit dem am 15. November 2002 vom Bundestag verabschiedeten BeitragssatzSicherungsgesetz (BSSichG) werden Honorare und Budgets für Ärzte, Zahnärzte und Krankenhäuser gedeckelt sowie Apotheken, Pharmagroßhandel und Arzneimittelhersteller zu Zwangsabgaben verpflichtet. Hierdurch sollen die Kassen im Jahr 2003 um 3,4 Mrd. Euro entlastet und verpflichtet werden, ihre Beitragssätze stabil zu halten. Gerechtfertigt wird diese neuerliche Welle staatlicher Dirigismen im Gesundheitswesen mit der angeblichen Notwendigkeit, den akuten Problemdruck zu verringern und Zeit zur Vorbereitung einer für 2004 in Aussicht gestellten durchgreifenden Strukturreform der GKV zu gewinnen. Angesichts der Tatsache, dass die derzeitige Bundesregierung schon eine Legislaturperiode im Amt ist und zu allen Problembereichen des Gesundheitswesens erschöpfende Expertisen vorliegen, ${ }^{1}$ ist der reklamierte Zeitbedarf zur

Siehe z. B. die inzwischen stattliche Zahl der Gutachten des Sachverständigenrates für die konzertierte Aktion im Gesundheitswesen (zuletzt: SVR KaiG 2001), das letzte Jahresgutachten des Sachverständigenrates zur Begutachtung der gesamtwirtschaftlichen Entwicklung (SVR 2002, S. 237 ff., 339 ff. und 427 ff.) o- 
Erstellung eines schlüssigen Reformkonzepts einigermaßen verwunderlich. Zudem läuft die Gesundheitspolitik Gefahr, dass längere Zeit über das zu erwartende Reformpaket spekuliert und einzelne, im Kontext eines umfassenden Konzepts durchaus erwägenswerte Maßnahmen im vorparlamentarischen Interessenkampf auf der Strecke bleiben.

So vergeht derzeit kaum ein Tag, an dem nicht "Gesundheitsexperten" aus Politik, Verbänden, Räten und Kommissionen mit einzelnen Reformvorschlägen an die Öffentlichkeit treten. Dabei kann man sich nicht des Eindrucks erwehren, dass manche dieser Ideen - wie Wahl- und Zusatztarife, Bonus- und Malusmodelle, wählbare Selbstbeteiligungen, Qualitätssicherungsagenturen, GKV-weite Arzneimittellisten oder Änderungen der Versicherungspflicht- und Beitragsbemessungsgrenze - eher „Reformarabesken" sind und vom Kern der Problematik ablenken. Die Gesundheitspolitik steht nämlich längerfristig vor drei zentralen Herausforderungen: die Qualität und Wirtschaftlichkeit der Versorgung wesentlich zu verbessern, den Versicherungs- und Gesundheitsleistungsmarkt europatauglich zu machen und die solidarische Finanzierbarkeit nachhaltig sicherzustellen. Während die ersten beiden Herausforderungen durch wettbewerbliche Steuerung aller Bereiche des Gesundheitswesens unter Wahrung des Solidarprinzips - d. h. im Rahmen einer konsequent ausgebauten "Solidarischen Wettbewerbsordnung" - reformpolitisch relativ leicht zu meistern wären (Cassel 2002; 2003), scheint es gegen die dritte Herausforderung keine schmerzfreie Therapie zu geben. Dies deshalb, weil das in der GKV praktizierte Umlageverfahren nicht demographieresistent ist und angesichts des demographischen Wandels nur drei Lösungsalternativen zulässt: den GKV-Leistungskatalog drastisch einzuschränken, die Finanzierungsbasis der GKV durch Einbeziehung von anderen Einkunftsarten und bisher beitragsfrei Mitversicherter zu verbreitern oder eine Beitragssatzexplosion in der GKV hinzunehmen. Wer diese "hard choices" vermeiden will, kommt nicht darum herum, die Umlagefinanzierung durch eine Kapitaldeckungskomponente zu ergän-

der den Schlussbericht der Enquête-Kommission Demographischer Wandel (2002) zu den Herausforderungen unserer älter werdenden Gesellschaft an den Einzelnen und die Politik. Die zuletzt genannte Expertise, die am 28. März 2002 dem Deutschen Bundestag vorgelegt wurde, ist derart aufschlussreich, dass die von der Bundesgesundheitsministerin am 21. November 2002 eingesetzte „Rürup-Kommission" für die Nachhaltigkeit in der Finanzierung der sozialen Sicherungssysteme überflüssig erscheint, will man darin nicht die Fortsetzung des in vielerlei Hinsicht fragwürdigen Politikstils der „runden Tische" (Engelhard/Fehl/ Geue 1998) erblicken. Ein aus der Vielzahl der vorliegenden Expertisen zusammengestellter „Referentenentwurf" für ein in sich schlüssiges Reformkonzept hätte zudem die getrennte und weitgehend sachwidrige Diskussion von einnahmen- und ausgabenseitigen Reformoptionen vermieden (Henke 2003). 
zen, aus der künftig zusätzliche Beiträge zur Finanzierung der GKV geleistet werden könnten.

\section{Demographischer Wandel und Beitragssatzexplosion in der GKV}

Der absehbare demographische Wandel vollzieht sich in einem "doppelten Alterungsprozess" der Gesellschaft: Zum einen wachsen nur schwach besetzte Jahrgänge nach, weil die Geburtenhäufigkeit seit Jahrzehnten auf einem historisch niedrigen Niveau verharrt; zum anderen nimmt die Lebenserwartung immer noch kontinuierlich zu. Beides lässt den Rentnerquotienten und das Durchschnittsalter der Bevölkerung ständig steigen. Dieser Alterungsprozess wird unter Status-quoBedingungen unweigerlich zu einer "Beitragssatzexplosion" in der GKV führen, weil von inm beachtliche Beitragssatz treibende Effekte ausgehen (Cassel 2001; Enquête-Kommission Demographischer Wandel 2002, S. $39 \mathrm{ff}$. und $409 \mathrm{ff}$.):

- Nimmt der Rentnerquotient zu, werden die Erwerbstätigen stärker zur Finanzierung der Gesundheitsausgaben für die Betagten herangezogen, weil deren beitragspflichtige Einkommen im Durchschnitt deutlich unter denen der Erwerbstätigen liegen (Abb. 1). Dies folgt aus dem in der GKV angelegten "Generationenvertrag", nach dem im Umlageverfahren die Erwerbstätigen die Rentner mitfinanzieren (Finanzierungseffekt).

- Nach der "Medikalisierungsthese" nimmt die Inanspruchnahme von Gesundheitsleistungen mit dem Alter stark zu; sie wird zudem durch den bei Alterskrankheiten und Krankheiten im Alter besonders relevanten medizintechnischen Fortschritt noch verstärkt, so dass die altersspezifischen Ausgabenprofile im Laufe der Zeit immer "steiler" werden (BuchnerMasem 2000; Abb. 1). Steigende Lebenserwartung und Rentnerlast gehen deshalb mit progressiv wachsenden Gesundheitsausgaben einher (Ausgabeneffekt). ${ }^{2}$

2 Zugegebenermaßen ist die "Medikalisierungsthese" nicht unumstritten. Vertreter der "Kompressionsthese" gehen denn auch davon aus, dass die Morbidität im höheren Alter dank einer immer leistungsfähigeren Medizin und Prävention nur noch geringfügig zunimmt und die Leistungsausgaben allenfalls kurz vor dem Tode stärker ansteigen. Dementsprechend schätzen sie die Beitragsdynamik weit geringer ein und warnen vor dem „Horrorszenario“ einer „Beitragssatzexplosion". Siehe z. B. Brockmann 2000; Kühn 2001; Kruse 2002; Pfaff 2002; Reinhardt 2002; Schmähl 2002. Abgesehen davon, dass dieser Disput lediglich den Ausgabeneffekt betrifft, muss zu denken geben, dass in der risikoäquivalent kalkulierenden privaten Krankenversicherung (PKV) die Prämie auf einer Risikoba- 
Abb. 1: Altersabhängige Beiträge und Leistungen in der GKV (schematische Darstellung)

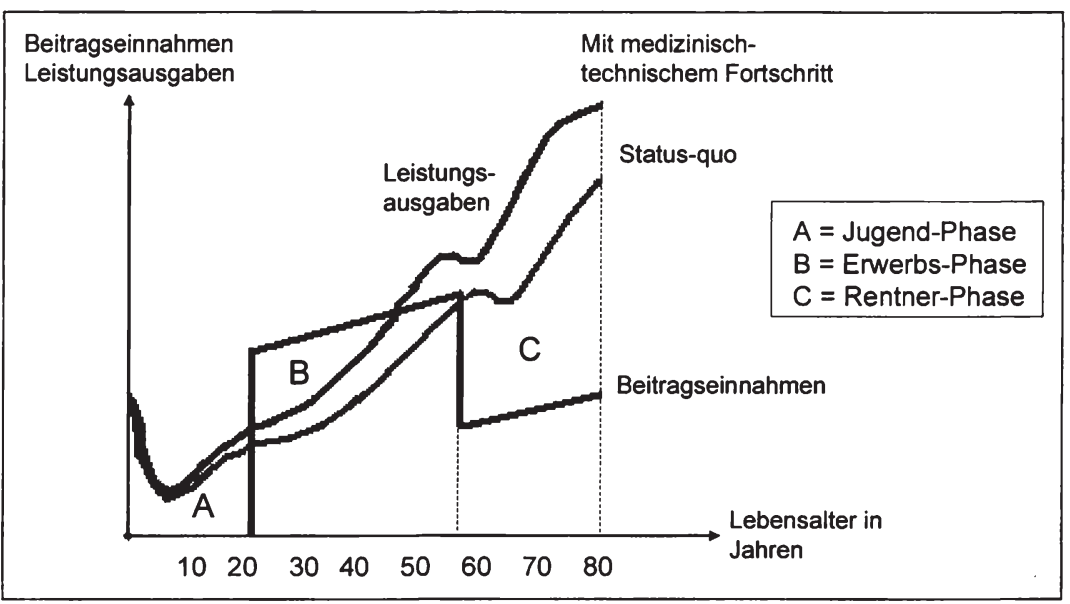

Neuere Schätzungen kommen denn auch bei expliziter Berücksichtigung des medizintechnischen Fortschritts einhellig zu dem Ergebnis, dass etwa vom Jahr 2010 an merklich steigende Beitragssätze erforderlich sein werden, um die demographiebedingt wachsende Lücke zwischen Ausgaben und Einnahmen in der GKV zu schließen. Wie Tabelle 1 zeigt, wird für das Jahr 2040 je nach Schätzansatz mit einem GKV-durchschnittlichen Beitragssatz zwischen 20,5 und 34 Prozent gerechnet.

sis - d. h. ohne Alterungsrückstellungen - für einen 30-jährigen Mann bei 97 Euro pro Monat liegt, während sie sich für einen 60-/70-/80-jährigen auf 235/368/514 Euro pro Monat stellt (Zahlen aus der PKV für 2002). Die Risikoprämie eines 70-jährigen Mannes beläuft sich demnach auf das 3,8fache, die eines 80 -jährigen auf das 5,3fache der Prämie eines 30-jährigen! Außerdem verteuert sich die PKV bei Prämienerhöhungen für ältere Versicherte regelmäßig stärker als für jüngere. Es ist deshalb nicht verkehrt, bei der Berechnung der künftigen Beitragssatzentwicklung die "Medikalisierungsthese" zu unterstellen und wenn auch nur als "Worst-Case-Szenario". 
Tab. 1: Neuere Status-quo-Prognosen des GKV-Beitragssatzes bis 2040

\begin{tabular}{|c|c|}
\hline $\begin{array}{l}\text { Institut } \\
\text { Autor }\end{array}$ & $\begin{array}{c}\text { Maximaler } \\
\text { Beitragssatz } \\
\text { im Jahr } 2040\end{array}$ \\
\hline $\begin{array}{l}\text { Institut der deutschen Wirtschaft (IdW) Köln } \\
\text { Bernd Hof (2001) }\end{array}$ & $20,5 \%$ \\
\hline $\begin{array}{l}\text { Universität Konstanz/Greifswald } \\
\text { Friedrich BreyerNolker Ulrich (2000) }\end{array}$ & $23,0 \%$ \\
\hline $\begin{array}{l}\text { Universität Freiburg } \\
\text { Stefan Fetzer/Bernd Raffelhüschen (2002) }\end{array}$ & $24,7 \%$ \\
\hline $\begin{array}{l}\text { Universität Duisburg } \\
\text { Veit Oberdieck (1998) }\end{array}$ & $31,2 \%$ \\
\hline $\begin{array}{l}\text { Universität Münster } \\
\text { Dirk Sauerland (2002) }\end{array}$ & $31,2 \%$ \\
\hline $\begin{array}{l}\text { Deutsches Institut für Wirtschaftsforschung (DIW) Berlin } \\
\text { Friedrich Breyer/Markus Grabka/Klaus Jacobs u. a. (2001) }\end{array}$ & $34,0 \%$ \\
\hline
\end{tabular}

Legt man die eher pessimistische Prognose von Oberdieck (1998) zugrunde, ist 2040 mit einem Beitragssatz von 31,2 Prozent zu rechnen, von dem fast 24 Prozentpunkte für die Krankenversicherung der Rentner aufzuwenden sind (Abb. 2). Um die nach der Oberdieck-Prognose zu erwartende "Dramatik" noch deutlicher zu machen, lässt sich die Beitragssatzentwicklung für die Erwerbstätigen und Rentner getrennt berechnen. Wie Abbildung 3 zeigt, würde der rechnerische Beitragssatz in einer fiktiven Rentner-Krankenversicherung (RKV) bis 2040 auf 141,4 Prozent steigen, während er in der fiktiven ErwerbstätigenKrankenversicherung (EKV) sogar von gegenwärtig 9 Prozent auf 8 Prozent sinken würde. Wenngleich es sich bei diesen Berechnungen nur um "Status-quo-Prognosen" handelt, wird zumindest eines klar: Der "Härtetest" für das GKV-System und die Gesundheitspolitik steht erst noch bevor. 
Abb. 2: Beitragssatzentwicklung in der GKV und Subventionsbedarf der Rentner-Krankenversicherung in Beitragssatzpunkten, 1970 - 2040

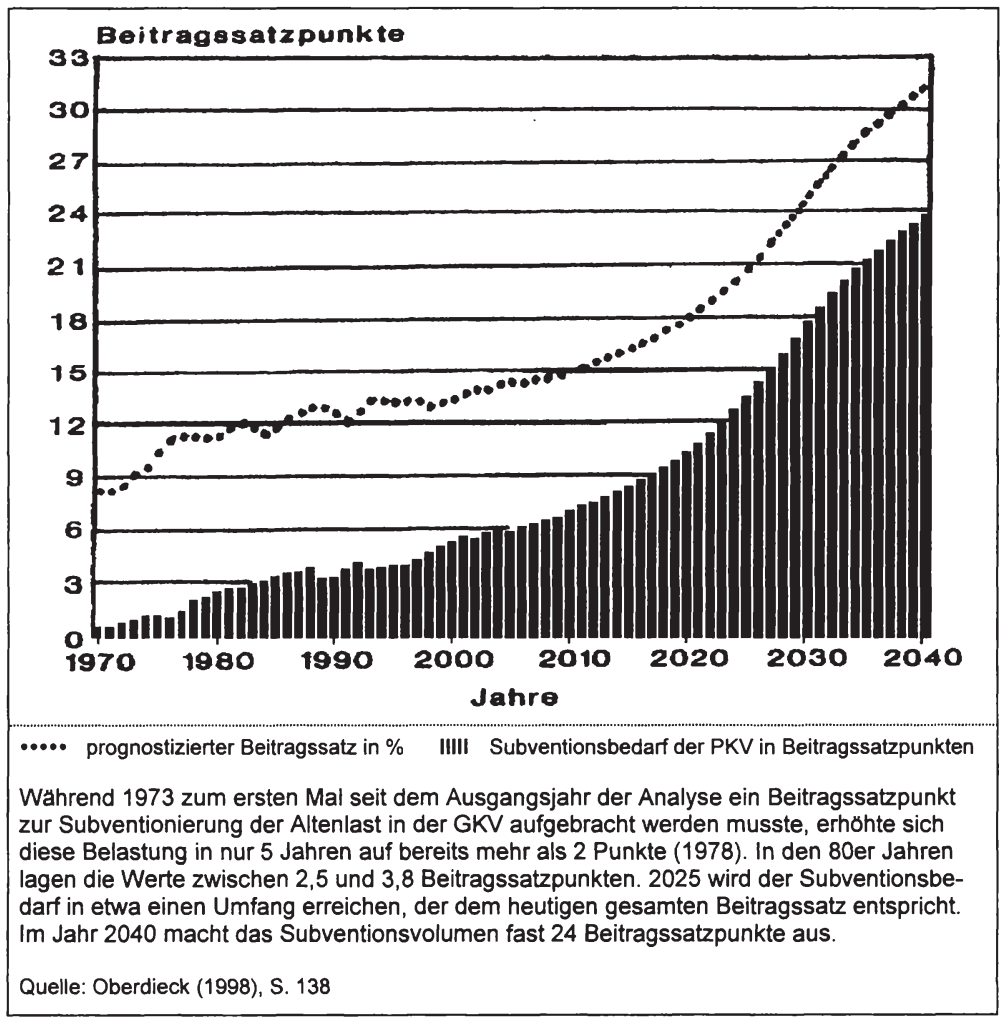


Abb. 3: Beitragssatzentwicklung in der GKV mit und ohne intergenerativem Solidarausgleich auf Grundlage der Oberdieck-Prognose, 1991 - 2040

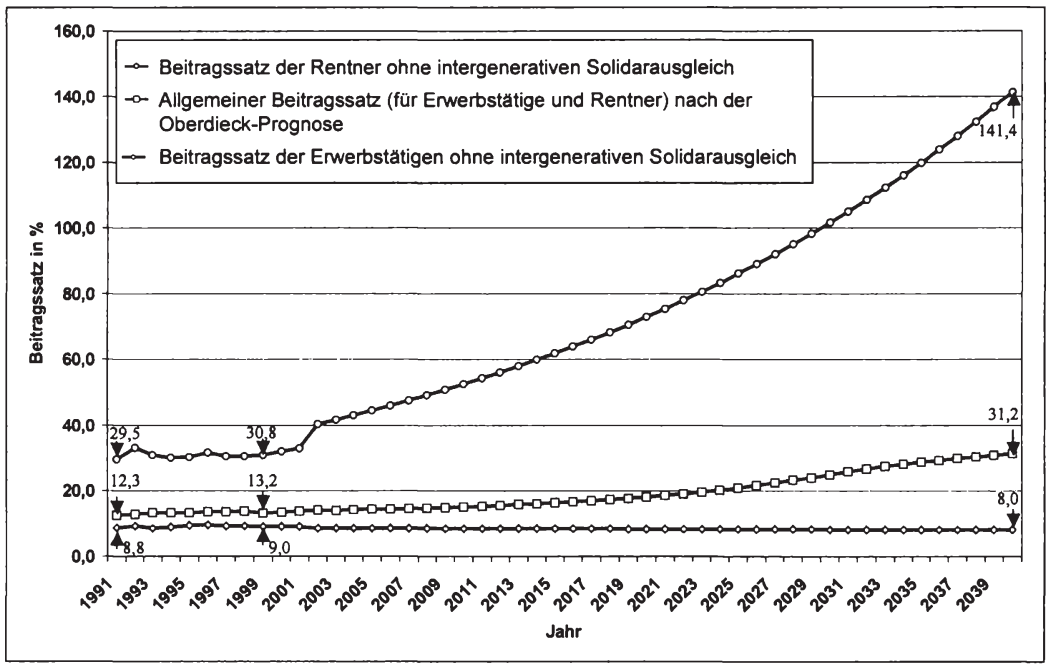

So wichtig die oben genannte Reformoption "Wettbewerb" und die von ihr unter anderem zu erwartende Ausschöpfung von Wirtschaftlichkeitspotenzialen auch sind, sie ändern nichts daran, dass die Beitragssätze demographisch bedingt in den nächsten Jahrzehnten merklich ansteigen werden, wenn das hohe Versorgungsniveau gehalten und wie bisher im Umlageverfahren finanziert werden soll. Und selbst eine merkliche Verbreiterung der Beitragsbemessungsgrundlage oder die Finanzierung der versicherungsfremden Leistungen der GKV aus dem allgemeinen Steueraufkommen wird nur einen temporären Entlastungseffekt bewirken. Will man die durch den demographischen Wandel in Verbindung mit dem medizintechnischen Fortschritt künftig zu erwartende Beitragssatzdynamik vermeiden oder zumindest abschwächen, müsste deshalb unverzüglich mit einer GKV-spezifischen Kapitalrückstellung begonnen werden. $^{3}$

3 Die Erkenntnis der Notwendigkeit einer ergänzenden Kapitaldeckung auch in der sozialen Krankenversicherung ist ein wesentliches Motiv für den Vorschlag, die GKV auf Kopf- bzw. Pauschalprämien nach Schweizer Muster umzustellen und diese so zu kalkulieren, dass sie eine Kapitalstockbildung ermöglichen. Siehe hierzu Henke/Grabka/Borchardt 2002; Henke/Johannßen/Neubauer/Rumm/ Wasem 2002; Knappe/Arnold 2002. Im Unterschied dazu wird hier ein Konzept vertreten, das mit einkommensproportionalen Beiträgen vereinbar ist und insofern keinen Systemwechsel erfordert (Cassel/Oberdieck 2002). Entsprechend modifiziert, wäre es freilich auch in einem Kopfprämien-Modell realisierbar, das 


\section{Generationenvertrag und intergenerative Solidarität in der GKV}

Um zu verstehen, warum auch in der GKV kein Weg an einer ergänzenden Kapitaldeckung vorbeiführt, muss man sich den Finanzierungsmechanismus der in Bismarck'scher Tradition konzipierten sozialen Sicherungssysteme - wie die gesetzliche Renten- (GRV), Kranken- (GKV) und Pflegeversicherung (GPV) - verdeutlichen. Er besteht darin, dass die laufenden Ausgaben für Rentenzahlungen, Gesundheits- und Pflegeleistungen durch Beiträge gedeckt werden, die aus den laufenden Arbeitseinkommen der Erwerbstätigen aufzubringen sind, d. h., die Ausgaben einer Periode werden auf die beitragspflichtigen Einkünfte derselben Periode umgelegt. In diesem Umlageverfahren konkretisiert sich der so genannte Generationenvertrag, nach dem sich die jeweilige Erwerbstätigengeneration verpflichtet, die gleichzeitig lebende Rentnergeneration zu versorgen - und dies im Vertrauen darauf, dass die nachwachsende Generation Entsprechendes tut, wenn die jetzige Erwerbstätigengeneration in die Rentner-Phase eintritt. Dies gilt in reiner Form für die GRV, prägt aber auch die GKV: Die Überdeckung der Gesundheitsausgaben in der Erwerbs- und die Unterdeckung in der Rentner-Phase (Abb. 1) sind ebenso ein Beleg dafür, wie die in Beitragssatzpunkten gemessene "Subventionierung" der Rentner- durch die Erwerbstätigen-Krankenversicherung (Abb. 3). Schließlich werden die jeweils zur Hälfte von den Rentnern und der GRV gezahlten Beiträge zur GKV durch die Erwerbstätigen über die Rentenversicherungsbeiträge aufgebracht, so dass der Generationenvertrag so gesehen ohne Einschränkung auch auf die GKV zutrifft. ${ }^{4}$ Dies wird in der gesundheitspolitischen Diskussion kaum thematisiert, weil die GKV mit ihren morbiditäts-, alters-, geschlechts- und familienunabhängigen sowie einkommensproportionalen Beiträgen einen überaus weit gespannten Solidarausgleich bewirkt, in dessen vielfältigen Dimensionen die beabsichtigte Solidarität zwischen den Mitgliedern in der Erwerbs- und Rentner-Phase (intergenerative Solidarität I in Abb. 4) häufig übersehen wird.

unter allokativen und wettbewerblichen Gesichtspunkten durchaus Vorzüge gegenüber der jetzigen GKV hätte.

4 So wäre z. B. vorstellbar, dass die GRV Ausgaben deckende Beiträge für die Rentner zahlt, so dass die "Subventionierung" der RKV entfiele und die Erwerbstätigen innerhalb der GKV entlastet würden (Abb. 3). In diesem Fall hätten sie jedoch höhere Beiträge zur GRV zu leisten. 


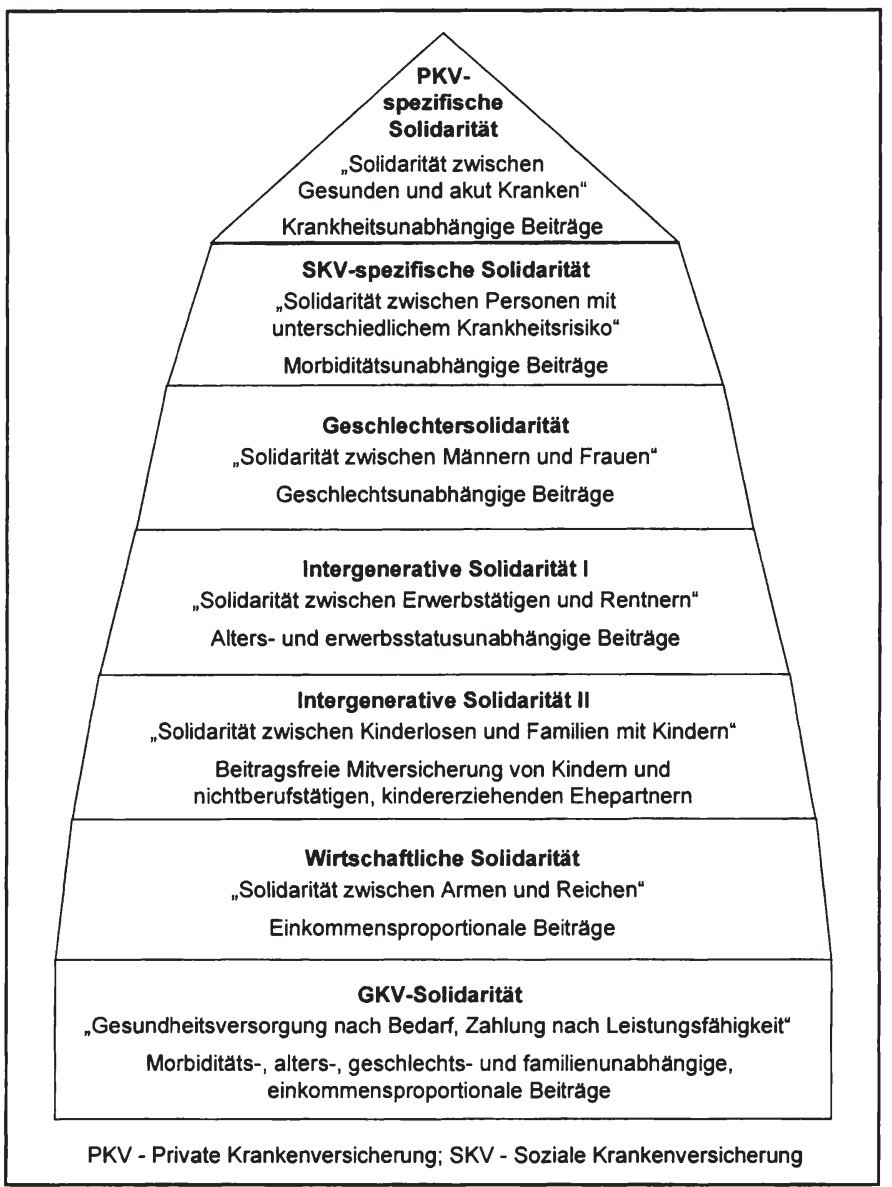

Die entscheidende Frage ist nun aber, ob der Generationenvertrag in der GKV noch intakt ist oder ob er nicht schon längst gebrochen wurde - mit der unausweichlichen Folge, dass die nachhaltige Finanzierung im Umlageverfahren nicht mehr gesichert wäre und eine Beitragssatzexplosion droht. Die Antwort hierauf erfordert einen kurzen Blick auf die Gesetzmäßigkeiten der intergenerativen Kapitalbildung, denn jede Gesellschaft hat nur zwei Möglichkeiten, für das Alter vorzusorgen: Entweder müssen ihre jungen, im erwerbsfähigen Alter stehenden Jahrgänge Humankapital bilden, indem sie Kinder in die Welt setzen, großziehen und möglichst gut ausbilden, oder sie müssen sparen und gesamtwirtschaftlich Realka- 
pital in Form sachlicher Produktionsmittel bilden ${ }^{5}$ am besten aber beides, weil Arbeit und Kapital im einkommensschaffenden Produktionsprozess komplementär, zumindest aber nicht vollständig substituierbar sind. Die "Generation 1" ist also als Erwerbstätige im Rahmen des Generationenvertrages gezwungen, zum einen die "Generation 0" ihrer Eltern aus ihrem Arbeitseinkommen als den kollektiven Erträgen aus Humankapital zu versorgen, zum anderen aber zugleich Investitionen in Humankapital und Realkapital zu tätigen (Abb. 5). Wird aufgrund individueller Investitionsentscheidungen ein privater Realkapitalstock gebildet, können die Investoren später, wenn die "Generation 1" in die Rentner-Phase eintritt, aus den daraus fließenden privaten Erträgen oder seinem Verzehr leben. Entscheiden sich Angehörige der "Generation 1", Humankapital zu bilden, $d$. h. Kinder zu bekommen und großzuziehen, tragen sie als Mitglieder der Sozialversicherung zwar die privaten Kosten dieser Investition, profitieren später aber nur kollektiv an den Beitragszahlungen ihrer Kinder, wenn diese als "Generation 2" in die Erwerbs-Phase eintreten. Die Altersvorsorge erfordert somit unter allen Umständen eine „Kapitaldeckung" - sei es als Real- oder Humankapitalstock; und die landläufige Unterscheidung in Umlage- und Kapitaldeckungsverfahren erscheint von daher in hohem Maße irreführend (Apolte 1998). ${ }^{6}$ Dennoch soll aus alter Gewohnheit daran festgehalten und das Humankapital-Deckungsverfahren weiterhin als Umlageverfahren (UV) und die Bildung eines Realkapitalstocks als Kapitaldeckungsverfahren (KV) bezeichnet werden.

5 Tatsächlich werden die Ersparnisse der Haushalte überwiegend nicht in Immobilien, Aktien oder Unternehmensanteilen angelegt, sondern in Finanzaktiva bei Banken oder auf dem Geldkapitalmarkt. Da sich, vom Zentralbankgeld einmal abgesehen, alle finanziellen Forderungen und Verbindlichkeiten in einer Volkswirtschaft saldieren und Nettoforderungen an das Ausland wie Realkapital behandelt werden können, bezieht sich das Kapitaldeckungsverfahren stets nur auf "Realkapital".

"Sicherlich ist die vielzitierte „Mackenroth-These" plausibel, nach der aller Sozialaufwand immer aus dem Nationaleinkommen der laufenden Periode gedeckt werden muss, weil Zahlungsströme, die von einer Generation zur anderen fließen, sich eben nicht "speichern" lassen. Daraus hat Mackenroth (1952, S. 43) gefolgert, dass es volkswirtschaftlich immer nur ein Umlageverfahren gäbe. Tatsächlich bedarf es aber stets eines Bestandes an Arbeit und Kapital, aus dessen Einsatz im Produktionsprozess jene Einkommen erwirtschaftet werden müssen, aus denen die Einkommenstransfers an die Rentner zu leisten sind. Demnach bleiben zur Alterssicherung immer nur die beiden Möglichkeiten der Human- und Realkapitalbildung. Siehe als Überblick dazu Postler (2002, S. 22 ff. und 34 ff.). 
Abb. 5: Kapitalbildung und intergenerative Transfers

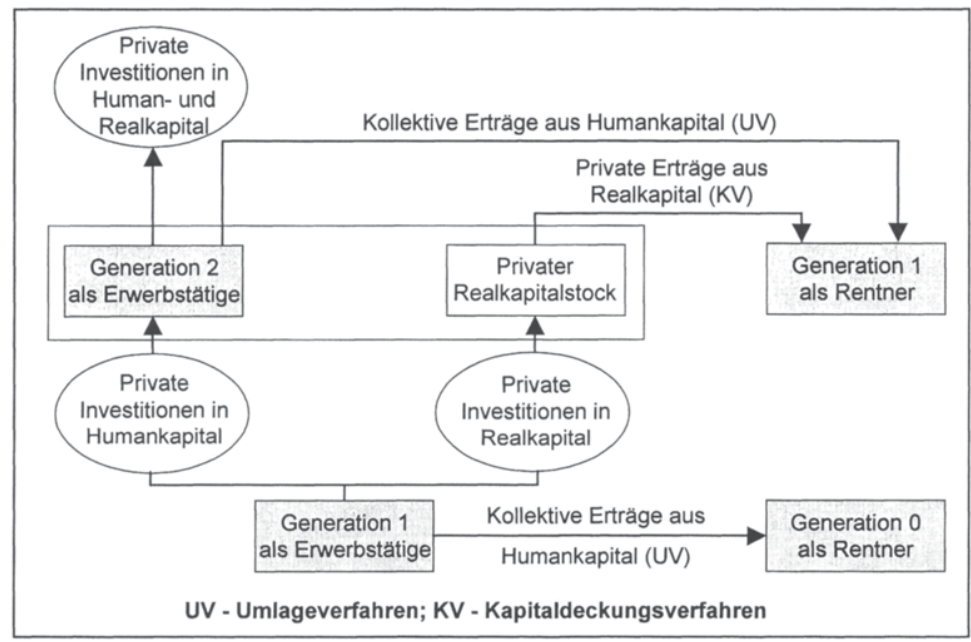

Wie eingangs bereits gezeigt wurde, ist die nachhaltige Finanzierung der GKV im Umlageverfahren ernsthaft gefährdet. Der Grund dafür liegt darin, dass die derzeitige "Generation 1 als Erwerbstätige" (Abb. 5) den Generationenvertrag durch ihre geringe Bereitschaft, in Humankapital zu investieren, also Kinder zu bekommen, großzuziehen und auszubilden, aufgekündigt hat: Die Nettoreproduktionsrate liegt seit drei Jahrzehnten bei etwa 0,65 , d. h., eine Frauengeneration im gebärfähigen Alter „reproduziert" sich nur zu 65 Prozent. Von Zuwanderungen aus dem Ausland einmal abgesehen, sind damit Schrumpfung und Alterung der Bevölkerung in Deutschland vorprogrammiert (Enquête-Kommission Demographischer Wandel 2002, S. 40 ff.). Dies wäre für sich genommen noch relativ unproblematisch, wenn statt Humankapital in ausreichendem Maße Realkapital gebildet würde; denn nur "eine Generation, die weder Human- noch Realkapital bildet, muss im Alter hungern" (Sinn 2003). Dem steht jedoch hinsichtlich der Gesundheitsversorgung im Alter das Versprechen der GKV entgegen, allen Versicherten einen „Rundumschutz" im Krankheitsfall zu gewähren. Wer jedoch darauf vertraut, bei Krankheit in jeder Lebensphase bedarfsgerecht, ausreichend und dem allgemein anerkannten Stand der medizinischen Erkenntnisse entsprechend mit dem medizinisch Notwendigen versorgt zu werden ( $\S 12$ [1] und 70 [1] SGB V), hat keinerlei Anlass, durch private Ersparnisbildung und Investition in Realkapital dafür vorzusorgen. 
Das aber hat zur Folge, dass die "Generation 1 als Rentner" (Abb. 5) zur ausreichenden Versorgung mit den notwendigen Gesundheitsleistungen in der GKV ganz und gar auf das Umlageverfahren angewiesen ist, das sie selbst mit ihrer mangelnden Fertilität in der Erwerbs-Phase unterminiert hat. So lässt sich mit Hilfe der Methode der GenerationenBilanzierung zeigen, dass inzwischen fast alle lebenden Generationen "Nettoleistungsempfänger" der GKV sind und praktisch keiner mehr auch nur annähernd den Barwert seiner voraussichtlichen Leistungsinanspruchnahme durch Beiträge aufbringt. ${ }^{7}$ Wenn aber alle Generationen nur noch Leistungen empfangen, für die sie nicht voll aufkommen, ist der Generationenvertrag längst gebrochen und zu einem „allgemeinen Bereicherungsabkommen zu Lasten künftiger Generationen" (Fetzer/ Raffelhüschen 2002, S. 11) mutiert.

\section{Zum Konzept der solidarischen Alterungsreserve}

Um das Umlageverfahren wieder funktionsfähig zu machen und die nachhaltige Finanzierbarkeit der GKV sicherzustellen, gibt es grundsätzlich drei Möglichkeiten:

- Erstens könnte man versuchen, den demographischen Wandel aufzuhalten, zumindest aber zu verlangsamen. Dazu wäre eine beträchtliche Erhöhung der Fertilität wie der Zuwanderung erforderlich (Enquête-Kommission Demographischer Wandel 2002, S. 57 ff.). Diese Politikoption dürfte nur schwerlich und nicht rasch genug gegen die Interessen der Bevölkerung und insbesondere der jüngeren Generation zu realisieren sein; außerdem käme sie für eine merkliche Entlastung der GKV zu spät.

- Zweitens ließe sich analog zur "Riester-Rente" der Aufbau eines privaten Realkapitalstocks forcieren. Dies würde freilich zwingend voraussetzen, dass der GKV-Leistungskatalog drastisch gekürzt und eine kapitalgedeckte Versicherung gegen die herausgefallenen Risiken zur Pflicht gemacht wird. Auch müssten dann sozial Schwache Transfers aus Steuermitteln erhalten, um sich diese Versicherung

7 Fetzer/Raffelhüschen (2002, S. 9 ff.) errechnen eine bereits jetzt aufgelaufene „implizite und statistisch nicht dokumentierte Verschuldung" der GKV in Höhe von 4,1 Bio. Euro, das sind beachtliche 203,8 Prozent des Bruttoinlandsproduktes (BIP). Dieses Ergebnis der Generationenbilanzierung ist die Kehrseite der von den Autoren unter Status-quo-Bedingungen prognostizierten Beitragssatzexplosion (auf 24,7 Prozent 2040; Tab. 1). 
leisten zu können. ${ }^{8}$ Diese Handlungsoption wird politisch kaum durchsetzbar sein, bedeutet sie doch einen Bruch mit dem gewachsenen GKV-System.

- Drittens schließlich könnte das Umlageverfahren der GKV durch ein Verfahren zur kollektiven Bildung von Realkapital in Form einer GKV-spezifischen "Solidarischen Alterungsreserve (SAR)" ergänzt und mit einer höheren Beitragsbelastung der künftigen Rentner verbunden werden (gestrichelte Linien in Abb. 6). Hierdurch würde die Finanzierung der Rentner-Krankenversicherung künftig auf drei Säulen ruhen: wie schon bisher auf den kollektiven Erträgen aus Humankapital, auf den kollektiven Erträgen oder dem Verzehr des kollektiv gebildeten Kapitalstocks sowie zusätzlich auf einer höheren Eigenleistung der Rentner.

Dieser Vorschlag hat mancherlei Vorteile: $\mathrm{Er}$ ist vereinbar mit den Grundprinzipien des GKV-Systems, setzt den Generationenvertrag wieder in Kraft, schafft mehr Generationengerechtigkeit und wäre zudem kurzfristig realisierbar. Sein entscheidender Nachteil besteht allerdings darin, dass die Bildung der SAR nicht ohne sofortige Beitragssatzerhöhung zu haben ist und von daher auf politischen Widerstand stoßen dürfte.

So schlagen Fetzer/Raffelhüschen (2002, S. 13 ff.) vor, die Zahnarzt- und Zahnersatzleistungen schrittweise aus dem GKV-Leistungskatalog auszugliedern, wodurch sich die bereits erwähnte "implizite Verschuldung" der GKV von 203,8 auf 167,8 Prozent des BIP verringern ließe (S. 17). Auf die Frage, wie dies sozial verträglich geschehen und zur privaten Kapitalbildung genutzt werden könnte, geben sie keine Antwort. Auch die wiederholte Forderung nach Aufteilung des GKV-Leistungskatalogs in Grund- und Wahlleistungen ließe sich unter diese Option subsumieren, falls mit "Grundleistungen" eine Versorgung gemeint ist, die auch nicht annähernd mehr das "Notwendige und Ausreichende" (§§ 12 [1] und 70 [1] SGB V) gewährleistet. 
Abb. 6: Kapitalbildung und intergenerative Transfers mit solidarischer Alterungsreserve in der GKV

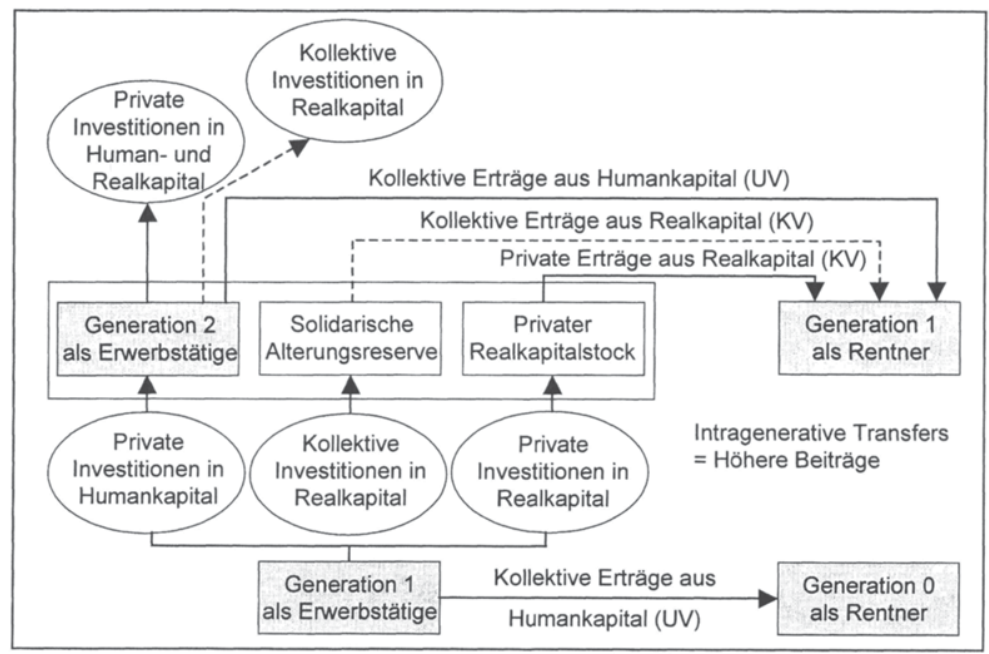

Die Idee einer ergänzenden Kapitaldeckung in der GKV ist eine Analogie zur PKV mit ihrer Bildung von Alterungsrückstellungen nach dem Anwartschafts-Deckungsverfahren (Terhorst 2000, S. 67 ff.): Um die mit dem Alter steigende Inanspruchnahme von Gesundheitsleistungen auszugleichen und keine altersbedingten Prämienerhöhungen vornehmen zu müssen, führen die privaten Krankenversicherungen einen Teil der Prämieneinnahmen ihrer jüngeren Versicherten einer zu verzinsenden Alterungsrückstellung zu, aus der Deckungsbeiträge zugesetzt werden, sobald die mit dem Alter zunehmenden Pro-Kopf-Ausgaben die altersabhängig nicht steigenden Prämien dieser Versicherten überschreiten.

Analog dazu könnten in der GKV die Beitragssätze in den nächsten Jahren um jeweils kasseneinheitliche "Beitragssatzaufschläge" angehoben werden, um aus den daraus zu erzielenden Mehreinnahmen einen Kapitalstock als Alterungsreserve zu bilden. Dieser wäre wie die Alterungsrückstellungen in der PKV verzinslich anzulegen und den Beitragseinnahmen der GKV wieder zuzusetzen, sobald die ausgabendeckenden Beitragssätze demographisch bedingt steigen und eine gesundheitspolitisch zu setzende Toleranzschwelle überschreiten. Damit wird, vordergründig betrachtet, die Absicht verfolgt, zur nachhaltigen Wahrung der Beitragssatzstabilität in der GKV beizutragen, indem der demographische Finanzierungs- und Ausgabeneffekt nach Ablauf der "demographischen Schönwetter-Periode" im zweiten Jahrzehnt dieses Jahrhunderts 
durch Rückgriff auf einen zuvor gebildeten Kapitalstock kompensiert werden könnte. ${ }^{9}$ Die eigentliche Zielsetzung ist jedoch, die jetzige Erwerbstätigen-Generation, die den Generationenvertrag gebrochen hat und ihren Kindern künftig eine immense Altenlast aufzubürden im Begriff ist, mit den Folgen ihres Handelns selbst zu belasten und die nachwachsende Generation zu entlasten.

Wie erste Simulationsrechnungen zeigen (Cassel/Oberdieck 2002), wäre eine ergänzende, kapitalgedeckte Finanzierung der GKV hinsichtlich der quantitativen Dimensionen durchaus machbar. So ergibt sich für das „Worst-Case-Szenario" der Status-quo-Prognose von Oberdieck (1998, S. 124 ff.; Abb. 4), nach der der GKV-durchschnittliche allgemeine Beitragssatz bis 2040 auf 31,2 Prozent steigen soll, folgende Handlungsoption: Würde der Beitragssatz im Jahr 2003 um 3,4 Beitragssatzpunkte auf 17,3 Prozent angehoben, könnte er bei einer unterstellten jahresdurchschnittlichen Kapitalstockrendite von 4 Prozent durch Bildung und spätere Auflösung der SAR auf diesem Niveau bis 2040 konstant gehalten werden. Wie Abbildung 7 zeigt, erreicht der prognostizierte Ausgaben deckende Beitragssatz im Jahr 2018 das Niveau des durchgehend erhobenen Beitragssatzes von 17,3 Prozent und steigt danach relativ stark an. Obwohl die SAR nur bis zum Jahr 2017 aus der Differenz der beiden Beitragssätze dotiert wird, baut sie sich wegen der Verzinsung noch bis zum Jahr 2027 weiter auf. Erst nach diesem Zeitpunkt schmilzt sie durch den Subventionsbedarf der Krankenversicherung der Rentner wieder ab. Dabei erreicht der Kapitalstock ein maximales Volumen von 724,1 Mrd. Euro (Tab. 2). ${ }^{10}$

„Beitragssatzstabilität" ( $§ 71$ SGB V) steht zwar an der Spitze der politischen Agenda, ist aber kein gesundheitspolitisches Ziel sui generis. Es leitet sich vielmehr aus der hälftigen Beitragsbelastung der Arbeitgeber und der Forderung nach Begrenzung der Lohnzusatzkosten ab. In einem durch Wettbewerb gesteuerten GKV-System ohne Arbeitgeberbeiträge wäre es ebenso irrelevant wie z. B. die Absicht des Staates, den Einkommensanteil der Ausgaben für Wohnen und Reisen stabil halten zu wollen. Deshalb fordern Gesundheitsökonomen seit jeher, die Arbeitgeberbeiträge abzuschaffen oder zumindest "einzufrieren“ und Beitragssatzstabilität als gesundheitspolitisches Ziel aufzugeben. Siehe z. B. Cassel (1997, S. 15 ff.).

Die Simulation eines „Best-Case-Szenarios" ergibt naturgemäß deutlich geringere Werte. So würde nach einer Status-quo-Prognose von Hof (2001) der Ausgaben deckende Beitragssatz bis 2040 "nur" auf 20,5 Prozent steigen (Tab. 1), so dass der zur Bildung der SAR erforderliche Beitragssatz lediglich auf 15,9 Prozent angebohen werden müsste. Der Kapitalstock würde sein Maximum ebenfalls 2027 erreichen, aber dann nur ein Volumen von 259 Mrd. Euro haben (Cassel/Oberdieck 2002, S. 18 ff.). In jedem Falle würde sich die „implizite Verschuldung" der GKV durch die SAR verringern. 


\section{Abb. 7: Beitragssatzentwicklung in der GKV mit und ohne solidarische Alte-}

rungsreserve, $2003-2040$

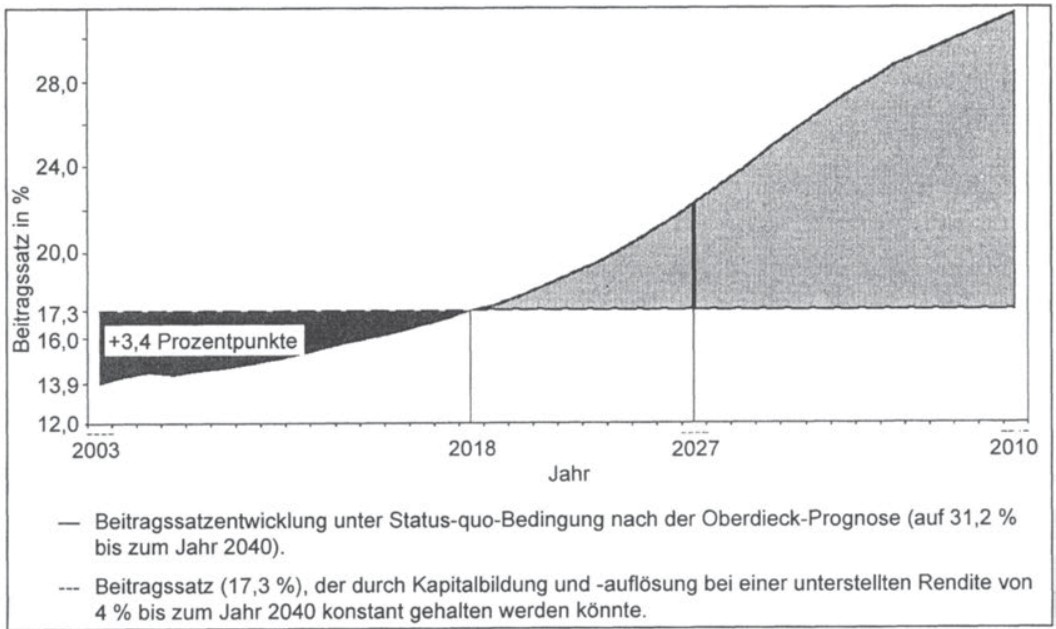

Tab. 2: Kapitalstockentwicklung im Konzept der solidarischen Alterungsreserve, $2003-2040$

\begin{tabular}{|c|c|c|c|}
\hline Jahr & $\begin{array}{c}\text { GKV-Beitragssatz- } \\
\text { prognose in \% }\end{array}$ & $\begin{array}{c}\text { Kapitalstock bei 4 \% } \\
\text { Rendite in Mrd. } €\end{array}$ & $\begin{array}{c}\text { Zu deckender Demographie- } \\
\text { effekt je RKV-Mitglied in } €\end{array}$ \\
\hline 1 & 2 & 3 & 4 \\
\hline 2003 & 13,9 & 36,3 & - \\
\hline 2005 & 14,4 & 108,0 & - \\
\hline 2010 & 15,0 & 314,5 & - \\
\hline 2015 & 16,3 & 507,1 & - \\
\hline 2016 & 16,6 & 538,8 & - \\
\hline 2017 & 16,9 & 567,1 & - \\
\hline 2018 & $\mathbf{1 7 , 3}$ & $\mathbf{5 8 9 , 7}$ & 65 \\
\hline 2019 & 17,6 & 612,2 & 155 \\
\hline 2020 & 18,0 & 633,9 & 904 \\
\hline 2025 & 20,8 & 715,6 & $\mathbf{1 . 3 7 3}$ \\
\hline 2027 & $\mathbf{2 2 , 3}$ & $\mathbf{7 2 4 , 1}$ & 2.257 \\
\hline 2030 & 24,8 & 691,4 & 3.996 \\
\hline 2035 & 28,7 & 470,8 & 5.675 \\
\hline 2040 & 31,2 & 25,1 & \\
\hline
\end{tabular}

Grundlage der Simulation ist die Oberdieck-Prognose des GKV-Beitragssatzes (Spalte 2). 2018 entspricht der Ausgaben deckende Beitragssatz dem annahmegemäß 2003 zur Bildung der SAR auf 17,3 Prozent heraufgesetzten Beitragssatz. 


\section{Solidarische Alterungsreserve als Reformoption}

Dieses Simulationsergebnis verbietet es, das Konzept einer GKVAlterungsreserve leichtfertig in das Reich der Utopie zu verweisen:

- $\quad$ Alle neueren Beitragssatzprognosen gehen von einem unter Statusquo-Bedingungen unvermeidlichen Beitragssatzanstieg aus, der sich ab dem nächsten Jahrzehnt demographisch und medizintechnisch bedingt erheblich beschleunigen wird. Die hier verwendete Prognosealternative lässt sich dabei als "Worst-Case-Szenario" interpretieren.

- Das gleiche gilt hinsichtlich der unterstellten Rendite: Zwar kalkuliert die PKV ihre Alterungsrückstellungen mit einer gesetzlich vorgeschriebenen Mindestrendite in Höhe von 3,5 Prozent, doch liegt die tatsächlich erzielte Nominalverzinsung im langfristigen Durchschnitt mehr als doppelt so hoch. Mit der unterstellten Rendite von 4,0 Prozent dürfte man somit auf der "sicheren Seite" sein.

- Um eine ausreichende Alterungsreserve bilden zu können, müsste der GKV-Beitragssatz im Modell sofort um 3,4 Prozentpunkte auf 17,3 Prozent angehoben werden. Angesichts der ohne Kapitaldeckung langfristig drohenden Beitragssatzexplosion dürfte dies kein unangemessen hoher "Preis" für vier Jahrzehnte Beitragssatzstabilität sein.

- Würde man die im GKV-System vermuteten Wirtschaftlichkeitsreserven heben und die krankenversicherungsfremden Leistungen ausgliedern, ließe sich der derzeitige Beitragssatz um mindestens drei Punkte senken, so dass der für die SAR erforderliche Beitragssatzzuschlag den Beitragssatz nicht oder nur unmerklich über das derzeitige Niveau anheben müsste. ${ }^{11}$

- $\quad$ Auch der maximal erforderliche Kapitalstock (ca. 725 Mrd. Euro bis 2027) relativiert sich, wenn man einerseits die auf 4,1 Bio. Euro geschätzte „implizite Verschuldung" der GKV und andererseits die derzeitigen Alterungsrückstellungen der PKV in Höhe von ca. 68,2 Mrd. Euro (2001) zum Vergleich heranzieht. Wäre für alle GKVVersicherten eine gleich hohe Alterungsrückstellung pro Kopf wie in

So schätzt Wille (2002, S. 993), derzeit Vorsitzender der KaiG, allein die durch Schließung der so genannten Verschiebebahnhöfe und die Ausgliederung „krankenversicherungsfremder Leistungen" erzielbare Einsparung auf 30 Mrd. Euro bzw. 3 Betragssatzpunkte. 
der PKV gebildet worden, beliefe sich der Kapitalstock derzeit auf rund $640 \mathrm{Mrd}$. Euro und läge damit "nur" etwa $85 \mathrm{Mrd}$. Euro unter dem in der Simulation maximal erforderlichen Kapitalstock.

Die ergänzende Kapitaldeckung wäre zudem mit dem bestehenden GKV-System völlig kompatibel: Weder verstieße sie gegen das GKVkonstitutive Solidarprinzip, noch würden grundsätzlich systemwidrige Elemente in die Umlage finanzierte GKV eingeführt. So wäre die SAR nicht aus risikoäquivalenten Prämien zu dotieren, sondern aus Zuführungen, die einkommensproportional nach dem Umlageverfahren durch kasseneinheitliche Aufschläge auf die jeweils Ausgaben deckenden Beitragssätze aufzubringen wären. Um die Lohnzusatzkosten nicht zu erhöhen, müsste der Beitragssatzaufschlag allerdings allein von den GKVMitgliedern getragen werden; denn es kann nicht Sache der Arbeitgeber sein, für die finanziellen Folgen des demographischen Wandels einzustehen.

Für die SAR spricht schließlich auch, dass im Falle einer kassenübergreifenden Pool-Lösung der wettbewerblich erwünschte Kassenwechsel - und damit die materielle Kassenwahlfreiheit - nicht beeinträchtigt würden: Weder entstünde ein individueller Anspruch auf den Kapitalstock, noch hätte die "Nichtmitgabe" von Kapitalstockanteilen beim Kassenwechsel negative wirtschaftliche Folgen für das wechselnde GKVMitglied. Dies ist ein erheblicher Vorteil gegenüber den Alterungsrückstellungen der PKV, die bis dato beim Wechsel des Versicherers nicht mitgegeben werden und deshalb die Versichertenmobilität und den Wettbewerb um die Bestandsversicherten zum Erliegen bringen.

Das hier vorgestellte Konzept scheint jedoch einen gravierenden "Haken" zu haben: Die Simulation ist methodisch so angelegt, dass jener Beitragssatz berechnet wird, der bis zum Jahr 2040 durch Bildung und Auflösung der Alterungsreserve konstant gehalten werden könnte. Ist der Kapitalstock aber verbraucht, müsste der Beitragssatz unter Status-quoBedingungen auf sein dann ausgabendeckendes Niveau - d. h. von 17,3 Prozent auf 31,2 Prozent angehoben werden. Man könnte somit in der ergänzenden Kapitaldeckung eine trügerische Scheinlösung sehen. Dennoch gibt es gute Gründe, die SAR als tragfähige Reformoption zu erwägen:

- So könnte die Beitragssatzdynamik durch Leistungskürzungen in der GKV, die Erschließung von Wirtschaftlichkeitsreserven, die Verbreiterung der Beitragsbemessungsgrundlage oder die Begrenzung der beitragsfreien Mitversicherung von Familienangehörigen ge- 
bremst werden (Jacobs/Schellschmidt 2002), so dass sich dadurch die Reichweite des Kapitalstocks erhöhen würde.

- In der Simulation wird alternativ mit Renditen gerechnet, die weit unter der dauerhaft erzielbaren Verzinsung von Deckungsstöcken in der privaten Assekurranz liegen. Eine auf Dauer erzielbare Verzinsung von 5 bis 6 Prozent würde den Kapitalstock erheblich vergröBern und ihn erst Jahrzehnte später abschmelzen lassen.

- Weil sich die Gesundheitspolitik „Beitragssatzstabilität“ als prioritäres Ziel gesetzt hat, wurde auch die Simulation auf einen im Zeitablauf konstanten Beitragssatz hin angelegt. Praktisch wäre es auch möglich, den erhobenen Beitragssatz von Jahr zu Jahr steigen zu lassen, seine Steigerungsrate jedoch deutlich unterhalb der des Ausgaben deckenden Beitragssatzes zu halten.

Insgesamt gesehen erscheint es angesichts der aufgezeigten Handlungsoptionen möglich, einen „Beitragssatzsprung" in ferner Zukunft zu vermeiden. Stattdessen die weitere Beitragssatzentwicklung abzuwarten und gegebenenfalls nur kosmetisch zu reagieren, hieße freilich, die Chance zu verpassen, unter den jetzt noch relativ günstigen demographischen Bedingungen einen hinreichenden Kapitalstock aufzubauen, der wirksamen Schutz vor der künftig hereinbrechenden Flut der „age wave" bieten könnte.

\section{Künftige Rentner stärker belasten?}

Falls in den nächsten beiden Jahrzehnten weder ein privater Realkapitalstock noch eine solidarische Alterungsreserve zur nachhaltigen Finanzierung der GKV aufgebaut werden, der derzeitige Leistungsumfang der GKV aber beibehalten wird, muss nach dem derzeitigen Erkenntnisstand ab dem nächsten Jahrzehnt mit drastisch steigenden Beitragssätzen gerechnet werden. Dies würde sowohl die künftige Rentner- als auch die jetzt heranwachsende Erwerbstätigen-Generation erheblich belasten. Geradezu unerträglich würde dabei die Belastung der letzteren, weil sie nicht nur erhebliche Transfers an die RKV zur Versorgung der Rentner zu leisten hätte, sondern auch durch Investitionen in Human- und Realkapital für ihre eigene Alterssicherung sorgen müsste (Abb. 6). Da die heutige Erwerbstätigen- und künftige Rentner-Generation diese Situation selbst herbeigeführt hat, weil sie nicht hinreichend Human- und Realkapital zu bilden bereit war, ist es zur Wahrung der intergenerativen Gerechtigkeit und zur Vermeidung ernsthafter Generationenkonflikte erforderlich, sie stärker zu belasten und die künftige ErwerbstätigenGeneration zu entlasten. 
Dies würde bedeuten, die Dimension der intergenerativen Solidarität I (Abb. 4) zumindest teilweise zu suspendieren und für enwerbstätige und nicht mehr erwerbstätige GKV-Mitglieder unterschiedliche Beitragssätze zu erheben. Da die krankenversicherungsspezifische Solidarität zwischen Gesunden einerseits und akut Kranken und Personen mit höherem Krankheitsrisiko andererseits unbedingt fortgelten sollte, böte sich als Kriterium für eine Differenzierung der Beitragssätze zwischen EKV und RKV nur der bereits eingangs erwähnte demographische Finanzierungseffekt an.

Wie aus der schematischen Abbildung 8 ersichtlich ist, könnte der Finanzierungsbeitrag der Rentner bis auf das beim Renteneintritt erreichte Niveau des Erwerbstätigen-Beitrages angehoben und dadurch eine Beitragsentlastung der Erwerbstätigen erreicht werden. Dementsprechend müssten die künftigen Rentner auf ihre deutlich unter den Erwerbseinkünften liegenden Renten einen im Vergleich zum GKV-einheitlichen Beitragssatz merklich höheren Beitragssatz leisten, während die Erwerbstätigen mit einem niedrigeren Beitragssatz rechnen könnten. ${ }^{12}$

\section{Abb. 8: Ausgleich des demographischen Finanzierungseffekts (schematische Darstellung)}

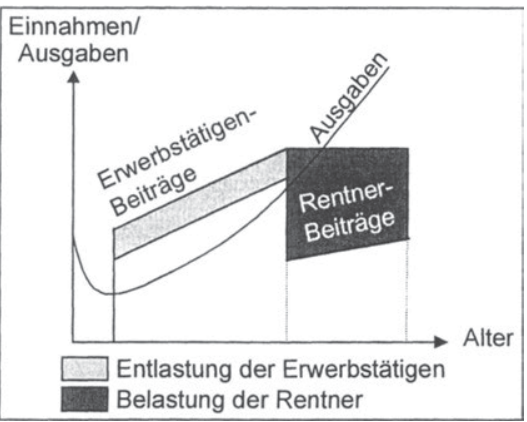

Wie sich die Beitragssätze bei einem vollständigen Ausgleich des Finanzierungseffektes nach der Oberdieck-Prognose entwickeln würden, zeigt Abbildung 9: Während der wie bisher berechnete GKV-einheitliche Beitragssatz auf 31,2 Prozent steigen würde (siehe auch Abb. 2), käme der

12 Dies wäre übrigens auch der Fall bei einheitlichen Kopf- bzw. Pauschalprämien: Da die Renten niedriger sind als die zuvor erzielten Erwerbseinkünfte, würde sich bei alters- und Erwerbsstatus-unabhängigen Kopfprämien die als „Beitragssatz" ausgedrückte relative Einkommensbelastung beim Renteneintritt sprunghaft erhöhen! 
Ausgaben deckende Beitragssatz in der EKV ohne Belastung durch den Finanzierungseffekt "nur" auf 23,4 Prozent. Dagegen müssten die Rentner in der RKV mit einem bis auf 84,8 Prozent drastisch steigenden Beitragssatz rechnen. Selbstverständlich wäre es unmöglich, die künftige Rentner-Generation derart zu belasten - wenngleich dies eine Folge des von ihr selbst zu vertretenden Mangels an rechtzeitiger Human- und Realkapitalbildung ist. Wie stark die künftigen Rentner zur Finanzierung inrer "notwendigen und ausreichenden" Gesundheitsversorgung herangezogen werden können, lässt sich objektiv kaum bestimmen und ist letztlich eine politische Entscheidung. ${ }^{13}$ Ihnen einen höheren Beitragssatz abzuverlangen als den künftigen Erwerbstätigen, wäre jedoch ein gangbarer und zu rechtfertigender Weg, falls das SAR-Konzept aktuell keine politische Mehrheit findet. Schließlich wäre auch ein Mittelweg möglich: nämlich die Generation 1 als Erwerbstätige in den nächsten beiden Jahrzehnten mit der Bildung einer SAR und danach als Rentner mit einem höheren RKV-Beitragssatz zu belasten. In beiden Fällen würden die erforderlichen Beitragssatzanhebungen unter dem Niveau bleiben, das bei alleiniger Realisierung der beiden Alternativlösungen nötig wäre.

Abb. 9: Beitragssatzentwicklung in der GKV mit und ohne Ausgleich des Finanzierungseffekts auf Grundlage der Oberdieck-Prognose, 1991-2040

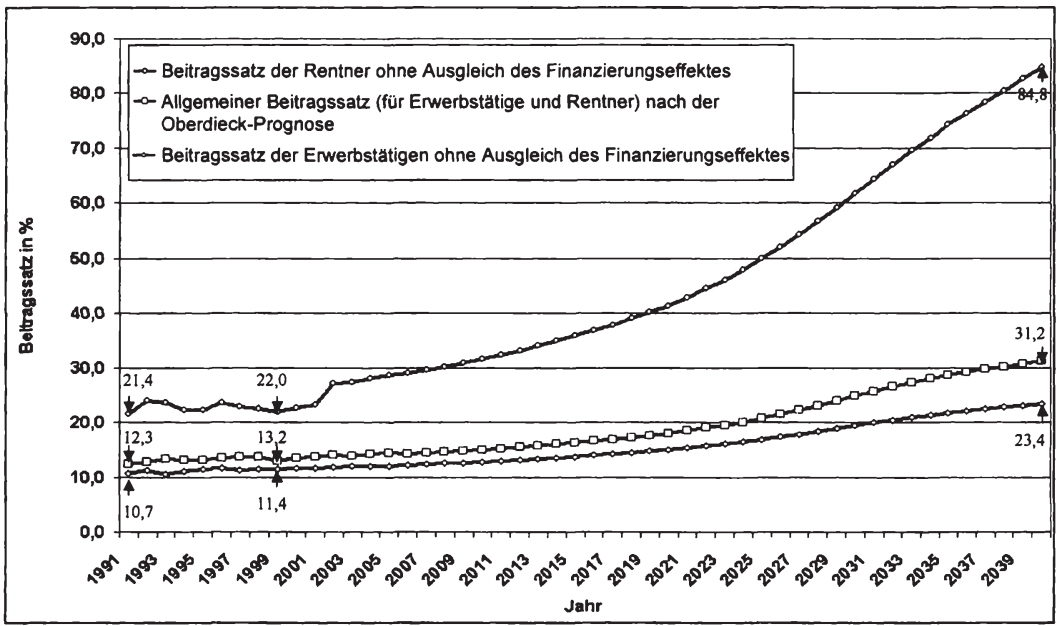

13 Es dürfte nicht falsch sein, anzunehmen, dass die sich mit dem Alter ändernde Bedürfnis- und Konsumstruktur Spielraum für einen deutlich höheren Teil des Einkommens schafft, der für Gesundheitsleistungen aufgewendet werden kann (siehe z. B. Miniaci/Monfardini/Neber 2002; Miles 2002). Den sozialen Belangen 


\section{Fazit: „Hard choices” erfordern „hard decisions”}

Eine weitere Reformoption sollte am Schluss nicht unerwähnt bleiben: So könnten die Folgen des demographischen Wandels für die GKV und notabene für alle anderen Umlage finanzierten Sozialsysteme durch eine Verkürzung der Ausbildungs- und Studienzeiten, ein höheres Rentnereintrittsalter, mehr Zuwanderung qualifizierter Erwerbspersonen und ein erhöhtes Produktivitätswachstum deutlich abgemildert werden. Hierdurch ließe sich womöglich die unter Status-quo-Bedingungen zu erwartende Beitragssatzexplosion abwenden. Zumindest aber wäre der gegenwärtig auf Politik und Gesellschaft lastende Handlungsdruck deutlich gemildert. Diese Option geht jedoch weit über den Kompetenzbereich der Gesundheitspolitik hinaus - und sie wird angesichts der generellen politischen Reformblockade in Deutschland auf absehbare Zeit eine unerreichte Wunschvorstellung bleiben.

Deshalb steht die Gesundheitspolitik nach Lage der Dinge vor der Wahl, sich vom Ziel der Beitragssatzstabilität zu verabschieden und der demographisch und medizintechnisch getriebenen Beitragssatzexplosion freien Lauf zu lassen, oder den Leistungskatalog der GKV drastisch einzuschränken und insbesondere die Leistungen für die Betagten zu rationieren. Einen Ausweg aus diesem Dilemma bietet das hier vorgestellte Konzept einer ergänzenden kapitalgedeckten Finanzierung der GKV in Verbindung mit höheren Beiträgen der künftigen Rentner.

Wie anhand von Simulationen und der gesundheitsökonomischen Würdigung ihrer Ergebnisse gezeigt wurde, ist das Konzept langfristig tragfähig, GKV-systemkonform und technisch machbar. Die Gesundheitspolitik hätte eine reelle Chance, mit dieser probaten Reformoption die absehbare Überforderung von Solidarprinzip und Generationenvertrag abzuwenden und den drohenden finanziellen Kollaps des GKV-Systems zu verhindern.

Der Preis dafür wäre freilich, die Beitragssätze in der GKV möglichst rasch um einen kasseneinheitlichen Beitragssatzaufschlag anzuheben und ein kassenübergreifendes Kapitalstockmanagement aufzubauen sowie den künftigen Rentnern höhere Beitragssätze abzuverlangen als den künftigen Erwerbstätigen. Man darf gespannt sein, ob die „RürupKommission" derartige Überlegungen aufgreift und ob die Gesundheitspolitik den Mut und die Durchsetzungsfähigkeit hat, sie gegen den Widerstand des sozialpolitischen Establishments zu realisieren.

wird dabei durch die Einkommensproportionalität der Beiträge sowie durch Härteklauseln Rechnung getragen. 


\section{Literatur}

Apolte, T., (1998), Ein System der Alterssicherung bei schrumpfender Bevölkerung, Diskussionsbeiträge der Fakultät für Wirtschaftswissenschaft der Gerhard-MercatorUniversität Duisburg, Nr. 252, Mimeo, Duisburg 1998.

Breyer, F.; Ulrich, V., (2000), Gesundheitsausgaben, Alter und medizinischer Fortschritt: eine Regressionsanalyse, in: Jahrbücher für Nationalökonomie und Statistik, $220(2000,1)$, S. $1-17$.

Breyer, F.; Grabka, M. M.; Jacobs, K.; Meinhardt, V.; Ryll, A.; Schulz, E.; Spieß, C. K., Wagner, G. G., (2001), Wirtschaftliche Aspekte der Märkte für Gesundheitsdienstleistungen. Ökonomische Chancen unter sich verändernden demographischen und wettbewerblichen Bedingungen in der Europäischen Union. Gutachten im Auftrag des Bundesministeriums für Wirtschaft und Technolgie, DIW Berlin unter Mitarbeit von IGES Berlin, Mimeo, Berlin 2002.

Brockmann, H., (2000), Why is health treatment for the elderly less expensive than for the rest of the population? Health care rationing in Germany, MPIDR Working Paper WP 2000-001, Rostock 2000.

Buchner, F.; Wasem, J., (2000), Versteilerung der alters- und geschlechtsspezifischen Ausgabenprofile von Krankenversicherern, in: Zeitschrift für die gesamte Versicherungswissenschaft, $89(2000,2 / 3)$, S. $357-392$.

Cassel, D., (1997), Ausbau der Wettbewerbskonzeption der gesetzlichen Krankenversicherung, in: Arbeit und Sozialpolitik, 51 (1997, 11 - 12), S. 10 - 18.

Cassel, D., (2001), Demographischer Wandel - Folgen für die gesetzliche Krankenversicherung, in: Wirtschaftsdienst, 81 (2001, 2), S. 87 - 91.

Cassel, D., (2002), Wettbewerb in der Gesundheitsversorgung: Funktionsbedingungen, Wirkungsweise, Gestaltungsbedarf, in: Arnold, M.; Klauber, J.; Schellschmidt, H., (Hg.), Krankenhausreport 2002. Schwerpunkt: Krankenhaus im Wettbewerb, Stuttgart-New York 2002, S. 1-20.

Cassel, D., (2003), Reformoptionen zur wettbewerblichen Gestaltung der gesetzlichen Krankenversicherung in Deutschland, in: Deszy, J.; Theurl, E., (Hg.), Therapievorschlag Wettbewerb: Chancen, Risiken, Evidenz, Wien, 2003.

Cassel, D.; Oberdieck, V., (2002), Kapitaldeckung in der gesetzlichen Krankenversicherung, in: Wirtschaftsdienst, $82(2002,1)$, S. $16-22$. 
Engelhard, P.; Fehl, U.; Geue, H., (1998), Konzertierte Aktionen, Runde Tische, Aktionsbündnisse: Machtbeteiligung und Machtkontrolle organisierter Interessen durch korporatistische Politikbeteiligung?, in: Cassel, D., (Hg.), 50 Jahre Soziale Marktwirtschaft. Ordnungstheoretische Grundlagen, Realisierungsprobleme und Zukunftsperspektiven einer wirtschaftspolitischen Konzeption, Stuttgart 1998, S. 741 - 768.

Enquête-Kommission Demographischer Wandel (2002), Herausforderungen unserer älter werdenden Gesellschaft an den Einzelnen und die Politik, Deutscher Bundestag, Referat Offentlichkeitsarbeit ( $\mathrm{Hg}$.), Berlin 2002.

Fetzer, S.; Raffelhüschen, B., (2002), Zur Wiederbelebung des Generationenvertrages in der gesetzlichen Krankenversicherung. Die Freiburger Agenda, Diskussionsbeiträge des Instituts für Finanzwissenschaft der Albert-Ludwigs-Universität Freiburg im Breisgau, Nr. 103/02, Mimeo, Freiburg 2002.

Henke, K.-D. (2003), Frau Schmidt irrt. Die Trennung der Leistungsausgaben von den Einnahmen widerspricht ökonomischen Grundsätzen, in: FAZ v. 6. Januar 2003, Nr. 4, S. 13.

Henke, K.-D.; Grabka, M. M.; Borchardt, K., (2002), Kapitalbildung auch im Gesundheitswesen? Auf dem Wege zu einer ordnungspolitischen Erneuerung der Krankenversicherung, in: Zeitschrift für Gesundheitswissenschaften, $10(2002,3)$, S. $196-210$.

Henke, K.-D.; Johannßen, W.; Neubauer, G.; Rumm, U.; Wasem, J., (2002), Zukunftsmodell für ein effizientes Gesundheitswesen in Deutschland, Vereinte Krankenversicherung AG ( $\mathrm{Hg}$.$) , München 2002$.

Hof, B. (2001), Auswirkungen und Konsequenzen der demographischen Entwicklung für die gesetzliche Kranken- und Pflegeversicherung, Köln 2001.

Jacobs, K.; Schellschmidt, H., (2002), Äquivalenz, Leistungsfähigkeit und Solidarität - Konturen einer GKV-Finanzierungsreform, in: G+G Wissenschaft, 2 (2002/ 3), S. $15-22$.

Kruse, A. (2002), Demographische Umgestaltung der Gesundheitsversorgung, in: Politische Studien, Sonderheft 2, 53 (2002, 7), S. $135-154$.

Kühn, H. (2001), Finanzierbarkeit der gesetzlichen Krankenversicherung und das Instrument der Budgetierung, in: Michaelis, W. (Hg.), Der Preis der Gesundheit. Wissenschaftliche Analysen, politische Konzepte, Landsberg/Lech 2001, S. 1- 25.

Mackenroth, G. (1952), Die Reform der Sozialpolitik durch einen deutschen Sozialplan, in: Schriften des Vereins für Socialpolitik, N. F., Bd. 4, Berlin 1952. 
Miles, D. (2002), The Influence of Aging on Capital Accumulation, in: Siebert, H. (Hg.), Economic Policy for Aging Societies, Berlin u. a. 2002, S. 131 - 154.

Miniaci, R.; Monfardini, C.; Weber, G. (2002), Changing Consumption Patterns, in: Siebert, H. (Hg.), Economic Policy for Aging Societies, Berlin u. a. 2002, S. 53 - 76.

Oberdieck, V. (1998), Beitragssatzexplosion in der gesetzlichen Krankenversicherung. Demographische und medizintechnische Determinanten der Beitragssatzdynamik und ihre reformpolitischen Implikationen, Hamburg 1998.

Pfaff, A. (2002), Exkurs: Auswirkungen des demographischen Wandels auf die Beitragssatzentwicklung, in: Enquête-Kommission Demographischer Wandel, Herausforderungen unserer älter werdenden Gesellschaft auf den Einzelnen und die Politik, Deutscher Bundestag, Referat Offentlichkeitsarbeit (Hg.), Berlin 2002, S. 416 - 420.

Postler, A. (2002), Finanzierungsalternativen in der gesetzlichen Rentenversicherung und Pflegeversicherung. Zur Diskussion um das Kapitaldeckungsverfahren und ihre Lehren für die gesetzliche Krankenversicherung, Ausgewählte Volkswirtschaftliche Diplomarbeiten, Fakultät 3 - Wirtschaftswissenschaft der Gerhard-Mercator-Universität Duisburg, Mimeo, Duisburg 2002.

Reinhardt, U. E. (2002), Health Care for the Aging Baby Boomers: How Serious a Problem, in: Siebert, H. (Hg.), Economic Policy for Aging Societies, Berlin u. a. 2002, S. $235-262$.

Sauerland, D. (2002), Gesundheitspolitik in Deutschland. Reformbedarf und Entwicklungsperspektiven, Gütersloh 2002.

Schmähl, W. (2002), Demographischer Wandel und Gesundheitssystem, in: Mut, Forum für Kultur, Politik und Geschichte, 423 (2002, 11), S. 62 - 73.

Sinn, H.-W. (2003), Rente nach der Kinderzahl. Kinderlose sollten nur die halbe Umlagerente erhalten und einen größeren Teil ihres Einkommens für die RiesterRente sparen; in FAZ v. 14. Januar 2003, Nr. 11, S. 12.

SVR (2002), Zwanzig Punkte für Beschäftigung und Wachstum, Jahresgutachten 2002/03, www.Sachverstaendigenrat.org, Bonn 2002.

SVR KAiG (2001), Bedarfsgerechtigkeit und Wirtschaftlichkeit, Bde. I-III, Bonn 2001.

Terhorst, E. (2000), Wahlfreiheit und Wettbewerb in der privaten Krankenversicherung. Versicherungstechnische Grundlagen, vorhandene Beschränkungen und reformpolitische Lösungsansätze, Berlin 2000. 
Wille, E. (2002), 20 Thesen zum Thema Solidarität, Wettbewerb und integrierte Versorgung vor dem Hintergrund sich verknappender Ressourcen. Bericht vom 25. Krankenhaustag: „Gesundheitspolitik - Anspruch und Wirklichkeit”, in: Das Krankenhaus, $94(2002,12)$, S. $990-994$. 


\section{Selbstbeteiligung der Patienten als Finanzierungs- und Steuerungsinstrument}

Eckhard Knappe

\section{Selbstbeteiligung - zwischen Effizienz und Solidarität}

Selbstbeteiligung ist eine politisch umstrittene, partielle Einzelmaßnahme, die isoliert gesehen in ihren Wirkungen schwer zu analysieren und $\mathrm{zu}$ beurteilen ist. Entscheidend ist, in welches ordnungspolitische Konzept sie eingebettet werden soll. Als Bestandteil der staatlich dominierten interventionistischen Gesundheitspolitik steht zumeist die finanzielle Entlastung der gesetzlichen Krankenversicherung im Vordergrund, auf Steuerwirkungen wird wenig Wert gelegt, allenfalls in einem negativen Sinne: Durch Selbstbeteiligung könnten Patienten von rechtzeitigen und notwendigen Arztbesuchen abgehalten und dadurch Krankheiten verschleppt werden.

Als Teil eines wettbewerblichen Ordnungsrahmens stehen dagegen die statischen und dynamischen Steuerungswirkungen im Mittelpunkt des Interesses.

Gesundheitspolitik agiert immer vor dem Hintergrund der beiden gesundheitspolitischen Oberziele, nämlich eines effizienten Versicherungsschutzes der Bevölkerung und einer effizienten Versorgung der Patienten mit Gesundheitsleistungen (was allein schon zwei unterschiedliche Ziele sind), und unter den verschiedenen Aspekten des (selten klar definierten ${ }^{1}$ ) Solidaritätszieles. ${ }^{2}$ Nach der Forderung einer "rationalen" Gesundheitspolitik wären die beiden Zielbereiche inhaltlich klar zu formulieren und bestehende Konflikte zwischen beiden Zielen zu minimieren. Bei nicht weiter zu verringerndem Zielkonflikt wäre dann der politisch optimale Kompromiss zu suchen. Von einer derartigen, rationalen Vorgehensweise ist die heutige Gesundheitspolitik weit entfernt. Noch immer wird überwiegend versucht, mit kurzfristigen Ad-hoc-Maßnahmen die Ausgabenentwicklung zu dämpfen, um die an die Bruttolöhne gekoppel-

1 Auseinanderzuhalten sind die gesundheitsbezogenen und die gesamtgesellschaftlichen Aspekte des Solidaritätszieles. Zu den gesundheitsbezogenen Aspekten gehören (1) Solidarität der aktuell Gesunden mit den aktuell Kranken (was das zentrale Anliegen jeder Krankenversicherung ist), aber auch die eher langfristig zu sehende (2) Solidarität derjenigen mit geringem Krankheitsrisiko (Junge etc.) mit denen, die ein hohes Krankheitsrisiko aufweisen. Zu den gesamtgesellschaftlichen Aspekten gehören der Familienlastenausgleich und die Einkommensumverteilung von „reich" zu „arm". 
ten Beiträge zu stabilisieren. Erst unter dem zunehmenden Druck der Sachprobleme (Arbeitslosigkeit, medizinischer Fortschritt, erste Auswirkungen des demographischen Wandels) und der zunehmenden Konflikte und Erfolglosigkeit der herkömmlichen Ausgabendämpfungspolitik ist man bereit, auch über ordnungspolitische Reformen der gesetzlichen Krankenversicherung nachzudenken und diese schrittweise umzusetzen. ${ }^{3}$ Kassenwahlfreiheit, Modellversuche zu integrierten Versorgungsformen, Fallpauschalen im Krankenhaus und (zukünftig wahrscheinlich) auch in der ambulanten Versorgung sowie Wahlleistungen (in einem erneuten Anlauf) ${ }^{4}$ sind erste Schritte in Richtung einer mehr wettbewerblich ausgerichteten Steuerung des Gesundheitswesens. Zwei weitere, für einen funktionsfähigen Wettbewerb in der GKV unverzichtbare „Reformbaustellen" werden zumindest von der derzeitigen Regierung noch nicht eröffnet, eine Reform der GKV-Finanzierung ${ }^{5}$ und die Frage, in welcher Form eine Selbstbeteiligung der Patienten einerseits die Effizienz der Gesundheitsversorgung verbessern, andererseits aber auch „sozial tragbar" sein könnte.

Selbstbeteiligungen der Patienten reduzieren einerseits den Umfang der Versicherungsdeckung, indem sie einen Teil des Ausgabenrisikos auf die Versicherten zurückverlagern, damit wird auch ein Teil der Finanzierungslast von der Krankenversicherung auf die Patienten übertragen, daraus resultiert ex definitione die Beitragsentlastung der Versicherten und Belastung als Patienten. Das bedeutet gleichzeitig, dass der Umfang des Solidarprinzips in allen vier Aspekten (Fußnote 1) entsprechend zurückgedrängt wird. All das sind keine "Auswirkungen“ der Selbstbeteiligung, sondern das „,ist" ex definitione die Selbstbeteiligung. Auswirkungen bestehen darin, dass sich durch eine Selbstbeteiligung das Verhalten der Betroffenen, der Patienten und der Leistungserbringer ändern

Hochrechnungen der Beitragssätze, die bei unveränderter Gesundheitspolitik durch medizinischen Fortschritt und demographischen Wandel erforderlich wären, kommen zu einer Größenordnung von weit über $20 \%$ im Jahre 2040, eine Größenordnung, die bei unverändertem GKV-System einerseits untragbar ist, andererseits aber durch Ausgabendämpfungspolitik allein nicht bewältigt werden kann. Vgl. Enquete-Kommission Demographischer Wandel, Schlussbericht 2002, S. $413 \mathrm{f}$.

4 Nachdem 1998 Wahlleistungen mit den "NOGs" eingeführt und durch die „Reform 2000" wieder zurückgenommen wurden, werden sie zurzeit wieder aktuell diskutiert. Vgl. FAZ vom 03.01.2003, S. 1 und 9.

5 Die derzeitigen lohnbezogenen Beiträge sind ungerecht, wettbewerbsverhindernd, Europa-unverträglich, Demographie-empfindlich und daher langfristig nicht durchzuhalten. Vgl. zur Diskussion um neue Finanzierungsformen Knappe, E./Arnold, R.: Pauschalprämie in der Krankenversicherung. Ein Weg zu mehr Effizienz und mehr Gerechtigkeit, Vereinigung der Bayerischen Wirtschaft e. V., München, 2002. Vgl. auch Bundesministerium für Gesundheit (Hrsg.): Zukunftsmarkt Gesundheit, Baden-Baden 2002, S. $191 \mathrm{ff}$. 
wird. So könnte sich die Effizienz der Gesundheitsversorgung verbessern, weil Patienten sich bei der Inanspruchnahme von Gesundheitsleistungen nicht nur den individuellen Nutzen, sondern auch die Kosten vor Augen halten, auf teure und wenig nützliche Leistungen verzichten und anbieterinduzierten Leistungen eine stärkere Gegenreaktion entgegensetzen. Sie könnten aber auch $z$. B. Leistungsinanspruchnahmen aus "gesundheitsfremden" Überlegungen ${ }^{6}$ als unsolidarisches und moralisch verwerfliches Verhalten "erkennen" und - unterstützt durch finanzielle Spürbarkeit - ablehnen.

\section{Steuerungswirkungen}

Die Verhaltenswirkung hängt dabei einerseits von der Höhe, aber auch von der Art der Selbstbeteiligung (prozentual, absolut etc.) ab. Heute zahlen "Patienten" ca. 11 Prozent aller "Gesundheitsausgaben" als Selbstbeteiligung aus eigener Tasche (1998 = 45,5 Mrd. DM). Im Rahmen der gesetzlichen Krankenversicherung sind es immerhin noch 3 Prozent $(1999=7 \mathrm{Mrd} \text {. DM })^{7}$, die sich aus den unterschiedlichsten Zuzahlungsformen zusammensetzen.

\begin{tabular}{|l|l|}
\hline Arzneimittel & $\begin{array}{l}\text { 4,00 Euro/4,50 Euro/5,00 Euro (je nach Packungsgröße), } \\
\text { 100 Prozent oberhalb des Festbetrages }\end{array}$ \\
\hline Heilmittel & 15 Prozent der Ausgaben \\
\hline Hilfsmittel & $\begin{array}{l}\text { 20 Prozent der übernommenen Kosten (durch die Kasse) } \\
\text { (Brillen: mind. 7,41 Euro pro Glas) }\end{array}$ \\
\hline Verbandmittel & 4,00 Euro pro Mittel \\
\hline Krankenhaus & 9,00 Euro pro Tag (bis 14 Tage/nicht bei Vorsorge und Reha) \\
\hline Zahnersatz & 50 Prozent (35 - 40 Prozent bei regelmäßiger Vorsorge) \\
\hline Fahrtkosten & 15,00 Euro pro einfache Fahrt \\
\hline $\begin{array}{l}\text { Med. Vorsorge/ } \\
\text { Reha für Mütter }\end{array}$ & 9,00 Euro pro Tag \\
\hline
\end{tabular}

Diese unterschiedlichen Formen der Selbstbeteiligung machen deutlich, dass kein durchgängiges Konzept erkennbar ist und dass eine Optimierung im Zielkonflikt zwischen Effizienz und Solidaritätszielen nicht beabsichtigt war. Die Steuerungswirkung wäre um einiges größer, wenn allein

6 Hierher gehören genauso Arbeitsunfähigkeit wegen Ärger am Arbeitsplatz wie auch Atteste von Studenten, um nicht an Prüfungen teilnehmen zu müssen, und vieles andere mehr.

7 Im Ausland ist die Selbstbeteiligung z. T. deutlich höher. Vgl. z. B. Wirtschaftsrat: Zur Selbstbeteiligung beim Arztbesuch, Arbeitspapier 5c vom 24.09.1999. 
diese Zuzahlungen, die in der Summe ca. $7 \mathrm{Mrd}$. DM pro Jahr ausmachen, in eine entsprechende einheitliche Zuzahlung von 3 Prozent auf alle Ausgaben umgewandelt würden (unter Beibehaltung der Härtefallregelung und der Überforderungsklauseln).

Generell können die unterschiedlichsten Arten von Selbstbeteiligungen unterschieden werden, die jeweils unterschiedliche Steuerungswirkungen haben und vor dem Solidaritätsziel unterschiedlich zu beurteilen sind:

Eine Selbstbeteiligung der Patienten an den Ausgaben für Gesundheitsleistungen kann

- durch Prämienvorauszahlung und im Nachhinein gewährte Beitragsrückerstattung organisiert werden

oder

- $\quad$ als Zuzahlung unmittelbar beim Bezug der Leistungen (Letzteres ist steuerungswirksamer).

Die drei wichtigsten Formen einer unmittelbaren Zuzahlung beim Bezug der Leistungen (von Gebühren ${ }^{8}$ sei wegen der geringen Steuerungswirksamkeit abstrahiert $\left.{ }^{9}\right)$ sind:

- Indemnitätstarif

- prozentuale Selbstbeteiligung

- absolute Selbstbeteiligung (Abzugsfranchise)

Der Indemnitätstarif, nach dem die Versicherung einen festen Betrag pro Leistung erstattet, entspricht dem Selbstverständnis einer sozialen Krankenversicherung, wenn für den Erstattungsbetrag eine ausreichende und wirtschaftliche Versorgung erhältlich ist. Wer mehr verlangt, muss dann entsprechend zuzahlen. Die Steuerungswirksamkeit ist in der Regel hoch.

Wegen des hohen bürokratischen Aufwandes (für jede Leistung ist ein angemessener ag vorzuschreiben) ist diese Form der Selbstbeteiligung vor allem für relativ einfache Versorgungsformen geeignet, die sich im

z. B. die 9,00 Euro Zuzahlung pro Krankenhaustag.

Ebenfalls abstrahiert sei hier von der Ausgliederung einzelner Bereiche aus dem Leistungskatalog der GKV, was mit der Einführung einer $100 \%$ igen Selbstbeteiligung der Patienten für eben diese Leistungsbereiche identisch ist. Vgl. zu einem möglichen Ausgliederungskatalog z. B. Pimpertz, J.: Leitlinien zur Reform der gesetzlichen Krankenversicherung, Beiträge zur Wirtschafts- und Sozialpolitik 271, Köln, 2002. 
Zeitablauf durch medizinisch-technischen Fortschritt vergleichsweise wenig verändern (z. B. Zahnersatz). Ungeeignet ist diese Form der Selbstbeteiligung dagegen für hochkomplexe und hochdynamische Versorgungen, wie z. B. den Arzneimittelbereich. Gerade in diesem Bereich wurde sie jedoch in Deutschland 1989 eingeführt.

Die prozentuale Selbstbeteiligung mit einem einheitlichen Zuzahlungssatz ist besonders steuerungswirksam, da sie z. B. die Nachfrage (je nach Nachfrage-Elastizität) beschränkt und die Preisstruktur sichtbar und spürbar macht. Teure Leistungen werden stärker gemieden. Ihr Nachteil besteht darin, dass selbst sehr moderate Zuzahlungsprozentsätze (vgl. die o. g. 3 Prozent) in Einzelfällen die Zahlungsfähigkeit eines Haushaltes durchaus überfordern können und daher in der Regel eine zusätzliche Absicherung nötig machen.

Die absolute Selbstbeteiligung ${ }^{10}$ (Abzugsfranchise) hat den Vorteil, dass eine Überforderung der Haushalte vermieden werden kann (mehr als eine bestimmte Maximalsumme pro Jahr kann auch im ungünstigsten Fall nicht auf den Versicherten zukommen, vgl. die von der Techniker Krankenkasse gerade eingeführte absolute Selbstbeteiligung von 300 Euro pro Jahr gegen einen Bonus von 240 Euro). Auch die Steuerungswirkung ist bei Kleinbeträgen sehr hoch, da zunächst eine Inanspruchnahme von Leistungen unterhalb der Selbstbeteiligungsgrenze vollständig aus eigener Tasche zu bezahlen ist. Allerdings leidet die Steuerungswirksamkeit darunter, dass bei Überschreitung der Selbstbeteiligungsgrenze keine Steuerungswirksamkeit mehr vorhanden ist. Im Gegenteil, es besteht ein Anreiz zur zeitlichen Verlagerung der Nachfrage in Perioden, in denen die Selbstbeteiligungsgrenze ohnehin überschritten wird.

In der politischen Diskussion wird die Steuerungsfunktion von Selbstbeteiligungen häufig zu Unrecht bezweifelt. Dabei geht man $u$. a. von der Vorstellung aus, die Nachfrage nach medizinischen Leistungen sei „preisunelastisch"11 oder ohnehin „überwiegend anbieterinduziert". Hinter dieser Vorstellung steht eine Verhaltensanpassung der Patienten, wie sie in der mikroökonomischen Theorie als Reaktion auf steigende Preise einzelner Güter analysiert wird. Dieser Effekt lässt sich am einfachsten

Vgl. Knappe, E.; Fritz, W.: Direktbeteiligung der Patienten: Auswirkungen eines absoluten Selbstbehalts, in: Schr. d. Vereins f. SP. 1985, S. $449-467$.

Preiselastizität ist eine Maßzahl für die (prozentuale) Reaktion von Nachfragern auf (prozentuale) Preisänderungen. Eine Preiselastizität von 0,8 besagt $z$. B., dass die Nachfrage bei einer Preiserhöhung von $10 \%$ um $8 \%$ sinkt. 
an der Einführung einer prozentualen ${ }^{12}$ Selbstbeteiligung von z. B. 20 Prozent verdeutlichen (Abb. 1).

Abb. 1

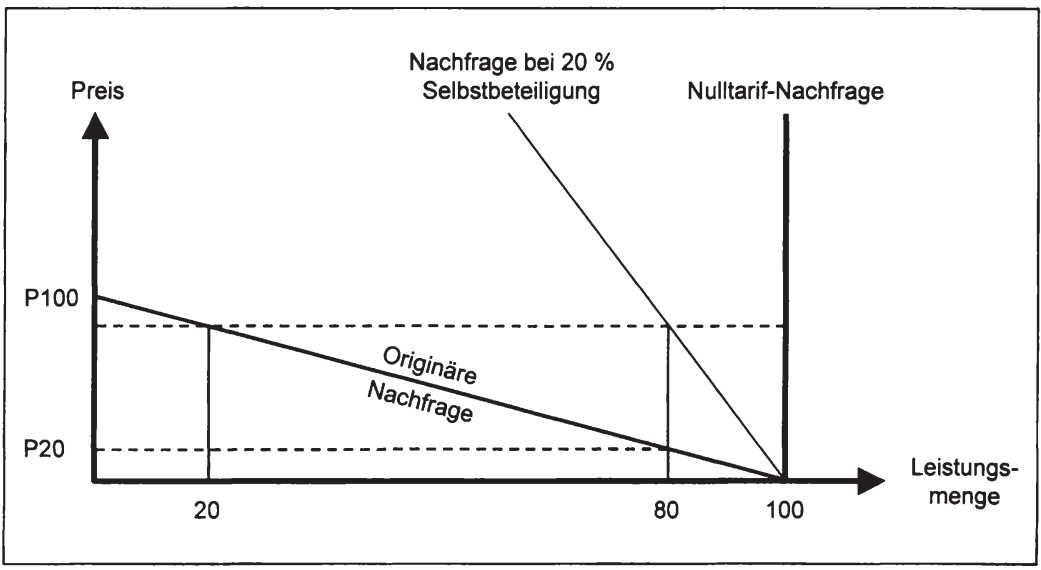

Unterstellt man auch für Gesundheitsleistungen, sofern sie nicht versicherungsgedeckt und zu 100 Prozent aus eigener Tasche zu bezahlen sind, eine normale Konsumentenreaktion auf unterschiedliche Preise, dann wäre diese Reaktion durch die "originäre Nachfragekurve" dargestellt. Je höher der Preis, umso geringer die Nachfrage. Diese typische Reaktion ist Folge eines eigennutzorientierten Verhaltens der Konsumenten. Für alle nützlichen Güter und Leistungen gilt, dass der Grenznutzen umso kleiner wird, je größer die Zahl der verfügbaren Leistungen bereits ist. Das gilt auch prinzipiell für Gesundheitsleistungen und hat nichts damit zu tun, „dass Gesundheit unser wichtigstes Gut ist und man davon gar nicht genug haben kann". Es geht nicht um Gesundheit an sich, da man diese ohnehin nicht "kaufen" kann, sondern es geht um „kaufbare" Leistungen, die häufig den Gesundheitszustand „erhalten, verbessern, wiederherstellen". Aber selbst für die wichtigsten und dringlichsten Einzelleistungen gilt das "Gesetz vom abnehmenden Grenznutzen", gibt es eine Menge, bei der eine weitere Inanspruchnahme offensichtlich sinnlos, nutzlos wird oder gar in Schädlichkeit umschlägt. Diese so genannte Sättigungsmenge sei in Abb. 1 durch die Menge (100) dargestellt. Diese Menge ist aus der Sicht von Patienten nur sinnvoll, wenn

12 Die Steuerungswirkungen anderer Selbstbeteiligungsformen werden z. B. dargestellt in Knappe, E.; Leu, R. E.; von der Schulenburg, J.-M.: Der Indemnitätstarif, Berlin u. a. 1988, S. $48 \mathrm{ff}$. 
sie kostenlos (ohne einen Preis bezahlen zu müssen) zur Verfügung stünde, denn nur dann würde sich ein Grenznutzen (von Null) mit den "Grenzkosten des Bezuges" (ebenfalls von Null) ausgleichen. Jeder zu zahlende Preis würde es sinnvoll erscheinen lassen, weniger Leistungen in Anspruch zu nehmen, denn jeder zu zahlende Preis beansprucht das verfügbare Haushaltsbudget und zwingt dazu, auf andere Bedarfe zu verzichten. Es ist daher sinnvoll, stattdessen nach billigeren Ersatzlösungen Ausschau zu halten und/oder - falls diese nicht zur Verfügung stehen - auf Teile der Inanspruchnahme gänzlich zu verzichten. Mit steigendem Preis geht daher die Nachfrage umso stärker zurück, je leichter auf Ersatzlösungen (Substitutionsmöglichkeiten) umgestiegen werden kann und/oder je leichter der Verzicht auf die betrachtete Leistung überhaupt fällt. $A b$ einer bestimmten Preishöhe wird daher gänzlich auf eine bestimmte Leistung verzichtet, "da diese zu teuer" ist. In Abb. 1 wäre das etwa bei einem Preis etwas oberhalb von $\left(P_{100}\right)$ der Fall.

Die Preiselastizität der Nachfrage misst eine Verhaltensänderung der Konsumenten im Laufe der Zeit. Daher wird die gemessene Preiselastizität auch von der Zeitperiode abhängen, in der die Preiselastizität ermittelt wird. Gerade im Gesundheitssektor, in dem die Patienten gewohnt sind, sich um Preise nicht kümmern zu müssen, wird es einer längeren Lernperiode bedürfen, bis entsprechende Preissignale zu größeren Verhaltensänderungen führen.

Die These, Gesundheitsleistungen seien völlig „preisunelastisch“, d. h. weder ein Verzicht sei möglich, noch seien Ersatzalternativen verfügbar, kann daher offensichtlich keinesfalls für alle Einzelleistungen des $\mathrm{Ge}$ sundheitswesens gelten, sondern gilt nur für ganz bestimmte wirksame und extrem dringliche Leistungsarten (lebensrettende Operation nach einem Unfall, bestimmte Arzneimittel). Da die Preiselastizität umso gröBer ist, je mehr Substitutionsmöglichkeiten verfügbar sind, ist sie in der Regel auch für einzelne Medikamente größer als $z$. B. für die Gesamtheit aller Einzelleistungen in einem Krankheitsfall. In der Regel wird die Nachfrage nach Gesundheitsleistungen der Nachfrage nach anderen wichtigen Konsumgütern weitgehend ähneln.

Die These von der preisunelastischen Nachfrage nach Gesundheitsleistungen kann jedoch auch anders interpretiert werden:

So könnte damit gemeint sein, dass man normativ nicht möchte, dass beim Bezug von Gesundheitsleistungen überhaupt ein Patient zu einem Nutzen-Preis-Vergleich angehalten werden soll, weshalb inm (alle?) Leistungen, trotz hoher Kosten, quasi kostenlos verfügbar sein sollen (so genannte Nulltarif-Regelung). Die aus Sicht des Patienten individuelle 
optimale Bezugsmenge wäre daher in Abb. 1 die Leistungsmenge (100). $\mathrm{Da}$ es sich um knappe Güter handelt, für die ein hoher kostenträchtiger Ressourceneinsatz erforderlich ist, muss der kostendeckende Preis bezahlt werden, und zwar über die Krankenversicherung, finanziert aus den Versicherungsbeiträgen aller Versicherten. Wäre dieser kostendeckende Preis z. B. $\left(P_{100}\right)$, so wäre ohne Nulltarif (100 prozentige Selbstbeteiligung) die Nachfragemenge gleich (20), die Ausgaben beliefen sich auf das Produkt aus Preis und Menge $\left(P_{100} \times 20\right)$. Da bei Nulltarif-Regelung die Inanspruchnahme bei (100) liegt, wären die erforderlichen Ausgaben (selbst wenn dadurch der kostendeckende Preis derselbe bliebe) höher $\left(P_{100} \times 100\right)$. Die höheren Ausgaben sind quasi "der Preis", der für die Nulltarif-Regelung (über die Versicherungsbeiträge) zu „zahlen“ ist. Da (unterschiedliche) Preise den Patienten direkt nicht berühren, wird die Nachfrage durch Preise auch nicht beeinflusst, die Nulltarif-Regelung macht die Nachfrage (bei der Sättigungsmenge 100) „preisunelastisch“ (in Abb. 1 die Senkrechte über Punkt 100). ${ }^{13}$

Diese Nulltarif-Regelung hat weitere Folgewirkungen, die hier nur angedeutet werden können. Da es für den Patienten aus finanziellen Gründen "egal ist", welche Menge er in Anspruch nimmt, wird er auch eine weit über (100) hinausgehende Inanspruchnahme akzeptieren, wenn ihm „der Arzt" das empfiehlt und er keine sonstigen Nachteile befürchtet. "Angebotsinduzierte Nachfrage" lässt sich bei Nulltarif-Regelung leicht realisieren. Da die Patienten nicht „preisempfindlich" sind, entsteht keine Preiskonkurrenz der Leistungserbringer und damit eine Tendenz zu überhöhten Preisen und Kosten. Preisdruck kann bestenfalls durch administrierte Preise (Fallpauschalen, Budgets etc.) künstlich geschaffen werden. „Richtiger, fairer" Preisdruck - wie auf Märkten bei Marktpreisen - kann so nicht entstehen. Auch ein Kompromiss zwischen Qualität und Preis, wie bei sonstigem Konsum nötig und sinnvoll, ist bei Nulltarif-Regelung individuell irrational, „das Beste, und zwar sofort" wird verlangt, die Null-

13 Auf eine weitere Fehlinterpretation im Zusammenhang mit Selbstbeteiligung und Nultarif-Regelung sei nur am Rande hingewiesen. Der Ausgangspunkt für die Einführung einer Selbstbeteiligung ist in der Regel ein Preis (für die Konsumenten) von Null oder eine (gemessen am tatsächlich kostendeckenden Preis) sehr geringe Gebühr. Angenommen, der kostendeckende Preis sei $P=100$. Der für Konsumenten zu zahlende Preis sei dagegen nur eine Geldeinheit. Steigt diese Zuzahlung durch Einführung einer Selbstbeteiligung nun auf $5 \mathrm{GE}$, dann misst die Preiselastizität die Nachfragereaktion (z. B. minus 10 Prozent) auf eine Preiserhöhung von plus 500 Prozent. Die gemessene Preiselastizität wäre demnach $(0,02)$ also ungewöhnlich gering, obwohl damit eine ganz normale Nachfragereaktion erfasst wird. Aus formalen Gründen des Messkonzeptes ist die Preiselastizität in der Nähe der Sättigungsmenge sehr gering, ohne dass das auf ein ungewöhnliches Verhalten hindeuten würde. 
tarif-Regelung fördert ein entsprechendes „Anspruchsdenken“. Da das aber nicht machbar ist, ist Enttäuschung der Patienten die Folge.

Eine (20 prozentige) Selbstbeteiligung an den Kosten und am Preis bewirkt, dass für die Patienten ein Fünftel des tatsächlichen Preises $(0,2 \times$ $P_{100}=$ P20) spürbar wird, ihre Reaktion ist eine entsprechende Mengenreduktion (in Abb. 1 von 100 auf 80 ). ${ }^{14}$ Daraus wird nochmals deutlich, dass die Konsumentenreaktion umso stärker sein wird, je höher die Selbstbeteiligung und je preiselastischer die originäre Nachfrage ist. Je höher die Selbstbeteiligung, umso mehr nähert sich die resultierende Nachfragekurve der originären Nachfragekurve an.

Abb. 2

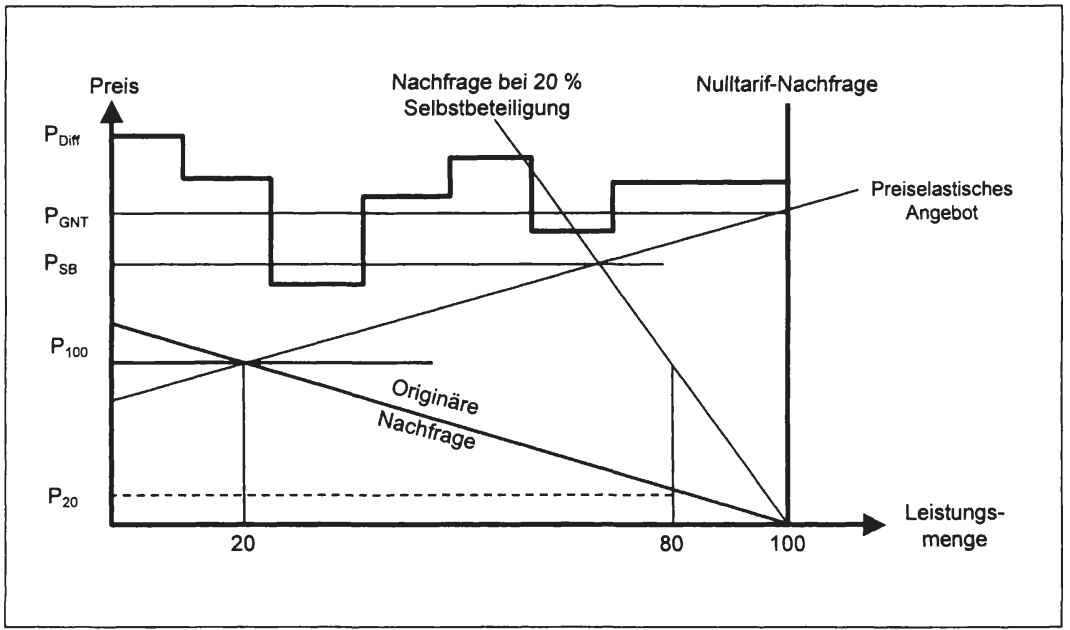

In ihrem Ausmaß weit bedeutender dürtten dagegen die Auswirkungen sein, die über die genannten Zusammenhänge hinaus wirksam werden. Solange eine Nulltarif-Regelung die Preise für die Patienten „unsichtbar" macht und solange keine anderen administrativen Preiskontrollen wirksam sind, solange können die Preise von den Anbietern weitgehend "nach Belieben" (als Mondpreise) festgesetzt werden. Die verschiedenen Anbieter werden daher nach Gutdünken ihre Preise (sehr unterschied-

14 In Abb. 1 ist die aus einer 20 prozentigen Selbstbeteiligung resultierende Nachfragereaktion eingezeichnet. 
lich) festlegen können (vgl. $P_{\text {Diff }}$ in Abb. 2). ${ }^{15}$ Nulltarif-Regelung erzwingt daher entweder weitere interventionistische Preiskontrollen oder eine über Selbstbeteiligung induzierte - Preisreaktion der Patienten. Durch die Einführung einer prozentualen Selbstbeteiligung werden die bestehenden Preisstrukturen für die Patienten sichtbar und finanziell spürbar. Bei unterschiedlichen Preisen für erkennbar homogene Leistungen werden sie die preiswerteren bevorzugen. Es kommt zu einem Preisangleichungszwang (nach unten, vgl. $P_{\mathrm{GNT}}$ ), das auf Wettbewerbsmärkten bekannte "Gesetz der Preisunterschiedslosigkeit" wird tendenziell wirksam. Das haben z. B. bei Einführung der Festbeträge für Arzneimittel diejenigen Anbieter, die inre Preise oberhalb der Festbeträge halten wollten, durch Absatzeinbußen empfindlich zu spüren bekommen, woraufhin sie ihre Preise auf Festbetragsniveau senken mussten. Allein dadurch, dass sich "Mondpreise" bei einer prozentualen Selbstbeteiligung nicht halten lassen, sind zusätzliche Einsparungen zu erwarten. ${ }^{16}$

$\mathrm{Da}$ - wie in Abb. 2 dargestellt - aller Wahrscheinlichkeit nach auch das Angebot preiselastisch sein wird, wird der Preisdruck nicht nur die Preise angleichen, auch das gesamte Preisniveau wird sinken, und zwar als Reaktion auf die insgesamt verringerte Nachfrage (vgl. $P_{S B}$ ).

Durch die Einführung einer Selbstbeteiligung werden sich auch die Verhaltensweisen der Leistungserbringer nachhaltig verändern. Preiswürdigkeit ihrer Angebote wird zu einem neuen Kriterium. Da es bei NulltarifRegelung nur um "Qualität" der Leistungen, weitgehend ohne Rücksicht auf Kosten und Preise, geht, wird auch der medizinische Fortschritt systematisch in eine Richtung gesteuert, die ausschließlich "mehr Qualität" anstrebt. Neue, bessere, zusätzliche Behandlungen sind das wichtigste Ziel (so genannte Produktinnovationen). Prozessinnovationen, die bekannte Behandlungsmethoden lediglich kostengünstiger und preiswerter machen, werden dagegen systematisch vernachlässigt. Insofern ist der medizinische Fortschritt "fehlgesteuert". Das ändert sich durch die Einführung einer Selbstbeteiligung, Prozessinnovationen werden dann vorteilhafter. ${ }^{17}$

Diese Situation galt vor allem in Deutschland für Arzneimittel bis 1989 (Einführung der Festbeträge) und im Krankenhaus bis heute (ab 2003 Einführung der Fallpauschalen; DRG). Im niedergelassenen Bereich gibt es dagegen einheitliche Einzelleistungs-Festpreise, festgelegt in Gebührenordnungen.

Vgl. Institut der deutschen Wirtschaft: Die Patienten mit ins Boot holen, in: iwd, Nr. 37, 12.09.2002, S. 3.

17 Vgl. Knappe, E.; Roppel, U.: Zur Stärkung marktwirtschaftlicher Steuerungselemente im Gesundheitssystem, Beiträge zur Wirtschafts- und Sozialpolitik, Institut der deutschen Wirtschaft 107/108, Köln 1982. Das gilt nicht für alle Formen der Selbstbeteiligung gleichermaßen, so z. B. nicht für Gebühren. 


\section{Eine „optimale Selbstbeteiligung“ zwischen „Sozialverträglichkeit und Steuerungswirksamkeit"}

Die höchste Steuerungswirksamkeit weist eine prozentuale Selbstbeteiligung in gleicher, spürbarer (z. B. 10 Prozent) Höhe auf alle Leistungen des Gesundheitswesens auf. Es ist vor allem die Möglichkeit zu Preisvergleichen - die Patienten werden mit der tatsächlichen Struktur aller Preise konfrontiert -, die wahrscheinlich den größten Steuerungseffekt auslöst. Auch bei Leistungen, bei denen die Preiselastizität der Nachfrage gering ist, werden die Patienten einen Anreiz haben, die günstigeren Anbieter zu suchen.

Eine prozentuale Selbstbeteiligung kann jedoch (ohne Obergrenze) dazu führen, dass in Einzelfällen - bei teurem, dauerhaftem und dringlichem Bedarf - die Belastungsfähigkeit von Haushalten überfordert wird. Das kollidiert mit dem Ziel der Sozialverträglichkeit, denn die Krankenversicherung soll ja gerade existentielle Risiken übernehmen und sie nicht den Haushalten anlasten. Um das zu vermeiden, gibt es prinzipiell zwei Möglichkeiten. Zum einen kann versucht werden, die Höhe der Direktbeteiligung nach dem Grad der Preiselastizität der Nachfrage zu staffeln. Je geringer die Preiselastizität, umso geringer die Selbstbeteiligung. Das würde zahlreiche soziale Härten auffangen, weil "geringe Preiselastizität" häufig bedeutet, dass es sich um einen dringlichen, unverzichtbaren $\mathrm{Be}-$ darf handelt. ${ }^{18}$ Dennoch ist von diesem Weg abzuraten, da eine objektive Messung der Preiselastizität schwierig ist, da sie nur ein schlechter Indikator für die Überforderung der Haushalte ist und weil staatliche Entscheidungsgremien nur mit einem erheblichen bürokratischen Aufwand mit einem derart differenzierten Konzept umgehen könnten. ${ }^{19}$

Zum anderen besteht die Möglichkeit, die Obergrenze der Zuzahlung direkt an der Wohlstandssituation und der Leistungsfähigkeit der Haushalte festzumachen. Einkommensstarke Haushalte können höhere Zuzahlungsbeträge verkraften als einkommensschwache. Ein einfacher Indikator wäre das Jahreseinkommen eines Haushaltes. Sehr viel besser

Vgl. zu einem ähnlichen Konzept für Arzneimittel MPS: Das Konzept der indikationsbezogenen Selbstbeteiligung, Bonn 1992.

19

Eine solche Selbstbeteiligung könnte im Idealfall „pareto-optimal“ gestaltet werden, d. h., es würde nur Gewinner und keine Verlierer geben. Die Nachteile (Wohlfahrtsverluste durch geringere Inanspruchnahme von Leistungen) wären vergleichsweise gering, weil dort, wo es "schmerzt" (bei dringendem Bedarf und geringer Preiselastizität), die Selbstbeteiligung gering ist. Dort, wo sie hoch ist (bei hoher Preiselastizität), wird zwar auf viel verzichtet, aber die Nachteile halten sich in Grenzen. Da aber insgesamt die Nachfrage und die Ausgaben erheblich zurückgehen, können auch die Beiträge erheblich gesenkt werden, was allen Vorteile bringt. Auf diese Weise gibt es nur Nettogewinner. 
würde die Leistungsfähigkeit eines Haushaltes durch das von der OECD vorgeschlagene, so genannte Äquivalenzeinkommen abgebildet, das das gesamte Haushalts-Nettoeinkommen (nach individuellem Bedarf gewichtet) auf die Personenzahl des Haushaltes "umlegt" (gewichtetes Haushalts-Pro-Kopf-Einkommen). ${ }^{20}$ Die Überforderungsklausel könnte als ein haushaltsbezogener Höchstbetrag für die tragbare Belastung durch die Selbstbeteiligung (z. B. maximal 5 Prozent des Haushaltseinkommens) oder für die Ausgaben für Gesundheit insgesamt (Krankenversicherungsbeitrag und Selbstbeteiligung, z. B. maximal 15 Prozent) festgelegt werden. ${ }^{21}$

\section{Ergänzende Reformmaßnahmen}

Im Rahmen einer auf Versicherungswettbewerb abzielenden Rahmenordnung des Gesundheitswesens erscheint es sinnvoll, unterschiedliche Formen und Ausgestaltungen von Selbstbeteiligungen den Kassen anheim zu stellen und im Wettbewerb erproben zu lassen. ${ }^{22}$ Es käme dann dazu, dass die Krankenkassen mehrere unterschiedliche Selbstbeteiligungsmodelle anbieten könnten und sich die Angebote von Kasse zu Kasse unterscheiden würden. Solange allerdings die Beiträge der Krankenkassen kein Preis für einen bestimmten Versicherungsumfang sind, sondern als Prozentsatz vom Bruttolohn erhoben werden (so genannte solidarische Finanzierung), käme es zu entsolidarisierenden Effekten. Wer hohen Lohn erhält und deshalb hohe Beiträge bezahlt, würde bei Wahl eines hohen Selbstbehaltes einen besonders hohen Beitragsnachlass erhalten. Auf diese Weise würde er sich einen Teil seiner (über den Beitrag zu zahlenden) Unterstützung für einkommensschwache Mitglieder sparen. Eine Beitragserhöhung für alle wäre die Folge. Auch besonders "gute Risiken" hätten einen Anreiz, besonders hohe Selbstbeteiligungstarife zu wählen, die „schlechten Risiken" blieben im Volltarif unter sich, wodurch ebenfalls deren Beiträge steigen würden. Es spricht daher einiges dafür, im Bereich der solidarisch finanzierten Pflichtversicherung den gesetzlich vorgeschriebenen Mindest-Versicherungsumfang einheit-

20 Faik, J.: Institutionelle Äquivalenzskalen als Basis von Verteilungsanalysen, in: Becker, I./Hauser, R. (Hrsg.): Einkommensverteilung und Armut, Frankfurt/Main, 1997.

Die heute vorgesehenen Härtefallregelungen nach $\S 61$ (Sozialklausel; vollständige Befreiung von der Zuzahlungspflicht) und § 62 SGB V (Überforderungsklausel) knüpfen die Befreiung von bzw. die maximale Höhe der Zuzahlung an Einkommensgrenzen.

In einer Mitgliederbefragung der Techniker Krankenkasse von 1997 sprachen sich z. B. 32 Prozent für eine hohe absolute Selbstbeteiligung $(1.500,2.500$ und $3.500 \mathrm{DM}$ pro Jahr) gegen eine Beitragsermäßigung (1.000, 1.500 und $2.000 \mathrm{DM})$ aus. 
lich für alle zu definieren. Dieser Regelleistungskatalog sollte gegenüber dem Status quo auf den Bereich der unerlässlichen Absicherungsnotwendigkeit reduziert werden. Da eine Durchforstung des Leistungskataloges im politischen Wettbewerb der Parteien schwierig ist, sollte der Leistungsumfang pauschal durch eine für alle geltende Selbstbeteiligung reduziert werden. Über den Regelleistungskatalog hinaus könnte für eine weitergehende Versicherungsdeckung gegen zusätzliche Beiträge Wahlfreiheit im Wettbewerb bestehen. Es wäre jedoch darauf zu achten, dass derartige "Zuwahlleistungen“ möglichst keine negativen Rückwirkungen auf den Regelleistungsbereich haben. ${ }^{23}$ Wären z. B. zahnärztliche Leistungen im Regelleistungskatalog enthalten, Zahnersatz aber ausgegliedert, könnte jemand Zahnersatz als zusätzliche Wahlleistung bei derselben oder einer anderen Versicherung abdecken. Durch den zusätzlichen Versicherungsschutz erhielte er jedoch einen Anreiz, diese Leistungen - und damit verbunden auch mehr zahnärztliche Leistungen - in größerem Umfang in Anspruch zu nehmen. Dasselbe würde gelten für Zuwahlverträge, die eine einheitliche Selbstbeteiligung im Regelleistungsbereich reduzieren. Gilt z. B. im Regelleistungsbereich eine 10prozentige Selbstbeteiligung für alle und würde jemand diese Zuzahlung als Wahlleistung durch einen ergänzenden Versicherungsvertrag abdecken, so würde er sich wie ein Vollversicherter mit Nulltarif-Regelung verhalten. Ein in Deutschland existierendes Beispiel wäre die Beihilferegelung im öffentlichen Dienst, die einer (staatlichen) Krankenversicherung mit bis zu 50 Prozent Selbstbeteiligung gleichkommt. Fast alle Beihilfeberechtigten decken diese hohe Selbstbeteiligung durch Zusatzverträge in der privaten Krankenversicherung vollständig ab, dementsprechend verhalten sie sich wie Vollversicherte. Als Vollversicherter hat man einen Anreiz, insgesamt mehr Leistungen in Anspruch zu nehmen. Das müsste aber auch im Regelleistungsbereich zu einem Prämienzuschlag führen, wenn dadurch die Versichertengemeinschaft nicht zusätzlich belastet werden soll. Solche ergänzenden Verträge, die die allgemeine Selbstbeteiligung verringern, dürften daher nur bei derselben Versicherung erworben werden, bei der auch der Regelleistungsvertrag besteht, oder müssten dieser zumindest angezeigt werden.

Selbstbeteiligungen in einem wettbewerblichen Umfeld, aber bei weiterhin über lohnbezogene Beiträge finanzierten Krankenkassen, müssen daher durch Maßnahmen ergänzt werden, die das Solidarprinzip absichern. Allerdings - darauf wurde eingangs bereits hingewiesen - kann das Solidarprinzip durch lohnbezogene Beiträge ohnehin nur sehr unvollständig und mit zahlreichen Widersprüchen und Ungerechtigkeiten

Vgl. Jacobs, K.: Königsweg Selbstbehalt, in: Gesundheit und Gesellschaft, 09/2002, S. $14-15$. 
realisiert werden. Da wegen der Rückwirkungen auf den Arbeitsmarkt und wegen der demographischen Abhängigkeit die lohnbezogenen Beiträge ohnehin nicht durchzuhalten sind, muss in absehbarer Zeit das Finanzierungssystem der GKV grundlegend reformiert werden. Würde man dabei z. B. zu individuellen Pauschalprämien (Kopfpauschalen) übergehen, könnten auch die $0 . \mathrm{g}$. Wettbewerbsprobleme mit Selbstbeteilungsmodellen entschärft werden.

\section{Literatur}

Bundesministerium für Gesundheit (Hrsg.): Zukunftsmarkt Gesundheit, BadenBaden, 2002.

Faik, J.: Institutionelle Äquivalenzskalen als Basis von Verteilungsanalysen, in: Becker, I./Hauser, R. (Hrsg.): Einkommensverteilung und Armut, Frankfurt/Main, 1997.

Frankfurter Allgemeine Zeitung vom 03. 01. 2003, S. 1 und 9.

Institut der deutschen Wirtschaft: Die Patienten mit ins Boot holen, in: iwd, Nr. 37, 12. Sept. 2002.

Jacobs, K.: Königsweg Selbstbehalt, in: Gesundheit und Gesellschaft, 09/2002, S. 14 - 15. Knappe, E., Roppel, U.: Zur Stärkung marktwirtschaftlicher Steuerungselemente im Gesundheitssystem, Beiträge zur Wirtschafts- und Sozialpolitik, Institut der deutschen Wirtschaft 107/108, Köln, 1982.

Knappe, E., Fritz, W.: Direktbeteiligung der Patienten: Auswirkungen eines absoluten Selbstbehaltes, in: Schr. d. Vereins f. SP. 1985, S. 449- 467.

Knappe, E.: Selbstbeteiligung im Gesundheitswesen. Eine Bestandsaufnahme empirischer Untersuchungen, in: Oberender, P. (Hrsg.): Gesundheitswesen im Umbruch, Bayreuth 1987, S. $49-75$.

Knappe, E., Leu, R. E., von der Schulenburg, J.-M.: Der Indemnitätstarif, Berlin u.a., 1988.

Knappe, E., Arnold, R.: Pauschalprämie in der Krankenversicherung. Ein Weg zu mehr Effizienz und mehr Gerechtigkeit, Vereinigung der Bayerischen Wirtschaft e.V., München, 2002.

MPS: Das Konzept der indikationsbezogenen Selbstbeteiligung, Bonn, 1992. 
MPS: Alternative Modelle der Selbstbeteiligung, Bonn, 1990.

Pimpertz, J.: Leitlinien zur Reform der gesetzlichen Krankenversicherung, Beiträge zur Wirtschafts- und Sozialpolitik 271, Köln, 2002.

Wirtschaftsrat: Zur Selbstbeteiligung beim Arztbesuch, Arbeitspapier $5 \mathrm{c}$ vom 24. Sept. 1999. 
Manfred Albring and Eberhard Wille - 978-3-631-75562-4

Downloaded from PubFactory at 01/11/2019 03:33:01AM

via free access 


\section{Versicherungsfremde Leistungen und Verschiebebahnhöfe}

Helmut Laschet

\section{Einige Grundsätze der Analyse}

In einem Punkt gibt es bei allen Beteiligten im Gesundheitswesen eine Einmütigkeit, die sonst selten ist: in der Beurteilung der so genannten Verschiebebahnhöfe zwischen Staatshaushalten und den Sozialversicherungszweigen sowie unter den Sozialversicherungen. Der Grund liegt auf der Hand: Per Saldo ist die gesetzliche Krankenversicherung entweder durch zusätzliche Ausgaben oder durch Entzug von Einnahmen in der Vergangenheit belastet. Das eint Krankenkassen und Leistungserbringer in dem Bemühen darin, die Sperre nach außen zu richten: Verantwortung für Defizite und Streitbeitragssätze trage der Gesetzgeber. Diese wären vermeidbar gewesen, hätte die Politik den Krankenkassen nicht ständig neue Pflichten auferlegt.

Mit ähnlichen Argumenten wird über versicherungsfremde Leistungen geklagt, die der Gesetzgeber aus sozialpolitischen oder aus opportunistischen Erwägungen den Krankenkassen aufgebürdet hat. Geholfen hat das Murren der Betroffenen nicht. Und das kann bedeuten: Entweder gab es für die zusätzlichen Belastungen des GKV-Systems wirklich gute Gründe - oder der machtpolitische Opportunismus des Gesetzgebers war durchschlagender als die Sachargumente aus dem Gesundheitswesen.

In der folgenden Analyse gehe ich von einigen Prämissen aus:

a) Die gesetzliche Krankenversicherung ist eine Versicherung. Ihre Zweckbestimmung ist es, ein für den einzelnen nicht kalkulierbares Risiko durch Prämien (oder Beiträge) in kalkulierbare Kosten zu überführen.

b) Die gesetzliche Krankenversicherung hat eine sozialpolitische Funktion. Ihre Beiträge werden nicht nach dem Äquivalenzprinzip kalkuliert, sondern im Prinzip nach der Leistungsfähigkeit der Beitragszahler.

c) Die gesetzliche Krankenversicherung versichert Risiken, die aus Krankheit resultieren. Dazu gehört nicht nur die unmittelbare medizinische Leistung, sondern dazu gehören auch Leistungen als Lohnersatz. 
Ich möchte prüfen, ob Verschiebebahnhöfe und versicherungsfremde Leistungen - abgesehen von einem Einmaleffekt, der das Ausgabenniveau erhöht - insofern ein Risiko für die Finanzstabilität der gesetzlichen Krankenversicherung darstellen, als diesen Aufgaben eine besondere Dynamik innewohnt. Die Frage ist nämlich, ob es sich auf Dauer überhaupt lohnt, eine kräftezehrende politische Debatte zu führen, die innerhalb der sozialen Sicherungssysteme Kostenträger einer Leistung sein soll - es sei denn, es bestünde Bereitschaft, diese Leistung mehr oder weniger zur Disposition zu stellen.

\section{Politische Entscheidungen zu Lasten der gesetzlichen Kran- kenversicherung}

"Zur Stärkung der Einnahmenbasis fordern die Ersatzkassen die Beendigung der Politik der Verschiebebahnhöfe, wodurch der GKV von 1995 bis 2002 rund 30 Mrd. Euro entzogen worden sind."

So heißt es in einer Pressemitteilung der Ersatzkassenverbände vom 8. Mai 2002 - eine Aussage, der sicherlich alle anderen Kassenarten, aber auch alle Leistungserbringer im Gesundheitswesen beitreten würden. Auf den ersten Blick erweckt die Summe vom $30 \mathrm{Mrd}$. Euro den Eindruck, als seien damit wesentliche Probleme des Gesundheitswesens lösbar, würde man die Krankenkassen von diesen zusätzlichen Aufgaben wieder entlasten. Ein solcher Eindruck täuscht, weil sich nachweisen lässt, dass an manchen Zahlenwerken aus optischen Gründen gern manipuliert wird, bis sich der erwünschte Eindruck einstellt.

\subsection{Die Relevanz von „Verschiebebahnhöfen“ für den Beitragssatz der GKV}

Bevor ich mich einzelnen Rangierfahrten zwischen den verschiedenen Sozialversicherungszweigen zuwende, möchte ich den Blick auf das relative Gewicht der Zusatzbelastungen am Gesamthaushalt der GKV lenken.

Dabei ist festzustellen: In den Jahren 1995 bis 2000 liegen die jährlichen Verschiebebahnhöfe zwischen knapp 2,7 Mrd. und gut 3,0 Mrd. Euro. Bei GKV-Gesamtausgaben zwischen 124 und $134 \mathrm{Mrd}$. Euro liegt der Anteil, den die GKV an andere Sozialversicherungszweige zusätzlich hat abgeben müssen, zwischen knapp 2,2 und knapp 2,5 Prozent. Erst im Jahr 2001 springt die Rangierlast auf knapp 2,8 Prozent und erreicht ab 2002 einen Höchststand von gut 3 Prozent. 
Festzuhalten bleibt also: Das Ausmaß der Verschiebebahnhöfe hat zwar zugenommen - ihr Gewicht an den Gesamtausgaben ist aber nach wie vor vergleichsweise gering.

Aber : Kann es dennoch sein, dass Leistungen für andere Sozialversicherungszweige die Ursache oder eine der Ursachen für die Defizite der GKV und insofern für steigende Beitragssätze waren?

Tatsächlich sehen wir in den Jahren 1995 und 1996 bei Defiziten von 3,7 und 3,6 Mrd. Euro eine Rangierlast von 2,7 und 2,9 Mrd. Euro. In den Folgejahren machen die gesetzlichen Krankenkassen jedoch bei fast stabilem Beitragssatz trotz tendenziell umfangreicher werdenden Verschiebebahnhöfen Überschüsse. Erst im Jahr 2001 scheinen Rangierlast und Defizit zu korrelieren. Allerdings: Die Jahre 1995 und 1996 waren, ebenso wie das Jahr 2001 - und entgegen allen Erwartungen auch das Jahr 2002 -, Jahre mit geringem Wirtschaftswachstum und steigender Arbeitslosigkeit. Bleiben wir noch einen Moment bei der Globalbetrachtung und schauen, wie sich die Verschiebebahnhöfe auf den Beitragssatz auswirken. So lassen sich 1995 0,28 Beitragssatz-Prozentpunkte durch Finanzströme zugunsten anderer Sozialversicherungszweige und zu Lasten der gesetzlichen Krankenversicherung erklären. Nach einem zeitweiligen Anstieg sinkt der Anteil im Jahr 2000 auf 0,26 Beitragssatzpunkte, erreicht dann aber im Jahr 2001 mit 0,37 Beitragssatzpunkten einen Höchstwert. Die Differenz zu 1995 beläuft sich auf 0,09 Punkte. Zur Jahreswende 2001/2002 war aber der durchschnittliche Beitragssatz der GKV mit 14 Prozent um 0,85 Punkte höher als im Jahr 1995.

Das vorläufige Fazit ist also: Verschiebebahnhöfe sind durchaus im Beitragssatz wirksam - sie erklären aber bestenfalls einen Bruchteil, etwa ein Zehntel des Anstiegs der GKV-Beiträge. Die eingangs genannte, kumulierte Belastung der GVK insinuiert insofern mit einer gewissen demagogischen Zielsetzung ein Problemvolumen, das sich mit der Wirklichkeit nicht deckt. Solche Zahlenspiele sind in der gesundheitspolitischen Debatte nicht eben Seltenheit.

\subsection{Einige ausgewählte Belastungsverschiebungen}

Tab. 1 zeigt in einer von Fritz Beske erarbeiteten Übersicht diejenigen Eingriffe des Gesetzgebers, die belastend für die gesetzliche Krankenversicherung zugunsten anderer Sozialversicherungszweige gewirkt haben. Auffällig dabei ist, dass diese einzigen Maßnahmen - die Senkung der beitragspflichtigen Einnahmen für Leistungsbezieher nach dem Arbeitsförderungsgesetz durch das Rentenreformgesetz 1992 - mit 17,5 Mrd. Euro fast 60 Prozent der Verschiebebahnhöfe zwischen 1995 
und 2002 erklärt. Ich will deshalb besonders in diesem Punkt der Frage nachgehen, ob der Gesetzgeber seiner Entscheidung eine nachvollziehbare Systematik zugrunde gelegt hat oder ob er primär willkürlich oder aus opportunistischen Erwägungen gehandelt hat.

Tab. 1: Defizite durch Verschiebebahnhöfe?

\begin{tabular}{|c|c|c|c|}
\hline Jahr & $\begin{array}{c}\text { Finanzierungssaldo } \\
\text { in Mrd. } €\end{array}$ & $\begin{array}{c}\text { Durchschnittlicher } \\
\text { Beitragssatz in } \%\end{array}$ & $\begin{array}{c}\text { Verschiebebahnhof } \\
\text { in Mrd. } €\end{array}$ \\
\hline 1995 & $-3,659$ & 13,15 & 2,670 \\
\hline 1996 & $-3,552$ & 13,48 & 2,894 \\
\hline 1997 & 0,861 & 13,58 & 3,078 \\
\hline 1998 & 0,277 & 13,62 & 2,918 \\
\hline 1999 & 0,284 & 13,60 & 2,861 \\
\hline 2000 & $-0,015$ & 13,57 & 2,613 \\
\hline 2001 & $-2,801$ & 13,54 & 3,830 \\
\hline 2002 & ${ }^{*}-2,500$ & 14,00 & 4,483 \\
\hline
\end{tabular}

*Schatzung BMG am Jahresende 2002

Quelle: BMG, Statistisches Taschenbuch Gesundheit 2001; Fritz Beske, Politische Entscheidungen zu Lasten der GKV, Kiel 2002

Rechtsgrundlage ist das im Dezember 1989 beschlossene Rentenreformgesetz, mit dem auch die $\S \S 157,163,166$ des damaligen Arbeitsförderungsgesetzes (SGB III) geändert wurden. Mit der Gesetzesänderung wurde die Beitragsbemessung für die Beitragszahlungen der Bundesanstalt für Arbeit an die GKV für solche Personen, die Leistungen nach dem Arbeitsförderungsgesetzes erhalten, von 100 Prozent auf 80 Prozent gesenkt. In der offiziellen Begründung dazu heißt es: „Denn in dieser Zeit - wenn also Leistungen nach dem Arbeitsförderungsgesetz bezogen werden - liegt der gesamte Lebensstandard des Leistungsbeziehers niedriger als zur Zeit seiner Beschäftigung."

Für die GKV hat die Regelung Auswirkungen in zwei Ausprägungen:

- Bei konstanter Arbeitslosigkeit sinkt die Einnahmenbasis für die GKV beim Kreis der Arbeitslosen um 20 Prozent.

- Zum Zweiten wird die GKV bei wachsender Arbeitslosigkeit durch weitere Einnahmenausfälle belastet. 
In seiner Begründung hat sich der Gesetzgeber das der gesetzlichen Krankenversicherung innewohnende Prinzip der Solidarität zu eigen gemacht. Danach knüpfen Beiträge in der GKV zumindest im Prinzip an die wirtschaftliche Leistungsfähigkeit an, gemessen ia der Höhe des Arbeitseinkommens. Ceteris paribus leisten dabei Bezieher höherer Einkommen einen Finanzierungsbeitrag für die Bezieher niedrigerer Einkommen. Genau dieses Prinzip hat der Gesetzgeber auf Lohnersatzleistungen angewendet, bei denen er - zu Recht - unterstellt, dass sie niedriger sind als das ursprüngliche Arbeitseinkommen.

Dabei ist immerhin zu bedenken, dass der Staat den Parafiscus GKV immer noch besser stellt als sich selbst: denn Lohnersatzleistungen werden netto ausgezahlt, müssen also nicht versteuert werden; der Staat verzichtet insofern zu 100 Prozent auf Einnahmen aus der Einkommenssteuer (wobei eingeräumt werden soll, dass der Staat weitere Einnahmequellen hat, während Krankenkassen einzig auf Beitragseinnahmen angewiesen sind). Erstaunlich ist aber in diesem Fall, wie unterschiedlich die Belastungen angerechnet werden:

- Die gesetzliche Krankenversicherung beziffert die jährliche Belastung in einer Erklärung aus dem Jahr 2001 (also expost) auf konstant 2,3 Mrd. Euro pro Jahr.

- Der Gesetzgeber geht - freilich basierend auf den im Jahr 1989 zur Verfügung stehenden Fakten und einer darauf aufbauenden Prognose - von Belastungen für die GKV von 0,6 bis gut 0,4 Mrd. Euro aus. Dem Gesetzgeber ist dabei wohl zugute zu halten, dass er die Folgen der Wiedervereinigung kaum zutreffend vorausschätzen konnte.

- Berechnungen der Basis der KJ1-Statistik unter Verwendung der Arbeitslosenzahl des jeweiligen Jahres von Fritz Beske kommen zu einem wohl realistischen Ergebnis zwischen etwa 1,8 und gut 2,0 Mrd. Euro zu Lasten der gesetzlichen Krankenversicherung.

Eine weiter vom Volumen her relevante Umfinanzierungsmaßnahme, die die GKV mit höheren Ausgaben belastet hat, war die Anhebung der Beiträge von Krankengeldbeziehern an die gesetzliche Renten- und Arbeitslosenversicherung durch das Rentenreformgesetz von 1992.

Bis Ende 1994 war das Krankengeld selbst Bemessungsgrundlage für die Beiträge an Renten- und Arbeitslosenversicherung. Dabei darf die Höhe des Krankengeldes nach § 47 SGB V das vor der Krankheit erzielte Nettoentgelt nicht übersteigen. Im Schnitt beträgt das Nettoentgelt 
etwa 60 Prozent des Bruttoentgeltes. Die Neuregelung sieht vor, dass die Krankenversicherung Renten- und Arbeitslosenbeiträge nun nicht mehr auf der Basis von 60 Prozent des ursprünglichen Bruttoentgeltes, sondern auf der Basis von 80 Prozent des Bruttoeinkommens an die anderen Versicherungszweige entrichtet.

Man erkennt also die korrespondierende Systematik zur Änderung der Beitragszahlungen nach dem Arbeitsförderungsgesetz an die GKV. Nach diesen beiden Änderungen sind nun alle Versicherungszweige gleichgestellt: Sie leisten und erhalten Ersatzbeiträge auf der Basis von 80 Prozent. Was also von interessierter Seite immer wieder als Verschiebebahnhof zu Lasten der GKV dargestellt wurde, ist in Wirklichkeit die Korrektur der ursprünglichen Begünstigung der Krankenkassen. Mit anderen Worten: Auf dem Rangierbahnhof wurden die Kurswagen der verschiedenen Sozialversicherungszweige in eine nachvollziehbare Systematik geordnet.

Man könnte, wenn man wollte, den Rangierbahnhof natürlich noch erweitern und für die Zahlungen unter den Versicherungszweigen auf eine Hundert-Prozent-Brutto-Systematik umstellen. Dann würden alle Lohnersatzleistungen der vollen Einkommenssteuerpflicht unterliegen, was freilich dazu führen würde, dass Krankenkassen und Arbeitsämter nach dem Quellsteuerverfahren eine Art Lohnersatzsteuer an das Finanzamt abführen müssten. Unter dem Gesichtspunkt der Steuergerechtigkeit wäre eine solche Lösung nicht ohne Charme. Denn im heutigen System mit einem stark progressiven Steuerverlauf ist zumindest ein Arbeitsloser mit Nichterwerbseinkommen begünstigt und kann seine Nettoposition verbessern - bei 100 Prozent Freizeit. Bei der Umstellung auf ein Hundert-Prozent-Brutto-System wäre auch endlich Ruhe auf dem Verschiebebahnhof eingekehrt - weil mehr als 100 Prozent nicht geht.

Zu guter Letzt auch noch ein Beispiel, das zeigt, wie schwierig die Berechnungen der Auswirkungen an Verschiebebahnhöfen sind. Als Folge einer beispiellosen Kampagne der Arbeitgeberverbände gegen angeblich zu hohe Lohnnebenkosten ließ sich die damals konservativ-liberale Bundesregierung dazu plattschlagen, die gesetzliche Lohnfortzahlung von 100 Prozent auf 80 Prozent des Lohnbruttogehaltes zu kürzen. Entsprechend sinkt dann die Beitragsbemessung für die gesamte Sozialversicherung. Die gesetzliche Krankenversicherung selbst schätzt ihre gesamten Einnahmenausfälle ex post auf 260 Mio. Euro jährlich für 1997 und 1998. Fritz Beske kommt in eigener Berechnung auf 55 Mio. bis 110 Mio. Euro, die der GKV jährlich entgangen sind - freilich wieder auf Basis diverser Hypothesen. Tatsache ist jedoch: Das Gesetz war weitestgehend wirkungslos, da die hundertprozentige Lohnfortzahlung ent- 
weder tarifvertraglich zusätzlich abgesichert war oder von Arbeitgebern um des Betriebsfriedens willen freiwillig fortgeführt wurde. Für eine Kündigung der entsprechenden Manteltarifverträge waren die Arbeitgeber zu feige. Mit dem Regierungswechsel im Herbst 1998 wurde das Gesetz wieder einkassiert. Man hat nicht gehört, dass deswegen in den Vorstandsetagen der Krankenkassen die Sektkorken geknallt hätten, weil nun in großem Umfang neue Mittel in die Kassen der GKV fließen.

Lassen sie mich ein Fazit ziehen:

a) Über das Ausmaß der Verschiebebahnhöfe existieren verschiedene Versionen. Die von den Krankenkassen behaupteten Volumina sind jedenfalls kaum glaubwürdig.

b) Die zusätzlichen Belastungen der Verschiebebahnhöfe haben zweifellos einen sichtbaren Einfluss auf die Beitragssätze. Es gibt aber keine Besorgnis erregende Dynamik innerhalb der Verschiebebahnhöfe, die eine ernsthafte Gefahr für die Stabilität der GKVFinanzen darstellen würde.

c) Alles in allem haben die Eingriffe des Gesetzgebers dazu geführt, ehemals bestehende Vorteile der gesetzlichen Krankenversicherung im Vergleich zu anderen Sozialversicherungszweigen zu beseitigen und insofern eine neu und somit besser begründbare Symmetrie der Finanzierungsbeziehung der Sozialversicherungszweige untereinander hergestellt.

d) Auf die Dauer müsste geprüft werden, ob nicht auch Lohnersatzleistungen steuerpflichtig gemacht werden müssten. Dies ist in jedem Fall dann sinnvoll, wenn Bezieher von Lohnersatzleistungen, die nicht nach Bedürftigkeit bezahlt werden, andere Einkünfte erzielen, die ihrerseits steuerpflichtig bleiben, aber wegen Wegfalls des steuerpflichtigen Lohns dann einer günstigeren Progression unterliegen.

\section{Versicherungsfremde Leistungen}

Zweckbestimmung einer Krankenversicherung ist es, die gesundheitlichen Risiken, die für den Einzelnen nicht kalkulierbar sind, über eine hinreichend große Versichertengemeinschaft in kalkulierbare Kosten zu überführen. Bei der gesetzlichen Krankenversicherung tritt für die Kalkulation der Beiträge der Solidargedanke hinzu, der an die wirtschaftliche Leistungsfähigkeit der GKV-Mitglieder anknüpft. Nicht versicherungs- 
fähig wären demnach solche Leistungen,

- die entweder nichts mit einem Krankheitsrisiko zu tun haben oder

- die, wie beispielsweise sichere Ereignisse, kein Risiko beinhalten.

Ein solches absolut sicheres Risiko ist der Tod. Ihn dergestalt zu versichern, indem die Krankenkassen ein Sterbegeld als Zuschuss zu den nur einmalig im Leben anfallenden Beerdigungskosten zahlen, ist insofern eine typische, nicht versicherungsfähige Leistung, die volkswirtschaftlich gesehen sogar Verschwendung bedeutet, weil bei der Versicherung dafür gewisse Verwaltungskosten anfallen. Das sozialpolitische Relikt aus wilhelminischer Zeit ist daher mit Recht im Rahmen des Gesundheitsreformgesetzes von 1989 für ab diesem Zeitpunkt Versicherte gestrichen und für die Altfälle in der GKV zu Recht im Rahmen des Beitragssicherungsgesetzes um 50 Prozent gekürzt worden. Immerhin kostete das Sterbegeld 1999 noch 1,6 Mrd. DM - gleichwohl lohnt eine ernsthafte gesundheitsökonomische Debatte darum nicht, weil es sich um einen sozialpolitischen Auslaufposten handelt.

Selten lässt sich aber eine Leistung nach dem SBG $V$ so eindeutig als versicherungsfremde Leistung qualifizieren, wie dies beim Sterbegeld der Fall ist. Ich will dies am Beispiel der Prävention skizzieren. Dabei unterstelle ich, dass es noch als offen gelten kann, ob der Einsatz präventiver Maßnahmen einen insofern gesamtgesellschaftlichen Aspekt hat, als dadurch über das Gesamtleben eines Versichertenkollektivs per Saldo Kostenersparnis durch verminderte Gesamtmorbidität erzielt wird. Es mag ausreichen, dass eine Präventionsmaßnahme, die auf die Verhinderung einer bestimmten Krankheit zielt, diese auch effektiv verhütet.

Nun ist eindeutig klar, dass der Einsatz einer präventiven Maßnahme unter der Voraussetzung einer hinreichenden Evaluation für den Einzelnen sowohl einen kalkulierbaren als auch einen durchweg tragbaren Kosteneinsatz erfordert. Damit existiert kein Risiko, das durch eine Versicherung kalkulierbar gemacht werden müsste.

Gleichwohl kann die Erstattung solcher Leistungen durch die GKV sowohl im Einzelfall als auch gesamtgesellschaftlich einen hohen Nutzen stiften, wie das Beispiel der Gruppenprophylaxe zur Verhütung von Zahnerkrankungen nach § 21 SGB V zeigt. Tatsächlich erfordert diese Leistung vom Einzelnen nur einen minimalen, in jedem Fall kalkulierbaren Einsatz, der deshalb keineswegs Leistung einer Versicherung sein müsste. Tatsache ist aber: Mit der Einführung der Gruppenprophylaxe für Kinder ist es gelungen, den eher schlechten Zahnzustand bei Kindern und vor allem die Verhinderung von Karies auf ein heute in internationa- 
lem Vergleich gutes Niveau angehoben zu haben. Die jährlichen Kosten dafür belaufen sich auf gut 60 Mio. DM (1999).

Ein weiteres Beispiel: Impfprophylaxe.

Dieses Thema ist insofern pikant, als Vorsorge durch Impfung nicht nur das geimpfte Individuum effektiv vor Krankheit schützt, sondern der Geimpfte zugleich als Ansteckungsquelle für andere ausfältt. Damit haben Impfungen sowohl den Charakter eines privaten als auch eines öffentlichen Gutes. Daraus ließe sich eine besondere Verpflichtung der Krankenkassen ableiten, in ihrer Leistungsgewährung darauf hinzuwirken, eine hohe Durchimpfungsquote zu erzielen, weil nur so der erwünschte gesellschaftliche Nutzen erreicht werden kann. Hinzu kommt, dass Impfstrategien auf der Basis der Empfehlungen der ständigen Impfkommission einen hohen Grad an Evidenzbasierung aufweisen, so dass Kostenträger sich auf der Basis qualitätsgesicherten Bodens bewegen, wenn sie diese Leistungen bezahlen. Tatsächlich ist aber die Performance - nicht zuletzt aufgrund der Beliebigkeit regionaler Impfvereinbarungen zwischen Krankenkassen und Kassenärztlichen Vereinigungen höchst unzureichend, so dass vor allem der erwünschte öffentliche Nutzen nicht erreicht wird. Als Alternative käme hier natürlich der Staat als Leistungsträger selbst in Frage, der diese Aufgabe dem öffentlichen Gesundheitsdienst übertragen könnte. Im Fall der Ausrottung der Pocken ist dies mit einer medizinhistorisch wohl einmaligen Aktion gelungen. Im Fall der Polio-Bekämpfung ist dies zeitweilig praktiziert worden. Nur hat sich der Staat entschieden, den öffentlichen Gesundheitsdienst zu verschlanken, so dass diese Aufgabe bei den gesetzlichen Krankenkassen gelandet ist. Deshalb ist die Frage zu stellen, ob man nicht erwarten darf, dass ein Versicherungskartell mit einem Marktanteil von fast 90 Prozent der Bevölkerung mit einem gesetzlichen Auftrag zur Gesundheitsversorgung in einem Sachleistungssystem nicht auch die Aufgabe übernehmen kann und soll, ein effektives System der Impfprophylaxe zu installieren und zu praktizieren.

Die beiden Beispiele zeigen Folgendes: Gesundheitspolitische Entscheidungen lassen sich nicht in ein stringentes ökologisches KriterienSchema pressen, obgleich der Nutzen der Zahnprophylaxe bei Kindern rein privater Natur ist und die Prävention an sich wegen geringer und kalkulierbarer Kosten keine versicherungsfähige Leistung darstellt, macht die Organisation dieser Leistung über das Sachleistungssystem der gesetzlichen Krankenversicherung durchaus Sinn. Etwas anders ist die Sache bei der Impfprophylaxe gelagert. Wir haben hier sowohl ein privates als auch ein öffentliches Gut. Auch in diesem Fall würde eigentlich nur Pragmatismus weiterhelfen: die Organisation effektiver Impfver- 
einbarungen in der Breite, begleitet von entsprechender Aufklärung.

Dies bedeutet keineswegs, dass alles, was an Prävention möglich und denkbar ist, in den Leistungskatalog der GKV überführt werden sollte oder auch als öffentliche Aufgabe verstanden werden müsste. Vielmehr ist wohl immer im Einzelfall zu prüfen,

- ob ein definierter Input in eine Präventionsmaßnahme mit hinreichender Wahrscheinlichkeit einen gesundheitlichen Outcome bewirkt,

- ob dieser Input nicht zum alläglichen Lebensaufwand eines jeden einzelnen zählt und deshalb per se privat zu finanzieren ist,

- inwieweit die Organisationsmacht der GKV einer erwiesenermaßen wirksame Präventionsstrategie zur Breitenwirkung verhelfen kann,

- ob es Aufgabe parastaatlicher Organisation oder auch des Staates selbst sein kann, sich in die Präferenzen von Individuen einzumischen, die ja auch die Vorliebe für ungesunde Lebensweisen beinhaltet.

\section{Sekundärprävention}

Ich möchte weiter bei den Grautönen bleiben, weil sie letztlich interessanter sind als Schwarz-Weiß-Malereien und klare Ja/Nein-Antworten.

Bei der Sekundärprävention stehen wir der Situation gegenüber, dass bestimmte Risikomerkmale vorhanden sind, die die Wahrscheinlichkeit für ein ernsthaftes Krankheitsereignis erhöhen. Eine Krankheit selbst ist dann noch nicht gegeben, lediglich bestimmte Surrogat-Parameter lassen erwarten, dass es dazu kommen könnte. In diesem Sektor wird eigentlich das große Geld in der Medizin verdient, und in diesem Sektor findet auch die eigentliche Ausgabendynamik statt. Das Problem dabei ist, dass wir uns hier nicht in einer deterministischen Welt befinden, sondern in multiplen stochastischen Prozessen, und zwar mindestens auf drei Ebenen:

a) Das Vorhandensein eines Risikofaktors bedeutet, dass eine Krankheit mit einer Wahrscheinlichkeit $X$ eintreten kann, wobei $X$ auch für Kollektive selten ganz eindeutig definiert ist. 
b) Der medizinische Input gegen den Risikofaktor reduziert die Wahrscheinlichkeit des Eintritts einer Krankheit nur um den Faktor Y, keineswegs jedoch mit Sicherheit.

c) Zugleich ist der medizinische Input mit einer Wahrscheinlichkeit Z verbunden, dass dem delinquenten Patient unerwünschte Wirkungen zugemutet werden.

Die Aufgabe der GKV ist es dabei, dem Versicherten und Noch-nichtganz-Patienten den Einsatz in diesem multiplen Lotteriespiel zu finanzieren. Ich habe bewusst eine ganz allgemeine und wenig konkrete Beschreibung gewählt, um deutlich zu machen, wie wenig eindeutig die Erkenntnis ist, ob die Entscheidungen zur Finanzierung medizinischer Leistungen abgestützt werden. 
Manfred Albring and Eberhard Wille - 978-3-631-75562-4

Downloaded from PubFactory at 01/11/2019 03:33:01AM

via free access 


\section{Versicherungsfremde Leistungen und Verschiebebahnhöfe}

Andreas Meusch

Es gibt keine Verschiebebahnhöfe. Ich kann Ihnen das auch beweisen, und Sie können das zu Hause nachvollziehen. Setzen Sie sich an Ihren Computer, gehen ins Internet und geben Sie mal "www.verschiebebahnhof.de" ein. Sie werden feststellen, dass Ihr Computer Ihnen eine Fehlermeldung gibt, obwohl er in Ordnung ist. Nicht einmal die Deutsche Bahn meldet sich. Zweiter Versuch: Gehen Sie zu Google, geben Sie "Verschiebebahnhof" ein, und innerhalb von Bruchteilen von Sekunden kommen 10.000 Meldungen. Dann geben Sie einmal ein "Verschiebebahnhof" und "Gesundheitswesen" ein. Sie werden überrascht sein, was Sie finden werden: das Werbebanner von der DKV, sonst nichts, null Treffer bei Google. Also, das erste Problem haben wir gelöst (die Technikerkrankenkasse hat inzwischen übrigens die Rechte an www.verschiebebahnhof.de erworben).

Was will ich mit dieser These sagen? Es gibt keine öffentliche Diskussion über Verschiebebahnhöfe, und deswegen ist die Grundannahme von Herrn Professor Beske falsch, die ich jetzt vorlese: „... In der öffentlichen Diskussion wird diese Problematik unter dem Stichwort Verschiebebahnhof behandelt". Stimmt nicht, es gibt keine öffentliche Diskussion zum Thema "Verschiebebahnhof". Die Diskussionen zu diesem Thema bleiben auf einen engen Kreis von Fachleuten beschränkt. Wir können darüber diskutieren, ob es eine öffentliche Diskussion gibt über das Liebesleben von Dieter Bohlen. Da gibt es möglicherweise eine, aber über Verschiebebahnhöfe gibt es keine.

Ich stelle diese These an den Anfang, weil ich deutlich machen will: Wenn es uns nicht gelingt, die Dinge in die Öffentlichkeit zu tragen, dürfen wir uns nicht wundern, dass hin- und hergeschoben wird. Es ist uns überhaupt nicht gelungen, in den ganzen Diskussionen, in guten Studien, die wir gemacht haben, ein Problembewusstsein in der Öffentlichkeit dafür zu generieren. Warum das so ist, können Sie an dieser Folie sehen, die mir Herr Professor Knappe dankenswerterweise zur Verfügung gestellt hat. Er hat in seinem Referat die "moral hazard"-Probleme und die "free rider"-Mentalität graphisch dargestellt: Was nichts kostet, wird viel in Anspruch genommen. 
Abb. 1

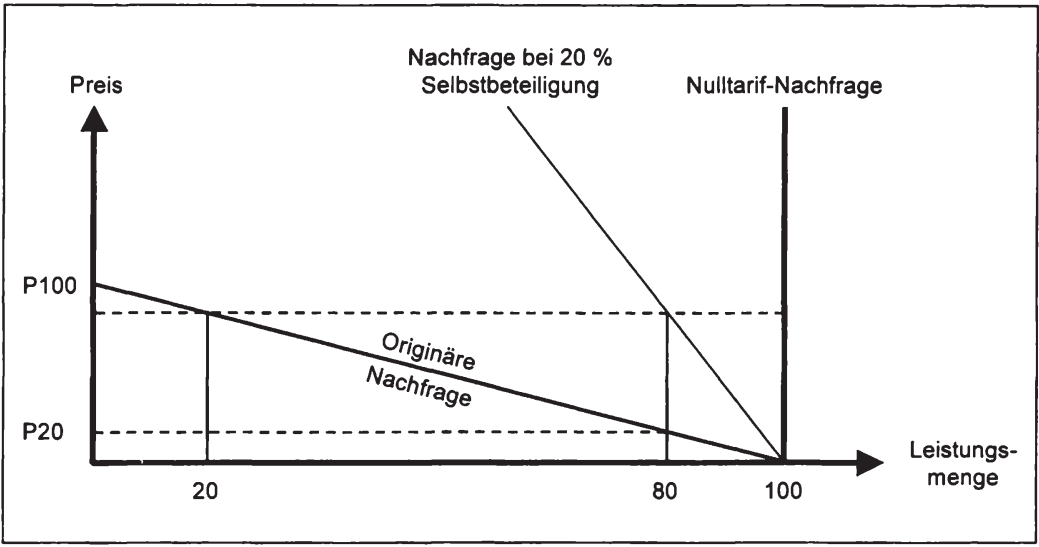

Diese Folie können Sie auch auf das Problem der Verschiebebahnhöfe anwenden. Politiker greifen zu diesem Mittel, weil die „Kosten“ in Form von Wählerstimmen gegen Null tendieren.

Warum werden Verschiebebahnhöfe gemacht? An dieser Folie können Sie sehen - aus der Perspektive der Politiker - „Es kostet nichts“. Welche Folgen hat ein Politiker zu erwarten, der Verschiebemaßnahmen zwischen GKV, Rentenversicherung, Arbeitslosenversicherung oder Steuern macht? Gar keine. Es gibt keine Selbstbeteiligung der Politiker. Dass dies so ist, kann jeder auch leicht feststellen. Wie groß muss die Summe der Verschiebebahnhöfe sein, damit Sie Ihre persönlichen Wahlpräferenzen ändern? 30 Mrd. Euro, 60 Mrd. Euro? Ist einer hier im Raum, der sagt, wo die Schmerzgrenze ist, ab wie viel Mrd. Euro er eine andere Partei wählen wird? Wer meint, die Leser der Ärzte Zeitung, die KV-Ärzte oder die Krankenkassen-Mitarbeiter mit Hinweis auf mehr Verschiebebahnhöfe zu bewegen, Wahlabsichten zu ändern? Niemand. Selbst wenn: Es wäre nicht genug.

Verschiebebahnhöfe versprechen Politikern sogar einen hohen politischen Profit: Sie können Handlungsfähigkeit beweisen. Jeder, der in der Politik etwas tut, hat einen Bonus auf seiner Seite: Es passiert etwas. Es gibt keine politischen Kosten, die zu erwarten sind, und deswegen werden wir Verschiebebahnhöfe haben, solange es Sozialpolitik gibt.

Jetzt der Punkt, warum ich auch ein Stück weit Herrn Laschet widerspreche. Sinngemäß hat er die Summen, um die es geht, zu "peanuts" erklärt. Das Geld ist aber durchaus auch relevant. Es gibt aber in der Tat wichtigere Gründe, warum wir darüber reden und uns darum kümmern 
müssen, dass das Thema im öffentlichen Bewusstsein bleibt. Zum einen Vertrauensschutz. Wir haben ja festgestellt, mit welcher Beliebigkeit Dinge hin- und hergeschoben werden. Mein Lieblingsbeispiel stammt aus dem Bereich der Arbeitsförderung. Norbert Blüm hat es geschafft, in der 8. Arbeitsförderungsnovelle das Thema Förderung des Hauptschulabschlusses durch die Bundesanstalt für Arbeit ins Gesetz zu schreiben, um zwei Novellen später die Regelung rückgängig zu machen und dies als Ende der Verschiebebahnhöfe zu feiern. Wie sollen die Menschen diesem Staat im Allgemeinen und dem Sozialstaat im Besonderen vertrauen, wenn ihr Geld mit solcher Beliebigkeit verwendet wird? Beliebigkeit und Willkür zerstören das Vertrauen und verhindern, dass die Menschen mit Mut und Entschlossenheit die Zukunft gestalten. Durch die Vielfalt der Verschiebebahnhöfe, in welche Richtung auch immer, wird das Gesamtsystem diskreditiert und verliert das Vertrauen, das es braucht, um zukunftsfähig zu sein.

Der dritte Punkt ist: Es gibt überhaupt niemanden mehr, der die Unterschiede zwischen einem gegliederten System in der Sozialversicherung und gesamtstaatlichen Aufgaben sieht. Dass das so ist, können Sie in der "Welt" von heute nachlesen. Dort steht, dass das staatliche Sterbegeld gekürzt wird - das "staatliche Sterbegeld“. Dass das etwas mit Krankenversicherung zu tun hat, weiß niemand, dass die Krankenversicherung nicht der Staat ist, nimmt auch niemand mehr wahr. Das heißt, wir müssen Mittel und Wege finden, dass dies den Menschen wieder klar wird, wenn wir verhindern wollen, dass das gegliederte System kaputt gemacht wird: Verschiebebahnhöfe sind vor allem ein kommunikatives Problem.

Wenn es uns nicht gelingt, das Thema zumindest bei Politikern zu verankern, haben wir ein Problem als Gesamtsystem GKV. Keiner weiß mehr, wo die Grenze zwischen Staat und beitragsfinanzierter Versicherung ist. Ich nenne ein Beispiel aus der heutigen Diskussion: Herr Dr. Leienbach sagt, dass die PKV die GKV dadurch alimentiert, dass sie die Krankenhausinvestitionen tätigt oder dafür mehr bezahlt. Nach geltendem Recht müsste an sich der Staat dafür aufkommen und nicht die GKV. Dass das nach dem so genannten "Fassadenurteil" heute anders ist, ist keine Alimentation der GKV, sondern die PKV alimentiert - wenn überhaupt - den Staat. Wir haben selbst in dieser fachkundigen Runde offenbar kein Bewusstsein mehr für das, was des Staates und was der Versichertengemeinschaft ist, und erwarten von der Politik, dass sie solche Dinge berücksichtigt.

Meine entscheidende Botschaft ist: Die Verschiebebahnhöfe sind primär ein kommunikatives Problem. Das müssen wir anpacken, wenn wir die 
Grundlagen des Systems retten wollen. Mein Vorschlag - halb ironisch, halb ernst gemeint: Wir brauchen eine ähnliche Konstruktion, wie es der Steuerzahlerbund gemacht hat mit der Schuldenuhr. Dass wir einfach etwas ins Bewusstsein bringen, Rituale schaffen, mit denen wir das öffentliche Bewusstsein wach halten. Vielleicht müssen wir wirklich einmal im Jahr hingehen und dem jeweils amtierenden Gesundheitsminister ein Modell eines Verschiebebahnhofes von Märklin überreichen und die Fehlallokation von Mitteln über "Verschiebebahnhöfe“ benennen. Vielleicht ist der richtige Tag der Todestag von Bismarck dafür.

Entweder es gelingt uns, die Problematik zumindest ins Bewusstsein der Politiker zu bringen, oder es erodieren die Grundlagen unseres eigenen Systems - mit langfristig fatalen Folgen für die politische Stabilität in Deutschland. 


\section{Versicherungsfremde Leistungen und Verschiebebahnhöfe - Anmerkungen aus praktischer Sicht}

Jürgen Wasem

1. Ein Vergleich der allgemeinen Wirtschaftsentwicklung (festgemacht am Indikator BIP je Einwohner bzw. BIP je Erwerbstätigen) mit der Entwicklung der Leistungsausgaben in der GKV je Mitglied zeigt deutlich, dass die Ausgabenentwicklung in der GKV in den vergangenen 25 Jahren vergleichsweise unauffällig gewesen ist. Demgegenüber ist die Einnahmenbasis der GKV deutlich hinter der allgemeinen Wirtschaftsentwicklung zurückgeblieben (vgl. Abb. 1). ${ }^{1}$ Die Beitragssatzsteigerungen im gleichen Zeitraum von 11,3 auf nunmehr 14 Beitragssatzpunkte sind daher nicht auf eine im Vergleich zur allgemeinen Wirtschaftsentwicklung aufsehenerregende Ausgabenentwicklung, sondern eine erodierende Einnahmenbasis zurückzuführen.

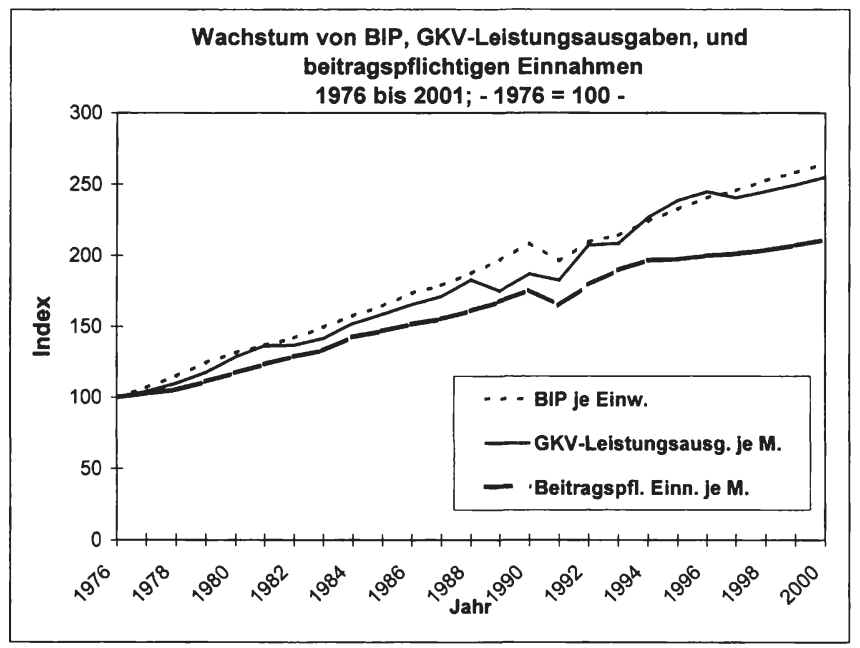

1 Für ein korrektes Bild ist es, wie in der Abbildung geschehen, für die Zeit vor 1995 erforderlich, die beitragspflichtigen Einnahmen der GKV zu rekonstruieren, da diese in der Statistik nicht ausgewiesen sind: Sie setzen sich aus der (regelmäßig ausgewiesenen) Grundlohnsumme in der Allgemeinen Krankenversicherung (AKV) und den beitragspflichtigen Einnahmen aus Renten und Versorgungsbezügen zusammen, die aus den Beitragseinnahmen und den entsprechenden Durchschnittsbeitragssätzen rückgerechnet werden müssen. 
Auch wenn vermutlich noch nennenswerte Effizienzreserven im deutschen Gesundheitssystem zu verorten sind, spricht $m$. E. wenig dafür, dass es dauerhaft leistbar ist, die Einnahmenentwicklung der GKV von der allgemeinen Wirtschaftsentwicklung abzukoppeln. Ohne eine Reform auch auf der Einnahmenseite, die die Lücke zumindest tendenziell schließt, ist entweder Beitragssatzstabilität oder die Beibehaltung des heutigen Versorgungsniveaus (nicht erst) auf mittlere Sicht illusorisch. Dies zu sagen, entbindet allerdings nicht von der Verpflichtung, gleichwohl auf der Ausgabenseite die Wirtschaftlichkeitsreserven zu heben. Denn ohne einen Produktivitätsschub durch Veränderungen in der Struktur der Leistungserbringung, ist das Gesundheitssystem für die künftigen Herausforderungen schlecht gewappnet.

2. Die erodierende Einnahmenbasis ist im Wesentlichen zwei Einflussfaktoren geschuldet:

- Verschiebebahnhöfe auf der Einnahmenseite zugunsten der Renten- und Arbeitslosenversicherung. Diese „unendliche Geschichte" beginnt bereits mit dem KVKG von 1977, bei dem die Beitragsbemessungsbasis der Rentenversicherung für die Krankenversicherung der Rentner um ein Drittel abgesenkt wurde, und setzt sich bis heute fort. Mit diesem Faktor ist auch die Massenarbeitslosigkeit in mehrfacher Weise verknüpft.

- Unterschiedliches Wachstum der Einnahmen, die beitragspflichtig zur GKV sind (und teilweise nicht im BIP enthalten sind, z. B. die Rentenzahlungen der GRV), und der Einkommensarten, die das BIP determinieren (und teilweise nicht in den Beitragsbemessungs-Grundlagen der GKV enthalten sind, z. B. bei Versicherungspflichtigen die Einnahmen aus Vermietung und Verpachtung, Kapitalvermögen etc.).

Auch aktuell ist bereits erneut abzusehen, dass weitere Verschiebebahnhöfe zu Lasten der GKV eintreten werden; der Umfang der Finanzmittel, die durch das Vorschaltgesetz beschafft werden sollen, ist offenbar auch bereits in Antizipation dieser Verschiebebahnhöfe anvisiert. Der Schaden, den die Politik hierdurch anrichtet, ist beträchtlich, tragen diese Aktionen doch zu einer stetigen Delegitimierung des Gesundheitssystems bei.

Da die Schwere zwischen BIP- und Leistungsausgaben-Wachstum auch durch die unterschiedlichen Wachstumsdynamiken bestimmt ist, sollte die Beitragsbemessungs-Basis m. E. auf die sieben Ein- 
kunftsarten des Steuerrechts erweitert werden. Dies trägt auch zu einer Entlastung der Arbeitskosten bei. Dass die "Parität" dabei dann „auf's Spiel gesetzt" wird, ist nicht zwangsläufig (ohnehin ist sie eine lllusion, aber offenbar eine sehr wirkmächtige).

3. Allerdings würde der Eindruck fehlerhaft sein, dass die Ausgabenentwicklung für sich genommen auf keinerlei Reformdruck schließen ließe. Denn die weitgehende Parallelität zwischen Wachstum von BIP und GKV-Leistungsausgaben wäre sicherlich nicht ohne kontinuierliche, im Zeitablauf tendenziell an Beschleunigung gewinnende, gesetzgeberische Interventionen zu beobachten gewesen. Es ist also nicht eine sich selbst steuernde, unauffällige Ausgabenentwicklung, sondern diese ist das Ergebnis eines KostendämpfungsMarathons des Gesetzgebers. Die wenigen Phasen, in denen der Gesetzgeber hierauf verzichtet hat, sowie die Zeit vor der Kostendämpfungs-Politik (etwa: 1970 bis 1976) zeigen dann auch deutlich die Tendenz überdurchschnittlich steigender Gesundheitsausgaben.

4. Die demographische Entwicklung hat in der Vergangenheit auf die Einnahmenseite der GKV nur einen vergleichsweise untergeordneten Einfluss gehabt. Für die Zukunft wirken hier sehr gegensätzliche Faktoren ein, die in ihrem quantitativen Gewicht unterschiedlich eingeschätzt werden können: Einerseits ist gewiss, dass der Rentneranteil an den GKV-Mitgliedern zunehmen wird - damit aber sinkt ceteris paribus die Einnahmenbasis der GKV, da Rentnereinkünfte niedriger als Erwerbstätigen-Einkünfte sind und davon auszugehen ist, dass diese Differenz im Zuge der Bemühungen zur Entlastung der Rentenversicherungs-Finanzen eher zunehmen wird. Andererseits kann infolge der demographischen Entwicklung auf dem Arbeitsmarkt Entlastung eintreten, was unter sonst gleichen Umständen zu einer Verbesserung der Einnahmensituation der Krankenkassen führt, weil Erwerbstätige ein höheres und rascher wachsendes beitragspflichtiges Einkommen als Arbeitslose erzielen. Je nach Annahmen, die man trifft, überwiegen die positiven oder die negativen Tendenzen in einer Prognoserechnung. Darauf zu setzen, dass von der Einnahmenseite her Entlastung angesichts der demographischen Herausforderung zu erwarten ist, ist daher zwar eine denkbare, jedoch keineswegs die einzig denkbare Entwicklung - während vergleichsweise unstrittig ist, dass auf der Ausgabenseite eher von einer Belastung auszugehen ist (deren konkretes Ausmaß allerdings ebenfalls wiederum von einer Vielzahl von Faktoren abhängt und wo eine Status quo-Prognose zwar legitim, vermutlich aber ziemlich unrealistisch ist). 
5. Der nationalökonomische Streit um „Umlageverfahren versus Kapitaldeckungs-Verfahren" als Finanzierungsform der sozialen Sicherungssysteme ist nach wie vor nicht eindeutig entschieden oder abgeschlossen. Jedes der beiden Systeme hat seine spezifischen Vorund Nachteile. Drei Feststellungen erscheinen mir allerdings wichtig:

- Teilweise wird der Übergang zu kapitalgedeckten Systemen gefordert, um die Einkommensumverteilung aus dem System herauszunehmen und es dann wettbewerblich zu organisieren. Klar ist aber, dass das Krankenversicherungs-System auch mit Umlage und mit Einkommensumverteilung wettbewerblich organisiert werden kann. Wer umgekehrt im KapitaldeckungsVerfahren Kassenwettbewerb um Qualität und Wirtschaftlichkeit der Versorgung organisieren will, benötigt auch Mechanismen, die Risikoselektionen verhindern - entweder einen den Besonderheiten des Kapitaldeckungs-Verfahrens Rechnung tragenden RSA oder die Mitgabe prospektiver individueller AlterungsRückstellungen.

- Wenn Kapitaldeckung zur demographischen Vorsorge gewollt wird, setzt dies nicht zwingend ein individualisiertes Anwartschaftsdeckungs-Verfahren voraus; vielmehr lässt sich ein Kapitalstock auch kollektiv auf- und wieder abbauen. Zwar wird ein solcher kollektiver Vorgang nicht völlig frei von intergenerationellen Verteilungseffekten sein, aber die völlige Abwesenheit intergenerationeller Umverteilung ist auch beim Kapitaldeckungs-Verfahren in der institutionellen und praktischen Wirklichkeit von Krankenversicherungs-Systemen nicht darstellbar.

- Konzeptionell ist es richtig, dass die Einkommensumverteilung über das Steuersystem schlüssiger erfolgt als über die GKV: Beitragsbemessungsgrenze und proportionaler Beitragssatz bewirken ebenso wie der Individualbezug eine krude Form von Verteilungseffekten. Zu bedenken ist allerdings, dass diese tendenziell gleichwohl in die "richtige" Richtung zielende - Umverteilung im Zeitablauf verlässlich ist, während dies von der Umverteilung über das Steuersystem weniger fest gesagt werden kann. Zugespitzt formuliert: Würde die Einkommensumverteilung aus der GKV herausgenommen, wäre die dann notwendige Subjektförderung tendenziell schon vom Finanzminister als Manövriermasse eingeplant, bevor sie überhaupt ihre Wirkung entfalten könnte. Im Ergebnis wäre nicht gerechtere, sondern schlicht weniger Umverteilung. Dies kann man ja wollen, aber dann sollte man es auch so sagen. 
6. Wohl kaum ein Thema der Einnahmenseite wird so ideologisiert diskutiert wie die gegenwärtige und mögliche künftige Rolle von Zuzahlungen. Drei Feststellungen können zur Entideologisierung beitragen:

- Es ist davon auszugehen, dass obligatorische Selbstbeteiligungen nicht nur einen Finanzierungseffekt, sondern auch einen Steuerungseffekt haben - darauf deuten zumindest die Ergebnisse des RAND-Experimentes in den USA hin, die am ehesten Aussagen über die Wirkungen von obligatorischen Selbstbeteiligungen zulassen. Die Daten zeigen allerdings, dass der Effekt bei niedrigen Einkommen größer ist als bei hohen (auch, wenn eine Härtefallregelung besteht) und dass der Effekt bei den veranlassten Leistungen deutlich geringer als beim Erstkontakt zum Arzt ist.

- Andere Daten deuten auch darauf hin, dass die Preiselastizität mit dem Gesundheitszustand abnimmt: der Steuerungseffekt ist im Vergleich zum Finanzierungseffekt bei den Kranken gering ausgeprägt - was angesichts der extrem schiefen Ausgabenverteilung in den Gesundheitssystemen auch nicht überraschen kann.

- Bei einer wahlweisen Selbstbeteiligung überlagern sich Steuerungseffekte mit Selbstselektionseffekten: Je gesünder, umso höher der gewählte Selbstbehalt. Über die relativen Größenordnungen beider Effekte können gegenwärtig offenbar noch keine abschließenden Aussagen getroffen werden. 
Manfred Albring and Eberhard Wille - 978-3-631-75562-4

Downloaded from PubFactory at 01/11/2019 03:33:01AM

via free access 


\section{Themenkreis 3}

\section{Der Wettbewerb als Koordinationsinstrument in der ambu- lanten und stationären Versorgung}

Rolf Hoberg

Mit der folgenden systematischen Einführung soll eine Skizze für den Hintergrund geliefert werden, vor dem in den nun folgenden Beiträgen unterschiedliche Marktteilnehmer ihre jeweiligen Einschätzungen abgeben werden.

Die Diskussion um Wettbewerb als Koordinierungssystem in der gesetzlichen Krankenversicherung muss in einer Vielzahl von Dimensionen geführt werden:

\section{Ordnungspolitische Alternativen}

Es ist zu unterscheiden, inwieweit bei den ordnungspolitischen Alternativen Staat und Administration gegen Markt als Koordinationsinstrument steht und ob Verbände die Träger der Auseinandersetzungsprozesse um optimale Leistungen in der wettbewerblichen Koordination sein sollen. Schlussendlich ist auch, wie die Realität zeigt, ein Mix aus diesen Alternativen möglich.

\section{Felder, in denen Koordination durch Wettbewerb erfolgen kann}

Hier ist es am einfachsten, entlang der Aufgaben der gesetzlichen Kranken- und Pflegeversicherung die Felder Prävention, Kuration, Rehabilitation und Pflege zu unterscheiden. Auch die Schnittstellen können entsprechend den ordnungspolitischen Alternativen mehr oder weniger wettbewerblich ausgestaltet sein.

\section{Parameter}

Schließlich ist hinsichtlich der Wettbewerbsdimensionen danach zu fragen, welche Parameter für die wettbewerbliche Auseinandersetzung durch den Gesetzgeber freigegeben werden. Soll es hier auf Preis und Inhalt begrenzt bleiben oder sollen sowohl Kapazität und Menge als auch Qualitäten zum Gegenstand des Wettbewerbs gemacht werden? Daher ist auch zu prüfen, inwieweit die Felder von Über-, Unter- und 
Fehlversorgung durch wettbewerbliche Parameter explizit adressiert werden sollen.

\section{Akteure}

Den Wettbewerb gestalten und beeinflussen kann der Staat als Ordnungsgeber und Regulator. Akteur auf der Krankenversicherungsseite können sowohl dann die einzelne Krankenkasse, ein Kassenverband oder die gesamte gesetzliche Krankenversicherung einheitlich und gemeinsam handelnd sein. Auf der Leistungserbringerseite treten Organisationen der Leistungserbringer, wie z. B. die Kassenärztlichen Vereinigungen als Körperschaft des öffentlichen Rechts, aber auch Vereine wie die Deutsche Krankenhausgesellschaft, auf; denkbar sind als Wettbewerbspartner auch die einzelnen Leistungserbringer. Es kann auch in der vertrauten Form die gemeinsame Selbstverwaltung der heute verfassten Art bleiben. Der Versicherte oder die Versichertenverbände sind künftig nicht nur als umworbene, sondern auch gestaltend als Wettbewerbspartner in diesem Feld zu erwarten.

\section{Ebenen}

Hinsichtlich der Ebenen sind wir es gewohnt, den Wettbewerb auf der Bundes- und Landesebene zu erleben. Man muss aber sehen, dass sich hierüber die Wettbewerbsdimension Europa spannt, aber auch auf kleineren Regioneneinteilungen unterhalb der Landesebene könnte künftig eine wettbewerbliche Auseinandersetzung möglich werden.

\section{Instrumente}

Von den zur Verfügung stehenden Instrumenten für die Festlegung des benötigten Leistungsangebotes kommen sowohl die normative Steuerung als Rahmensetzung in Frage als auch die Ansätze ökonomischer Steuerung im Wettbewerb durch Vertragssysteme von einer Marktseite gegenüber den Akteuren der Marktgegenseite etablierten Anreizsystemen und die von Leistungsnachfragern getragene Ausschreibung.

\section{Informationsmanagement}

Eine Voraussetzung für eine funktionierende Wettbewerbsordnung ist die Transparenz in Bezug auf das Marktgeschehen. Hierfür ist es erforderlich, dass sowohl die Angebotsstruktur als auch Inhalte, Qualität und Preise wesentlich transparenter als heute dargeboten werden und in einer Form aufbereitet sind, die den verschiedenen Akteuren Steuerungs- 
möglichkeiten eröffnen. Dazu muss ein datenträgergestütztes Datenmanagement ausgestaltet werden, das den Datenschutzanforderungen Rechnung trägt. Inwieweit dieses für die Beteiligten in eine gemeinsame Gesundheitsberichterstattung einmündet oder auch wieder wettbewerblich organisiert ist, ist eine Entscheidungsfrage.

\section{Abb. 1}

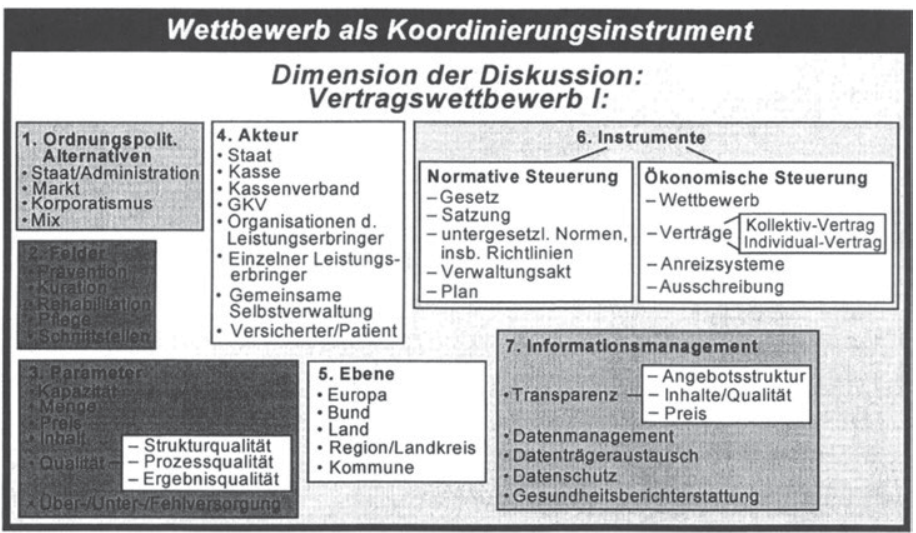

\section{Kontrahierungszwang versus selektives Kontrahieren}

In den Diskussionen um den Vertragswettbewerb werden immer wieder die Alternativen Kontrahierungszwang oder selektives Kontrahieren als Grundlagen für die Ausgestaltung einer wettbewerblich orientierten Vertragssystematik diskutiert. Zu den Dimensionen, in denen diese beiden Steuerungsansätze miteinander verglichen werden können, zählen Anreize zur Qualitätssicherung, die Zahl der Anbieter, die einbezogen sind, der Verwaltungsaufwand für die jeweilige Regelung, die KompetenzenZuordnung für die Ausgestaltung des Vertragsgeschehens, die Stabilität einer solchen Regelung, die Möglichkeit, die Kapazität in der Zahl und Qualität effektiv zu steuern, die Möglichkeiten einer Einflussnahme, insbesondere der Kostenträgerseite, und schlussendlich, in Bezug auf die Zukunft, die Offenheit für Innovationen. Folgt man diesen Dimensionen, so stellt sich ein sehr unterschiedliches Bild für den Kontrahierungszwang und selektives Kontrahieren dar. Je nach verfolgter Zielsetzung wird die Entscheidung für oder gegen selektives Kontrahieren ausfallen. 
Abb. 2

Dimension der Diskussion Vertragswettbewerb II:

\begin{tabular}{|c|c|c|c|}
\hline & & $\begin{array}{c}\text { Kontrahierungs- } \\
\text { zwang }\end{array}$ & $\begin{array}{c}\text { Selektives } \\
\text { Kontrahieren }\end{array}$ \\
\hline 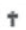 & Anreize zur Qualitätssicherung & niedrig & hoch \\
\hline 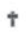 & Anbieterzahl & hoch, hohe Dichte & nach Bedarf \\
\hline+ & Verwaltungsaufwand & relativ niedrig & tendenziell hoch \\
\hline 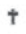 & Kompetenzzuordnung & eindeutig & eindeutig \\
\hline+ & Systemstabilität & hoch & $\begin{array}{l}\text { niedrig, aber höhere } \\
\text { Flexibilität }\end{array}$ \\
\hline$t$ & Kapazitätssteuerung & gering & hoch \\
\hline+ & $\begin{array}{l}\text { Einflussmöglichkeiten der } \\
\text { Kostenträger }\end{array}$ & gering & hoch \\
\hline$t$ & $\begin{array}{l}\text { Innovationspotential } \\
\text { (differenzierte Versorgungs- } \\
\text { strukturen) }\end{array}$ & wenig & stark ausgeprägt \\
\hline
\end{tabular}

\section{Kollektivverträge versus Einzelverträge}

Die Ausprägung von Kontrahierungszwang und selektivem Kontrahieren kann durch ein Kollektivvertragssystem oder durch ein Einzelvertragssystem ausgestaltet werden. Allerdings zeigt das Kollektivvertragssystem deutliche Nähe zum Kontrahierungszwang. Wesentliche Vorteile eines Kollektivvertragssystems sind die gleichmäßige flächendeckende Versorgung, die gesicherte Ordnungsfunktion und die Ermöglichung einheitlicher Qualitätsanforderungen. Dem steht aber gegenüber, dass durch die sektorale Abschottung falsche ökonomische Anreize in einer sehr inflexiblen Struktur gesetzt werden, die sich, was Innovationen angeht, als eher hemmend darstellen. 
Abb. 3

\begin{tabular}{|c|c|}
\hline \multicolumn{2}{|c|}{ Kollektivvertragssystem } \\
\hline Wesentliche Vorteile & Wesentliche Nachteile \\
\hline $\begin{array}{l}\text { Gleichmäßige, flächendeckende } \\
\text { Versorgung }\end{array}$ & $\begin{array}{c}\text { Abschottung der Sektoren } \\
\text { Falsche ökonomische Anreize }\end{array}$ \\
\hline Ordnungsfunktion & Fehlende Flexibilität \\
\hline $\begin{array}{l}\text { Ermöglichung einheitlicher } \\
\text { Qualitätsanforderungen } \\
\text { (Standards) }\end{array}$ & $\begin{array}{l}\text { Unzureichende Kapazitätssteuerung } \\
\text { Verzögerung von Innovationen } \\
\text { Marktungleichgewichte }\end{array}$ \\
\hline
\end{tabular}

Für das Einzelvertragssystem werden wesentliche Vorteile in der stärkeren Versichertenorientierung, in ökonomischen Anreizen zur Verbesserung der Versorgungsqualität, in der Flexibilität in der Vertragsgestaltung und in einer bedarfsgerechten Vertragsgestaltung gesehen. Allerdings stehen dem auch deutliche Nachteile gegenüber in der Zersplitterung der Versorgung, in den Schwierigkeiten einer globalen Steuerung und einer Begrenzung der Ausgaben gegenüber. Auch dürfte ein solches System mit einer Einschränkung der freien Arztwahl (zum Teil auf freiwilliger Basis) verbunden sein, und die Wahrscheinlichkeit von Machtungleichgewichten ist bei unzureichender Austarierung des Einzelvertragssystems eher gegeben.

Abb. 4

\begin{tabular}{|c|c|}
\hline \multicolumn{2}{|c|}{ Einzelvertragssystem } \\
\hline Wesentliche Vorteile & Wesentliche Nachteile \\
\hline Stärkere Versichertenorientierung & Zersplitterung der Versorgung \\
\hline $\begin{array}{l}\text { Ökonomische Anreize zur } \\
\text { Verbesserung der Versorgungsqualität }\end{array}$ & Keine globale Steuerung \\
\hline $\begin{array}{l}\text { Flexibilisierung } \\
\text { der Vertragsgestaltung }\end{array}$ & $\begin{array}{c}\text { Einschränkung der freien Arztwahl } \\
\text { Machtungleichgewichte }\end{array}$ \\
\hline Bedarfsgerechte Vertragsgestaltung & \\
\hline
\end{tabular}


Manfred Albring and Eberhard Wille - 978-3-631-75562-4

Downloaded from PubFactory at 01/11/2019 03:33:01AM

via free access 


\section{Kassenwettbewerb im Spannungsfeld von Patientenauto- nomie und Solidarität}

Franz Knieps

Bei aller Unübersichtlichkeit in der Diskussion über die künftige Ausgestaltung des deutschen Gesundheitswesens ist es weitgehend unstreitig, dass zur Erhöhung von Effizienz und Qualität primär wettbewerbliche Steuerungsinstrumente in ein weitgehend korporativ strukturiertes System implementiert werden sollen. Alle im Bundestag vertretenen Parteien erheben diese Forderung. Arbeitgeber und Gewerkschaften demonstrieren hier Einigkeit. Viele, aber nicht alle Leistungserbringer-Organisationen stimmen dem zu. Und natürlich steht ein „sozialorientierter Wettbewerb" auch im Zentrum der politischen Positionierung bei den gesetzlichen Krankenkassen.

So einig sich die meisten Akteure in der politischen Grundausrichtung sind, so differenziert fallen die einzelnen Positionierungen zur konkreten Ausgestaltung des Wettbewerbes im Gesundheitswesen aus. Es würde den Rahmen dieses Beitrages sprengen, detailliert auf die unterschiedlichen Vorstellungen der einzelnen Akteure im Gesundheitswesen einzugehen. Diese fallen vor allem bei den Fragen des Systemwettbewerbs zwischen sozialer und privater Krankenversicherung und bei der Ausgestaltung der Wettbewerbsparameter - speziell im Hinblick auf die Disponibilität von Leistungen und Beiträgen - weit auseinander.

Wer 10 Jahre nach Verabschiedung des Gesundheitsstrukturgesetzes eine Bilanz der Steuerung und Koordinierung über Wettbewerb zu ziehen versucht, der wird nicht umhin kommen, festzustellen, dass der Wettbewerb über den Beitragssatz und den Kundenservice die Erwartungen nicht (ausreichend) erfüllt hat, dämpfend auf den Ressourceneinsatz zu wirken und die Qualität der Versorgung zu verbessern. Wer die Ergebnisse des heutigen Kassenwettbewerbs kritisch hinterfragt, wird damit aber noch nicht automatisch zum Befürworter einer Rückkehr zum Status quo ante. Auch wenn das Gespenst der Einheitsversicherung nicht nur an Halloween beschworen wird und die zurzeit wieder einmal neu angefachte Debatte über die Zahl der Krankenkassen und die Besoldung ihrer Vorstände primär populistische Züge trägt, ein Zuweisungssystem oder ein einheitlicher Versicherungsträger stehen politisch nicht zur Diskussion. Sie werden gleichwohl als Keulen geschwungen, wenn man die Gliederung in Kassenarten oder besondere Privilegien im Kassenorganisationsrecht in Frage stellt. Institutionelle Voreingenommenheit muss man aber beiseite schieben, wenn man Erwartungen und 
Ergebnisse des Kassenwettbewerbs näher untersucht und aus dieser Analyse Vorschläge für eine konsistente Wettbewerbsordnung ableitet.

Unstreitig hat die Einführung der Kassenwahlfreiheit für alle Versicherten im Gesundheitsstrukturgesetz dazu geführt, dass die Kundenorientierung bei allen Krankenkassen exponentiell gestiegen ist. Versicherte werden nicht mehr gottgegeben einer Krankenkasse zugewiesen, sondern müssen umworben werden. Nicht mehr das graue Kollektiv, sondern die bunte und vielfältige Welt der Individuen bestimmt die Geschäftspolitik von Krankenkassen. Damit die Kunden den Rollenwechsel der Krankenkassen von gesichtslosen Bürokratien zu modernen Dienstleistungsunternehmen spüren konnten, mussten die Krankenkassen sich nach auBen und innen modernisieren. Der regelhafte Normenvollzug musste durch betriebswirtschaftliche Steuerungsinstrumente ergänzt, manchmal sogar ersetzt werden. Dieser Prozess der „nachholenden Modernisierung" ist noch keineswegs abgeschlossen.

Nach Einführung der Kassenwahlfreiheit für (fast) alle Versicherten in der GKV - ein Zustand, von dem frustrierte PKV-Versicherte nur träumen können - ist zwar der große Big Bang ausgeblieben, die Versicherten haben aber in anderer Weise von ihren neuen Freiheiten Gebrauch gemacht, was die meisten Experten nicht erwartet haben. Es kam nicht zur Vermischung, sondern zur Entmischung von Risikostrukturen, weil nahezu ausschließlich gesunde und flexible Versicherte von ihrem Kassenwahlrecht aktiv Gebrauch machen. Wer krank ist, denkt offenbar nicht im Traum daran, die Kasse zu wechseln, selbst wenn er nicht mit deren Leistungen oder Service unzufrieden sein sollte. Folglich ist es für eine Kasse zumindest vordergründig und kurzfristig lohnender, sich um die Zusammensetzung ihrer Versichertenstruktur zu kümmern als um deren Versorgung. Im Gegenteil: Viele Kassen haben Angst, sich versorgungspolitisch zu profilieren, weil sie mit dem Zugang schlechter Versichertenrisiken rechnen.

Zwar ist diese Befürchtung angesichts des tatsächlichen Wanderungsverhaltens weitgehend aus der Luft gegriffen, sie reflektiert jedoch die heutigen Fehlanreize im Kassenwettbewerb. Daran kann auch der bisherige Risikostrukturausgleich nur begrenzt etwas ändern. Die Faktoren Einkommen, Alter und Geschlecht bilden die sozioökonomischen Verhältnisse der Versicherten ab. Deren Gesundheitszustand und damit deren Kostenprofil bleiben jedoch außen vor. Folglich führt an der Morbiditätsorientierung dieses Ausgleiches kein Weg vorbei, auch wenn einige Akteure immer noch glauben, den Strom der Geschichte aufhalten oder umlenken zu können. Eine solche Weiterentwicklung des Risikostrukturausgleiches erfolgt nicht aus Kalkül, dessen Verteilungswirkungen zu er- 
höhen, sondern dient primär dazu, die Wettbewerbsanreize für die Kassen von der volkswirtschaftlich unsinnigen und ethisch bedenklichen Risikoselektion unter den Versicherten auf die Ausgestaltung der Versorgung, insbesondere für chronisch Kranke, zu lenken. Dabei geht es nicht um tumbe Versuche der Diskriminierung von einzelnen Versicherten, sondern um Fehlanreize für die kollektiv ausgerichtete Markt- und Versorgungspolitik der jeweiligen Krankenkasse. Deshalb korrespondiert der morbiditätsorientierte Risikostrukturausgleich als wesentliche Rahmenbedingung für erweiterten Kassenwettbewerb mit der Erweiterung der Möglichkeiten für Vertragswettbewerb.

Heute werden die meisten Verträge zwischen Krankenkassen und Leistungserbringern auf der Verbandsebene einheitlich und gemeinsam für alle Kassenarten abgeschlossen. Dementsprechend dominieren auf der Anbieterseite monopol- oder kartellartige Strukturen in fast allen Versorgungsbereichen. Selbst dort, wo Differenzierungen möglich wären, hat sich de facto ein einheitliches und gemeinsames Vorgehen auf Verbandsebene entwickelt. Dagegen wäre prinzipiell nichts einzuwenden, wenn auf diese Weise ein schnelles, zielgerichtetes und ressourcenschonendes Handeln bewirkt worden wäre. Leider muss man aber täglich erleben, dass der kleinste gemeinsame Nenner von acht Kassenarten mit ganz unterschiedlichen Interessen ein zu geringer ist, um innovative Vorstellungen zeitgerecht in die Praxis umzusetzen. Dies gilt erst recht, wenn zusätzlich auf Seiten der Leistungserbringer die vielfältigen Interessen der unterschiedlichen Klientelgruppen zu berücksichtigen sind. Das kümmerliche Schicksal der integrierten Versorgung, und die politisch motivierten Verzögerungen und Blockaden bei den DiseaseManagement-Programmen mögen als Begründung dafür ausreichen, dass die Beziehungen zwischen Krankenkassen und Leistungserbringern grundlegend reformiert werden müssen.

Es ist kaum ein rotierender Grund dafür erkennbar, dass der Patient stets durch einen Kleinunternehmer behandelt werden muss, solange er sich nicht in ein Krankenhausbett legt. Umgekehrt ist es natürlich nicht zu verachten, dass die Infrastruktur des Krankenhauses nur denjenigen zugute kommt, die nicht mehr laufen können. Erst recht ist es nicht einzusehen, dass Krankenkassen mit jedem Leistungserbringer einen Vertrag schließen müssen, wenn er die geringen Zulassungshürden für den Eintritt ins System überwunden hat. Auch wer skeptisch gegenüber marktwirtschaftlichen Instrumentarien im Gesundheitswesen ist, sieht keine Alternative dazu, diese Beziehungen zwischen Krankenkassen und Leistungserbringern künftig stärker wettbewerblich auszugestalten. 
Will man es noch länger dem „Focus“ überlassen, Versicherte und Patienten über Qualitätsunterschiede in der Versorgung aufzuklären? Wenn Krankenkassen ihren Anteil an der Wertschöpfungskette halten oder gar ausbauen wollen, müssen sie Navigatorenfunktionen für ihre Mitglieder im Dschungel des Gesundheitswesens übernehmen und das Angebot im Interesse ihrer Mitglieder selektieren. Dies bedeutet, dass sie neben oder anstelle des Kollektivvertrages über Individualverträge besondere Beziehungen zu den Leistungserbringern aufbauen, die aus ihrer Sicht für Qualität und Wirtschaftlichkeit der Versorgung bürgen. Dies bedeutet auch, dass Kassen ihre Versicherten über solche Angebote informieren und beraten dürfen.

Ein Plädoyer für mehr Vielfalt in den Beziehungen zwischen Krankenkassen und Leistungserbringern bedeutet nicht, dass die Einheitlichkeit der Versorgung, die ja heute auch nur auf dem Papier steht, durch ein atomistisches Kleinklein von hunderten, tausenden, zehntausenden von Verträgen ersetzt werden sollte. Es ist schlicht nicht praktikabel, mit jeder Praxis oder sonstigen Institutionen des Gesundheitswesens individualisierte Verträge auszuhandeln. Die Kassen sollten vorrangig das Instrument der Ausschreibung nutzen, schon um wettbewerbs- und kartellrechtlichen Vorgaben zu entsprechen. Dabei ist es denkbar, die Zugangsbedingungen einheitlich zu regeln, aber die Inhalte und die Vergütung kassenspezifisch zu vereinbaren. Außerdem sollte das Instrument der "Einzelverträge" primär zur Organisation von Versorgungsnetzen und Versorgungsketten genutzt und regional oder indikationsspezifische Versorgungsaufträge eingesetzt werden. Dabei wird es ein Nebeneinander unterschiedlicher Versorgungsformen geben, in denen der Kollektivvertrag bedeutsam bleiben wird. Auch wird es Dinge geben, die der wettbewerblichen Steuerung verschlossen bleiben. Ob diese dann in der herkömmlichen gegliederten Verbandsstruktur erledigt werden müssen, darf zumindest hinterfragt werden. Das gilt sowohl für die Seite der Leistungserbringer als auch für die Krankenkassen.

Es ist mehr als eine Pflichtübung, darauf hinzuweisen, dass die Chancen für eine wettbewerbliche Differenzierung im Sozialrecht bereits existieren. Allerdings wird das Berufsrecht als Blockade und Verzögerungsinstrument eingesetzt oder wirkt zumindest entsprechend. Wiederholt wurde nachhaltig darauf aufmerksam gemacht, dass Unternehmens- und Betriebsformen für integrierte Versorgungseinrichtungen noch gar nicht entwickelt sind. Auch macht die sektorale Unterscheidung mit daran angeknüpften Finanzierungs- und Honorierungsanreizen der integrierten Versorgung schwer zu schaffen. Schließlich setzt Vertragswettbewerb andere Kompetenzen und Fähigkeiten auf beiden Seiten voraus. All die- 
se Erfordernisse sind allerdings nicht als Einwände, sondern als Chancen für die Entwicklung entsprechender Konzepte zu verstehen.

Der AOK-Bundesverband hat deshalb ein multidisziplinäres Gutachten zum Thema Vertragswettbewerb bei Wissenschaftlern aus den Gebieten Recht, Ökonomie und Medizin in Auftrag gegeben. Die Wissenschaftler Ebsen, Greß, Jacobs, Szecsenyi und Wasem wollen an den beiden Ausformungen des Solidarprinzips, nämlich dessen Inanspruchnahme nach Bedarf und der Finanzierung nach der ökonomischen Leistungsfähigkeit, festhalten. Sie sehen in der Komplexität der Regulierungen und in der fehlenden Koordinierung der Versorgung die Hauptursache für Verkrustungen, ständische Strukturen und wechselseitige Interessenblockaden. Die sektorale Zersplitterung stehe einer möglichen Produktivitätssteigerung entgegen und begünstige Über-, Unter- und Fehlversorgung. Für die Kassen bestünden keine hinreichenden Ansätze, aktiv auf mehr Qualität und Wirtschaftlichkeit der Versorgung einzuwirken. Dies ändere sich erst bei der Einführung des morbiditätsorientierten Risikostrukturausgleiches. Außerdem stünden den Kassen zu wenig Instrumente zur Beeinflussung von Qualität und Wirtschaftlichkeit der Versorgung zur Verfügung. Aufgrund eines starren Kontrahierungszwanges hätten Kassen keinen oder nur geringen Einfluss darauf, welche Leistungsanbieter zu welchen Bedingungen die Versorgung erbringen. Die Förderung von Vertragswettbewerb als Bestandteil eines umfassenden wettbewerblichen Gesamtkonzeptes für die gesetzliche Krankenversicherung könne den reinen Preiswettbewerb zwischen Krankenkassen durch einen Wettbewerb um Qualität und Wirtschaftlichkeit ersetzen. Basis des Vertragswettbewerbs sei ein einheitlicher Leistungskatalog. Eine Öffnung zum Angebot von Chronisch- und Wahlleistung innerhalb der GKV würde Möglichkeiten zu unerwünschten Risikoselektionen für die Krankenkassen beträchtlich erhöhen. Voraussetzung und Folge des Vertragswettbewerbes sei eine erhöhte Transparenz über Versorgungsleistungen und ihre Qualität. Die Vereinbarung und Einhaltung von Qualitätszielen wird in wesentlich höherem Ausmaß zwischen Verträgen von Krankenkassen und Leistungsanbietern sein.

Als Einstieg in den Vertragswettbewerb wählen die Gutachter die integrierte Versorgung. Sie plädieren jedoch auch dafür, gleichzeitig erste Schritte zum Abbau von Überregulierung außerhalb der integrierten Versorgung zu unternehmen. Sie sehen die Ursachen für die mehr als begrenzte Wirkung integrierter Versorgungsansätze vor allem darin, dass es bei den gesetzlichen Regelungen bislang nicht vorrangig um die gezielte Förderung neuer Versorgungsformen ging. Im Vordergrund habe vielmehr gestanden, die von der integrierten Versorgung möglicherweise ausgehenden Störungen bestehender und in ihrer Wirksamkeit fragwür- 
diger Kollektivregelungen zu minimieren. Diese Logik müsse man umkehren. Verträge über integrierte Versorgung sollten auch mit Leistungsanbietern geschlossen werden können, die außerhalb dieser Versorgung nicht zugelassen sind. Dies sollte auch für bisher nicht zulässige Rechtsformen von Leistungserbringern gelten. Einseitige nachträgliche Beitrittsrechte für Nichtbeteiligte sollten ausgeschlossen sein. Die Arzneimittelversorgung sollte in die integrierte Versorgung einbezogen werden. Berufsrechtliche Hemmnisse sollten durch sozialrechtliche Regelungen überwunden werden. Massiver Entwicklungs- und Förderbedarf bestehe vor allem im Hinblick auf leistungsorientierte integrierte Vergütungssysteme, vor allem in Form morbiditätsadjustierter Kopfpauschalen, sowie auf betriebswirtschaftliche Konzepte für managementfähige Angebotsformen der integrierten Versorgung einschließlich interner Vergütungsstrukturen. Die Gutachter wollen Anreize für mehr Vertragswettbewerb außerhalb der integrierten Versorgung, vor allem durch die Möglichkeit zur Vereinbarung kassenindividueller Zuschläge oder Abschläge auf die Basisfallwerte im Krankenhaus nach Einführung der DRGs durch kassenindividuelle Arznei-, Hilfs- und Heilmittelvereinbarungen und kassenindividuelle Versorgungsverträge mit Rehabilitationseinrichtungen, fördern. In allen Verträgen müssten Qualitätsindikatoren vereinbart werden, die die Qualität der Leistungserbringung anhand ausgewählter Merkmale anzeigen. Für alle Anbieter müsse eine diesbezügliche Informationspflicht gelten. Außerdem soll es Leistungserbringern möglich werden, darüber hinausgehende Informationen über die von ihnen gelieferten Qualitäten mitzuteilen. Diese Informationen sind auch in für Versicherte und Patienten geeigneten Formen zu kommunizieren.

Mit Befriedigung kann man feststellen, dass mit der Koalitionsvereinbarung der politische Wille manifestiert worden ist, den hier skizzierten Weg zu gehen. Im Spannungsfeld von Patientenautonomie und Solidarität ist der Vertragswettbewerb ein Instrument, beiden Zielen gerecht zu werden. Auch der wirksamsten Lobbymacht der Akteure im Gesundheitswesen wird es nicht mehr gelingen, ihn von der politischen Tagesordnung abzusetzen. 


\section{Kassenwettbewerb im Spannungsfeld von Patientenauto- nomie und Solidarität}

Norbert Klusen

Nach mehr als sechs Jahren Kassenwahlfreiheit kann man eine positive Bilanz ziehen: Die Versicherten sind kritischer geworden. Sie machen von ihrem Recht Gebrauch, Preise und Leistungen zu vergleichen und Kassenstrukturen zu hinterfragen. Dabei rückt vor allem auch die Frage der Patientenautonomie immer stärker in den Fokus. Ist der Patient heute in der Lage, selbstverantwortlich eigene Entscheidungen zu treffen und Therapieoptionen gegeneinander abzuwägen?

Patienten müssen und wollen heute immer mehr selbst entscheiden. Allerdings: Wer nicht informiert ist, wird finanzielle und gesundheitliche Folgen spüren. Das paternalistische System - der Arzt entscheidet allein über die Therapie, der Patient stimmt lediglich zu - lassen wir in Deutschland gerade hinter uns. Patienten sind heute meist nicht mehr unmündig und unwissend. Neue Kommunikationswege, wie z. B. das Internet, tragen ganz wesentlich dazu bei. Allerdings entscheidet der Arzt oftmals immer noch allein, wenn auch die Patientenbedürfnisse mit in diese Entscheidung einfließen (Prinzipal-Agent-System). Therapien werden immer noch mehr verordnet, statt mit dem Patienten gemeinsam besprochen.

Patient und Arzt befinden sich nicht auf der gleichen Ebene des Informationszugangs und der Informationsbewertung. Aufgrund dieser ungleichen Informationsverteilung kann der Patient oft nicht entscheiden, wie sie im Einzelfall zu bewerten sind und welche Schlussfolgerungen für sein individuelles gesundheitliches Verhalten zu ziehen sind.

Zudem kann der Patient sich meist nicht der Beeinflussung durch den Arzt, die auch ungewollt und durchaus positiv gemeint ist, entziehen. Ebenso nimmt der Einfluss durch entsprechende Werbung zu, so dass der Patient auch dort einer immer größeren Informationsüberflutung ausgesetzt ist. Er kann dabei oftmals nicht erkennen, ob die Werbeversprechungen („Brustkrebs jetzt heilbar") tatsächlich begründet sind.

\section{Krankenkassen - Motor für das Gesundheitswesen}

Krankenkassen, die im Wettbewerb bestehen wollen, müssen als Motor im Gesundheitswesen eine zentrale Rolle spielen. Sie müssen ihre Angebote und ihren Service auf die Wünsche und Bedürfnisse der Patien- 
ten ausrichten, also echte Hilfe bieten. Was die Versicherten wollen, ist: Information, Transparenz, echte Entscheidungsalternativen und ein Mitspracherecht bei ihrer Gesundheit und gesundheitlichen Versorgung. Krankenkassen werden gezwungen sein, ihr ganz individuelles Profil herauszuarbeiten und so optimale Versicherungsangebote für ihre Versicherten anzubieten. Das ist auch eine Möglichkeit, Qualität und Preis zu steuern.

Sicherlich gibt es nicht den idealtypischen Patienten. Einige Patienten verlangen nach mehr Informationen über ihre Erkrankung, andere wiederum vermeiden eine weitergehende Aufklärung darüber, weil sie eine negative Diagnose befürchten. Umso bedeutsamer ist es, den Patienten in die Lage zu versetzen, die Kompetenz seines Arztes und die Wirksamkeit von Behandlungen einzuschätzen. Er will verstehen, in welcher Form seine Krankheit oder die Therapie des Arztes Auswirkungen auf sein Leben hat. Wer gut informiert ist, ist auch eher bereit, sich seinem Arzt anzuvertrauen.

Patientenautonomie befähigt den Patienten dazu, eigene Entscheidungen zu treffen. Voraussetzung dafür ist eine ausreichende Transparenz im Gesundheitswesen. Information und Schulung des Patienten sind dabei ebenso unabdingbar wie die Verankerung von Patientenrechten. Es müssen neue Wege zu einer besseren Wahrnehmung von Patientenbedürfnissen gefunden werden, und der Patient muss in diesem Rahmen als ein mit den Interessen gleichberechtigter Partner in der Gesundheitsversorgung akzeptiert werden. Wenn dies gelingt, ist ein Schritt in Richtung Qualitätssicherung im Gesundheitswesen erreicht.

\section{Medizinisches Wissen für Patienten unabdingbar}

Um sich entscheiden zu können, muss der Patient aber zumindest ansatzweise eine Ahnung von dem medizinischen Wissen erwerben und z. B. auch unter den verschiedenen Leistungserbringern auswählen können. Was in allen Wirtschaftsbereichen längst üblich ist: Qualitätsinformation und Qualitätskontrolle müssen auch für den Patienten gegenüber dem Gesundheitswesen möglich und spürbar werden.

Das Internet wird dabei eine wesentlich Rolle spielen. Der interessierte Patient findet heute $z$. B. eine Fülle von medizinischen Websites, wo er Wissenswertes über Krankheiten, Diagnostik und Therapie erfahren kann. Allerdings stehen Informationen von Ärzten, Forschern und Selbsthilfegruppen neben Äußerungen von Wunderheilern und Quacksalbern. Für den Internet-User präsentieren sich die Informationen zunächst als gleichwertige Treffer nach Eingabe eines Suchbegriffes. Der 
Patient muss erkennen können, welche Information wichtig, richtig und aktuell ist oder welches Krankenhaus zum Beispiel für inn geeignet ist.

Die Informationsqualität rückt im sensiblen Bereich Gesundheit immer mehr ins Zentrum. Ziel einer Krankenkasse muss es sein, qualitätsgesicherte Informationsangebote für Versicherte zu schaffen oder nachzuweisen. Solche Angebote müssten Folgendes umfassen:

- umfassende Informationen zu Symptomen, Erkrankungen, Diagnose- und Behandlungsmöglichkeiten

- Informationen und interaktive Angebote zur Gesundheitsförderung und Krankheitsvorsorge

- einen "Lotsendienst" (Suche nach Arzt und Krankenhaus)

Bei der TK haben wir bereits eine solche internet- und telefongestützte Informationsplattform mit dem Namen "Medizin \& Gesundheit" eingerichtet. Qualifiziertes medizinisches Hilfspersonal und Fachärzte beantworten die Fragen unserer Versicherten. Die große Zahl der User belegt, dass eine solche "neutrale Meinung" eines Arztes, der einen nicht kennt und auch nicht an einem verdient, eine hohe Akzeptanz hat. Die Einbindung einer Online-Geschäftsstelle stellt sicher, dass nicht nur medizinische Nachfragen, sondern alle versicherungsrelevanten Fragen und Anliegen kompetent und schnell bearbeitet werden. 87 Prozent der Versicherten bewerten den Service als außerordentlich und sehr gut. Die Stiftung Warentest hat attestiert, dass die TK den Versichertenbedürfnissen gerecht wird und über Information und Service die Versichertenautonomie stärkt. Viele tausend Benutzer täglich belegen die hohe Akzeptanz dieses Services.

Dass auch wir als Krankenkasse als vertrauenswürdiger und kompetenter Ansprechpartner in Gesundheitsfragen vom Versicherten akzeptiert werden, zeigt unsere Umfrage aus dem Jahr 2001 (Abb. 1). Im Gegensatz zur allgemeinen Öfentlichkeit wissen die TK-Mitglieder die Kompetenz ihrer Krankenkasse zu schätzen. 


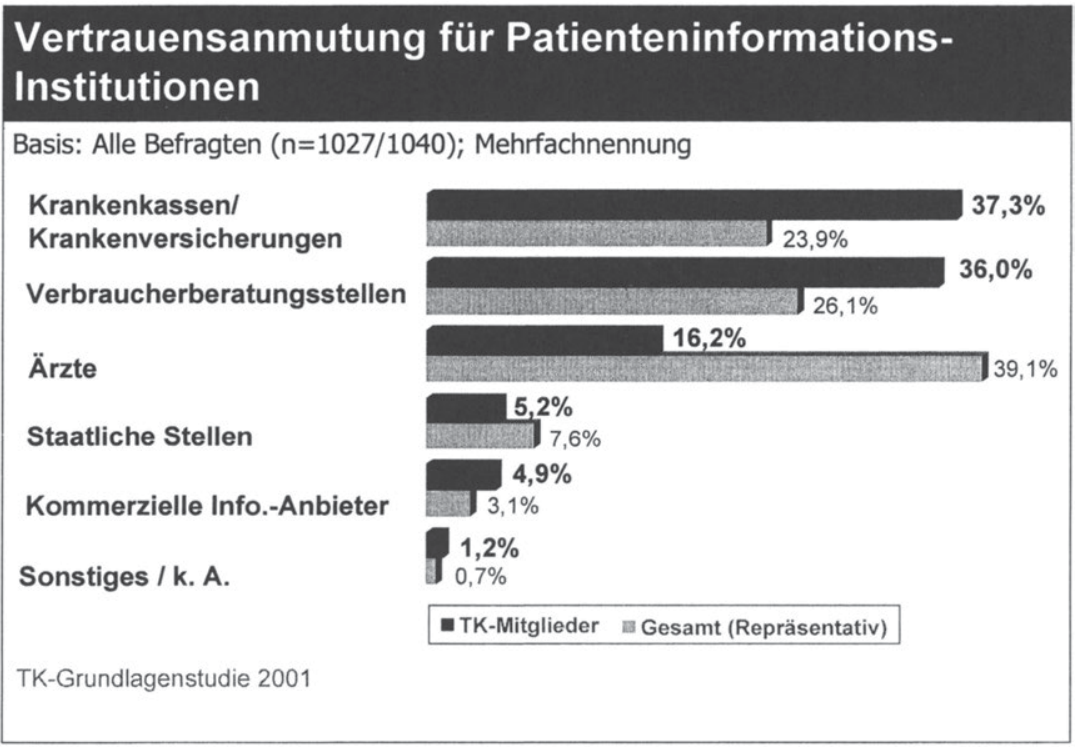

\section{Solidarität versus Patientenautonomie?}

Auch wenn Kritiker dies anders sehen: Patientenautonomie trägt ganz entscheidend zur Solidarität bei. Der "mündige Patient" stützt wesentlich stärker das solidarische System. Er kostet weniger, weil er die Diagnostik und Therapie - an der er ja aktiv mitwirkt - auch versteht. Studien aus den USA und aus Frankreich belegen, dass $z$. B. Krebspatienten, die gut informiert waren, seltener über Beschwerden berichteten und weniger Schmerz empfanden. Durch gezielte Information und die Entscheidung für bestimmte Therapieformen kann der Teufelskreis Schmerz - Angst Anspannung - Schmerz durchbrochen werden.

Auch ein anderer Aspekt ist dabei sicherlich nicht zu vernachlässigen: Abwanderungen von jungen Menschen aus dem System der gesetzlichen Krankenkassen könnten sicherlich stärker vermieden werden, wenn das System verständlicher wäre und es die Patienten nicht bevormunden würde. Obwohl wir seit 1996 die Kassenwahlfreiheit haben und der Wettbewerb zur Qualitätssteigerung vielfach beschworen wird, verfügen wir über ein System, das dem Versicherten und der gesetzlichen Krankenversicherung kaum Handlungsspielraum gibt. 
Das heutige Gesundheitssystem kann daher immer noch beschrieben werden als:

- intransparent (Patienten erfahren nichts bzw. wenig über

- die Qualität der Ärzte/Krankenhäuser

- die abgerechneten Leistungen

- Behandlungsstandards)

- $\quad$ undifferenziert (außer Beitragssatz und Service gibt es kaum Unterscheidungsmerkmale der Kassen und damit keine echten Entscheidungsalternativen für Versicherte)

- $\quad$ überreguliert (den Krankenkassen sind bei ihrer Vertragsgestaltung weitgehend die Hände gebunden)

Dies stößt bei vielen Versicherten auf Unverständnis. Es muss eher darum gehen, durch mehr Patientenautonomie mehr Solidarität zu schaffen und das Solidarsystem auf diese Weise zukunftsfähig zu machen.

Solidarität kann nur in einem System funktionieren, in dem der Solidargedanke die Solidarität der Gesunden, Jungen und Gutverdienenden mit den Kranken, Alten und Armen umfasst. Eine Solidarität nur unter kranken, alten und armen Menschen funktioniert nicht. Ein Gesundheitssystem, aus dem sich immer mehr Gesunde, Junge und Gutverdienende verabschieden, ist nicht finanzierbar: Will man also die Solidargemeinschaft sichern, muss man ihre Basis sichern. Dazu müssen die gesetzlichen Krankenkassen attraktiv sein und ihren Versicherten bedarfsgerechte und differenzierte Angebote liefern. Das bestehende System muss aus sich heraus modernisiert werden, so dass die Abwanderung in die private Krankenversicherung vermieden wird.

Wir fragen uns daher: Was erwarten die Menschen, und was wollen sie? Bei unseren Umfragen stellen wir fest, dass es ein deutliches Bekenntnis für das solidarische Gesundheitssystem gibt. Weit über 80 Prozent der Versicherten (TK-Versicherte 90 Prozent) unterstützen das Solidarprinzip unseres Gesundheitswesens.

Innerhalb dieses System sind die Versicherten auch eher bereit, eine Beitragssteigerung zu akzeptieren, als auf Leistungen zu verzichten. Gleichzeitig haben die Versicherten ein großes Interesse daran, zusätzliche Leistungsangebote innerhalb der gesetzlichen Krankenversicherung wahrzunehmen. Diese beziehen sich Z. B. auf Versicherungsschutz im Ausland oder alternative Heilmethoden. Aber auch neue Tarifoptionen 
stoßen bei den Versicherten auf großes Interesse: Über die Hälfte der TK-Mitglieder beurteilen Selbstbehalttarife als positiv.

Es geht dabei nicht darum, durch Abwahlmöglichkeiten von Leistungen das solidarische System zu schwächen, sondern durch Zuwahlleistungen oberhalb des bestehenden Leistungskataloges die gesetzliche Krankenversicherung zu stärken.

Um dies zu erreichen, ist es notwendig, gute Informationsmöglichkeiten für Patienten anzubieten, die Transparenz zu verbessern, Entscheidungsalternativen zu schaffen. Darüber hinaus sollten Patienten für ein aktives Rollenverständnis motiviert und nicht zuletzt die Handlungsmöglichkeiten der Krankenkassen erweitert werden.

Dazu gehört es auch, den Versicherten praktische Hilfestellungen zu geben:

- Behandlungsquittungen - erste Erfahrungen werden derzeit im Modellprojekt in Rheinhessen gesammelt

- Information über Erfahrung, Weiterbildung und Erfolgsraten von Leistungserbringern

- Patientenleitlinien zur Übersetzung von medizinischen Leitlinien in eine verständliche, patientenorientierte Sprache

- Information über Patientenrechte und -pflichten

- "Information über die Information“, d. h. Hilfestellung zur Bewertung der Qualität von Gesundheitsinformationen

Um die Handlungsmöglichkeiten der Krankenkassen zu erweitern und damit dem Versicherten Entscheidungsalternativen zu eröffnen, ist es notwendig, die Vertragsfreiheit einzuführen. Bislang ist dies im Gesundheitswesen nicht möglich. Stellen Sie sich vor, dass der Verband der Automobilindustrie für alle Mitglieder die gleichen Bauteile zum gleichen Preis bei einem Zulieferer einkaufen müsste. In der gesetzlichen Krankenversicherung ist das bislang Alltag. Erst durch die Vertragsfreiheit wird es den Krankenkassen möglich sein, Einzelverträge mit Ärzten zu schließen und somit qualitäts- und wettbewerbsorientierte Angebote zu schaffen.

Dem Versicherten könnten Zuwahlmöglichkeiten im Bereich der Reiseversicherung oder auch der Alternativmedizin dabei helfen, ein individu- 
elles Versicherungspaket zu schnüren. Ebenso würden Selbstbehalttarife die Versichertenautonomie und -verantwortung und das solidarische Gesundheitssystem stärken.

\section{Gemeinsame Entscheidungsfindung}

Insgesamt müssen wir alle im Gesundheitswesen dazu beitragen, dass wir einen Weg finden, Patienten und Versicherten aktiv in medizinische und gesundheitliche Entscheidungen einzubinden. In Zukunft wird zunehmend die Wichtigkeit der gemeinsamen Entscheidungsfindung („Shared Decision Making") ins Blickfeld rücken (Abb. 2).

\section{Abb. 2: Shared Decision Making}

\section{Meilensteine auf dem Weg zum Ziel}

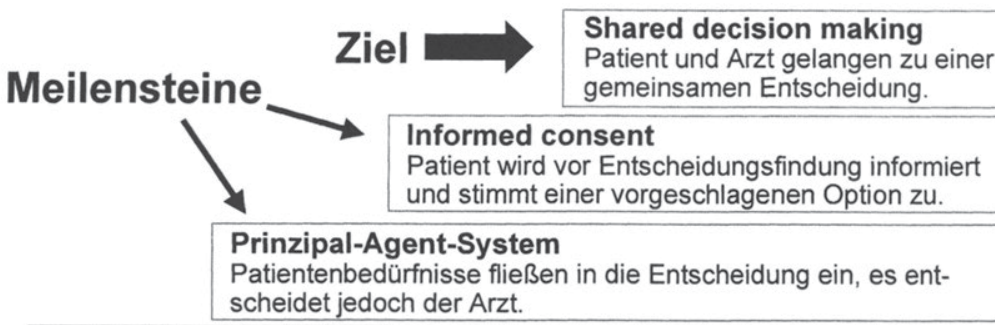

Paternalistisches System

Arzt entscheidet allein über die Therapie, Patient stimmt lediglich zu.

Beim „Shared Decision Making“ gelangen Arzt und Patient zu einer gemeinsamen Entscheidung. Denn: Bei vielen Erkrankungen gibt es nicht immer die "richtige" oder die "falsche" Therapie, sondern Therapieoptionen sind gegeneinander abzuwägen. So stellt sich bei vielen Krebserkrankungen die Frage, welche Therapie die optimale für den Patienten ist.

Arzt und Patient entscheiden gemeinsam, abhängig von der Diagnose, ob beispielsweise ein chirurgischer Eingriff, eine Bestrahlung und/oder 
eine Chemotherapie die beste Lösung darstellen. Seitdem dieses System in den USA umgesetzt wird, führte die umfassende Information des Patienten und die Diskussion mit seinem behandelnden Arzt dazu, dass chirurgische Eingriffe beim Prostatakrebs um ca. 70 Prozent zurückgingen. Der Patient musste in diesen Fällen Vor- und Nachteile der jeweiligen Therapie gegeneinander abwägen.

Zukünftig werden auch immer mehr Versicherte darauf bestehen, eigenverantwortliche Entscheidungen zu treffen. Sie werden sich nicht mehr sagen lassen, wie und was sie versichern sollen. Dabei wird es auch notwendig sein, Verbandsstrukturen zu überdenken und Vertragsfreiheit, Tarif- und Leistungsdifferenzierung zu ermöglichen. 


\section{Öffnung des Kollektivvertragsrechts und Übergang zu Ein- zelverträgen?}

Karl-Heinz Schönbach

In ihrer spezifischen Tradition zwischen konsensorientierter Globalsteuerung und pragmatischem Interventionismus hat sich die Gesundheitspolitik in Deutschland wieder einmal ins Aus manövriert: Obwohl die Beitragssätze auf hohem Niveau steigen, sind alle Beteiligten mit den Ergebnissen unzufrieden. Neue Weichenstellungen sind unvermeidlich. Dazu zielt die aktuelle Koalitionsvereinbarung der Regierungsparteien auf den Kern des Systems, die Vertragsbeziehungen an der Drehscheibe der ambulanten ärztlichen Versorgung. Vorgegeben wird ein klarer politischer Handlungsrahmen für den Übergang vom bestehenden Kollektivvertragssystem zu Einzelverträgen, an denen neben den Vertragsärzten auch Krankenhäuser und Gesundheitszentren teilnehmen. Im Ergebnis der hier vorgelegten ersten Analyse zeigt sich, dass auch dieser Reformansatz der Koalition ebenso wie die integrierte Versorgung ins Leere ginge, wenn es bei wie auch immer justierten ambulanten Pauschalen pro Kopf der Versicherten für die Region einer Kassenärztlichen Vereinigung (Kopfpauschale) bliebe.

\section{Ausgangslage}

Während sich die Medizin in immer mehr Spezialisten und Subspezialisten verzweigt, nehmen nicht nur ihre Fähigkeiten zu, angebotsinduzierte Nachfrage hervorzubringen. Vielmehr rücken auch ihre anerkannten akutmedizinischen Erfolge gemeinsam mit der langfristigen demographischen Entwicklung die chronischen Erkrankungen in den Vordergrund. Beide Entwicklungen schreiten voran, ohne dass bisher in gleicher Weise die Kooperation der Spezialisten untereinander sowie mit den Hausärzten oder die qualifizierte Langzeitbetreuung chronisch Kranker verbessert worden wäre. Isolierte Ansätze reichen dazu nicht aus. Benötigt wird zudem ein ordnungspolitisches Konzept, das nicht länger gegen betriebswirtschaftliche Logik gerichtet ist.

Ein solches Konzept für die Drehscheibe der ambulanten ärztlichen Versorgung nutzbar zu machen, würde einen entscheidenden Beitrag dazu leisten, angestrebte Gesundheitsziele zu erreichen und übermäßigen Ressourcenverbrauch zu vermeiden. Es würde auch dazu beitragen, Ärztinnen, Ärzten und vielen anderen Beteiligten wieder eine höhere Berufszufriedenheit zu ermöglichen, die auch den Patienten zugute käme. Für die Leistungsseite der GKV ist dies der Kern des Problems. 
Während bisher alle "Strukturmaßnahmen", wie insbesondere die "Wahl des Hausarztes" durch den Versicherten ( 73 SGB V), "Modellvorhaben" zur Leistungserbringung ( $\$ 63$ SGB V), die "Integrierte Versorgung" ( $\S 140$ a-h SGB V) und "Disease-Management-Programme" ( $137 \mathrm{ff}$. SGB V) aufgrund des fehlenden Wettbewerbes in der ambulanten ärztlichen Versorgung blockiert wurden, zielt die Koalitionsvereinbarung gerade auf die Ursache der Blockade.

- Für mehr als 120.000 Ärztinnen und Ärzte in tausenden Einzelpraxen kann nur jeweils eine Kassenärztliche Vereinigung Verträge schließen.

- Die Krankenkassen unterliegen dabei hinsichtlich der Qualifikationen undifferenziert, unwiderruflich und über den Bedarf hinaus dem Kontrahierungszwang.

- Jenseits der freiberuflichen Kleinbetriebe sind andere Betriebsformen wie Gesundheitszentren und andere Ärzte wie Krankenhausärzte i. d. R. von der ambulanten ärztlichen Versorgung ausgeschlossen.

- Es gibt weithin keine Preise, sondern Verrechnungspunkte einer Verteilbürokratie, woraufhin kaum ausreichend bezahlte Einzelleistungen in immer höherer Zahl erbracht oder auch nur abgerechnet werden.

- Zu amerikanischen oder Schweizer Preisen wäre das deutsche Gesundheitswesen schon vor 10 Jahren unfinanzierbar gewesen. Bei amerikanischen oder Schweizer Zeiten je Patientenkontakt hätte aber auch nur die Hälfte der Leistungen abgerechnet werden können.

- Dass auch die Frequenzen technischer Leistungen in "schwindelnder" Höhe liegen, findet mit der jüngsten Untersuchung der Universität zu Köln eine ganz neue Interpretation: Jede zweite Röntgenleistung ist danach für den Hausarzt unbrauchbar.

- Und damit sich nie nichts ändern kann, haben sich die Beteiligten mit sektoralen Budgets und Honorarverteilungen eingegraben, die zu falschen Anreizen führen.

Gerade diese Elemente einer strukturellen Blockade geht die Koalitionsvereinbarung an. Zitate aus der Koalitionsvereinbarung sind im folgenden Text kursiv gesetzt. 


\section{Anpassen oder angepasst werden}

Die aktuelle Blockade der Disease-Management-Programme (DMP) durch die Kassenärztlichen Vereinigungen ist nur der politische Auslöser einer überfälligen Neuausrichtung der Gesundheitspolitik. Und dennoch oder gerade deshalb nehmen Ärzte und Krankenkassen die Koalitionsvereinbarung unterschiedlich auf. In der Hoffnung, die Diskussion zunächst einmal ins Leere laufen lassen zu können, argumentiert die Kassenärztliche Bundesvereinigung (KBV), die Koalitionsvereinbarung eröffne der Regierungskoalition einen „breiten Handlungsspielraum", da „alle möglichen Vertragstypen aufgeführt werden", deren "systematische Neuordnung"1 aber unterbleibe. Zwar erkennt die KBV, dass ihr ordnungspolitischer Anspruch durch Einzelverträge "neben“ Kollektivverträgen nicht aufrecht erhalten werden kann, ${ }^{2}$ zieht aber aus der Zusicherung der Koalition, dass eine "wohnortnahe Versorgung" bei "freier Arztwahl" gewährleistet bleibe, die eigentümliche Gewissheit, dass dies (ja) ohne ihren alleinigen Sicherstellungsauftrag nicht gehe und insoweit alles offen sei. Dies ist reines Wunschdenken, denn

- eine "wohnortnahe" Versorgung schließt nur aus, dass notwendige Teile der ambulanten ärztlichen Versorgung überregional in Schwerpunkteinrichtungen konzentriert werden. Ebenso gibt es heute eine "wohnortnahe Krankenhausversorgung", soweit nicht Krankenhäuser der Maximalversorgung angesprochen sind.

- eine "freie Arztwahl" schließt nur ein, dass der Patient einen Arzt seines Vertrauens wählen kann. Bei einer Beteiligung von Krankenhäusern und Gesundheitszentren wird die Auswahl für den Patienten erhöht.

- $\quad$ nur wenn es bei (wie auch immer modifizierten) Pauschalen je Versicherten für eine Region (Kopfpauschalen) bliebe, wäre die Monopol-KV tatsächlich unentbehrlich. Diese sind denn auch Dreh- und Angelpunkt der neuen KBV-Strategie. Denn eine (erschöpfende) "Kopfpauschale" verhindert de facto jeden Wettbewerb neben der KV.

Aber auch den Krankenkassen ist das ebenso überfällige wie energische Konzept der Koalitionsvereinbarung alles andere als einerlei. Schließlich

1 Vgl. Kontext Symposium der KBV vom 24./25. Oktober 2002, Papier „Neuausrichtung der Gesundheitspolitik?", Ergebnisse der Arbeitsgruppe 2, Vertragsbeziehungen.

2 Gefordert wird von den KVen stattdessen eine Differenzierung in Grund- und Zusatzverträge „unter dem Dach der KV“. 
werden sie sich schneller als gedacht auf den Zerfall des korporatistischen Systems einstellen müssen. Mit regionalen Einheitsverträgen haben die KVen den Vertragswettbewerb bisher fast ausgeschaltet. Dem Gift der Kopfpauschalen müssen mithin auch die (Verbände) der Krankenkassen entwöhnt werden. Nach dem neuen Konzept wird es darauf ankommen, gegenüber der Konkurrenz auch in Verträgen vor Ort gut aufgestellt zu sein. Dass die Koalition das Kollektivvertragssystem nur öffnen, nicht aber ad hoc abschaffen will, gibt Ärzten und Krankenkassen Zeit zur Anpassung.

Machen sich die Kassenarten nicht entschlossen auf den Weg zum/zur Unternehmen/Unternehmensgruppe im Wettbewerb, wird womöglich die Politik aktiv. Denn in der Koalitionsvereinbarung heißt es: "Die gesetzlichen Krankenkassen werden im Rahmen einer Organisationsreform in die Lage versetzt, Ihren Beitrag zu einem notwendigen Qualitätswettbewerb zu leisten. "Da eine Organisationsreform nicht ohne den Bundesrat zu machen ist, spielen die Oberverbands-Szenarios einzelner Strategen keine Hauptrolle. Man wird aber fein auf Zwischentöne aus dem Bundesrat achten müssen, wie im Übrigen die meisten Maßnahmen eines hier angesprochenen Reformpaketes nicht ohne den Bundesrat verabschiedet werden können, es sei denn, die Bundesregierung betreibt schlicht einen „Rückbau bestehender Behörden“. Der geht i. d. R. ohne die Länderkammer.

\section{Neuordnung der Angebotsstruktur}

Zweifellos ist die Koalition entschlossen, das Monopol freiberuflicher Ärzte aufzuheben. So heißt es bereits eingangs: „In der ambulanten Versorgung können neben den freiberuflichen Ärztinnen und Ärzten Gesundheitszentren tätig werden." Gesundheitszentren im Sinne des SGB V sind Polikliniken nach $\S 311$, die nach Abs. 2 auf das Beitrittsgebiet beschränkt sind. In diesen Einrichtungen sind auch nichtfreiberufliche Ärzte ambulant tätig. Die KVen haben nach Herstellung der staatlichen Einheit mit Unterstützung der Krankenkassen und der Politik alle Anstrengungen unternommen, die Einrichtungen komplett scheitern zu lassen. Wenn es nun eine Renaissance von Gesundheitszentren geben soll, bietet sich dazu eine Anlehnung an einzelne Krankenhäuser an, die dem DRG-System entgegensehen und ihr ambulantes Vorfeld im Auge haben.

Dahin schaut offenbar auch die Koalition, wenn sie postuliert: „Krankenhäuser, medizinische Zentren und andere Gesundheitsberufe werden in das System der Einzelverträge einbezogen. Der Sicherstellungsauftrag wird entsprechend den veränderten Bedingungen angepasst." Diese Ab- 
sichtserklärungen zielen darauf ab, die Krankenhäuser zumindest in den Wettbewerb um die fachärztliche Versorgung einzubeziehen. Danach werden die KVen den Sicherstellungsauftrag allenfalls in der hausärztlichen Versorgung ungeteilt behalten, wenn die Belange der Hausärzte eigenständig vertreten werden. Die integrierte Versorgung ist bereits außerhalb des Sicherstellungsauftrages der KV geregelt. Hier wird es darauf ankommen, die Teilnahme der Leistungserbringer vom Zulassungsstatus im Kollektivvertragssystem zu trennen. Nur so kommt die gewollte Integration voran.

Ist das Ziel aller Beteiligten in der Tat die "Integrierte Versorgung" und der neue Ordnungsrahmen für Einzelverträge schlüssig, braucht es gesetzlich definierter "Sonderwirtschaftsbereiche" wie "§§ 140 a-h SGB V" auf Dauer nicht. Ebenso ist das Nebeneinander von "Modellvorhaben" (§§ 63, 64 SGB V), „Versichertenbonus beim Hausarzt" (§§ 65a SGB V), Strukturverträgen ( $\S \S 73 a$ SGB V) und der integrierten Versorgung (§§ 140 a-h SGB V) Ausdruck homöopathischer Polypragmasie des Gesetzgebers. Im Ergebnis überweisen die Krankenkassen nach wie vor erst alle Mittel für die ambulante Versorgung an die Monopol-KV, um dann (vergeblich) um „Budgetbereinigung“ für einen Wettbewerb nach Vorschrift anzustehen. Damit aber auch gar kein Vertrag zustande kommen kann, droht die KV via Rahmenvertrag glaubhaft, sich als „Zwangspartner" in Einzelverträge einklagen zu wollen.

Nunmehr beabsichtigt die Koalition, nicht nur ein System von Einzelverträgen "neben" die Kollektivverträge zu stellen, das sozusagen "hinzu kommt". Vielmehr soll in den Kernbestand der Kollektivverträge eingegriffen werden: "Der Kontrahierungszwang wird modifiziert." Dazu muss die traditionelle Zulassung und Bedarfsplanung allein mit der KV fallen, wenn in einem Bedarfsplanungsgebiet mehrere Angebotsformen parallel am Markt sind. Drittangebote werden mithin ebenso wie Drittparteien in die Bedarfsplanung einbezogen. Wie beim Wegfall des Postmonopols wird zudem jeder Anbieter, der einen Mindestmarktanteil überschreitet, Sicherstellungsaufgaben wie den Notdienst mit gewährleisten müssen. Die zusammenfassende Regie kann als gemeinsame Auftragsleistung der Beteiligten ausgeschrieben werden. Ein Monopol dafür wird kaum vermisst werden. Zahlreiche ambulante Notarztpraxen bestehen ohnehin inzwischen an Krankenhäusern, die Ordnungsfunktion wird weithin bereits von den Ärztekammern getragen.

Für die Sicherstellung einer umfassenden und bedarfsgerechten Versorgung der Versicherten ohne Kontrahierungszwang der einzelnen Krankenkasse gegenüber jedem Arzt gibt es verschiedene Modelle, die in der weiteren Diskussion bewertet werden müssen. 
- Den Kontrahierungszwang - wie von Beratern des BMG vorgeschlagen - bei der Erfüllung qualitativer Mindeststandards beizubehalten und nur darüber hinaus Vertragsfreiheit einzuführen, reichte nach Auffassung und Erfahrung des Autors nicht aus, da schon die erste von der KV besetzte Vertragsstufe 100 Prozent der Mittel absorbieren könnte, während Sonderverträge wie heute zusätzlich finanziert werden müssten.

- Allerdings müssen für die Krankenkassen bei einem „einheitlichen Leistungskatalog" auch Pflichten zur Kontrahierung bestehen, damit das Angebot, für das aus dem Risikostrukturausgleich Einnahmen zugerechnet werden, auch sichergestellt wird. Diese Pflicht wird allerdings nicht allein einem Monopol freiberuflicher Ärzte in der KV gegenüber erfüllt, sondern mit einem integrierten Angebot, einschließlich Krankenhäusern und Gesundheitszentren.

- Von daher wird vorgeschlagen, eine Kontrahierungspflicht der Krankenkassen/-gruppen/-arten zu formulieren, die für den Bereich des relevanten Marktes eine nach ärztlichen Gebieten umfassende Versorgung, gemessen an Verhältniszahlen Arzt/Versicherten, gewährleistet. Darüber hinaus besteht keine Vertragspflicht, sondern ein Vertragsrecht. Angebote, die den Mindeststandard unerfüllt lassen, sind nicht zu berücksichtigen.

Wettbewerbsregelungen, bei denen die Krankenkassen ohne Kontrahierungszwang Versorgungsaufträge ausschreiben, stehen verfassungsrechtliche oder EU-rechtliche Gesichtspunkte nicht entgegen. Dies ist das nicht unerwartete Ergebnis einer umfassenden Analyse, die Volker Neumann (Rostock) anlässlich der diesjährigen Berliner Tagung der Bertelsmann-Stiftung zum verfassungsgemäßen Spielraum der Gesundheitspolitik vorgelegt hat. Die Publikation wird erwartet. Der deutsche Gesetzgeber kann das tun, wenn er es politisch durchsetzen kann. Die Koalition wäre aus rechtlichen Gründen nicht gehindert, ihr Vorhaben durchzusetzen.

\section{Wandel der Vertragsrechte}

Einzelverträge werden attraktiv ausgestaltet sein müssen, soll die Abwärtsspirale der Punktwerte mit immer mehr abgerechneten Einzelleistungen gestoppt werden. In der Schweiz ebenso wie in den USA oder Schweden sind die Konsultationszeiten je Patient um ein Mehrfaches höher als in Deutschland. Das gilt in der Tendenz auch für die Qualität. Wir geben neben der Schweiz und den USA die meisten Mittel für die 
gesundheitliche Versorgung aus, ohne dass die Ergebnisse, gemessen an Gesundheitszielen, dem entsprächen.

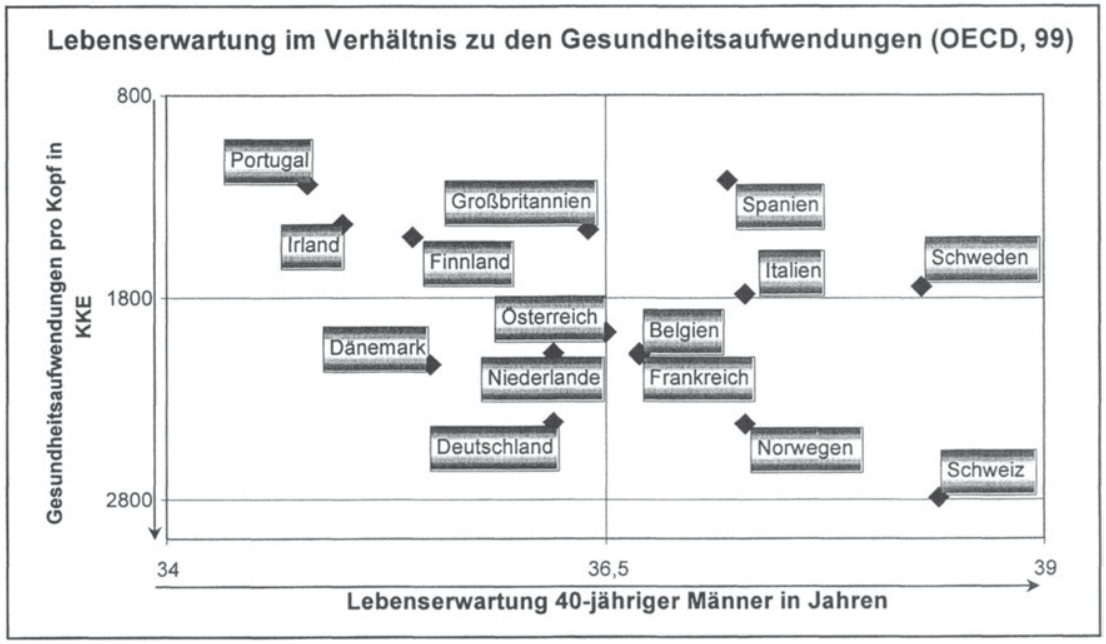

Soll dieses Dilemma überwunden werden, kann nicht jedes zusätzliche Angebot einschließlich der allgemeinen Zunahme der Arztzahlen automatisch und ohne Unterschied einbezogen und mitfinanziert werden. Dies ist dem Wirtschaftssystem auch ansonsten fremd.

- Wenn künftig der Zustrom von Anbietern über den Bedarf hinaus dem Wettbewerb ausgesetzt wird, können Finanzierungsspielräume geschaffen werden, um aus dem Teufelskreis der Verteilungspolitik mit "Kopfpauschalen" auszusteigen. Es gibt keinen anderen Weg, ohne weiter auf steigende Ausgaben und Beitragssätze zu im vorhinein kalkulierbaren Vergütungen für den Arzt zu kommen.

- Wird dem von den Berufsvertretern entgegengehalten, die Neigung junger Ärzte, sich niederzulassen, nehme ohnehin ab, spricht dies umso mehr für den Einbezug der Krankenhäuser in die ambulante Versorgung, weil der Niederlassungszwang für die Ärzte damit gemildert wird, soweit betriebswirtschaftliche Vorteile (z. B. Gerätenutzung) eingelöst werden können.

\section{Sicherung von Qualität und Wettbewerb}

Einzelverträge werden keine Flächenverträge mehr sein, sondern ein Gesamtangebot aus unterschiedlichen wettbewerblichen Verträgen ent- 
stehen lassen. Wettbewerb und Kontrahierungszwang passen nur bedingt zueinander. Insbesondere, wenn Krankenhäuser und Gesundheitszentren als Partner für Einzelverträge hinzukommen, würde ein Kontrahierungszwang bestehende Überkapazitäten weiter erhöhen. Daher stellt die Koalitionsvereinbarung heraus: „Krankenkassen und Anbieter werden in die Lage versetzt, neben den notwendigen kollektiven Verträgen Einzelverträge mit festgelegten Qualitätsniveaus abzuschließen." Die Qualitätsniveaus sollen über den Koordinierungsausschuss beschrieben werden. Dies bezieht sich bisher schon nicht nur auf evidenzbasierte Medizin für chronisch Kranke ( $(137 \mathrm{f}$ SGB V), sondern auch auf die Durchsetzung von Qualitätskriterien ( $\$ 137$ e SGB V) der Versorgung in der Breite.

Dies ist auch eine Voraussetzung dafür, Qualitätskriterien tatsächlich auch einfordern zu können. Damit dies keine unerfüllte Hoffnung bleibt, soll offenbar ein "Deutsches Zentrum für Qualität in der Medizin" den Koordinierungsausschuss für die ambulante und stationäre Versorgung unterstützen. Hier darf allerdings kein Antagonismus erzeugt werden, soll die Selbstverwaltung im Koordinierungsausschuss die Qualitätssicherung weiter tragen. Das Institut sollte der Selbstverwaltung zuarbeiten. Die Selbstverwaltung konkretisiert den Ordnungsrahmen, sie ist aber nicht gleich immer auch "wirtschaftlicher Akteur im Wettbewerb". Denn die unverzichtbare Beachtung, mit der die Standards tatsächlich durchgesetzt und weiterentwickelt werden, bietet nur der potentielle Nachteil im Wettbewerb.

Für die GKV kommt dies einem Balanceakt gleich: Wettbewerb funktioniert nur mit strikten und verbindlichen Vorgaben, die die Beteiligten selbst nicht nach Kassenstand oder politischer Opportunität ändern können. ${ }^{3}$ Mehr Wettbewerb heißt danach auch zumindest ordnungspolitisch "zuverlässigere" Regulierung. Zum Beispiel sind - soweit Drittwirkungen erzielt werden müssen - etwa die Richtlinien des Bundesausschusses der Ärzte und Krankenkassen unzureichend und dem Wettbewerbsrecht standhaltenden Einzelverträgen beileibe unterlegen. Arzneimittelrichtlinien und -informationen an Ärzte mit potentieller Drittwirkung werden von den Kartellsenaten gestoppt, bevor sie überhaupt wirksam werden können. Wenn die GKV aber de facto das Wettbewerbsrecht nicht ausschalten kann, muss sie es sich zu eigen machen. Soweit die Krankenkassen/-verbände also zur Daseinsvorsorge als "Behörde in hoheitlichem Auftrag" tätig sind und staatliche Vorgaben etwa zum Leistungskatalog konkretisieren, kann Wettbewerbsrecht nicht gelten. Die Alterna-

Vgl. Schönbach, K. H.: Offentlich-rechtliches Vertragsrecht und Wettbewerb in der GKV, Vortrag bei der Hans-Böckler-Stiftung im April 2001, veröffentlicht in Arbeit und Sozialpolitik, Heft 5-6/2001, S. 4 ff. 
tive wäre die Verstaatlichung. Das sieht auch die EU-Kommission im Vorfeld der EuGH-Entscheidungen so. Dort aber, wo die Krankenkassen als "wirtschaftlicher Akteur" tätig sind, muss Wettbewerbsrecht angewandt werden. Dazu ist der von der Koalition avisierte Übergang zu Einzelverträgen anstelle von Kollektivverträgen unabdingbar. Schließlich geht es nicht um den Komfort der Institutionen, sondern um das Ergebnis für die Versicherten.

Neben qualitativen Vorgaben treten dann ökonomische. Diese bestehen im Wesentlichen in der Einhaltung des (EU-)Wettbewerbsrechts. Die Teilnehmer auf beiden Seiten - Ärzte und Krankenkassen - dürfen keine marktbeherrschende Stellung beziehen bzw. ausnutzen. Zum Teil werden Anforderungen und Auflagen des Wettbewerbsrechts erfüllt werden müssen, die etwa auch zur Teilung von Vergabemaßnahmen führen können. Ebenso sind Zusammenschlüsse von Anbietern nur im Rahmen des Wettbewerbsrechts erlaubt. Das wird von den neue Kartelle schmiedenden Anbietern gerne übersehen. Dennoch muss die Selbstverwaltung in ihren ordnungspolitischen Funktionen wirksam bleiben können.

- Soweit die Ärzte/Krankenhäuser/Gesundheitszentren oder Krankenkassen als Unternehmen nach Wettbewerbsrecht agieren, müssen sie einer einheitlichen und kompetenten Wettbewerbsaufsicht unterliegen. Das geht über die Vereinheitlichung der heutigen Aufsicht hinaus. Die Aufsichtsbehörden sind auch inhaltlich neu aufzustellen.

- Soweit Ärzte/Krankenhäuser/Gesundheitszentren als Unternehmen der Daseinsvorsorge agieren, können sie oder ihre Verbände auch an ordnungspolitischen Vorgaben mitwirken. Die Grenzen sind dabei offen zu legen.

Inzwischen werden die Koalitionsvereinbarungen in den zu Beginn der Legislaturperiode offenbar unvermeidlichen Vorschaltgesetzen um die Variante "Einzelverträge zwischen Krankenkassen und Herstellern von Arzneimitteln" ergänzt. Dabei ist davon auszugehen, dass die Option zu Einzelverträgen mit Herstellern insbesondere dann wirksam genutzt werden kann, wenn auch aufgrund von Einzelverträgen mit Ärzten Nachfrageänderungen bewirkt werden können. Die Mittel der KV wären dazu viel zu grobschlächtig und konfliktbehaftet. Die ursprünglich erwogenen Einzelverträge der Krankenkassen mit Apotheken sind allein schon deswegen für die weitere Gesetzgebung zurückgestellt worden, weil dazu erst einmal wettbewerbsfähige Angebotsstrukturen auf der Vertriebsseite erlaubt werden müssen: Versandapotheken und Filialbetriebe. 


\section{Vergütungspolitik}

Damit die Modernisierungs-Blockade überwunden werden kann, müssen für Versorgungsregionen vereinbarte Kopfpauschalen der Mitglieder oder Versicherten künftig der Vergangenheit angehören. Denn bei diesen „Planfonds" floaten die Punktwerte (Preise) unter der Hoheit der KV als Gewährträger der Versorgung in der Region. Es ist nicht verwunderlich, dass sich die KVen entgegen ihrer populären Positionierung politisch nicht für die Vergütung nach Einzelleistungen einsetzen, sondern für (modifizierte) „Kopfpauschalen“. Kopfpauschalen erhöhen die institutionelle Existenzberechtigung der KV, die sich dann das verteilungspolitische Zerlegen des Ganzen zu eigen machen kann.

- Tatsächlich ist die Anpassung bestehender Kopfpauschalen an den aktuellen Leistungsbedarf nur eine "Schrittinnovation“. Vorschläge dazu sind gemacht. ${ }^{4}$ Angesichts der Koalitionspläne besteht kein Hindernis, diesen Schritt zu überspringen.

- Eine diskutierte „Morbiditätsjustierung“ der Vergütungen zielt auf die adäquate Weiterentwicklung politisch gedeckelter Gesamtvergütungen. Regionale Gesamtvergütungen stehen aber jedem Wettbewerbskonzept entgegen.

Regionale Gesamtvergütungen nach Art der Kopfpauschalen bei der KV zementieren zudem die starren Grenzen zwischen ambulant und stationär. Wer diese Grenzen beseitigen will, darf nicht den Kopfpauschalen das Wort reden, auch nicht morbiditätsadjustierten Kopfpauschalen. Vielmehr müssen die Krankenkassen ihre (morbiditätsadjustierten) Einnahmen nach den in Anspruch genommenen Leistungen einsetzen.

4 Vgl. Schönbach, K. H.: Arzthonorare: Die Aktualisierung der Kopfpauschalen, in:

DIE BKK, Heft 12/2000, S. 517 ff. 


\section{Abb. 1: Pauschale Gesamtvergütungen für korporative Versorgungssektoren}

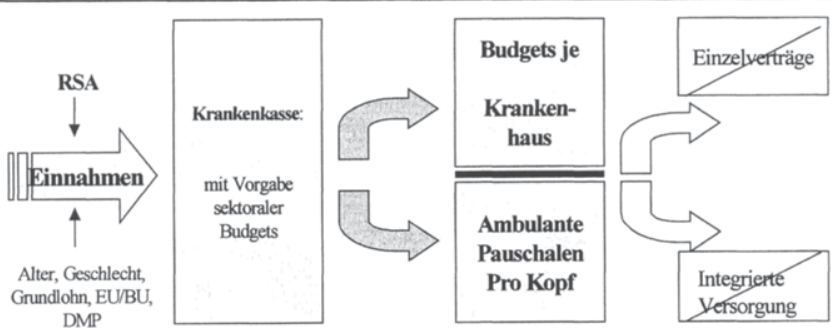

- Vollständige Kontrahierung

- Verteilende Bedarfsplanung

- Einnahmen nach Ausgabenprofil

- sektorale Budgets
- Kopfpauschalen $¥$ Leistungsbedarf

- Vergütungen nach HVM

- keine integrierte Versorgung

- Allokation gem. Angebot/Verteilung

\section{Abb. 2: Leistungssystem der GKV nach den Eckpunkten der Koalition}

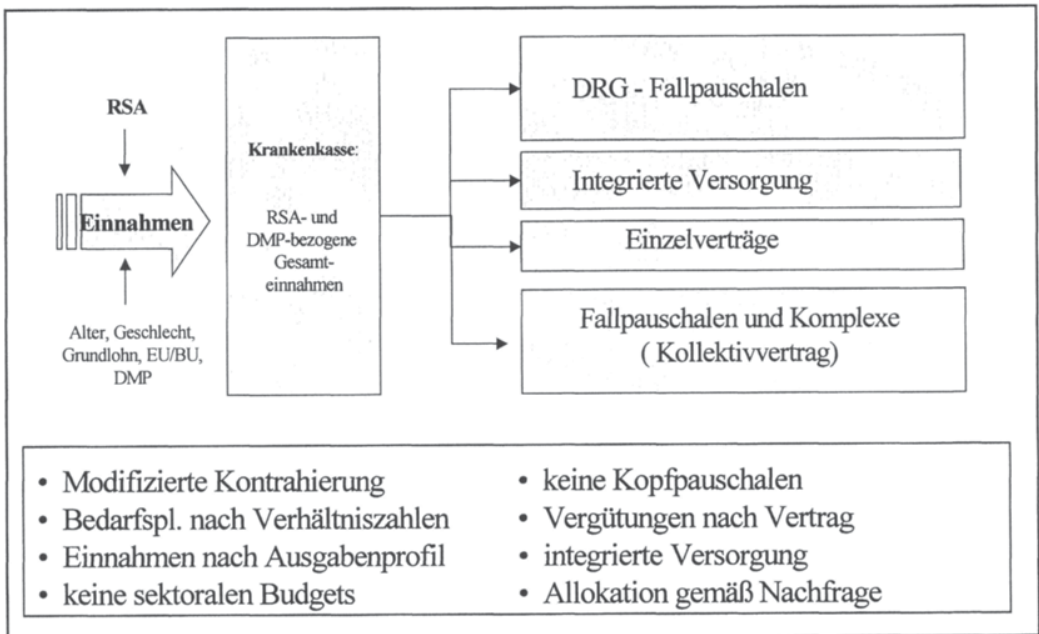


Abb. 3: Reformoption „unter dem Dach der Kassenärztlichen Vereinigungen“

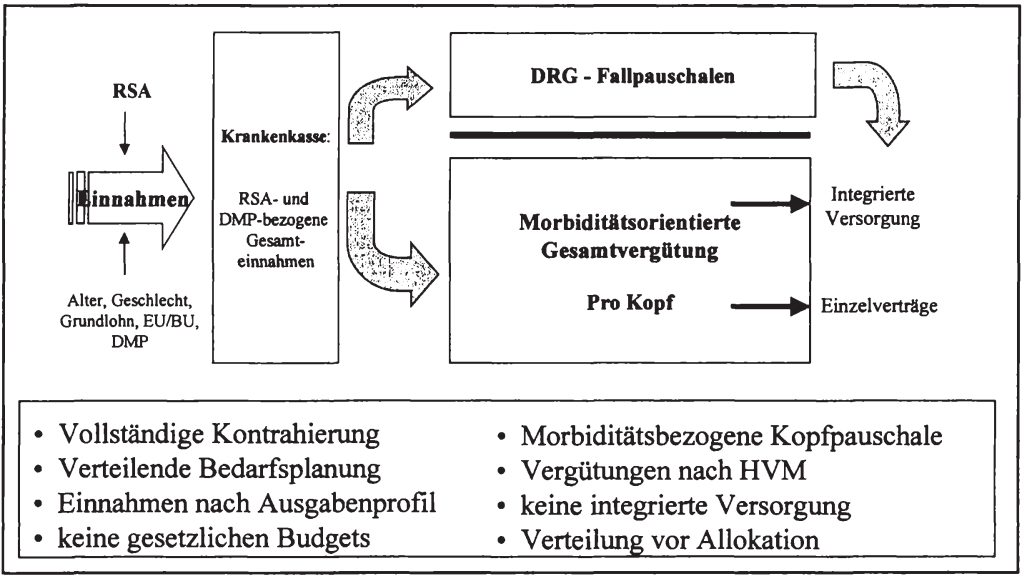

Im Rahmen dieses kurzen Beitrages können die Implikationen unterschiedlicher Ansätze nicht vollständig ausdiskutiert werden. Vielmehr werden der Status quo (Abb. 1), die Koalitionsvereinbarung (Abb. 2) und die Vorstellungen unter Einbezug morbiditätsjustierter Kopfpauschalen der KBV (Abb. 3) gegenübergestellt. In dem jeweils unten stehenden Kasten sind die wesentlichen Merkmale der Alternativen notiert. Dabei wird (hier auf wenige Aussagen zugespitzt) deutlich:

- Die Koalitionsvereinbarung (Abb. 2) hebt die Trennung zwischen ambulant und stationär nur dann auch finanztechnisch auf und ermöglicht zudem die integrierte Versorgung, wenn es keine Pauschalen pro Kopf der Versicherten mehr gibt. Sektorale Budgets sind mit dem Ansatz der Koalition (DRGs und Einzelverträge) nicht vereinbar. Sie können bei Modifizierung des Kontrahierungszwangs zu den Anbietern und Beitragssatzwettbewerb der Krankenkassen auch fallen.

- Das Antikonzept der KBV (Abb. 3) bleibt bei „Kopfpauschalen“ und hebt weder die Trennung ambulant zu stationär auf, noch ermöglicht es eine Finanzierung der integrierten Versorgung. Die bei der integrierten Versorgung vereinbarte Budgetbereinigung kann die KV ja praktisch nicht leisten, wie immer wieder behauptet und zu sehen ist. Die sektoralen Budgets werden auch mit der KBV-Forderung nach morbiditätsorientierten Kopfpauschalen bewusst prolongiert. 
- $\quad$ Sicherstellung/Kontrahierungszwang könnten sich künftig danach richten, ob eine Bedarfsplanungsregion unter Einschluss kontrahierender Drittanbieter nach Verhältniszahlen ArztNersicherte unterversorgt ist oder nicht. In unterversorgten Regionen bestünde nach wie vor vollständiger Kontrahierungszwang. In den übrigen Regionen könnten die Krankenkassen jenseits dieser Schwelle wettbewerblich ausschreiben.

Kurzum: Die wettbewerbliche (Nachfrage-)Steuerung setzt auf Preise. Gerade der Übergang auf Preise in Form von DRG-Fallpauschalen für die stationäre Versorgung macht auch ein Preissystem für die ambulante Versorgung unverzichtbar. Denkbar sind hier für unterschiedliche Versorgungsformen unterschiedliche Fallpauschalen, Komplexgebühren, Einzelleistungsvergütung mit Obergrenze oder Höchstbeträge. Dubiose Systeme der Mischfinanzierung der KV mit Honorarverteilung nach innenpolitischen Mehrheiten der Ärzte werden der Vergangenheit angehören.

Die Krankenkassen müssen weithin ins Risiko, müssen Anbieter und Angebote bewerten und auswählen, Verträge wie im richtigen Leben schließen und einhalten sowie Kunden gewinnen und mit guter Versorgung überzeugen. Trotz struktureller Nachfrageänderungen auf der Seite der einzelnen Krankenkassen über viele Jahre prolongierte Gesamtverträge, die, ohnehin über die autonome Honorarverteilung der KV konterkariert, nichts mit der Versorgung zu tun haben, werden der Vergangenheit angehören.

\section{Integrierte Versorgung}

Ein Testfeld für mehr Wettbewerb im Gesundheitswesen hätte in den letzten Jahren die integrierte Versorgung sein sollen. Allerdings haben die Spitzenverbände der Krankenkassen und die KBV den gesetzlichen Vorgaben des $\S 140$ a-h SGB V mit ihrer Rahmenvereinbarung die Wirkung genommen. Trotz gesetzlicher Fristsetzung wurde die Rahmenvereinbarung erst mit fast 2 Jahren Verspätung vor dem Schiedsamt verhandelt. Das Ergebnis trägt nicht:

- Zum einen wurde die Beteiligung an der ambulanten Versorgung auch unter diesem Regime vom alten Zulassungsstatus abhängig gemacht, das muss jetzt fallen, damit die Integration vorankommt.

- Zum anderen blieb die vertragliche Beteiligung auch nach dem von der KBV verzögerten Schiedsamtverfahren in der Schwebe. Kein In- 
vestor konnte unter diesem Kuratel die notwendigen Entscheidungen treffen.

Spätestens mit den „DMP im RSA“ war zudem „indirekt“ die Renaissance der KV eingeläutet. Was zunächst aussah wie die Definition von Qualität in der Medizin durch die Krankenkassen, entpuppte sich bei näherem Hinsehen als die Umverteilung im RSA durch die Ärzte. Alles spricht für eine rasche politische Abkehr von dieser belasteten Verknüpfung. Dafür gibt es auch politische Stimmen bei der AOK, auch wenn diese fürchten, der Morbi-RSA werde durch den Zwischenschritt der DMP gestoppt.

Nun will die Koalition die „Systeme der integrierten Versorgung stärken, eine bessere Abstimmung zwischen stationärem, teilstationärem und ambulantem Bereich ermöglichen und das Honorar- und Entgeltsystem entsprechend ausrichten." Mit der Verknüpfung aus Einzelvertragssystem und Beteiligung der Krankenhäuser an der integrierten Versorgung könnte das tatsächlich gelingen. Denn die Krankenhäuser

- $\quad$ sind anders als die niedergelassenen Ärzte selbst mit Management ausgestattet,

- $\quad$ sind unter DRG-Finanzierung an der Steuerung ihres ambulanten Versorgungsvorfeldes interessiert,

- $\quad$ sind in der Lage, ambulante Ärzte mit hoher Eigenmotivation zu binden.

Die Hauptrichtung gesundheitspolitischer Strategien wird damit umgekehrt. Bisher galt das Prinzip „ambulant vor stationär“ meist (erfolglos) "gegen" die Krankenhäuser. Mit Einführung der DRG-Fallpauschalen wird dieses Prinzip in einer Wettbewerbslandschaft auch mit (einzelnen) Krankenhäusern erreichbar. „Ambulant vor stationär" ist keine Plattitüde in einem widersinnigen Antagonismus zwischen Krankenhäusern und Freiberuflern mehr. Einzelne Krankenhäuser oder Krankenhausketten können und werden sich vielmehr als Vollanbieter positionieren. Und das könnten die Niedergelassenen im Prinzip auch: Ihnen fehlt es aber nach all der Selbstbeschränkung an allem: Kapital, Organisation, Management, Rechtsformen. Das wird nun fatal.

\section{Organisationsreform}

Die organisatorischen Konsequenzen der Absichten der Koalition liegen auf der Hand. „Die Organisationen der Leistungserbringer (z. B. Kassen- 
ärtliche Vereinigungen) werden zu wirksamen Dienstleistern fortentwickelt." Die bisherige KV als umfassender Hoheitsträger und Tarifpartner zugleich hat ausgedient. Die Leistungen der KV werden im Rahmen der Dienstleistungsfunktion nachgefragt. Die Ordnungsfunktionen bleiben bei der Kassenärztlichen Bundesvereinigung, die auch im Bundesausschuss und im Koordinierungsausschuss mitwirkt. Die KVen werden aber nicht mehr selbst einziger wirtschaftlicher Akteur der ambulanten Versorgung sein, sondern im Rahmen des Kollektivvertragsrechts einer der Wettbewerber und ansonsten Dienstleister.

Dabei dürften die „alten KV-Funktionen“ im Wesentlichen für die Hausärzte weiter wirken. Die Koalition will ,... die Handlungsmöglichkeiten der Hausärzte innerhalb der Kassenärztlichen Vereinigungen (stärken)." Aufgebaut werden kann dabei auf die GKV-Gesundheitsreform, mit der die Gesamtvergütungen der Haus- und Fachärzte getrennt worden sind. Nun können die Hausärzte ein Verhandlungsmandat in der KV erhalten.

\section{Konsequenzen für die Organisation der GKV}

Die Organisationsfolgen werden - wie bereits angeführt - nicht bei den Ärzten verharren. Die Krankenkassen sollen ,... im Rahmen einer Organisationsreform in die Lage versetzt (werden), ihren Beitrag zu einem notwendigen Qualitätswettbewerb zu leisten." Was immer das auch heißen soll: Bei der Logik der Politik ist die Symmetrie oft nicht weit. Entsprechend könnten auch bei den Krankenkassen die wirtschaftlichen Akteure in größere Verantwortung rücken und im Übrigen Ordnungs- und Dienstleistungsfunktionen getrennt werden.

Fazit: Der Angebotsbereich zieht nun beim Wettbewerb mit dem Versicherungssektor gleich. Dies wird massive organisatorische Konsequenzen haben. Parallel kommen die Fragen der Finanzierungsbasis und der Finanzierungsform der GKV auf die Tagesordnung. Die Kommissionen dazu gehen an den Start. Man wird sich bemühen müssen, um nicht das Nachsehen zu haben. 
Manfred Albring and Eberhard Wille - 978-3-631-75562-4

Downloaded from PubFactory at 01/11/2019 03:33:01AM

via free access 


\section{Die GKV zwischen Ausgabendynamik, Einnahmenschwä- che und Koordinierungsproblemen}

Manfred Richter-Reichhelm

Sehr geehrte Damen und Herren, Zeitpunkt und Besetzung dieser Bad Orber Gespräche sind ausgesprochen gut gewählt. Dafür möchte ich dem Veranstalter meine Anerkennung aussprechen. Denn - Sie alle wissen es - mit dem kürzlich vorgelegten Vorschaltgesetz tobt der Bär. Nullrunde für Leistungserbringer, verordnete Absenkungen bei der Pharmaindustrie, bei den Apotheken, beim Großhandel sowie eine Festschreibung der Beitragssätze der Krankenkassen, das gibt Diskussionsund Zündstoff. Frau Schmidt nennt das etwas euphemistisch "Luft verschaffen" für die anstehenden Reformen. Wir können gespannt sein, wie sie - bzw. die von ihr eingesetzte Kommission - diese Luft nutzt.

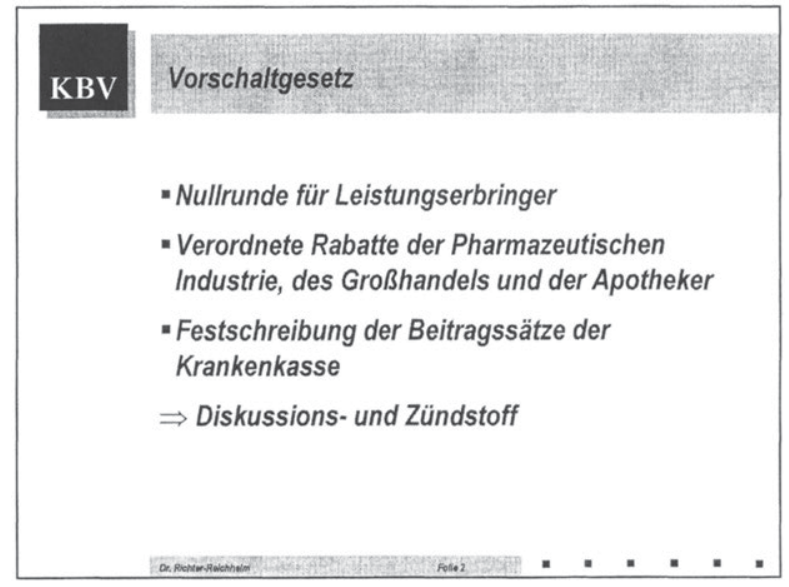

Eines ist jetzt schon sicher dabei: Der Wettbewerb soll gestärkt werden. Dazu hat die Regierung schon in der letzten Legislaturperiode, vor allem im Krankenhaus, mit der Einführung der Diagnoses Related Groups (DRGs) den Weg bereitet. Aber auch das Thema Disease Management Programme (DMP) geht in diese Richtung. Schließlich soll die integrierte Versorgung Regelversorgung für alle chronisch Kranken werden. All das - so wird wenigsten von einigen Expertokraten behauptet - ginge nur, wenn die so genannten Monopolisten entmachtet werden. Gemeint sind damit derzeit die Kassenärztlichen Vereinigungen (KVen) und das bisher gültige Kollektivertragssystem. 


\section{Wettbewerb im Gesundheitswesen}

Wettbewerb ist aber kein Wert an sich, sondern sein Wert bemisst sich daran, ob er die berühmte „ordnende Hand" sein kann. Gerade im Gesundheitswesen ist das fraglich. Denn Krankheit ist ein existenzielles Risiko, das jeden treffen kann. Unser ethischer Anspruch ist daher, für jeden - völlig unabhängig von seiner finanziellen Leistungskraft - das medizinisch Notwendige zur Verfügung zu stellen. Finanziert wird das durch die Solidargemeinschaft, in der Junge für Alte, Gesunde für Kranke, Reiche für Arme, Singles für Familien einstehen.

Wettbewerb soll mehr Effizienz und Effektivität in die Versorgung bringen. Nie aber darf er zu Lasten der Patienten gehen. Sinnvoller Wettbewerb ist zuzulassen, Wettbewerb ist einzuschränken, wo er schädlich ist. Dazu hat die Kassenärztliche Bundesvereinigung (KBV) ein Vertragskonzept entwickelt, das ich später kurz skizzieren werde. Wichtig ist: $\mathrm{Zu}$ viel staatliche Regulierung ist ebenso schädlich wie der reine Wettbewerb, weil das Gesundheitswesen besondere Rahmenbedingungen hat.

\section{Solidarleistungen}

Für die KBV ist klar, dass der Anspruch auf medizinisch notwendige Leistungen erhalten bleiben muss. Aber der Leistungskatalog muss stringenter als bisher gefasst werden. Es muss weiterhin definierte, einheitliche Solidarleistungen aller Krankenkassen geben, die für eine bedarfsgerechte medizinische Versorgung nach dem gesicherten Stand der medizinischen Erkenntnisse notwendig und ausreichend sind. Dazu gehören auch Präventionsleistungen, soweit deren Wirksamkeit und Effizienz nachgewiesen ist und sie zur Vermeidung von Erkrankungen oder deren Früherkennung geeignet sind.

Der Bundesausschuss der Ärzte und Krankenkassen ist als das für die Konkretisierung zuständige Organ zu stärken. Die Entwicklung und Etablierung von medizinischen Behandlungsleitlinien als Orientierungsrahmen ist voranzutreiben. Dabei muss die ärztliche Therapiefreiheit gewahrt bleiben.

Diese Solidarleistungen dürfen nicht dem Wettbewerb überlassen werden. Sie müssen in einem geregelten Gesamtsystem erbracht werden, das die Garantie dafür übernimmt, dass jeder Patient, unabhängig von seiner Kassenzugehörigkeit, seinem Wohnort und seinem Geldbeutel diese notwendigen Leistungen erhält. Dafür brauchen wir auch weiterhin ein kollektives Vertragssystem, das die Grundlage hierfür bietet. 
Andererseits dürfen Leistungen, die im weitesten Sinne dem Bereich Wellness zuzuordnen sind, nicht auf Solidarkosten erbracht werden. Leistungen, deren Wirksamkeit nicht nachgewiesen ist, sind von der Erstattung auszunehmen. Der Bundesausschuss der Ärzte und Krankenkassen hat das notwendige Know-how, Leistungen daraufhin zu überprüfen. Er braucht dazu eine größere Rechtssicherheit, und verbindliche Regeln zur Anhörung Betroffener müssen erstellt und umgesetzt werden. Dadurch wird die dringend nötige Transparenz in diesem wichtigen Bereich erhöht. Gleichzeitig wird die Patientenbeteiligung gestärkt, was die KBV für richtig hält und nachhaltig unterstützt.

Auch bei Leistungen, die durch zeitgerechte Prävention und Eigenvorsorge hätten vermieden werden können, muss eine stärkere Inanspruchnahme des Einzelnen erfolgen. Das Beispiel Zahnersatz zeigt, was hier möglich ist.

\section{Individualleistungen}

Aus der solidarischen Leistungspflicht sollten auch individuelle Leistungen wie Sterilisationen und künstliche Befruchtung herausgenommen werden. Diese Leistungen sind aus gesellschaftspolitischen Erwägungen der GKV zugeordnet worden. Will die Regierung sie weiterhin für die Bevölkerung bereitstellen, müssen sie steuerfinanziert oder privat abgesichert werden. In diesem Bereich können nach unseren Vorstellungen auch die gesetzlichen Krankenversicherungen Wahltarife anbieten, die dann in vollem Wettbewerb mit den Wahltarifen anderer Versicherungen stehen. Bei diesen Leistungen ist es auch richtig und angemessen, wenn sie nicht dem kollektiven Vertragssystem unterliegen, sondern sie können dem freien Vertragssystem überlassen werden.

\section{Abbau von Strukturverwerfungen}

Dass die starre Sektorengrenze im deutschen Gesundheitswesen zu Verwerfungen führt, ist fast schon ein Allgemeinplatz. Bislang sind alle Anstrengungen, eine bessere Verzahnung und Kooperation zu implementieren, an der sektoralen Budgetierung gescheitert: Solange es keine Möglichkeiten gibt, Geld aus dem einen in den anderen Sektor zu leiten, je nachdem, wo eine Leistung erbracht wird, wird es niemals tragfähige und zukunftssichere, sektorübergreifende Versorgungsformen geben. Vorwürfe, dass die KVen diese notwendige und von der KBV immer geforderte Entwicklung blockieren würden, sind schlichtweg unbegründet. Wahr ist vielmehr, dass diese angebliche Blockade der KVen von eini- 
gen Expertokraten als Begründung missbraucht wird, um aus ideologischen Gründen die Entmachtung der KVen zu fordern.

KVen sind aber unverzichtbar, will man eine geordnete, flächendeckende und qualitätsgesicherte Versorgung aller Versicherten, unabhängig von Wohnort und Kassenzugehörigkeit, aufrechterhalten.

Aber wir brauchen auch strukturelle Veränderungen, um eine bessere Kooperation zwischen den Ebenen und Sektoren zu etablieren und sinnvollen, geregelten Wettbewerb auch in diesem Bereich umzusetzen.

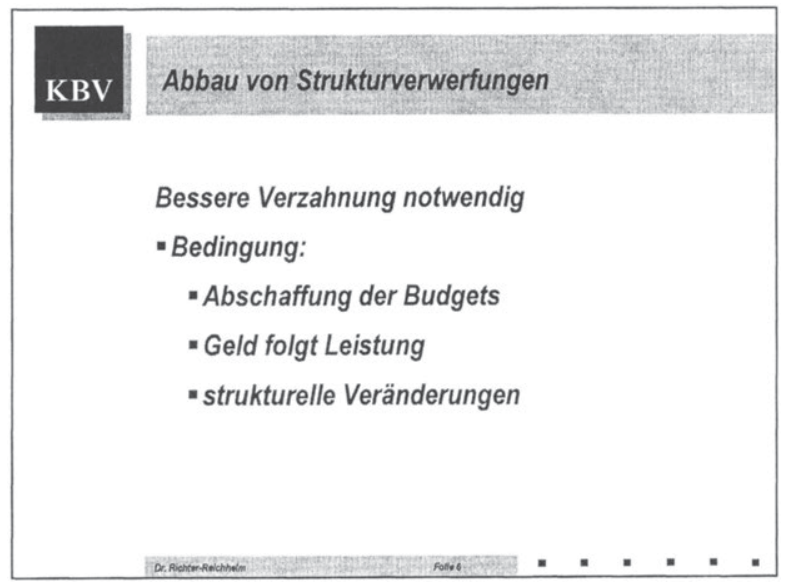

\section{Flexiblere Vertragsstrukturen}

Die KBV hat bereits konstruktive und praktikable Vorschläge für eine flexiblere Vertragsstruktur vorgelegt. Das Ziel ist dabei ein geordnetes Nebeneinander von Kollektivverträgen für alle Ärzte und kassenspezifischen Einzelverträgen auf der Basis von Ausschreibungen und kollektiven Rahmenverträgen.

Das rot/grüne Koalitionspapier lässt vom Wortlaut her dieses Konzept zu. Entscheidend aber ist die Antwort auf die Frage: Wenn Krankenhäuser, Gesundheitszentren und Einzelärzte in den Genuss von KassenDirektverträgen kommen sollen, geschieht das innerhalb der Bedarfsplanung? Oder beabsichtigt die Regierungskoalition, neben der KassenarztBedarfsplanung ein neues Feld im freien Wettbewerb zu öffnen? Für mich wäre dann die Bedarfsplanung rechtlich nicht mehr zu halten. 
Grundvoraussetzung für die Umsetzung dieses Konzeptes ist für die KBV die Abschaffung der Budgets, nicht nur der sektoralen Trennung. An deren Stelle treten vertragliche Regelungen über Leistungen und Leistungsmengen, die zu einem festen Euro-Wert erbracht werden. Diese Vertragsstrukturen würden einerseits sicherstellen, dass eine flächendeckende Versorgung für alle gegeben ist, andererseits aber den Erfordernissen des Wettbewerbs genügen, da Kassen im KBV-Konzept mit zugelassenen Leistungserbringern Einzelverträge entsprechend den Bedürfnissen ihrer Versicherten abschließen könnten.

Die Einführung eines Globalbudgets anstelle der bisherigen sektoralen Budgets lehnen wir strikt ab. Ein Globalbudget würde die Probleme nicht lösen, es würde neue und gravierende Probleme aufwerfen.

Eine vernünftige Steuerung der Ausgaben ist darüber nicht möglich; Leistungssteuerung muss direkt abhängig sein von dem tatsächlichen Leistungsbedarf der Versicherten. Diesen muss man feststellen und dann vertraglich regeln, wer diesen Bedarf zu welchen Bedingungen deckt. Dazu dient unser Modell der flexiblen Vertragsstrukturen.

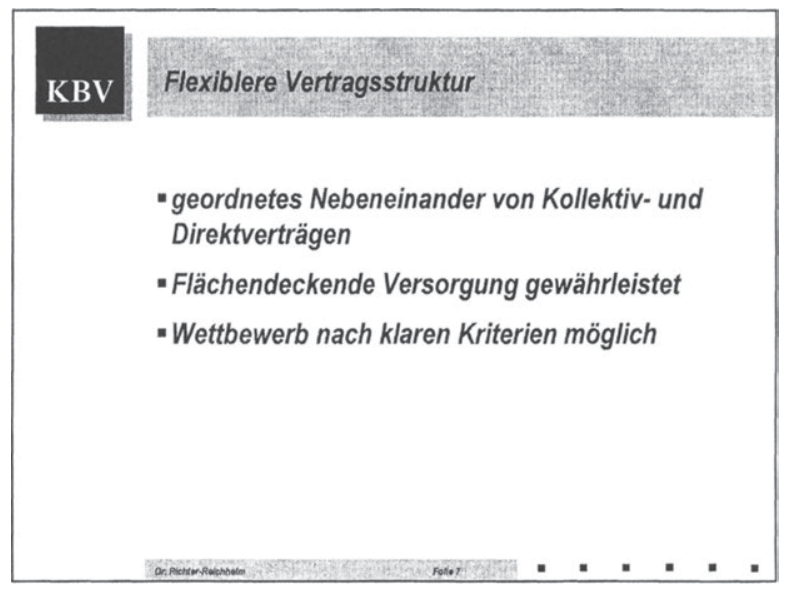

\section{KBV-Konzept der flexiblen Verträge}

Kollektiver Rahmen

Das Konzept der KBV sieht eine kassenartenbezogene Differenzierung von Bundesmantelverträgen auf Bundesebene und Gesamtverträgen auf Landesebene unter Einbeziehung dreiseitiger Verträge (§§115 ff. 
SGB V) vor. Diese Verträge können durch Verträge mit Einzelkassen weiter differenziert werden. Notwendige Voraussetzung für eine tragfähige Umsetzung ist die Vereinheitlichung der Vergütungsstrukturen und Qualitätsanforderungen für die Versorgung in und an der Klinik und in der Praxis. Die einheitlichen Leistungsgrundlagen werden durch die Beibehaltung kassenartenübergreifender Bundesausschusskompetenz gewährleistet.

Für die differenzierte Vertragsgestaltung gilt eine bedarfsabhängige Vertragsarztzulassung zur Teilnahme an der flächendeckenden Regelversorgung. Diese Zulassung ist auch Grundvoraussetzung, um an den differenzierten Einzelverträgen teilnehmen zu können. Diese regeln eine versorgungsauftragsgebundene Regelversorgung mit qualitativen Anforderungen für den teilnehmenden Vertragsarzt. Besondere Qualifikationen und besondere Vorhaltungen einer Praxis können so anders bewertet werden als bisher.

Gleichzeitig bieten auch gesetzliche Krankenkassen ihren Versicherten Wahltarife an. Beispielsweise könnte sich ein Versicherter in einen Hausarzttarif einschreiben und sich damit verpflichten, zunächst immer seinen Hausarzt aufzusuchen und nur nach dessen Überweisung zu einem Facharzt zu gehen. Er könnte dafür einen niedrigeren Beitrag zahlen als andere Versicherte, die ihre Freiheit, einen Facharzt direkt aufzusuchen, nicht einschränken wollen. Dies würde gleichzeitig eine Stärkung der Lotsenfunktion der Hausärzte bedeuten.

\section{Integrationsverträge}

Zur Etablierung einer besseren Verzahnung zwischen den Sektoren können sektorübergreifende Integrationsverträge einzelner Krankenkassen abgeschlossen werden. Voraussetzung ist im KBV-Konzept eine kollektivvertragliche Grundlage, welche die unabdingbaren Rahmenbedingungen regelt. Ärzte können aufgrund einer Ausschreibung an diesen Integrationsverträgen teilnehmen, soweit sie die dafür erforderlichen Voraussetzungen erfüllen.

\section{Einbeziehung von Krankenhäusern}

Krankenhausärzte können bedarfsabhängig und versorgungsauftragsgebunden durch eine Kasse und die KV in die ambulante Versorgung vertraglich eingebunden werden. Für definierte hochspezialisierte Leistungen unter Wahrung von Wettbewerbsgleichheit können auch Krankenhäuser für die Erbringung ambulanter Leistungen im Rahmen dieser Verträge zugelassen werden. 


\section{Stärkung der Hausärzte}

Durch Hausarzttarife würde die erwünschte Stärkung der Stellung und Funktion der Hausärzte im System erreicht. Voraussetzung dafür ist allerdings, dass die Versichertenkarte entsprechend umgestaltet wird.

\section{Hausarzt-KV?}

In einem solchen System wären auch die Gedankenspiele des Hausärzteverbandes in Bezug auf eine eigene Hausarzt-KV überflüssig geworden.

Diese Forderung hält die KBV insgesamt für nicht zielführend. Denn in jedem System mit einheitlichem Leistungskatalog und - durch den EBM 2000 plus ja geplanten - arztgruppenspezifischen Vergütungssätzen bedarf es der gleichen Vergütungsstruktur für alle ärztlichen Bereiche. Eine hausarztspezifische KV würde dem Ziel einer besseren Verzahnung der Ebenen und Sektoren zuwiderlaufen und neue Abschottungen schaffen.

\section{Gleiche Wettbewerbsbedingungen ambulant - stationär}

Gleiches gilt für die Vergütungsstrukturen zwischen dem ambulanten und dem stationären Bereich. Die massiven Auswirkungen des DRGSystems auf den ambulanten Bereich machen es unbedingt notwendig, eine durchgehende, sektorübergreifende einheitliche Vergütungsstruktur zu schaffen. Es müssen gleiche Wettbewerbsbedingungen für Krankenhäuser, Reha-Kliniken und niedergelassene Ärzte herrschen.

Die gravierenden Veränderungen, die sich voraussichtlich mit den DRGs ergeben werden, bergen derzeit noch nicht einschätzbare Risiken: Mit großer Wahrscheinlichkeit wird es zu Leistungsverlagerungen kommen. Diese gilt es genau zu beobachten und ggf. gegenzusteuern. Unter der Prämisse, dass gleiche Leistung auch gleiche Vergütung - selbstverständlich unter Anrechnung der unterschiedlichen Vorhaltekosten - bedeutet, unterstützt die KBV die Umstellung der Vergütungen auf ein durchgängiges Fallpauschalensystem. Es ist allerdings ständig auf Plausibilität und medizinische Angemessenheit zu überprüfen.

Auf der Grundlage der jetzt vorliegenden Rechtsverordnung ist zu vermuten: Krankenhäuser werden leichte Fälle an sich ziehen, vor allem die Day-Cases oder die Fälle, die mit einer Mindestverweildauer von einem Tag belegt sind. Sie kassieren nach derzeitiger Sachlage dafür häufig sehr viel höhere Vergütungen (trotz ggf. Abschläge) als die niedergelassenen Fachärzte. Die Koloskopie zum Beispiel bringt rund 600 Euro in 
der Klinikambulanz, aber derzeit nur rund 200 Euro in der Praxis, auskömmlichen Punktwert vorausgesetzt.

Sie werden die schweren Fälle so früh wie möglich entlassen. Diese werden dann die ambulante Versorgung belasten. In beiden Fällen ist denkbar, dass dem Krankenhaus assoziierte Ärzte Vorteile gegenüber denjenigen ambulant tätigen Fachärzten haben werden, die nicht in räumlicher Nähe zum Krankenhaus arbeiten. Die Gefahr, dass die freiberufliche Niederlassung der assoziierten Ärzte austrocknet und eine existenzielle Abhängigkeit entsteht, ist groß. Daher ist es notwendig, gleiche Wettbewerbsvoraussetzungen für alle zu schaffen, damit wir eine effiziente Leistungsallokation erreichen. Dies gilt für die Vergütungsstrukturen und für die Vertragsstrukturen.

Sehr geehrte Damen und Herren, es ist hoffentlich deutlich geworden, dass die KBV sich keineswegs gegen ein Öffnung des Kollektivvertragssystems sperrt. Unter den skizzierten Rahmenbedingungen halten wir eine Öffnung für richtig und sinnvoll. Eines aber muss klar sein: Eine Rosinenpickerei der Krankenkassen werden die KVen nicht zulassen. Sollte das Einkaufsmodell ohne entsprechenden kollektiven Rahmen durchgesetzt werden, können und werden KVen nicht zum Restverwalter des Schwierigen werden.

Die KBV hat als erste konstruktive, vor allem praktikable und umsetzbare Konzepte erarbeitet. Ich möchte aber nochmals feststellen, dass

- $\quad$ es einer klaren Regelung der Sicherstellung bedarf,

- die Bedarfsplanung für Kollektiv- und Direktverträge gelten muss,

- die Vergütungsstrukturen zwischen den Ebenen und Sektoren gleich sein müssen,

- Leistungssteuerung sich an der Morbidität ausrichten muss,

- Budgets Gift für eine morbiditätsorientierte Versorgung sind,

- Wahltarife durch Veränderung der Chip-Karte missbrauchssicher gemacht werden müssen.

Dann können wir sinnvollen Wettbewerb umsetzen. 


\section{Wettbewerbsoptionen im Rahmen der stationären Behand- lung}

Eugen Münch

Wie ein roter Faden durchzieht die Diskussion über das Gesundheitswesen - wie auch auf dieser Tagung - die Frage: Wettbewerb im Gesundheitswesen, ja oder nein? Es wird dann mit Leidenschaft die Frage behandelt, welches Glück oder Unglück im Wettbewerb steckt, und man fragt sich, zu welchem Zweck die Diskussion geführt wird, wenn man die Realitäten betrachtet.

Die Tatsache, dass es die Rhön-Klinikum AG gibt, entspringt einem Wettbewerb, der real stattgefunden hat und stattfindet, obwohl die eingangs gestellte Frage diskutiert wird.

Die Marktverhältnisse in der Pharmaindustrie sind Ergebnisse des Wettbewerbes.

Die niedergelassenen Ärzte stehen im Wettbewerb um gute Kassensitze und um Patienten, und die Krankenkassen haben früher und heute um die besten Plätze in der Parlamentslobby und am Tisch der Gesetzesund Verordnungsgeber sowie heute auch noch um Mitglieder gekämpft.

Es geht also bei der Diskussion, die in scheinheiliger Weise geführt wird, nicht um den Wettbewerb an sich, sondern um die Frage, wie der Wettbewerb um Patienten bzw. deren beste Behandlung mit dem Preis des größten Vorteils für den Gewinner erreicht oder vermieden wird.

Dabei hört man sehr wenige Stimmen, die sich für einen direkten Wettbewerb um den Patienten vehement einsetzen. Stattdessen wird immer um einen indirekten Wettbewerb gekämpft.

Warum ist das so? Die Antwort ist einfach: Wenn die Mutter entscheidet, wen die Tochter heiratet, wird sich der gesamte Hofstaat aller Schwiegersöhne in spe um sie ranken und nicht um die Tochter. Das Argument „Das kann der Patient nicht entscheiden" dient also nur dem Vormund der Regierung -, die für inn alles regelt (dann wird sie gewählt); die Krankenkasse, der Arzt oder wer auch immer die Interessen des Patienten "modelliert", er tut es zu seinem eigenen Nutzen und Frommen.

Solange es - jedenfalls vom Prinzip her - freie Krankenhauswahl gibt, ist das Krankenhaus relativ nah am Patienten, insbesondere, seit die staat- 
liche Investitionsförderung auf dem Rückzug ist und sich dadurch der Wettbewerb um die besten politischen Kontakte mit dem Ziel, für sein Krankenhaus die Mittel für einen Neubau zu bekommen, zur Fruchtlosigkeit neigt. Mit der Einführung der DRGs könnte die Nähe zum Patienten noch eine Steigerung erfahren und die Ausrichtung auf die Interessen des Patienten, wenn das Geld der Leistung folgt, sogar erheblich verstärkt werden. Wenn aber eine Deckelung oder weitere stringente Budgetierung erfolgt, wäre das Ergebnis anders, weil man sich nicht auf einen Patienten einstellt, für den man kein Geld bekommt. Dies hat im Übrigen nichts mit der Rechtsform oder der Frage privater oder öffentlichrechtlicher Trägerschaft zu tun, sondern nur mit der Frage, bei wem der Erfolg des Tuns ankommt.

Was sind die Parameter des Wettbewerbs im Krankenhaus? Dabei vernachlässige ich als privater Unternehmer die Frage des Einwerbens von Fördermitteln wegen geringer Aussicht auf Erfolg, da sie nicht mehr wesentlich wettbewerbswirksam ist. Es ist im Gegenteil schon so, dass derjenige, der bei der Ausrichtung seines Krankenhauses auf öffentliche Mittel setzt, wertvolle Zeit und mentale Kraft für die Wettbewerbsfähigkeit direkt am Patienten verliert.

Primäre Zielgruppe der Krankenhäuser sind und bleiben die Patienten, da mit deren Nachfrage zur Not auch eine Krankenhausplanung gekippt werden könnte. Jeder fünfte Deutsche geht - statistisch betrachtet einmal im Jahr ins Krankenhaus, dabei die Jungen weniger, die Älteren viel mehr. Krankenhaus ist somit etwas, was gerade die Älteren und $\mathrm{Ge}$ sundheitssensibleren besonders interessiert, und das "Ins-Krankenhausgehen" führt zu einem Entscheidungsprozess des Betroffenen. Für Informationen über das Krankenhaus, seine medizinische Leistung, seine Betreuungsqualität und sein Ambiente wird entscheidungserheblich Zeit und Energie eingesetzt. 
Abb. 1

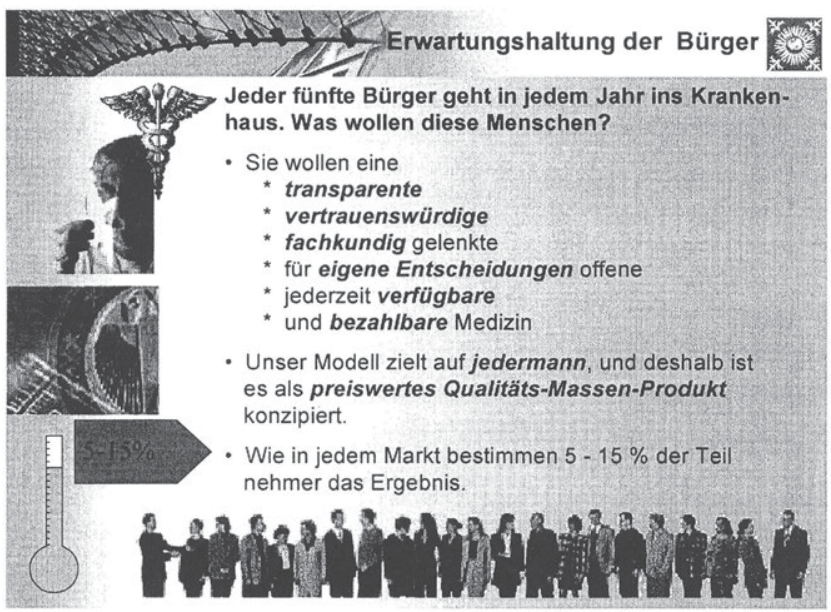

Noch keine Rolle für die Wahl eines Krankenhauses spielt der Preis als Relation zur gebotenen Leistung. Trotzdem gehen wir, da er indirekt bei den Krankenkassen an Bedeutung gewinnt, von einer Wirksamkeit des Parameters aus und haben unsere „Produktionstechnik" für Gesundheitsdienstleistungen als ein möglichst preiswert im Prozess herstellbares Produkt gestaltet. Dabei werden selbstverständlich die Kriterien der Ergebnis- und somit Reinvestitionsmaximierungen besonders beachtet.

Jeder kennt die oft negierte, aber auch bei Krankenhäusern wirksame Ausrichtung von im Wettbewerb stehenden Systemen, wonach sich diese - wegen der abnehmenden Grenzkosten - immer an den Nachfragern ausrichten, die zu den letzten Prozenten der Auslastung ihrer Kapazität führen. Das bedeutet, dass man sich im gut geführten Krankenhaus fragt, was der mobile und gut informierte Patient möchte, und dass man sich an dessen Bedingungen ausrichten wird, da er sonst zur Konkurrenz abwandert. Das bedeutet jedoch nicht, dass ein Krankenhaus die Notaufnahme negieren kann, um sich auf diese selektiven Patienten zu konzentrieren. Im Gegenteil: Gerade für den Patienten mit Alternativen gilt das, was er von der Notfallqualität des Krankenhauses hört, als Kompetenznachweis. 
Abb. 2

Der Krankenhaussektor ist wie der gesamte Gesundheits-
dienstleistungsbereich im Umbruch - und er ist ein Wachs-
tumsmarkt. Die Determinanten hierfür sind bekannt:
Medizinischer und medizin-technischer Fortschritt
- Demographische Entwicklung (die Menschen werden immer
älter)
Verändertes „Konsumverhalten“ = Patientenverhalten etc.
Der Privatisierungsdruck im Krankenhausbereich steigt,
aufgrund
- Finanznot der Öffentlichen Haushalte etc.
Der Wettbewerb um Patienten gewinnt an Schärfe
Dies wirft die Frage auf:
Wie können sich die Krankenhäuser auf den zunehmen-
den Wettbewerb einstellen?

Wie bereits angedeutet, ist eine steigende Ausrichtung des Wettbewerbes in Bezug auf das Patienteninteresse zu verzeichnen, wobei der medizinische Fortschritt und die demographisch bedingte Interessenverschiebung als Determinanten in Betracht zu ziehen sind für das, was man in der freien Wirtschaft mit steigendem Konsumverhalten umschreiben würde. Dieses steigende Konsumverhalten führt einerseits zur Erosion des alten Systems, das als Versicherungs- und Leistungssystem auf Notlagen der Mitglieder einer jüngeren Gesellschaft und nicht auf den konsumtiven Reparaturbetrieb einer alten Gesellschaft ausgerichtet war. Aufgrund seiner caritativen Ausrichtung, nämlich seiner Existenz zur Nothilfe, aber insbesondere aufgrund seiner staatlichen Planungsstarrheit ist das alte System nicht in der Lage, den sich sehr viel schneller wandelnden Bedürfnissen einer konsumtiv orientierten Nachfrage gerecht zu werden.

Die Sensibilität und die Menge der Patienten aus dem Gesamtkollektiv, die auf die genannten Wettbewerbsanreize reagieren, sind noch nicht in den Fokus wissenschaftlicher Untersuchung gekommen, obwohl gerade deren Kenntnis eine Beschreibung des aktuellen Grades der Wettbewerbsabhängigkeit heutiger Krankenhäuser erlauben würde. Um eine Aussage machen zu können, biete ich hilfsweise eine Einteilung in Form einer persönlichen Beobachtung an. Danach sind bei einem Krankenhaus der Flächenversorgung, also nicht einer Einrichtung der Spezialversorgung, 70 bis 80 Prozent der Patienten auf das Haus ihres Wohnbereiches fixiert. 
20 bis 30 Prozent der Patienten könnten aus regionalen Gründen - und weil sie informierter sind - das Krankenhaus wechseln. Dieser Teil der Patienten ist es, der den Wettbewerb erzeugt und auf den sich erfolgreiche Krankenhäuser ausrichten.

Abb. 3

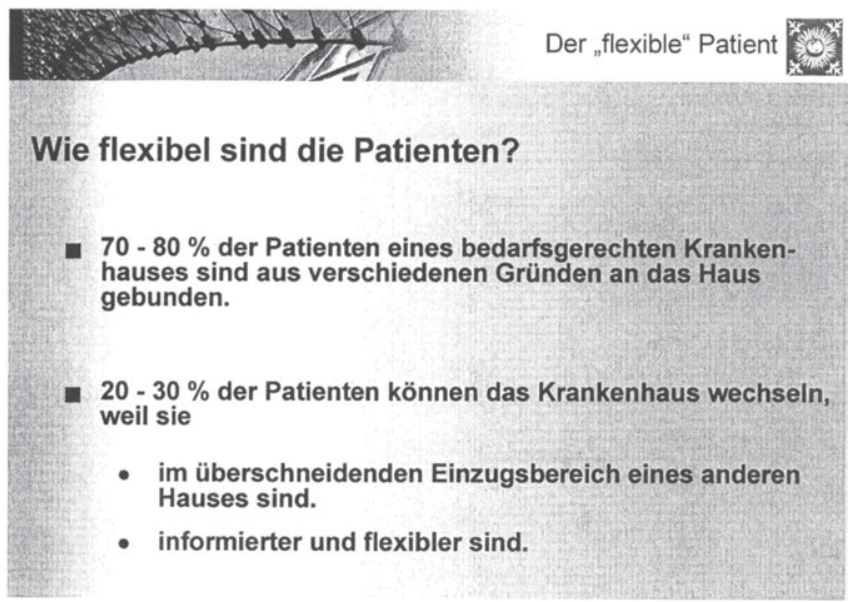

Aufgrund ihrer starken Vorhaltung und der Personalorientierung sind Krankenhäuser stark von Fixkosten geprägt. Deshalb sind es die flexiblen Patienten, welche $\mathrm{zu}$ hoher Auslastung und damit zu sinkenden Grenzkosten und zu überproportional steigenden Deckungsbeiträgen führen oder bei Fernbleiben zu deren Gegenteil.

Um Wettbewerb im eigenen Interesse aktiv zu gestalten, ist Handlungsfähigkeit erforderlich. Handlungsfähigkeit entsteht durch überdurchschnittliche Produktivität, woraus überdurchschnittliche Deckungsbeiträge resultieren, die gestaltend verwendbar sind. Durch eine hohe Auslastungsquote, die zumeist auf einer erforderlichen Mengenerhöhung basiert, was gleichzeitig Wiederholung, also Übung, und Rationalisierung bedeutet, kann regelmäßig eine gesteigerte Qualität und damit ein wichtiger Parameter der Wettbewerbsfähigkeit erreicht werden. 


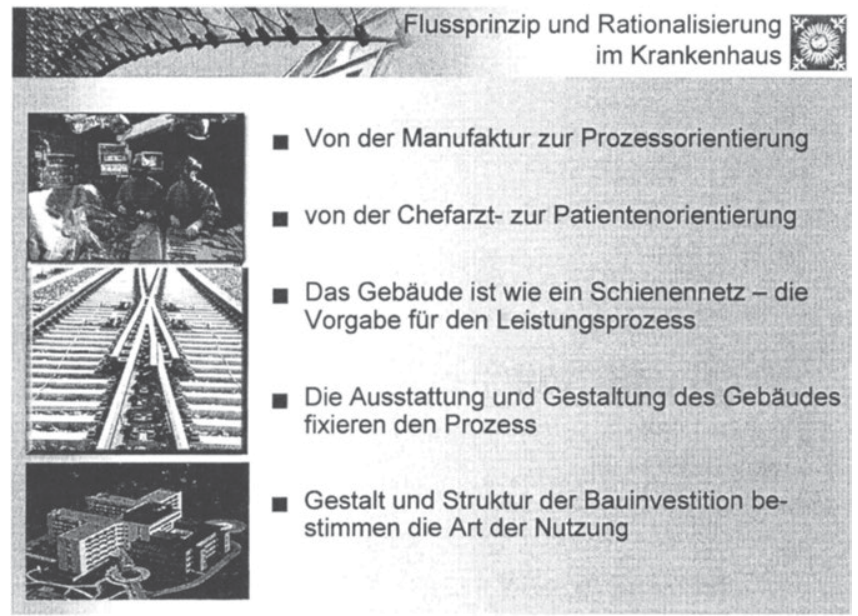

Bei der angesprochenen Gestaltungsfähigkeit handelt es sich um die Fähigkeit, Veränderungen der Organisation - insbesondere durch Investitionen - so zu gestalten, dass Leerkosten, unnötige Rüstzeiten und unnötige Vorhaltungen sowie lange Wege vermieden werden. Der Leistungs-/Produktionsprozess ist so zu gestalten, dass ein Maximum der Leistung den Patienten erreicht und nicht für Nebenziele verbraucht wird. Dem Interesse eines Politikers zu dienen, rechtzeitig vor der Wahl ein neues Gebäude einzurichten oder einen blinden Bittsteller an der Krankenhausrezeption wählerwirksam unterzubringen, kann getrost als Nebenziel beschrieben und nur dann vermieden werden, wenn die Deckungsbeiträge aus der Produktivität so hoch sind, dass auf die Unterstützung des Politikers bei der Einwerbung von Fördermitteln verzichtet werden kann.

Um Qualität und Produktivität zu erhöhen, ist es notwendig, die Krankenhäuser von ihrer Manufakturstruktur in eine Prozessorientierung zu überführen, bei der durch sich wiederholende, arbeitsteilige Flusskonzepte eine kostengünstige und qualitätsvolle Leistung entsteht, welche Deckungsbeiträge für die zu tätigenden Investitionen ergibt.

Die Investitionsfähigkeit ist Dreh- und Angelpunkt der Wettbewerbsfähigkeit eines Krankenhauses. Denn: Investitionen sind einerseits Mittel für rationelle und patientengerechte Leistungserbringung, gleichzeitig stabilisieren Investitionen das veränderte System und dienen somit einer nachhaltig rationellen Leistungserbringung. 
Es gibt nun allerdings zunehmend Krankenhäuser, deren Basiskonzept durch mangelnde Anpassung in einer Weise von der Wettbewerbsfähigkeit entfernt wurde, dass ohne eine grundlegende Erneuerung und die Schaffung eines neuen systemischen Ansatzes sowohl diese Häuser als auch die Flächenversorgung als solche - keine Zukunftschance hätten. Damit sind die alten Grundversorgungskrankenhäuser gemeint. Sie sind geprägt von einer inneren Abteilung, einer fast alles operierenden Allgemeinchirurgie und manchmal noch einer Gyn-Geburtshilfe-Abteilung, die weit unter den aus qualitativen und wirtschaftlichen Erwägungen notwendigen Geburtenzahlen liegt.

Vor 50 Jahren war das Konzept dieser kleinen, alles umfassenden Einrichtungen, in deren Chirurgie vormittags eine Schilddrüse, nachmittags ein Enddarm saniert und abends noch ein Schlüsselbein gerichtet wurde - auch mangels anderer Alternativen -, ausreichend. Heute fahren die mobilen und informierten Patienten an solchen Einrichtungen vorbei und suchen das nächstliegende Großkrankenhaus mit seinen vielfältigen Spezialisten auf. Da Mobilität und Informiertheit nichts mit dem Schweregrad der Erkrankung zu tun hat, ist die gewachsene Selbstselektion der Patienten kaum sachgerecht. Die Folge ist, dass sowohl das Großkrankenhaus als auch das Kleinkrankenhaus Patienten hat, die dort aus qualitativen und auch aus Kostengründen nicht hingehören. Die betriebswirtschaftliche Konsequenz wird spätestens bei einer Vergütung nach DRGs sein, dass die Häuser ihr Equipment auf die bestehende Klientel ausrichten oder im Wettbewerb - und das heißt Angebot und Information - die Patienten in das richtige Haus bringen müssen. Diese Funktion planwirtschaftlich durch Einschränkung des Arztwahlrechtes zu erreichen, ist nachhaltig nicht möglich. Indirekte Versuche, dies durch Einschreibungsmodelle beim Hausarzt zu erreichen, erscheinen ebenso wenig nachhaltig. Jemand, der zugunsten eines Bonusses bei der Versicherungsprämie sein Recht aufgibt, über sein Schicksal selbst zu entscheiden, glaubt lediglich, dass diese Entscheidung nicht ansteht. Sobald sie ansteht und der Arzt nicht willfährig den Wünschen nachkommt, wird er den Arzt wechseln. Auch hier gilt: Lenken lassen sich die unflexiblen 70 Prozent, die bereits bei dem oben genannten Wettbewerbsmodell eine Rolle gespielt haben. Der Entwicklungstrend aber wird von den restlichen 30 Prozent bestimmt.

Zukunftsorientiert geht es also um die Frage, wie die unterschiedlichen Krankenhäuser im Rahmen der Flächenversorgung positioniert sein müssen, damit sie in einem solchen Wettbewerb erfolgreich bestehen können. Letztlich werden die informierten Patienten bestimmend sein, welche Krankenhäuser erfolgreich sein werden und welche nicht. Da ein Haus nur als erfolgreich definiert werden kann, wenn es auch wirtschaft- 
lich erfolgreich ist, d. h. nachhaltig die Leistung stimmt, muss in diesem Zusammenhang auch die Frage nach den Entwicklungstrends der Medizin gestellt werden.

Abb. 5

Krankenhäuser als Flächenversorger sind das Ziel
Flussprinzip und Rationalisierung bestimmen prägen die
Organisation
Das alte Grundkrankenhaus ist in der Sackgasse zwischen
Profession und Breite
Entwicklung in der Medizin - Gentechnik
Entwicklung in der Medizin - Bildgebende Verfahren
Entwicklung in der Medizin - Elektronische Patientenakten
der Weg ist das Ziel

Das Ergebnis von sehr umfangreichen Recherchen und langjähriger Entwicklungsbeobachtung, in knappen Worten zusammengefasst, zeigt, dass wir in der Gentechnik vor allem mittelfristig eine Unterstützung von Anamnesen durch Gentests erwarten. Gentests werden uns mit zunehmendem Entstehen von Langzeitbeobachtungen durch Risikoprofile bei unklaren Erkrankungen eine Hilfe in der Auswahl von Suchfeldern bei der Diagnose sein. Die mit der Digitalisierung von Patientendaten entstehende enorme Datenflut wird mittels Gentestergebnissen, abgeglichen mit Anamnesedaten, zur Suchfeldbestimmung genutzt. Die über entsprechende Fragestellung an die Suchmaschine beliebig strukturierbare elektronische Akte ergibt fast zwangsläufig einen je nach Fragestellung geordneten Prozess bzw. zeigt rückwirkend dessen Logik oder Unlogik. Dieser Vorgang wird zurzeit von der Diskussion über Datenschutz, der überwiegend der Verschleierung aktueller "Nichtprozesse, Doppel- und Mehrfachleistungen" dient, behindert. 
Abb. 6

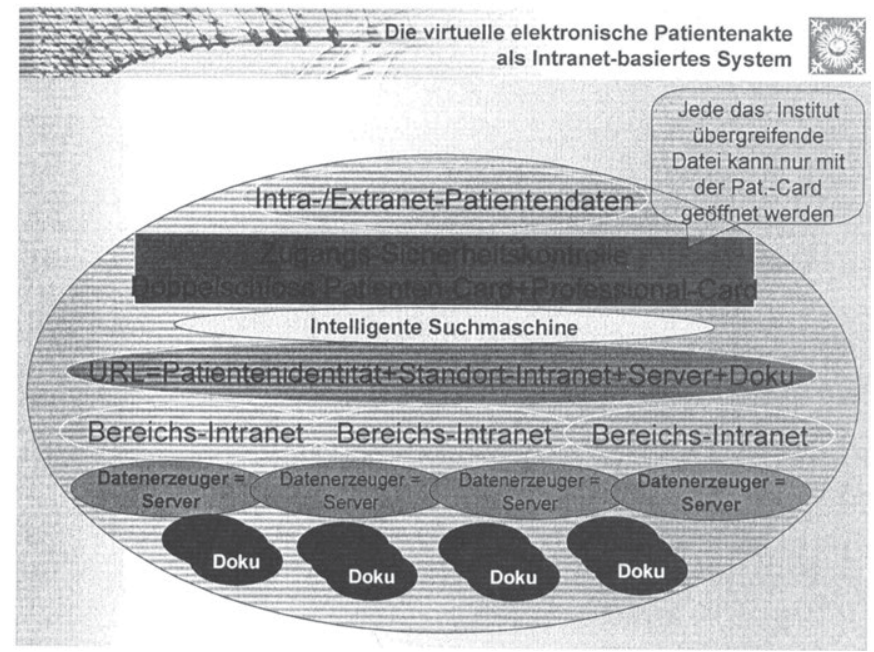

Mit der enorm schnellen Entwicklung der bildgebenden Verfahren entsteht die Möglichkeit der so genannten One-Stop-Diagnostic als Umkehrung der heute gültigen Stufendiagnostik, die aus einer veralteten Wirtschaftlichkeitsbetrachtung relativ unabhängig vom medizinisch Sinnvollen vorsieht, die so genannte billige Handarbeitsmedizin vor der als teuer geltenden Technik einzusetzen.

Wir sind in Feldversuchen und Konzeptbetrachtungen zum Ergebnis gekommen, dass die alten Denkmuster bald überholt sein können und die bildgebenden Verfahren die Diagnosefindung dominieren werden. Wir aber auch andere - arbeiten daran, diese Verfahren im Rahmen von Scan-Programmen einzusetzen. Damit werden sich gleichzeitig neue Formen der Arbeitsteilung zu neuen Prozessketten zwischen einweisenden Ärzten und Krankenhäusern und Krankenhäusern gestufter Funktionalität entwickeln. Die Prozesskette entsteht durch eine intranetbasierte elektronische Patientenakte, die - wie oben dargestellt - über eine Suchmaschine mit dem Zugriff auf alle Datenhalter im System aufgebaut ist. Die Steuerung erfolgt über Wissen und Beratung und nicht - wie es bei den heutigen Versuchen zum Disease-Management geschieht - über strukturellen Zwang. Die Stellung des Patienten wird gestärkt, weil er über die Zugangsberechtigung verfügt. Die Qualität würde gesichert, indem den Prozessbeteiligten die Prozessdaten verfügbar sind und somit eine wechselseitige latente Plausibilitätskontrolle aller am Prozess beteiligten Professionals stattfindet. 
Als Quintessenz unserer Überlegungen haben wir das Modell einer Teleportalklinik entwickelt und sind zurzeit dabei, an einigen Standorten Prototypen davon zu konzipieren.

Abb. 7

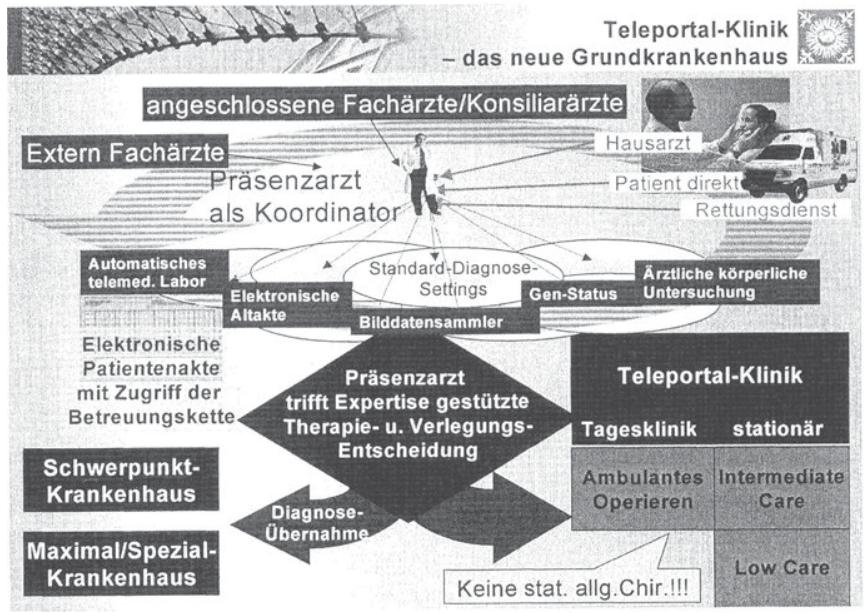

Die Teleportalklinik ist die Kombination einer Hochleistungs-Diagnoseeinheit, bei der die Hardware (Diagnosetechnik) regional unter Aufsicht ärztlicher Operatoren im Einzugsgebiet des Patienten jederzeit und für jedermann verfügbar ist und das Know-how für Diagnose und Handlungsempfehlung von online rund um die Uhr verfügbaren Partnern eingeholt wird. Die Teleportalklinik verfügt durch Kooperation mit niedergelassenen Fachärzten, die als Teilangestellte tätig sind, über eine umfangreiche Tagesklinik, einschließlich tagesklinischer Operationen, und einer internistisch ausgerichteten Bettenabteilung, in der Patienten mit wesentlich pflegerischem Handlungsbedarf und solche, die keiner Spezialeinrichtungen bedürfen, untergebracht werden können. Patienten, für welche die Diagnose mit anschließender Empfehlung den Behandlungsbedarf in einer spezialisierten Einrichtung ergibt, werden unter Ausschöpfung der tagesklinischen Möglichkeiten in Kooperationshäuser verlegt. Die Möglichkeit zu invasiven Eingriffen jeder Art endet dort, wo sie entweder fachlich nicht abgedeckt sind, oder wenn die Behandlung der Patienten tagesklinisch nicht möglich ist; diese Patienten werden in jedem Fall verlegt. Mit dieser Begrenzung wird die heute vielfach übliche, aber versorgungstechnisch völlig unsinnige Spezialisierung kleiner Versorgungskliniken unterbunden; der Zugewinn an Behandlungs- und Versorgungsqualität wird erheblich sein. 
Abb. 8

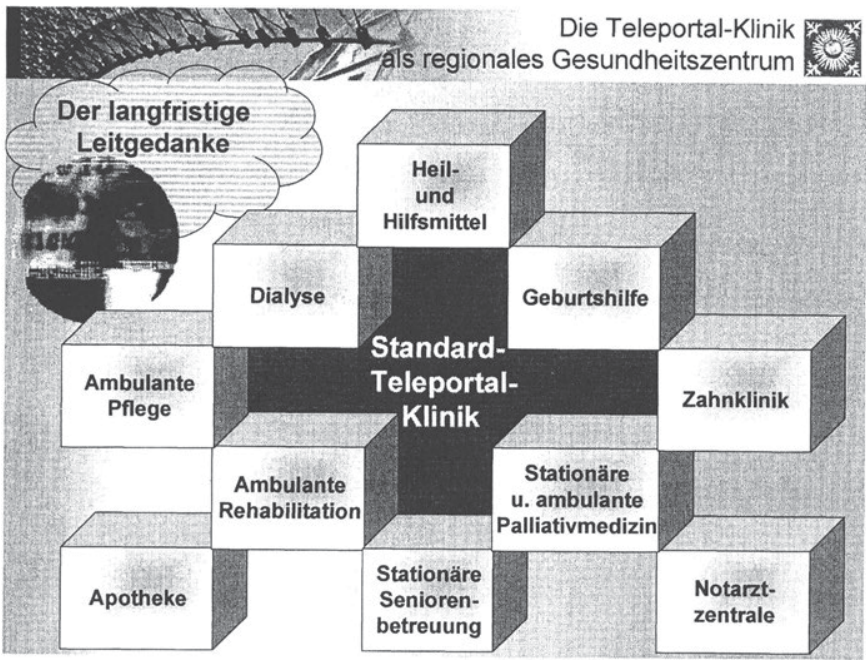

An diesem wohnortbezogenen, stationären und teilstationären Diagnoseund Behandlungs-Krankenhaus können - verschieden für die regionale Versorgung - erforderliche weitere Leistungsangebote, die kooperativ mit Spezialanbietern darstellbar sind, zum umfassenden Gesundheitszentrum zusammengefasst werden. Durch die über den Online-Zugang zur elektronischen Akte eingewiesenen Patienten wird die Betreuungskompetenz der verbundenen Hausärzte erheblich gestärkt und damit die Patientenbindung auch im Sinn anschließender Prävention erheblich verbessert.

Im Falle der routinemäßigen Einschaltung des Fach- und Spezialwissens der kooperativ und online verbundenen Fachabteilung des Schwerpunktoder Spezialkrankenhauses wird - verbunden mit den optimalen technischen Bedingungen - ein in Qualität dem Fachkrankenhaus gleichwertiger und bezüglich Zugänglichkeit und Schnelligkeit weit überlegener Anlaufpunkt für regionale Patienten und damit der im Wettbewerb erforderliche Vorteil erreicht. 


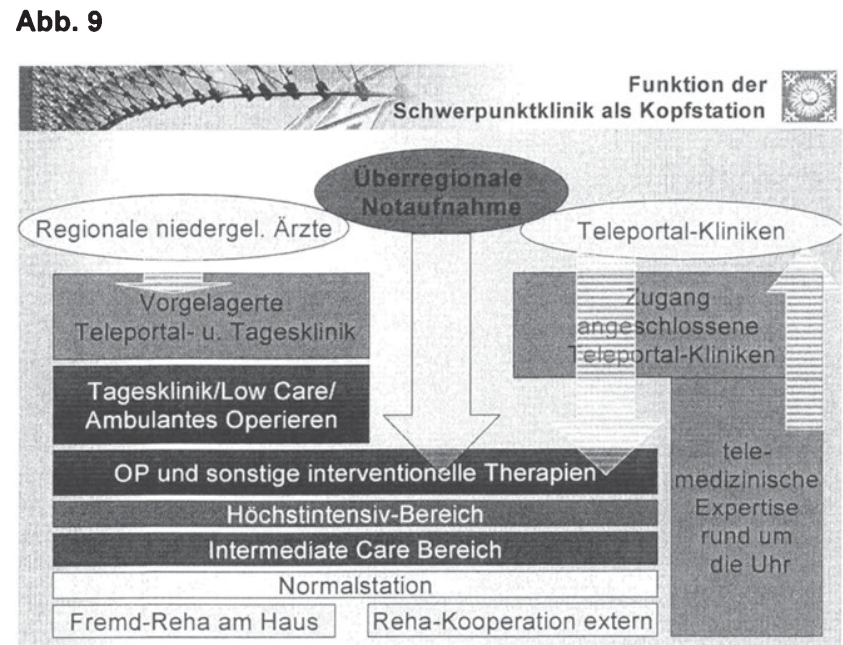

Die mit diesem Konzept generierte Nachfrage nach telemedizinischer Leistung wird auch die Großkrankenhäuser verändern und zu einer anderen Zusammensetzung der Patienten führen. Patienten, die in Teleportalhäusern aufgenommen und dort behandelt werden können, werden im Großkrankenhaus nur in der Menge erscheinen, wie sie zum regionalen Einzugsgebiet gehören. Ihre Behandlung soll aus Qualitäts- und Kostengründen in vorgeschalteten Einheiten, die dem Modell der Teleportalklinik entsprechen, erfolgen. Damit würde sich in den Fachabteilungen das Patientenpotenzial ansammeln, das dieser Leistungsdichte bedarf. Im Ergebnis dieser Umschichtung wären die Leerkosten des Systems deutlich gesenkt und - wenn die DRGs das Geld der Leistung folgen ließe - die Bedingung einer erfolgreichen Rationalisierung gegeben. Die in diesem System operierenden Krankenhäuser würden sich durch verbesserte Qualität und verbesserte Ressourcennutzung Handlungsspielraum im Sinne der Wettbewerbsfähigkeit verschaffen.

Es mag viele Einwände gegen ein solches Modellkonzept geben. Es mag auch an manchen Stellen aus den Erkenntnissen, die sich in der Realität der Versuche herausstellen, noch verändert werden. Das Konzept wird aber im Trend nicht aufzuhalten sein, wenn - und an dieser Stelle sind wir uns sehr sicher - es einen nachhaltigen Nutzen im Sinne von Qualität und Preiswürdigkeit für den Patienten bringt. Gelingt dies, wäre es ein Beitrag, den in unserer Gesellschaft gültigen sozialen Ansatz der medizinischen Leistung für jedermann zu jeder Zeit zu fordern, gerecht zu werden. Soziale Marktwirtschaft kann im Gesundheitswesen 
funktionieren, wenn Wettbewerb um Patienten mit geeigneten Preis- und Anreizsystemen dazu führen, dass es lukrativ ist, einer Vielzahl von $\mathrm{Pa}$ tienten preiswert den Zugang zur Versorgung unter Nutzung der $\mathrm{Ge}$ setzmäßigkeiten des Marktes und der Betriebswirtschaft zu bieten und sie als "Kunden" zu gewinnen. Daran gemessen ist der Wettbewerb um Subventionen, Konzessionen und Zulassungsrechte zu gegen Wettbewerb geschützten Refugien, die besetzt sind von entmündigten und gegängelten Patienten, einer demokratischen Gesellschaft nicht würdig. Die Behauptung, solche "wettbewerbsfernen" Konzepte wären nötig, weil nur "man selbst" des rechten Glaubens sei und deshalb berechtigt und verpflichtet, über andere zu entscheiden, ist falsch, da jeder für sich selbst natürlich die Ausnahme reklamiert. 
Manfred Albring and Eberhard Wille - 978-3-631-75562-4

Downloaded from PubFactory at 01/11/2019 03:33:01AM

via free access 


\section{Wettbewerbsoptionen im Rahmen der stationären Behand- lung}

Susanne Renzewitz

Das Thema Wettbewerb begleitet seit rund zwei Jahrzehnten die Reformbemühungen im Gesundheitswesen. Die Diskussionen ranken sich um Begriffe wie Kassenwettbewerb, Qualitäts-, Leistungs- und Preiswettbewerb und deren ordnungspolitischen Konsequenzen. Anlass ist die Hoffnung, durch Wettbewerb Qualitäts- und Wirtschaftlichkeitsdefizite in der Gesundheitsversorgung wirksamer beheben zu können.

Ob Wettbewerb oder Wettbewerbselemente ein Ansatz sein können, insbesondere finanzielle Probleme unseres Systems besser zu lösen, hängt maßgeblich davon $a b$, in welcher Art und Weise dies umgesetzt werden soll. Konkrete Aussagen über die wahrscheinlichen Wirkungen und denkbaren Nachteile wettbewerblicher Instrumente für das deutsche Gesundheitssystem allgemein und speziell für den Krankenhausbereich können lediglich mit Blick auf Erfahrungen anderer Länder getroffen werden. Wettbewerblich organisierte Gesundheitssysteme, wie beispielsweise in den USA, lassen den Schluss zu, dass ein reines Wettbewerbssystem teurer und für einen Großteil der Bevölkerung nicht bezahlbar ist.

Eine rein marktwirtschaftliche Selbststeuerung kann daher nicht das Ziel anstehender Reformen sein. Vielmehr muss an den Grundprinzipien eines solidarischen Gesundheitssystems und der sozialstaatlichen Verpflichtung zur Daseinsvorsorge auch zukünftig festgehalten werden. Damit sind marktwirtschaftlichen Gestaltungsinstrumenten Grenzen gesetzt.

Auch wenn die politischen und wissenschaftlichen Diskussionen über das $\mathrm{Ob}$ und Wie von Wettbewerb längst noch nicht abgeschlossen sind, ist nüchtern festzustellen, dass mit der "Gesundheitsreform 2000" und dem „Fallpauschalengesetz" bereits ordnungspolitische Grundsatzentscheidungen für eine stärkere wettbewerbliche Orientierung der Anbieter von Versorgungsleistungen getroffen worden sind. Diese sollen - so die Koalitionsvereinbarung - zukünftig weiter ausgebaut werden. Die Eckpunkte der Koalitionsvereinbarung decken sich hinsichtlich der Organisation der Leistungserbringer weitgehend mit den in der letzten Legislaturperiode erfolgten Diskussionen am „Runden Tisch im Gesundheitswesen“: mehr Qualität und mehr Wettbewerb. Das Bekenntnis der Koalitionsregierung zu einem Nebeneinander von Einzel- und Kollektivverträ- 
gen beruht jedoch auf keiner neuen Vision, sondern schließt insoweit an die Gesundheitsreform 2000 an. Die Probleme liegen allerdings in der Umsetzung.

\section{Vorboten des Wettbewerbs}

Weichenstellende Wettbewerbsoptionen für den Krankenhausbereich ergeben sich aus

a) der Einführung eines diagnoseorientierten Fallpauschalensystems,

b) der Qualitätssicherung,

c) der Einführung von Disease-Management-Programmen und

d) integrierten Versorgungsformen.

\section{Einführung eines diagnoseorientierten Fallpauschalensystems}

Die Reform des Vergütungssystems für Krankenhäuser ist ein zentraler Ausgangspunkt für eine stärkere wettbewerbliche Orientierung nicht nur des Krankenhausbereiches, sondern auch der übrigen Leistungsanbieter. Mit der Einführung eines Diagnose-orientierten Fallpauschalensystems (DRG)

- $\quad$ werden sich Krankenhäuser zunehmend als Unternehmen verstehen und sich in einem konkurrierenden Umfeld positionieren müssen,

- $\quad$ wird der Leistungswettbewerb durch eine Neuordnung der Strukturen (Konzentration, Kooperation, Spezialisierung etc.) gefördert,

- wird die Qualität der medizinischen Leistungen ein maßgeblicher Wettbewerbsparameter sein.

Diagnose-orientierte Fallgruppen führen dazu, dass die Leistungen des Krankenhauses - und damit sein Produkt - transparent abgebildet werden. Die Transparenz der Leistungen wird eine verschärfte Konkurrenzsituation unter den Krankenhäusern auslösen. Durch ein gezieltes Benchmarking werden Krankenhäuser strukturelle Entscheidungen treffen müssen, um sich am Markt auch zukünftig behaupten zu können. Mögliche Handlungsoptionen sind beispielsweise die Konzentration auf spezielle Leistungsbereiche sowie Krankenhauskooperationen oder auch Fusionen.

Ein solcher Leistungswettbewerb wird unterschiedliche Ausprägungen haben angesichts der Tatsache, dass Krankenhausleistungen ortsge- 
bunden erbracht werden und die einzelnen Krankenhäuser sich in völlig unterschiedlichen Konkurrenzsituationen befinden.

Transparenz des medizinischen Leistungsgeschehens fördert gleichzeitig einen Qualitätswettbewerb. Qualitätsgesichtspunkte sind ein wesentliches Kriterium der Auswahl unter mehreren Leistungsanbietern auf dem Markt.

Die ordnungspolitischen Rahmenbedingungen sind derzeit ausschließlich für die Einführungs- und Konvergenzphase des DRG-Systems nach dem gegenwärtigen Zeitplan, folglich bis Ende des Jahres 2007, festgelegt. Krankenhäuser sollen in diesem Zeitrahmen das DRG-System unter folgenden schützenden Bedingungen einführen:

- budgetneutrale Einführung in den Jahren 2003 und 2004

- Konvergenzphase in den Jahren 2005 und 2006

- sektorales Budget

- Festpreise

- Sicherstellungszuschlag

Durch die budgetneutrale Phase sollen ohne finanzielle Auswirkungen Erkenntnisse vor allem in zwei Bereichen gewonnen werden: Zum einen darüber, inwieweit sich das bisherige krankenhausindividuelle Leistungsspektrum im Rahmen der DRG-Klassifikation darstellt. Zum anderen kann ermittelt werden, in welchem Verhältnis die sich daraus abzuleitenden Vergütungen zum bisherigen individuellen Pflegesatz/Krankenhausbudget steht.

In der Konvergenzphase soll eine Angleichung der individuellen Preise an einen Durchschnittspreis erfolgen mit dem Ziel, gleicher Preis für gleiche Leistung.

Das sektorale Budget und Festpreise sind unverzichtbare Voraussetzungen, um strukturelle und finanzielle Auswirkungen der Umstellung auf das DRG-System gegenüber der bisherigen Vergütungssystematik für den stationären Bereich überhaupt bewerten zu können.

Der Sicherstellungszuschlag ist ein notwendiges Korrektiv, um auch unter DRG-Bedingungen eine bedarfsgerechte, flächendeckende und gleichmäßige Versorgung zu gewährleisten. Soweit Leistungen aufgrund eines geringen, jedoch notwendigen Versorgungsbedarfs mit DRGEntgelten nicht erbracht werden können, müssen Krankenhäuser, die dieses Angebot vorhalten sollen, auch angemessene finanzielle Zuschläge erhalten.

Allein die Umstellung auf das neue Vergütungssystem wird zu erheblichen Strukturveränderungen in der Krankenhauslandschaft führen, aus 
der das einzelne Krankenhaus entweder als Gewinner oder Verlierer hervorgehen wird.

Hinsichtlich der zukünftigen ordnungspolitischen Rahmenbedingungen muss frühzeitig politisch entschieden werden, ob das Fallpauschalensystem unter marktwirtschaftlichen Bedingungen oder als staatliches Steuerungsinstrument eingesetzt werden soll.

Im Zuge der mit der Einführung des Fallpauschalensystems erwarteten Reduzierung der Verweildauer im Krankenhaus muss zukünftig auch eine qualifizierte und patientengerechte ambulante Weiterbehandlung gewährleistet sein. Insoweit wird das DRG-System auch Auswirkungen auf die ambulante Versorgung haben. Hinsichtlich des Verlagerungspotentials können vor Einführung des Systems nur Erkenntnisse aus anderen Ländern herangezogen werden. Es ist allerdings davon auszugehen, dass eine Neuordnung auch der ambulanten Strukturen unumgänglich sein wird. Dabei muss Krankenhäusern zukünftig die Möglichkeit eingeräumt werden, die ambulante Nachsorge gleichberechtigt zum vertragsärztlichen Bereich übernehmen zu können. Dies gilt umso mehr, soweit die erforderliche Versorgung - insbesondere unter Qualitätskriterien - im vertragsärztlichen Bereich nicht sichergestellt werden kann. Der geltende enge gesetzliche Rahmen der nachstationären Behandlung durch Krankenhäuser ist hierzu nicht ausreichend. Dies ist im Rahmen der Weiterentwicklung des DRG-Systems zu verfolgen. Eine Lösung stellt die DKGForderung "Behandlungsfreiheit des Krankenhauses nach Einweisung" dar.

\section{Qualitätssicherung}

Gute Qualität und ihre Sicherung dienen in erster Linie dem Wohl des Patienten. Eine konsequente Qualitätsorientierung ist Ausdruck der Führung und Verantwortungsstruktur im einzelnen Krankenhaus.

Qualitätssicherung ist in einem stärker wettbewerblich ausgerichteten Gesundheitswesen ein unverzichtbares Regulativ. Qualitätssicherungsmaßnahmen verhindern, dass - wie zum Teil befürchtet wird - infolge der Fallpauschalenvergütung unter Wettbewerbsbedingungen stationäre Patienten zu früh entlassen werden. Wollen Krankenhäuser nicht Gefahr laufen, über kurz oder lang vom Markt zu verschwinden, werden sie den Nachweis der erforderlichen Qualität erbringen müssen. Entsprechende Qualitätssicherungsmaßnahmen für den stationären Bereich sind sowohl im SGB $\vee$ als auch im Fallpauschalengesetz verbindlich festgelegt.

Gute Qualität ist aber auch ein Wettbewerbsinstrument. Bei zunehmender Konkurrenz wird der Nachweis guter Qualität ein strategisches Mittel 
sein, um Patienten zu werben. Zu nennen ist hier die Teilnahme an Zertifizierungsverfahren wie z. B. KTQ.

Welch hohen Stellenwert die Krankenhäuser dem Qualitätsgedanken entgegenbringen, zeigt nicht nur die beachtliche Beteiligung am BMGDemonstrationsprojekt "Qualitätsmanagement im Krankenhaus", sondern auch das große Interesse an Krankenhaus-spezifischen Zertifizierungsverfahren. Daneben gehen viele Krankenhäuser inzwischen den Weg, ihre Qualitätsphilosophie in einem Unternehmensleitbild zu verankern und den Qualitätsgedanken auch funktional umzusetzen. Der stationäre Sektor ist Vorreiter und kann beispielgebend für die Qualitätsorientierung anderer Leistungserbringer im Gesundheitswesen sein.

\section{Einführung von Disease-Management-Programmen}

Auf Grundlage der $\S \S 137 \mathrm{f}$ und g SGB V sollen strukturierte Behandlungsprogramme für bestimmte chronische Erkrankungen (DiseaseManagement-Programme - DMP) von den Krankenkassen eingeführt werden. Die Anforderungen an diese Programme legt die 4. Verordnung zur Änderung der Risikostruktur-Ausgleichsverordnung für die Krankheiten Diabetes mellitus Typ 2 und Brustkrebs fest.

Disease-Management an sich ist kein Instrument des Wettbewerbes, sondern der Versorgungssteuerung. Disease-Management umfasst sektorübergreifende Maßnahmen zur Verbesserung der Behandlungsqualität von Erkrankungen mit zumeist chronischem Verlauf und einem hohen Betroffenheitsgrad der Bevölkerung. Vorrangiges Ziel soll die Vermeidung/Verzögerung schwerer und zumeist mit hoher Mortalität verbundener Komplikationen und Begleiterkrankungen sowie die Verbesserung der Lebensqualität sein.

Durch die Verknüpfung mit dem Risikostrukturausgleich und durch die vertraglichen Umsetzungsoptionen werden DMP jedoch als Instrument des Kassenwettbewerbes und des Wettbewerbes unter den Leistungserbringern eingesetzt. So können zur Umsetzung von DMP Einzelverträge mit Leistungserbringern geschlossen werden. Dies führt bei gleich qualifizierten Leistungsanbietern zu einer Konkurrenzsituation.

Für die erfolgreiche Durchführung von Disease-Management-Programmen sind die medizinische Fachkompetenz, die ManagementErfahrungen sowie die räumliche und technische Infrastruktur des Krankenhauses unverzichtbar. Die Vertragsfreiheit einerseits und die Anforderungen an die Strukturqualität andererseits bewirken eine gesundheitspolitisch erwünschte Konzentration der Versorgung von DMPPatienten in entsprechend geeigneten Krankenhäusern.

Die strikte Trennung der Versorgungsbereiche behindert jedoch eine Kontinuität der Versorgungsabläufe in Disease-Management-Program- 
men. Einen notwendigen Schritt für eine stärkere Verzahnung von ambulanter und stationärer Versorgung bei der Behandlung chronischer Erkrankungen sieht die DKG in der Öffnung von Krankenhäusern für die ambulante Versorgung. Die Bereitstellung der akutstationären Behandlung und die ambulante Betreuung sowie Nachsorge aus einer Hand ist unter Aspekten der Qualität, Effizienz und Patientenorientierung sinnvoll, um die Vorteile von Disease-Management-Programmen optimal zu nutzen. Für jedes Disease-Management-Programm ist daher, bezogen auf die jeweilige Krankheit, unabhängig von sektoralen Grenzen festzulegen, von welchem Leistungsbereich die erforderlichen Behandlungen erbracht werden sollen.

\section{Integrierte Versorgungsformen}

Mit den Regelungen zu integrierten Versorgungsformen hat der Gesetzgeber die auf eine Leistungssektoren-übergreifende Versorgung beschränkte Möglichkeit zum Abschluss von Einzelverträgen eingeführt. Hierin liegt eine Chance, effizientere und innovative Versorgungsformen durch mehr marktwirtschaftliche Anreize zu fördern.

Die DKG hat die Regelungen zur integrierten Versorgung im Sinne einer Flexibilisierung des Versorgungsgeschehens ausdrücklich begrüßt und auf dieser Grundlage mit den GKV-Spitzenverbänden am 17.12.2001 eine Rahmenvereinbarung nach $\S 140$ e SGB V konsentiert.

Die derzeitigen gesetzlichen Grundlagen führen bei der inhaltlichen Ausgestaltung der Verträge zur integrierten Versorgung, jedoch auch zu objektiven Schwierigkeiten:

Dies gilt für die Vergütung der Leistungen und die Bereinigung von Vergütungen außerhalb der integrierten Versorgung.

Dies gilt für den Grundsatz der Beitragssatzstabilität. Strikte staatliche Budgetierungsregelungen widersprechen einem Wettbewerb um Leistungsverträge und müssen folglich aufgehoben werden.

Dies gilt für die getrennten Leistungsbereiche, die die Anbieter von Versorgungsleistungen in ihrer inhaltlichen Gestaltungsfreiheit behindern. Die Vertragspartner von Integrationsverträgen müssen darüber entscheiden können, wo und von wem welche Leistungen eines konkreten integrierten Versorgungsangebotes, insbesondere unter dem Gesichtspunkt von Strukturqualität, sinnvollerweise erbracht werden sollen. Diese Gestaltungsfreiheit erfordert auch die ungehinderte, gesetzlich abgesicherte Möglichkeit, dass Krankenhäuser über ihren Zulassungsstatus 
hinaus weitergehende ambulante Leistungen erbringen können. Andernfalls würde durch die gegenwärtige Ausgestaltung der Regelungen $\S 140$ a ff. SGB V die Trennung von vertragsärztlicher und stationärer Versorgung faktisch weiter aufrechterhalten.

\section{Wettbewerb erfordert Neuordnung}

Wettbewerbsoptionen erfordern einen Ordnungsrahmen, der das Verhältnis von Wettbewerb und staatlicher Versorgungssteuerung sinnvoll regelt. Die Bereiche und Bedingungen für staatliche Regulierung und für wettbewerbliche Steuerung sind verbindlich festzulegen.

Die bislang gesundheitspolitisch vorgegebene Ausgabenbegrenzung für die gesetzliche Krankenversicherung in Form des Grundsatzes der Beitragssatzstabilität ist mit wettbewerblichen Grundsätzen nicht vereinbar. Dies bedingt auch eine Abkehr von der lohngebundenen Finanzierung der gesetzlichen Krankenversicherung. 
Manfred Albring and Eberhard Wille - 978-3-631-75562-4

Downloaded from PubFactory at 01/11/2019 03:33:01AM

via free access 


\section{Wettbewerbsfelder zwischen Fachärzten und Krankenhäu- sern}

Helmut Altland

Die Versorgung gesetzlich Krankenversicherter in Deutschland ist durch den Dualismus der strikt getrennten ambulanten und stationären Versorgung gekennzeichnet. Nur im Ausnahmefall werden Krankenhausärzte für die ambulante Versorgung ermächtigt, wobei der Vorrang der persönlichen gegenüber der institutionellen Ermächtigung gilt.

\section{Krankenhaus: ärztliche Notwendigkeiten häufig unberücksichtigt}

Bisher ist es nicht gelungen, die sektorale Trennung zu durchbrechen. Dies hat vor allem wirtschaftliche Gründe. Die Krankenhäuser wären, wenn sie die sich innen eröffneten Möglichkeiten der ambulanten Versorgung wirklich vollständig nutzen würden, zu erheblichen betriebswirtschaftlichen Umstellungen veranlasst. Schon bei nur oberflächlicher $\mathrm{Be}$ trachtung der Elemente der stationären Versorgung wird offenbar, wie wenig ein Krankenhaus dazu angelegt ist, auch ambulant tätig zu werden:

- Das Krankenhaus hat einen hohen Raumbedarf.

- Die ärztliche Seite ist abhängig von der Krankenhausverwaltung, und zwar sowohl bei den organisatorischen Abläufen als auch bei den Investitionen.

- Ärztliche Kompetenz und nichtärztliches Management sind getrennt mit der Folge, dass Entscheidungen aus unterschiedlichem Blickwinkel getroffen werden.

Oft wird außerdem in herkömmlichen Krankenhäusern (Städte, Landkreise oder Kirchen als Träger) eher kameralistisch - sprich innovationsverhindernd - entschieden als nach ärztlichen Notwendigkeiten. Dies wird vor allem immer wieder in der Radiologie festgestellt: Langjährige Krankenhaus-Chefärzte standen vor der Situation, entweder auf einer "Rumpfradiologie" zu sitzen oder sich zum Freiberufler zu wandeln. Die Schlüsselstellung der Radiologie im Krankenhaus wird nicht erkannt.

Zudem: Der Krankenhausbereich ist durch eine hohe Kapitalbindung gekennzeichnet. Der hohe Raumbedarf und die komplizierte Infrastruktur 
binden erhebliche Mittel, die - bisher - weitgehend durch staatliche Förderung zur Verfügung gestellt werden.

Im Krankenhaus ist ohne Probleme eine Beschäftigung von Angestellten möglich und bis auf den Chefarzt, der eine Zwitterstellung hat, sogar die Regel - mit allen Konsequenzen wie vor allem arbeitsrechtlichem Arbeitnehmerschutz. Ausweitungstendenzen sind im Krankenhaus auch dadurch Grenzen gesetzt, dass die vorhandenen Strukturen genutzt werden müssen und meistens von Seiten der Krankenhausverwaltung keine Bereitschaft besteht, durch zusätzliche Investitionen neue Kapazitäten zu schaffen.

\section{Niederlassung: der Arzt als Unternehmer und Investor}

Die ambulante Versorgung ist dagegen durch folgende Elemente gekennzeichnet:

- Freiberuflichkeit: Der niedergelassene Arzt muss gleichzeitig Arzt und Unternehmer sein, alle anderen Ansätze führen mehr oder weniger in finanzielle Engpässe oder sogar in die Illiquidität.

- Flexibilität: Der niedergelassene Arzt ist freier in seinen Investitionsentscheidungen, die Praxisführung erfolgt in Personalunion als Arzt und Investor. Die Personalführung erfolgt weit flexibler und individueller. Erfolg und Einsatz wirken sich unmittelbarer aus.

- Kostenvorteile: Die niedergelassene Praxis hat aufgrund ihrer Flexibilität Kostenvorteile gegenüber dem Krankenhaus, teilweise auch bedingt durch geringere Vorhaltekosten (Sicherstellung nur während der Praxisöffnungszeiten).

\section{Outsourcing: Nutzung von Rationalisierungsreserven}

Ist also die Durchbrechung der dualen Versorgung in der einen Richtung nicht gelungen, gibt es in einigen Fächern immer wieder typische Fallkonstellationen für den umgekehrten Weg: Niedergelassene Fachärzte lassen sich am Krankenhaus nieder und sind sowohl ambulant als auch stationär tätig. Dies ist in der Radiologie inzwischen nicht selten, gefördert auch durch die Großgeräte-Bedarfsplanung aus den 90er Jahren, als die Krankenhaus-Bedarfsplanung diesen Weg ausdrücklich vorsah. In derartigen Fällen kommt es zunächst häufig zu einer Übernahme der Krankenhausausstattung. Dies ist meist ein Zwischenstadium, als Endlösung entspricht es in der Regel nicht den Interessen beider Seiten: Der 
Freiberufler-Arzt will selbst entscheiden, das Krankenhaus will sich gedanklich von der Unternehmerschaft in diesem Bereich verabschieden. Die Konsequenz: Der Arzt investiert.

Die Gründe für das Outsourcing sind bekannt: Gerade in den investitionsintensiven Fächern können erhebliche Rationalisierungsreserven genutzt werden, wenn die Geräte besser ausgelastet sind. Managementverantwortung kann abgegeben werden, an den Vorteilen der freiberuflichen Ressourcennutzung kann auch das Krankenhaus partizipieren.

Folgende Wettbewerbsfelder sehen wir für Krankenhäuser und ambulante Fachärzte: Onkologie, Dialyse, Labor, Pathologie, Strahlentherapie, Nuklearmedizin, Radiologie.

\section{Wie geht es im ambulanten Bereich weiter?}

Die rot-grüne Koalition hat sich für diese Legislaturperiode folgende Maßnahmen vorgenommen:

- Die integrierte Versorgung soll bei chronischen Krankheiten zur Regelversorgung werden.

- Das Sicherstellungsmonopol der Kassenärztlichen Vereinigungen soll gebrochen und die Möglichkeit geschaffen werden, Einzelverträge zwischen Kosten- und Leistungsträgern zu schließen.

- Die Kassenärztlichen Vereinigungen sollen als Dienstleister profiliert werden.

- Gesundheitszentren nach dem „Vorbild“ der Polikliniken aus den neuen Ländern sollen auch im Westen etabliert werden mit der Möglichkeit, angestellte Ärzte zu beschäftigen.

- Der Hausarzt soll Lotse im System sein.

- Hausärzte sollen morbiditätsorientiert, Fachärzte diagnoseorientiert nach Fallpauschalen vergütet werden, ähnlich wie im Krankenhaus mit den DRGs.

Dies alles ist mit dem gegenwärtigen Vergütungssystem nicht realisierbar. Es ist allgemeine Meinung, dass vor Abschaffung der sektoralen Budgets eine Durchlässigkeit der Bereiche ambulant/stationär nicht durchgesetzt werden kann. Der Facharzt ist schließlich einer „Vergü- 
tungshierarchie" ausgesetzt (viele Sonderentgelte gehen im Vorfeld ab), bevor er sein Honorar sozusagen als Restgröße in dieser Kette erhält.

Zur geplanten Maßnahme, das Monopol der Kassenärztlichen Vereinigungen aufzubrechen, ist außerdem noch wichtig: Die Bedarfsplanung darf nicht unterlaufen werden, es geht nur mit zugelassenen Vertragsärzten. Im Übrigen wird man davon ausgehen können, dass Einzelverträge insbesondere die Bereiche ambulantes Operieren, Impfen, Labor, Radiologie, Nuklearmedizin und Strahlentherapie betreffen werden.

\section{Welche Folgen werden die DRGs im Krankenhaus haben?}

Absicht des Gesetzgebers ist es, durch wirtschaftliche Optimierung der stationären Versorgung die Finanzierbarkeit der gesetzlichen Krankenversicherung langfristig zu sichern. Mittel dazu sind die DRGs. Es ist bereits jetzt absehbar, dass dies zu einer Spezialisierung der Krankenhäuser führen wird, verbunden mit längeren Wegen für den Patienten, der ein solches Krankenhaus aufsuchen muss. Liegezeitverkürzung ist danach die einzige Handlungsmaxime für die Krankenhäuser. Dies bedeutet eine diametrale Abkehr vom gegenwärtigen System der Vergütung nach Pflegesätzen.

Im Hinblick auf den Weg des Patienten durch das Krankenhaus und die Kostenminimierung werden die Krankenhäuser darauf achten, dass der Patient nach optimaler ambulanter Vorbereitung - vor allem in der bildgebenden Diagnostik - in das Krankenhaus kommt. Lässt sich dies nicht durchführen (z. B. bei Akutfällen), wird die rechtzeitige und schnelle Diagnose einen ganz neuen Stellenwert für eine effiziente Behandlung erhalten. Die Krankenhäuser werden ihre eigene ambulante Tätigkeit reduzieren, sie werden nach Möglichkeit versuchen, niedergelassene Fachärzte ans Krankenhaus zu holen, um sich einen entsprechenden Einzugsbereich zu sichern. Wo die räumliche Nähe es nicht zulässt, wird sich der zunehmende Einsatz der Telemedizin auswirken.

\section{Welche Chancen haben Krankenhaus-Kooperationen?}

Der Wettbewerb unter den Krankenhäusern wird zunehmen. Dabei wird es um Einweiser-Potentiale niedergelassener Fachärzte an das Krankenhaus gehen. Es wird feste Honorarvereinbarungen zwischen den Beteiligten geben. Diese werden einen Ausgleich für sinkende Punktwerte bei Honorierung nach EBM und HVM bringen. Dabei ist nicht zu unterschätzen, dass eine Krankenhauspraxis einen Statusvorteil gegenüber einer anderen niedergelassenen Praxis haben kann. 
Die Perspektiven für Fachärzte lassen sich folgendermaßen umreißen:

- Wir werden vom Einzelvertragsarzt Abschied nehmen müssen.

- Die Leistungserbringung wird durch Teamärzte und in beiden Bereichen - sowohl ambulant als auch stationär - erfolgen.

- Die Beteiligten werden in Arztnetze eingebunden sein.

- Die Arzt-Patienten-Bindung wird lockerer.

- Für die klinischen Methodenfächer werden sich vergleichsweise geringere Umstellungen ergeben als für die anderen „Organ“-Gebietsärzte.

\section{Welche Erwartungen gehen an die Politik?}

Aus den genannten Gründen sollte die Politik die Daseinsberechtigung niedergelassener Fachärzte akzeptieren. Dies nicht als Selbstzweck, sondern um deren Kompetenz und wirtschaftliche Praxisführung zu nutzen. Unabdingbar muss aber - auch aus Wettbewerbs-Gesichtspunkten - die finanzielle Chancengleichheit sein, für die die duale Krankenhausfinanzierung und vor allem die unterschiedliche Honorierung immer noch ein wesentlicher Hemmschuh ist. Die statusrechtlichen Rahmenbedingungen müssen geschaffen werden, sowohl im Zulassungs-, Steuer- als auch im Berufsrecht.

Manko ist auch, dass das Zulassungsrecht und auch die Rechtsprechung, die sich am geltenden Recht orientieren muss, nicht Rücksicht nimmt auf ärztliche Zusammenschlüsse. Solange das System den Einzelarzt immer noch wie den Partner einer Gemeinschaftspraxis gleich behandelt, kann eine rationalisierte Leistungserbringung nicht stattfinden. Dies gilt insbesondere für die klinisch methodendefinierten Fächer. Für diese ist auch ein verzahnter Versorgungsauftrag für lokale Versorgungsbereiche (Versorgungssitz) geeigneter als das Zulassungsrecht mit gerade in den kleineren Fächern wenig aussagefähigen Planzahlen in der Bedarfsplanung.

Im Steuerrecht ist bisher die Großgerätenutzung von Niedergelassenen an Krankenhausgeräten umsatzsteuerbegünstigt, nicht jedoch der umgekehrte Fall. Partnerschaftlichen Kooperationen zwischen Krankenhäusern und niedergelassenen Ärzten steht die Gewerbesteuerpflicht von Nichtärzten im Wege. Das gleiche gilt für den sonstigen Leistungsaus- 
tausch wie Personal oder Material, die jeweils regelmäßig wegen Vorliegens eines Leistungsaustausches zur Umsatzsteuerpflicht führen.

\section{Fazit für die Radiologie}

$\mathrm{Ob}$ in der Niederlassung, im Krankenhaus oder zwischen beiden Bereichen: Gerade im Zuge der größer werdenden Gemeinschaftspraxen und neuen Kooperationsformen müssen wir wegkommen von dem häufig immer noch anzutreffenden „Einzelkämpfertum". Teamfähigkeit und partnerschaftliches Denken sind gefragt. Wenn diese Bereitschaft nicht da ist, ist ein Scheitern vorprogrammiert. Das wissen wir aus leidvoller Erfahrung.

Es wird außerdem darauf ankommen - und dies sei an die Politik gerichtet -, bei der Vergütung gleiche Rahmenbedingungen zwischen Krankenhaus und Niederlassung zu schaffen. Es kann nicht angehen, dass gleiche Leistungen unterschiedlich vergütet werden.

Und ein Letztes: Wir brauchen einen Schutz für Minderheiten, für die kleinen Facharztgruppen wie die Radiologen. Den Egoismen der großen Gruppen, sich einen unverhältnismäßig hohen Anteil aus dem Honorartopf zu sichern, muss ein Ende gemacht werden. 


\section{Der Leistungskatalog der GKV im Wandel - Anmerkungen aus praktischer Sicht}

Alfred Holzgreve

\section{Koordinierungsprobleme im deutschen Gesundheitssystem}

Wenn wir über die Zukunft der GKV sprechen, dann geht es nicht nur um die Ausgabendynamik und die Einnahmenschwäche, sondern vor allem auch um vielfache Koordinierungsprobleme im deutschen Gesundheitssystem. Das Thema "Schnittstellen zwischen den einzelnen Bereichen im Gesundheitssystem" ist so alt wie die Diskussion um das deutsche Gesundheitswesen überhaupt. Es ist erstaunlich, wie gleichbleibend seit vielen Jahren immer wieder die Nachteile durch die Abgrenzung der Sektoren gegeneinander in Deutschland betont werden. Auffallend ist nur, dass die Analysen seit langer Zeit gleich sind, sich aber offensichtlich bisher an den Koordinierungsproblemen nur sehr wenig geändert hat.

In der nächsten Zeit gibt es jetzt zum ersten Mal die berechtigte Hoffnung, dass die Zergliederung des deutschen Gesundheitssystems effektiv zum Thema gemacht wird und es endlich in vielfacher Weise eine Überwindung der Sektoren gibt, die zu einer echten integrierten Versorgung führt im Sinne der Patienten mit Qualitätsverbesserung in Diagnostik und Therapie und Steigerung der Effizienz und Wirtschaftlichkeit.

\section{Schnittstellenprobleme}

Die Ist-Situation weist vielfältige Koordinierungsdefizite in Deutschland auf. Schon innerhalb der Sektoren gibt es sie: z. B. im Krankenhaus zwischen den Gastroenterologen und den Visceralchirurgen, zwischen den Radiologen und den Gefäßchirurgen, zwischen den Pädiatern und den Kinderchirurgen usw. Hier sind die Stichwörter zur Verbesserung der Situation: interdisziplinäre Leitlinien der medizinischen Fachgesellschaften, Prozessablaufoptimierungen, problemorientierte Zentren usw.

Auch im ambulanten Sektor gibt es Koordinationsdefizite: z. B. zwischen Internisten und onkologischen Schwerpunktpraxen, zwischen Hausärzten und Fachärzten usw.

Bekannter und gravierender sind jedoch die Schnittstellenprobleme zwischen den Sektoren: zwischen Krankenhaus und den Rehaeinrichtungen, zwischen Krankenhaus und den ambulanten Diensten, zwischen 
Hausarzt und Krankenhaus, zwischen Hausarzt und Facharzt, zwischen Hausarzt und Krankenhaus auf der einen Seite und allen komplementären Einrichtungen auf der anderen Seite (Selbsthilfegruppen, Beratungseinrichtungen, Geriatrieeinrichtungen, Altersheimen usw.).

\section{Doppelstruktur der Fachärzte}

Eine besondere Berufsgruppe ist die der Fachärzte, da es sie gleichzeitig in zwei Sektoren des deutschen Gesundheitssystems gibt: im Krankenhaus und im ambulanten Sektor. Hier hat sich tatsächlich eine echte Doppelstruktur etabliert, die einmalig ist und die ein Wettbewerbsfeld geschaffen hat, in dem zwei getrennte Arztgruppen, die in der Qualifikation völlig identisch sind, zum großen Teil um dieselben Patienten konkurrieren.

Wettbewerb an sich ist natürlich nichts Schlechtes, aber dieser Wettbewerb zwischen zwei identischen Berufsgruppen in getrennten Sektoren ist schädlich, da er Doppelstrukturen nötig macht, teure Infrastrukturen parallel aufbaut, für die Patienten immer wieder unnötige Mehrfachuntersuchungen provoziert und letztendlich kostbare Ressourcen sinnlos vergeudet.

Es spricht vieles dafür, diese Doppelstruktur in Deutschland endlich abzuschaffen, so dass sich die Fachärzte in Zukunft - obwohl sie in beiden Sektoren dieselbe ärztliche Tätigkeit ausführen - nicht mehr vor Berufsbeginn für einen der Sektoren entscheiden müssen. Für beide Facharztgruppen ergeben sich nach Abschaffung der Doppelstruktur gleichermaBen nur Vorteile.

In der heutigen Zeit spricht nichts mehr dagegen, die Doppelstruktur aufzulösen und die Fachärzte zusammenzuführen; es sind auch keine Nachteile mehr durch die Abschaffung der Doppelstruktur im deutschen Gesundheitswesen zu erwarten, da sich inzwischen die Rahmenbedingungen geändert haben. Sowohl ökonomisch als auch medizinisch qualitativ gibt es im Sinne der Patienten keinen Grund mehr für die Doppelstruktur der Fachärzte.

Wichtig ist nur, dass der Veränderungsprozess sich nicht dirigistisch, sondern dynamisch im Wettbewerb vollzieht und die Patienten letzten Endes selbst frei entscheiden können, in welcher Struktur sie ihren Facharzt aufsuchen wollen.

Warum haben wir überhaupt Doppelstrukturen bei den Fachärzten in zwei verschiedenen Sektoren? 
Selbstverständlich ist das nicht. Sachlich begründbar ist es heute auch nicht mehr. Schon allein die Tatsache, dass es diese Struktur in vielen anderen Ländern, in denen das Gesundheitssystem genauso gut oder sogar besser als in Deutschland funktioniert, nicht gibt, spricht dagegen, dass es so sein muss wie in Deutschland. Der wesentliche Grund für die Doppelstruktur ist ein historischer. Und wie so oft sind die Bedingungen, die aus guten Gründen irgendwann einmal zu etwas geführt haben, heute schon lange nicht mehr da, und deswegen hat sich auch die Sache selbst überlebt und beinhaltet heute mehr Nach- als Vorteile.

\section{Historische Gründe für die Doppelstruktur}

Die Ursprünge der in Deutschland gewachsenen Struktur gehen weit in das vorige Jahrhundert zurück. Krankenhäuser haben sich aus Siechenheimen, also mildtätigen Einrichtungen, entwickelt, welche - ähnlich wie heute Seniorenzentren oder so genannte Altersheime - nicht durch fest angestellte Ärzte versorgt wurden. Die Patienten brachten sich sozusagen ihre Ärzte zur individuellen Weiterbetreuung in das Krankenhaus mit. Das Krankenhaus wurde wegen der Notwendigkeit einer „Krankenhauspflege" aufgesucht; nicht etwa, weil es im Krankenhaus einen besonderen fachlichen Ärzteverstand oder besondere bzw. höherwertige medizinische Prozeduren gab.

Erst Ende des 19. Jahrhunderts, Anfang des 20. Jahrhunderts, erhielten niedergelassene Ärzte einen festen Vertrag mit den Krankenhäusern und wurden so immer enger an das Krankenhaus gebunden. Danach begann allmählich eine „Aufrüstung" des Krankenhauses auf medizinischem Gebiet durch die Weiterentwicklung in der Medizin, umfangreichere Medizintechnik usw. Es wurden den niedergelassenen Vertragsärzten immer mehr „ärztliche Gehilfen“ an die Seite gestellt - Assistenzärzte und Oberärzte, die nur noch im Krankenhaus beschäftigt waren,. Alle Assistenz- und Oberärzte durften nur noch Patienten behandeln, die einen Behandlungsvertrag mit dem Krankenhaus hatten, ebenso die Chefärzte (also die, die vertraglich als Niedergelassene an das Haus gebunden wurden). Diese Chefärzte allerdings durften weiter auch noch ihre eigenen „Privatpatienten“ im Krankenhaus behandeln.

Alle Ärzte im Krankenhaus waren somit zum ersten Mal im Status eines "Erfüllungsgehilfen" des Krankenhausträgers und nicht etwa mehr freie Ärzte oder Niedergelassene, die das Krankenhaus nur nutzten, wenn es von der Pflege her notwendig war. 


\section{Fachliche Spezialisierung in den Krankenhäusern}

1960 waren etwa 22.600 Ärzte im Krankenhaus beschäftigt. Seit den 50er Jahren, verstärkt in den 60er und 70er Jahren, passierte dann in allen Krankenhäusern in Deutschland eine medizinisch-fachliche Spezialisierung und eine massive technische Aufrüstung, so dass im Jahre 1980 bereits 65.200 Ärzte im Krankenhaus beschäftigt waren (davon etwa 9.500 als leitende Ärzte bzw. Chefärzte). Insgesamt gab es also fast dreimal so viele Ärzte innerhalb von 20 Jahren im Krankenhaus als 1960.

Die Krankenhausgesetzgebung hat zu all den Entwicklungen maßgeblich beigetragen und diese bewusst gefördert, insbesondere die Gesetze zur Krankenhausfinanzierung. Spätestens seit 1980 war bei insgesamt 3.200 Krankenhäusern flächendeckend eine gute, hoch gerüstete Facharztstruktur in allen Krankenhäusern Deutschlands etabliert mit den besten Geräten und der besten Technik.

Von den 65.200 Krankenhausärzten im Jahre 1980 hatten nur die etwa 9.500 Chefärzte eine unbegrenzte Lebensposition erhalten, während die Oberärzte entweder auf den Aufstieg zum Chefarzt warteten oder aber wie die meisten Assistenzärzte nach Erreichen des Facharztes in die freie Praxis als Kassenarzt strebten.

\section{Ausbau der Facharztstruktur im ambulanten Sektor}

Da es über Jahre eine sehr hohe Zahl von Absolventen gab in den Krankenhäusern gab, die zum Facharzt ausgebildet wurden, hat das Krankenhaus selbst durch die immer mehr zunehmende "Produktion" direkt die immer größer werdende Facharztdichte im niedergelassenen Bereich gefördert und überhaupt erst möglich gemacht. 1980 waren bereits im niedergelassenen Sektor über die Hälfte der Ärzte Fachärzte für ein Spezialgebiet: von 62.000 etwa 34.000 (während es 1960 noch fast dreimal so viele Nichtfachärzte wie Fachärzte bei den Niedergelassenen gab). Heute (2001) sind von fast 130.000 niedergelassenen Ärzten nur 10.000 Nichtfachärzte. Die Spezialisierung ist also im niedergelassenen Sektor viel weiter als im Krankenhaus vorangetrieben worden, so dass man in diesem Sinne auch von einer Überspezialisierung sprechen kann. Im Krankenhaus sind noch heute weit über die Hälfte der Ärzte „nur Assistenzärzte", und nur die Hälfte aller Ärzte im Krankenhaus haben eine Facharzt-Anerkennung. Insofern ist die Spezialisierung bzw. Überspezialisierung im ambulanten Sektor entgegen der herkömmlichen Meinung eklatanter ausgeprägt als im Krankenhaus. 
Die „Aufrüstung“ im niedergelassenen Bereich (sowohl bezogen auf die Anzahl der Fachärzte als auch auf die medizinisch-technische Ausrüstung der Praxen) stimmte damals mit der Philosophie überein, die von einer kompletten ärztlichen Versorgung im ambulanten Sektor (bezogen auf alle Fachgebiete) neben den Strukturen im Krankenhaus ausging. Bis weit in die 80er Jahre hinein bestand die Auffassung, dass von der Grundversorgung bis zur ausdifferenzierten Spitzenversorgung (natürlich einschließlich der kompletten Medizintechnik) im ambulanten Sektor alles vorgehalten werden müsse, was die medizinische Wissenschaft entwickelte.

Auch die öffentliche Meinung hat diesen Prozess damals intensiv gefördert: Am Ende der 60er Jahre und in den 70er Jahren wurde den niedergelassenen Ärzten vorgeworfen, sowohl vom "Know-how" als auch von der Ausrüstung der Praxen her ein unzureichendes Angebot an ärztlichen Leistungen vorzuhalten. Unter dem Slogan "Opas Praxis ist tot" rüsteten daraufhin noch einmal zusätzlich die niedergelassenen Kassenärzte ihre Praxen mit aller zur Verfügung stehenden Medizintechnik auf, was finanziell durch ein Vergütungssystem massiv unterstützt wurde, das durch die Vergütung von Einzelleistungen die Anwendung z. B. der Labor- und Gerätemedizin besonders honoriert. Auch bei den Krankenhäusern gab es natürlich damals den gleichen negativen Effekt durch das entsprechende Finanzierungssystem mit falschen Anreizen und schließlich ähnlichen Fehlentwicklungen.

Endeffekt all dieser historischen Fakten war: Zwei verschiedene Sektoren haben parallel eine flächendeckende Facharztstruktur aufgebaut; beide technisch bestens ausgerüstet und beide Sektoren auf hohem medizinischem Niveau. Zur Verbesserung der Effizienz hat allerdings all dies nicht viel beigetragen, sondern eher zur unnötigen Belastung der Patienten und zu einer gigantischen Ressourcenvergeudung geführt.

\section{Vorteile der augenblicklichen Facharzt-Doppelstruktur}

Seit den 70er Jahren, zunehmend in den 80er Jahren und dann massiv in den 90 er Jahren, ist viel über die Facharzt-Doppelstruktur geredet und geschrieben worden, und immer wieder ist sie als ein Hauptgrund für Ressourcenverschleuderung und Ineffizienz im deutschen Gesundheitssystem benannt worden (gerade auch im Vergleich zu anderen Ländern). Bevor ich aber auf die Kritikpunkte und die heutigen Nachteile dieser historischen Entwicklung eingehe, seien die Vorteile bzw. immer wieder angeführten so genannten Vorteile"dieser Doppelstruktur bei den Fachärzten angeführt. 
Als wesentlicher Vorteil für den Patienten wird angegeben, dass er alle Fachärzte in seiner Nähe hat und somit für alle medizinischen Probleme - gleich aus welchem medizinischen Fachgebiet - der Anfahrtsweg für inn immer sehr kurz ist. Als zweiter Vorteil für den Patienten wird oft angeführt, dass er immer zu demselben Facharzt gehen kann und nicht etwa - wie durchaus im Krankenhaus üblich - von verschiedenen Ärzten behandelt wird. Dadurch könne besser eine persönliche, vertrauensvolle Beziehung aufgebaut werden. Der Patient habe also somit eine freie Arztwahl nicht nur beim Hausarzt, sondern auch beim Facharzt.

Darüber hinaus wird meist vorgebracht, dass die Atmosphäre in einer niedergelassenen Praxis in der Regel sehr viel ruhiger und angenehmer ist als $z$. B. im Krankenhaus, wo oft mehr Hektik vorherrscht, zumindest aber viel mehr Publikumsverkehr ist als in einer einzelnen Praxis.

Als Hauptargument wird aber für einen niedergelassenen Facharzt immer angegeben, dass er die medizinischen Fachleistungen deutlich preisgünstiger und ökonomisch effizienter als im Krankenhaus erledige natürlich bei gleich hoher Qualität. Hierdurch würden ohne Qualitätsverlust Beitragsgelder gespart, was für die Patienten letzten Endes ein ganz wichtiger Vorteil sei, da nur so die Krankenkassen ausreichend Geld für wirklich notwendige, aber sehr kostenintensive Behandlungen im Krankenhaus hätten.

Meiner Ansicht nach ist es nicht mehr erlaubt, von diesen genannten Vorteilen zu sprechen, da es sie zum großen Teil nicht mehr gibt. Wenn ich z. B. auf den so genannten Hauptvorteil eingehe, dass der niedergelassene Facharzt die medizinischen Leistungen effizienter und kostengünstiger erbringe als der entsprechende Facharzt am Krankenhaus, mag dies vielleicht heute noch in Einzelfällen stimmen.

Dies ist aber zumindest in Zukunft irrelevant, da natürlich der Krankenhausfacharzt nur dasselbe Geld für die Behandlung bekommen darf wie der Niedergelassene. Wenn die Erstattungen für eine fachärztliche Behandlung gerade einmal kostendeckend sind, hat auch der Krankenhausarzt in Zukunft überhaupt keine andere Chance als die, genauso kostengünstig zu arbeiten wie der niedergelassene Arzt im ambulanten Sektor. In Zukunft ist durch eine diagnose- und behandlungsbasierte einheitliche Bezahlung der Fachärzte im ambulanten Sektor und im Krankenhaus bei gleicher Leistung der finanzielle Aufwand für die Krankenkassen völlig identisch. Außerdem sind schon heute an vielen Krankenhäusern bereits „ambulante Zentren“ eingerichtet worden und an weiteren gerade geplant oder kurz vor der Fertigstellung, die personalmäßig und vom Aufwand her genauso betrieben werden wie es die nie- 
dergelassenen Ärzte in ihrer Praxis und in ihren Praxiskliniken auch machen. Die ambulanten Zentren in den Krankenhäusern werden inzwischen sogar sehr gern von niedergelassenen Ärzten angemietet, da diese wissen, dass man hier mittlerweile alle Voraussetzungen hat, um genauso kostengünstig zu arbeiten wie im ambulanten Sektor. Gleichzeitig wird durch diese neuen Krankenhausstrukturen mit speziell eingerichteten „ambulanten Zentren“ erreicht, dass die Atmosphäre im Krankenhaus genauso ruhig und angenehm für die Patienten ist wie in der Praxis.

Der weitere genannte Vorteil des niedergelassenen Facharztes, dass der Patient immer zum selben Facharzt gehen kann, ist inzwischen auch im Krankenhaus weitgehend erreicht; beim Chefarzt ist es sowieso schon immer so, aber auch darüber hinaus haben immer mehr Kliniken bzw. Abteilungen feste Fachärzte in ihrer Ambulanz wie auch bei der prä- und poststationären Versorgung, so dass auch hier die personelle Kontinuität wie bei den Niedergelassenen gewährleistet ist.

Ein weiterer wesentlicher Vorteil, der immer wieder angeführt ist, ist die Wohnortnähe des niedergelassenen Facharztes für den Patienten. Es muss allerdings gefragt werden: ist das wirklich ein wesentlicher Vorteil? Oft ist das Krankenhaus genauso weit entfernt für den Patienten wie der niedergelassene Facharzt (dies gilt insbesondere in großen Städten und in Ballungsräumen). Oft muss der niedergelassene Facharzt den Patienten sogar ohnehin sekundär in eine Klinik oder zu einem anderen Facharzt weiterleiten. Jeder niedergelassene Facharzt hat irgendwo seine Grenzen in seinem Fachgebiet. Im Krankenhaus dagegen hat der Patient alles an einer Stelle, und wenn er nur zu zwei verschiedenen Fachärzten gehen muss - was bei der heute oft durchgeführten multimodalen Therapie überhaupt keine Seltenheit ist -, ist der Weg einmal in ein etwas entfernteres Krankenhaus schon kürzer als zweimal zu verschiedenen, etwas weniger weit entfernten Fachärzten. Wenn der niedergelassene Facharzt ambulante Leistungen am Krankenhausstandort erbringt, was immer mehr geschieht, nimmt er ohnehin den Patienten mit ins Krankenhaus. Also sprechen die Tatsachen nicht dafür, dass die "kurze" Wegstrecke für den Patienten ein wesentlicher Vorteil des niedergelassenen Facharztes ist, schon gar nicht in einer Stadt bzW. Großstadt wie Berlin oder in Ballungsräumen.

Das bisher Gesagte gilt nicht in gleicher Weise für die niedergelassenen Hausärzte, die in der Fläche so wohnortnah wie möglich als Ansprechpartner für alle medizinischen Probleme vorhanden sein sollten, sondern nur für niedergelassene Fachärzte mit medizinischen Spezialgebieten. 
Alle genannten „Vorteile" für die Facharzt-Doppelstruktur sind nur vor einigen Jahren bzw. Jahrzehnten relevant gewesen, heute jedoch in aller Regel nicht mehr, im Gegenteil: Fast alle vermeintlichen Vorteile haben sich inzwischen in Nachteile verkehrt. Selbst wenn es noch kleine Vorteile für die augenblickliche Struktur geben sollte, dann ist diese Doppelstruktur in der heutigen Form trotzdem nicht mehr in Zukunft finanzierbar - was andere Länder viel eher erkannt haben. Spätestens seit den 70er/80er Jahren sind die medizinische Ausrüstung und die Medizintechnik in nahezu jedem medizinischen Fachgebiet so kostenintensiv geworden, dass in Zukunft Doppelstrukturen in Spezialfachgebieten auch in Deutschland nicht mehr finanzierbar sein werden und sich daher von vornherein verbieten.

\section{Nachteile der Facharzt-Doppelstruktur}

Die Nachteile der heutigen Facharzt-Doppelstruktur in Deutschland sind gravierend: Durch die unterschiedlichen Finanzierungssysteme und die unterschiedlichen Interessen der Beteiligten in den getrennten Sektoren geht die Transparenz von Kosten und Leistungen ebenso unter wie jegliche Anreize für deren ganzheitliche Optimierung. Systematisch und auf Dauer bessere Gesamtqualitätsstandards zu erreichen und unnötige Kostensteigerungen zu vermeiden, ist unter den heutigen Bedingungen der deutlich voneinander getrennten Sektoren nur sehr schwer und letztendlich gar nicht zu erreichen. Die heutige Vergütungsstruktur führt im ambulanten Bereich zu einer ungewollten Mengenausweitung (Stichwort:

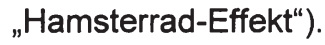

Nicht nur aus Kostengründen sind hier unbedingt Korrekturen erforderlich. Es geht nämlich auch um den Schutz der Patienten vor Doppeluntersuchungen und nicht notwendigen Therapien: Warum gibt es eigentlich so deutlich mehr und nicht begründbare Herzkatheter-Untersuchungen in Deutschland als in vergleichbaren anderen Ländern? Es ist jedenfalls den Ärzten auf die Dauer nicht zuzumuten, ständig mehr "Menge" bzw. Quantität erzeugen zu müssen, nur um ihre Einnahmen stabil zu halten. Warum sind die Mammographien nicht alle auf gleich hohem Niveau? Auch dies hat mit falschen Anreizen zu tun. Es gibt in diesem Zusammenhang viele Beispiele für Fehlsteuerungen: z. B. die Mengenausdehnung bei den Arthroskopien, z. B. die zuviel angefertigten Röntgenbilder usw.

Noch einen anderen Negativeffekt hat das heutige inadäquate Anreizsystem. Der niedergelassene Facharzt erhält heute keinerlei Anreize für eine intensive Zusammenarbeit im Sinne der Patienten mit stationären Leistungserbringern - im Gegenteil: Aus seiner Interessenlage heraus ist 
es günstiger, schwierige und betreuungsintensive Fälle ins Krankenhaus zu überweisen, obwohl sie gar nicht stationär liegen müssten. Denn diese Patienten belasten das gedeckelte ambulante Budget des niedergelassenen Facharztes, ohne für Zusatzeinkünfte zu sorgen.

Bis vor kurzem gab es im Krankenhaus natürlich ebenfalls ein inadäquates Anreizsystem: Die Krankenhäuser hatten kein Interesse, die Patienten frühzeitig aus der stationären Behandlung zu entlassen, da sie dann das Budgetziel an Pflegetagen nicht erreichen konnten und den Umsatz bei gleich bleibenden Kosten noch gesenkt haben. Dieser Fehlanreiz ist jetzt bzw. in Kürze aber nicht mehr vorhanden durch die Abrechnung über DRGs, und viele Krankenhäuser verfahren bereits heute so, als ob es die DRGs-Abrechnung schon gäbe.

Neben dem fehlenden adäquaten Anreizsystem, vernünftig und effizient sektorübergreifend zusammenzuarbeiten im Sinne der Patienten, mangelt es heute vor allem auch an der ganz banalen Kommunikation zwischen den Ärzten beider Sektoren. Es herrscht keine gegenseitige Transparenz (sowohl bei den Kosten als auch bei der Leistung), und es wird auf beiden Seiten nicht gegenseitig der Erfolg bei allen einzelnen Maßnahmen nachgewiesen.

Ein Aufrechterhalten der Doppelstruktur beider Facharztsysteme ist in der heutigen Form in Zukunft mit Sicherheit nicht mehr möglich, da kein Gesundheitssystem doppelt die teure innovative Medizintechnik aufbauen kann, die aber für fachärztliche Spezialdiagnostik und Therapie auf hohem Niveau notwendig sein wird. Es wird in Zukunft nicht mehr akzeptabel sein, dass derartige kostenträchtige medizinische Geräte nicht voll ausgelastet irgendwo stationiert sind, zumal sicher bald die Anreize zur unbegründbaren Mengenausweitung wegfallen werden.

All das hier Gesagte kann nur zu der Schlussfolgerung führen: Die Doppelstruktur muss bei den Fachärzten aufgehoben werden, und es muss zu integrativen sektorübergreifenden Versorgungsstrukturen kommen.

\section{Integrierte sektorübergreifende Versorgungsstrukturen}

Wenn man effektive integrierte sektorübergreifende Versorgungsstrukturen schaffen will, muss man die Dinge bis zu Ende denken und darf nicht „zu kurz springen“, da man so sicher das Problem nicht lösen wird. Bisher wurde aber meist - trotz oft guten Willens - die integrierte Versorgung nicht konsequent und effektiv verwirklicht. Eine sektorübergreifende Versorgungsstruktur ohne Abschaffung der doppelten Facharztgruppen ist ineffektiv und von vornherein zum Scheitern verurteilt. Deswegen 
sind auch alle bisherigen Versuche auf diesem Gebiet in Deutschland in den Anfängen steckengeblieben. Wenn die Doppelstrukturen nicht aufgegeben werden und der Gesamtbehandlungsauftrag (abgesehen von den Hausärzten - aber bei den Hausärzten liegt ja auch keine Doppelstruktur vor) nicht in einer Hand liegt mit einem Budget, können keine nennenswerten Effekte erzielt werden, da die Anreize zu gering sind und es letzten Endes nur bei irgendwelchen Formen des „Verschiebebahnhofs" zwischen den Sektoren bleiben wird.

\section{Nachteile der bisherigen Modelle der integrierten Versorgung in Deutschland}

Unter den neuen gesetzlichen Rahmenbedingungen der letzten Jahre wurde in Deutschland - meist in Modellvorhaben - schon auf verschiedene Art und Weise versucht, eine integrierte spezialärztliche Versorgung mit einer bewusst und überlegt gestalteten Zusammenarbeit von Fachärzten im Krankenhaus und von den niedergelassenen Fachärzten zu erreichen. All diese Versuche mussten natürlich vor dem Hintergrund immer noch sehr enger und vielfältiger Grenzen zwischen den Sektoren gestaltet werden. Beispiele hierfür sind: das Belegarztwesen (an Belegärzte wird allerdings selten von niedergelassenen Ärzten überwiesen), konsiliarische Leistungen von Vertragsärzten in Krankenhäusern, prä-/ poststationäre Versorgung, gemeinsame Großgerätenutzung, Ermächtigungen von Fachärzten in Krankenhäusern durch die KV (allerdings in letzter Zeit oft deutlich eingeschränkt), Zusammenarbeit im Notdienst, Ausgliederung von Abteilungen wie z. B. Pathologie, Labormedizin und Radiologie, vor allem wenn die Abteilung anschließend als Praxis am Krankenhaus geführt und eine vertragsärztliche Tätigkeit der ehemaligen Krankenhausärzte möglich wird. Niedergelassenen Vertragsärzten wird immer öfter angeboten, ihre Praxis in Räumlichkeiten des Krankenhauses bis zur Errichtung eines Ärztehauses auf dem Krankenhausgelände zu betreiben, usw.

Alle genannten Modelle haben sicherlich Vorteile, viele funktionieren auch gut, alle haben auch noch erhebliche Nachteile und stoßen immer wieder an die Grenzen, die noch durch die getrennten Sektoren entstehen. Die weitestgehend integrierte Versorgungsform ist zumindest theoretisch nach dem $\S 140$ SGB V möglich. Allen ist aber bekannt, was es in diesem Zusammenhang immer noch für erhebliche Schwierigkeiten und Differenzen zwischen Theorie und Praxis gibt.

Solange die zwei Sektoren bestehen und, bezogen auf die Fachärzte, eine Doppelstruktur vorhanden ist, wird immer - und dies ist eine Feststellung des "gesunden Menschenverstandes" und gar nicht so sehr eine 
Kritik! - sowohl im niedergelassenen Bereich als auch im Krankenhaus das Handeln zumindest mitgeprägt durch das Bestreben, Besitzstände für den jeweiligen Sektor zu wahren. Auch sollte nicht verschwiegen werden, dass immer dann, wenn bei diesen Modellversuchen finanzielle Anreize für die beteiligten Ärzte fehlen oder sich kaum spürbar auswirken und das ganze "nur" auf Freiwilligkeit beruht, dass dann (auch das sagt der "gesunde Menschenverstand") die beteiligten Ärzte kaum bereit sind, die strukturellen Veränderungen wirklich zu unterstützen und im Sinne des Patienten zum Erfolg zu führen.

In der Vergangenheit waren leider bei der Ausgestaltung wirksamer Anreizsysteme die Kassenärztlichen Vereinigungen nicht gerade immer förderlich. Sie wandten sich immer wieder gegen eine - wie sie es nannten - „Spaltung der niedergelassenen Ärzteschaft" durch Separatverträge zwischen Ärztegruppen und Krankenkassen und damit letztendlich auch gegen echte integrierte Versorgungsmodelle mit einem echten Leistungs- und Effizienzwettbewerb. Ich betone bewusst, in der Vergangenheit war das so: Wenn die Kassenärztlichen Vereinigungen nicht völlig an Bedeutung verlieren und als der große "Verlierer" im deutschen System in Zukunft dastehen wollen, müssen sie sich in dieser Beziehung ändern. Es gibt Anzeichen dafür, manche Optimisten meinen sogar, dass sich die Kassenärztlichen Vereinigungen in Zukunft an die vorderste Front der Bewegung für integrierte Versorgungsformen setzen werden. Insgesamt sieht es jedenfalls so aus, dass in Zukunft echte Modelle entstehen können, die tatsächlich die Sektoren vollständig aufheben und adäquate finanzielle Anreize setzen.

Weitere Nachteile der heutigen Modelle: fehlende Transparenz, Kommunikationsschwierigkeiten (da geht es um nicht vorhandene Software, aber auch um Datenschutz usw.) und viele andere Dinge mehr.

Wichtig ist auch insgesamt bei jeder Form der integrierten Versorgung, dass diese nicht die Angst vor Versorgungsmodellen fördert, die ökonomische Prinzipien über das medizinisch maximal Machbare stellen. Das macht die Bevölkerung niemals mit. Alle Versicherten reagieren empfindlich, wenn der Eindruck entsteht, die Mitgliedschaft oder die Teilnahme an einer integrierten Versorgung könnte sie eventuell im Ernstfall von der besten verfügbaren Behandlung ausschließen.

\section{Sinnvolle Zukunftsstruktur auf dem Facharztsektor}

Wie müsste also nach all dem Gesagten die Zukunft auf dem Facharztsektor, also der medizinischen Spezialbehandlung, aussehen, wenn im Sinne der Patienten unter Qualitätsgesichtspunkten und zum Erreichen 
größter Effizienz und Wirtschaftlichkeit die Grenzen der Sektoren effektiv aufgelöst und die Doppelstruktur der Fachärzte abgeschafft wird? Als oberste Überschrift müsste über allem stehen: Durch die integrierte Versorgung soll es zu mehr medizinischer Qualität bei günstigerem Preis kommen. Niemals darf der Slogan maßgeblich sein: „Preisnachlass durch Einschränkung!"

Die oft genannten, allgemein bekannten Ziele einer integrierten Versorgung sind natürlich die Voraussetzung für jede erfolgreiche Umsetzung: z. B. Vermeidung von Doppeluntersuchungen, Vermeidung von Doppelvorhaltungen, Ablauf- und Prozessoptimierung bei der Diagnostik und Therapie, ambulant vor stationär, Transparenz, gemeinsame Leitlinien, Vernetzung über ein gemeinsames EDV-System, gute Kommunikationsstrukturen, Aufbau von Qualitätszirkeln, Vorbeugungsprogramme, gemeinsame Einkaufsmodelle, gemeinsame Dienstleistungen, Integration von Selbsthilfegruppen, ständige organisierte Fortbildung usw.

Um möglichst viele der genannten Ziele in einem integrierten Versorgungssystem realisieren zu können, müssen folgende Hauptvoraussetzungen erfüllt sein:

1. Es muss einen umfassenden einheitlichen Versorgungsauftrag aus einer Hand geben, der keine sektoralen Grenzen mehr kennt und damit parallele Doppelstrukturen abbaut.

2. Das führende und koordinierende Element kann in diesem System letzten Endes nur das Krankenhaus als Gesundheitszentrum in der Mitte des Systems sein. Aber natürlich müssten partnerschaftliche Strukturen zwischen allen Beteiligten aufgebaut werden.

3. Die Kassen müssen ein Globalbudget mit den beteiligten Ärzten unter der Führung des Krankenhauses als einzigem Verhandlungspartner abmachen, das unabhängig von irgendwelchen KV-Richtlinien ist und durch diese nicht eingeschränkt werden darf.

4. Es darf keine Monopole geben, sondern es muss einen Wettbewerb zwischen diesen integrativen Versorgungsnetzen geben, um möglichst effektive und wirtschaftlich effiziente Strukturen zu schaffen.

5. Die Zahl der beteiligten Ärzte muss vom Krankenhaus in Übereinstimmung mit den beteiligten niedergelassenen Ärzten festgelegt und begrenzt werden, so wie es dem Leistungsbedarf entspricht. 
6. Die interne Vergütung darf nur nach krankheitsbezogenen und schweregradgewichteten Gesamtpauschalen vorgenommen werden und nicht etwa durch die Vergütung von diagnostischen und therapeutischen Einzelmaßnahmen.

7. Das System muss mindestens das Krankenhaus und die niedergelassenen Fachärzte umfassen. Es sollte später durch ambulante Rehaeinrichtungen und weitere Versorgungsbereiche ergänzt werden (Pflege, Info-Betreuungsangebote, Prävention usw.) - also im Sinne eines Disease-Managements.

8. Eine umfassende integrierte Versorgung müsste auch die Hausärzte mit einschließen. Dies ist aber nicht in der gleichen Struktur wie bei den Fachärzten notwendig, da es bei den Hausärzten ja nicht um Doppelstrukturen geht. Allerdings müsste in jedem Fall eine enge, organisierte Zusammenarbeit vorhanden sein, wenn auch nicht in der oben beschriebenen Strukturform.

9. Alle Leistungen müssten exakt dokumentiert und sowohl bezogen auf die Prozedur als auch auf das medizinische Ergebnis regelmäBig den Kassen, den Patienten und auch den anderen Anbietern zugänglich gemacht werden.

10. Hauptziel bleibt: jede Über-, Fehl- und Unterversorgung muss vermieden werden. Das bedeutet, dass alle beteiligten Ärzte nur nach gemeinsamen Leitlinien sowohl bei der Diagnostik als auch bei der Therapie und beim gesamten Case-Management vorgehen können.

$\mathrm{Zu}$ einigen der genannten Punkte sind etwas genauere Ausführungen notwendig, zumal sicher einige Aussagen kontrovers gesehen werden können oder sogar - je nach Standpunkt - massiv abgelehnt werden: Dass der Versorgungsauftrag in einem derartigen integrierten Versorgungssystem umfassend und einheitlich sein muss, ist evident, da jede Art der Splittung die Sektorengrenzen bestehen lassen würde. Es würden interne Abgrenzungskonflikte und "Verschiebebahnhöfe" entstehen und bestehen bleiben, und letzten Endes würde im Sinne des Patienten keine echte integrierte Versorgung entstehen. Wenn es aber einen einheitlichen Versorgungsauftrag gibt, dann muss dort letzten Endes auch nur einer "den Hut aufhaben", damit das Ganze ein Erfolg wird. Dies könnten theoretisch die niedergelassenen Ärzte bzw. die Kassenärztlichen Vereinigungen sein, indem der bestehende Sicherheitsauftrag auch auf die ärztlichen Leistungen im stationären Sektor erweitert wird. Ich glaube aber, dass dieses eine Überforderung der KV wäre. Auch eine neu geschaffene "Krankenhaus-KV“ wäre kontraproduktiv. 
Es bleibt also nur das Krankenhaus, das in jedem Fall die Infrastruktur für alle fachärztlichen Spezialmaßnahmen in der Diagnostik und Therapie vorhält und immer der natürliche Kristallisationspunkt einer echten integrativen Versorgung sein wird. Auch bei integrierten Versorgungsformen bleibt für den Patienten zunächst nach wie vor die Wahlfreiheit bestehen, sich den Facharzt in der Fläche aus dem niedergelassenen Bereich oder in dem Krankenhaus auszusuchen. Das können bisher nur die "Privatpatienten", auch wenn der Arzt oder Chefarzt keine kassenärztliche Ermächtigung hat. Da aber viele Privatpatienten die Facharztkompetenz am Krankenhaus schon jetzt in Anspruch nehmen, kann man davon ausgehen, dass sie in der Regel von den Patienten als nicht schlecht angesehen wird. Warum sollten nicht alle Patienten diese Wahlmöglichkeit haben und nicht nur, wie bisher, die Privatpatienten?

Wichtig ist bei der Schaffung einer echten integrativen Versorgung nicht, dass die Fachärzte aus der Fläche verschwinden. Dies ist auch nicht das Ziel, sondern vielmehr, dass eine Einheit der Fachärzte entsteht - egal, ob sie am Krankenhaus oder in einer niedergelassenen Praxis arbeiten. Damit wäre die durch die Sektionen begrenzte Doppelstruktur aufgegeben, es wäre nur noch weiterhin so, dass einige Fachärzte am Krankenhaus, einige in der Fläche in einer Praxis angesiedelt sind. Für die Patienten würden aber alle Nachteile der Schnittstellenproblematik zwischen den beiden Sektoren verschwinden.

Die Frage, ob in der Fläche mehr oder weniger Fachärzte angesiedelt sein müssen als heute, ist nicht entscheidend. Vieles spricht dafür, dass in Ballungsgebieten eine flächenhafte Facharztstruktur nicht notwendig ist. Aber dies wird die Zukunft zeigen; es könnte auch sehr gut sein, dass es durch die immer teurer werdende Medizintechnik in Zukunft gar nicht mehr finanzierbar ist, die aufwendige Infrastruktur im Krankenhaus noch einmal parallel bei den niedergelassenen Fachärzten in der Fläche abzubilden. Dies würde dazu führen, dass nach Auflösung der Sektoren sich automatisch immer mehr Fachärzte aus der Fläche zum Krankenhaus hin konzentrieren würden.

Eine umgekehrte Entwicklung ist übrigens nicht möglich, da die Krankenhäuser für komplexe und schwierige Behandlungen in jedem Fall die Infrastruktur benötigen. Insofern ist die Entwicklung, zumindest bezogen auf medizinische Fachgebiete, mit notwendiger, sehr teurer Medizintechnik vorgezeichnet, z. B. für Radiologen, Nuklearmediziner, Strahlentherapeuten usw. Ein anderer Nebenaspekt, der für die Krankenhäuser spricht, ist noch die vorhandene Infrastruktur als Knotenpunkt mit einem Krankenhaus-Informationssystem, das bereits jetzt schon viele ver- 
schiedene Teilnehmer hat und nur die zusätzlichen Fachärzte in der Fläche anbinden muss.

Das wohl beste Argument für ein Krankenhaus im Sinne des Patienten, bezogen auf die Facharztvorhaltung, ist allerdings die vorhandene Vielfalt an einem Ort, d. h. in der Regel auf einem räumlichen Gelände: Alle Fachärzte sind direkt nebeneinander angesiedelt, was für die Patienten natürlich bei den immer häufiger notwendigen multimodalen Therapien bei vielen Krankheitsbildern für die Gesamtbehandlung sehr kurze Wege bedeutet.

Ein typisches Beispiel für die oft interdisziplinäre Behandlung ist auch die Notfallbehandlung. Es ist interessant, dass in diesem Zusammenhang der vertragsärztliche Bereich niemals die ambulante Notfallversorgung durch die Krankenhäuser in Frage gestellt hat, obwohl ja gerade hier eine Wohnortnähe günstig und komfortabel für die Patienten wäre.

\section{Zusammenfassung und Ausblick}

Die Doppelstruktur der Fachärzte sollte so schnell wie möglich aufgehoben werden, womit gemeint ist, dass innerhalb der Fachärzteschaft keine Sektorengrenze mehr sein sollte. Es muss eine echte integrierte Versorgung zwischen dem Krankenhaus und den Fachärzten etabliert werden mit einem Budget, wobei der eigentliche Vertragspartner der Kassen das Gesundheitszentrum Krankenhaus zusammen mit den Fachärzten ist. Ob immer Fachärzte in der Fläche bleiben oder nur am Krankenhaus, ist nicht entscheidend. Wahrscheinlich werden sich aber durch die notwendigen teuren Infrastrukturen auf die Dauer immer mehr Fachärzte am Krankenhaus ansiedeln. In Ballungsgebieten wäre dies auch für die Patienten überhaupt kein Nachteil. In jedem Fall muss es bei der integrierten Versorgung ein einheitliches Globalbudget zwischen den Kassen auf der einen und den Krankenhäusern und allen anderen im Netzwerk Beteiligten (insbesondere den Fachärzten) auf der anderen Seite geben.

Hausärzte, die keine Doppelstruktur aufweisen wie die Fachärzte, sollten nicht auf die gleiche Weise strukturell in dieses System eingebaut werden. Um aber die Schnittstelle zu den Hausärzten problemfrei zu gestalten, können auch diese in ferner Zukunft mit in das Gesamtbudget genommen werden, ebenso wie Rehaeinrichtungen usw.

Pauschalierte krankheitsbezogene und sektorübergreifende Honorarsysteme, so genannte kombinierte Budgets, führen zu einer geringeren Mengenausweitung als ein Einzelleistungs-Vergütungssystem, so dass kostentragende Doppeluntersuchungen oder nicht notwendige Kranken- 
hauseinweisungen unterbleiben. Die in diesem Zusammenhang notwendige Vereinbarung von Leitlinien fördert eine rationale Krankenversorgung, ein echtes positives Disease-Management.

Die Fachärzte in diesem System der integrierten Versorgung sind genauso wichtig wie vorher, sie werden auch nicht zwischen dem Krankenhaus und den Hausärzten „zerrieben“, sie sind vielmehr nur zusammengeführt. Es verläuft keine Sektorengrenze mehr innerhalb der Fachärzte, und Nachteile der Doppelstruktur im deutschen Facharztsystem sind im Sinne der Patienten beseitigt.

Die Aufgabe wird es jetzt sein, festzulegen, welche medizinischen Fachgebiete in Zukunft nach Auflösung der Doppelstruktur noch in der Fläche vorhanden sein sollten und welche mehr und mehr an den Standort des Krankenhauses konzentriert werden sollten. Wichtig bleibt, dass diese neuen Strukturen nicht dirigistisch von oben vorgegeben werden, sondern im Wettbewerb entstehen und sich bewähren müssen. Nur so können die Krankenkassen sich für Behandlungsaufträge an die qualitativ und ökonomisch besten Anbieter wenden und damit effizient im Sinne der Patienten agieren.

Welche Strukturen endgültig in den jeweiligen Regionen entstehen, sollten uns die Patienten selbst durch ihre "Abstimmung mit den Füßen" vorgeben. Auf diese Weise werden am ehesten lokale Begebenheiten ausreichend berücksichtigt. Möglicherweise werden die Strukturen der integrativen Versorgungen am Ende auch auf dem Lande anders aussehen als in den Ballungsräumen und in den Städten. Möglicherweise werden neu gebaute "Teleportalkliniken" mit einer Konzentration an Fachärzten (siehe Konzept der Rhön-Kliniken) neben Netzwerken ohne Schaffung neuer baulicher Strukturen, die die bereits vorhandenen $\mathrm{Ge}$ gebenheiten nutzen (siehe Konzept von Vivantes), und viele weitere Modelle die verschiedenen Ausprägungen der zukünftigen integrativen Versorgung ausmachen. Alle Verantwortlichen im deutschen Gesundheitssystem sollten ab jetzt dazu beitragen, die Voraussetzungen zu schaffen, die für eine echte integrative Versorgung mit Überwindung der heute vorhandenen sektoralen Grenzen notwendig sind. 


\section{Verzeichnis der Referenten}

Ahrens, Dr. iur. Hans Jürgen

Altland, Dr. med. Helmut

Bausch, Dr. med. Jürgen

Cassel, Prof. Dr. rer. pol. Dieter

Ganten, Prof. Dr. med. Detlev

Hoberg, Dr. rer. pol. Rolf

Holzgreve, Prof. Dr. phil. Dr. med. Alfred

Jacobs, Dr. rer. pol. Klaus

Klusen, Prof. Dr. rer. oec. Norbert

Knappe, Prof. Dr. rer. oec. Eckhard

Knieps, Franz

Laschet, Helmut

Leienbach, Dr. rer. pol. Volker

Meusch, Andreas

Münch, Eugen
Vorsitzender des Vorstandes des AOK Bundesverbandes, Bonn

1. Vorsitzender des Berufsverbandes der Deutschen Radiologen, Siegburg

Ehrenvorsitzender der Kassenärztlichen Vereinigung Hessen, Frankfurt

Lehrstuhl für Wirtschaftspolitik an der Universität Duisburg, Duisburg

Vorsitzender des Max-Delbrück-Centrums für Molekulare Medizin Berlin-Buch in der Helmholtz-Gemeinschaft e.V., Berlin

Stellvertretender Vorsitzender des Vorstandes des AOK Bundesverbandes, Bonn

Regionaldirektor Süd, Klinikum Neukölln, Vivantes Netzwerk für Gesundheit $\mathrm{GmbH}$, Berlin

Wissenschaftliches Institut der AOK, Institutsleitung; Gesundheitspolitik und Systemanalysen, Bonn

Vorsitzender des Vorstandes der Techniker Krankenkasse, Hamburg

Lehrstuhl für Volkswirtschaftslehre, Schwerpunkt Services Administration \& Management an der Universität Trier, Trier

Geschäftsführer Stabsbereich Politik im AOK Bundesverband, Bonn

Stellvertretender Chefredakteur der Ärztezeitung, Berlin

Verbandsdirektor und geschäftsführendes Vorstandsmitglied des Verbandes der privaten Krankenversicherung e.V., Köln

Leiter der Landesvertretungen der Techniker Krankenkasse, Hamburg

Vorsitzender des Vorstandes der Rhön-Klinikum AG, Bad Neustadt 
Oberender, Prof. Dr. rer. pol. Peter Lehrstuhl für Volkswirtschaftslehre der Universität Bayreuth, Bayreuth

Pfeiffer, Dr. Doris

Raffelhüschen, Prof. Dr. sc. pol.

Bernd

Renzewitz, Susanne

Richter-Reichhelm, Dr. med. Manfred

Schönbach, Karl-Heinz

Schulte, Gerhard

Schupeta, Eckhard

Scriba, Prof. Dr. med. Dr. h. c. Peter

Ulrich, Dr. rer. pol. Volker

Wasem, Prof. Dr. rer. pol. Jürgen

Wille, Prof. Dr. rer. pol. Eberhard
VdAK - Verband der Angestellten-Krankenkassen e.V. und AEV - Arbeiter-ErsatzkassenVerband e.V., Siegburg

Direktor des Institutes für Finanzwissenschaft und Volkswirtschaftslehre I, Freiburg

Rechtsanwältin und Leiterin Politik der Deutschen Krankenhausgesellschaft, Berlin

1. Vorsitzender des Vorstandes der Kassenärztlichen Bundesvereinigung, Köln; Vorsitzender des Vorstandes der Kassenärztlichen Vereinigung Berlin, Berlin

Leiter der Hauptabteilung Verträge des Bundesverbandes der Betriebskrankenkassen, Essen

Vorsitzender des Vorstandes des Landesverbandes der Betriebskrankenkassen in Bayern, München

Stellvertretender Vorsitzender des Vorstandes der Deutschen Angestellten Krankenkasse, Hamburg

Mitglied im Sachverständigenrat für die Konzertierte Aktion im Gesundheitswesen, Medizinische Klinik, Klinikum der Universität-Innenstadt, München

Lehrstuhl für Volkswirtschaftslehre, insb. Finanzwissenschaft an der Ernst-Moritz-ArndtUniversität Greifswald, Greifswald

Lehrstuhl für Gesundheitsmanagement an der Ernst-Moritz-Arndt-Universität Greifswald, Greifswald

Vorsitzender des Sachverständigenrates für die Konzertierte Aktion im Gesundheitswesen; Lehrstuhl für Volkswirtschaftslehre, Planung und Verwaltung, öffentliche Wirtschaft an der Universität Mannheim, Mannheim 


\section{Verzeichnis der Teilnehmer}

Ahrens, Dr. jur. Hans Jürgen

Albring, Dr. med. Manfred

Altland, Dr. med. Helmut

Bausch, Dr. med. Jürgen

Becker, Maria

Cassel, Prof. Dr. rer. pol. Dieter
Vorsitzender des Vorstandes des AOK Bundesverbandes, Bonn

Leiter der Abteilung Gesundheitswesen der Schering Deutschland $\mathrm{GmbH}$, Berlin

1. Vorsitzender des Berufsverbandes der Deutschen Radiologen, Siegburg

Ehrenvorsitzender der Kassenärztlichen Vereinigung Hessen, Frankfurt

Referentin der Arbeitsgruppe Gesundheit der CDU/CSU-Bundestagsfraktion, Berlin

Lehrstuhl für Wirtschaftspolitik an der Universität Duisburg, Duisburg

Dierks, PD Dr. iur. Dr. med. Christian

Ganten, Prof. Dr. med. Detlev

Hebel, Dieter

Helming, Dr. med. Hans-Joachim

Hoberg, Dr. rer. pol. Rolf

Holzgreve, Prof. Dr. phil. Dr. med. Alfred

Jacobs, Dr. rer. pol. Klaus

Jobelius, Dr. rer. pol. HansJoachim

Kirschner, Klaus
Rechtsanwalt und Arzt, Dierks \& Bohle, Rechtsanwälte, Berlin

Vorsitzender des Max-Delbrück-Centrums für Molekulare Medizin Berlin-Buch in der Helmholtz-Gemeinschaft e.V., Berlin

Vorsitzender des Vorstandes der Gmünder Ersatzkasse, Schwäbisch Gmünd

Vorsitzender des Vorstandes der Kassenärztlichen Vereinigung Brandenburg, Potsdam

Stellvertretender Vorsitzender des Vorstandes des AOK Bundesverbandes, Bonn

Regionaldirektor Süd, Klinikum Neukölln, Vivantes Netzwerk für Gesundheit $\mathrm{GmbH}$, Berlin

Wissenschaftliches Institut der AOK, Institutsleitung; Gesundheitspolitik und Systemanalysen, Bonn

Geschäftsführer brain \& more $\mathrm{GmbH}$, Troisdorf

Vorsitzender des Ausschusses für Gesundheit der SPD-Bundestagsfraktion, Berlin 
Klusen, Prof. Dr. rer. oec. Norbert Vorsitzender des Vorstandes der Techniker Krankenkasse, Hamburg

Knappe, Prof. Dr. rer. oec. Eckhard Lehrstuhl für Volkswirtschaftslehre, Schwerpunkt Services Administration \& Management an der Universität Trier, Trier

Knieps, Franz

Kossow, Prof. Dr. med. Klaus

Langlouis, Dr. med. Wolfgang

Laschet, Helmut

Leienbach, Dr. rer. pol. Volker

Meusch, Andreas

Moldenhauer, Claus

Müller, Rolf Dieter

Münch, Eugen

Münnich, Prof. Dr. rer. pol. Frank

Naase, Birgit
Geschäftsführer Stabsbereich Politik im AOK Bundesverband, Bonn

Bundesvorsitzender des Berufsverbandes der Deutschen Allgemeinărzte-BDA, Achim-Uesen

Stellvertretender Vorsitzender des Berufsverbandes der Radiologen in Bayern

Stellvertretender Chefredakteur der Ärztezeitung, Berlin

Verbandsdirektor und geschäftsführendes Vorstandsmitglied des Verbandes der privaten Krankenversicherung e.V., Köln

Leiter der Landesvertretungen der Techniker Krankenkasse, Hamburg

Landesgeschäftsführer der DAK-Landesgeschäftsstelle Baden-Württemberg, Stuttgart

Vorsitzender des Vorstandes der AOK Berlin, Berlin

Vorsitzender des Vorstandes der Rhön-Klinikum AG, Bad Neustadt

Mitherausgeber des Gesundheitspolitischen Informationsdienstes Broll \& Lehr, Königswinter

Gesundheitspolitische Referentin der FDPBundestagsfraktion, Berlin

Oberender, Prof. Dr. rer. pol. Peter Lehrstuhl für Volkswirtschaftslehre der Universität Bayreuth, Bayreuth

Paquet, Dr. Robert Leiter BKK Bundesverband Büro Berlin, Berlin

Raffelhüschen, Prof. Dr. sc. pol. Bernd
Direktor des Institutes für Finanzwissenschaft und Volkswirtschaftslehre I, Freiburg 
Rebscher, Herbert

Renzewitz, Susanne

Richter-Reichhelm, Dr. med. Manfred

Schaub, Dr. rer. oec. Vanessa Elisabeth

Schmidt, Peter

Schönbach, Karl-Heinz

Schulte, Gerhard

Schupeta, Eckhard

Schwoerer, Dr. med. Peter

Scriba, Prof. Dr. med. Dr. h. c. Peter

Seeger, Stefan

Smigielski, Dr. rer. oec. Edwin

Tesic, Dusan
Vorsitzender des Vorstandes des VdAK - Verband der Angestellten-Krankenkassen e.V. und AEV - Arbeiter-Ersatzkassen-Verbandes e.V., Siegburg

Rechtsanwältin und Leiterin Politik der Deutschen Krankenhausgesellschaft, Berlin

1. Vorsitzender des Vorstandes der Kassenärztlichen Bundesvereinigung, Köln; Vorsitzender des Vorstandes der Kassenärztlichen Vereinigung Berlin, Berlin

Abteilung Gesundheitswesen der Schering Deutschland $\mathrm{GmbH}$, Berlin

Referent der Arbeitsgruppe Gesundheit der SPD-Bundestagsfraktion, Berlin

Leiter der Hauptabteilung Verträge des Bundesverbandes der Betriebskrankenkassen, Essen

Vorsitzender des Vorstandes des Landesverbandes der Betriebskrankenkassen in Bayern, München

Stellvertretender Vorsitzender des Vorstandes der Deutschen Angestellten Krankenkasse, Hamburg

Leitender Arzt und stellvertretender Geschäftsführer des MDK Baden-Württemberg, Lahr

Mitglied im Sachverständigenrat für die Konzertierte Aktion im Gesundheitswesen, Medizinische Klinik, Klinikum der Universität-Innenstadt, München

Geschäftsführer der Schering Deutschland $\mathrm{GmbH}$, Berlin

Leiter der Abteilung Gesundheitsversorgung und Krankenversicherung im Bundesgesundheitsministerium, Bonn

Hauptgeschäftsführer der Kassenärztlichen Vereinigung Berlin, Berlin 
Ulrich, Dr. rer. pol. Volker

Vorderwülbecke, Dr. iur. Ulrich

Wasem, Prof. Dr. rer. pol. Jürgen

Widmann-Mauz, MdB Annette

Wille, Prof. Dr. rer. pol. Eberhard

Zalewski, Dr. rer. pol. Thomas
Lehrstuhl für Volkswirtschaftslehre, insb. Finanzwissenschaft, an der Ernst-Moritz-ArndtUniversität Greifswald, Greifswald

Geschäftsführer Marktordnung/Gesundheitssysteme, VFA - Verband Forschender Arzneimittelhersteller e.V., Berlin

Lehrstuhl für Gesundheitsmanagement an der Ernst-Moritz-Arndt-Universität Greifswald, Greifswald

Mitglied des Ausschusses für Gesundheit der CDU/CSU-Bundestagsfraktion, Berlin

Vorsitzender des Sachverständigenrates für die Konzertierte Aktion im Gesundheitswesen; Lehrstuhl für Volkswirtschaftslehre, Planung und Verwaltung, öffentliche Wirtschaft an der Universität Mannheim, Mannheim

Hauptgeschäftsführer der Kassenärztlichen Vereinigung Nord-Württemberg, Stuttgart 


\section{STAATLICHE ALLOKATIONSPOLITIK IM MARKTWIRTSCHAFTLICHEN SYSTEM}

Band 1 Horst Siebert (Hrsg.): Umweltallokation im Raum. 1982.

Band 2 Horst Siebert (Hrsg.): Global Environmental Resources. The Ozone Problem. 1982.

Band 3 Hans-Joachim Schulz: Steuerwirkungen in einem dynamischen Unternehmensmodell. Ein Beitrag zur Dynamisierung der Steuerüberwälzungsanalyse. 1981.

Band 4 Eberhard Wille (Hrsg.): Beiträge zur gesamtwirtschaftlichen Allokation. Allokationsprobleme im intermediären Bereich zwischen öffentlichem und privatem Wirtschaftssektor. 1983.

Band 5 Heinz König (Hrsg.): Ausbildung und Arbeitsmarkt. 1983.

Band 6 Horst Siebert (Hrsg.): Reaktionen auf Energiepreissteigerungen. 1982.

Band 7 Eberhard Wille (Hrsg.): Konzeptionelle Probleme öffentlicher Planung. 1983.

Band 8 Ingeborg Kiesewetter-Wrana: Exporterlösinstabilität. Kritische Analyse eines entwicklungspolitischen Problems. 1982.

Band 9 Ferdinand Dudenhöfer: Mehrheitswahl-Entscheidungen über Umweltnutzungen. Eine Untersuchung von Gleichgewichtszuständen in einem mikroökonomischen Markt- und Abstimmungsmodell. 1983.

Band 10 Horst Siebert (Hrsg.): Intertemporale Allokation. 1984.

Band 11 Helmut Meder: Die intertemporale Allokation erschöpfbarer Naturressourcen bei fehlenden Zukunftsmärkten und institutionalisierten Marktsubstituten. 1984.

Band 12 Ulrich Ring: Öffentliche Planungsziele und staatliche Budgets. Zur Erfüllung öffentlicher Aufgaben durch nicht-staatliche Entscheidungseinheiten. 1985.

Band 13 Ehrentraud Graw: Informationseffizienz von Terminkontraktmärkten für Währungen. Eine empirische Untersuchung. 1984.

Band 14 Rüdiger Pethig (Ed.): Public Goods and Public Allocation Policy. 1985.

Band 15 Eberhard Wille (Hrsg.): Öffentliche Planung auf Landesebene. Eine Analyse von Planungskonzepten in Deutschland, Österreich und der Schweiz. 1986.

Band 16 Helga Gebauer: Regionale Umweltnutzungen in der Zeit. Eine intertemporale Zwei-Regionen-Analyse. 1985.

Band 17 Christine Pfitzer: Integrierte Entwicklungsplanung als Allokationsinstrument auf Landesebene. Eine Analyse der öffentlichen Planung der Länder Hessen, Bayern und Niedersachsen. 1985.

Band 18 Heinz König (Hrsg.): Kontrolltheoretische Ansätze in makroökonometrischen Modellen. 1985.

Band 19 Theo Kemp: Theorie und Empirie betrieblicher Ausbildungsplatzangebote. 1985.

Band 20 Eberhard Wille (Hrsg.): Konkrete Probleme öffentlicher Planung. Grundlegende Aspekte der Zielbildung, Effizienz und Kontrolle. 1986.

Band 21 Eberhard Wille (Hrsg.): Informations- und Planungsprobleme in öffentlichen Aufgabenbereichen. Aspekte der Zielbildung und Outputmessung unter besonderer Berücksichtigung des Gesundheitswesens. 1986.

Band 22 Bernd Gutting: Der Einfluß der Besteuerung auf die Entwicklung der Wohnungs- und Baulandmärkte. Eine intertemporale Analyse der bundesdeutschen Steuergesetze. 1986.

Band 23 Heiner Kuhl: Umweltressourcen als Gegenstand internationaler Verhandlungen. Eine theoretische Transaktionskostenanalyse. 1987. 
Band 24 Hubert Hornbach: Besteuerung, Inflation und Kapitalallokation. Intersektorale und internationale Aspekte. 1987.

Band 25 Peter Müller: Intertemporale Wirkungen der Staatsverschuldung. 1987.

Band 26 Stefan Kronenberger: Die Investitionen im Rahmen der Staatsausgaben. 1988.

Band 27 Armin-Detlef Rieß: Optimale Auslandsverschuldung bei potentiellen Schuldendienstproblemen. 1988.

Band 28 Volker Ulrich: Preis- und Mengeneffekte im Gesundheitswesen. Eine Ausgabenanalyse von GKV-Behandlungsarten. 1988.

Band 29 Hans-Michael Geiger: Informational Efficiency in Speculative Markets. A Theoretical Investigation. Edited by Ehrentraud Graw. 1989.

Band $30 \mathrm{Karl}$ Sputek: Zielgerichtete Ressourcenallokation. Ein Modellentwurf zur Effektivitätsanalyse praktischer Budgetplanung am Beispiel von Berlin (West). 1989.

\section{ALLOKATION IM MARKTWIRTSCHAFTLICHEN SYSTEM}

Band 31 Wolfgang Krader: Neuere Entwicklungen linearer latenter Kovarianzstrukturmodelle mit quantitativen und qualitativen Indikatorvariablen. Theorie und Anwendung auf ein mikroempirisches Modell des Preis-, Produktions- und Lageranpassungsverhaltens von deutschen und französischen Unternehmen des verarbeitenden Gewerbes. 1991.

Band 32 Manfred Erbsland: Die öffentlichen Personalausgaben. Eine empirische Analyse für die Bundesrepublik Deutschland. 1991.

Band 33 Walter Ried: Information und Nutzen der medizinischen Diagnostik. 1992.

Band 34 Anselm U. Römer: Was ist den Bürgern die Verminderung eines Risikos wert? Eine Anwendung des kontingenten Bewertungsansatzes auf das Giftmüllrisiko. 1993.

Band 35 Eberhard Wille, Angelika Mehnert, Jan Philipp Rohweder: Zum gesellschaftlichen Nutzen pharmazeutischer Innovationen. 1994.

Band 36 Peter Schmidt: Die Wahl des Rentenalters. Theoretische und empirische Analyse des Rentenzugangsverhaltens in West- und Ostdeutschland. 1995.

Band 37 Michael Ohmer: Die Grundlagen der Einkommensteuer. Gerechtigkeit und Effizienz. 1997.

Band 38 Evamaria Wagner: Risikomanagement rohstoffexportierender Entwicklungsländer. 1997.

Band 39 Matthias Meier: Das Sparverhalten der privaten Haushalte und der demographische Wandel: Makroökonomische Auswirkungen. Eine Simulation verschiedener Reformen der Rentenversicherung. 1997.

Band 40 Mantred Albring / Eberhard Wille (Hrsg.): Innovationen in der Arzneimitteltherapie. Definition, medizinische Umsetzung und Finanzierung. Bad Orber Gespräche über kontroverse Themen im Gesundheitswesen 25.-27.10.1996. 1997.

Band 41 Eberhard Wille / Manfred Albring (Hrsg.): Reformoptionen im Gesundheitswesen. Bad Orber Gespräche über kontroverse Themen im Gesundheitswesen 7.-8.11.1997. 1998.

Band 42 Manfred Albring / Eberhard Wille (Hrsg.): Szenarien im Gesundheitswesen. Bad Orber Gespräche über kontroverse Themen im Gesundheitswesen 5.-7.11.1998. 1999.

Band 43 Eberhard Wille / Manfred Albring (Hrsg.): Rationalisierungsreserven im deutschen Gesundheitswesen. 2000.

Band 44 Manfred Albring / Eberhard Wille (Hrsg.): Qualitätsorientierte Vergütungssysteme in der ambulanten und stationären Behandlung. 2001. 
Band 45 Martin Pfaff / Dietmar Wassener / Astrid Sterzel / Thomas Neldner: Analyse potentieller Auswirkungen einer Ausweitung des Pharmaversandes in Deutschland. 2002.

Band 46 Eberhard Wille / Manfred Albring (Hrsg.): Konfliktfeld Arzneimittelversorgung. 2002.

Band 47 Udo Schneider: Theorie und Empirie der Arzt-Patient-Beziehung. Zur Anwendung der Principal-Agent-Theorie auf die Gesundheitsnachfrage. 2002.

Band 48 Manfred Albring / Eberhard Wille: Die GKV zwischen Ausgabendynamik, Einnahmenschwäche und Koordinierungsproblemen. 2003. 
Manfred Albring and Eberhard Wille - 978-3-631-75562-4

Downloaded from PubFactory at 01/11/2019 03:33:01AM

via free access 
Manfred Albring and Eberhard Wille - 978-3-631-75562-4

Downloaded from PubFactory at 01/11/2019 03:33:01AM

via free access 
Manfred Albring and Eberhard Wille - 978-3-631-75562-4

Downloaded from PubFactory at 01/11/2019 03:33:01AM

via free access 